
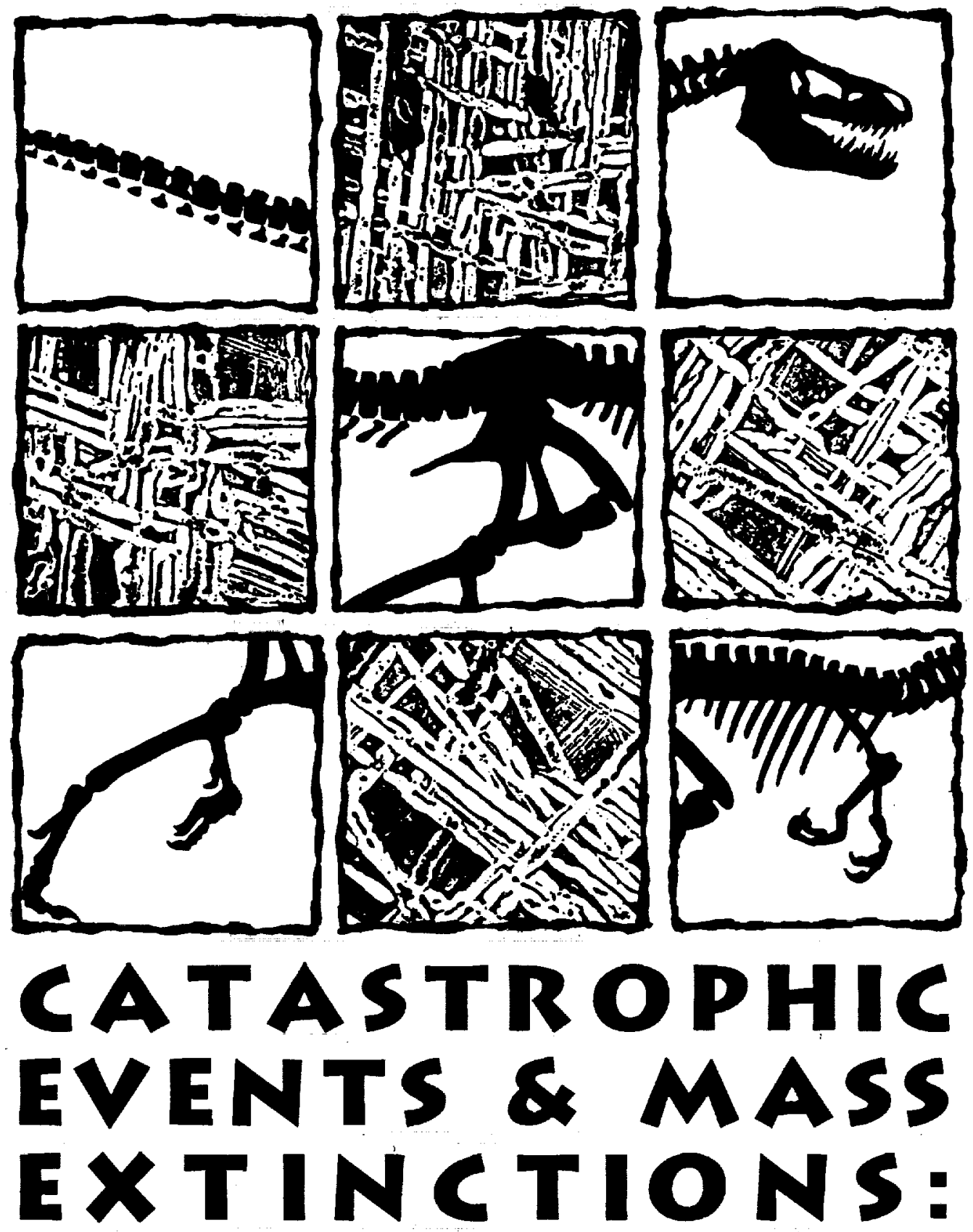

IMPACTS AND BEYOND VIENNA IULY $9-12,2000$ 


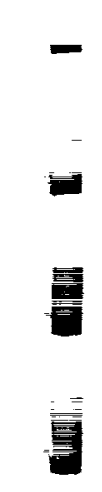

息

i:

E

E

$\underline{\underline{\underline{\underline{\bar{E}}}}}$

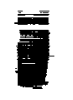

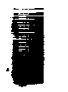

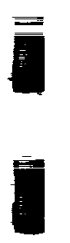

I

稁

1

1

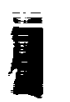

] 


\title{
Catastrophic Events and Mass Extinctions: Impacts and Beyond
}

\author{
July $9-12,2000$ \\ Geozentrum \\ University of Vienna, Austria \\ Sponsors \\ University of Vienna, Austria \\ Lunar and Planetary Institute \\ European Science Foundation IMPACT Program \\ Barringer Crater Company \\ Federal Ministry of Science and Transport, Austria \\ Geological Survey of Austria \\ Vienna Convention Bureau \\ City of Vienna \\ Austrian Airlines \\ International Association of Geochemistry and Cosmochemistry \\ -.... Finnegan \\ Micromass \\ Cameca Instruments, Inc. \\ International Organizing and Program Committee \\ Walter Alvarez (University of California, Berkeley) \\ Eric Buffetaut (CNRS Paris) \\ Douglas H. Erwin (Smithsonian Institution) \\ Iain Gilmour (The Open University) \\ Christian Koeberl (University of Vienna) \\ W. Uwe Reimold (University of the Witwatersrand) \\ Graham Ryder (Lunar and Planetary Institute) \\ Charles A. Sandberg (U.S. Geological Survey, Denver) \\ Jan Smit (Free University, Amsterdam) \\ Peter D. Ward (University of Washington, Seattle) \\ Local Organizing Committee \\ Christian Koeberl (Chair, University of Vienna) \\ Franz Brandstätter (Natural History Museum, Vienna) \\ Heinz Huber (University of Vienna) \\ Wolfgang Kiesl (University of Vienna) \\ Gero Kurat (Natural History Museum, Vienna) \\ Anton Preisinger (Technical University, Vienna) \\ Hans Peter Schönlaub (Geological Survey, Vienna)
}

Lunar and Planetary Institute 3600 Bay Area Boulevard Houston TX 77058-1113

LPIContribution No. 1053 
Compiled in 2000 by

LUNAR AND PLANETARY INSTITUTE

The Institute is operated by the Universities Space Research Association under Contract No. NASW-4574 with the National Aeronautics and Space Administration.

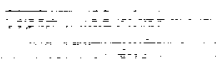

Material in this volume may be copied without restraint for library, abstract service, education, or personal research purposes; however, republication of any paper or portion there of requires the written permission of the authors as well as the appropriate acknowledgment of this publication.

$$
=-x=2, \cdots+\cdots
$$

Abstracts in this volume may be cited as

Author A. B. (2000) Title of abstract. In Catastrophic Events and Mass Extinctions: Impacts and Beyond, p. XX. LPI Contribution No. 1053, Lunar and Planetary Institute, Houston.

This volume is distributed by

\section{ORDER DEPARTMENT}

Lunar and Planetary Institute

3600 Bay Area Boulevard

Houston TX 77058-1113, USA

Phone: 281-486-2172

Fax: $281-486-2186$

E-mail: order@lpi.usra.edu 


\section{Preface}

This volume contains abstracts that have been accepted for presentation at the conference on Catastrophic Events and Mass Extinctions: Impacts and Beyond, July 9-12, 2000, in Vienna, Austria.

Administration and publications support for this meeting were provided by the staff of the Publications and Program Services Department at the Lunar and Planetary Institute. 


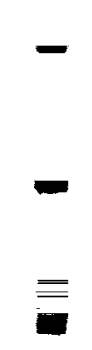

$\underline{\overline{\underline{\underline{B}}}}$

$\bar{E}$

竞

를

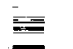

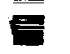

E

톨를

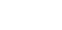

䇏

$\underline{\underline{\underline{\underline{\underline{\underline{a}}}}}}$

$=$

$\overline{0}$

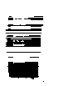

$\underline{\underline{\underline{\underline{ }}}}$

$\underline{\underline{\underline{\underline{\underline{E}}}}}$

$\overline{\underline{\underline{\underline{\underline{\underline{\underline{\underline{E}}}}}}}}$

$\underline{\underline{\underline{\underline{\underline{E}}}}}$ 


\section{Contents}

The Cretaceous-Tertiary Boundary at Bjala, Eastern Bulgaria: Evidence for a Multi-Event Scenario

T. Adatte, G. Keller, K. H. Stoykova, M. I. Ivanov, V. Minkovska,D. Vangelov, U. Kramar, and D. Stüben.

The Permian-Triassic Event: Progress and Doubts

W. Alvarez and D. O'Connor.

Planktic Foraminiferal Mass Extinction Across the K/T Boundary at La Ceiba and Bochil (México):

A Comparison with El Kef Stratotype (Tunisia)

I. Arenillas, L. Alegret, J. A. Arz, E. Cedillo-Pardo, J. M. Grajales-Nishimura, C. Liesa,

A. Meléndez, E. Molina,C. Rosales, and A. R. Soria.

Shock Metamorphic Effects Caused by Impacts into Water Basin

N. A. Artemieva and V. V. Shuvalov

Analysis of Siderite Thermal Decomposition by Differential Scanning Calorimetry

M. S. Bell, I.-C. Lin, and D. S. McKay.

Late Ordovician Mass Extinctions: Causes and Consequences - A View from Laurentia

W. B. N. Berry

Mössbauer Spectroscopy of K/T Boundary Clays: Characteristics of Iron Bearing Minerals

N. Bhandari, H. C. Verma, A. Tripathi, C. Upadhyay, and R. P. Tripathi.

High-Precision Geochronology and Mass Extinctions: Chronometric Tests of Extinction Mechanisms

S. A. Bowring, M. W. Martin, and M. D. Schmitz

Search for Impact Evidence at the Permo-Triassic Boundary in the Northeastern Free State

Province, South Africa

D. Brandt, P. J. Hancox, W. U. Reimold, and C. Koeberl

Testing the Impact Model: High Resolution Organic Walled Dinoflagellate Cyst Analysis Across

the Cretaceous/Tertiary Boundary

H. Brinkhuis, T. B. Van Hoof, S. Galeotti, and J. Smit

Palladium and Gold as Indicators of $\mathrm{K} / \mathrm{T}$ Boundary Sections

R. R. Brooks, A. W. Cook, and R. B. Stewart.

Paleontological Constraints on the Duration of K/T Boundary Extinction Events

E. Buffetaut .

Impact Lethality and Risks

C. R. Chapman

What Is Exactly the Role of Evaporites in the Chicxulub Event?

$P$. Claeys 
Global Distribution of Chicxulub Ejecta

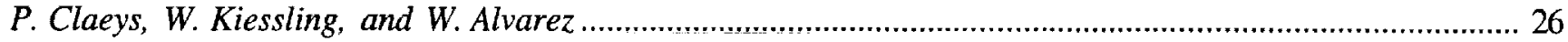

Long-Term Environmental Perturbations Following a Late Eocene Impact? Evidence from the

Massignano GSSP, Italy

R. Coccioni, D. Basso, H. Brinkhuis, S. Galeotti, S. Gardin, S. Monechi,

and S. Spezzaferri.

Radio Search for Extrasolar Cometary Impacts at $22 \mathrm{GHz}$ (Water MASER Emission)

C. B. Cosmovici, S. Pogrebenko, S. Montebugnoli, and G. Maccaferri

3016

Comparison of the Chemical Composition Between Bosumtwi Rocks and Ivory Coast Tektites:

Search for a Meteoritic Component in Impact Breccias

X. Dai, C. Koeberl, W. U. Reimold, and I. McDonald

Laboratory Impact Experiments and Calculations vs. Natural Impact Events

P. S. DeCarli, A. P. Jones, and G. D. Price

Multi-Scale Condensation in Impact-produced Vapor Clouds

D. de Niem

Carbon Isotopic Studies of Mass Extinctions and Recoveries

S. D'Hondt and J. C. Zachos

The Cretaceous-Tertiary Boundary "Cocktail" in Westem Cuba, Greater Antilles

C. Díaz Otero, M. Iturralde-Vinent, and D. García Delgado.

Paleozoic Diamictites in the Central Andes: Tillites, Gravity Flows or Impact Ejecta?

E. Díaz-Martínez $39+22$

Impact Events in Spain: Evidence and Potential Impactoclastic Units in the Sedimentary Record

E. Díaz-Martínez, E. Sanz-Rubio, and J. Martínez-Frías

The End-Permian Mass Extinction and Early Triassic Biotic Recovery

D. H. Enwin

Compelling New Evidence for Paleocene Dinosaurs in the Ojo Alamo Sandstone, San Juan Basin,

New Mexico and Colorado, USA

J. E. Fassett, S. G. Lucas, R. A. Zielinski, and J. R. Budahn

$45 \cdot 35$

Explosive Evolution in Tertiary Birds and Mammals Following the K-T Cataclysm

A. Feduccia

Ecology and Evolution During Precambrian Glaciations

E. J. Gaidos

Oligotrophic Oceans and Minimalist Organisms: Restructuring the Marine Community After the

K/T Mass Extinction

W. B. Gallagher 
Production of Toxins During an Impact and Their Possible Role in a Biotic Mass Extinction

M. V. Gerasimov

Oceanic Impacts and Related Environmental Perturbations

$R$. Gersonde

$53-30$

The Organic Geochemical Record of Environmental Change at the K/T Boundary

1. Gilmour and M. A. Sephton..... $54-31$

Asteroid/Comet Mega-Impact Connections of Archaean Crustal Evolution: Evidence from

Impact Fallout Deposits

A. Y. Glikson .

Woodleigh - A New 120 km-diameter Buried Multi-Ring Impact Basin, Carnarvon Basin,

Western Australia, of Pre-Jurassic Post-Early Permian Age: Evidence of a Meteoritic

Component Injected into Sub-Crater Basement

A. Y. Glikson, T. P. Mernagh, A. J. Mory, R. P. Iasky, and F. Pirajno

Origin of the Timor Sea Late Eocene-Pre-Miocene Strewn Crater Field

J. D. Gorter and A. Y. Glikson

$60-34$

Formation of the Boltysh Impact Structure: Catastrophe of Regional Scale

E. P. Gurov and N. V. Bobina.

$62-35$

Tsunami(?) Deposit of Terminal Eocene Age, South Australia: The Inferred Effects of a

Low-Angle Multiple Impact Event

P. W. Haines

$63-36$

Mass Extinctions and Sea-Level Changes
A. Hallam

$65-37$

The Permo-Triassic Boundary in the Northwest Karoo Basin

P. J. Hancox

$66-38$

New Data on the Late Cenomanian Mass Extinction Event

M. B. Hart and G. D. Price

$68-39$

Structure of the Chicxulub Crater

A. R. Hildebrand and M. Pilkington

$69-40$

Abrupt Extinction and Subsequent Reworking of Cretaceous Planktonic Foraminifera Across the

K/T Boundary: Evidence from the Subtropical Atlantic

B. T. Huber and K. G. MacLeod

The Foraminiferal Response to the Early Toarcian Extinction Event

M. D. Hylton, M. B. Hart, and G. D. Price

The Properties of the Nucleus of Short-Period Comets Dangerous for the Earth

Kh. I. Ibadinov. 
The K/T Boundary Impact Layer in Cuba: Update of an International Project

M. Iturralde-Vinent, D. García Delgado, C. Díaz Otero, R. Rojas Consuegra,

R. Tada, H. Takayama, and S. Kiyokawa

Crust and Mantle Deformation Under Chicxulub: Test for Models

B. A. Ivanov

How Strong Was Impact-induced $\mathrm{CO}_{2}$ Degassing in the $\mathrm{K} / \mathrm{T}$ Event?

$B$. A. Ivanov, F. Langenhorst, A. Deutsch, and U. Hornemann

Pattern of Marine Mass Extinction near the Permian-Triassic Boundary in South China

Y. G. Jin, Y. Wang, W. Wang, Q. H. Shang, C. Q. Cao, and D. H. Erwin

The Late Devonian Mass Extinction - Impact or Earth-bound Event

M. M. Joachimski and W. Buggisch

Devastation of Terrestrial Ecosystems at the K-T Boundary in North America: The First

Calibrated Record of Plant and Animal Response to the Chicxulub Impact

K. Johnson, D. Nichols, C. Labandeira, and D. Pearson

Impact Induced Volcanism on Earth; Searching for the Evidence. Crustal Magma Chambers

A. P. Jones

$87-50$

Geophysical Investigation of the Lake Bosumtwi Impact Crater

T. Karp, B. Milkereit, P. Janle, S. Bussat, S. Danuor, J. Pohl,B. Scheu, M. Froehler,

H. Berckhemer, B. Baier, G. Zacher, C. A. Scholz (Lake Bosumtwi Working Group)

Mass Extinctions, Catastrophes and Environmental Changes

G. Keller.

Composition and Variability of the Crystalline Basement at the Chicxulub Target Site

Deduced from Geochemical-Petrographical Data of Clasts in Impactites

B. Kettrup and A. Deutsch

Transport and Abrasion Experiments with Micrometeorites - Relevance for the Preservation

of Ejecta Material and Cosmic Debris in the Geological Record

D. Kettrup and A. Deutsch

Spatial Patterns of the KT Event

W. Kiessling and P. Claeys

Evidence Confirming Meteoritic Impact at Wetumpka Crater, Alabama, USA

D. T. King Jr., T. L. Neathery, L. W. Petruny, C. Koeberl, and W. E. Hames

Orbital Cyclicities Above and Below the Cretaceous-Tertiary Boundary,

Umbria-Marche Region, Italy

D. T. King Jr, L. W. Petruny, M. R. Rampino, A. Prokoph, K. Pope, A. G. Fischer,

A. Montanari, and A. C. Ocampo

$98-5^{1}$ 
More than $500 \mathrm{~m}$ Thick K/T Boundary Sequence; Cacarajicara Formation, Western Cuba.

Impact Related Giant Flow Deposit

S. Kiyokawa, R. Tada, T. Oji, E. Tajika, Y. Nakano, K. Goto, S. Yamamoto,

H. Takayama, K. Toyoda, R. Rojas, D. Garcia, M. A. Iturralde-Vinent, and T. Matsui

$100-58$

Meteoroid Fall into the Ocean: Impact on Stratospheric Ozone

B. A. Klumov

$102-59$

Comparison of Os and $\mathrm{Cr}$ Isotopic Methods for the Detection of Meteoritic Components in

Impact Melt Rocks from the Morokweng and Vredefort Impact Structures, South Africa

C. Koeberl, B. Peucker-Ehrenbrink, W. U. Reimold, A. Shukolyukov,

and G. W. Lugmair

Multiple Impacts and Mass Extinction

H. Koshiishi, H. Kurosaki, Y. Iwata, C. Komori, J. Terazono, M. Naka,

and H. Yamamoto $105-6 /$

Impact-induced Hydrothermal Activity and Potential Habitats for Thermophilic and

Hyperthermophilic Life

D. A. Kring

$106-62$

The Extraterrestrial Component in Sediments and Inferences on Earth's Accretion History

F. T. Kyte

$108 \cdot 63$

Biodiversity of Late Maastrichtian Dinosaurs

J. Le Loeuff and Y. Laurent. $110-64$

Estimations of Physical Effects of an Terrestrial $1 \mathrm{~km}$ Size Asteroid Impact

S. Lenzner

$111-65$

Production, Acceleration and Distribution of Microtektites on Earth, Mars, Venus and Titan

R. D. Lorenz

Contributions to the Mineralogy of Chicxulub: In Situ Raman Spectroscopy Evidence

of Coesite in Suevite

E. Lounejeva, M. Ostroumov, and G. Sánchez-Rubio

$115-67$

Towards Modeling Long Term Climatic Effects of Impacts

T. Luder, W. Benz, and T. F. Stocker

$116-68$

Physical Properties of Near-Earth Asteroids as Principal Impactors onto the Earth

D. F. Lupishko

Asteroid Hazard: Core of the Problem

D. F. Lupishko and T. A. Lupishko

Evidence for a Small $(\sim 0.000030)$ but Resolvable Increase in Seawater ${ }^{87} \mathrm{Sr} /{ }^{86} \mathrm{Sr}$ Ratios

Across the K/T Boundary

K. G. MacLeod, B. T. Huber, and P. D. Fullagar 
Raup's Dictum and the Role of Paleontological Data in Identifying Controls on Phanerozoic

Background and "Mass" Extinction Patterns

N. MacLeod 12472

Giant Beds — Impact Induced Deep-Marine Deposits

T. Marjanac.

$125-73$

The Cretaceous-Tertiary Boundary Impact Ejecta at Blake Nose (ODP Leg 171B) as

Record of the Chicxulub Impact

F. Martinez-Ruiz, M. Ortega-Huertas, I. Palomo, and J. Smit

Sulfur Isotopic Compositions Across Terrestrial K-T Boundary Successions

T. Maruoka, C. Koeberl, J. Newton, I. Gilmour, and B. F. Bohor

The Impact Cratering Record of Africa: An Updated Inventory of Proven, Probable, Possible, and Discredited Impact Structures on the African Continent

S. Master and W. U. Reimold... $131-76$

Extraordinary Variation of Lanthanide Tetrad Phenomenon Recorded in Conodonts:

Mass Extinction at Late Devonian

A. Masuda, J. Shimoda, S. K. Sahoo, and H. Goto

Noble Gases in a Large Bubble in Moldavite: A Comparison with Philippinite

J. Matsuda, T. Matsumoto, A. Seta, A. Tsuchiyama, Y. Nakashima, and S. Yoneda

Catastrophic Global Tsunami Induced by K/T Impact

T. Matsui, F. Imamura, E. Tajika, Y. Nakano, and Y. Fujisawa.

Platinum-Group Elements in the Morokweng Impact Melt Sheet: Evidence for an L-Chondrite

Giant Impactor at the $\mathrm{J} / \mathrm{K}$ Boundary

I. McDonald, M. A. G. Andreoli, R. J. Hart, and M. Tredoux

$139-80$

Can Impacts Induce Volcanic Eruptions?

H. J. Melosh.

Evidence from Iberia and the Central Atlantic Ocean for an Oceanic Impact near the

Cenomanian-Turonian Boundary

J. F. Monteiro, M. R. Rampino, A. Ribeiro, and J. Munha

Geophysical Constraints on the Size and Structure of the Chicxulub Impact Crater

J. Morgan and M. Warner.

A 3.5 Billion Year Record of Solar System Impacts, and the Recent (0.4 Gyr) Increase

R. A. Muller

Origin of Cretaceous Tertiary Boundary in Moncada, Western Cuba and Its Relation to K/T Event

Y. Nakano, R. Tada, T. Kamata, E. Tajika, T. Oji, S. Kiyokawa,H. Takayama, K. Goto,

S. Yamamoto, K. Toyoda, D. Garcia, R. Rojas, M.Itturalde-Vinent, and T. Matsui 
Palynology of the K-T Boundary in the Raton Basin, Colorado and New Mexico - New Data and Interpretations from the Birthplace of K-T Plant Microfossil Studies in Nonmarine Rocks

D. J. Nichols and C. L. Pillmore 15056

Mass Failure of the North Atlantic Margin Triggered by the Cretaceous/Paleogene Bolide Impact

R. D. Norris, J. Firth, J. Blusztajn, and G. Ravizza

Impact Mechanics and Implications for Extinction

J. D. O'Keefe, J. R. Lyons, and T. J. Ahrens

The Solar System Linked to a Gigantic Interstellar Cloud, During 500 Myr: Implications for a

Galactic Theory of Terrestrial Catastrophism

C. A. Olano

$156-85$

Progress in the Search for an Impact Layer at the Triassic-Jurassic Boundary

in Eastern North America

P. E. Olsen, C. Koeberl, H. Huber, and A. Montanari.

Cretaceous-Tertiary Boundary Events on the New Jersey Continental Margin

R. K. Olsson, J. D. Wright, K. G. Miller, J. V. Browning, and B. S. Cramer

$160-91$

Timing the End-Triassic and Early Jurassic Mass Extinctions

J. Pálfy, P. L. Smith, and J. K. Mortensen

$1-92$

Natural Fullerenes from the K/T Boundary Layer at Anjar, Kutch, India

G. Parthasarathy, N. Bhandari, M. Vairamani, A. C. Kunwar, and B. Narasaiah $162-53$

Chicxulub and Climate: Assessing the Climate Forcing of the Sulfate Aerosols

E. Pierazzo $164-94$

A New ${ }^{40} \mathrm{Ar} /{ }^{39} \mathrm{Ar}$ Age Determination on the K/T Boundary Interval: Possible Constraints

on the Timing of the K/T Event and Sedimentation Rates of the K/T Sequence

C. L. Pillmore and D. P. Miggins. $166-95$

Can SOHO Comets be Earthcrossers?

E. M. Pittich and N. A. Solovaya $167-96$

Cretaceous/Tertiary (K/T) Profile, Rhythmic Deposition and Geomagnetic Polarity Reversals of Marine Sediments near Bjala, Bulgaria

A. Preisinger, S. Aslanian, F. Brandstätter, F. Grass, H. Stradner, and H. Summesberger $168-97$

Biospheric Traumas Caused by Great Impacts

R. G. Prinn $169-98$

Known and Unknown Meteorite Impact Events, as Recorded in the Epicontinental Lower Palaeozoic Sedimentary Sequence of the Baltic Region

V. Puura, L. Ainsaar, M. Eriksson, T. Flodén, K. Kirsimäe, A. Kleesment, M. Konsa, and $K$. Suuroja 
Alteration of Crater Silicate Rocks: Examples of Dissimilar Environments from Kärdla and Manson Structures

V. Puura, A. Kärki, J. Kirs, K. Kirsimäe, A. Kleesment, M. Konsa, and K. Suuroja $172-100$

Geochemical Aspects of the Frasnian-Famennian Mass Extinction: The Polish Example

M. Racka and G. Racki $174 \div 10$

Periodic Comet Showers, Mass Extinctions, and the Galaxy

M. R. Rampino and R. B. Stothers

Abrupt Changes at the Permian/Triassic Boundary: Tempo of Events from High-Resolution

Cyclostratigraphy

M. R. Rampino, A. Prokoph, and A. C. Adler

$176-10^{3}$

Impact Events in Estonia and Their Possible Environmental Consequences

A. Raukas.

Seawater ${ }^{187} \mathrm{Os} /{ }^{188} \mathrm{Os}$ Variations Across the Cretaceous-Tertiary Boundary

G. Ravizza, B. Peucker-Ehrenbrink, J. Blusztajn, and R. Norris

Physical Characteristics of Deposition of Impact Breccias and Pan-African Basement

Affinities of Chicxulub Crater

M. Rebolledo-Vieyra, P. Vera-Sánchez, J. Urrutia-Fucugauchi, and L. E. Marin $180-106$

Extraterrestrial Spinel in Marine Sediments: An Overview

E. Robin, I. Lefevre, and R. Rocchia

Taphonomic and Palaeoecological Observations on the Peñalver Formation, Westem Cuba

R. Rojas-Consuegra

The Ancient Lunar Impact Record, the Ancient Terrestrial Impact Record, and Possible

Environments for the Origin of Life

G. Ryder

Possible Impact Origin of the Enigmatic Early Late Devonian Amönau Breccia,

Rheinisches Schiefergebirge, Germany

C. A. Sandberg, J. R. Morrow, and W. Ziegler

$187-/ 10$

Late Devonian Events and Mass Extinctions

C. A. Sandberg. W. Ziegler, and J. R. Morrow

$188=11$

Late Cretaceous Theropod Dinosaur Diversity: Latitudinal Differences in North America and

Implications for the K/T Extinctions

J. T. Sankey

A Neoproterozoic Snowball Earth

D. P. Schrag and P. F. Hoffman

$191-113$ 
Biostratigraphic and Geochemical Analyses Across the K/T Boundary in the Sinai, Egypt:

Relation to a Bolide?

I. K. Sengüler, A. Dakrory, C. Koeberl, and M. Satir.

Exploring the Chicxulub Impact Basin Through Scientific Drill-Coring: Historical Perspective and Current Plans

V. L. Sharpton. $193-1 / 5$

Permian-Triassic Transitional Environment in Spiti Valley, Himalayas, India

A. D. Shukla, N. Bhandari, and P. N. Shukla

Extraterrestrial Matter on Earth: Evidence from the $\mathrm{Cr}$ Isotopes

A. Shukolyukov and G. W. Lugmair

Atmospheric Erosion and Radiation Impulse Induced by Impacts

V. V. Shuvalov and N. A. Artemieva

$99-1 / 8$

Condensation in an Impact Vapor Plume: Estimates of Gas and Aerosol Emissions Generated by the Chicxulub Impact

D. Siret, E. Robin, F. Le Guem, and B. Cheynet

$201-119$

Mineralogical Studies of Experimentally Shocked Dolomite: Implications for the Outgassing of Carbonates

R. Skála and F. Hörz

$202-120$

The Fate of Planktic Foraminifers Crossing the KT Boundary (or Not): A Review

J. Smit

$204-121$

Mineralogy and Trace Elements Geochemistry of the Cretaceous/Tertiary Boundary (K/T) at

Gabal Qreiya Section, Nile Valley, Egypt: Evidence for a Pre-K/T Impact

M. F. Soliman, H. Palme, A. El Goresy, and B. Spettel

$206 / 22$

Earth Collision with High Inclination Asteroids

N. A. Solovaya and E. M. Pittich $208-123$

The Theory of Breakage and Asteroid Size Distribution

D. H. Speidel

$209-124$

Paleoenvironments of the Late Cretaceous-Early Paleogene Tethys; Building a Baseline for

Assessing Past Global Change

R. P. Speijer

$211-125$

Bursts of Methane from the Deep Sea and the Spread of Anoxia into Epicontinental Basins at the

End of the Paleocene - A Causal Relationship Involving Sea-Level Change?

R. P. Speijer and T. Wagner

$212-126$

Multiparameter Stratigraphy of the Late Paleocene Thermal Maximum Along a Southern Tethyan

Paleoslope Transect

R. P. Speijer, S. Monechi, A. M. Morsi, and B. Schmitz

$214-127$ 
Terrestrial Multiple Impact Events

J. G. Spray and S. P. Kelley $216 / 28$

The Age of the Chicxulub Impact and Other Events in the KT Transition: New Data from

NE Mexiço

W. Stinnesbeck, P. Schulte, G. Keller, T. Adatte, D. Stïben, and U. Kramar

High Resolution Carbon and Oxygen Isotope Profiles of Foraminifera and the Ca-normalized

Sr Curve from Late Maastrichtian Across the KTB at Elles, Tunisia

D. Stüben, U. Kramar, Z. Berner, M. Leosson, G. Keller, W. Stinnesbeck,

and Th. Adatte

The Early Ordovician Catastrophic Event on Osmussaar Island (Estonia) - Result of an Impact

or Earthquake?

K. Suuroja and S. Suuroja $222-131$

The Impact-related Sediments of the Kärdla Crater (Hiiumaa Island, Estonia)

S. Suuroja and K. Suuroja

Grazing Impacts as a Cause of the Global Catastrophes

V. V. Svetsov $224-133$

A Giant Tsunami Deposit at Cretaceous-Tertiary Boundary in Cuba

R. Tada, H. Takayama, T. Matsui, M. Iturralde Vinent, E. Tajika, T. Oji, S. Kiyokawa,

D. Garcia, H. Okada, K. Toyoda, and T. Hasagawa

Physical and Geochemical Processes in the Global Glaciation: Implication for Snowball Earth

$$
\text { E. Tajika }
$$

Numerical Simulations of Chicxulub Impact Cratering

T. Takata $230^{-13^{6}}$

Global Atmospheric Perturbations Caused by Natural Hazards

A. V. Teterev and L.V. Rudak

Impact Heating During Formation of the Vredefort Structure

E. P. Turtle and E. Pierazzo.

The P/T Boundary on Land: A Summary

P. D. Ward.

Changing Fluvial Environments in the Karoo Basin, South Africa, as a Result of the

Permian/Triassic Mass Extinction

P. Ward, D. R. Montgomery, and R. Smith

Primary Ejecta, Tsunami Reworking, Tectonic Dismemberment: Reconstructing the Late

Devonian Alamo Breccia and Crater, Nevada

J. E. Warme and A. K. Chamberlain 
Large Aerial Bursts; An Important Class of Terrestrial Accretionary Events

J. T. Wasson and M. B. E. Boslough.

Extent and Duration of the Permo-Triassic Superanoxic Event

P. B. Wignall

Palaeoecology of a Post-Extinction Reef: Famennian (Late Devonian) of the Canning Basin, Western Australia

$R$. Wood.. 

THE CRETACEOUS-TERTIARY BOUNDARY AT BJALA, EASTERN BULGARIA: EVIDENCE FOR A MULTI-EVENT SCENARIO. T. Adatte ', G. Keller ${ }^{2}$, Stoykova, K.H ${ }^{3}$, Ivanov M.I. ${ }^{4}$, Minkovska, V. ${ }^{4}$, Vangelov ${ }^{4}$, D. Kramar U. ${ }^{5}$, and Stüben D. ${ }^{5}$. ${ }^{1}$ Institut de Géologie, 11 Emile Argand, 2007 Neuchâtel, Switzerland, thierry.adatte@geol.unine.ch. ${ }^{2}$ Department of Geosciences, Princeton University, NJ 08544 USA. ${ }^{3}$ Geological Institute of Bulgarian Academy of Sciences, 113 Sofia, Bulgaria. ${ }^{4}$ Sofia University "St. Kliment Okhridski", 1000 Sofia, Bulgaria. ${ }^{5}$ Geologisches Institut, Universitaet Karlsruhe 76128, Germany.

We report the results of preliminary investigations of two $\mathrm{K}-\mathrm{T}$ boundary sections which are about $1.2 \mathrm{~km}$ apart and located near Bjala in eastern Bulgaria. The study is based on high resolution sampling, lithological observations, biostratigraphy, bulk rock and clay mineralogy and geochemistry. At the Bjala-2 section the uppermost Maastrichtian consists of alternating grey marls and marly limestones with an undulating upper surface. Overlying this surface is a variably 3 to $6 \mathrm{~cm}$-thick dark grey clay layer that contains common reworked late Cretaceous planktic foraminifera and rare $P$. eugubina. The age of this clay layer could be either P0 or mixed with the overlying Pla assemblage. An Ir anomaly of 1$1.6 \mathrm{ppb}$ is present. A marly limestone with a diverse early Danian zone Pla planktic foraminiferal assemblage overlies the clay layer. The undulating erosional surface of the Maastrichtian limestone layer, the variably thick clay layer, and the mixed foraminiferal assemblage all suggest an incomplete sequence due to erosion and/or non-deposition.

A more continuous sequence is present at Bjala- 1 where the K-T transition consists of alternating marls and marly hemipelagic limestones with two thin dark clay layers. Agewise the section spans from Late Maastrichian Micula Prinsii zone to the Early Danian zone NP1(Biantholithus sparsus) and NP2 (Cruciplacolithus tenuis, 1-2). Lithological examinations at the cm-interval reveal a complex depositional history. The top of the uppermost Maastrichtian grey marly limestone has an irregular, bioturbated (chondrites) surface which is overlain by a $1-3 \mathrm{~cm}$-thick dark grey to black clay. This clay-layer-1, which is nearly devoid of calcite, marks the $\mathrm{K}$ - $\mathrm{T}$ boundary since it contains a PO planktic foraminiferal assemblage (as well as common reworked late Cretaceous species), though it contains a very low iridium concentration of $<0.5 \mathrm{ppb}$. In contrast, (3) earlier reported a mega Ir anomaly of $6.1 \mathrm{ppb}$ from the K-T boundary of this section, though he did not mention the presence of a second clay layer. Clay layer-1 is topped by a $10 \mathrm{~cm}$-thick marly limestone which is strongly bioturbated (Chondrites) and has an undulating upper surface that suggests a period of reduced or nondeposition. A $10 \mathrm{~cm}$-thick marl layer overlies the marly limestone and contains abundant Parvularugoglobigerina eugubina and other early Danian species indicating deposition during zone Pla. No significant Ir enrichment is observed in either the marly limestone or marl layer.

So far the sequence of events at Biala-1 parallels that of other continuous K-T boundary sections. What is different is the second $1-2 \mathrm{~cm}$-thick clay layer that overlies the marl layer. Clay layer- 2 is enriched in Ir $(0.22 \mathrm{ppb})$ and $\mathrm{Pd}(1.34 \mathrm{ppb})$ and may correlate with the second Ir peak detected (3). A diverse early Danian zone Pla planktic foraminiferal assemblage is present including abundant $P$. eugubina. The presence of a distinct clay layer and a very diverse and evolutionarily more advanced faunal assemblage in clay layer- 2 indicates that this represents a separate event from clay layer-1 below, which occurred at least $100 \mathrm{ky}$ after the K-T boundary event. The presence of the second Ir anomaly is an enigma. It can be explained by either reworking of the K-T Ir anomaly that is represented in clay layer-1, or by a second event. We believe that the latter is more likely because there is increasing evidence of a second Ir-bearing event in the early Danian zone Pla in Haiti $(4)$, Guatemala $(5 ; 6)$ and Brazil (7). We therefore suggest a multi-event scenario with a second impact, or volcanic event, in the early Danian following the K-T boundary event.

\section{References :}

(1) Stoykova, K., Ivanov, M.I. (1992). An interrupted section across the Cretaceous/Tertiary boundary at the town of Bjala, Black Sea coast (Bulgaria). Comptes rendus Acad. Bulg. Sciences, 45, 7, p.61-64. (2) Ivanov, M.I., Stoykova, K. (1994). Cretaceous/tertiary boundary in the area of Bjala, eastern Bulgaria - biostratigraphical results. Geologica Balcanica, 24, 6, Sofia, p. 3-22. (3) Preisinger, A. , Aslanian, S. , Stoykova, K. , Grass, F., Mauritsch, H. J., Scholger, R. (1993). Cretaceous/Tertiary boundary sections on the coast of the Black Sea near Bjala (Bulgaria), Palaeogeography, Palaeoclimatology, Palaeoecology, 104 (1-4), p. 219. 228. (4) Keller, G., Adatte, T. Stinnesbeck, W., Stüben, T., Kramar, U. \& Berner Z. (in press): Age and Biostratigraphy of Haiti spherule-rich deposits: a Multievent K-T scenario. Canadian Journal of Earth Sciences. (5) Fourcade, E., Rocchia, R., Gardin, S. , Bellier, J. P., Debrabant, P., Masure, E., Robin, (1998). Age of the Guatemala breccias around the Cretaceous-Tertiary boundary; relationships with the asteroid impact on the 
Yucatan, Comptes Rendus de l'Académie des Sciences, Serie II. Sciences de la Terre et des Planetes, 327 (1), p. 47-53. (6) Debrabant, P., Fourcade, E., Chamley, H, Rocchia R, Robin, E., Bellier, J-P., Gardin, S. \& Thiebault, F. (1999). Les argiles de la transition CretaceTertiaire au Guatemala, témoins d'un impact d'asteroide. Bulletin de la Société Géologique de France, 170 (5), p. 643-660. (7) Koutsoukos, E. A. M. (1998) An extraterrestrial impact in the early Danian; a secondary $\mathrm{K} / \mathrm{T}$ boundary event? Terra Nova, 10 (2), p. 68-73. 
THE PERMIAN-TRIASSIC EVENT: PROGRESS AND DOUBTS. Walter Alvarez ${ }^{1}$ and Diane O'Connor ${ }^{1}$, 'Department of Geology and Geophysics, University of California, Berkeley, CA 94720-4767.

Although the Permian-Triassic (PT) event is thought to have been the greatest mass extinction in Phanerozoic time, progress in understanding it has been slow in comparison with the advances over the last two decades in understanding the other mass extinctions, especially the Cretaceous-Tertiary (KT) event.

Research on the Permian-Triassic event has been impeded by the fact that the 250-Ma PT event is almost 4 times older than the $65-\mathrm{Ma}$ KT event. The deep-marine, shallow-marine, and continental sedimentary records of the PT event are each plagued with a different set of difficulties. (1) Whereas the KT event can be studied in many ocean sediment cores, no ocean crust of PT age remains, so deep-sea sediments of PT boundary age can only be studied in off-scraped remnants in tectonic situations which often are highly deformed and poor in fossils. (2) Complete shallowmarine PT sections have been reliably identified in only a few areas, notably Pakistan, the Southern Alps, and especially South China, so most of the detailed stratigraphic work on the PT boundary is now being done in China.

However, global correlation is problematic because of endemic faunas and unstable taxonomy, so interpretations of PT events elsewhere are difficult to tie to the Chinese sections. (3) Continental sediments across the PT boundary are difficult to interpret because of the probability of episodes of nondeposition and because terrestrial fossils are rare and seldom useful for global correlation. Nevertheless, some conclusions about the Permian-Triassic event are becoming accepted. (1) The rarity of shallow-marine sediments and Upper Permian fossils suitable for correlation is interpreted as evidence for a sea-level low-stand across the PT event. (2) Evidence has emerged favoring a double extinction event, with pulses at the end of the Middle Permian and the end of the Late Permian, although this may instead indicate a long, drawn-out interval of extinctions. (3) The Siberian Traps flood basalt has been dated to the PT boundary with high precision. (4) The biostratigraphy and chronostratigraphy of the Permian are now thought to be on firm footing, with the establishment of an internationally accepted set of type sections.

A reconsideration of the basis for each of these conclusions raises doubts about the reliability of current knowledge of PermianTriassic events, as well as opportunities for new lines of research. 
<smiles>[C]1C#CC=CCCCCC1</smiles>

PLANKTIC FORAMINIFERAL MASS EXTINCTION ACROSS THE K/T BOUNDARY AT LA CEIBA AND BOCHIL (MÉXICO): A COMPARISON WITH EL KEF STRATOTYPE (TUNISIA). Ignacio Arenillas $^{1}$, Laia Alegret ${ }^{1}$, José A. Arz ${ }^{2}$, Esteban Cedillo-Pardo ${ }^{3}$, José M. Grajales-Nishimura ${ }^{3}$, Carlos Liesa ${ }^{1}$, Alfonso Meléndez $z^{1}$, Eustoquio Molina ${ }^{1}$, Carmen Rosales ${ }^{3}$, and Ana R. Soria ${ }^{1},{ }^{1}$ Facultad de Ciencias de la Tierra, Universidad Autónoma de Nuevo León, Linares, MEX- 67700, Mexico, ${ }^{2}$ Departamento de Ciencias de la Tierra, Universidad de Zaragoza, E-50009, Spain, ${ }^{3}$ Gerencia de Geociencias, Subdirección de Exploración y Producción, Instituto Mexicano de Petróleo, D.F., MEX-07730, Mexico.

A micropaleontological study across the Cretaceous/Tertiary $(\mathrm{K} / \mathrm{T})$ boundary from La Ceiba and Bochil sections (Mexico) was performed to examine K-T planktic foraminiferal biostratigraphy and assemblage turnover. These sections with the El Kef stratotype (Tunisia) to analyse the planktic foraminiferal extinction pattern across the $\mathrm{K} / \mathrm{T}$ boundary and the cause-effect relation between $\mathrm{K} / \mathrm{T}$ planktic foraminiferal mass extinction and Chicxulub impact.

At La Ceiba, the $\mathrm{K} / \mathrm{T}$ boundary is marked by a $>1$ m-thick clastic unit, intercalated between two pelagic marly units (Méndez and Velasco Formations) and displays a general finning upwards sequence similar to a turbidite sequence. This unit contains a basal subunit with calcareous marls rich in millimetre-size spherules (microtektites) altered to clay minerals and shocked quartz. The sedimentological features of La Ceiba support an impactgenerated sediment gravity flow genesis at lower bathyal depths (more than $1000 \mathrm{~m}$ according to benthic foraminiferal assemblages). The clastic unit was deposited under a high sedimentation rate in upper flow regimes and emplaced in a single-pulse event as turbidites.

At Bochil, the $\mathrm{K} / \mathrm{T}$ boundary is represented by a finning upwards clastic sequence that can be subdivided into three main subunits: (a) $>60 \mathrm{~m}$ thick basal coarse carbonate breccia with blocks of up to 2$3 \mathrm{~m}$ in diameter, followed by, (b) a $4 \mathrm{~m}$ thick medium-grained breccia, including a $2 \mathrm{~m}$ thick bed with round calcareous objects in a whitish matrix, and (c) a $\sim 2 \mathrm{~m}$ thick sandstone to claystone subunit with abundant loose benthic foraminifera, altered glass fragments and shocked quartz. The Ir anomaly was reported from the clay topping the sequence. We interpreted that the basal coarse breccia represents a gravity flow deposit formed by seismic shacking triggered by the impact at Chicxulub. Subunits $b$ and c were originated by a combination of mechanisms including ballistic sedimentation (ejecta deposits) later reworked and mixed with local material by the backwash of the tsunamis. The Iridium-bearing uppermost part of the subunit $\mathrm{c}$ represents the wanning stage of turbulent flow where sediments are deposited by settling of fine-grained suspensions. The strati- graphic and micropaleontological studies support this interpretation.

The El Kef section was officially designated the $\mathrm{K} / \mathrm{P}$ boundary global stratotype section and point (GSSP) in 1989 at the 28th International Geological Congress in Washington. The $\mathrm{K} / \mathrm{T}$ boundary was defined at the base of a $50-60 \mathrm{~cm}$ thick marly clay layer, which is intercalated between Maastrichtian and Danian pelagic marly sediments. The basal part of the $\mathrm{K} / \mathrm{T}$ boundary clay at El Kef stratotype has an Ir anomaly, crystalline microspherules (aitered microtektites), Ni-rich spinels and shocked minerals. According to the $\mathrm{K} / \mathrm{T}$ stratotype definition from $\mathrm{El}$ Kef (Tunisia), the K/T boundary at La Ceiba must be placed at the base of the clastic (microspherules) layer since it is equivalent to the base of the boundary clay at El Kef. Similarly, the K/T boundary at Bochil must be placed at the base of the $\mathrm{K} / \mathrm{T}$ sandstone complex just below the impact-generated polymict debris-flow.

We considered five biozones: Abathomphalus mayaroensis Biozone and Plummerita hantkeninoides Biozone (Cretaceous), Guembelitria cretacea Biozone, Parvularugoglobigerina eugubina Biozone and $\bar{P}$ arasub̧ $\bar{b}$ otina pseudobulloides Biozone (Tertiary). The bases of these biozones were placed at the first appearance of the eponymous species, except for the base of $G$. cretacea Biozone which was situated at the last appearance datum of $A$. mayaroensis, precisely at the $\mathrm{K} / \mathrm{T}$ boundary. Since $P v$. eugubina and $P v$. longiapertura are considered synonyms by some authors, the $P v$. longiapertura FAD has frequently been used to situate the base of the P0, which is not exactly equivalent to the $P v$. eugubina Biozone we used. These five biozones were recognized at El Kef. At La Ceiba, a hiatus affects the lower part of the Danian, including Guembelitria cretacea and Parvularugoglobigerina eugubina Biozones and the lower part of the Parasubbotina pseudobulloides Biozone. At Bochil, we only studied the lower part of the $G$. cretacea Biozone (approximately $\mathrm{PO}$ zone and lower part of P1 zone).

Terminal Maastrichtian planktic foraminiferal assemblages were very abundant and diverse at La Ceiba (Gulf of Mexico) as well as El Kef 


\section{PLANKTIC FORAMINIFERAL MASS EXTINCTION: Arenillas et al.}

(Tethys). These assemblages included 67 stable identified species at El Kef and 63 species at La Ceiba. At El Kef, $1(1.6 \%)$ species disappeared in last meter of the Maastrichtian, $46(74.1 \%)$ species at the K/P boundary and $15(24.2 \%)$ ranging into the earliest Danian. At La Ceiba, nearly all Maastrichtian planktic foraminiferal species were found in the last Maastrichtian sample and there was no support for a gradual mass extinction pattern in the terminal Cretaceous. This pattern of catastrophic mass extinction constitutes the largest and most sudden extinction event in the history of planktic foraminifera and is very compatible with the possible catastrophic effects caused by the impact of a large extraterrestrial asteroid. Furthermore, a planktic foraminiferal evolutionary radiation occurs in the earliest Danian. This radiation always begins above the $\mathrm{K} / \mathrm{T}$ boundary and never below, which also is very compatible with the impact theory.

Danian planktic foraminiferal species evolved sequentially in $\mathrm{K} / \mathrm{T}$ boundary continuous sections. Since these gradual Tertiary species appear over an extensive stratigraphic interval at the lower part of the Danian from El Kef, this section is considered one of the most continuous and expanded marine $\mathrm{K} / \mathrm{T}$ boundary sections known at the Tethys. The comparative study of Tethyan and Gulf coast sections helps identify four quantitative stages in the planktic foraminiferal population in the lowermost part of the Danian. Initially, the planktic foraminiferal assemblages were dominated by Guembelitria (Stage 1). This stage spanned the lower part of the $G$. cretacea Biozone (= P0). Stage 2 is predominated by Parvu- larugoglobigerina and Globoconusa and it spanned the upper part of the $G$. cretacea Biozone and the lower part of the Pv. eugubina Biozone. Later, Chiloguembelina and Woodringina were the most abundant (Stage 3). This stage spanned the upper part of the $P$ v eugubina Biozone and the $P$. pseudobulloides Biozone. Finally, they were replaced in abundance by Eoglobigerina, Parasubbotina, Praemurica and Globanomalina. The partial or complete identification of these stages allowed us to further recognize and quantify the hiatus span across the $\mathrm{K} / \mathrm{T}$ boundary, since these stages do not depend on problematic taxonomic assignments of species.

All stages were identified in the El Kef stratotype. On the contrary, Stages 1 and 2 were not identified at La Ceiba and Stages 3 and 4 were not studied at Bochil. The simultaneous first tertiary planktic foraminiferal appearances at La Ceiba sections mark a hiatus that also affects the lower part of the Danian. This hiatus did not allow us to investigate the last and first appearance datum of possible Maastrichtian survivor species and new Danian evolving species at La Ceiba. However, the identification of the Stages 1 and 2 at Bochil is very significant because it supports two views: (1) the $\mathrm{K} / \mathrm{T}$ boundary and mass extinction are placed below the impactgenerated polymict debris-flow and sandstone complex; (2) the planktic foraminiferal evolutionary radiation also occurs just above impact-generated complex sandstone in Gulf of Mexico. Consequently, our micropaleontological and sedimentological evidence are consistent with the $\mathrm{K} / \mathrm{T}$ impact theory and the asteroid impact on the Yucatan peninsula. 


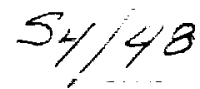

6 Catastrophic Events Conference

SHOCK METAMORPHIC EFFECTS CAUSED BY IMPACTS INTO WATER BASIN. N.A.Artemieva, V.V.Shuvalov Institute for Dynamics of Geospheres, 38 Leninsky prospect, Moscow 117979, Russia. E-mail: art@idg.chph.ras.ru, shuvalov@idg.chph.ra.ru

Introduction. The most part of asteroids should hit the ocean, but modern geological data reveal an appreciable deficiency of underwater craters. At least, two reasons are evident: impact cratering is weakened by water column and even giant crater is crushing by dynamic plate-tectonic movements on the crust. However, impact affected materials may conserve beneath the bottom and may be found during ocean drilling projects. Numerical simulations of the impact, including estimates of maximum pressure value in the material, allow to estimate the size of shock zones at the bottom and to define the region of fine-grained ejecta (microtektites) deposition.

Shock metamorphism (SM) is a set of physical, chemical and mineralogical changes in the rocks under the shock loading. Most crystalline solids undergo structural rearrangements at successively higher pressures (in the range of 5-40 GPa) or melting (at the pressure above 50-60).

Numerical simulations of the meteoroid impacts into the ocean [1-3] have been conducted for huge impactors with diameter exceeding the ocean depth. Undeniably, these impactors reach the ocean floor, form underwater crater (with SM) and giant waves. But it is not clear yet whether it is possible to find shock zones for smaller impacts? What are the critical impactor size, impactor velocity and ocean depth?

Laboratory experiments $[4,5]$ have demonstrated that strong bottom effects (SM) may be found, if the ratio of ocean depth to impactor diameter is less than 2.5 , and some other signs may be found if this ratio is less than 25 . However, these results were obtained for the small $(2.5-5 \mathrm{~km} / \mathrm{s})$ velocities.

Extrapolation of the experimental results to the velocities typical for asteroids $(15-30 \mathrm{~km})$ can lead to the mistakes, because the depth of the impactor penetration into water (and, hence, shock wave in water) strongly depends on the velocity.

The main purpose of this paper is to study the problem using detailed numerical simulations. The SOVA multi-material hydrocode [6] is applied to model the impact. We use ANEOS [7] for impactor and ground material and Tillotson EOS [8] for water. To determine maximum pressures in the floor material, we use tracer particles, which are initially placed near the impact site and than move together with the material and note maximum pressure value for appropriate mass particle. About 30 - 50 thousands markers are usually used.

Three regions of shock compression are recognized in our calculations: first - above $60 \mathrm{Gpa}$ (melting), second - between 40 and $60 \mathrm{GPa}$ (incipient melting), third - above $15 \mathrm{GPa}$ (low pressure phase LPP - high pressure phase HPP transformations).

Hydrodynamic equations descriptive of the impact process are self-similar, i.e. they do not change if we multiply all linear dimensions and time by constant value, except of the gravity, which is not essential at the initial stage of the impact and hydrostatic pressure on the floor, which is small $(0.04 \mathrm{GPa})$ in comparison with the shock pressure necessary for SM. Thus, the results for the one fixed value of impactor diameter ( $1 \mathrm{~km}$ in this study) can be recalculated to all other diameters.

Impact into deep water. First we model the impact into water without floor and define pressure in the shock as a function of water depth. In a wide range of the impact velocities (from 15 to $40 \mathrm{~km} / \mathrm{s}$ ) we can see two sharply distinguished regions of the shock wave decay: isobaric core (depth/diameter ratio is less than 2), where shock pressure is proportional to $r^{-0.15}$ and far region where pressure drops quickly, as $r^{-3}$.

For the lowest velocity under consideration (15 $\mathrm{km} / \mathrm{s}$ ) melting does not take place, if the ocean depth exceeds two impactor diameters. Any floor effects are not evident (pressure is less than $5 \mathrm{GPa}$ ) for depth greater than 6. In the case of highest velocity of 40 $\mathrm{km} / \mathrm{s}$ sufficient amount of melting may be found at the oceanic depth of 4 impactor diameters. Pressure drops below $5 \mathrm{GPa}$ at the distances of 8 impactor diameters.

Vertical impact into finite depth water. To take into account the complex flows near the floor and to determine the size of shock affected region numerical modeling of the vertical impact is performed for various oceanic depths and for various impact velocities.

Strong shock waves are well visible in water and in the floor. Excavation of the water crater leads to strong upward flow. It is just the flow, which leads to surge formation later. It is easily seen that crater formation in the floor is associated with highly compressed water, which operates as a giant piston, not with the impactor itself.

Variations of the impact velocity from 15 to 40 $\mathrm{km} / \mathrm{s}$ with fixed oceanic depth of $2 \mathrm{~km}$ have shown that in the case of low velocities $(15-20 \mathrm{~km} / \mathrm{s})$ impactor does not mix with the floor material and for higher 
impact velocity it is mixed with the floor strongly. The size of the bottom crater increases with the increase of the velocity. Certainly, it is not the final shape of the crater. Later excavation stage begins, but in the case of underwater crater this stage is far weaker than in the case of solid-solid impact, because, first, impact itself is weaker due to water layer, and second, excavation is bounded by water, filling water crater.

It is well seen that mass of shock modified material sharply increases with velocity increase. Layers of bottom material, affected shock compression, have a spherical shape. They are clearly separated and are not mixed, at least at this stage of the impact. Even for the smallest velocity of $15 \mathrm{~km} / \mathrm{s}$ the substance is melted in the shock. For the case of highest velocity of $40 \mathrm{~km} / \mathrm{s}$ the zone of melting is positioned $2 \mathrm{~km}$ below the ocean floor, and the zone of HPP $4 \mathrm{~km}$ below it.
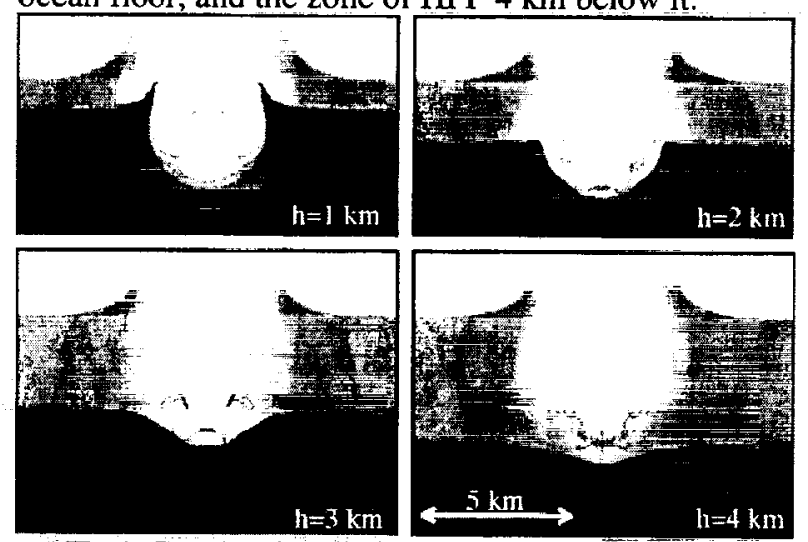

Fig.1. Density distributions in $1 \mathrm{~s}$ after the impact for different ocean depth. Impact velocity equals $20 \mathrm{~km} / \mathrm{s}$.

Variations of oceanic depth with constant impact velocity of $20 \mathrm{~km} / \mathrm{s}$ (Fig.1) have shown that for shallow water impact underwater crater practically looks like the impact crater without water layer. The ejecta curtain begins to form, as the rim of the crater cavity moves upward and outward. But the maximum pressure in the floor is approximately 2 times lower than in the case of solid-solid impact. For oceanic depths exceeding two impactor diameters, the influence of the water layer is important. This layer strongly smoothes down impact effects. Underwater crater looks like a shallow bowl - the deeper is the ocean, the more shallow is the bowl. For oceanic depth of $4 \mathrm{~km}$ underwater crater is practically invisible. Pressure markers favor the great role of the water layer thickness. For the depths exceeding two impactor diameters, high pressure modifications of quartz do not arise, and mass of quartz, exposed to pressures above $15 \mathrm{GPa}$, sharply diminishes.

Summarizing results on the vertical impact, we can say that increase of oceanic depth (or decrease of the impactor diameter) is equivalent to the decrease of the impact velocity - the same effects may take place for higher velocity or for smaller impactor size.

Oblique impact. The most probable angle of the impact equals $45^{\circ}$. We model oblique impact with velocity of $20 \mathrm{~km} / \mathrm{s}$ into ocean of $1-2 \mathrm{~km}$ depth.

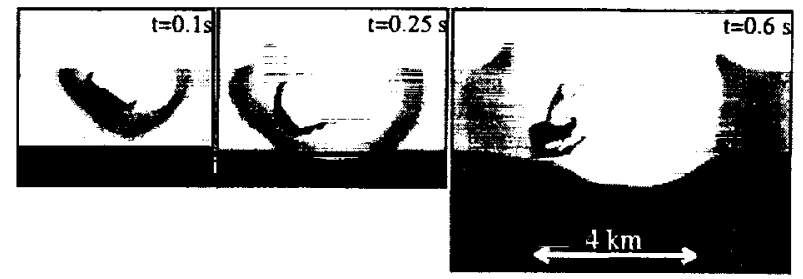

Fig.2. Density distributions for the oblique impact.

Shock wave in the water is not hemispherical - it is weaker behind the impactor, and stronger in the direction of its flight (Fig.2). Bottom crater is more shallow. Two parts of this crater may be distinguished: the first is associated with initial shock in the water, the second is connected with additional compression from the near-floor impactor. The projectile does not reach the floor, some parts of the projectile separate from it very early and move upward together with water excavation. The total mass of shock modified materials is essentially less than in the case of vertical impact with the same initial conditions.

Ejecta deposition. Long-term (up to $100 \mathrm{~s}$ ) calculations demonstrate space distribution of shockmodified (primarily melt) ejecta. In the case of vertical impact the cloud, consisting of vapor-liquid mixture, rises to the altitude of tens $\mathrm{km}$, its radius exceeds 20 $\mathrm{km}$. The next fate of the cloud material depends on the local atmospheric conditions, impact induced disturbances are small.

Results of numerical simulations together with geological data allow to estimate preimpact conditions and the size of impact affected region for the case of shallow (Chesapeake, Chicxulub) and deep (Eltanin) oceanic impacts. The results may be applied to the search of parent crater for the North-American and Australasian microtektites.

References: 1. Ahrens T.J. and O'Keefe J.D. (1983). $J G R$, 88, suppl.: A799-A806. 2. D.J.Roddy, S.H. Schuster et al. (1987). Int. J. Impact Engng. 65: 525 -541. 3. Nemtchinov I.V. et al. (1994). Solar System Research. 28: 81-99. 4. Gault D.E. and Sonett Ch.P. (1982). Geol.Soc.Amer.Spec. 190: 69-92. 5. Schmidt and Holsaple (1982). Geol.Soc.Amer.Spec. 190: 93-162. 6. Shuvalov V.V. et al. (1999) Int J. J.Impact Engng. 23: 847-858. 7. Thompson S.L. and H.S.Lauson (1972). Sandia National Laboratory Report SC-RR-71 0714. 8. Tillotson J.H. (1962) General Atomic Report GA-3216. 
ANALYSIS OF SIDERITE THERMAL DECOMPOSITION BY DIFFERENTIAL SCANNING CALORIMETRY. M. S. Bell', I.- C. Lin $^{2}$, and D. S. McKay ${ }^{2}$, ${ }^{1}$ University of Houston/Lockheed Martin, Houston, TX 77058, msbell@ems.jsc.nasa.gov , ${ }^{2}$ NASA Johnson Space Center, SN2, Houston, TX 77058

Introduction: Characterization of carbonate devolitilization has important implications for atmospheric interactions and climatic effects related to large meteorite impacts in platform sediments. On a smaller scale, meteorites contain carbonates which have witnessed shock metamorphic events and may record pressure/temperature histories of impact(s). ALH84001 meteorite containes zoned $\mathrm{Ca}-\mathrm{Mg}$-Fe-carbonates [1] which formed on Mars [2]. Magnetite crystals are found in the rims and cores of these carbonates and some are associated with void spaces leading to the suggestion by [3] that the crystals were produced by thermal decomposition of the carbonate at high temperature, possibly by incipient shock melting or devolitilization [4]. Golden et al. recently synthesized spherical $\mathrm{Mg}-\mathrm{Fe}$-Ca-carbonates from solution under mild hydrothermal conditions that have similar carbonate compositional zoning to those of ALH84001 [5]. They have shown experimental evidence that the carbonate-sulfidemagnetite assemblage in ALH84001 can result from a multi step inorganic process involving heating possibly due to shock events. Experimental shock studies on calcium carbonate prove its stability to $\sim 60 \mathrm{GPa}$, well in excess of the $\sim 45 \mathrm{GPa}$ peak pressures indicated by other shock features in ALH84001 [6] [7] [8]. In addition, Raman spectroscopy of carbonate globules in ALH84001 indicates no presence of $\mathrm{CaO}$ and $\mathrm{MgO}$ [9]. Such oxide phases should be found associated with the magnetites in voids if these magnetites are high temperature shock products, the voids resulting from devolitilization of $\mathrm{CO}_{2}$ from calcium or magnesium carbonate. However, if the starting material was siderite $\left(\mathrm{FeCO}_{3}\right)$, thermal breakdown of the ALH84001 carbonate at $470^{\circ} \mathrm{C}$ would produce iron oxide $+\mathrm{CO}_{2}[10]$. As no documentation of shock effects in siderite exists, we have begun shock experiments to determine whether or not magnetite is produced by the decomposition of siderite within the $<45 \mathrm{GPa}$ pressure window and by the resultant thermal pulse to $\sim 600^{\circ} \mathrm{C}$ experienced by ALH84001 [11]. Here, we report thermal and compositional characterization of unshocked siderite and its transition to magnetite.

Experimental: The same powdered siderite prepared for shock experiments (120 to 250 micron fraction) was used in our thermal experiments. X-ray diffraction (XRD) mineralogy of siderite starting material and magnetite decomposition product were determined on a Scintag XDS 2000 diffractometer using $\mathrm{CuK} \alpha$ radiation over the angular range 10 to $70^{\circ} 2 \theta$ counting continuously at 0.5 degrees $\min ^{-1}$. Differential scanning calorimetry (DSC) was performed using a Perkin-Elmer DSC-7, which was modified to conduct reduced pressure experiments [12] [13]. The DSC experiments were carried out at a heating rate of $20^{\circ} \mathrm{C} / \mathrm{min}$. Pressure was $0.1 \mathrm{bar}$ and gaseous atmosphere was flowing $\mathrm{CO}_{2}$ to approximate conditions on Mars.

Results and discussion: Siderite undergoes an endothermic reaction at around $500^{\circ} \mathrm{C}$ during heating (Fig. 1). This broad transition is related to the decarbonation of siderite. The depression in the peak is the exothermic oxidation of decarbonated iron oxides. This peak is diminished compared to peaks produced in higher pressure experiments [see fig. 2 in 10] indicating reduced endothermic processes under Mars-like conditions. Lower atmospheric 
pressure may result in a greater pressure gradient for the pathway of diffusion and facilitate the $\mathrm{CO}_{2}$ diffusing from the siderite lattice. The final product under Mars-like conditions and a thermal pulse $>600^{\circ} \mathrm{C}$ was magnetite $\left(\mathrm{Fe}_{3} \mathrm{O}_{4}\right)$.

Conclusions: It is postulated that ALH84001 has experienced peak shock pressures of $\sim 45 \mathrm{GPa}$ which should produce temperatures reaching $\sim 600^{\circ} \mathrm{C}$. Results of siderite heating experiments under Mars-like conditions predict decarbonation and transition to magnetite at the peak shock pressure evident in ALH84001.

References: [1] Mittlefeldt (1994) Meteoritics 29, 2, p214-221. [2] Borg et al. (1999) Science v.286 n.5437, p. 90-94. [3] Brearley et al. (1998) LPSC XXIX, CD-ROM. [4] Scott et al (1997) Nature, 387, 22, p.377-379. [5] Golden et al. (2000) LPSC XXXI, CDROM. [6] Bell et al. (1998) LPSC XXIX, CD-ROM. [7] Bell et al. (1999) LPSC XXX, CD-ROM. [8] van der Bogert et al. (1998) LPSC XXIX, CD-ROM. [9] Bell et al. (1999) GSA Annual Meeting, 31, 7, A45. [10] Lin et al., (2000) LPSC XXXI, CD-ROM. [11] Stoffler (2000) LPSC XXXI, CD-ROM. [12] Golden et al. (2000) LPSC XXX, CD-ROM. [13] Lauer et al. (2000) LPSC XXX, CDROM.

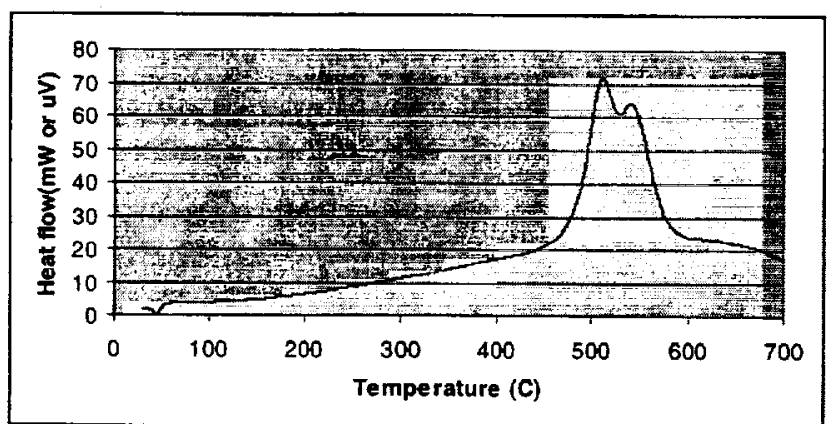

Figure 1. DSC scan for siderite, $0.1 \mathrm{bar}, \mathrm{CO}_{2}$ atmosphere. 
LATE ORDOVICIAN MASS EXTINCTIONS: CAUSES AND CONSEQUENCES - A VIEW FROM LAURENTIA. William B.N. Berry, Department of Earth and Planetary Science, 301 McCone Hall, University of California, Berkeley, California 94720 USA. bberry@uclink4.berkeley.edu

Introduction: Sepkoski [1] closely studied the generic-level Ordovician taxonomichistories of most marine invertebrates and concluded that the early part of the "Ordovician Period encompasses one of the most profound evolutionary radiations and marine faunal transitions of the Phanerozoic." That dramatic radiation was truncated abruptly in the Late Ordovician by one of the two or three most severe mass extinctions among marine organisms to occur within the Phaneroic. In that extinction Sepkoski [1] noted, generic diversity dropped to about the level of the pre-early-Ordovician proliferation. The Late Ordovician extinctions took place during a 1 to 2 million year interval of continental glaciation which developed in north-central Africa. Marine environmental and faunal consequences of that glacial interval have been examined closely in a number of Laurentian Plate stratigraphic successions. The Laurentian Plate lay within the tropics of the time. The studies reveal patterns inherent in the mass extinction and suggest a possible cause.

The Great Basin: One such study [2] has involved refined sedimentologic and biostratigraphic analyses of Late Ordovician environments representative of an inner shelf, an outer shelf and slope on the shelf margin. The area investigated lay on the western (in terms of modern orientation) side of Laurentia and is within the Great Basin. Graptolites and conodonts abound in the slope and ourter shelf successions. Conodonts and organic-walled microfossils are found in shelf strata. Inner shelf strata bear brchiopods, corals, crinozoans and bryozoans. The following patterns have been documented in study of the Great basin successions: 1) Late Ordovician graptolites inluded taxa that lived close to or on the periphery of oceanic oxygen minimum zones and taxa that lived in relatively more oxic waters, relatively removed from oxygen minimum zones. An oxygen miniumum zone existed along the Laurentian Plate margin during the latter part of the Ordovician. Sedimentologic evidence indicates that as sea level dropped, presumably as a result of glacio-eustacy, a shelf-marginal oxygen minimum zone became diminished and, ultimately, disappeared during glacioeustatic lowstand. Graptolites living near the oxygen minimum zone became extinct as their habitat disappeared. Disappearances were not synchronous, for those living closer to the oxygen minimum zone became extinct prior to those living near the periphery of the zone. Those graptolites living in oxic waters survived all oceanic changes during the glacial episode and even proliferated modestly during it. 2) Conodont taxa in the same stratal successions as the graptolites continued to survive as sea level fell. When depositional environments shallowed significantly, conodonts living in slope/basinal waters disappeared first. Their disappearance was followed by loss of the shelf-dwelling taxa. 3) Significant faunal turnovers occurred among the brachiopods [3] and most other shelly taxa as sea level fell. Among brachiopods, this turnover led to establishment of a new faunal association which persisted through the glacial episode. When deglaciation commenced and sea level rose, a second faunal turnover took place during which elements of the faunas that typify the Silurian appeared [3].

Carbon Isotopes: .Carbon isotope studies of whole rock carbonates bearing conodonts and graptolites in Nevada [2] reveal a sudden marked shift toward enhanced carbon-12 values at onset of glacio-eustatic sea level fall, followed by a marked enrichment in carbon- 13 that persisted throughout marine lowstand. Potential sinks for carbon-12 during the glacial interval include 


\section{LATE ORDOVICIAN MASS EXTINCTION: W. B. N. Berry}

wetland organisms inhabiting former marine depositional sites and within cold ocean water sinking in high latitudes.

Potential Cause. The Late Ordovician depositional record of the eastern (in modern directions) side of the Laurentian Plate suggests a potential factor that resulted in glaciation. Siliclastic sediments accumulated in a complex of fluviatile and deltaic environments (the Queenston delta) that spread widely on the eastern side of the Laurentian Plate, with the thickest deposits found in Pennsylvania, New York, and adjacent states [4]. Dennison [4] described this deltaicfluviatile complex, suggesting that it developed during glacio-eustatic sea level fall. As sea level dropped, base level was lowered and siliclastics, including red silts and muds, spread westward from an eastern highland source. This source resulted from plate collisions with Laurentia in the Late Ordovician [5]. Potentially, weathering of siliclastics that composed the source highlands of the Queenston deltaic complex could lowered atmospheric carbon dioxide concentrations and been a causal element leading to glaciation.

Tectonic Overprint. Interestingly, a latest Ordovician-early Silurian tectonic overprint is seen on Laurentian Plate margins. Dennison [4] described an unconformity separating Queenston deltaic sediments from superjacent Silurian strata. Great Basin slope sediments bearing latest Ordovician graptolites are overlain by early-late Silurian graptolite-bearing strata [2]. Similarly mid-early Silurian strata overlie latest Ordovician slope strata on the southern (in modern directions) Laurentian margin. Latest Ordovician-early Silurian tectonism on most Laurentian plate margins led to a depositional hiatus between glacial episode strata and those of mid to Late Llandovery age.

References: [1] Sepkoski, J. J. ( 1995) Ordovician odyssey: Short papers for the Seventh International Symposium on the Ordovician System. Pacific Section Society for Sedimentary Geology, 393-396. [2] Finney, S.C., Berry, W.B.N., Cooper, J.D., Ripperdan, R.L., Sweet, W.C., Jacobson, S.R., Soufiane, A., Achab, A. and Noble, P.J. (1999) Geology, 27, 215-218. [3]Sheehan, P.M., Coorough, P.J. and Fastovsky, D.E. (1996) Geol. Soc. America Special Paper 307, 477-489. [4] Dennison, J.M. (1976) The Ordovician System: Proceedings of a Palaeontological Association Symposium. University of Wales Press and National Museum of Wales, 107-120. [5]Robinson, P., Tucker, R.D., Bradley, D., Berry, H.N. IV and Osberg, P. (1998) $G F F, 120,119-148$. 
MÖSSBAUER SPECTROSCOPY OF K/T BOUNDARY CLAYS: CHARACTERISTICS OF IRON BEARING MINERALS. N. Bhandari ${ }^{1}$, H.C. Verma ${ }^{2}$, Amita Tripathi ${ }^{3}$, C. Upadhyay ${ }^{2}$ and R.P. Tripathi ${ }^{3}$ ${ }^{1}$ Physical Research Laboratory, Navrangpura, Ahmedabad 380009, India (bhandari@prl.ernet.in), ${ }^{2}$ Department of Physics, Indian Institute of Technology, Kanpur 208 016, India, ${ }^{3}$ Department of Physics, Jai Narain Vyas University, Jodhpur 342011, India.

Introduction: The $\mathrm{K} / \mathrm{T}$ boundary in the marine sediments is generally characterized by a thin band of limonitic clay. Geochemical anomalies in KTB clays have been attributed to impact of a large bolide on Earth, 65 M.Y. ago [1]. Several studies have been made to determine the nature of the impactor, climatic conditions arising from the impact and their biological effects. On the basis of the isotopic composition of chromium $\left({ }^{53} \mathrm{Cr} /{ }^{52} \mathrm{Cr}\right)$ the impactor appears to belong to the carbonaceous chondrite group of meteorites [2]. These meteorites have high concentration of iron $(-20 \%)$ in form of silicates, magnetite and other iron bearing minerals. Normally limonitic layers in terrestrial sediments are formed by subaerial exposure and represents a hiatus, but the limonitic layer at the KTB has been formed in a different process. A possible scenario can be described as follows. A large fraction of the impactor material and some target material would have vaporized and ejected into the atmosphere at high velocities during the impact. Because of its high abundance in the bolide as well as the large volume of the terrestrial material involved in crater formation, iron is expected to be a major component of the vapor cloud. The temperature of the vapor is likely to be high enough to dissociate many of the minerals. While the coarse ejecta would deposit in and around the foreground of the site of impact, the fine particulate material formed during the high temperature reactions in the vapor cloud followed by fast quenching is expected to disperse throughout the globe. The micron size nickel rich spinels [3] and the iridium nuggets[4] found to be associated with iridium in the limonitic layers were probably formed in such processes [5]. However, little is known about the nature of submicron particles, formed in such processes. They would be transported across the globe by atmospheric migration, followed by scavenging and deposition on land and oceans, and under the action of acid rain accompanying the large impact at KTB, resulted in formation of the limonitic layer. The variation in iron mineralogy across KTB can provide information about the chemical processes occurring in the atmosphere and the chemical environment prevailing at the deposition sites following the impact. We have therefore studied the limonitic layers from a few KTB sites, using ${ }^{57} \mathrm{Fe}$ Mössbauer spectroscopy, which is ideally suited for understanding the physico-chemical processes responsible for their formation.
Sample details: Mössbauer analysis was carried out on iridium rich (KTB) layers from Gubbio, Meghalaya, Anjar and Turkmenia and some samples from above and below the KTB layers. Gubbio (Bottaccione) section in Italy is a deep marine section where the Ir anomaly was first discovered [1] in the mass-extinction horizon and several other impact markers (Ni rich spinels, shocked quartz, soot, etc.) have been found. Meghalaya is a near coastal marine section in the eastern India [6] whereas Anjar (Kutch) is a continental lake section in the Deccan volcanosedimentary sequence in western India [7]. Both these sites were located outside the fallout zone according to the demarcations made by Alvarez [8] for various ballistic velocities. The Meghalaya section has anomalously high Ir and Ni-rich spinels [9] at KTB whereas three well separated layers with high iridium have been observed in the Anjar section [7]. Turkmenia shows iridium anomaly and characteristic excursions of $\mathrm{C}$ and $\mathrm{O}$ isotopes.

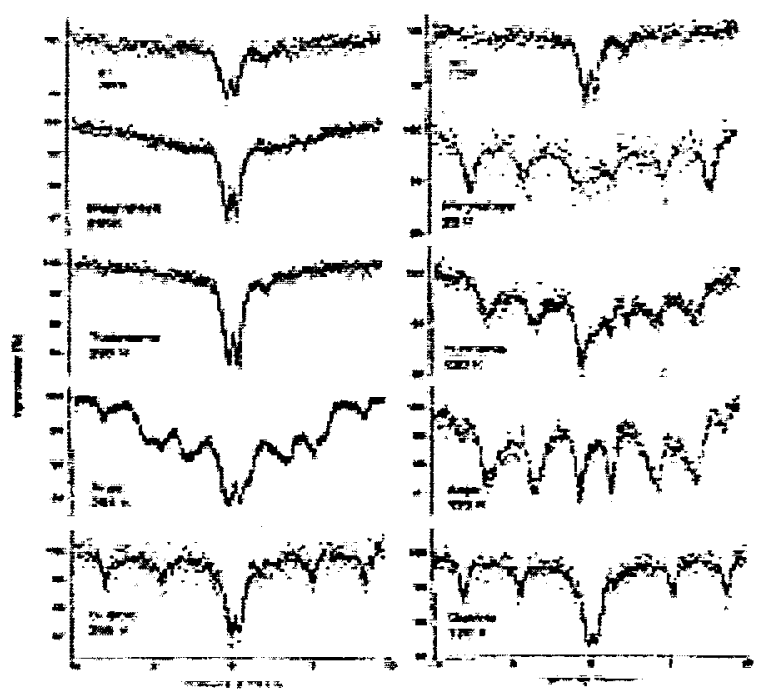

Fig. 1 Mössbauer transmission at $295 \mathrm{~K}$ (left) and at $120 \mathrm{~K}$ (right) for various KTB clays. Mössbauer spectra of sample B1 away from KTB is given for comparison.

Experimental method: The Mössbauer spectroscopy was carried out using a conventional constant acceleration Mössbauer spectrometer at IIT, Kanpur. The absorbers for Mössbauer spectroscopy were prepared from the powdered samples. ${ }^{57} \mathrm{Co}$ in $\mathrm{Rh}$ matrix was used as the Mössbauer source. A 
liquid nitrogen cryostat was used for cooling, except for temperatures below $80 \mathrm{~K}$ where a close-cycle helium cryostat system from APD Cryogenics was used. X-ray diffraction patterns were recorded using a Seifert Iso-Debyflex 2002 diffractometer using $\mathrm{Cu}$ $\mathrm{K}_{\alpha}$ radiation.

Results: Fig. 1 shows the Mössbauer spectra of KTB samples studied at $295 \mathrm{~K}$ (RT) and at $120 \mathrm{~K}$ (LT). The Mössbauer parameters show that all the KTB samples have magnetic phases of iron together with $\mathrm{Fe}^{3+}$ in clay minerals (largely illite). At RT, Gubbio shows a well developed six line pattern whereas Anjar shows partially relaxed spectrum. The RT spectra of Meghalaya and Turkmenia do not show magnetic splitting at RT but both of these are superparamagnetic (SPM) as confirmed by their low temperature spectra. Considering that the particle size of iron component is related to the blocking temperature at which the sextet collapses to a doublet, we find that particle size in the Gubbio KTB sample is well above $10 \mathrm{~nm}$, whereas the particle size of the magnetic iron phases is smaller in Anjar and still smaller in Meghalaya and Turkmenia KTB samples. Such fine size is also inferred from the broadness of the XRD peaks. The particle size shows a decreasing trend with distance from the Chicxulub crater. Gubbio shows hyperfine magnetic field (HMF) of $522 \mathrm{kOe}$, indicating the presence of hematite $\left(\alpha \mathrm{Fe}_{2} \mathrm{O}_{3}\right)$ as the main magnetic phase. Anjar also has a small component of hematite but the major part is with HMF of $415 \mathrm{kOe}$ or lower showing the presence of göthite, and possibly maghemite $\left(\gamma \mathrm{Fe}_{2} \mathrm{O}_{3}\right)$. The HMFs of Meghalaya and Turkmenia spectra correspond to goethite. These observations are supported by the X-ray diffraction patterns. The Mössbauer parameters for the central doublet in Gubbio, Meghalaya and Turkmenia correspond to $\mathrm{Fe}^{3+}$ in illite, which is a common clay mineral. Thus we find that the oxide phases of iron appear at all sites irrespective of the lithology of the local sediments, indicating a global nature of the chemical environment at $\mathrm{KTB}$.

Fig. 2 shows the Mössbauer spectra of the Anjar samples at $100 \mathrm{~K}$ collected at various stratigraphic distances above and below the limonitic layer. The sharp variation in the iron phases at KTB is quite clear. Magnetic oxides appear suddenly at KTB and disappear above and below it. The off-KTB samples are devoid of magnetic phases as well as iridium. The amount of magnetic phases of iron correlates with iridium content, indicating that they probably have a common origin. Similar correlation is found for the Meghalaya and other sites.

Discussion: The presence of oxide and hydroxide phases of iron at all the KTB layers irrespective of the local lithology is indicative of the climatic excursion at KTB. It is possible that these oxide and oxyhydroxide iron phases are formed by leaching of iron by the accompanying acid rains. The presence of hematite indicates severe environmental conditions (arid and warm) whereas göthite forms under milder conditions of temperature and aridity. Such information may be used to infer about the climatic conditions in various parts of the Earth at the $\mathrm{K} / \mathrm{T}$ boundary. The decreasing size of SPM particles from impact to deposition site is consistent with atmospheric migration as discussed above. Based on these limited studies we suggest that sudden appearance of iron based oxide particles with a size distribution dominated by nanometer range at a geological boundary may be indicative of large-

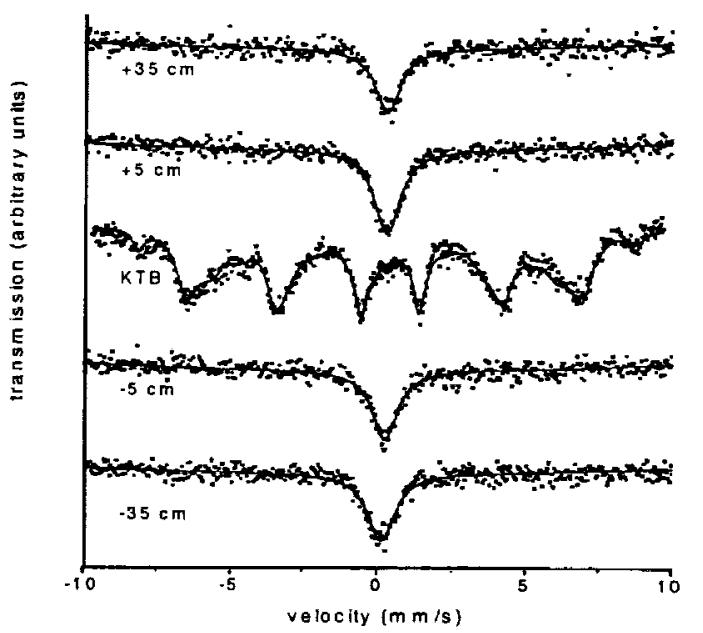

Fig. 2. Mössbauer spectra of samples at different stratigraphic distance from the KTB in Anjar section.

bolide impact. Work is in progress to confirm the magnetic phases present at other boundaries, such as at P/T boundary.

References : [1] Alvarez, L.W. et al. (1980) Science, 208, 1095-1109. [2] Shukolyukov A. and Lugmair G.W. (1998) Science, 282, 927-929. [3] Robin, E.et al. (1992), Earth Planet. Sci. Lett., 108, 181-190. [4] Schuraytz B.C. et al. (1996), Science, 271, 1573-1576 [5] Kyte F.T., et al. (1996) Geol. Soc. Am. Spec. Pap.,307, 389-401. [6] Bhandari N. et al. (1994) Chem. Geol., 113, 45-60. [7] Bhandari, N. et al (1995). Geophys. Res. Letts., 22, 433-436. [8] Alvarez W. (1996) Geol. Soc. Am. Spec. Pap., 307, 141-150. [9] Bhandari N. (1998) Proc. Ind. Acad. Sci. 107, 251-263. 
HIGH-PRECISION GEOCHRONOLOGY AND MASS EXTINCTIONS:CHRONOMETRIC TESTS OF EXTINCTION MECHANISMS. S.A. Bowring, M.W. Martin, and M.D. Schmitz, Massachusetts Institute of Technology, Dept. Earth, Atmospheric and Planetary Sciences, Bldg. 54-1126, Cambridge, MA 02139, USA.

Introduction: High-precision geochronology has the potential to revolutionize our understanding of mass extinctions and biotic recoveries. Of particular importance for evaluating extinction mechanisms and recoveries is a precise temporal framework for the distribution of fossils and chemostratigraphic signals in the stratigraphic record before, during, and following an extinction event. A major question is whether the six major Phanerozoic extinctions have a common mechanism(s). Recent improvements in geochronological techniques and the recognition that the distribution of time in the rock record can, in some cases, be highly resolved using a combination of ash-beds interlayered with fossil bearing strata allows new insight into the six major Phanerozoic extinctions. Critical tests of extinctions caused by global catastrophes such as bolide impacts where ejecta layers have not been identified, involve establishing the contemporanity of paleontologically or chemostratigraphically defined boundaries in both marine and terrestrial settings at maximum possible resolution $(0.1 \%$ or better). Test of volcanically influenced extinctions (e.g. SiberianTraps) will rely on precise chronometric constraints of extinction horizons and volcanic centers. We will review the temporal constraints on the major extinction events and possible causes.

Geochronological tools which are the most useful for resolving the tempo of extinction events are U-Pb (zircon) and ${ }^{40} \mathrm{Ar} /{ }^{39} \mathrm{Ar}$ (feldspar,biotite, hornblende). However due to uncertainties in decay constants and flux monitors (Renne et. al;, 1998;1999; Schmitz and Bowring, 1999), for example, comparisons of dates using the two systems at the $500 \mathrm{~K}$ year level is impossible. In addition, $\mathrm{U}-\mathrm{Pb}$ zircon geochronology can be complicated by complex $\mathrm{Pb}$-loss and inheritance (Bowring et al; 1998; Mundil et al;. 1999).

However, these impediments can and will be overcome and the the tempo of extinctions and recoveries throughout the Phanerozoic determined

References: [1] Renne, P.R., et al. (1998) Science 282, 1840-1841. [2] Renne, P.R. et al. (1998) Chem. Geol. 145, 117-152. [3] Schmitz, M.D. and Bowring, S.A. (1999) $9^{\text {th }}$ Ann. Goldschmidt Conf. Abstr., 262-263. [4] Bowring, S. A. et al. (1998) Science 284, 1039-1045. [5] Mundil, R. et al. (1999) Geol. Soc. Am. Abstr. and Prog., A289. 
SEARCH FOR IMPACT EVIDENCE AT THE PERMO-TRIASSIC BOUNDARY IN THE NORTHEASTERN FREE STATE PROVINCE, SOUTH AFRICA. D. Brandt ${ }^{1}$, P.J. Hancox ${ }^{1}$, W.U. Reimold ${ }^{1}$ and C. Koeberl', 'Impact Cratering Research Group, Department of Geology, University of the Witwatersrand, Private Bag 3, Wits 2050, South Africa; 065dion@cosmos.wits.ac.za; ${ }^{2}$ Institute of Geochemistry, University of Vienna, Althanstr. 14, A-1090 Vienna, Austria.

Introduction: The Permo-Triassic faunal crisis has long been considered to be the greatest mass extinction event in the history of our planet [e.g., 1]. The cause of this crisis, especially in the terrestrial realm, is, however, not well understood. Although microspherules, spinels, and iridium anomalies have been reported from a number of Permo-Triassic boundary sections, all have been disputed. Strong evidence for any causal relationship to an impact event, for example, in the form of shock deformation, has not yet been observed in Permo-Triassic boundary rocks [e.g., 2].

In the southem part or the main Karoo Basin of South Africa, the Permo-Triassic boundary has recently become the focus of several detailed studies in terms of its stratigraphy, palaeontology $[3,4]$, palaeomagnetics [5; Rampino, pers.comm.], as well as carbon and oxygen isotope signatures [6-8]. In the northwestern part of the basin, the boundary is less studied and has been placed at the contact marking the faunal changeover from the Dicynodon to Lystrosaurus assemblage zones [8]. Lithostratigraphically, this coincides with the contact between the Normandien (=Balfour) and Verkykerskop (Katberg) Formations $[9,10]$. Near the town of Senekal in the Free State Province, the boundary is placed within an old quarry (now a nursery) to the northeast of the town [11] and is marked by a zone of brown weathering calcareous nodules and concretionary structures. This section is no longer easily accessible, but better exposures exist to the south and southeast of the town. In 1998, one of the new sections was drilled for palaeomagnetic studies (Kirschvink, pers.comm), although, it was not sampled for geochemical analysis. This section is also currently the focus of various palaeontological and stratigraphic studies. For these reasons we decided to sample the two sections, south and southeast of Senekal, in detail in order to search for evidence of the cause of this extinction event in the nonmarine realm of the northeastern Karoo Basin. Samples collected from these sections have been studied petrographically for possible evidence of shock deformation and analysed for major and trace element contents by XRF and INAA (in progress).

Results: The sections sampled consisted of planar bedded to massive interbedded clays and fine sands, overlain by a massive, planar bedded and planar cross-bedded sandstone, containing ironoxide nodules. The iron-oxide nodules are found predominantly in the lower $15 \mathrm{~cm}$ of the overlying sandstone unit. The Permo-Triassic boundary is thought to be at, or close to, this lithological boundary. It should be noted that the sandstones display an erosive lower contact; that is, they may well have scoured away a significant portion of the originally underlying clay surface. In thin section, the siltstone/clay-rich sediment shows banding on a millimeter to a sub-millimeter scale. The silt sized grains consist predominantly of quartz and kaolinite, with interspersed, slightly larger grains of diagenetic muscovite. Iron oxide staining (originally organic rich bands) is primarily responsible for the darker bands. The sandstones consist predominantly of well sorted, rounded to very angular (overall angular) quartz grains. Minor feldspar (mostly plagioclase), biotite and muscovite (diagenetic) are also present. These fine-grained sediments are cemented by silica and iron oxide. The quartz grain boundaries show evidence of pressure solution, which is probably responsible, in part, for the relatively high angularity of the grains.

None of the samples from this interval displays any petrographic evidence of shock metamorphism. 
To date, XRF results for the two profiles have been obtained. INAA experiments on both sample suites are in progress and results will be reported at the conference. From the XRF data currently available, no significant siderophile element anomaly $(\mathrm{Co}, \mathrm{Ni})$ seems evident.

Conclusions: Clay pellet conglomerates have been reported to contain shocked quartz at nonmarine P/T sections in Antarctica and Australia [12]. To date, no planar deformation features have been identified in the section studied, as well as elsewhere within the Permo-Triassic sequence in South Africa. The search for other Permo-Triassic sections in southern Africa is underway, in an attempt for further investigations of this nature. Unlike the $\mathrm{K} / \mathrm{T}$ boundary, evidence for a major impact at the Permo-Triassic boundary is less forthcoming. Retallack et al. [12] have shown the possibility of shocked quartz and iridium anomalies in fluvially dominated sequences in Antarctica and Australia, however, a similar search in the northeastern Karoo Basin of South Africa, has, so far, proved fruitless. This could be accounted for by a number of possibilities including the incorrect stratigraphic placement of the contact studied here, and non-preservation of the boundary, in that the contact is marked by an erosional or hiatal surface where sediment did not actively accumulate during the time of the $\mathrm{P} / \mathrm{T}$ crisis.

References: [1] Erwin D. (1994) Nature, 367, 231-236. [2] Yang Z.Y et al. (1995) GSSP; Episode, v.1E, 49-53. [3] Smith R.M.H. (1995) Palaeogeogr. Palaeoclimat. Palaeoecol., 117, 81104. [4] Macleod K.G. et al. (1998) Nature, in press. [5] Kirschvink J.L. and Ward P.D. (1998). J. Afr. Earth Sciences, 27 (IA), Special Abstract Issue, Gondwana 10, 124 pp. [6] Thackeray J.F. et al. (1990) Nature, 347, 751-753. [7] Smith R.M.H. and Macleod K.G. (1998) J. Afr. Earth Sciences, 27 (1A), Special Abstract Issue, Gondwana 10, 185-186. [8] Hancox P.J. this volume. [9] Groenewald G.H. (1984) Unpubl. M.Sc.Thesis, Rand Afrikaans University, Johannesburg, South Africa. [10] Groenewald G.H. (1990) Palaeont. Afr., 27, 21-30. [11] Kitching J.W. (1977) BPI Palaeontology Res., Memoir 1, Wits University, South Africa, 131 pp. [12] Retallack G.J. et al. (1998) Geology, 26 (11), 979-982. 


\section{TESTING THE IMPACT MODEL: HIGH RESOLUTION ORGANIC WALLED DINOFLAGELLATE CYST ANALYSIS ACROSS THE CRETACEOUS/TERTIARY BOUNDARY. H. Brinkhuis ${ }^{1}$, T. Van Hoof ${ }^{1}$, S. Galeotti ${ }^{2}$ and J. Smit ${ }^{3}$, ${ }^{1}$ Laboratory of Palaeobotany and Palynology, Utrecht University, Budapestlaan 4, 3584CD Utrecht, The Netherlands (H.Brinkhuis@ bio.uu.nl), ${ }^{2}$ Istituto di Geologia and Centro di Palinologia, Universita di Urbino, loc. Crocicchia, I-61029 Urbino, Italy, ${ }^{3}$ Dept. of Geology, Inst. of Earth Sciences, Vrije Universiteit Amsterdam, De Boelelaan 1085, 1081 HV Amsterdam, The Netherlands.}

Organic-walled cyst producing dinoflagellates were not pushed to extinction at or near the Cretaceous/Tertiary boundary (KTB). This aspect makes this plankton group well-suited for high-resolution cross-KTB paleoenvironmental analysis, including the testing of the model(s) of the global environmental consequences of the proposed KTB giant impact event.

Quantitative analysis of organic-walled dinoflagellate cyst (dinocyst) assemblages from closely spaced samples across the KTB at sites like El Kef (Tunisia), Caravaca (Spain), Brazos River (USA) and Stevns Klint (Denmark) allows for reconstructions of sea surface temperature (SST) trends. The combined dinocyst-based SST curves indicate relatively stable warm conditions during the latest Maastrichtian in contrast to strongly fluctuating and on average cooler conditions during the earliest Danian. In detail, the results indicate cooling across the KTB, immediately followed by an interval of pronounced warming, the latter recorded in all studied sections. Two more cooling pulses may be recognized in the overlying interval followed by a gradual return to stable, relatively warm conditions. Our data furthermore show that these KTB-related climatic changes invoked distinct migration among organic-walled producing dinoflagellates, recordable in both hemispheres. In the shallow water setting of the El Kef boundary stratotype section, quantitative changes shown by dinocyst assemblages are associated, at the KTB, with a sharp spike in the proportion of sinistral individuals of the benthic foraminifera Cibicidoides pseudoacutus possibly indicating that a concomitant cooling of surface and bottom water occurred in the lowermost Danian (Fig 1).

Recent models predict periods varying between several months to 8-13 yr of global cooling ('impact winter') and reduced solar transmission as a direct result of the Chicxulub KTB impact, followed by relatively long-term, excess $\mathrm{CO}_{2}$-related global warming. Our results are inline with such models, but suggest that the impact-related cooling phase may have lasted longer, and that marked climatic instability continued to some 100,000 yrs following the KTB event(s). 
TESTING THE IMPACT MODEL: $H$. Brinkhuis et. al.

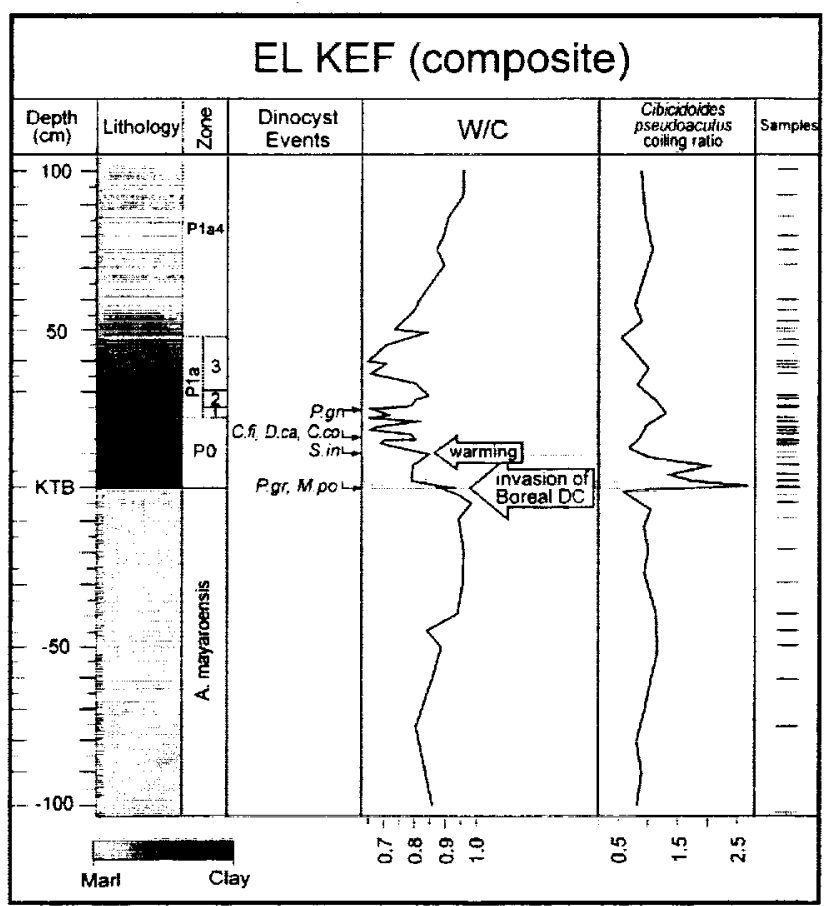

Figure 1: lithology, sample positions, planktic foram zones, dinoflagellate events, and dinocystbased Warm/Cold SST curve of the (composite) El Kef section from Brinkhuis et al., 1998. In addition, the coiling ratio of the benthic foraminifera Cibicidoides pseudoacutus from Galeotti \& Brinkhuis (subm.) is plotted. 
PALLADIUM AND GOLD AS INDICATORS OF K/T BOUNDARY SECTIONS. R. R. Brooks ${ }^{1}$, A.W. Cook ${ }^{1}$ and R. B. Stewart', 'Soil and Earth Sciences, Institute of Natural Resources, Massey University, Palmerston North New Zealand, r.brooks@massey.ac.nz and r.b.stewart@massey.ac.nz.

Introduction: When the idea was first suggested that enhanced iridium concentrations in $\mathrm{K} / \mathrm{T}$ boundary clays were indicative of a meteoritic impact [1], it was only because of the constraints of chemical analysis that this particular element had been cited. At that time, the scientific community had been wedded to the use of the highly regarded techniques of radiochemical and instrumental neutron activation analysis (RNAA and INAA) whereby iridium was the platinum group metal (PGM) with the lowest limit of detection among these six elements. As an indicator of extraterrestrial material in boundary clays, gold or any one of the other five PGM would have served equally well since their concentrations in chondritic material are much higher than in the Earth's crust.

The main disadvantages of RNAA and INAA are that reactor-based facilities are not available in most laboratories, and that limits of detection for iridium are much lower than for the other PGM, some of which, such as palladium, are very difficult to quantify by these methods. The development of plasma emission mass spectrometry (ICP-MS) has provided a means of determining gold and all the PGM with a high degree of sensitivity. Unfortunately, this instrumentation is expensive and not available in most laboratories.

The technique of graphite furnace atomic absorption spectrometry (GFAAS) is a procedure that provides sensitivity comparable to INAA and ICP-MS. It complements INAA extremely well because palladium, platinum and ruthenium can be determined at much lower limits of detection (l.o.d.) than INAA, yet the other three PGM have better 1.o.d. by INAA. Instrumentation for GFAAS is common in many laboratories and is an inexpensive alternative to INAA or ICP-MS. For the past 15 years, we have regularly used GFAAS to quantify gold and palladium in $\mathrm{KTT}$ boundary material and present our findings below.

Analytical methods: Using a method developed in our laboratory [2], finely ground samples $(1 \mathrm{~g})$ were digested with $10 \mathrm{~mL}$ of a 1:1 mixture of hydrofluoric and nitric acids and taken to dryness. The residue was then treated with $10 \mathrm{~mL}$ of aqua regia and evaporated almost to dryness. The residue was taken up with $5 \mathrm{M}$ hydrochloric acid to which was added $0.2 \mathrm{~mL}$ of a $100 \%(w / v)$ solution of potassium iodide. The gold and palladium were then extracted as their iodo complexes into methylisobutyl ketone (MIBK). The organic layers were transferred to a GFAAS instrument and gold and palladium quantified by atomising at $2500^{\circ} \mathrm{C}$ after ashing at $400^{\circ} \mathrm{C}$ and $900^{\circ} \mathrm{C}$ respectively.

Mineralogical analysis [3] was carried out on K/T boundary material. Samples were treated with liquids of different density to separate out the clay, silt and sand fractions that were then analysed by GFAAS.

Results and Discussion: Our samples consisted of $\mathrm{K} / \mathrm{T}$ boundary material from Woodside Creek, the original locus classicus described by Alvarez et al. [1], and from Chancet Quarry (Flaxbourne River), a nearby site with a well preserved section containing most of the diagnostic microfossils [4]. There was a very highly significant $(\mathrm{P}<0.001)$ relationship between the Pd vs. Ir and $\mathrm{Au}$ vs. Ir concentrations in both of the above sections. This is illustrated in Figs. 1-4.

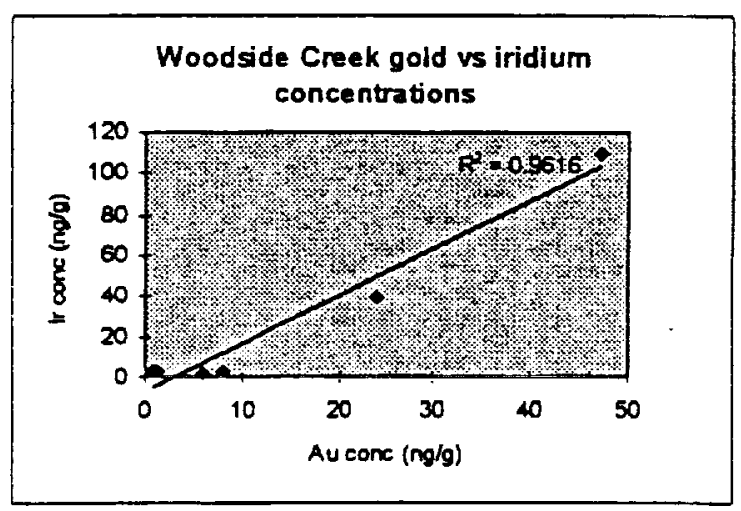

Figure 1

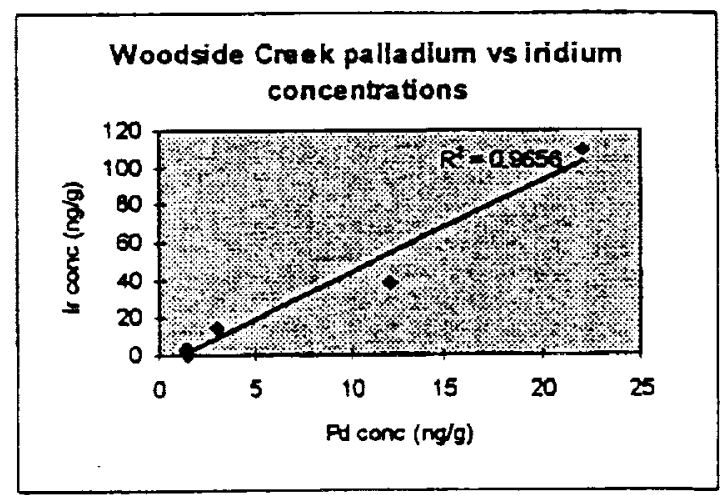

Figure 2 
PALLADIUM AND GOLD AS INDICATORS: R. R. Brooks et al.

Elemental abundances and concentration quotients of gold, iridium and palladium are given in Table 1 Palladium and gold indicators of $\mathrm{K} / \mathrm{T}$ boundaries that also includes data for $\mathrm{Cl}$ carbonaceous chondrites [5].

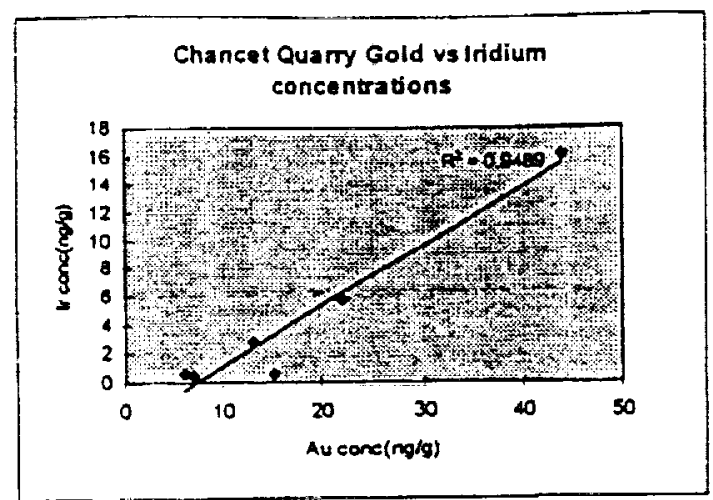

Figure 3

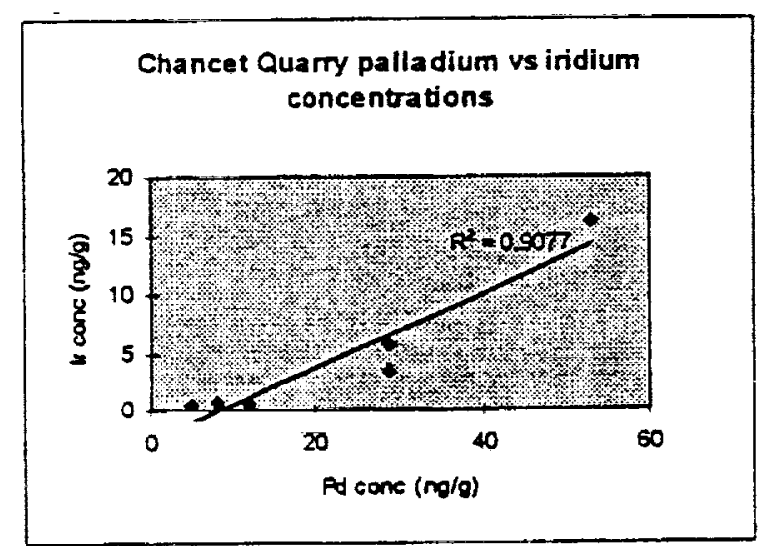

Figure 4

Table 1. Elemental abundances $(\mathrm{ng} / \mathrm{g}=\mathrm{ppb})$ and concentration quotients in $\mathrm{K} / \mathrm{T}$ boundary material

\begin{tabular}{|c|c|c|c|c|c|}
\hline & Bulk & Sand & Clay & Silt & $\mathrm{C} 1 *$ \\
\hline \multicolumn{6}{|c|}{ Woodside Creek } \\
\hline $\mathrm{Au}$ & 55 & 280 & 15 & 110 & 140 \\
\hline $\mathrm{Pd}$ & 20 & 8 & 28 & 2.5 & 560 \\
\hline Ir & 110 & $17^{* *}$ & $33^{* *}$ & - & 481 \\
\hline $\mathrm{Pd} / \mathrm{Ir}_{\mathrm{r}}$ & 0.18 & 0.47 & 0.85 & - & 1.16 \\
\hline $\mathrm{Au} / \mathrm{Ir}$ & 0.50 & 16 & 0.45 & - & 0.29 \\
\hline $\mathrm{Pd} / \mathrm{Au}$ & 0.36 & 0.03 & 1.87 & - & 4.00 \\
\hline \multicolumn{6}{|c|}{ Chancet Quarry (Flaxbourne River) } \\
\hline $\mathrm{Au}$ & 44 & 2 & 14 & 12 & 140 \\
\hline $\mathrm{Pd}$ & 53 & 6 & 4 & - & 560 \\
\hline Ir & 16 & - & - & - & 481 \\
\hline $\mathrm{Pd} / \mathrm{Ir}$ & 3.30 & - & - & - & 1.16 \\
\hline $\mathrm{Au} / \mathrm{Ir}$ & 2.80 & - & - & - & 0.29 \\
\hline $\mathrm{Pd} / \mathrm{Au}$ & 1.20 & - & - & - & 4.00 \\
\hline
\end{tabular}

${ }^{*} \mathrm{C} 1$ chondrites [5], ${ }^{* *}$ Data from [6].
Although gold and palladium concentrations in $\mathrm{K} / \mathrm{T}$ boundary material closely follow those of iridium, there is clear disproportionality in their distribution among the different mineral phases and between sites. The Woodside Creek site is more heavily oxidised than is Chancet Quarry, having been exposed to weathering for a very long period, whereas the Chancet Quarry site is pristine and was uncovered by rock blasting only about 10 years ago. Compared with $\mathrm{Cl}$ chondrites, there is at Woodside Creek, a deficiency of palladium and excess of gold. This is probably because palladium behaves in meteorites more like a chalcophile element than a siderophile [7]. Extensive weathering and oxidation has resulted in a strong residual gold signature at this site.

At Chancet Quarry, the lesser degree of oxidation and weathering has resulted in concentrations of palladium that are higher than at Woodside Creek, with a consequent increases in the elemental concentration quotients dependent on these higher levels.

It is concluded that gold and palladium concentrations in $\mathrm{K} / \mathrm{T}$ boundary material define the boundary equally as well as iridium and can moreover be determined analytically at lower cost as well as with equal sensitivity. Although palladium is classified as siderophile, it is unique among the PGM in having some characteristics of a chalcophile element in meteoritic material and thereby can serve as an indicator of the degree of oxidation and/or weathering of a given site when comparing abundance quotients with this element and gold or other PGM.

References: [1] Alvarez L.W. et al. (1980) Science, 208, 1095-1108. [2] Brooks R.R. and Lee B.S. (1988) Anal. Chim. Acta, 204, 333-337. [3] Whitton J.S. and Churchman G.J. (1987) N.Z. Soil Bureau Sci. Rep. \#79. [4] Strong C.P. et al. (1987) Geochim. Cosmochim. Acta, 2769-2777. [5] Anders E. and Grevisse N. (1989) Geochim. Cosmochim. Acta, 53, 197-214. [6] Evans N.J. et al. (1994) Meteoritics 29, 223-235. [7] Wasson J.T. (1985) Meteorites, Freeman, New York. 
PALEONTOLOGICAL CONSTRAINTS ON THE DURATION Ö K/T BOUNDARY EXTINCTION EVENTS. Eric Buffetaut, Centre National de la Recherche Scientifique, 16 cour du Liégat, 75013 Paris, France. Eric.Buffetaut@wanadoo.fr.

One of the major contentious issues among paleontologists concerning the extinctions of the Cretaceous-Tertiary boundary is the duration of the extinction process itself, with tenants of gradual extinctions thinking in terms of millions of years and catastrophists posutlating much shorter time spans. As already emphasized elsewhere [1], a catastrophic model of impact-induced extinctions apparently fits the available paleontological data concerning vertebrates better than a gradual one. This leads to a further question : can the duration of the extinction events be estimated with any accuracy?

It is now widely accepted that the prime causal factor for mass extinction on a global scale at the $\mathrm{K} / \mathrm{T}$ boundary was the injection of enormous amounts of dust into the atmosphere following the Chicxulub impact, which caused sufficient light reduction to stop photosynthesis and thus led to the collapse of various food chains. Although estimates about the length of this period of darkness have varied, it is commonly accepted that it may have lasted for several months. Independently from phyical models about the dust cloud, paleontological data also provide evidence about the possible duration of the event and its biological consequences. Some approaches which may prove valuable for estimates of the duration of the extinction event are presented below.

The hypothesis implies that during the period of darkness there was a drastic decline in plant productivity, but that many plants could survive the unfavorable period by going into dormancy, and that vegetation could reestablish itself from seeds, spores, etc., once sufficient amounts of solar energy became available again. This would seem to be in agreement with a pariod of darkness lasting for several months, or possibly much longer, considering the resistance of some seeds to adverse conditions. A possibly interesting appraoch would be to estimate what is the minimum duration required for a period of darkness to lead to a significant devastation of plant life (both in the oceans and on land).

A second step is the collapse of food chains following devastation of plant communities. In other words, how long would it take for plant-eating animals to starve as a consequence of the lack of plants? A precise estimate is not easy for extinct forms with no living counterparts, such as dinosaurs, since their physiological requirements are not well known. However, if dinosaurs possessed relatively high metabolic rates, as has often been suggested, the large herbivorous forms probably required a considerable daily intake of plant food, in which case extinction by starvation may have been a rapid process. Again, a few months of darkness would seem to have been sufficient.

The final step in the collapse of food chains is the extinction of predators by starvation. On land, this mainly means carnivorous dinosaurs, although some other forms (such as giant terrestrial lizards) may also have been affected. Again, the high metabolic rates envisioned for theropods would suggest rapid starvation.

On land at least, it would thus appear that a period of darkness lasting for several months may well have been suficient to cause widespread extinctions through food chain collapse. It should be remembered, however, that things certainly were much more complicated than simple starvation leading to extinction. What must be envisioned is very rapid ecosystem decay on a large (global) scale, with resulting complex patterns of extinction (and survival) which will probably be very difficult to unravel. This may explain some of the extinctions for which a simple explanation is not obvious, such as that of small carnivorous dinosaurs (which, at least in theory, should have been able to survive on mamals, lizards and other small surviving animals). Because of the long-term effects of ecosystem disruption, the duration of the mass extinction event probably exceeded that of the period of darkness, and may have been spread over years or decades.

Groups of organims that survived the mass extinction also provide clues as to the duration of the events. Freshwater communities are known to have suffered comparatively few extinctions. This can be explained by the fact that the freshwater food chains ultimately depend on particles of organic matter in the water rather than on living plants. However, the ultimate source of organic matter in freshwater is living organisms, including thoe living on land, and this implies that organic productivity cannot have stopped for a very long period - otherwise the supply of organic matter to the freshwater environment would have dried up. The same applies to the community of small terrestrial animals, the survival of which is ascribed to a food chain based on organic matter in humus and soil, and to benthic communities, which supposedly survived on organic matter in bottom mud. Again, 
PALEONTOLOGICAL CONSTRAINTS: E. Buffetaut

quantitative estimates are not easy, but survival patterns at the $\mathrm{K} / \mathrm{T}$ boundary are in agreement with a shortduration event.

Temperature change is a poorly understood factor in the $\mathrm{K} / \mathrm{T}$ mass extinction. Some models predict a severe temperature drop, with sub-freezing temperatures lasting for months. This is not in agreement with the survival of reptiles with living representatives known to be unable to endure low temperatures (such as crocodilians). Although hibernation processes may have helped survival under adverse conditions, they probably would not have been sufficient to ensure it if very low temperatures lasted for months. If a severe temperature drop occurred, it cannot have lasted very long. Again, more accurate estimates are not easy to provide.

It thus appears that paleontological and biological data can provide some constraints concerning the duration of the extinction events at the Cretaceous-Tertiary boundary. On the whole, they do not suggest a longlasting period of extreme environmental stress. Paleontological data are thus in generally good agreement with impact scenarios involving a period of deep environmental crisis lasting for some months, although some aspects (especially the often suggested drastic temperature drop) are problematic. The bulk of the extinctions may have taken place within a very short time geologically speaking, probably only a few months, even though the longer lasting consequences of ecosystem disruption may have caused additional extinctions over a more extended time span. However, beyond listing victims and survivors, unravelling the extinctions events that took place 65 million years ago and precisely estimating their duration will be an extremely difficult task, both because of the imperfection of the fossil record and because of the insufficient temporal resolution currently available, although some of the approaches outlined above may eventually provide chronological constraints.

[1] Buffetaut, E., Journal of Conference Abstracts, 4, 1, 268, 1999. 


\section{Impact Lethality and Risks}

Clark R. Chapman

Southwest Research Institute

Suite 426, 1050 Walnut St.

This invited review will summarize our current understanding of the modern impact hazard from asteroids and comets and place it in the larger context of Earth history. The numbers of impactors of various sizes is quite well known. There is improved understanding of the kinds of physical and environmental consequences to be expected from impacts of various sizes. There is only a poor understanding of how various species, including human beings (and our civilization), might fare under various impact scenarios. Surely our political and economic structures, and our own psychology, are poorly adapted to dealing with very rare events of unprecedented consequence.

We may look for analogs in several places. First, there is a body of knowledge (called "surety") that undertakes to reduce very small risks, for example in nuclear weapons and airliner safety contexts. Second, there are other hypothetical but possibly very real risks from modern technological society (e.g. potential plagues, terrorism involving toxic substances or nuclear weapons, and hypothesized accidents from experimental physics). Finally, we may look to the historical record -- especially on our own planet -- for insight about potential strategies for dealing with the impact hazard.

It is very unlikely that, within our lifetimes, we will be threatened with what doomed most fossil species during the $\mathrm{K} / \mathrm{T}$ extinction. But the chances of a cosmic catastrophe are not zero. 


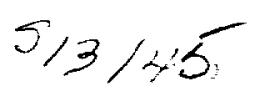

24 Carastrophic Events Conference

WHAT IS EXACTLY THE ROLE OF EVAPORITES IN THE CHICXULUB EVENT? P. Claeys, Institut f. Mineralogie,
Museum f. Naturkunde, D-10099 Berlin, Germany, (philippe.claeys@ @ rz.hu-berlin.de)

Precisely how the Chicxulub impact affected the global Earth System remains to be clearly documented. There is a general agreement that the enormous amount of energy abruptly released by the impact caused a major perturbation of the atmosphere and the oceans, which ultimately lead to the observed mass extinction of organisms. To clearly understand the effect of the Chicxulub event on the biosphere, it is capital to know the composition and concentration of volatiles released by the impact. Unfortunately these depend on two poorly constrained factors.

1) The behavior of carbonates and evaporites under the high shock pressure is not fully understood. The precise amount of $\mathrm{CO}_{2}$ released from shocked carbonates is not known. Experiments carried on in different labs and thermodynamic calculations disagree significantly as to the onset pressure of degassing $[1,2,3]$. In evaporites $\mathrm{SO}_{3}$ outgassing begins around 30 to $40 \mathrm{GPa}$ shock loading pressure and is completed at 60 to $80 \mathrm{GPa}$ [4]. But recovery experiments by Ivanov et al. showed no decomposition of anhydrite shocked at $63 \mathrm{Gpa}$ and these authors concluded that reliable values of shock pressures required for partial or complete anhydrite decomposition are still not available [5]. Obviously further experimental work is needed.

2) At the scale of the crater, the composition of Yucatan target rock is not well known. The basement underneath the Yucatan Peninsula is of Pan African age ( $\pm 550 \mathrm{Ma}$ ) and consists of quartz chlorite schist, quartzite, granites and volcanic rocks such as rhyolites [6]. Clastic red beds, siltstones, sandstones and silty dolomite of either Triassic or Jurassic to Early Cretaceous ages occur above the silicate basement. The extension and thickness of these units appear poorly constrained. The overlying Cretaceous is composed of a 2 to $3 \mathrm{~km}$ thick sequence of shallow water limestones and dolomite interbedded with anhydrite. Several authors have assumed that the $3 \mathrm{~km}$ thick sedimentary component of the Yucatan target rock contains 30 to almost $60 \%$ evaporites $[6,7]$. These estimations were based essentially on the study of well cuttings and the old Pemex cores drilled in or near the Chicxulub structure. This of $30 \%$ evaporites has been used in several models illustrating the effect of Chicxulub on the atmosphere. Evaporite clasts and thick layered evaporites have been recovered in the breccia from the shallow wells drilled by UNAM at or near the crater rim [8]. Their exact proportion has not yet been estimated in detail. No evaporite occurs in the distal part of the Chicxulub ejecta blanket which mainly consist of dolomite blocks locally eroded from the underlying strata. The Chicxulub impact fractured the margin of the Yucatan platform margin. Thick breccia formed of shallow water carbonate blocks then accumulated in deep water environment offshore the platform [9]. These shallow water carbonate blocks found at the KT boundary in the states of Tabasco and Chia. pas do not contain pseudomorph of evaporite minerals as is expected when carbonate beds are interlayered with thick sequences of evaporites. Based on field work and core observation, it is difficult to confirm that evaporites formed $30 \%$ (or more) of the Yucatan platform layers.

Another approach to learn about the target rock is to use impact glass chemistry to identify the different end-members. Blum and Chamberlain [10] showed that the stable isotope composition of the Beloc (Haiti) glasses fall on a mixing line between isotopically heavy Ca-rich and a lighter silica end members. They interpret their results has the product of mixing Yucatan deep basement and with a carbonate sedimentary cover allowing only for a small contribution of evaporitic material $(<10 \%)$. Koeberl [11] came to the same conclusion based on rare earth and trace element compositions of the black and yellow impact glasses. The yellow, high Ca-rich impact glass from Beloc (Haiti) contains $<1$ wt\% sulfur. Its abundance in the ejecta bed is difficult to estimate because it alters faster than the $\mathrm{SiO}_{2}$-rich black glass. Chaussidon et al. [12] showed that all isotopic signatures of this yellow glass ( $11 \mathrm{~B}, \cdot 180, \cdot 34 \mathrm{~S}$ ) can be explained by mixing of variable proportion of andesite ( 31 to $75 \%$, mean $49 \%$ ), sulfate ( 5 to $47 \%$, mean $30 \%$ ), red sandstone ( 3 to $26 \%$, mean $14 \%$ ) and carbonate $(0$ to $26 \%$, mean $7 \%$ ). This result is still ambiguous and unconstrained. Also, since impact glass originated from a specific region of the crater, its signature may not be representative of the whole the target rock.

Petrography of the crater impactite and ejecta product also provide constrains as to the type and physical state of the sedimentary components involved in the Chicxulub event. For example, the production of carbonate melt is often not considered. Former melted-carbonates grains (Fig 1) occurs in both the Chicxulub suevite and in the ejecta. Melting of carbonate was thus a significant process, which needs to be accounted for when estimating the amount of $\mathrm{CO} 2$ released. More information on the amount of evaporite present in the target rock can be obtained from the composition of the clasts found in the suevite. The fall-back suevite recovered from the well Yucatan 6 (Y6) on the side of the Chicxulub crater peak ring contains abundant clasts originating from the different lithologies which form the Yucatan target. The upper part of the Y6 suevite (sample N13, N-14) located on the side of the peak ring is clearly dominated by sedimentary clasts from the upper $3 \mathrm{~km}$ of the target. Detailed point counting of the available material indicates that much less than $10 \%$ of the sedimentary clasts present in the suevite are composed of anhydrite (Fig 2). SEM observation indicate that the matrix which probably condensed from the vapor cloud, also contains very little anhydrite. But secondary anhydrite occurs also as void-filling material in both the suevite and underlying melt rock. Suevite clast proportion should be determined at other location of the crater and the present $1 / 10$ evaporite to carbonate proportion based on only a few samples taken from a $\sim 200 \mathrm{~m}$ thick suevite. This value may thus not be representative of the whole unit. Nevertheless, it is recommended to use the proportion of only $10 \%$ evaporite in the target rock when modeling the atmospheric consequences of the Chicxulub impact. 
[1] Tyburczy, J. A., and Ahrens, T. J., (1986), JGR 91, 4730-4744. [2] Martinez, I., et al., (1995), JGR 100, 1546515476. [3] Pierazzo, E., Kring, D. A., and Melosh, H. J., 1998, JGR 103, 28607-28625. [4] Badjukov, D., Dikov, Y.P., Petrova, T.L., and Pershin, S.V., (1995), Abstract LPSC XXVI 63-64. [5] Ivanov, B.A., et al., (1996), in Ryder, G., Fastovsky, D., and Gartner, S., eds., GSA Spec. Pub. 307, 125-140. [6] Lopez Ramos, E., (1975), in Naim, A. E. M., and Stehli, F. G., eds., The gulf of Mexico and the Caribbean, 3: New York, Plenum, 257-282. [7] Ward, W.C., Keller, G., Stinnesbeck, W., and Adatte, T., (1995), Geology, 23, 873876. [8] Urrutia-Fucugauchi, J., Marin, L., and Trejo-Garcia, A., (1996), GRL 23, 1565-1568. [9] Grajales et al., (2000) in press Geology. [10] Blum, J.D., and Chamberlain, C.P., (1992), Science, 257, 1104-1107. [11] Koeberl, C., (1993), Geology, 21, 211-214. [12] Chaussidon, M., Sigurdsson, H., and Metrich, N., (1996), GSA Spec. Pub. 307, 253-262.
Fig. 1 Two feathery calcite crystals rapidly quenched from a carbonate melt found in the suevite of Y6 (field of view 1.5

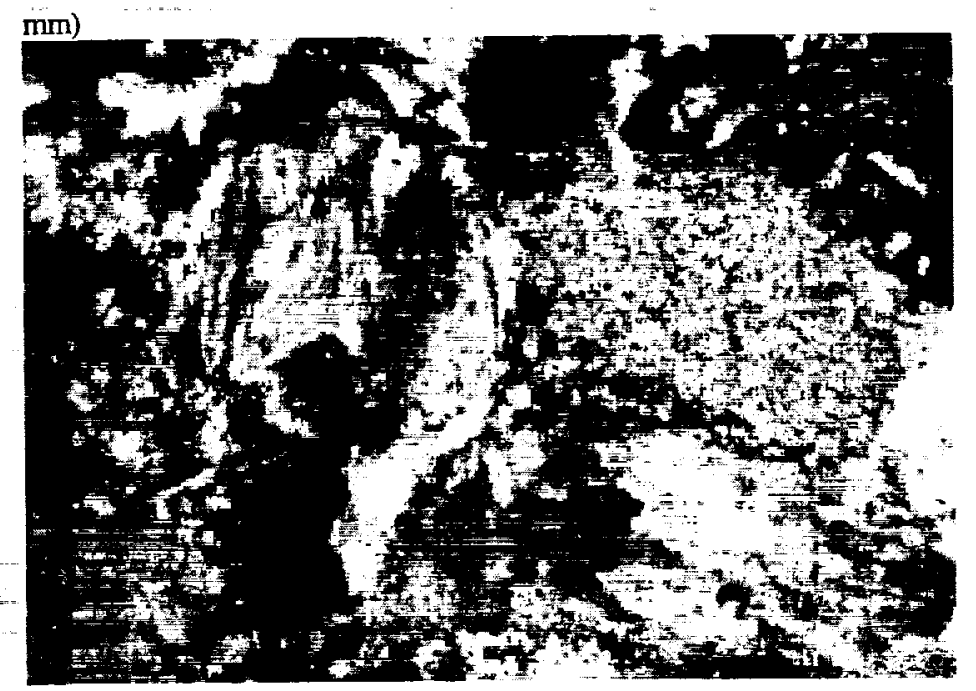

Fig. 2 thin section photo (scale in mm on the left), only one anhydrite grain was found, most of the others are carbonates, along with a few basement and melt clasts.

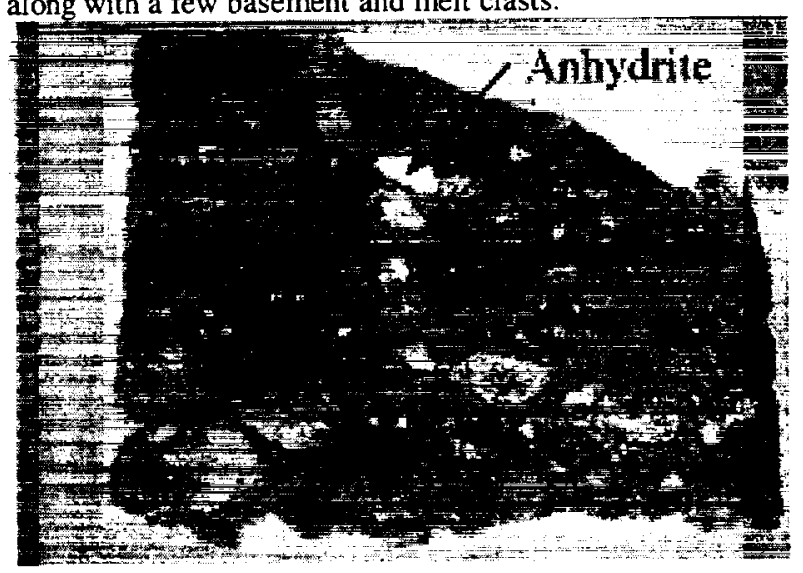


GLOBAL DISTRIBUTION OF CHICXULUB EJECTA. P. Claeys ${ }^{1} \mathrm{~W}$. Kiessling ${ }^{1}$ and W. Alvarez ${ }^{2},{ }^{1}$ Institut fuer Mineralogie, Museum fuer Natrukunde, Berlin, D-10099 Germany (philippe.claeys@rz.hu-berlin.de), ${ }^{2}$ Dept. of Geology and Geophysics, University of California, Berkeley, CA. 94720-4767, USA (platetec@socrates.berkeley.edu).

Chicxulub, - the only crater to have well preserved, proximal to distal ejecta deposit sequence - can be used to study crater-ejecta relationships. Our KT boundary data base (KTbase) contains detailed mineralogical, geochemical and sedimentological information on the type, abundance and characteristics of the ejecta. It is coupled with a Geographic Information System (GIS) to document the global distribution of the ejecta (Fig. 1).

Fig. 1 Distribution of KT ejecta maybe inducelocal tsunamis as those reported in the Atlantic. In Southern Mexico, collapse of the margins of the Yucatan platform is demonstrated by the accumulation in deeper water of a thick breccia formed of shallow water carbonate material (Fig. 2) [5]. The ejecta blanket extends all over Yucatan up to $-300 \mathrm{~km}$ from the crater rim (Fig. 2). In the UNAM 5, 6, and 7 wells it is formed of a polymict breccia mixing basements, evaporite and carbonate clasts. Further away, the breccia contain essentially locally reworked material admixed by secondary cratering and ero-

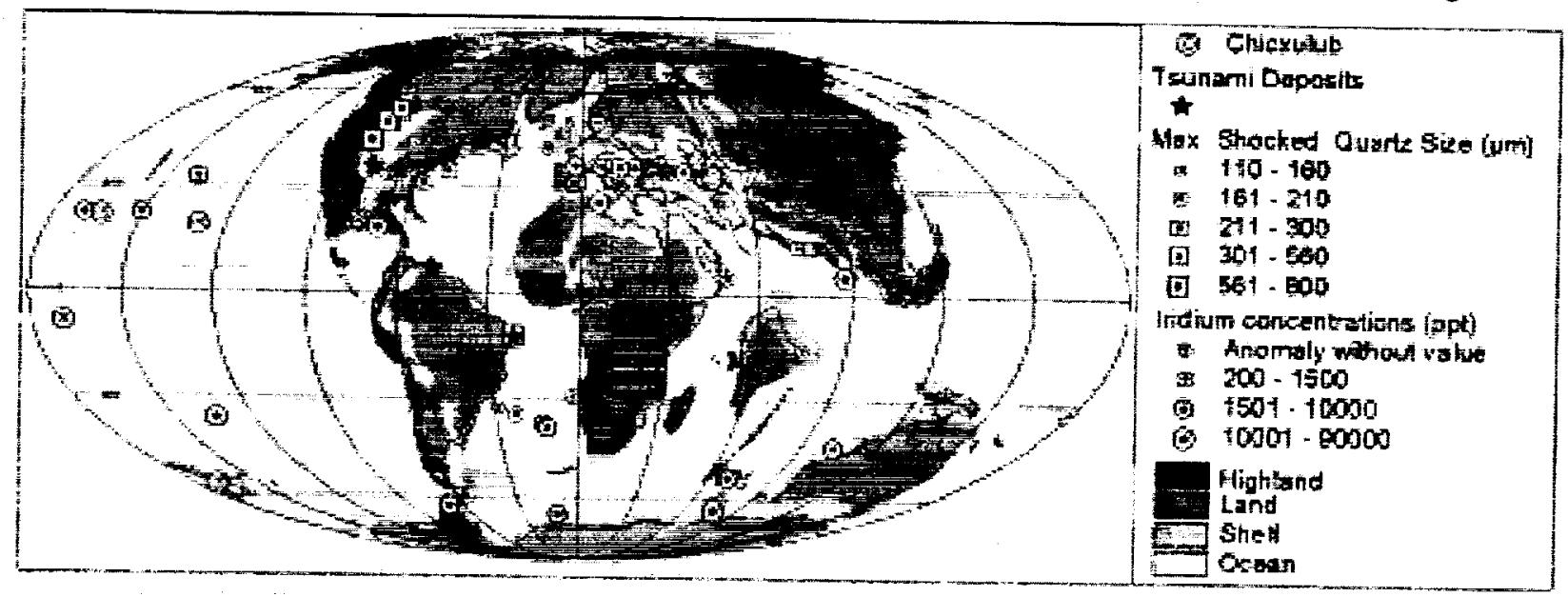

The concentration of the Ir anomaly does not correlate with distance from the crater. The lower concentrations detected at proximal KT sites can be attributed due to the dilution of the If carrier by the high volume of sediment in suspension in the Gulf of Mexico waters, due to tsunami effects and the collapse of the platform edges. The westward skewed distribution of shocked quartz is corroborated. The presence of large grains in Brazil [1] conflicts with the view that this distribution results from an oblique impact originating from the southwest [2]. It is perhaps more compatible with the hypothesis that the rotation of the Earth affects differently the ballistic trajectory and orbit of the eastbound and westbound particles [3]. More data is needed from KT boundary sites in the Northem part of South America. Altered glass spherules with tektite-like morphologies are found within a $-4000 \mathrm{~km}$ radius from Chicxulub (Fig. 2). In the Gulf of Mexico region only, they occur together with limestone fragments of comparable size and shape. Their close association and intimate mixing of carbonate and silicate phases indicates that they coalesced in flight in an ejecta curtain formed of a mixture of solid, shocked and molten silicate and carbonate material. Tsunami deposits are restricted to the Gulf of Mexico region (Fig. 2). But mass failure of the slope margin extends along the Eastern margin of North America all the way to the Bermuda raise [4]. These can sion. In Quitana Roo, Campeche and Belize, it is formed by a $>20$ thick diamictite-like breccia with large $(>10 \mathrm{~m})$ dolomite blocks [6]. The breccia rests on upper Cretaceous stratified dolomite which bedding becomes progressively fractured upward. Basal Paleocene strata (P. eugubina) is missing above the diamictite. Little primary crater material occurs in the breccia, mainly in the form of millimeter-size greenish spherules (Fig. 3). Locally metric-size pockets of pure clay mineral are visible. They resemble glass-bombs and contain millimeter-size fragments similar to the basement clasts from the Chicxulub suevite.

[1] Albertão, G.A., and Martins, P.P.J., (1996), , Sedimentary Geology, 104, 189-201, [2] Schultz, P. H., and D'Hondt S., (1996), Geology, 24, 963-967, [3] Alvarez, W., Claeys, P., and Kieffer, S.W., (1995), Science, 269, 930-935, [4] Norris, R. D., (1999), GSA, 31 th annual meeting, Abstracts with Programs, 31, A-123, [5] Grajales et al., (2000), Geology in press, [6] Pope et al., 1999, EPSL, 170, 351-3 
Fig. 2 Distribution of proximal ejecta

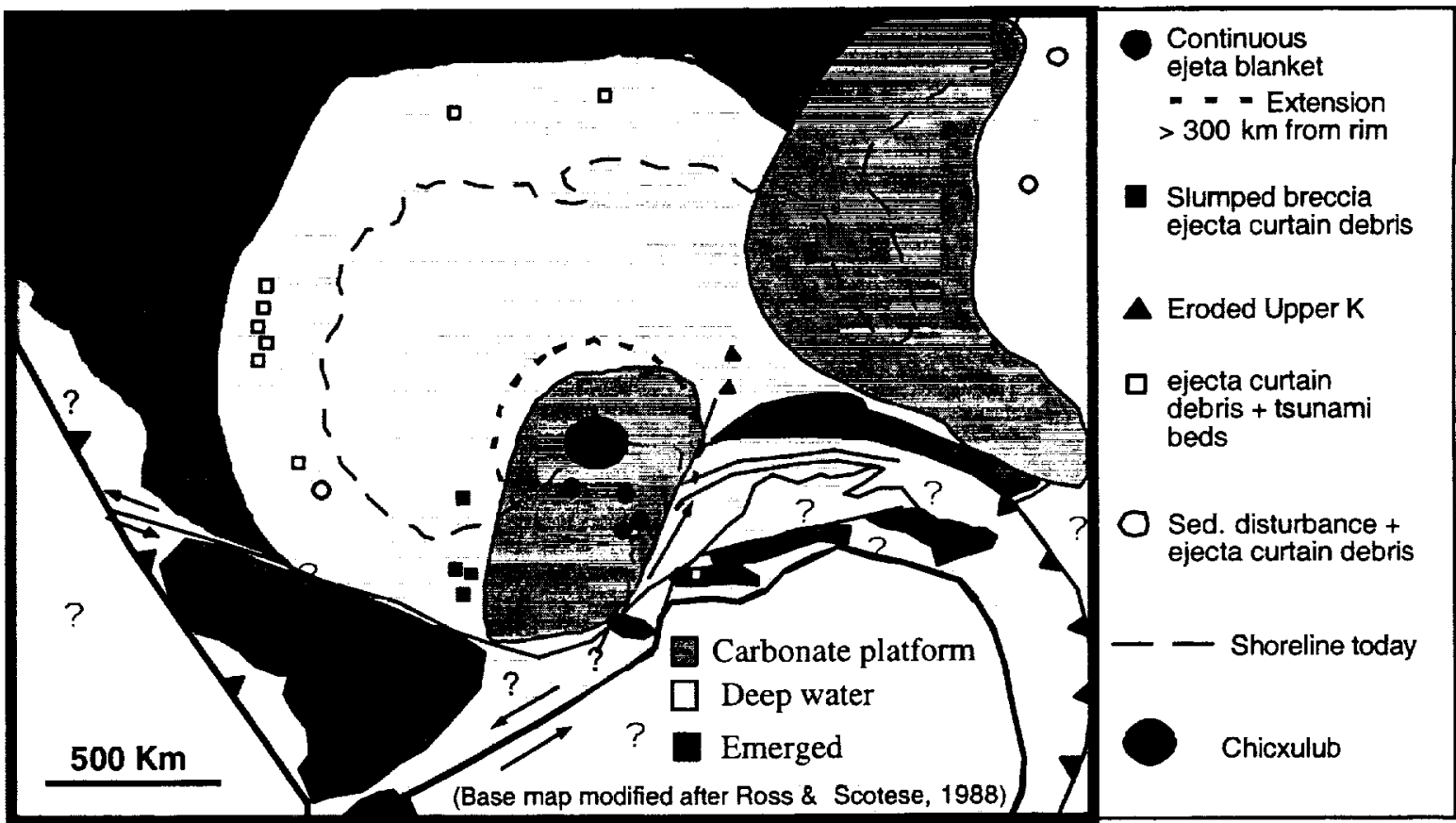

Fig. 3 Altered glass spherule from the ejecta blanket near the Mexican-Belize border.

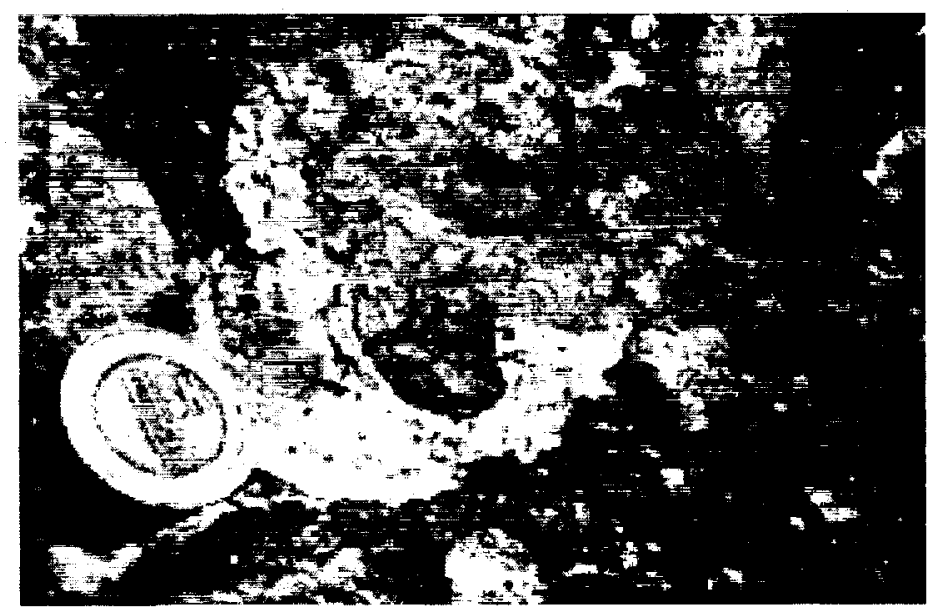


LONG-TERM ENVIRONMENTAL PERTURBATIONS FOLLOWING A LATE EOCENE IMPACT? EVIDENCE FROM THE MASSIGNANO GSSP, ITALY. R. Coccioni ${ }^{1}$, D. Basso ${ }^{2}$, H. Brinkhuis $^{3}$, S. Galeotti $^{1}$, S. Gardin ${ }^{4}$, S. Monechi ${ }^{5}$, and S. Spezzaferri ${ }^{2}, 1$ Istituto di Geologia e Centro di Palinologia dell'Università, Campus Scientifico, Località Crocicchia, 61209 Urbino, Italy e-mail: cron @info-net.it; 2 Dipartimento di Scienze della Terra, Via Mangiagalli 34, 20133 Milano, Italy e-maili silvia@erdw.ethz.ch; 3 Laboratory of Palaeobotany and Palynology, Utrecht University, Budapestlaan 4, 3584 CD Utrecht The Netherlands, e-mail: H.Brinkhuis@bio.uu.nl; 4) ESA-CNRS 70731761 Département de Géologie Sédimentaire, Université Pierre et Marie Curie, 4 Place Jussieu, 75252 Paris, France, e-mail: gardin@ccr.jussieu.fr; 5 Dipartimento di Scienze della Terra, Via La Pira 4, 50121 Firenze, Italy, e-mail: Monechi@steno.geo.unifi.it

The Eocene-Oligocene (E-O) transition (37-33 $\mathrm{Ma}$ ) witnessed long-term important changes in oceanic circulation and climate (see [1], for a review).

In such a context of global changes, the late Eocene is characterised by a striking concentration of extraterrestrial body impact evidence with the two largest known impact craters (Popigai and Chesapeake Bay) of the Cenozoic Era occurring almost synchronously at about $35.6 \mathrm{Ma}$ [2], [3]. Moreover, $3 \mathrm{He}$ based evidence indicates that a comet shower wich, in many cases, produced impact debris [4] invested our planet across these major impact events.

Most of these cosmic signatures are recorded in the 23 m-thick Massignano Section, the Global Stratotype Section and Point (GSSP) for the E-O boundary [5]. In particular, two Ir-rich layers occur at $5.65 \mathrm{~m}$ and $10.25 \mathrm{~m}$ above the base of the section [6] and are associated with major spikes of extraterrestrial ${ }^{3} \mathrm{He}$ [4]. The impactoclastic layer at $5.65 \mathrm{~m}$ which contains high concentrations of shocked quartz grains [7] and Ni-rich spinel crystals [8], is dated as old as $35.7 \pm 0.4$ Ma [6], [7] and has been correlated to the Pacific strewn field ([6], [7] [9] [10]).

A high resolution, multidisciplinary analysis based on dinoflagellate cysts (dinocysts), calcareous nannofossils, and foraminifera suggests that the impact event recorded at Massignano had no abrupt, dramatic effects on marine biota in terms of extintion. However, significant quantitative changes in the calcareous plankton and dinoflagellate cyst assemblages occurred following the impact event.

An abrupt shift towards lower values in the planktonic foraminiferal SST curve occurs above the impact layer suggesting that a major cooling pulse took place shortly after, though not immediately following, the impact. A marked increase in the abundance of deep and/or cooler and intermediate water planktic foraminifera accompanied the shift of planktic foraminiferal SST curve. This indicates that a water structure re-organization (e.g. more superficial thermocline, enhanced water stratification) followed the impact.

Besides fossil evidences, a sudden change of sediment color from reddish to greenish occurs across the impact layer testifying a major decrease of ventilation on the sea floor.

The observed pattern is intepreted as reflecting a long-term water structure re-organization (e.g. shallower thermocline and/or water stratification).

We interpret the long-term trend observed after the impact as the expression of a feedback mechanism that might have sustained for a longer time the environmental perturbation produced by the impact itself. In a context of ongoing global cooling such a feedback mechanism might have been relied upon increased extension of snow-cover in the Antarctic region in turn caused by increased albedo and/or seasonality.

A similar pattern of long-term environmental changes (e.g. accelerated cooling) has been reported by [10] across the same impact layer in the southern high-latitude ODP Site 689B (Maud Rise) suggesting a global extension of the impact-induced perturbation.

\section{References:}

[1] Prothero, D.R. (1994) The Eocene-Oligocene Transition - Paradise Lost: Columbia University Press, $291 \mathrm{p}$.

[2] Koeberl, C., Poag, C.W., Reimold, W.H., and Brandt, D. (1996), Science, 271, 1263-1266.

[3] Bottomley , R., Grieve, R., York,, D., and Masaitis, V. (1997) Nature, 388, 365-368.

[4] Farley, K.A., Montanari, A., Shoemaker, E.M., and Shoemaker, C.S. (1998) Science, 280, 1250-1253.

[5] Premoli Silva, I., and Jenkins, D.G., 1993, Episodes, 16, 379-381.

[6] Montanari, A., Asaro, F., Michel, H.V., and Kennett, J.P. (1993) Palaios, 8, 420-437.

[7] Clymer, A.K., Bice, D.M., and Montanari, A. (1996) Geology, 24, 483-486.

[8] Pierrard, O., Robin, E., Rocchia, R., and Montanari, A. (1998) Geology, 26, 307- 310.

[9] Langenhorst, F., and Clymer, A.K. (1996) Geology, 24, 487-490.

[10] Vonhof, H.B., PhD Thesis, Academisch Proefshrift, University of Utrecht. 
Long-Term environmental perturbation : R. Coccioni et al.

GLOBAL STRATOTYPE SECTION AND POINT FOR THE EOCENE/OLIGOCENE BOUNDARY THE GSSP OF MASSIGNANO
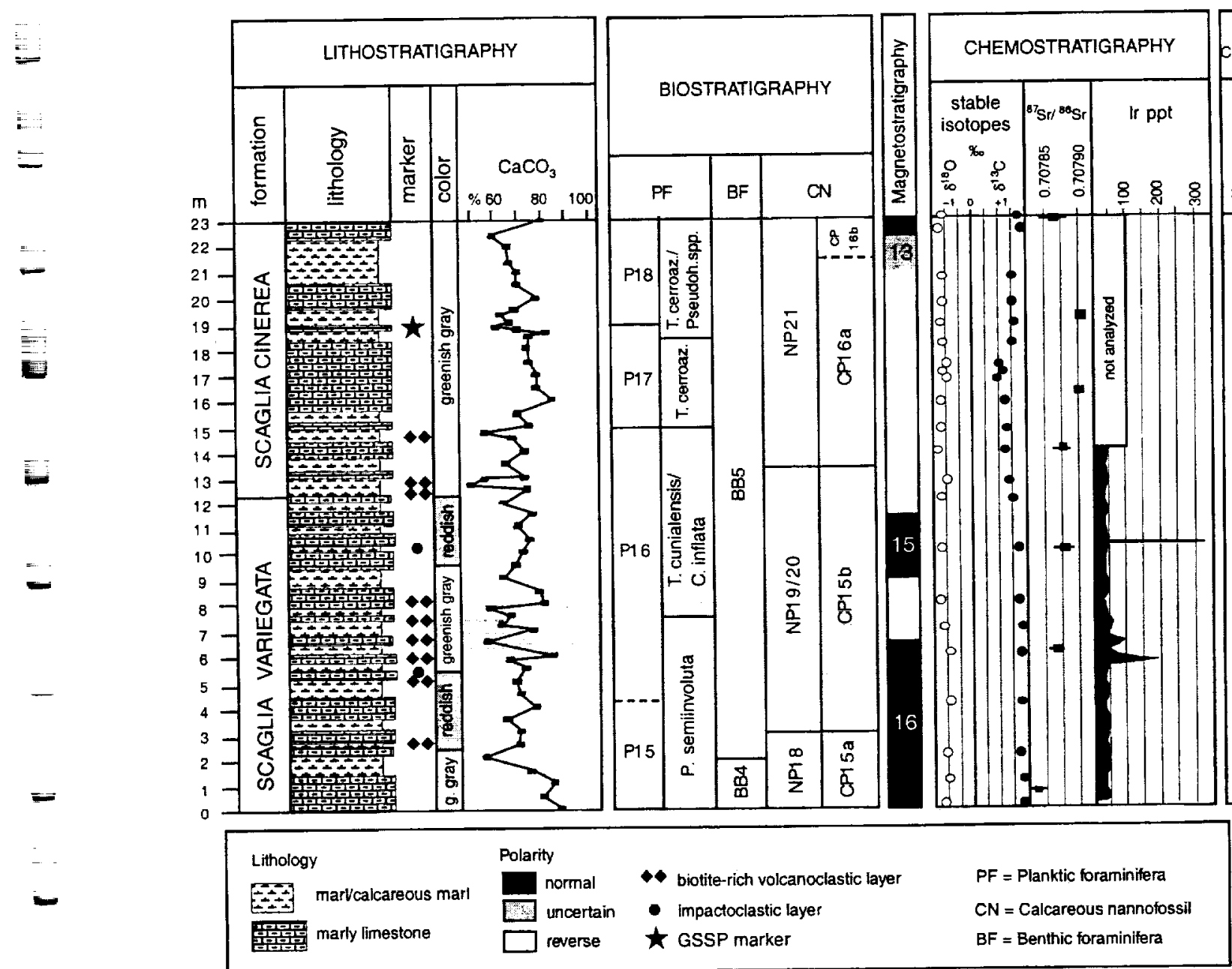

Figure 1. Integrated stratigraphy of the GSSP for the E/O boundary at Massignano. The present study is focused on the $4-8 \mathrm{~m}$ segment which is marked by the shaded band 
RADIO SEARCH FOR EXTRASOLAR COMETARY IMPACTS AT 22 GHz (WATER MASER EMISSION). C. B.Cosmovici ${ }^{1}$, S. Pogrebenko ${ }^{2}$, S. Montebugnoli ${ }^{3}$, and G. Maccaferri $^{3}$, 'IFSUCNR, Fosso del Cavaliere 100, Roma, Italy, ${ }^{2}$ JIVE, P.B. 2, 7990 AA Dwingeloo, The Netherlands, ${ }^{3}$ IRA/CNR, Via Fiorentina, 40060 Villa Fontana, Bologna, Italy.

The impact of 21 fragments of Comet Shoemaker-Levy/9 with the jovian atmosphere in July 1994 gave astronomers for the first time the opportunity to study the chemistry and physics of a planet during a catastrophic impact. A great amount of scientific data could be achieved by using space- and ground-based facilities and one of the most important results was the delivery of water and new molecules into the atmosphere of Jupiter. These observations could support the theory that, between 4.5 and 4 billion of years ago, the necessary water and organics were delivered to Earth by showers of comets, thus permitting the development of life. As comets are universal objects and the organics contained in their nuclei are originated in interstellar clouds responsible for stellar and planetary origins, we may assume that comets are delivering the "bricks" of life, containing the same biochemical information, everywhere in the galaxy.

By using a 132.000 channel spectrometer coupled to the $32 \mathrm{~m}$ dish of the Medicina radiotelescope (Bologna,Italy), we were able during the impact of the cometary nuclei with the upper atmosphere of Jupiter not only to detect water at $22 \mathrm{GHz}$, but to observe for the first time in the solar system a water MASER emission induced by a catastrophic impact [1]. This emission line was originated by a water cloud released from cometary ices after the explosion of the nuclei in the upper atmosphere of Jupiter. Thus water MASER emission can be used as a powerful diagnostic tool for planetray search outside the solar system, as comets are able to deliver huge amounts of water (about 50 billion tons per comet) in planetary atmospheres rising the probability of life development. We started therefore a search program at Medicina using the same multichannel spectrometer in order to cover the Doppler shifts due to planetary rotation. The most suitable candidates for such a search, within 50 light years, are stellar systems like Epsilon Eridani and Beta Pictoris where clouds of comets surrounding the stars have been discovered.

References: [1] C. B.Cosmovici, S.Montebugnoli, A.Orfei, S.Pogrebenko, and P.Colom (1996) Planet. Space. Sci., 44, 735 . 
COMPARISON OF THE CHEMICAL COMPOSITION BETWEEN BOSUMTWI ROCKS AND IVORY COAST TEKTITES: SEARCH FOR A METEORITIC COMPONENT IN IMPACT BRECCIAS. X. Dai ${ }^{1}$ and C. Koeberl' ${ }^{1}$ W. U. Reimold ${ }^{2}$ and I. McDonald ${ }^{3}$, Institute of Geochemistry, University of Vienna, Althanstrasse 14, A1090 Vienna, Austria (christian.koeberl@univie.ac.at), ${ }^{2}$ Department of Geology, University of the Witwatersrand, P. O. Wits, Johannesburg 2050, South Africa, ${ }^{3}$ School of Earth and Environmental Sciences, University of Greenwich, Chatham Maritime, Kent ME4 4A W, UK.

The Bosumtwi crater in Ghana, which has a rim-torim diameter of about $10.5 \mathrm{~km}$ and almost completely filled by Lake Bosumtwi, was inferred to be the source crater for the Ivory Coast tektites, based on the geographical proximity, the same ages $(1.07 \mathrm{Ma})$ of the crater and tektites, similar chemical and isotopic compositions between the tektites and crater rocks [1]. This makes the Bosumtwi crater one of only three impact structures that have been identified as source craters of a tektite strewn field. The other two are the Chesapeake Bay impact structure (eastern coast of the U.S.A.), which is the source of the North American tektite strewn field, and the Ries crater in Germany, which is the source of the Central European tektite strewn field. In total, four tektite strewn fields are known; no source crater has yet been identified for the Australasian strewn field. Strewn fields are usually defined based on the geographic distribution of microtektites (in deep sea cores) and tektites (on land). All tektites represent distal ejecta. Besides tektites, there are several other distal ejecta layers known in the geological record. Some, such as the $\mathrm{K} / \mathrm{T}$ boundary ejecta layer, are associated with significant siderophile element anomalies, which are thought to represent an extraterrestrial (meteoritic) contribution. On the other hand, none of the tektite strewn field seems to be associated with a significant meteoritic component. A minor Ir anomaly was discovered in a microtektite-bearing layer from the Australasian strewn field. Of the known tektites, only the Ivory Coast tektites were found to contain a distinct meteoritic component, which, based on Os isotopic studies, was determined to be slightly less than $1 \%$ [2]. Here, we try to compare the meteoritic component found in the tektites with the siderophile element anomalies in the target rocks and impact breccias at the Bosumtwi crater.

In 1997 and 1999, representative samples of impact breccias and target rocks were collected from the Bosumtwi impact crater, to conduct the petrographic, geochemical and paleomagnetic studies. In this work, the major and trace elemental composition, as well as the platinum group element (PGE) abundances, were analyzed in the selective target rocks (including shale, graywacke and two different types of granites) and suevite-derived impact glass samples. Major elements were determined by X-ray fluorescence spectrometry analysis (XRF), and trace elements (expect the PGEs) by instrumental neutron activation analysis (INAA).
The PGEs were measured by ICP-MS after NiS fire assay [3] and by NAA after an anion resin preconcentration procedure.

Here, the major and trace element abundances in five suevite-derived impact glass samples at the crater were compared with Ivory Coast tektite and microtektite data [4]. The chondrite-normalized abundance patterns of the rare earth elements (REE) for all the impact glass samples were agree very well with those for the tektites. Meanwhile, the uniform content of lithophile elements ( $\mathrm{Sc}, \mathrm{Rb}, \mathrm{Sr}, \mathrm{Zr}, \mathrm{Ba}, \mathrm{Hf}, \mathrm{Ta}, \mathrm{Th}, \mathrm{U}$ ), the reduced content of siderophile elements $(\mathrm{Cr}, \mathrm{Co}, \mathrm{Ni})$, and the increased content of volatile elements $(\mathrm{Zn}, \mathrm{As}, \mathrm{Sb}, \mathrm{Cs})$ for the impact glass samples were found, in comparison with the tektite and microtektite. Furthermore, the range of chemical composition of the target rocks is wider than that of the Ivory Coast tektites, but overlap the tektite compositions. Our data support the interpretation that the Bosumtwi structure and Ivory Coast tektites formed during the same impact event.

In the previous investigations $[1,3]$, the geochemistry of target rocks and breccias from the Bosumtwi crater was studied for comparison with Ivory Coast tektites. However, another important line of research, which is necessary for the identification of a meteoritic component in impact breccias and melt rocks, namely the determination "of siderophile elements (especially the PGEs) in the target rocks at the crater, has so far been somewhat neglected. Here, the contribution of meteoritic component will be also calculated in the light of the content of PGEs in the target rock samples, which will help to access the extraterrestrial component in the tektites.

Acknowledgments: We are grateful to the Geological Survey of Ghana for logistical support. This research was supported by the Austrian FWF, project Y-58 (to C. K.). The support of Austrian Academic Exchange Service (to X. Dai) is also appreciated.

References: [1] Koeberl C. et al. (1998) Geochim. et Cosmochim. Acta, 62, 2179-2196. [2] Koeberl C. and Shirey S.B., Science, 261, 595-598. [3] Koeberl C. et al. (1999) Meteoritics Planet Sci., 34, A66. [4] Koeberl C. et al. (1997) Geochim. et Cosmochim. Acta, 61, 17451772 . 


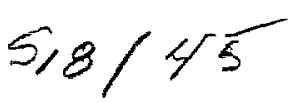

LABORATORY IMPACT EXPERIMENTS AND CALCULATIONS VS. NATURAL IMPACT EVENTS P. S. DeCarli 1,2 , A. P. Jones ${ }^{2}$, G. D. Price ${ }^{2}$. 'SRI International, Menlo Park CA 94025, USA, pdecarli@unix.sri.com, ${ }^{2}$ University College London, Gower Street London WC1E 6BT adrian.jones@ucl.ac.uk

Introduction: It is customary, in studies of natural impact craters and meteorites, to interpret observations on the basis of laboratory impact experiments and/or computational modeling of impact events. In this paper, we describe some of the significant differences between laboratory impact experiments and the conditions of natural impact events. We also point out some of the limitations of computational modeling of impact events. Finally, we describe a strategy for advancing our understanding of large impact events.

Much of our current knowledge of shock metamorphic effects on minerals is based on the results of laboratory shock loading experiments, including both equation-of-state measurements and recovery experiments. The effective high-pressure duration of a typical laboratory shock loading experiment is of the order of a microsecond. In a large natural impact resulting in a ca. $100-\mathrm{km}$ diameter crater, the effective high pressure duration at a depth of $7 \mathrm{~km}$ will be about a second. The relevance of the laboratory studies to the interpretation of large craters obviously depends on whether kinetic effects are significant in the development of shock metamorphic features.

Our current understanding of the details of large cratering events is imperfect, to say the least. The region of interest is experimentally inaccessible; we must rely on largescale calculations. However, because of computational limitations, most cratering calculations to date have been very crude. In order to keep computation times within reasonable bounds, calculators have resorted to use of large mesh sizes, simplified models of impact geometry and stratigraphy and simplified material models

Background: Hugoniot measurements on quartz and feldspar have long been interpreted in terms of a phase transitions, complete above about $50 \mathrm{GPa}$, to much (about $40 \%$ ) denser structures. These phases are stishovite-like (quartz) or hollandite-like (feldspar), but do not necessary have long range order. During unloading, the material remains in the dense phase down to pressures below the stability line of the high-pressure phase and then expands to a lower density form. Recovery experiments indicate that this lower density form, the so-called diaplectic glass, appears to have formed without melting, via a solid-solid transformation. Both the dynamic measurements (Hugoniot and release adiabat) and the recovery experiments indicate that the transition is smeared out over a wide pressure range in microsecondduration experiments.

Evidence for Kinetic Effects: One might look for kinetic effects by increasing the duration of the experiment at a given pressure and temperature. This is not practical for shock experiments; the effective duration scales with the cube root of the critical dimensions of the experiment. A typical microsecond-duration laboratory shock experiment might use $10 \mathrm{~kg}$ of high explosive. Ten tons of high explosive would be required if one wished to increase the duration by a factor of ten. However, there is evidence from quasi-static experiments, in which quartz and feldspars transform at room temperature and at about $20 \mathrm{GPa}$ to amorphous forms on a time scale of minutes. The static experiments were not designed to obtain kinetic data, but they could be.

Alternatively, one might vary temperature at a given pressure and duration to obtain evidence of kinetic effects. Two independent sets of recovery experiments on preheated quartz samples show that the conversion to diaplectic glass increases with preheat.

Finally, one finds strong evidence for kinetic effects in comparing Hugoniot data on initially porous quartz with data on non-porous quartz. For example, the transformation of Coconino sandstone appears to begin at about $10 \mathrm{GPa}$, where the initially porous material becomes denser than the initially solid material. At a shock pressure of $10 \mathrm{GPa}$, the internal energy content of the sandstone is about $700 \mathrm{~J} / \mathrm{g}$ higher than the initially solid material. One may quantify energy differences, but only qualitative statements can be made about the kinetics. It is well known that the distribution of energy (temperature) is very inhomogeneous over the sub-microsecond time scale relevant to Hugoniot measurements. Recent shock recovery experiments on porous quartz show the importance of thermodynamic loading path; results of earlier experiments with high impedance containers may have little relevance to natural events. Indeed, it is possible that many observations of diaplectic glass are actually observations of once molten material.

Validation of Cratering Calculations: In principle, complex calculations can be validated by comparing the results of calculations with results of actual experiments. In practice, validation is an iterative process in which numerous sources of discrepancy (e.g., inappropriate zoning, inaccurate material models, even bad Physics) are successively identified and corrected until the difference between calculation and experiment becomes acceptably small. In general one must obtain agreement between simple (e.g., onedimensional) experiments and calculations before progressing to more complex cases.

One might argue that it is unnecessary to validate cratering calculations. The physical principles of shock wave propagation are well understood and have been incorporated into computer codes that have been validated by comparison of calculated and measured shock wave profiles in numer- 
ous well-designed high explosive experiments in a variety of geologic media. Assuming that the resolution of the calculation is adequate, the agreement between calculation and experiment depends primarily on the accuracy with which the loading and unloading response of the material is modeled. It is particularly important to accurately model the hysteretic phase transition behavior of quartz and feldspar over the peak shock pressure range between $10 \mathrm{GPa}$ and $100 \mathrm{GPa}$.

However, there are significant differences between the cited high explosive experiments and a large impact. The timescale of the high explosive experiments is comparable to the timescale of the laboratory experiments in which $\mathrm{Hu}$ goniots and release adiabats are measured. The timescale of a Popigai is six orders of magnitude longer. One big unknown is whether it is necessary to incorporate kinetic effects into the material models of the geologic media. Furthermore, peak pressures associated with a large impact are well above the range for which experimental Hugoniot and release data are available. Finally, in the case of the laboratory experiments, the source function (the high explosive) is known. In the case of a large impact, the source function (impactor material, mass and geometry, impact velocity, and angle of impact) is one of the questions to be answered.

There is clearly good reason to question the validity of a calculation of a large impact event. However, the situation is not hopeless. We do have ground truth, in the form of various impact craters with which the calculations can be compared. In the past, many field workers have used the calculations as an aid to understanding their observations. We suggest it would be better to use the field observations to test the calculations.

Validation Example: A recent calculation of the Canyon Diablo impact concentrates on the shock history of the impacting body, assumed to be an iron sphere of $15 \mathrm{~m}$ in radius vertically impacting at 15 or $20 \mathrm{~km} / \mathrm{s}$ on $80 \mathrm{~m}$ of limestone overlaying a quartzite basement. (1) Previous calculations had established that the spatial resolution of $\mathbf{3 0}$ cells per radius was probably sufficiently fine. The $20 \mathrm{~km} / \mathrm{s}$ calculation indicates that about $15 \%$ of the mass of the iron remains solid. The prediction thus is that the total mass of solid fragments, the Canyon Diablo meteorites, should be about 15000 tons. Ground truth, the total mass of Canyon Diablo that has been collected, is about 30 tons.

Although the discrepancy in solid fragments is nearly three orders of magnitude, it would be fairer to compare the predicted melt fraction of $85 \%$ with the inferred ground truth value of nearly $100 \%$. It appears that this calculation is a very reasonable approximation of reality. Furthermore, the calculation is described in sufficient detail that one can examine the possible sources of error that would lead to an underestimate of the melt fraction. In particular, we note that the value of $271 \mathrm{GPa}$ chosen (on the basis of experimental data) for complete melting refers to pressure re- quired for melting on the Hugoniot. The temperature of interest is the temperature at the foot of the release isentrope. The appropriate question is if the temperature at the foot of the release isentrope exceeds the melting point of nickel-iron, what is the Hugoniot pressure at the head of the release isentrope? An estimate of about $200 \mathrm{GPa}$ would be consistent with the results of thermodynamic calculations by McQueen et. al.. (2) One also may note that the calculated fraction of unmelted material is extremely sensitive to small changes in the slope of the release adiabat in the pressure regime above $200 \mathrm{GPa}$. One may suspect that the ANEOS data for pure iron do not provide sufficiently accurate approximations of the Hugoniot and release adiabats of the two-phase (kamacite and taenite) Canyon Diablo impactor.

We commend the authors of this paper for providing the important details of the calculation, and we hope that future authors of calculational papers follow their example. We also commend the reviewers.

Future Directions: The time is ripe for detailed calculations of large impact cratering events and close comparison of the calculations with ground truth. Some of the elements that might be compared include crater morphology and dimensions, melt volume, and volume of fractured material. Ideally, one would begin with the least weathered craters, such as Canyon Diablo, where the initial geologic setting is reasonably well constrained and where corrections for erosion are small. In principle it should be possible, via iterative calculations (incorporating sound mineral physics), to constrain both the source function and possible kinetic effects on the loading and unloading response of the geologic media of interest.

References: [1] Schnabel et. al., (1999) Science 285, 85-88 [2] McQueen et al, (1970) Appendix E in HighVelocity Impact Phenomena, ed. Ray Kinslow, Academic Press 

IMPACT-PRODUCED VAPOR CLOUDS. D. de Niem, Institute of Space Sensor Technology and Planetary Exploration, German Aerospace Center, Berlin, Germany, (detlef.deniem@dlr.de).

In hypervelocity impacts of asteroids or comets on the surface of a planetary body, depending on the impact velocity, part or all of the projectile material and some of the target material can be vaporized and expands as a dense gas cloud $[6,8]$. Purely hydrodynamic treatment using an equation of state valid for thermodynamic equilibrium [9] does not cover the case when the vapor is quenched into a metastable state before condensation sets in. During the expansion, density and pressure fall by many orders of magnitude, making it difficult to treat the process with conventional hydrodynamic algorithms. Heis, for expansion into vaccuum, an analytical solution due to Zeldovich and Raizer [3] is used to approximate hydrodynamics. In the presence of an atmosphere, a numerical solution based on a second-order accurate Godunov method with van der Waal's equation of state is constructed.

After the poineering work of Raizer [1] who investigated the fate of condensation products of an iron meteroite expanding into vacuum, only few authors have studied the problem of condensation in impacts (e.g. O'Keefe and Ahrens [2]). Qualitatively, the main theoretical results of Raizer stayed unchanged. The conventional view of the order of events during condensation is as follows (see [3], e. g.):

- the adiabate of the vapor reaches the coexistence curve, the vapor becomes saturated, further expansion along the gas adiabate leads to supercooling

- at some critical degree of supercooling, the nucleation rate becomes high enough that a large number of critical nuclei of the new phase forms

- nucleation terminates, and clusters grow into droplets of macroscopic dimensions, the gas pressure drops

- at some moment, the flux of molecules at the surface of the droplets is so low that the degree of condensation freezes, a non-zero mass fraction of gas remaining

In this work, a numerical solution of the kinetic equations for moments of the size distribution of growing droplets and of the energy equation is presented. It is demonstrated that the above order of events is a too simplistic scenario and that nucleation events in impact-generated vapor appear several times at different temporal and spatial scales. The degree of supercooling follows a complicated oscillating pattern on a logarithmic time scale, see fig. 1. In this way, several 'generations' of droplets are formed, with very different final dimensions. The distribution of sizes such is no more dominated by a single scale, but rather characterized by several 'generations' of droplets of different characteristic sizes (each time a new 'generation' appears, the r.m.s. size of droplets decreases, because the older and large drops are outnumbered by finer, newly-formed droplets, see fig. 2).

Thermodynamic conditions at the moment of the various nucleation events are very different, in terms of temperatures

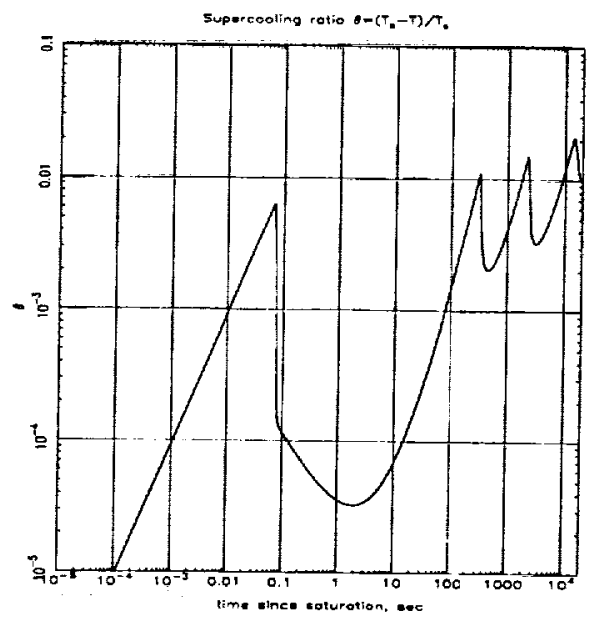

Figure 1:

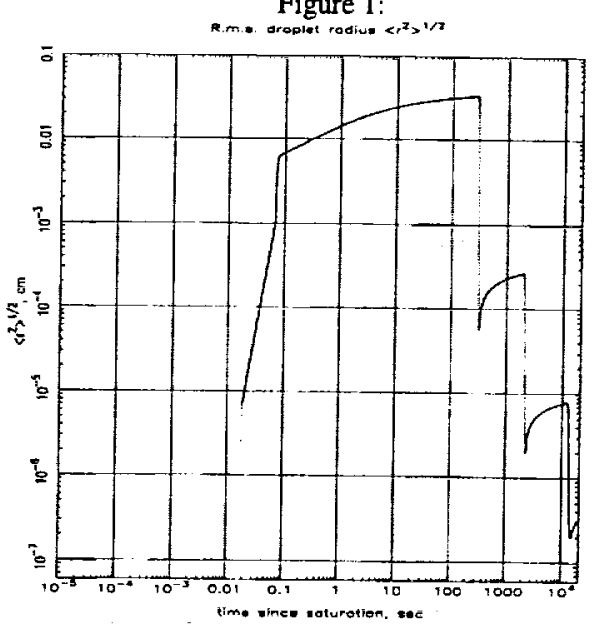

Figure 2:

and pressures. The density distribution is the only input required for the kinetics and adiabatic evolution of the liquidvapor mixture, since no back-reaction of condensation on hydrodynamics is assumed. This is justified, if the degree of condensation reaches large values at rather late times, only. If an atmosphere exists, more detailled considerations are necessary because of the density gradient in the atmosphere and the role played by the atmospheric shock. Condensation begins in a layer near the boundary of the original vapor material with the swept-up atmospheric gas (the shock wave is travelling ahead of this zone). The geometry of shock-wave propagation in the atmosphere is complicated (see fig. 3), because the vertical density gradient hinders lateral propagation and leads to acceleration vertically upward, see Newman et al. [7], e. g. Here, Lagrangean tracer particles are used to derive the 


\section{MULTI-SCALE CONDENSATION: D. de Niem}

comoving mass density and the temperature where the coexistence curve is crossed, these variables being the input for the nucleation kinetics, and no back-reaction of condensation on the further hydrodynamic evolution is assumed. No detailled model for the release of gases in the course of crater formation is made, however, since the density and pressure scales in the crater and in the expanding vapor are too different to allow a combined treatment. Results are available for different sizes of impactors, to investigate scaling properties. The kinetic equations used here follow from the classical Becker-DöringZeldovich theory of nucleation (e.g. Frenkel [4], or Abraham, [5]). A system of ordinary differential equations is obtained, that gives the time evolution of the degree of condensation and of several moments of the droplet size distribution. The kinetic equations are in a form that allows to incorporate more general droplet models (other than the capillarity approximation used by Zeldovich and Raizer [3]).

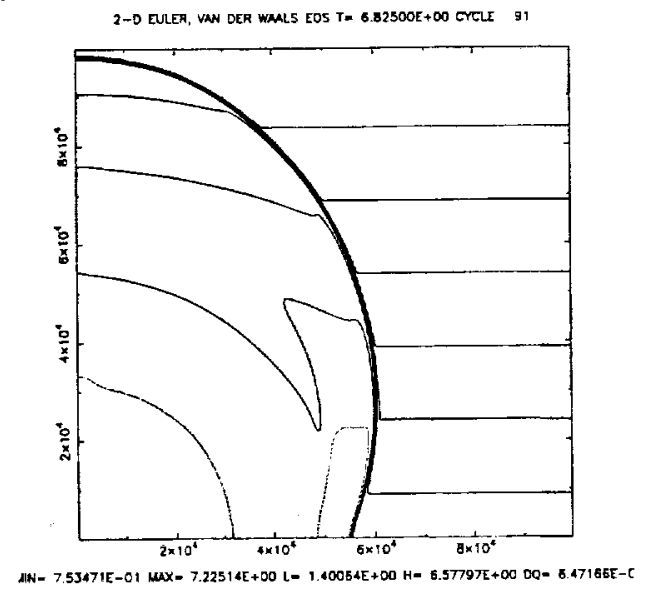

Figure 3: Logarithmic pressure contours, at $t=6.825 \mathrm{~s}$. $\log _{10} P$ in Pascal. Contour interval $\sim$ factor of 4.4377 . Initial conditions: uniform hemisphere of $5 \mathrm{~km}$ radius, specific energy corresponding to [9], isothermal (exponential) atmosphere. Note the excellent resolution of the shock wave by the Godunov method.

\section{References}

[1] Raizer, Yu. P. 1959: On Condensation of a cloud of vaporous matter expanding into vacuum. Soviet Phys. JETP 37 No. $12,1741-1750$.

[2] O'Keefe, J. D., Ahrens, T. J. 1982: The interaction of the Cretaceous/Tertiary extinction bolide with the atmosphere, ocean and solid earth, Geol. Soc. Amer. Special Papers, 103-120.

[3] Zeldovich, Ya. B. , Raizer, Yu. P.: Physics of Shock Waves and High-Temperature Hydrodynamic Phenomena, Academic Press, New York, San Francisco, London, 1967.

[4] Frenkel, Ya. I.: Kinetic theory of liquids. Oxford University Press, 1946.

[5] Abraham, F. F.: Homogeneous Nucleation Theory. Advances in Theoretical Chemistry, Supplement I, Academic Press, New York, London, 1974.

[6] Melosh, H. J.: Impact Cratering. A Geological Process. Oxford University Press, 1989.

[7] Newman, W. I., Symbalisty, E. M. D., Ahrens, T. J., and Johnes, E. M. 1999: Impact Erosion of Planetary Atmospheres: Some Surprising Results. Icarus 138, 224-240.

[8] Pierazzo, E., Kring, D.A., Melosh, H. J. 1998: $H y-$ drocode Simulation of the Chicxulub impact event and the production of climatically active gases. J. Geophys. Res. 103, 28607-28626.

[9] Melosh, H. J., Pierazzo, E. 1997: Impact vapor plume expansion with realistic geometry and equation of state. 28th Ann. Lunar and Planet. Sc. Conf., p. 935. 
CARBON ISOTOPIC STUDIES OF MASS EXTINCTIONS AND RECOVERIES. S. D'Hondt ${ }^{1}$ and $J$. C. Zachos', 'Graduate School of Oceanography, University of Rhode Island, Narragansett, RI 02882, USA, dhondt@gso.uri.edu, ${ }^{2}$ Department of Earth and Marine Sciences, University of California, Santa Cruz, CA 95064, USA.

Mass Extinctions and the Global Carbon $\mathbf{C y}$ cle.: Carbon isotopic studies can be used to document effects of mass extinctions and biological recoveries on the global carbon cycle. For example, many studies have shown that the carbon isotopic $\left(\delta^{13} \mathrm{C}\right)$ values of bulk marine carbonates decreased by about $2.0 \%$ at the time of the Cretaceous/Tertiary impact (e.g., [1]). Carbon isotopic values remained low for more than three myrs after the impact before recovering to their pre-boundary level [1]. A similar decrease in the carbon isotopic values of bulk carbonates approximately coincided with the Permo/Triassic boundary event (e.g., [2]). Comparison to $\mathrm{U} / \mathrm{Pb}$ radiometric dates [3] indicates that carbon isotopic values remained low for at least one million years into the Triassic. The simplest explanation of the decreased early Paleocene and early Triassic carbon isotopic values is a small decrease in the global organic carbon burial rate for the first one to few million years after these mass extinctions (e.g., [4]).

The long-lasting early Paleocene decrease in carbon isotopic values of bulk carbonates bulk was paralleled by a radical decrease in the carbon isotopic values difference between carbonates secreted by planktic and benthic marine organisms [1]. These decreased differences probably resulted from a large extinction-driven decrease in the sinking of organic matter to the deep ocean [1]. It is not yet known whether a similar response followed the Permo/Triassic mass extinction because carbon isotopic studies of the Permo-Triassic interval are largely limited to bulk limestone and bulk organic records.
Carbon Isotopes and Ecological Strategies: Stable carbon isotopes can also be used to document the disappearance and re-appearance of specific ecological strategies (such as life span, seasonality of growth, relative depth of habitat, and photosymbiont reliance) during mass extinctions and evolutionary recoveries. For example, taxonomically focused isotopic studies show that (1) strong reliance on photosymbiosis disappeared among planktic foraminifera during the impact-driven Cretaceous-Tertiary mass extinction, but re-appeared a few million years later in unrelated taxa as the global carbon cycle recovered [5].

Conclusions: In short, studies of the Cretaceous/Tertiary and and Permo/Triassic intervals show that these large mass extinctions changed the way that carbon moved through the world for millions of years. We can infer from those changes in the carbon cycle that large-scale ecosystem structures did not fully recover for the same intervals of time.

References: [1] DHondt S. et al. (1998), Science, 282, 276-279. [2] Holser, W. T. (1997), Palaeogeography, Palaeoclimatology, Palaeoecology, 132, 5173-5182. [3] Bowring S. A et al. (1998), Science, 280, 1039-1045. [4] Kump, L. R. (1991), Geology, 19, 299-302. [5] DHondt S. and Zachos J. C. (1998), Paleobiology, 24, 512-523. 
THE CRETACEOUS-TERTIARY BOUNDARY "COCKTAIL" IN WESTERN CUBA, GREATER ANTILLES. C. Díaz Otero ${ }^{(1)}$, M. Iturralde-Vinent ${ }^{(2)}$ and D.García Delgado ${ }^{(1)} \cdot{ }^{1}$ Instituto de Geología y Paleontología, Via Blanca y Linea de Ferrocarril, San Miguel de Padron, CP 11000 La Habana, Cuba (igpenig@ceniai.inf.cu); ${ }^{2}$ Museo Nacional de Historia Natural, Obispo \#61, 10100 La Habana, Cuba (geopal@mnhnc.inf.cu)

Recently Bralower and Leckie (1998) described the Cretaceous-Tertiary boundary (KTB) in the Caribbean as characterized by a "cocktail"of fossils elements reworked from strata older than Paleocene. A similar distinctive mixture of reworked foraminifers was found in several formations of western Cuba, associate with shocked quarz, spherules and an enrichment of Ir.

The fossiliferous composicion of both the Moncada calcarenites and the Peñalver formation in western Cuba, confirm the model of the "cocktail", as reworked micro- and macrofossils of different ages within the Cretaceous are found in the samples.

The Moncada calcarenites (Iturralde-Vinent, 1997), and the Peñalver Formation (Pszczolkowski, A.; 1986 and Iturralde-Vinent, 1992) were generally characterized as calcareous clastics strata probably related with the KTB impact.

The Moncada calcarenites overlie black indiferentiated Cretaceoous limestones, and contein planktic foraminifera and radiolaria of Aptian, Albian-Cenomanian, Santonian, Campanian and Maastrichtian in age. No Paleocene taxa were found (Table I).

The Peñalver Formation overlies the Campanian-Maastrichtian Via Blanca Formation and include both bentic and planktic foraminifera, radiolaria, nannofossils, etc. The larger amount of reworked microfossils belong to the Campanian-Maastrichtian interval, probably eroded from the Via Blanca Formation; both also contain older Cretaceous fossils of different ages. No Paleocene taxa were found (Table I).

The recognition of the paleontological "cocktail" in different formationas of western Cuba, strongly suggest that these units probably belong to the KTB

\section{References}

Caron, M., 1985. Cretaceous planktic foraminifera in: Plankton stratigraphy (ed. H. M. Bolli, J. B. Saunders y Perch-Nielsen. Cambridge University Press (4): 17-86.

Iturralde-Vinent, M.1992. A short note on the Cuban late Maastrichtian megaturbidite (an impact-derived deposit?): Earth \& Planetary Science Letters, 109: 225-228.

Iturralde-Vinent, M., 1997. Field Guide. Sedimentary Geology of Western Cuba. $1^{\text {st }}$ SEPM Congress on Sedimentary Geology, St. Pete Beach, Florida, 21 pp.

Premoli Silva, I. And Sliter, W. V.; 1995. Paleontographia Italica. LXXXII.

Psczczlkowski, A., 1986. Megacapas del Maestrichtiano en Cuba occidental y central. Bulletin of the Polish Academy of Earth Science, 34(1): 82-94.

Sliter, W. V.; 1989. Bioestratigraphy zonation for Cretaceous planctonic foraminifers examinad in thin section. Journal of Foraminiferal Research. 19(1): 1-19.

Sliter, W. V.; 1999. Cretaceous planctonic foraminifers examinad in thin section. U.S. Geological Survey . Special Publication. 
THE CRETACEOUS-TERTIARY BOUNDARY: C. Ciaz Otero et al.

Table I. Foraminiferal assemblage found in the Moncada calcarenites and Peñalver Formation.

${ }^{*}$ ) species which do not occur at the top of the Maastrichtian

\begin{tabular}{|c|c|c|c|}
\hline Planktic Foraminiferes & Age & $\begin{array}{l}\text { Moncada } \\
\text { calcarenites }\end{array}$ & $\begin{array}{l}\text { Peñalver } \\
\text { Formation }\end{array}$ \\
\hline Abathomphalus mayaroensis & Late Maastrichtian & $\mathrm{X}$ & $\mathrm{X}$ \\
\hline Archaeoglobigerina cretacea & Coniacian-Early Maastrichtian & $\mathrm{X}$ & $\mathrm{X}$ \\
\hline Dicarinella hagni & Turonian & $\mathrm{X}$ & - \\
\hline Globigerinelloides barri & Albian & $\mathrm{X}$ & - \\
\hline Globigerinelloides bentonensis & Albian & $\mathrm{X}$ & - \\
\hline Globotruncana arca & Late Santonian-Maastrichtian* & $\mathrm{X}$ & $\mathrm{X}$ \\
\hline Globotruncana bulloides & Late Santonian-Early Maastrichtian & $\mathrm{X}$ & $\mathrm{X}$ \\
\hline Globotruncana falsostuarti & Late Campanian-Maastrichtian* & - & $\mathrm{X}$ \\
\hline Globotruncana linneiana & Cenomaniaan-Early Maastrichtian & $\mathrm{X}$ & $\mathrm{X}$ \\
\hline Globotruncana mariei & Santonian-Early Maastrichtian & $\mathrm{X}$ & $\mathrm{X}$ \\
\hline Globotruncanella havanensis & Late Campanian-Maastrichtian & $\mathrm{X}$ & $\mathrm{X}$ \\
\hline Globotruncanella petaloidea & Late Maastrichtian & $\mathrm{X}$ & $\bar{X}$ \\
\hline Globotruncanita calcarata & Late Campanian & - & $\mathrm{X}$ \\
\hline Globotruncanita conica & Late Maastrichtian & $\mathrm{X}$ & $\mathrm{X}$ \\
\hline Globotruncanita elevata & Late Santonian-Late Maastrichtian* & $\mathrm{X}$ & - \\
\hline Globotruncanita stuarti & Late Campanian-Maastrichtian & $\mathrm{X}$ & $\mathrm{X}$ \\
\hline Globotruncanita stuartiformis & Campanian-Maastrichtian* & $\mathrm{X}$ & $\mathrm{X}$ \\
\hline Guembelitria cretacea & Late Maastrichtian & $\mathrm{X}$ & - \\
\hline Hedbergella delrioensis & Albian-Early Santonian & $\mathrm{X}$ & - \\
\hline Hedbergella excelsa & Albian & $\mathrm{X}$ & - \\
\hline Hedbergella holmdelensis & Coniacian-Maastrichtian & - & $\mathrm{X}$ \\
\hline Heterohelix striata & Campanian-Maastrichtian & - & $\mathrm{X}$ \\
\hline Marginotruncana sp. & Turonian-Santonian & $\mathrm{X}$ & - \\
\hline Planoglobulina glabatra & Santonian-Early Campanian & - & $\mathrm{X}$ \\
\hline Praeglobotruncana stephani & Albian-Turonian & $\mathrm{X}$ & - \\
\hline Praeglobotruncana delrioensis & Albian-Cenomanian & $\mathrm{X}$ & - \\
\hline Pseudotextularia elegans & Late Campanian-Maastrichtian & $\mathrm{X}$ & $\mathrm{X}$ \\
\hline Racemiguembelina fructicosa & Late Maastrichtian & $\mathrm{X}$ & $\mathrm{X}$ \\
\hline Rotalipora cf. brotzeni & Cenomanian & $\mathrm{X}$ & - \\
\hline Contusotruncana contusa & Late Maastrichtian & $?$ & $\mathrm{X}$ \\
\hline Contusotruncana fornicata & Late Santonian-Maastrichtian* & $\mathrm{X}$ & $\mathrm{X}$ \\
\hline Contusotruncana walfischensis & Late Maastrichtian & - & $\mathrm{X}$ \\
\hline Rugoglobigerina macrocephala & Late Maastrichtian & $\mathrm{X}$ & - \\
\hline Rugoglobigerina cf. reicheli & Late Maastrichtian & - & $\mathrm{X}$ \\
\hline Rugoglobigerina rugosa & Late Campanian-Maastrichtian & $\mathrm{X}$ & $\mathrm{X}$ \\
\hline Rugoglobigerina scotti & Late Maastrichtian & $\mathrm{X}$ & - \\
\hline Ventilabrella cf. multicamerata & Late Maastrichtian* & $\mathrm{X}$ & - \\
\hline
\end{tabular}




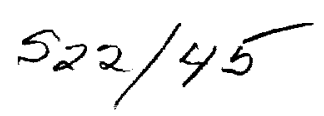

PALEOZOIC DIAMICTITES IN THE CENTRAL ANDES: TILLITES, GRAVITY FLOWS OR IMPACT EJECTA? E. Díaz-Martínez, Centro de Astrobiología (CSIC-INTA), Crtra. Torrejón-Ajalvir km. 4, 28850 Torrejón de Ardoz, Madrid, Spain <diazme@inta.es>

Introduction: The Central Andes of Peru, Bolivia, and northern Argentina exhibit some of the thickest and most complete Paleozoic stratigraphic sequences in South America. A maximum total composite thickness exceeding $15 \mathrm{~km}$ was deposited during the Paleozoic at what then was the active margin of Gondwana, recording important geodynamic, paleogeographic and paleoclimatic events. The Paleozoic record of the Central Andes includes two conspicuous diamictite units with fairly well constrained ages: latest Ordovician-earliest Silurian, and latest Devonian. The coincidence of the time of deposition of these two units with important known periods of global climatic, eustatic and biotic changes has traditionally fostered their interpretation as a result of glaciations. Despite the many recent advances, knowledge about these units is still very limited with regard to detailed sedimentology, geochemistry and biostratigraphy, but presents wide possibilities for future research. The reconstruction of the Paleozoic basins in South America (Fig. 1) identifies large areas of marginal and intracratonic basins, although the Paleozoic stratigraphic record is poorly preserved in most of them, due to later deformation and erosion. The study of the Paleozoic of the Central Andes has undergone important advances during the last two decades. In this paper I attempt to summarize the evidence regarding the Paleozoic diamictites, to review their interpretation, and to propose future lines of research. Whereas interpretations such as local tectonism and/or glaciation have traditionally been accepted, meteorite impacts have never been considered as an alternative interpretation. Evidence described below shows that they may be related with impact events.

The mid-Paleozoic basin of the Central Andes of Peru and Bolivia (Peru-Bolivia basin) extended southwards into northern Argentina and western Paraguay, connecting with the Paraná basin through the Asunción Arch. To the north, it continued into Ecuador, connecting with the mid Paleozoic record of Colombia and Venezuela, and into Brazil (Solimōes and Amazonas basins) to the northeast (Fig. 1). The mid Paleozoic Peru-Bolivia basin has been interpreted as a foreland basin [1-4] located in a retroarc position with respect to the magmatic arc represented by (a) the San Nicolás batholith along the southern Peruvian coast [5], and (b) other igneous rocks in northern Chile [6].

Latest Ordovician-earliest Silurian diamictites: These diamictites extend throughout the Central Andes, from Peru to Argentina, as a conspicuous unit within the otherwise monotonous siliciclastic Ordovician-
Silurian package. It is called San Gabán Fm. in central and southern Perú, Cancañiri Fm. in Bolivia, and Zapla Fm. in northern Argentina [7]. The total modern extent of the outcrop area exceeds $1500 \mathrm{~km}$ in length (NNWSSE) and $600 \mathrm{~km}$ in width (WSW-ESE). It consists of diamictites, sandstones and mudstones interpreted as submarine resedimented material (debris flows, slided slabs, slumps, turbidites, etc.) $[8,9]$. The lower contact is a disconformity or slight regional unconformity (locally angular unconformity) overlying different Ordovician units ranging in age from Tremadocian to Ashgillian [10]. A precise age has not yet been determined and is still under discussion due to the frequent recycled character of fossils and lack of detailed studies. In Brazil, equivalent units have been dated as Llandovery [11], whereas in northern Argentina most authors assign a late Ashgillian age. The thickness varies greatly

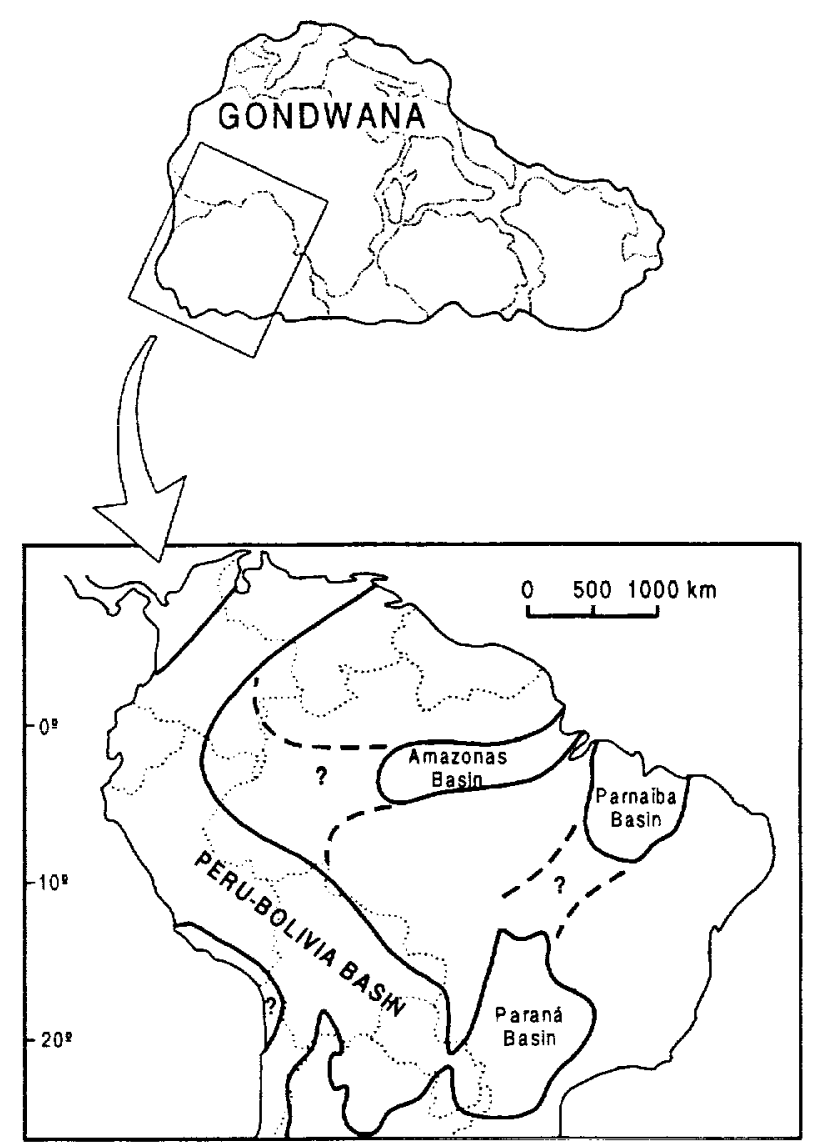

Figure 1: Location of the study area with approximate paleogeography for the mid Paleozoic.

from a few meters or not being present at all, to more than $1500 \mathrm{~m}$. Apart from the large intrabasinal resedi- 


\section{PALEOZOIC DIAMICTITES IN THE CENTRAL ANDES: E. Díaz-Martínez}

mented clasts, boulders and slabs, the diamictite unit also includes faceted and estriated polymictic extraclasts, mostly composed of sedimentary rocks, but also outsized clasts of igneous plutonic rocks which may exceed $2 \mathrm{~m}$ in diameter. The source of the sediments is interpreted to be located towards the $S W$, as indicated by the increase in clast size and thickness of the unit $[3,8,9]$. The depocenter of the diamictite unit is located in southern Bolivia, coinciding with the area where striated clasts are more frequent.

Latest Devonian diamictites: A diamictite unit is present in the northern Bolivian Altiplano (Cumaná Fm.; Fig. 2) and parts of the Bolivian Eastern Cordillera and Sub-Andes (Toregua and Itacua Fms.) near the Devonian-Carboniferous boundary [12-14]. Together with the previously mentioned Cancañiri Fm., it is also a rather conspicuous unit within the otherwise monotonous mid-Paleozoic siliciclastic package.

Figure 2: Stratigraphy of the Late Devonian Cumaná Forma-

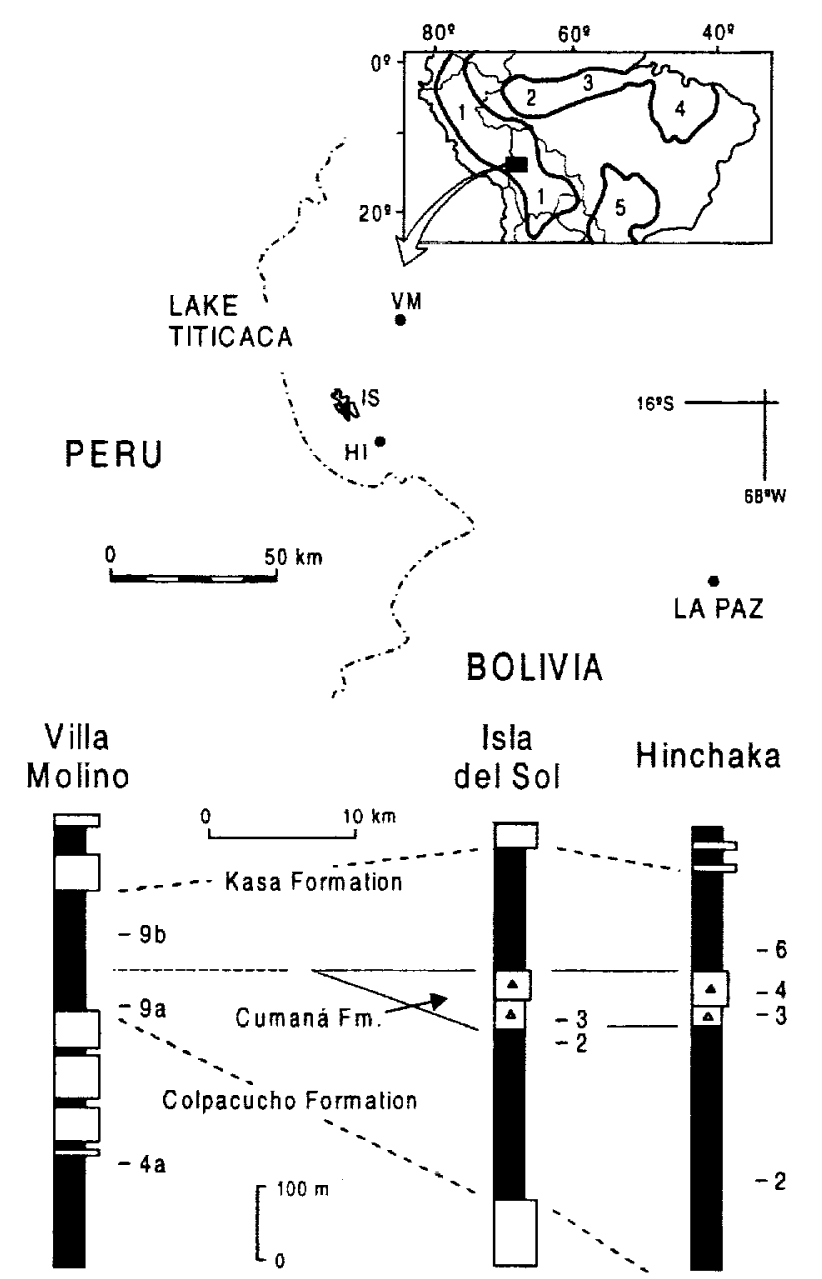

tion. Numbers in sections indicate palynology samples.

The total modern extent of the outcrop area of these latest Devonian diamictites is around $1000 \mathrm{~km}$ in length (NNW-SSE) and $600 \mathrm{~km}$ in width (WSW-ESE). It mostly consists of diamictites, with few sandstone and mudstone interbeds, and is interpreted as submarine resedimented material (debris flows, slided slabs, slumps, turbidites, etc.) related with local tectonism $[14,15]$. The lower contact is a disconformity or slight regional unconformity overlying mid or late Devonian units. A precise age of late Famennian ( $\mathrm{Fa} \mathrm{2c-d,} \mathrm{paly-}$ nozone PL) has been determined by means of detailed palynology [15-17]. The thickness varies greatly from not present at all, to $120 \mathrm{~m}$. As with the previous unit, faceted and striated clasts are frequent, and mostly composed of resedimented intrabasinal siliciclastic sedimentary rocks. Other lithologies are also present, such as metamorphic and igneous plutonic and volcanic rocks. Granite boulders may exceed $4 \mathrm{~m}$ in diameter. In the $\mathrm{N}$ Altiplano and $\mathrm{N}$ Eastern Cordillera, thickness and clast size increase towards the $S E$, identifying a probable source towards the south.

According to all the evidence, and also considering recent proposals for the reassessment of diamictite units [18-20], both diamictite units are excellent candidates to be impact deposits, and research should be pursued considering this possibility.

References: [1] Sempere, T. (1989) $28^{\text {th }}$ Int. Geol. Congress, 3, 73. [2] Sempere, T. (1993) $2^{\text {nd }}$ Int. Symp. Andean Geodynamics, 547-550. [3] Sempere (1995) AAPG Mem., 62, 207-230. [4] Isaacson, P.E. \& E. DíazMartínez (1995) AAPG Mem., 62, 231-249. [5] Mukasa, S.B. \& D.J. Henry (1990) J. Geol. Soc. London, 147, 27-49. [6] Breitkreuz, C. et al. (1989) J. South Am. Earth Sci., 2, 171-189. [7] Laubacher, G. et al. (1982) J. Paleont., 56, 1138-1170. [8] Díaz-Martínez, E. (1996) $3^{\text {rd }}$ Int. Symp. Andean Geodynamics, 343-346. [9] DíazMartínez, E. (1997) Geogaceta, 22, 55-57. [10] SuárezSoruco, R. (1995) Rev. Téc. YPFB, 16, 51-54. [11] Grahn, Y. \& M.V. Caputo (1992) Palaeogeogr., Palaeoclim., Palaeoecol., 99, 9-15. [12] Díaz-Martínez, E. (1991) Rev. Téc. YPFB, 12, 295-302. [13] DíazMartínez, E. et al. (1993) XII Int. Congr. Carboniferous-Permian, 2, 203-222. [14] Díaz-Martínez, E. (1994) CSPG Mem., 17, 511-522. [15] Díaz-Martínez, E. et al. (1999) Abh. Geol. Bundesanstalt, 54, 213-237. [16] Vavrdová, M. et al. (1991) Rev. Téc. YPFB, 12, 303313. [17] Vavrdová, M. et al. (1993) XII Int. Congr. Carboniferous-Permian, 1, 187-199. [18] Oberbeck, V.R. et al. (1993) J. Geol., 101, 1-19. [19] Rampino, M.R. (1994) J. Geol., 102, 439-456. [20] Ormö, J. \& M. Lindström (2000) Geol. Mag., 137, 67-80. 
IMPACT EVENTS IN SPAIN: EVIDENCE AND POTENTIAL IMPACTOCLASTIC UNITS IN THE SEDIMENTARY RECORD. E. Díaz-Martínez, E. Sanz-Rubio \& J. Martínez-Frías, Centro de Astrobiología (CSICINTA), Crtra. Torrejón-Ajalvir km. 4, 28850 Torrejón de Ardoz, Madrid, Spain <diazme@inta.es>

Introduction: The sedimentary record of Spain presents evidence for impact events, as well as units with potential to be interpreted as impactoclastic beds (some of them currently under study). We herein summarize and review the information available on the sedimentary record of meteorite impacts in Spain, most of it published in Spanish journals. In addition, we propose other stratigraphic units with potential for future research.

Distal record of impact events: Evidence for distal impact ejecta is found in relation with the Dogger-Malm and Cretaceous-Tertiary boundaries. The Middle-Upper Jurassic (Dogger-Malm) boundary at Ricla and Pozuel del Campo (Tberian Range) presents conspicuous geochemical anomalies (e.g., heavy metals, platinum-group elements), volcanic and hydrothermal activity, submarine corrosion, high concentration of spherules, and $\mathrm{Fe}$ Mn bacterial-fungal stromatolites [1]. The K-T boundary has been thoroughly studied at several stratigraphic sections with deep marine deposits (Zumaya and Eibar in the western Pyrenees -corresponding to the eastern Basque-Cantabrian basin-, Agost and Caravaca in the Bethic Cordillera, etc.), where unequivocal evidence was found for an impact origin in relation with a major faunal turnover [2-15]. At Caravaca, a marked Ir anomaly was found, in conjunction with $\mathrm{V}, \mathrm{Cr}, \mathrm{Fe}, \mathrm{Ni}, \mathrm{Zn}$ and As anomalies, and abundant spherules [2,3]. The absence of volcanic products at this section strengthens the case for an extraterrestrial hypothesis $[10,11]$. Highresolution biostratigraphy of planktic foraminifera at Osinaga and Musquiz (Navarra Pyrenees) has further detected a small hiatus with iron oxides at the K-T boundary [16], to be considered in the interpretation of related biotic changes. Many other sections exist in Spain with continuous exposure and detailed biostratigraphy of the K-T boundary, and with potential to identify distal impact ejecta within them.

Proximal record of impact events: The only proximal impact ejecta bed in Spain is the Pelarda Formation, related with the Azuara impact structure, near Zaragoza (Spain). After its first recognition and international consideration [17-19], a strong debate arose regarding its tectonic or impact origin [20-24]. The Azuara impact structure is located on the eastern branch of the NW Iberian Range, which separates the Tertiary Ebro and Calatayud-Montalbán basins. The diameter of the ring-like remanent structure is $30 \mathrm{~km}$, and the total original diameter is estimated between 35 and $40 \mathrm{~km}$. It is considered as late Eocene-Oligocene in age [20], and is outlined by Mesozoic and Paleozoic rocks. The rem- nants of the ejecta blanket deposits (Pelarda Formation; [25]), with an outcrop of roughly $30 \mathrm{~km}^{2}$ and a thickness of $200 \mathrm{~m}$, overlie clastic alluvial fan deposits of the adjacent Calatayud-Montalbán basin. Part of our current research focuses on the sedimentological and paleontological evidence in both the Ebro and CalatayudMontalbán basin, to contribute to solve the controversial impact vs. tectonic origin of the Azuara structure, and to determine the age of the Pelarda Fm.

Potential impactoclastic beds: One important criteria for the recognition of impact-related units in the sedimentary record is the presence of breccia or diamictite beds or well-dated massive extinction events with ages roughly coinciding with those of known meteorite impacts. Breccia and diamictite beds are frequent in Spain, although they are usually interpreted as synsedimentary redeposition related with slope and/or tectonic instability, and more rarely as glacigenic deposits. Apart from those more clearly related with active tectonism or eustacy, other units exist displaying a strong potential as impact-induced. For most of them, evidence is not unequivocal, and many features still remain to be explained.

Vendian-Cambrian boundary. Deep marine breccias and olisthostromes of the "Nivel de Fuentes" (Fuentes Bed, Membrillar Megabreccias and Olisthostrome, Navalpino Breccia) in the Valdelacasa and Navalpino anticlines (Central Iberian Zone of the Hercynian Massif) broadly coincide with the Vendian-Cambrian boundary [26-33], and have been traditionally related to the Cadomian/Pan-African orogeny.

Latest Ordovician. Shallow-marine Hirnantian diamictites (the so-called "Pelitas con fragmentos" or fragment-bearing shales) are present throughout the Central Iberian Zone with different formational names [34-36]. They have been generally assigned to coeval north African glaciation.

Late Devonian. Shallow-marine diamictites within the "Phyllite-Quartzite Group" of the Iberian Pyrite Belt (South-Portuguese Zone of the Hercynian Massif) are commonly interpreted as mega-debris flows related with tectonism $[37,38]$.

Triassic-Jurassic boundary. In most of Spain this boundary is marked by a regional erosional unconformity and/or earliest Jurassic (Hettangian) breccias. Some are interpreted as related with rifting and eustacy [39-42], whereas others are considered the result of collapse after evaporite dissolution [43].

Cenomanian-Turonian boundary. Impact ejecta have recently been found north of Nazaré (Mesozoic Lusi- 


\section{SEDIMENTARY RECORD OF IMPACT EVENTS IN SPAIN: E. Díaz-Martínez et al.}

tanian basin of Portugal), near the CenomanianTuronian boundary, and in probable relation with the Tore seamount impact structure located off the coast of Portugal [44-47]. The potential exists in Spain to find distal ejecta in the frequent excellent exposures of shallow and deep marine sequences covering this same interval (Cenomanian-Turonian boundary). Some of these Spanish sections are already well dated based on calcareous nannoflora, planktic foraminifera, and ostracod biostratigraphy [48-49].

The present contribution attempts (a) to bring the attention of the international community towards recent and ongoing research relating the sedimentary record of impact events in Spain, and (b) to promote new research regarding the aforementioned units to search for evidence of an impactogenic origin.

References: [1] Meléndez, G. et al. (1987) Geogaceta, 2, 5-7. [2] Smit, J. \& J. Hertogen (1980) Nature, 285, 198-200. [3] Smit, J. \& G. Klaver (1981) Nature, 292, 47-49. [4] Smit, J. \& W.G.H.Z. ten Kate (1982) Cretaceous Res., 3, 307-332. [5] Groot, J.J. et al. (1989) EPSL, 94, 385-397. [6] Lamolda, M.A. (1990) Global Bio-Events, Springer, 8, 393-399. [7] Smit, J. (1990) Geologie en Mijnbouw, 69, 187-204. [8] Canudo, J.I. et al. (1991) Marine Micropal., 17, 319-341. [9] Arz, J.A. et al. (1992) III Congr. Geol. España, 1, 487-491. [10] Martínez-Ruíz, F. et al. (1992) Chemical Geology, 95, 265-281. [11] Martínez-Ruíz, F. et al. (1992) Geogaceta, 12, 30-32. [12] Molina, E. et al. (1994) Eclogae Geol. Helv., 87, 47-61. [13] Molina, E. et al. (1996) Rev. Micropal., 39, 225-243. [14] Baceta, J.I. et al. (1997) Geogaceta, 22, 225-231. [15] Arz, J.A. et al. (1998) Geogaceta, 23, 15-18. [16] Arenillas, I. et al. (1997) Geogaceta, 21, 25-28. [17] Ernstson, K. et al. (1985) EPSL, 74, 361-370. [18] Ernstson, K. et al. (1987) Meteoritics, 22, 373. [19] Grieve, R.A.F. (1987) Ann. Rev. Earth Planet. Sci., 15, 245-270. [20] Ernstson, K. \& J. Fiebag (1992) Geol. Runds., 81, 403425. [21] Aurell, M.et al. (1993) Geol. Runds., 82, 750755. [22] Ernstson, K. \& J. Fiebag (1993) Geol. Runds., 82, 756-759. [23] Cortés, A.L. \& A.M. Casas (1996) Rev. Soc. Geol. España, 9, 51-66. [24] Langenhorst, F. \& A. Deutsch (1996) LPS XXVIII, 2, 725-726. [25] Ernstson, K. \& F. Claudín (1990) N. Jb. Geol. Paläont. Mh., 10, 581-599. [26] Moreno, F. (1974) Bol. Geol. Minero, 85, 396-400. [27] Moreno, F. (1975) Est. Geol., 31, 249-260. [28] Herranz, P. et al. (1977) Est. Geol. 33, 327-342. [29] San José, M.A. (1984) Cuad. Geol. Ibérica, 9, 81-117. [30] Álvarez-Nava, H. et al. (1988) II Congr. Geol. España, 1, 19-22. [31] Pardo, M.V. \& R. Robles (1988) II Congr. Geol. España, 2, 165-168. [32] Santamaría, J. \& M.V. Pardo (1994) Geogaceta, 15, 10-13. [33] Santamaría, J. \& E. Remacha (1994) Geogaceta, 15, 14-16. [34] Portero, J.M. \& C. Dabrio (1988) II Congr. Geol. España, I,
161-164. [35] Robardet, M. \& F. Doré (1988) Palaeogeogr., Palaeoclim., Palaeoecol., 66, 19-31. [36] García-Palacios, A. et al. (1996) Geogaceta, 20, 19-22. [37] Moreno, C. \& R. Sáez (1990) Geogaceta, 8, 62-64. [38] Moreno, C. et al. (1995) Geogaceta, 17, 9-11. [39] Aurell, M. et al. (1992) III Congr. Geol. España, 1, 5054. [40] San Román, J. \& M. Aurell (1992) Palaeogeogr., Palaeoclim., Palaeoecol., 99, 101-117. [41] Gallego, R. et al. (1994) Geogaceta, 15, 26-29. [42] Campos, S. et al. (1996) Geogaceta, 20, 887-889. [43] Gómez, J.J. \& A. Goy (1998) Geogaceta, 23, 63-66. [44] Pena dos Reis, R.P. et al. (1997) Geogaceta, 22, 149-152. [45] Monteiro, J.F. et al. (1997) $L P S X X I X, 2$, 967. [46] Monteiro, J.F. et al. (1998) Meteoritics \& Planet. Sci., 33, A112-A113. [47] Monteiro, J.F. et al. (1999) Rep. Polar Res., 343, 64-66. [48] Gil, J. et al. (1993) Geogaceta, 13, 43-45. [49] Gorostidi, A. \& M.A. Lamolda (1996) Geogaceta, 20, 887-889.

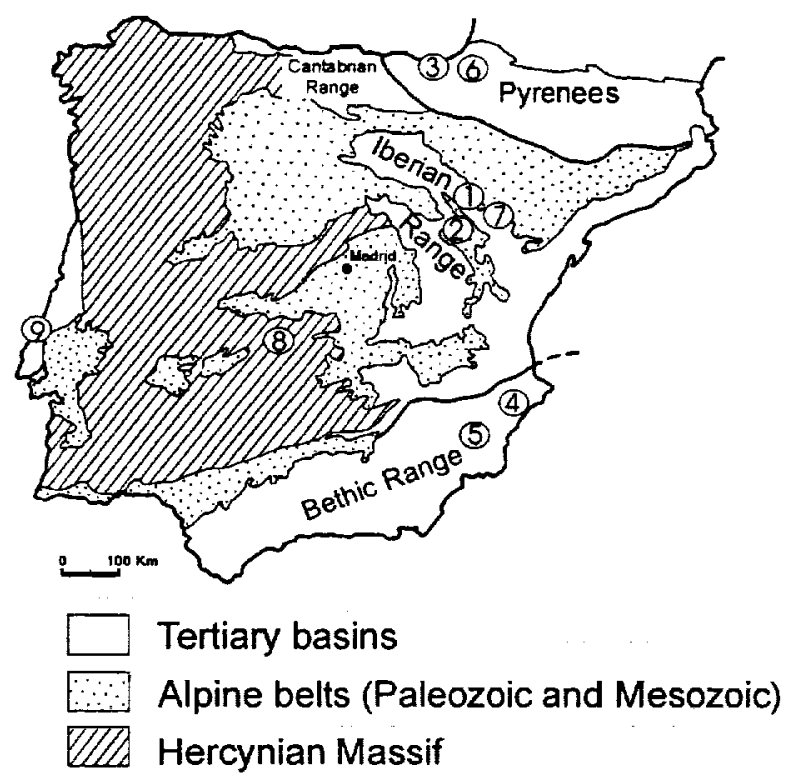

Figure I: Localities mentioned in text: (1) Ricla, (2) Pozuel del Campo, (3) Zumaya and Eibar, (4) Agost, (5) Caravaca, (6) Osinaga-Musquiz, (7) Azuara, (8) ValdelacasaNavalpino, (9) Nazaré 
THE END-PERMIAN MASS EXTINCTION AND EARLY TRIASSIC BIOTIC RECOVERY. D. H. Erwin', 'Dept. Of Paleobiology, MRC-121, National Museum of Natural History, Washington, D. C., 20560, USA. Email: erwin.doug@nmnh.si.edu

Introduction: Our understanding of the end-Permian mass extinction has been revolutionized over the past decade. In 1990, Teichert [1] and Erwin [2] argued the extinction occurred over ten million years, or more. Stanley and Yang [3] and Jin et al [4], however, demonstrated the existence of two discrete pulses of extinction, one at the close of the Capitanian Stage of the middle Permian, the second at the end of the final, Changhsingian Stage of the Permian. More recently, Bowring et al. [5] showed that this second pulse of extinction occurred in less than $500 \mathrm{kyr}$, and the rapidity of the biological and geochemical changes at the Permo-Triassic boundary appears increasingly similar to the end-Cretaceous mass extinction. The calculated sediment accumulation rates from the Meishan PT boundary section in south China [5], coupled with new carbon isotopic data suggest the extinction probably occurred in less than 165,000 years, but could have been even more rapid. Other developments over the past few years have also constrained the possible explanations for the endPermian mass extinction, eliminating some suggestions, but enhancing other possibilities. The end-Capitanian extinction phase remains less well known that the second pulse, which will be emphasized here.

Constraints on mechanisms: Bowring et al [5] and subsequent work have summarized the following constraints on the cause of the end-Permian extinction: 1) widespread evidence for deep-sea anoxia across the PT boundary, and for shallow-water anoxia at or close to the PT boundary; 2) a $\delta^{13} \mathrm{C}$ shift from +2 to -2 per mil essentially coincident with the extinction horizon; 3) a close temporal correlation with the eruption of the Siberian flood basalt [6]. Additionally, there is growing evidence for an interval of climatic warming during the earliest Triassic, which may be related to the cause of the extinction. Evidence for this global warming comes from fossils and sediments in northern Canada, the Karoo Basin of South Africa, and Australia [7,8]. The close correlation between the Siberian flood basalt and the extinction suggests a correlation [7,9], but several aspects remain unexplained by that hypothesis, including the magnitude and rapidity of the shift in carbon isotopes. The isotopic shift is often considered a whole ocean shift, but may actually involve a whole ocean shift from +2 to 0 and a transient surface water shift to -1 or -2 per mil [5]. This correspondingly reduces the volume of organic carbon required to produce the shift.

Plausible mechanisms: The available evidence remains consistent with several possible mechanisms, but difficulties exist with each of them. The first possibility is the eruption of the Siberian traps introduced large volumes of carbon and sulfates into the atmosphere, triggering climatic changes and extensive acid rain $[7,9]$. To explain the marine extinctions and the isotopic shift, the associated climatic warming must have been sufficient to warm the surface ocean enough to release a minimum of 1200 gigatons of methane carbon. As originally noted in 1993 [10], the release of gas hydrates is the most straightforward solution to the shift in carbon isotopes. However the explanation in 1993 relied upon a drop in sea-level during the extinction, while more recent data clearly demonstrate that sea-level was rising $[6,11$, 12], requiring a different mechanism to release the methane gas hydrates [5]. Methane release triggered by the Siberian flood basalts may also explain the other aspects of the extinction, including the anoxia.

Other possible mechanisms are not yet excluded by the data, however. A tsunami and heat released by the impact of an extra-terrestrial object could also be sufficient to cause the release of gas hydrates, causing the isotopic shift; if the impactor was an icy object, it could have directly introduced the requisite carbon [5]. Although there remains no direct evidence for an impact at the PT boundary, the geological and paleontological evidence is strikingly reminiscent of some evidence for the KT mass extinction. The temporal constraints on the PT extinction strengthen the possibility of an impact, although, again, there is no direct evidence in favor of this possibility.

Patterns of biotic recovery: The end-Permian mass extinction marked the demise of groups which had dominated marine ecosystems for over 200 million years, and the subsequent radiation established those groups which continue to dominate marine communities today. Thus a critical component of research into the extinction involves the postextinction recovery [13-15]. The Early Triassic is a highly anomalous interval of time. Although some clades rebound quickly, in most clades the biotic recovery is considerably delayed, with the survival interval extending for millions of years to near the Smithian/Spathian boundary [10]. Most other survival intervals last less than 1 myr [14]. Whether this lag reflects continuing environmental dampening, precluding biotic recovery, or the magnitude of the ecological disruption caused by the extinction[13] has been the subject of considerable discussion. Recovery of coniferous forests in Europe follows a lengthy period of lycopsid dominance [16]. Anomalous carbonate cements from the western US suggest continuing high alkalinity into the Smithian/Spathian [17], and environmental dampening of the recovery. In contrast, analysis of sections from northern Italy 
[18] and the western US [19] indicate that these shallow marine sections exhibit normal marine conditions by the late Greisbachian. While there may be considerable biogeographic variation in the pattern of recovery, as documented for the KT extinction [20], there is little evidence for environmental dampening continuing through most of the Early Triassic. A more powerful explanation for the delayed recovery comes from a recent cross-correlation of origination and extinction rates throughout the Phanerozoic, based on Jack Sepkoski's data. This analysis suggests an approximately $10 \mathrm{my}$ lag between extinctions and originations, independent of the scale of the extinction [21]. This surprising result suggests, contrary to the views of some studying biotic recoveries, that originations do not simply represent refilling of empty ecospace, but the active creation of a new ecological fabric. The positive feedback effects of recovery thus entail a delay before the onset of recovery, but then a very rapid rebound once it begins $[21,22]$

\section{References:}

[1] Teichert, C. B. (1990) in: Kauffman, E. G. and Walliser, O. H. eds. Extinction Events in Earth History pp. 199-238. (Springer, Berlin). [2] Erwin, D. H. (1990) Ann. Rev. Ecol. Syst. 21, 69-91. [3] Stanley, S. M. and Yang, X. (1994) Science 266, 1340-1344. [4] Jin, Y. G., et al (1994) Can. Soc. Pet. Geol. Mem. I7, 813-. [5] Bowring, S. A., et al. (1998) Science 280, 1039-104. [6] Renne, P. R., et al (1995) Science 269, 176-177. [7] Retallack, G. J. (1999) GSA Bull. 111, 52-70. [8] Retallack, G. J. and Krull, E. S. (1999) 46, 785-812. [9] Visscher, H. et al. (1996) Proc. Nat. Acad Sci., USA 93, 2155-2158. [10] Erwin, D. H. (1993) The Great Paleozoic Crisis (Columbia Univ. Press, New York). [11] Wignall, P. B. and Hallam, A. (1992) Palaeogeogr. Palaeoclimatol. Palaeoecol. 93, 21-46. [12] Wignall, P. B., and Twitchett, R. J. (1996) Science 272, 1155-1158. [13] Erwin, D. H. (1996) in Jablonski, D., Erwin, D. H. and Lipps, J. eds. Evolutionary Paleobiology pp. 398-418, (Univ. Chicago Press, Chicago). [14] Erwin, D. H. (1998) Trends Ecol. Evol. 13, 344-349. [15] Erwin, D. H. (2000) Proc. Nat. Acad Sci., USA, in press. [16] Looy, C. V. (1999) Proc. Nat. Acad Sci., USA 96, 13857 13862. [17] Woods, et al., (1999) Geology 27, 645648. [18] Twitchett, R. J. (1999) Palaeogeogr. Palaeoclimatol. Palaeoecol. 154, 27-37. [19] Schubert, J. K. and Bottjer, D. J. (1995) Palaeogeogr. Palaeoclimatol. Palaeoecol. 116, 1-39. [20] Jablonski, D. (1998) Science 279, 1327-1330. [21] Kircher, J. W. and Weil, A. (2000) Nature 404, 177 180. [22] Erwin, D. H. (2000) Nature 404, 129-130. 


$$
525 / 45
$$

COMPELLING NEW EVIDENCE FOR PALEOCENE DINOSAURS IN THE OJO ALAMO SANDSTONE, SAN JUAN BASIN, NEW MEXICO AND COLORADO, USA. J.E. Fassett ${ }^{1}$, S.G. Lucas ${ }^{2}$, R.A. Zielinski ${ }^{1}$, and J.R. Budahn'. ${ }^{1}$ U.S. Geological Survey, P.O. Box 25046, MS 939, DFC, Denver, Colorado 80225 (jassett@usgs.gov), ${ }^{2}$ New Mexico Museum of Natural History, 1801 Mountain Road, N.W., Albuquerque, New Mexico, 87104 (slucas@nmmnh.state.nm.us)

The San Juan Basin is in the Western United States in the states of New Mexico and Colorado (fig. 1). A hiatus of about 8 m.y. separates Late Cretaceous from Tertiary rocks in the Basin. Most of the missing strata are from the Maastrichtian Stage. The unconformity is overlain by the Ojo Alamo Sandstone in the south and underlain by the Kirtland or Fruitland Formation at most other places in the basin. Isopach lines on figure 1 show that the pre-Ojo Alamo unconformity beveled underlying Upper Cretaceous rocks southeastward by more than $640 \mathrm{~m}$. (2,100 ft., fig. 1).

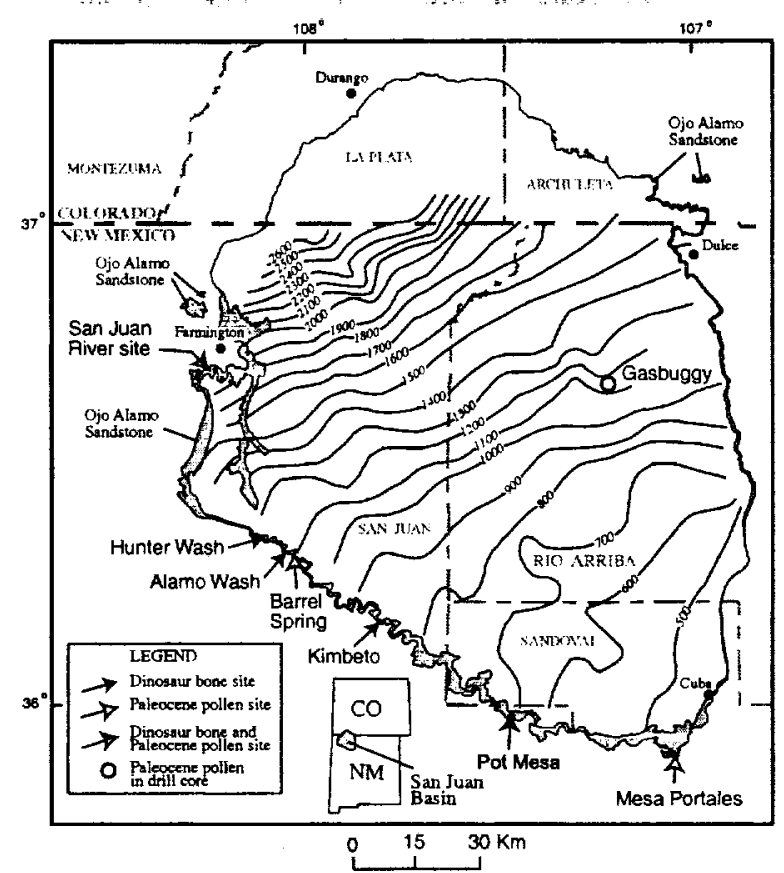

Figure 1 - Index map of San Juan Basin showing outcrop of Tertiary, Ojo Alamo Sandstone and locations of dinosaurbone and (or) pollen collection sites. Isopached interval is from the Huerfanito Bentonite Bed of the Lewis Shale to the base of the Ojo Alamo Sandstone. Line delimiting northern part of basin is base of Tertiary Animas or Nacimiento Formation. Modified from Fassett et al [1].

The Ojo Alamo Sandstone was defined at Alamo Wash (fig. 1) as two conglomeratic sandstone beds separated by a medial, sandy-shale unit and was assigned a Cretaceous age because of its abundant dinosaur fauna [2]. Elsewhere in the basin, the Ojo Alamo consists of a series of lensing, overlapping, multistoried channel sandstone bodies, conglomeratic in the north and west and non-conglomeratic in the south and east. Paleocurrent studies $[3,4]$ show that the Ojo Alamo was deposited by high-energy, braided streams with a north to northwest source. Numerous papers [2] have suggested new member names for parts of the Ojo Alamo and the upper part of the Kirtland Shale. In this report, the name Ojo Alamo is used as first formally applied but is considered to be entirely Paleocene in age.

Two publications $[5,1]$ focused on the contradictory evidence of Paleocene pollen and dinosaur bone within the Ojo Alamo in the basin. These reports tentatively concluded that pollen was the more accurate age indicator and therefore the Ojo Alamo dinosaurs were Paleocene in age. The conclusion was tentative because Paleocene pollen nowhere occurred at exactly the same locality as dinosaur bone. Paleocene pollen is present, however, in the Ojo Alamo near Barrel Spring, within one mile of the Alamo Wash bone locality (fig. 1). Fassett et al [1] discussed the recent discovery of a large hadrosaur femur in the Ojo Alamo at the San Juan River site (fig. 1) and showed a photograph of this bone, in place (fig. 2A). Subsequently, the bone was excavated, cleaned, and mounted for display at the Department of Earth and Planetary Science, at the University of New Mexico, Albuquerque, N.M. (fig. 2B).
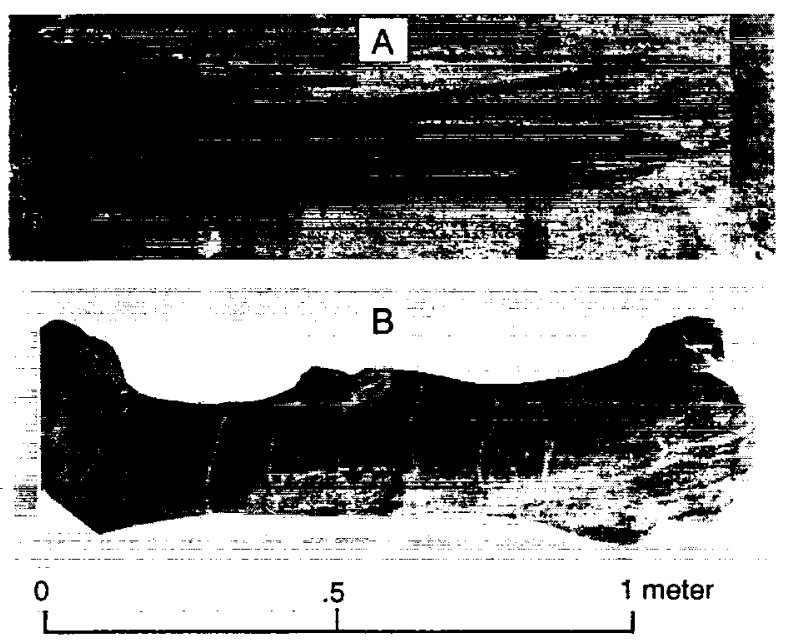

Figure 2 - Right femur of a hadrosaurian dinosaur from the San Juan River site (fig. 1). A -- bone in place in the Tertiary Ojo Allamo Sandstone, west-central San Juan Basin, New Mexico; photograph from Fassett et al [1]. B -- bone after excavation, preparation, and mounting. Bone in $B$ is rotated on its long axis about 180 degrees from view in $A$. 
Following the excavation of the hadrosaur femur from the San Juan River site, a coaly, carbonaceous shale bed was discovered about $160 \mathrm{~m}$ west of the dinosaur-bone locality and $3 \mathrm{~m}$ stratigraphically below the level from which the bone had been excavated. Samples of this coaly bed were collected and analyzed for their pollen and spore content and were found to contain a diverse assemblage, including Momipites tenuipolis, indicating a Paleocene age for these rocks.

Figure 3 is a composite stratigraphic column showing the stratigraphy of the lower part of the Ojo Alamo Sandstone at the San Juan River site.

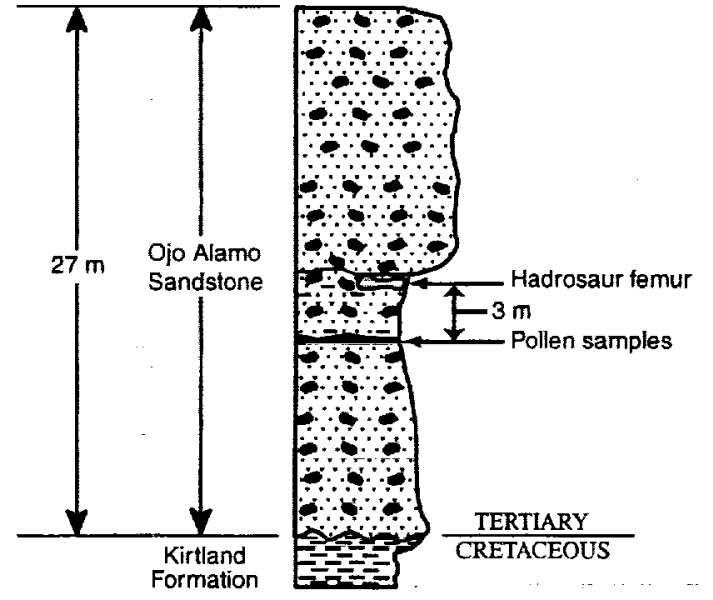

Figure 3 - Stratigraphic column of the lower part of the Ojo Alamo Sandstone at the San Juan River site (fig. 1). Modified From Fassett et al [1].

The data from the San Juan River site demonstrate that the large hadrosaur femur found there was preserved in rocks of Paleocene age. Because this is a single bone, however, the question of possible reworking from the underlying Kirtland Formation of Cretaceous age must be addressed. We find that possibility unlikely to impossible, for the following reasons: 1) The base of the Ojo Alamo Sandstone is a planar surface in this area with no local topographic highs in the underlying Cretaceous strata extending $15 \mathrm{~m}$ upward into the Ojo Alamo to the level of the bone; the isopach lines of figure 1 also indicate a very flat surface at the base of the Ojo Alamo in the vicinity of the San Juan River site, 2) Uppermost Kirtland strata were certainly at the same level as the San Juan River site bone a few miles to the northwest, but given the size of this bone and its silicified weight of more than $150 \mathrm{Kg}$, it would have been practically impossible for this bone to have been transported even a few meters, not to mention a few miles southward to the San Juan River site, and 3) The bone, (fig. 2B) has a pristine outer surface with no abrasions or scratches and with all of its delicate outer processes intact. There is thus no evidence of transport of this bone.
We suggest that this animal lived in Tertiary time and died near the place where this silicified femur was found. As the corpse decayed, river currents disarticulated the skeleton, dispersing the lighter elements, and leaving this large massive bone behind to be quickly buried and silicified.

The fully documented Paleocene dinosaur bone from the Ojo Alamo Sandstone at the San Juan River site, bolsters conclusions $[5,1]$ that the dinosaur-bone assemblage from the Ojo Alamo Sandstone in the vicinity of Alamo Wash is also of Paleocene age, even though vertebrate paleontologists have assigned a Lancian age to that assemblage.

We have initiated trace-element analyses of dinosaur bone from the Ojo Alamo to further resolve the reworking question. Instrumental neutron activation analysis of 14 bone samples from the southern San Juan Basin, seven from the Kirtland and seven from the Ojo Alamo, indicate distinct differences in the concentration of rare earth elements (REE) and uranium (U) in the two populations. Chondritenormalized REE abundances in Kirtland bone indicate a markedly steeper slope $(\mathrm{La} / \mathrm{Yb}=16.1 \pm 7.8)$ compared to Ojo Alamo bone ( $\mathrm{La} / \mathrm{Yb}=5.7 \pm 3.9)$. Kirtland samples also have markedly lower concentrations of $U$ (2.1 to $38.3 \mathrm{ppm})$ compared to Ojo Alamo samples (166 to $834 \mathrm{ppm})$. Uptake of $\overline{\mathrm{REE}}$ and $\mathrm{U}$ by apatite is believed to occur rapidly during early diagenesis and to reflect differences in pore-water environments $[6,7]$. REE abundances preserved in fossil bone have been used to identify reworked bone in other settings [6]. The distinctive REE pattern and U content of Ojo Alamo bones suggests that they are not reworked Cretaceous bones. Fission-track radiography will be used to determine if the distribution of uranium in Ojo Alamo bone is consistent with early diagenetic uptake in apatite or with secondary introduction of $U$. An unexpected finding is that iridium concentrations in these bone samples are high, ranging from $0.1-2.77 \mathrm{ppb}$.

References:

1. Fassett, J.E. et al (1987) in Fassett and Rigby, eds., GSA SP 209, 17-34.

2. Fassett, J.E. (1973) in Fassett, ed., Four Corners G.S. Memoir, 123-130.

3. Powell, J.S. (1973) in Fassett, ed., Four Corners G.S. Memoir, 111-122.

4. Sikkink, P.G.L. (1987) in Fassett and Rigby, eds., GSA SP 209, 81-104.

5. Fassett, J.E., (1982) in Silver and Shultz, eds., GSA SP 190 , 435-447.

6. Trueman, C. N. and Benton, M. J. (1997) Geology, v. 25, p. 263-266.

7. Rae, A. M. and lvanovich, M. (1986) Applied Geochem. vol. 1, p. 419-426. 
EXPLOSIVE EVOLUTION IN TERTIARY BIIRDS AND MAMMALS FOLLOWING THE K-T CATACLYSM. A. Feduccia, Department of Biology, Coker Hall, CB\# 3280, University of North Carolina, Chapel Hill, North Carolina 27599-3280, USA. [feduccia@bio.unc.edu].

The traditional view of avian evolution over the past century has largely been one of sluggish gradualism. Most of the living orders of birds and mammals were thought to have originated beginning at approximately the mid-Cretaceous or so, and progressively and gradually evolved into the present orders, passing unblemished through the K-T boundary. As a consequence of this early origin, many groups of birds and mammals were considered vicariant passengers on the Cretaceous drifting continents. For example, groups such as the ostriches and rheas were thought to have evolved on the southern landmass from a single flightless ancestor and drifted on the African and South American landmasses, respectively. Several recent molecular studies [13 ] have also suggested that birds and mammals are much older (by some 50 to $90 \%$ ) than the fossil record indicates and one study [1] suggests that the continental breakup was an important mechanism in the ordinal diversification of birds and mammals.

However, for modern bird and mammal orders to have originated in the mid-Cretaceous would require that the fossil record of these two groups is horribly incorrect, and there is every reason to believe that the fossil record is fairly accurate. Obviously, one side or the other is simply wrong. Too, recent discoveries of fossil birds have revolutionized our view of avian evolution during both the Mesozoic and Cenozoic, and suggest a dramatic departure from the time-honored phylogenetic picture. According to this new model [4], birds endured massive extinctions at the end of the Cretaceous, underwent a dramatic K-T bottleneck, and then closely paralleled mammals in an explosive phyletic evolution in the early Tertiary. Birds, then, like mammals, underwent an initial Mesozoic adaptive radiation of archaic types, were devastated by the event that closed the Cretaceous Period, and underwent a major reorganization in the early Tertiary, with perhaps initial landbird and shorebird descent. All the major lineages of birds evolved within a time period of some 10 million years, with all the major orders appearing by the late Paleocene or early Eocene [5]. Gap analyses [6] support the hypothesis that the avian orders diverged from a common ancestor over a brief time interval following the K-T cataclysm.

References: [1] Hedges, S. B., Parker, P. H., Sibley, C. G., and Kumar, S. (1996) Nature, 381 , 226-229. [2] Cooper, A. and Penny, D. (1997) Science, 275, 1109-1113. [3] Kumar, S., and Hedges, S. B. (1998) Nature, 392, 917-920. [4] Feduccia, A. (1995) Science, 267, 637-638. [5] Feduccia, A. (1999) The Origin and Evolution of Birds, $2^{\text {nd }}$ ed., New Haven, Yale University Press. [6] Bleiweiss, R. (1998) Geology, 26, 323-326. 
ECOLOGY AND EVOLUTION DURING PRECAMBRIAN GLACIATIONS. E. J. Gaidos, Division of Geology \& Planetary Science, California Institute of Technology, Pasadena CA 91125, USA, (gaidos@gps.caltech.edu).

There is accumulating evidence that Precambrian glaciations reached equatorial latitudes [1,2]. Kirschvink proposed that cooling of the Earth and subsequent low-latitude glaciation created an albedo-driven runaway to a "Snowball Earth" state in which pack ice covered the world ocean, halting the hydrological cycle and curtailing primary marine productivity [3]. The theory explains several unique features in the Neoproterozoic sedimentary rock record [4] and a similar event has been proposed to explain anomalous Paleoproterozoic diamictites metalliferous deposits $[5,6]$.

A climate catastrophe of this magnitude should have resulted in drastic reduction of the biosphere and appears to be recorded in carbonate $\delta^{13} \mathrm{C}$ values. However, the Precambrian fossil record is sparse and predominantly microbial: Species or clades of microbial organisms can be difficult or impossible to distinguish based on morphology alone. Without this information it is not possible to discriminate between a mass extinction (reduction in biodiversity) and a mass culling (reduction in biomass). Terminal Neoproterozoic units do include megascopic fossils of the oldest Metazoa and the enigmatic Ediacara, whose relationship to the former is debated [7]. Fossils contemporaneous with the Paleoproterozoic events, which predate the oldest plausible fossil of a eukaryote [8], will be strictly microbial.

An improved description of possible ecologies during the onset, total, and aftermath phases of a snowball event will aid interpretation of the fossil record. A critical refugia for life will be the oceans. Although surface temperatures will average $-50^{\circ} \mathrm{C}$ or below [9] upwelling heat will prevent the oceans from freezing solid and instead a thick ice shell will develop. The global average ice thickness will be determined by the mean surface temperature and the heat flow through oceanic crust and will vary with geologic time due to the increasing luminosity of the Sun and the decreasing heat flow of the Earth with time. Mean ice thickness was approximately $700 \mathrm{~m}$ in the Neoproterozoic and $400 \mathrm{~m}$ in the Paleoproterozoic. Ice this thick will not develop penetrating cracks [10]. Hydrothermal vents at mid-ocean ridges, deprived of the oxidants in deep water, could support only sulfur reduction and methanogenesis metabolisms.

However, McKay [11] has shown that under certain conditions absorption of sunlight within the ice results in ice as thin as $\sim 2 \mathrm{~m}$. These areas will be initially restricted to the equator near the equator but may expand as atmospheric $\mathrm{CO}_{2}$ levels, unchecked by weathering, rise. Areas of high ablation will produce blue, regelated ice which because of its low albedo and low scattering properties, will remain warmer and thinner than mean conditions. These regions may become selfpropagating if ablation rates increase because of the greater absorbed heat. In addition, flows of ablating ice around or between obstacles (e.g., islands) could result in cracking either due to shear forces between the grounding line and moving ice field, or compression forces in the windward side of an obstacle. These regions will support photosynthetic communities, including eukaryotic algae at the sea-ice interface. The production of oxygen in a predominantly reducing ocean will, in turn, create a microecology within bacteria which use oxidants and reductants of varying electrochemical potential can survive. This would lead us to predict that the glaciations did not lead to extinction of bacterial species or their metabolic pathways. In poorly ventilated shallow seas oxidation of the entire water column could produce the iron and manganese deposits that appear in the rock record.

The coincidence between the last global glaciation and the emergence of modern metazoa has been noted by many researchers, beginning with Kirschvink. The Ediacara fauna appear briefly in the terminal Neoproterozoic and their radiation and subsequent disappearance from the fossil record at $\mathrm{ca}$. $550 \mathrm{Ma}$ has also been ascribed to a glaciation sovolutionary aftermath [12]. However, Ediacara-like fossils have now been found in the Cambrian as well [13], suggesting that more complex taphonomic and ecological factors may have played a role. The large surface area to volume ratios and the quilted pneu structures suggest that many types of these organisms were adapted to low-oxygen environments. Their soft-bodies forms also suggest an ocean chemistry unfavorable to the stability of carbonates or phosphate skeletons.

Life itself may have influenced global climate and the occurence of severe glaciation events: Hoffman et al. suggested that the advent of burrowing animals increased overturn of sediments and the efficiency with which organic carbon is re-oxidized and returned to the atmosphere as $\mathrm{CO}_{2}$ [12]. Conversely, the rise in atmospheric oxygen and the formation of a UV-screening ozone shield could have allowed intense microbial and fungal colonizatin of the continents, increasing the rates of silicate weathering and pulling atmospheric $\mathrm{CO}_{2}$ levels and temperatures down [14].

References: [1] P.W. Schmidt and G.E. Williams (1995) Earth Planet. Sci. Lett. 134, 107. [2] D.A. Evans et al. (1997) Nature 386, 262. [3] J.L. Kirschvink (1992) in The Proteroizoic Biosphere, Shopf and Klein, eds. [4] P.F. Hoffman $e t$ al. (1998) 281, 5381. [5] H. Tsikos and J.M. Moore (1998) S. Afr, J. Geol. (1998) 101, 287. [6] J.L. Kirschvink et al. (2000) Proc. Natl. Acad. Sci. USA, in press. [7] Narbonne 1998 GSA Today 8, 1. [8] Han \& Runnegar 1992 Science 257, 232. [9] G.S. Jenkins and S.R. Smith (1999) Geophys. Res. Lett. 26, 2263. [10] Gaidos (2000) Proc. Lunar Planet. Sci. Conf.. [11] McKay (2000) Geophys. Res. Lett., submitted. [12] Hoffman (1999) J. Afr. Earth Sci. 28, 17. [13] Gaidos (2000) Proc. Americ. Geophys. Union Conf. [14] Jensen et al. (1998) Nature 393, 567. 


\section{OLIGOTROPHIC OCEANS AND MINIMALIST ORGANISMS: RESTRUCTURING THE MARINE COMMUNITY AFTER THE K/T MASS EXTINCTION. Gallagher, Wil- liam B., Natural History Bureau, New Jersey State Museum, PO Box 530, Trenton, NJ 08625- 0530. Email: wgallagh@museum.sos.state.nj.us.}

Mass extinctions in the marine realm are often marked by reductions in the diversity and abundance of plankton. Diversity reduction among the plankton is documented for the Frasnian/Fammenian event, the Permo-Triassic mass extinction, and the $\mathrm{K} / \mathrm{T}$ boundary. The effects of this population crash in the base of the food chain should reverberate upward to higher levels of the trophic pyramid. What evidence can we see in the fossil record of mass extinctions for confirmation of this hypothesis?

Across the $\mathrm{K} / \mathrm{T}$ boundary in eastern North America, there is evidence for a resetting of the evolutionary clock in Danian marine ecosystems, which are dominated by faunas of Paleozoic aspect. Widespread diverse Cretaceous molluscan assemblages are replaced temporarily in the Danian by a sponge-brachiopod-coral dominated assemblage. In particular, fossil concentrations in the $\mathrm{K} / \mathrm{T}$ section of the Atlantic Coastal Plain show a diverse oyster bank ecosystem replaced by a brachiopod dominated shell gravel where large terebratulids of one species (Oleneothyris harlani) can form up to $99 \%+$ of the bioclasts. The Oleneothyris zone can be traced from New Jersey in the north down into southeastem North Carolina at the same level in Paleocene outcrops. The brachiopods are often accompanied by a sponge (Peridonella dichotoma) and a solitary coral (Flabellum mortoni). Dwarfed bivalves form an insignificant proportion of this fauna.

During and immediately after the Frasnian-Fammanian mass extinction, hexactinellid sponges proliferated and diversified while numerous other groups

were being decimated (1). After the most severe extinction event, the Permo-Triassic, demosponges became important in the Triassic. Again, after the Triassic/Jurassic mass extinction, sponges are part of the reef community in the Jurassic.

Sponges are minimalist organisms, able to filter up to 10,000 to 20,000 times their own body volume of water per day (2). They specialize in extricating smaller bits of nutrients from the water column. In mass extinction events such as the $\mathrm{K} / \mathrm{T}$ event, the kinds of plankton (e.g., foraminifera) left over after the event are generally smaller than the larger and more ornate forms found before the extinction. Therefore sponges are liable to be favored as survivors since they are more effective at filtering out small particles, and processing large amounts of water for these particles.

Brachiopods are also minimalist organisms. They are able to survive at lower oxygen levels, and in general have lower food requirements and lower metabolism than other exoskeletonized benthos. (3) The abundance of a single species such as Oleneothyris harlani over a wide area after the $\mathrm{K} / \mathrm{T}$ event suggests it was a opportunistic species that could thrive in the oligotrophic ocean of the Danian.

Hypothesized effects of large body impacts such as reduction in solar radiation reaching earth's surface, acid rain, and near-destruction of the ozone layer would all have negative effects on the plankton population. As Olsson and Liu (4) have shown, only three species of planktonic foraminifera survived the $\mathrm{K} / \mathrm{T}$ boundary. The resulting Danian marine community would have to be adapted to severe reduction in food resources in an oligotrophic ocean, especially in waters closer to the Chicxulub impact site, for example in eastern North America. Such a pattern is demonstrated in the minimalist assemblage of the Danian of the Atlantic Coastal Plain. 
The plankton crash also probably affected those organisms that reproduced by means of planktotrophic larvae. Normally, wide dispersal patterns and large numbers of planktotrophic larvae were favored during times of high planktonic productivity; but when the planktonic populations crashed at the $\mathrm{K} / \mathrm{T}$ boundary, those organisms that depended upon a developmental stage in the plankton were severely affected. This explains why ammonites, which were planktotrophic reproducers, went extinct, while nautiloids, which lay lecithotrophic eggs on the sea bottom, survived. Brachiopods are larval brooders, while sponges can reproduce asexually.

Dwarfing among Danian benthos is explainable as a response to lower plankton levels in the post $\mathrm{K} / \mathrm{T}$ ocean. Danian representatives of Maastrichtian molluscan genera are generally smaller, if they survive at all (e.g., Pycnodonte, Cucullaea). Russian echinoids show dwarfing across the $\mathrm{K} / \mathrm{T}$ boundary (5), and dwarfing has been established as a common feature of earliest Paleocene marine faunas.

The niche of duraphagous predator was an important trophic level in the Cretaceous marine food web. There were a variety of shell-crushing carnivores taking advantage of the rich food resources of Cretaceous mollusks and crustaceans. Chimaerids, rays, certain sharks, various bony fish species, some turtles and a few mosasaurs (Globidens, Carinidens) show jaws or dentition adapted for shell crushing.

By contrast, marine predators of the Paleocene tend to be more generalized carnivores such as crocodiles or lamnid sharks. Duraphagy survived as a niche, but in the Danian opportunistic predators with broader tastes predominated. The scarce resources of the early Paleocene oligotrophic ocean affected specialized predators.

This pattern of extinction and survival across the $\mathrm{K} / \mathrm{T}$ boundary provides a model for the collapse of marine ecosystems under stresses generated by large-scale environmental disturbance, such as an asteroid impact. Such a pattern should be zonally distributed, reflecting decreasing intensity of impact effects farther away from the crater. Preliminary proof for this comes from new Late Cretaceous fossil discoveries in eastern North America; coelacanths and lungfish of Late Cretaceous age were wiped out in this part of the world but survived at the antipodes of the impact in the Indo-Australian region. This idea is also supported by the distribution of other well-known living fossils such as Neotrigonia, various plant families, and marsupials.

References: (1) G. R. McGhee, 1996. The Late Devonian Mass Extinction: The Frasnian/Fammenian Crisis. New York, Columbia University Press, 303 pp; (2) J. K. Rigby, 1983, Introduction to the Porifera. In: J. K. Rigby and C. W. Stearn (eds.), Sponges and Spongiomorphs. Univ. Tennessee Dept. of Geo. Sciences Studies in Geology \# 7, pp. 1-11.(3) Thayer, C. W. 1981. Ecology of Living Brachiopods, In J. T Dutro and R. S. Boardman (eds), Lophophorates, Univ.Tennessee Dept. of Geo. Sciences Studies in Geology 5, pp. 110-126. (4) R. K. Olsson and C. Liu. 1993, Palaios, 8: 127-139. (5) A. V. Markov and A. N. Soloviev. 1997. Echninoids at the Cretaceous -Paleogene Boundary. In: A. Y. Rozanov, P. Vickers-Rich, and C. Tassell (eds.), Evolution of the Biosphere. Records of the Queen Victoria Museum, No. 104, pp. 35-37. 
PRODUCTION OF TOXINS DURING AN IMPACT AND THEIR POSSIBLE ROLE IN A BIOTIC MASS EXTINCTION. M.V.Gerasimov, Space Research Inst., Russian Academy of Science, Profsoyuznaya st., 84/32, Moscow, 117810, Russian Federation, mgerasim@mx.iki.rssi.ru.

Impact of an asteroid size object produces a global catastrophy on the Earth. Such catastrophes could cause temporal changes in the composition and density of an atmosphere, climatic and oceanic circulation, and other changes that could be over a certain period of time equilibrated by endogenic processes to a regular state. Some changes could have no recovery to the former state, one possible example of which is the extinction of some forms of life.

Among different factors of an impact which are significant for the survivability of life forms we can separate physical (the action of shock waves, expansion and luminosity of the fireball, ejecta, tsunami, high amplitude earthquakes, etc.), chemical (the damage of the chemical equilibrium of the atmosphere by the release of impact generated gaseous components and chemical reactions between atmospheric gases and vapor cloud, formation of toxic components, acidic rains, change of $\mathrm{pH}$ in the ocean water, formation of aerosols, etc.), and climatic. The significance of physical, chemical and climatic factors changes with the distance from the center of an impact. Schematically it is shown on the Fig. 1. In the close vicin-

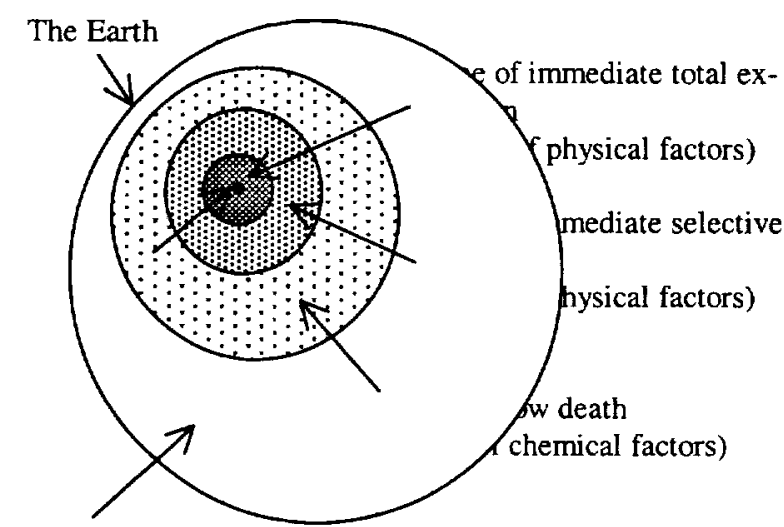

Zone of long-term mortal effects (result of chemical and climatic changes)

Fig. 1. Schematic zonning of a catastrophic impact effects.

ity of a crater there is a zone of immediate total extinction of all forms of life mainly due to the action of physical factors. Physical factors are reducing from the center of an impact and at some more distance there is a zone with immediate selective extinction. That means that some life forms can survive while other are extinct. At greater distances physical factors does not have mortal effect. Chemical factors are still can be significant since chemical products can be transported to long distances by wind and other mechanisms. Chemical changes in the environment can cause slow extinction of some sensitive to such changes life forms. If impact is catastrophic enough to cause climatic changes then the whole planet is the zone of dangerous environment for some life forms. Also some toxins being distributed globally can be dangerous even at low concentration.

The significance of chemical changes and the production of toxins during an impact has rather weak coverage in the literature and is not well understood. This paper is focused on the experimentally derived information about the chemistry of impacts and its possible mortal effect.

Our experimental approach included small scale impacts using light-gas-gun (LGG) facility and simulation of impact vaporization by use of laser pulse (LP) technique [1]. In our experiments we used a wide range of targets including different types of silicates from ultramafic to acidic and different salts modeling some specific sediments (e.g. gypsum, anhydrite and calcite for Chixculub case). We also performed experiments in different gas environments.

Investigation of the forming gas mixture shows the presence of large quantities of species which can be toxic for life forms: $\mathrm{CO}_{2}, \mathrm{CO}, \mathrm{HCN}, \mathrm{SO}_{2}, \mathrm{SO}_{3}, \mathrm{H}_{2} \mathrm{~S}$, $\mathrm{CS}_{2}, \mathrm{COS}, \mathrm{C}_{6} \mathrm{H}_{6}$, hydrocarbons, $\mathrm{H}_{2} \mathrm{SO}_{4}$ and other $[2,3,4]$. The amounts of released toxic gases into the atmosphere depended on the composition and dimension of a projectile and target rocks. Impact vaporization high-temperature chemistry shows weak dependency of the pattern of chemical products on physical parameters and on the scale of an impact. The composition of gases which are released during impacts are mainly depended on the relative quantities of volatile elements involved in reactions.

The interpolation of experimental data on the scale of the Chixculub impact with the amount of degassed $\mathrm{C}$ and $\mathrm{S}$ in the range of $2.4 \div 8.1 \times 10^{17} \mathrm{~g}$ [5] and $3 \div 38 \times 10^{16}$ g [6] correspondingly shows (see Table) that the produced amount of toxic gases exceeds 100 ppm level for the overall modern earth's atmosphere. Being distributed over the globe from the point of im- 
pact the concentration of toxic gases decreases with distance and time, but large areas such as continents could be subjected to high enough concentration of toxic cloud with inevitable extinction for some organisms. The problem of extinction is amplified by simultaneous action of all toxic components.

The table does not account all possible toxic components. Experiments also indicate a rather high production of PAH (see Fig. 2), also at oxidized conditions, some of which (e.g. 1,2-benzpyrene) could be extremely dangerous even at very low concentration.

Another possible danger for life forms is connected with the chemistry of chlorine. Being mobilized from the ocean water $\mathrm{Cl}$ also could be a noticeable component in the impact chemistry in case of shallow ocean impacts. Such components as phosgene $\left(\mathrm{COCl}_{2}\right)$ or dioxins could be synthesized in the vapor cloud during an impact but there is no data on their production efficiency. Dioxins are known as extremely dangerous components even at very low concentration.

References: [1] Gerasimov, M.V., et al., (1999) Physics and chemistry of impacts. In: "Laboratory Astrophysics and Space Research", ASSL, 236, eds. P. Ehrenfreund et al., KAP, Dortrecht, 279-330. [2] Mukhin, L.M., et al., (1989), Nature, 340, 46-48. [3] Gerasimov M.V., et al. (1997) In: Large meteorite impacts and planetary evolution (abstract), Sudbery, LPI Contr. No 922, 15-16. [4] Gerasimov, M.V., et al., (1994) In: LPSC XXV, 413-414. [5] Pierazzo E., et al. 1998, JGR, 108, 28607. [6] B.A.Ivanov et al. 1996, GSA Special Paper No 307, p. 125.

Table. Estimated values of toxic gases produced during the Chixculub event.

\begin{tabular}{|c|c|}
\hline Component & $\begin{array}{c}\text { Degassed by Chix- } \\
\text { culub event, g }\end{array}$ \\
\hline $\mathrm{CO}_{2}$ & $0.5 \div 1.6 \times 10^{18}$ \\
\hline $\mathrm{CO}$ & $3.4 \div 11 \times 10^{17}$ \\
\hline $\mathrm{COS}$ & $0.2 \div 2.5 \times 10^{16}$ \\
\hline $\mathrm{H}_{2} \mathrm{~S}$ & $0.2 \div 2.5 \times 10^{16}$ \\
\hline $\mathrm{CS}_{2}$ & $1.6 \div 20 \times 10^{16}$ \\
\hline $\mathrm{HCN}^{1}$ & $>2 \times 10^{13}$ \\
\hline $\mathrm{SO}_{2}$ & $0.4 \div 5 \times 10^{17}$ \\
\hline $\begin{array}{c}\mathrm{Hydrocarb} \\
\mathrm{C}_{1}-\mathrm{C}_{6}\end{array}$ & $0.5 \div 1.6 \times 10^{17}$ \\
\hline $\begin{array}{c}\text { benzene } \\
\mathrm{C}_{6} \mathrm{H}_{6}\end{array}$ & $1 \div 3.2 \times 10^{16}$ \\
\hline
\end{tabular}

-without account of reactions with atmospheric nitrogen.

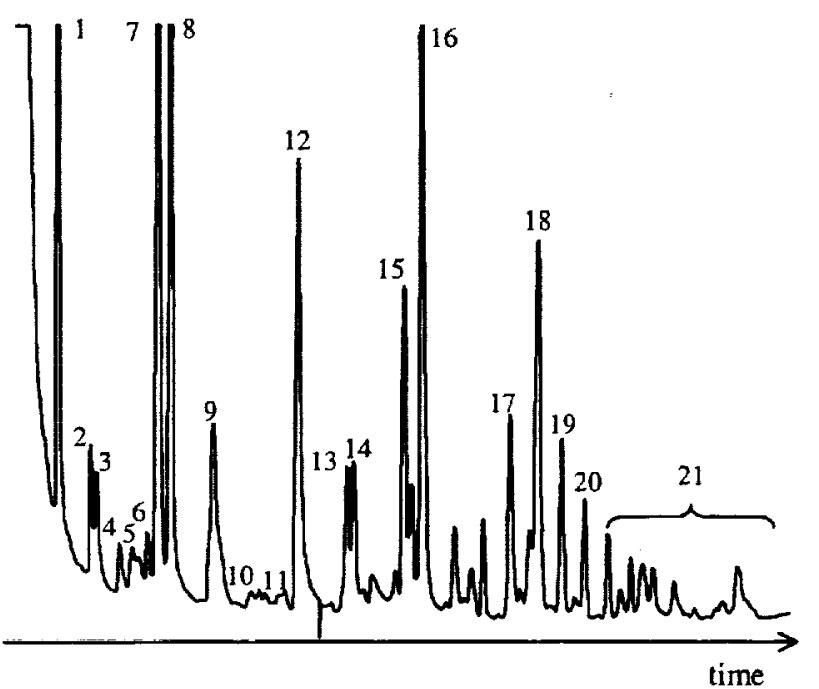

Fig. 2. The chromatogram of PAH extracted from the condensed phase in an experiment with vaporization of pyroxene in $\mathrm{CH}_{4}$ atmosphere: 1 . Naphthalene; 2, 3. Monometylnaphthalene; 4-8. Acenaphthene, Biphenyl, Dimethylnaphthalene; 9. Fluorene; 10. Monomethylbiphenil; 11. Monome-thylfluorene; 12. Antracene, phenanthrene; 13. ? $\mathrm{C}_{15} \mathrm{H}_{10} ; 14$. Dibuthyl phthalate; 15,16. Pyrene, Fluoranthene, Benzacenaphthene;17-20. Naphthacene, 1,2 benzanthracene, Hryzene, Threephenylene, 3,4 benzphenanthrene; 21. ? Benzpyrenes. 
OCEANIC IMPACTS AND RELATED ENVIRONMENTAL PERTURBATIONS. R. Gersonde, Alfred Wegener Institute, P.O. Box 120161, Bremerhaven 27515, Germany.

Only ca.13\% of the ca.165 known terrestrial impact structures have been identified to originate in marine environments. The marine impacts have been reported from shallow water marginal or epicontinental seas, except one, the Eltanin impact, that was discovered in the deep-sea basin of the southeast Pacific. Reasons for the mismatch between the numbers of continental and deep-sea impacts include (i) the relatively young age of oceanic basins, (ii) the post-impact burial of marine impact structures, (iii) the deceleration and disintegration of small projectiles in the water column preventing the formation of impact traces at the deep-sea floor, (iv) the inaccessibilty of the deep-sea floor, and (v) the lack of programs for the detection of oceanic impacts.

In contrast to continental impacts, oceanic impacts will generate megatsunamis that could potentially devastate coastlines. This includes destruction of coral reefs, destabilisation of shelf ice and shelf deposits and the backwash of terrestrial material. Future oceanic impacts represent a potential hazard because impact-generated large-scale tsunamis can cause enormous loss in populated coastal areas, including areas located at great distances of the impact ground-zero. Another specific threat related to oceanic impacts is the ejection of large quantities of water and salt into the atmosphere. Such deposition might lead to depletion of the ozone shield, to acidification of surface regions and could affect the Earth's albedo and the power of greenhouse forcing. Despite the great potential of oceanic impacts for causing sudden disturbance of past and future Earth's climate, environment and life, our knowledge on these processes is still quite limited.

To date, the only example for a deep-ocean impact is the late Pliocene (2.15 Ma) Eltanin impact in the $5000 \mathrm{~m}$ deep Bellingshausen Sea. Originally discovered in 1981, based on an Ir-anomaly[1], and documented in more detail in 1997 [2], the Eltanin impact represents a baseline for further impact-related studies and modeling, and the identification of other deep-sea impacts.

Combined with seismic and sediment core data, numeric modeling represents the most important tool to understand the complex impact-related processes such as short-term effects (pressure, velocities, shock waves) in the water column, large scale oceanic phenomena (e.g. tsunami generation and propagation), the effects of shock waves and oceanic processes on the sediment cover and basement, as well as perturbations in atmospheric and environment.

References: [1] Kyte, F.T. et al. (1981) Nature, 292, 417-420. [2] Gersonde, R. et al. (1997) Nature, 390, 357-363. 


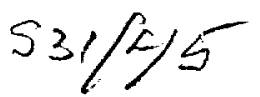

54 Catastrophic Events Conference

THE ORGANIC GEOCHEMICAL RECORD OF ENVIRONMENTAL CHANGE AT THE K/T BOUNDARY. I. Gilmour and M.A. Sephton, Planetary Sciences Research Institute, The Open University, Milton Keynes, MK7 6AA, United Kingdom. (I.Gilmour@open.ac.uk).

Introduction: The effects of an impact at the Cretaceous-Tertiary (K-T) boundary and, in particular, whether these were sufficiently severe and widespread to explain the extinction patterns observed remains controversial. The majority of evidence for biotic perturbations comes from the fossil record of marine sites combined with stable isotope evidence. Studies of the marine foraminiferal record across the K-T boundary have identified negative shift in $\delta^{13} \mathrm{C}$ of $1-2 \%$ which has been interpreted as evidence for depressed marine bioproductivity. Differences between the carbon isotopic values of planktonic and benthic forminifera suggest that the ocean ecosystem did not fully recover from for more than 3 million years after the mass extinction [1]. On land the K-T boundary sequences of the Western Interior of North America provide the most complete sequences of non-marine sediments available for study and their palynology has provided evidence of an ecological catastrophe following the impact [2]. Organic carbon at marine sites shows changes in $\delta^{13} \mathrm{C}$ values on a millimetre resolution scale though no consistent changes are observed between the upper Maastrichtian and lower Paleocene records [3]. Thus far few studies have been made of organic carbon in non-marine K-T sequences.

Organic Geochemistry: The presence of molecular biomarkers preserved in sedimentary organic matter provide 'chemical fossils' that can be used to reconstruct paleoenvironments. Specific biomarker molecules can be highly indicative of certain sources. For example, steranes are derived from sterols that are found in most higer plants but are rare or absent in prokaryotic organisms while longchain unsaturated ketones derive from Prymnesiophyte algae and dinoflagellates. The organic matter (OM) preserved in sediments falls into two categories: organic compounds that can be extracted by solvents (extractable $\mathrm{OM}$ ) and that which cannot (kerogen). Studies of the carbon and nitrogen isotopic composition of the latter have been interpreted as evidence for marine algal blooms in the lowermost Danian [3, 4].

The Marine Record: Comparatively few organic geochemical investigations have been undertaken of $\mathrm{K} / \mathrm{T}$ boundary successions. In part, this reflects the lithologies available for study, many of which are organic poor. However, when suitable material is available, evidence for a variety of environmetal perturbations have been found. For example, molecular studies of the lowermost Danian at the Geulhemmerberg $\mathrm{K} / \mathrm{T}$ site indicated the presence of a highly abundant long-chain ketone diagnostic of noncoccolithophorid Prymnesiophyte algae [5]. Further studies from the same group found that organic molecular markers, restricted to the basal section of the boundary clay at El Kef and Geulhemmerberg, indicated a short, intense period of fermentation of massive amounts of organic matter on the seafloor ( $\mathrm{J}$ de Leeuw et al, unpublished data). This provides some of the best evidence so far for mass mortality following the impact event [6].

The Terrestrial Record: We have used, coupled carbon and nitrogen isotope measurements together with molecular level isotope analysis of biomarker molecules [7] to assess environmental conditions at two non-marine K-T boundary sites in the Westem Interior of North America to examine the effects of the Chicxulub impact on freshwater ecosystems. Measurement of the carbon isotope compositions of individual molecules greatly increases the usefulness of biomarkers as indicators of specific sources.

The two sites chosen for study Raton Pass (New Mexico, USA) and Brownie Butte (Montana, USA), were selected to represent two different paleogeographical and paleoecological settings at the time of the impact.

Results. Saturated hydrocarbons (n-alkanes) isolated from Berwind Canyon and Brownie Butte indicated a major input from higher plants in samples from the Cretaceous. In samples overlying the top of the boundary clay higher plant input was reduced and n-alkanes from algae/bacteria are present with $\delta^{13} \mathrm{C}$ values in the range of higher plants, indicating that algae/bacteria fed upon the products of primary producers. Highly ${ }^{13} \mathrm{C}$ depleted hopanes from methanogenic and methanotrophic bacteria, and less ${ }^{13} \mathrm{C}$ depleted hopanes from other bacterial sources were also found in the earliest Tertiary layers at these sites (Figure 1).

These results indicate the onset of highly anoxic conditions with methanogenic bacteria living in anaerobic conditions and methanotrophic bacteria living above the oxic/anoxic interface. As at El Kef and Geulhemmerberg the anoxic environment was most likely brought about by a massive increase in the amounts of organic matter as a consequence of the mass annihilation of higher plant material

The distribution and carbon isotope composition of $n$ alkanes returns to Cretaceous values a few centimetres above the boundary. As noted previously [2] the severity of the biotic crisis in the terrestrial environment appears to have been restricted to a mass mortality, as opposed to a mass extinction, with much of the higher plant flora existing at a reduced level in the immediate post-impact environment and then recolonising relatively rapidly. 
References: [1] D'Hondt S. et al. (1998) Science, 282, 276-278. [2] Tschudy, R.H. et al. (1984) Science, 225, 1030-1032. [3] Gilmour I., Wolbach W. S., and Anders E. (1990) Geol. Soc. Amer. Spec. Paper 247, 383-390. [4] Hollander D.J., McKenzie, J.A., Hsu K.J. (1993) Paleogeog. Paleoclim. Paleoecol., 104, 229-237. [5] Yamamoto M. et al. (1996) Geol. En Mijnbouw, 75, 255-267. [6] Smit J. (1999) Ann. Rev. Earth Planet. Sci., 27, 75-113.

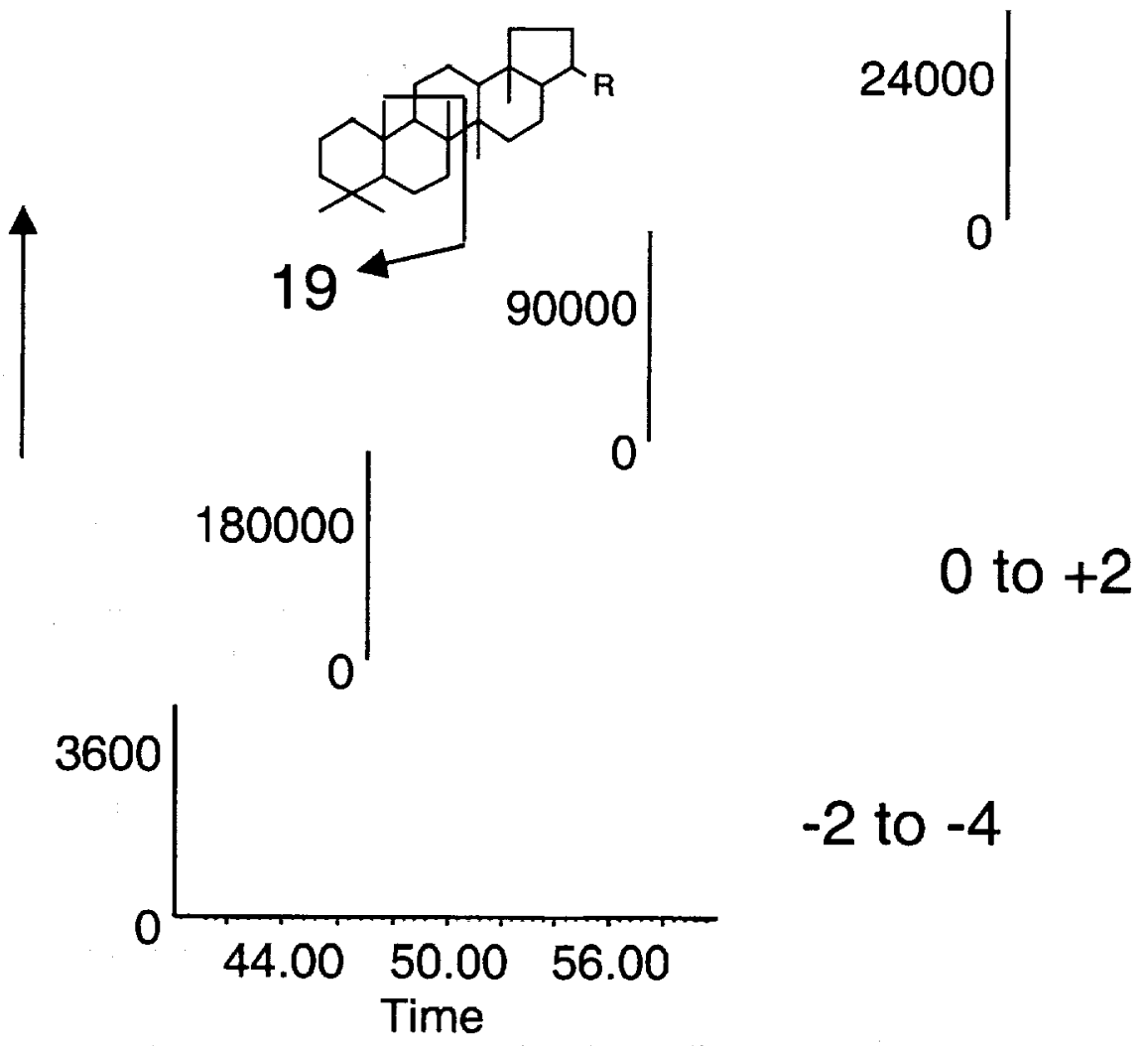

Figure 1. Mass chromatograms ( $\mathrm{m} / \mathrm{z}$ 191) showing the distribution of hopanes across the K/T boundary at Berwind Canyon, New Mexico. 


\begin{abstract}
ASTEROID/COMET MEGA-IMPACT CONNECTIONS OF ARCHAEAN CRUSTAL EVOLUTION: EVIDENCE FROM IMPACT FALLOUT DEPOSITS. Andrew Y. Glikson. Research School of Earth Science, Institute of Advanced Study, Australian National University, Canberra, ACT 0200 (andrew.glikson@anu.edu.au).
\end{abstract}

Geology being a geocentric science focused on endogenic processes, the assumption is generally made that from about $3.8 \mathrm{Ga}$ the impact factor can be neglected in the context of models of crustal evolution, including the emergence of early continental nuclei and plate tectonics. This paradigm is questioned in this paper.

The Late Heavy Bombardment (LHB - 4.2$3.8 \mathrm{Ga}$ ) in the Solar system, as preserved on the Moon, requires that the terrestrial upper mantle-crust system has been dominated by interactions between internal mantle processes and extraterrestrial impacts. From about 3.8 Ga the impact flux decreased by two orders of magnitude, from $4-9^{*} 10^{\wedge}-13 \cdot \mathrm{km}^{\wedge}-2 . \mathrm{yr}^{\wedge}-1$ to 3.8-6.3* $10^{\wedge}-15 . \mathrm{km}^{\wedge}-2 . \mathrm{yr}^{\wedge}-1$ (for asteroids $\mathrm{Dc}$ $>=18 \mathrm{~km}$ ), consistent with a cratering rate of $5.9+/-3.5^{*} 10^{\wedge}-15 . \mathrm{km}^{\wedge}-2 . \mathrm{yr}^{\wedge}-1$ estimated for near-Earth asteroids (NEA) and comets (Baldwin, 1985; Ryder, 1990; Shoemaker and Shoemaker, 1996). From the observed number of 6 continental impact structures with Dc $>=100 \mathrm{~km}$ (Vredefort [300 km]; Sudbury [250 km]; Chicxulub [170 km]; Woodleigh [120 km]; Manicouagan [100 km]; Popigai [100 km]), assuming an Earth surface occupied by time-integrated $>=80$ percent ocean crust since $3.8 \mathrm{Ga}$, a robust minimum number of post-LHB impacts is defined at $>=30$ craters with $\mathrm{Dc}>=100 \mathrm{~km}$ and $>=10$ craters with $\mathrm{Dc}>=200 \mathrm{~km}$. However, from lunar crater counts (Wilhelms, 1987) and the present-day asteroid flux the impact incidence was likely to have been higher by at least an order of magnitude than the number of directly observed craters $>=200 \mathrm{~km}$ (Glikson, 1993; 1996; 1999), with a possible decline in the impact frequency of the largest bodies $\mathrm{Dp}>=$ $20 \mathrm{~km}$.

Evidence for mare-scale impact basins in the Archaean emerges from 3.24 Ga-old impact vapour condensation-fallout layers in the Barberton greenstone belt, Transvaal (Lowe and Byerly, 1986; Lowe et al., 1989; Kyte et al., 1992; Byerly and Lowe, 1994), pointing to multiple oceanic impact basin of Dc $>=400$ $\mathrm{km}$. The extraterresrial connection of spherulitic fallout deposits is confirmed by Energy Dispersive Spectrometry and laser ICPMS analysis of Ni-rich chromites retained in some of these spherules, indicating anomalously high $\mathrm{Ni}$ levels (up to $23 \% \mathrm{NiO}$ ) and PGE levels (up to several hundred PPM). The PGE distribution patterns reflect a complex differentiation history, from vaporisation of the projectile, to stratospheric condensation in melt spherules, to crystallisation within the spherules, interaction with sea water, burial metamorphism and sulphur metasomatism.

Model of crustal evolution need to account for the inevitable magmatic and tectonic consequences of mega-impact events, particularly on impacted geothermally active oceanic crust and lithosphere. The neglect of this factor probably underlies the many inconsistencies between suggested plate tectonic-based models and the stratigraphic and structural elements of Archaean greenstone-granite terrains. A combination of the internal heat engine of Earth and the impact factors is capable of accounting for processes culminating in the formation of the early sialic nuclei, for the spatial and temporal localisation of major faulting and rifting events, and for ensuing 
plate tectonic patterns.

\section{References}

Baldwin, R.B., 1985. Relative and absolute ages of individual craters and the rates of infalls on the Moon in the post-Imbrium period. Icarus, 61, 63-91.

Byerly, G. R., and Lowe, D. R., 1994. Spinels from Archaean impact spherules. Geochimica et Cosmochimica Acta, 58, 3469-3486.

Glikson, A.Y., 1993. Asteroids and early Precambrian crustal evolution. Earth Sci. Rev., 35, 285-319.

Glikson, A.Y., 1996. Mega-impacts and mantle meiting episodes: tests of possible correlations. Aust. Geol. Surv. Org. J. Aust Geol. Geohys., 16/4, 587-608.

Glikson, A.Y., 1999. Oceanic mega-impacts and crustal evolution. Geology, 27, 387-341. Kyte, F.T., Zhou, L., and Lowe, D.R., 1992. Noble metal abundances in an early Archaean impact deposit. Geochim. et Cosmochim. Acta, 56, 1365-1372.

Lowe, D.R. and Byerly, G.R., 1986. Early Archaean silicate spherules of probable impact origin, South Africa and Western Australia. Geology, 14, 83-86.
Lowe, D.R., Byerly, G.R., Asaro, F., and Kyte, F.T., 1989. Geological and geochemical record of 3400 Million years old terrestrial meteorite impacts. Science, 245, 959-962.

Ryder, G., 1990. Lunar samples, lunar accretion and the early bombardment of the Moon.
Eos, $71,313-322$.

Shoemaker, E.M., Shoemaker, C.S., 1996. The Proterozoic impact record of Australia. Aust. Geol. Surv. Org. J. Aust. Geol. Geophys, 16, 379-398.

Wilhelms, D.E., 1987. The geological history of the Moon. U.S. Geol. Surv., Prof. Pap. 1348. 
WOODLEIGH - A NEW 120 KM-DIAMETER BURIED MULTI-RING IMPACT BASIN, CARNARVON BASIN, WESTERN AUSTRALIA, OF PRE-JURASSIC POST-EARLY PERMIAN AGE: EVIDENCE OF A METEORITIC COMPONENT INJECTED INTO SUB-CRATER BASEMENT. A.Y. Glikson ${ }^{1}$ T.P. Mernagh ${ }^{2}$, A.J. Mory ${ }^{3}$, R.P. Iasky ${ }^{3}$ and F. Pirajno ${ }^{3} .{ }^{1}$ Research School of Earth Science, Australian National University, Canberra, ACT 0200 (andrew.glikson@anu.edu.au); ${ }^{2}$ Australian Geological Survey Organisation, P.O. Box 378, Canberra, ACT 2601; ${ }^{3}$ Geological Survey of Western Australia, 100 Plain St., East Perth, WA 6004

In 1981 petroleum exploration drilling in the Gascoyne Platform, south Carvarvon Basin, recovered quartzo-feldspathic cuttings showing penetrative lamella in quartz interpreted at the time as mechanical effects of the drilling. Subsequently Bouguer anomaly and airborne magnetic surveys by the Australian Geological Survey Organisation disclosed a near-perfectly circular multiring structure which abruptly truncates the Adjana and Wandagee NSstriking regional structure formed in Palaeozoic rocks (Tasky and Mory, 1999; Glikson, 1999). Subsequent drilling and coring by the Geological Survey of Western Australia in March, 1999, encountered direct evidence of shock metamorphism and impact breccia, including:

1. At the centre of the $25 \mathrm{~km}$-diameter basement uplift the Woodleigh-1A drill hole intersected shock metamorphosed granitoid at a depth of $171 \mathrm{~m}$ - at least $1800 \mathrm{~m}$ higher than the gravity-modelled level of regional basement. The shocked granitoid features planar deformation lamella (PDF) in quartz and feldspar, penetrative pseudotachylite vein systems, and pervasive development of diaplectic glass in feldspars (Mory et al., 2000; Glikson, 2000).

2. An inner ring syncline drilled by Woodleigh-2A, $14 \mathrm{~km}$ off the centre of the multi-ring structure, contains a $\sim 70 \mathrm{~m}$ thick thermally modified diamictite overlain by $\sim 380$ $m$ of Lower Jurassic lacustrine deposits.
The Woodleigh structure is buried under thin regionally extensive Cretaceous cover and by lacustrine Lower Jurassic arenaceous sediments, representing crater fill. From drilling and gravity data the crater sediments thicken in ring synclines and overlap intervening circular ridges. An outermost diameter of 120 $\mathrm{km}$ for the Woodleigh impact structure is clearly defined by gravity, magnetic and surface drainage. The sharp intersection of the regional structure by the outer ring fault is analogous to relationships observed at Chicxulub and in the Shoemaker Impact Structure (formerly Teague Structure), Wiluna area, Western Australia (Pirajno and Glikson, 1998). At Woodleigh, Surface drainage area accord with late vertical isostatic readjustments of the lower density impact aureole.

Scanning electron microscopy (SEM), energy dispersive spectrometry (EDS), Laser Raman Spectroscopy and trace element analyses of samples from the shocked granitoid core indicate strong enrichment of the pseudotachylites in refractory elements $(\mathrm{Mg}, \mathrm{Al}, \mathrm{Ca})$ and depletion in Si and $\mathrm{K}$ relative to host granitoid composition. Whole rock analyses indicate anomalous siderophile trace metals $(\mathrm{Ni}, \mathrm{Co}$, $\mathrm{Cr}, \mathrm{V}, \mathrm{Cu}$ ) enrichments, mostly up to an order of magnitude higher than typical granitoids. There is a general, though inconsistent, agreement between chemical enrichment/depletion relations and boiling temperatures. Possible models include (1) shockinduced differential volatilisation and condensation effects, consistent with the results of 
$\mathrm{CO} 2$ laser experiments; (2) introduction of a ferromagnesian-rich component derived from the exploding projectile by melt transport and/or condensation from volatile phases. Preliminary ICPMS analyses indicate elevated PGE levels. Further testing of the second model, ie. a mass transfer of siderophile and magnesian trace elements, is currently under way.

The impact age of Woodleigh is constrained by overlying Lower Jurassic strata, reworked Early Permian palynomorphs in the Jurassic lacustrine section, and deformed Lower Devonian and older units. A regional thermal event identified by apatite fission track at 280-250 Ma hints at a possible Permian-Triassic boundary age for the impact, although the lack of Triassic fossils in the crater fill favours a late Triassic age. In view of its size, it is likely that Woodleigh, by analogy with other mega-impacts (Manicouagan - late Triassic; Morokweng - J-K boundary; Chicxulub - K-T boundary; Popigai and Chesapeake Bay - late Eocene) was associated with extinction. The pre-lower Jurassic post mid-Permian age of Woodleigh therefore suggest it may either belong to the late Triassic impact cluster, or alternatively represent a Permian-Triassic boundary impact. A hint supporting the latter possibility may be provided by a thermal high at $280-250 \mathrm{Ma}$ indicated by apatite fission tracks.

\section{References}

Glikson, A.Y., 1999. Research School of Earth Science, Australian National University, Annual Report for 1998, pp. 78-80

Glikson, A.Y., 2000. Research School of Earth Science, Australian National University, Annual Report for 1999, in press.

Iasky, R.P., Mory, A.J., 1999. Geology and petroleum potential of the Gascoyne Platform, southern Carnarvon Basin, Western Australia. Geol. Surv. W. Aust. Rep. 69.

Mory. A.J., Iasky, R.P., Glikson, A.Y., Pirajno, F., 2000. Woodleigh, Carnarvon Basin, Western Australia: a new $120 \mathrm{~km}$-diameter impact structure. Earth Planet. Sci. Lett., in press.

Pirajno, F. and Glikson, A.Y., 1998. Shoemaker Impact Structure in Western Australia. in: J. Henrard and S. Yabushita (editors), Dynamics of Comets and Asteroids and their roles in Earth history, Celestial Mechanics and Dynamical Astronomy, pp. 25 


\section{ORIGIN OF THE TIMOR SEA LATE EOCENE - PRE-MIOCENE STREWN}

CRATER FIELD. J.D. Gorter ${ }^{1}$ and A.Y. Glikson ${ }^{2}$; ${ }^{1}$ British-Bomeo Australia Limited, P.O. Box 1265, West Perth, W.A. 6872 (jgorter@british-borneo.com.au); ${ }^{2}$ Research School of Earth Science, Australian National University, Canberra, ACT 0200.

Since the majority of extraterrestrial impacts impinge on oceanic regimes, the identification of buried submarine impact structures from geophysical data, including $3 \mathrm{D}$ reflection seismic profiles, constitutes an essential step in unravelling the terrestrial impact record. However, the method suffers from severe difficulties inherent in the limitations on the amount of drilling and thus the on tests of candidate geophysical features and potential impact structures.

In the Timor Sea, north Bonaparte Gulf, Deep sea drilling and seismic reflection data encounter an at least 350 m-thick PGE-rich radioactive carbonate breccia lens at Fohn-1 exploration well (Gorter and Glikson, 2000). The data are interpreted in terms of a buried $4.8 \mathrm{~km}$-diameter impact crater of late Eocene to pre-Miocene age. The crater displays the classic elements of impact structures, including a central uplift and ring syncline. The presence in the breccia of redeposited Campanian and Maastrichtian microfossils suggests rebound of strata from levels deeper than $1250 \mathrm{~m}$ below the pre-Langhian unconformity. Morphometric modelling suggests an original transient crater depth at least $1400 \mathrm{~m}$ deep, consistent with the excavation of Cretaceous strata. Stratigraphic and palaeontological evidence suggests that the impact occurred between 38 and $24 \mathrm{Ma}$. The breccia contains altered glass components enriched in the inert platinum group elements (PGE) (Ir, $\mathrm{Ru})$ by factors of 5-12 above the values of common sediments. The more mobile PGE $(\mathrm{Os}, \mathrm{Pt}, \mathrm{Pd})$ show a wide scatter and terrestrial-type values. Opposite geochemical/stratigraphic trends pertain to different
PGE species - the relatively inert Ir-Ru group shows an overall concentration at the base of the section, whereas the more mobile Os shows peaks at median levels of the section suggesting upward diagenetic leaching. The near-chondritic PGE pattems at the base of the breccia pile are accompanied by near chondritic $\mathrm{Ni} / \mathrm{Cr}, \mathrm{Co} / \mathrm{Cr}, \mathrm{Ni} / \mathrm{Ir}, \mathrm{Ni} / \mathrm{Pt}$, and $\mathrm{Cu} / \mathrm{Pd}$ ratios. Departure from these values related to alteration at higher levels in the breccia pile is accompanied with high Sulphur levels $(\sim 1 \%)$.

Seismic reflection array studies of the North Bonaparte Basin (NBB), Timor Sea, disclose an ENE-striking $120 \times 25 \mathrm{~km}$-large swathe of more than 40 circular features excavated in the pre-Miocene - post-Eocene erosional surface and buried by Langhian sediments. Ten of the larger craters include central uplifts and circular troughs, display close similarities to the Fohn-1 impact structure and are considered as probable impact structures. The smaller circular features $\left(D_{c}<2.0 \mathrm{~km}\right)$ consist of crater-form and bulge-form structures, and may either represent deeply eroded impact structures or are of erosional origin. Limits on the degree of erosion are allowed at Fohn-1 impact structure from stratigraphic and morphometric estimates. The Timor Sea crater field may alternatively represent (1) high preservation rate of the 37.5-24 Ma impact flux; (2) a cometary fragmentation event similar to the Shoemaker-Levy-9 event on Jupiter, or (3) an atmospheric break-up of a low-angle asteroid.

In scenario (1), in so far as all the 40 circular features are considered of impact origin, their 
incidence over an area delimited by a rectangle $7750 \mathrm{~km}^{\wedge} 2$ large during a maximum period of $13.5^{*} 10^{\wedge} 6$ years $(37.5-24 \mathrm{Ma})$ yields an impact rate of $3.8^{*} 10^{\wedge}-10 \mathrm{~km}^{\wedge}-2 \mathrm{yr}^{\wedge}-1$. Such a flux is higher by two orders of magnitude than the present-day flux of $100 \mathrm{~m}$-scale asteroids, estimated as $2^{*} 10^{\wedge}-12 \mathrm{~km}^{\wedge}-2 \mathrm{yr}^{\wedge}-1$ by Chapman and Morrison (1994). Because scenario (2) would require global or large circle distribution of craters, scenario (3) is regarded as more likely on the basis of the limited spatial distribution of the craters (W. Bottke, pers. com., 1999).

\section{References}

Chapman, C.R. and Morrison, D., 1994. Impact on the Earth by asteroids and comets: assessing the hazard, Nature, 367, 33-37.

Gorter, J.D. and Glikson, A.Y., 2000. Origin of a late Eocene to pre-Miocene buried crater and breccia lens at Fohn-1, North Bonaparte Basin, Timor Sea: a probable extraterrestrial connection, Meteor. Planet. Sci. (in press). 
FORMATION OF THE BOLTYSH IMPACT STRUCTURE: CATASTROPHE OF REGIONAL SCALE E.P.Gurov and N.V.Bobina, Institute of Geological Sciences National Academy of Sciences of Ukraine, 55-b Oles Gonchar Str., Kiev 01054, Ukraine

The Boltysh impact crater is a circular depression about $24 \mathrm{~km}$ in diameter and $920 \mathrm{~m}$ depth formed in crystalline rocks of the Ukrainián shield. The central uplift, about $580 \mathrm{~m}$ height and $4 \mathrm{~km}$ in surface diameter, is surrounded by deep inner basin, $11 \mathrm{~km}$ in diameter and to $500 \mathrm{~m}$ depth. The inner basin is filled with impact melt rocks, suevites and breccias. Impact melt rocks form a circular sheet to $220 \mathrm{~m}$ thick around the central uplift. It is supposed that impact melt formed a circular lake around the central uplift in the deepest part of impact structure. The peripheral part of the crater is a shallow circular depression around the inner basin. A broken layer of allogenic breccia covers the depression floor [1]. The Boltysh structure is filled with post-crater sediments that are predominantly argillites and siltstones. Commercial reserves of oil shales occur in sedimentary crater fill.

Estimates of energy of the Boltysh crater formation were made using relationships in [2]. Energy limits are from $5.10^{5} \mathrm{Mt}$ in case of vertical impact to $1.110^{6} \mathrm{Mt}$ at impact by an angle of about $45^{\circ}$ to the surface. Thus energy of the Boltysh crater formation was accepted to be about $1.10^{6} \mathrm{Mt}$. The consequences of impacts with energy in range from $1.10^{5}$ to $1.10^{6} \mathrm{Mt}$ are considered as transitional events from regional to global scale and may be compared with consequences of nuclear war [3].

One of the most important consequences of impact is formation of ballistic ejecta layer. Intensively eroded ejecta now are a broken layer of allogenic breccia preserved in the area of about $6,500 \mathrm{~km}^{2}$. The thickness of breccia ranges from meters to some tens of meters and depends on distance from the crater center and pre-impact relief in this region. Edges of preserved ejecta layer are close to estimated margins of initial ejecta layer from $10 \mathrm{~m}$ thick and more. Estimated area of initial ejecta layer from $0.1 \mathrm{~m}$ thick to some hundreds meters thick near the crater rim is about $100000 \mathrm{~km}^{2}$. The breccia layer is composed of granite and gneiss clasts in fine matrix of the same composition. Rare clasts of intensively weathered impact melt rocks and sedimentary rocks occur in the breccia. Granite blocks up to $8 \mathrm{~m}$ in diameter are distributed within the ejecta basal horizon.

Ejecta of the high temperature dust plume into the stratosphere by gigantic impacts have a very severe effect on the environment. The thickness of fireball sediments formed by an impact with an energy of about $10^{6} \mathrm{Mt}$ is about $0.03 \mathrm{~mm}$ in case of a uniform distribution on whole Earth surface accordingly to relationship in [4]. Now this problematic layer of the Boltysh impact is unknown, although the Boltysh crater, $24 \mathrm{~km}$ in diameter, and the Steen River crater, $25 \mathrm{~km}$ in diameter, are mentioned as only two known impact structures formed at or near of the Cenomanian-Turonian boundary [4].

Another consequences of the Boltysh crater formation are not yet known, but the estimated area affected by a catastrophic earthquake and blowout of the atmosphere around the crater is about $100,000 \mathrm{~km}^{2}$. The Boltysh impact structure was formed in continental conditions, thus, no tsunami originated from that impact event. Therefore, the formation of the Boltysh crater was a catastrophic event of a regional scale on the territory of the Ukrainian shield and adjacent areas.

References. [1] Gurov E.P., and Gurova E.P. (1991) Geological structure and rock composition of impact structures. Kiev: Naukova Dumka Press, 160 p. (in Russian). [2] Shoemaker E.M., Wolfe R.F., Shoemaker C.S. (1990) Geol. Soc. Amer. Spec. Paper, 247, 155-170. [3] Toon O.B., Zahnle K., Morrison D., (1997) Rev. Geophys. 35, 41-78. [4] Rampino M.R., and Haggerty B.M. (1996) Geol. Soc. Amer. Spec. Paper, 307, 11-30. 
TSUNAMI(?) DEPOSIT OF TERMINAL EOCENE AGE, SOUTH AUSTRALIA: THE INFERRED EFFECTS OF A LOW-ANGLE MULTIPLE IMPACT EVENT. P. W. Haines, School of Earth Sciences, University of Tasmania, GPO Box 252-79 Hobart, Tasmania 7001, Australia (e-mail: Peter.Haines@utas.edu.au).

Introduction: The author has recently reported the discovery of two new impact structures near Adelaide in South Australia [1]. Both sites exhibit shock metamorphism and include an $8.5 \mathrm{~km}$ long elongate crater (Crawford), interpreted as the product of a very lowangle NNE-directed grazing impact, and a nearby structure considered to be of secondary origin (Flaxman), resulting from down-range ricochet of part of the projectile. These sites form part of an extensive $(230 \times 30 \mathrm{~km}) \mathrm{NNE}$-trending corridor of similar elongate features and breccia zones (Fig. 1). The corridor cuts obliquely across regional structural, stratigraphic and geophysical trends and defies conventional geological explanations. Although definitive shock metamorphism has yet to be discovered at the other structures, it has been hypothesised that the corridor is the consequence of a multiple low-angle impact event of substantial magnitude [1], resembling a scaled-up version of the Rio Cuarto crater field in Argentina [2]. The southern limit of the exposed corridor coincides with the shore of the Southern Ocean (on Kangaroo Island) and it is speculated here that the entire putative crater field may comprise secondaries from a single large grazing impact into the Southern Ocean south of Australia.

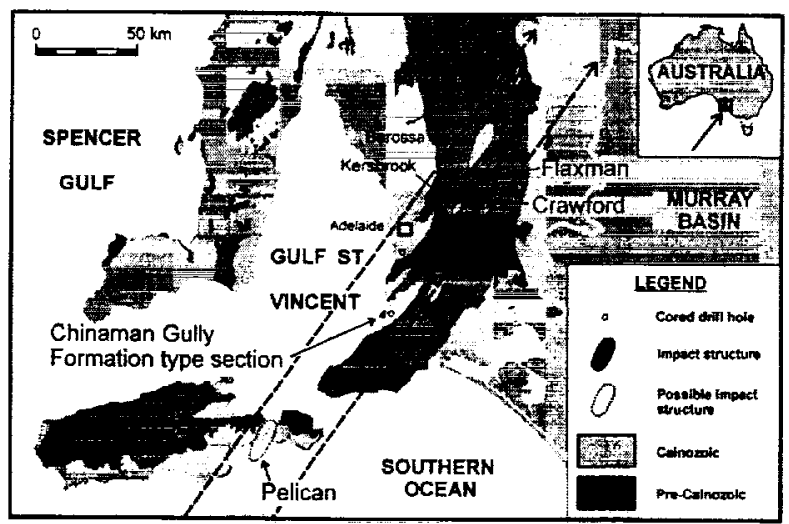

Fig. 1: Locality diagram.

Pelican: The southem-most candidate impact structure, here named Pelican (after Pelican Lagoon), is a mainly covered feature marked at surface by an anomalous gap in Cambrian outcrop on Kangaroo Island (Fig. 1). This gap is coincident with a significant gravity low, which has been modelled as an elongate NNE-trending sediment-filled basin. The basin extends from the near shore continental shelf of the Southern Ocean, across Kangaroo Island, to the southern margin of Gulf St Vincent. The shape, dimensions (ca. $18 \times 8 \mathrm{~km}$ ), orientation, and alignment are analogous to the craters and inferred craters further north, and in similar fashion the Pelican structure cuts at a high angle across structural, stratigraphic and geophysical trends in the surrounding area. The age of the infilling succession is unknown. From the only deep drill hole into the basin, Wade [3] infers a Tertiary age for the boulder-free, clay-rich fill. However, the cuttings were not examined palaeontologically and unfortunately were not archived. Gulf St Vincent is underlain by the St Vincent Basin, which has been undergoing almost continuous marine sedimentation since at least the Middle Eocene. Basin margin areas, now uplifted onshore, probably preserve a relatively complete shallow marine sequence from the Middle Eocene to the Middle Miocene [4]. Thus, if Pelican does represent an impact structure younger than Middle Eocene, its position straddling the margin of St Vincent Basin suggests that an impact tsunami/ejecta horizon should be preserved within the basin succession. This provides one test of the multiple impact hypothesis and could provide independent timing constraints. As most of the succession is comprised of low-energy muddy sediments, the preservation potential of a significant regional event horizon should be high.

Impact tsunami horizon?: The accessible basin stratigraphy was searched in outcrop and in the two available diamond drill cores. A unique and obvious candidate for a tsunami deposit was quickly located: namely the thin Chinaman Gully Formation (CGF), which has long been recognised as an important marker horizon within the basin stratigraphy. The CGF lies sharply above fossiliferous grey mudstones of the Blanche Point Formation. The sedimentary facies and microfauna of the Blanche Point Formation indicate a low energy marine environment with poor circulation and poor ventilation $[5,6]$. It has been considered that during Blanche Point time the link between the Southern Ocean and St Vincent Basin was significantly more tenuous than it is today [7]. At the $2 \mathrm{~m}$ thick type section $(60 \mathrm{~km} \mathrm{~N}$ of Pelican), the CGF consists of a series of graded sand beds interbedded with mudstones in the upper part. Most of the sand, although often intermixed with mud, has the texture of beach and dune sand and contains scattered terrestrial plant remains. The unit is bioturbated in its upper part with burrows concentrated at, and extending down from a single horizon consistent with the entire unit below representing a single (although pulsed) event deposit. In weathered surface outcrop the formation is leached and heavily iron stained. In drill core the CGF is dark coloured, carbo- 
IMPACT TSUNAMI(?) DEPOSIT, TERMINAL EOCENE, AUSTRALIA: P. W. Haines

naceous and pyritic, containing abundant terrestrial plant matter in some horizons. Micropalaeontological investigations reveal a mixture of marine (foraminifera, dinoflagellate cysts, acritarchs) and terrestrial (pollen, spores) indicators [8]. Based on sub-surface information, the CGF is thickest (up to $10 \mathrm{~m}$ ) and best developed close to the palaeo-shoreline, but is thinner, finer and sometimes difficult to recognise (from drill cuttings) in distal settings $[4,8]$. The CGF has long been interpreted as the result of a brief marine regression and most workers assume it to be largely of terrestrial origin $[4,5,6,8]$. The CGF is overlain sharply but conformably by the Aldinga Member of the Port Willunga Formation. This unit displays a more open marine fauna than the Blanche Point Formation and its basal part shows evidence of significant current activity, which decreases up section.

Microspherules: In both of the examined drill cores the upper parts of the CGF contain horizons of palagonitic microspherules (ca. $0.1-1 \mathrm{~mm}$ ). These are most abundant and best preserved right at the top of the formation in both holes, but are not found above. Shapes vary from spheres to ovoids and more rarely dumbbells, although those in contact with detrital sand grains are commonly deformed by compaction suggesting that palagonitisation was an early phenomenon. The microspherules display a thin whitish fragile shell and are hollow except for a 'loose' core of brown waxy palagonite of varying size. No relic glass has been observed. The microspherules appear to be similar to palagonitic K-T boundary spherules such as those reported from Haiti [9]. The microspherule-rich horizons are an obvious candidate for searching for shocked debris, as well as siderophile and isotopic anomalies associated with the putative projectile. Such studies are in progress.

Age: The exact position of the Eocene-Oligocene boundary in southern Australian Tertiary sections in general, and in the St Vincent Basin in particular, has long been a matter of speculation. A particular problem for the St Vincent Basin is that its restricted nature has precluded many of the open marine planktonic foraminifera on which the boundary is based elsewhere [10]. Traditionally the boundary has been placed a short distance above the top of the CGF near the top of the Aldinga Member of the overlying Port Willunga Formation [10]. Recently it has been argued that the boundary should be lowered to the base of the CGF [5]. This reasoning is based mainly on the assumption that the CGF represents a brief marine regression, which, if it were eustatically controlled, might be correlated with a brief regressive event placed at the boundary on global sea level curves. Of course this argument looses its strength if one accepts the tsunami hypothesis presented here. Pending further information the CGF is here considered to be of approximately 'terminal Eocene' age.

Discussion: Any major impact generated tsunami within shallow, confined Gulf St Vincent would be catastrophic on a local scale. It could be expected that a significant volume of water would be displaced onshore, the return of which would transport large volumes of marginal marine and terrestrial sediment and associated flora into the near shore marine zone. Giant waves would no doubt be reflected across the Gulf multiple times inducing a pulsed character on the resulting deposit. The rain of impact ejecta would be ongoing during tsunami activity and such material would thus be substantially dispersed, except that finer material such as microspherules should arrive last and be concentrated at the top of the deposit. Subsequent bioturbation by recolonising organisms seeking trapped organic matter would extend down from a single horizon at the top. It is considered that the sedimentological and other characteristics of the CFG are in much better agreement with these expectations than any predictions that could be based on the marine regression hypothesis. Any genetic association with the Pelican structure still remains highly speculative, and another unidentified impact site(s) could exist. However, the unique position of this feature, straddling the divide between Gulf St Vincent and the Southern Ocean, potentially explains another observation, ie. the more open marine and higher energy character of the basal Port Willunga Formation. It is speculated that the inferred impact event may have created a new and more direct pathway to the open ocean, temporarily establishing a new wave and tidal regime in the Gulf, until the connection silted up. The apparent transgressive character of the Aldinga Member may not be real, are there is thus no necessity for a significant changes in water depth across the CGF. Other workers have also speculated on the existence of a temporary marine connection in the same locality during the Tertiary [11].

References: [1] Haines P. W. et al. (1999) Meteoritics \& Planet. Sci., 34, A49-A50. [2] Schultz P. H. and Lianza R. E. (1992) Nature, 355, 234-237. [3] Wade L. K. (1944) Geol. Surv. S. Austral. Bull. 22. [4] Alley N. F. et al. (1995) Geol. Surv. S. Austral. Bull. 54, 151-217. [5] McGowran et al. (1992) EoceneOligocene climatic and biotic evolution. Princeton Uni Press. [6] McGowran B. and Beecroft A. (1986) Palaeogeog., Palaeoclim., Palaeoecol. 55, 23-34. [7] Glaessner M. F. and Wade M. (1958) J. Geol. Soc. Austral. 5, 115-126. [8] Cooper B. J. 1979. Geol. Surv. S. Austral. Rept. Invest. 50. [9] Bohor B. F. and Glass B. P. (1995) Meteoritics 30, 182-198. [10] Lindsay J. M. and McGowran B. (1986) Terminal Eocene events. Elsevier. [11] Cooper B. J. and Lindsay J. M. (1978) Q. Geol. Notes, Geol. Surv. S. Austral. 67, 4-5. 
MASS EXTINCTIONS AND SEA-LEVEL CHANGES. A. Hallam, School of Earth Sciences, University of Birmingham, Birmingham B15 2TT, UK.

Although the American geologist T.D. Chamberlin was the first to propose, early in the last century, that major faunal changes through time, which provided the basis for stratigraphic correlation, were under the ultimate control of epeirogenic movements of the continents and ocean basins, it was his palaeontological compatriot Norman Newell who began the modern study of mass extinctions. In a series of articles in the 1960s, he proposed a strong relationship between marine mass extinctions and eustatic falls of sea level. Of six major events he recognised, five have become generally accepted as the "big five" mass extinctions at the end of the Ordovician, Permian, Triassic and Cretaceous, and in the late Devonian (Frasnian-Famennian boundary). The causal relationship that Newell proposed involved loss of habitat areas in epicontinental seas, where most at least of the benthic biota are thought to have lived. After the classic publication by Luis Alvarez and colleagues reporting on the discovery of an iridium anomaly at the K-T boundary, interest became concentrated on bolide impact as a causal factor in mass extinctions in general. Insofar as attention was paid to marine regression, a certain amount of scepticism was expressed, for example at the rarity of extinctions that could be related to the evident glacioeustatic regressions of the Tertiary. In 1989 Hallam confirmed Newell's regression hypothesis for at least some major and minor extinction events, but pointed out that the spread of anoxic bottom waters associated with marine transgression, sometimes but not always preceded by a major regression, was also a potent extinction mechanism, presumably because of the severe reduction in viable habitat area. In their 1997 book Hall and Wignall observed that, apart from the K-T boundary, evidence of impact as a causal mechanism for mass extinctions was either weak or non-existent, and even for the $\mathrm{K}$ - $\mathrm{T}$ boundary there was evidence for major sea-level change that required further evaluation. Of the phenomena apparently related to sea-level change, anoxia associated with eustatic rise seemed to be more important than regression as a correlate of mass extinctions.

A review of the relevant literature coupled with personal fieldwork in some cases suggests that nearly all marine mass extinctions are associated with rapid, probably global, sea-level fluctuations, of which regressivetransgressive couplets are the most common; the most notable exception are the Frasnian-Famennian and endPalaeocene events. There is no general pattern as to where the extinction occurs within the regressiontransgressive cycle. Thus, the late Ordovician extinctions were a double event associated with both regression and transgression. Permian extinctions associated with regression were considerably separated in time from those at the end of the period associated with transgression. The end-Triassic extinctions are more obviously associated with regression than the subsequent transgression and accords well with Newell's hypothesis, but in other respects his hypothesis is not well supported as a model of general validity. Thus, two of his type examples, the late Devonian and end Permian, are now regarded as transgression/sea-level highstand phenomena. While the strong temporal correlation with latest Cretaceous regression and mass extinction holds, it is proving difficult to disentangle the environmental effects of regression from those due to late Maastrichtian climatic cooling and end Cretaceous bolide impact. The most frequent association of marine mass extinctions is with transgression and the spread of anoxic waters into epicontinental seas. This applies to one of the two events near the end of the early Cambian, the second phase of the end Ordovician, the Frasnian-Famennian boundary, the end Devonian, end Permian, early Toarcian and Cenomanian-Turonian boundary, Most workers favour anoxia as the direct kill mechanism.

With regard to the ultimate cause of the sea-level changes, the evidence of tillites provides support for a glacioeustatic origin for the end-Ordovician and end-Devonian events, with sea-level fall being promoted by the build-up of Gondwana ice caps and rise by subsequent melting. For all the other events, however, such evidence is lacking and in some cases is strongly against the kind of climate that would promote the growth of substantial ice-caps. The end-triassic event is especially interesting. The rate of sea-level change across the Triassic-Jurassic boundary in Europe appears to be too rapid to be accounted for by changing oceanic ridge-volume tectonoeustasy. Relatively sharp uplift followed quickly by subsidence can be related to the initiation of breakup of Pangaea by tensional activity recorded on both sides of the present central sector of the Atlantic ocean. This event is associated with extensive flood basalt extrusion and shallow intrusions of dykes and sills, an association that has been related to the existence of a mantle plume. Submarine volcanicity on a massive scale appears to be implicated in the likeliest scenario for the Cenomanian-Turonian boundary, with concomitant phenomena including sea-level rise, a possible runaway greenhouse effect and increased oceanic anoxia. Such a scenario could also be applicable to the end-Permian event, thereby helping to explain substantial extinctions on land as well as in the sea.

References: (1) Hallam, A. 1989. The case for sea-level changes as a dominant causal factor in mass extinction of marine invertebrates. Philos. Trans. R. Soc. London, B 325, 437-455. (2) Hallam, A. \& Wignall, P.B. 1997. Mass Extinctions and their Aftermath. Oxford Univ. Press, Oxford. (3) Hallam, A. \& Wignall, P.B. 1999. Mass extinctions and sea-level changes. Earth-Sci. Rev. 48, 217-250. 
THE PERMO-TRIASSIC BOUNDARY IN THE NORTHWEST KAROO BASIN. P.J.Hancox, Geology Department, University of the Witwatersrand, Private Bag 3, Wits 2050, South Africa.065PJH@Cosmos.Wits.Ac.Za

The Karoo Basin of South Africa is a retro-foreland that accumulated sediment from Carboniferous to Jurassic times in southwestern Gondwana. The sequence is highly asymmetrical in nature, being thickest in the south (proximal sector) and thinning dramatically to the north (distal sector). The exact placement of the Permo-Triassic boundary within this sequence is still a matter of some debate, however at present the contact is placed at the terrestrial, time equivalent extinction event of the marine faunal crisis. In the Karoo Basin this event is marked by a major extinction of herbivorous dicynodonts[1] and large amphibians. In the south of the basin it co-incides with an overlap zone which includes the last appearance datum (LAD) of Dicynodon and the first appearance datum (FAD) of Lystrosaurus. Lithostratigraphically this occurs within the predominantly fluviatile Palingkloof Member of the Balfour Formation (Beaufort Group; Karoo Supergroup). Sedimentologically these strata reflect a change from high sinuosity suspended load dominated deposits, to low sinuosity, bedload dominated systems[2] and this sequence has recently been the focus of renewed activity and research in terms of its stratigraphy, palaeontology[2,3], palaeomagnetics[4] and stable carbon and oxygen isotope signatures $[5,6]$.

The boundary in the north of the basin is not however as well known, with Kitching[7] and Smith et al. [8] placing it at the base of the Tarkastad Subgroup. Lithostratigraphically this is marked by the contact between the Balfour (Normandien) and Katberg (Verkykerskop) Formations[9,10] and occurs just above a level of brown weathering calcareous nodules and concretionary structures[7]. This sequence is well exposed above the town of Senekal in the northwestern Free State and is presently the focus of stratigraphic, palaeontological, palaeomagnetic (Kirschvink pers.comm) and geochemical (Brandt pers.comm) studies.

Fossils are scarce in this section however Dicynodon fossils are known from the basal and upper quarries. To date Lystrosaurus is not known from this section however to the east of Senekal the uppermost sandstone of the Katberg Formation produces fossils of the Triassic captorhinid reptile Procolophon. This sandstone lies some $50-80 \mathrm{~m}$ beneath a mudstone sequence (Burgersdorp or Driekoppen Formation) that contains Cynognathus Assemblage Zone (subzone A[11]) fossils of late Early Triassic (Olenekian) age. Bamford[12] has erected a preliminary biostratigraphy for the Permian and Triassic in the Karoo Basin based on the ranges of fossil wood and as silicified wood occurs throughout the section, this has been studied to try and aid in identifying the correct placement of the contact. This data is at present slightly ambiguous, but suggests that the lower part of the Katberg in the northwest may be of Permian age, and that the boundary has been placed too low in the sequence. The resolution is however still fairly poor and further material is being analyzed for biostratigraphic purposes.

This finding may be in line with recent modelling of the Karoo Basin[13] which has shown that the basin has two distinct tectonic settings, a proximal (foredeep) and a distal (foresag) sector. The two sectors have reciprocal stratigraphies, and as such, if the sequence in the south is temporally complete, with continuous sedimentation across the boundary, then in the north of the basin, the sequence would be expected to be represented by either an unconformity, condensed section or palaeosol. Although at present the exact placement and nature of the boundary in the northwest of 
the basin is therefore not as well understood as that in the south, ongoing studies will hopefully identify the correct nature and stratigraphic placement of the contact, which in turn will allow for better resolution of biotic turnover across the boundary, as well as aiding basin development studies.

References: [1] King, G.M. (1990). Palaeont.africana,27, 31-39. [2] Smith, R.M.H. (1995). Palaeogeogr. Palaeoclimat.Palaeoecol.,117, 81-104. [3] Macleod, K.G., Smith, R.M.H., Koch, P.L. \& Ward, P.D. (In Press). Nature. [4] Kirschvink, J.L. \& Ward, P.D. (1998). J.Afr.Earth.Sci.27( IA). 124. [5] Thackeray, J.F., Vandermerwe, N.J., Leethorp, J.A., Sillen, A., Lanham, J.L. Smith, R.M.H., Keyser, A., \& Monteiro, P.M.S. (1990). Nature, 347, 751-753. [6] Smith, R.M.H. \& Macleod, K.G. (1998). J.Afr.Earth.Sci.,27(1A), 185-186. [7] Kitching, J.W. (1977). Mem. Bernard Price Inst. Palaeont. Res., Univ. Witwatersrand, 1, 1-131. [8] Smith, R.M.H., Turner, B.R., Hancox, P.J. \& Groenewald, G.H. (1997). Guidebook $6^{\text {th }}$ International Conference on Fluvial Sedimentlogy, 9, 162pp. [9] Groenewald, G.H. (1989). Bulletin of the Geological Survey, South Africa, 96, 1-62. [10] Groenewald, G.H. (1996). Unpubl.Ph.D. Thesis, University of Port Elizabeth, South Africa. [11] Hancox, P.J., Shishkin, M.A., Rubdige, B.S. and Kitching, J.W. (1995). S.Afr.J.Sci., 91, 143-144. [12] Bamford, M. (1999). Palaeont.africana, 35, 25-40. [13] Catuneanu, O., Hancox, P.J. and Rubidge, B.S. (1998). Basin Research, 10, 417-439. 
NEW DATA ON THE LATE CENOMANIAN MASS EXTINCTION EVENT. M.B.Hart \& G.D.Price Department of Geological Sciences, University of Plymouth, Plymouth PL4 8AA, United Kingdom. (e-mail M.Hart@plymouth.ac.uk; G.Price@plymouth.ac.uk)

The late Cenomanian extinction event is one of those initially identified by Raup \& Sepkoski [1]. The "event" has long been recognised as one of the major features of the Cretaceous succession on all continents and, in many localities, is associated with dark/black mudstones [2]. The Bonarelli Event, as it is known in Europe (or CTBE in other areas) records a moderate turnover of both macrofauna and microfauna. Associated with these extinctions and biodiversification events are a number of geochemical signals, including REE's and Iridium. The sedimentary, isotopic, chemical, floral and faunal changes can be matched across continents and a detailed event stratigraphy generated. While there are distinct views as to how significant this event was, most authors recognise its importance.

Using data from localities in England (Sussex, Isle of Wight, Dorset, Devon and Humberside), the USA (Colorado), Germany, France, Tunisia and India the details of the event can be sequenced. The nature of the response recorded in the sedimentary record is a function of local geography and, in particular, palaeodepth. The level of anoxia recorded is very much a result of the local setting and may pre-date or post- date the recorded extinctions. The sedimentary record appears to be following the sea-level changes across the boundary and the other events, although related, are not directly caused by these changes.

There are a number of models for the event, including expansion of the oxygen minimum zone [3], sea level fall caused by glaciation [4] or a simple sea level rise [5]. Our model uses information from the sedimentary succession, microfossil groups (including disaster taxa), geochemistry, isotope studies, regional palaeogeography and some biometric analysis. The recent discovery of Iridium at the same stratigraphical level in Portugal will also be incorporated.

\section{References}

[1] Raup, D.M. \& Sepkoski, J.J. (1982) Science, 215, 1501-1503. [2] Schlanger S.O. \& Jenkyns, H.C. (1976) Geologie en Mijnbouw, 55, 179-184. [3] Jarvis, I. et al., (1988) Cretaceous Research, 9, 3-103. [4] Jeans, C.V. et al. (1991). Geological Magazine, $128,603-632$; [5] Hallam A. \& Wignall, P.B. (1999) Earth-Science Reviews, 48, 217-250. 
STRUCTURE OF THE CHICXULUB CRATER; A.R. Hildebrand ${ }^{1}$ and M. Pilkington ${ }^{2}$; 'Department of Geology and Geophysics, University of Calgary, Calgary, AB, Canada (hildebra@geo.ucalgary.ca); ${ }^{2}$ Continental Geosciences Division, Geological Survey of Canada, 615 Booth Street, Ottawa, ON, Canada (mpilking@NRCan.gc.ca)

Introduction: Chicxulub crater studies continue to emphasize gaps in our understanding of the structure of large craters (and areas where consensus is lacking amongst impact crater workers). As the crater and its ejecta are relatively well preserved for a terrestrial impact, and the impact's magnitude is unparalleled in the Phanerozoic, continued studies will probably yield additional insights into the cratering process (aside from its significance in illustrating the effect of large impacts on the terrestrial biosphere).

Crater Structural Elements: Three main structural elements compose the Chicxulub crater: the central structural uplift, the collapsed disruption cavity, and the zone of slumping(e.g., 1,2). The size of all of these elements has since been contended, although some convergence of inrepretation is now occurring.

\section{Collapsed Disruption Cavity}

The $\sim 90 \mathrm{~km}$ diameter of the collapsed disruption cavity (CDC) was first accurately determined from truncations of regional magnetic field anomalies at $\sim 45 \mathrm{~km}$ radius from the crater's centre (1). Magnetic data over Chicxulub have not been used by most previous structural studies, although they have provided useful insights. Continued studies using 2- to 3-dimensional forward and inversion modelling (e.g., 3) using more detailed magnetic survey data (Figure 1) have confirmed the truncation of the regional anomalies and located the magnetic source bodies associated with the thick melt sheet and breccias filling the CDC (average source depth of $\sim 2 \mathrm{~km}$ extending to $\sim 45 \mathrm{~km}$ radius). Modelling of detailed survey results over the $\mathrm{CDC}$ reveals shallow highly magnetized zones of $1-5 \mathrm{~km}$ width located in two roughly concentric distributions at radii of $\sim 20$ and $\sim 45 \mathrm{~km}$. These zones are thought to represent localized hydrothermal systems which cooled the melt sheet.

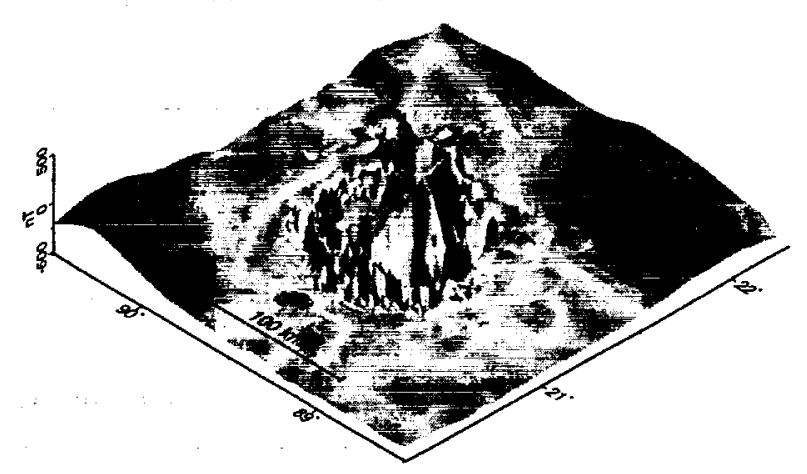

Figure 1: Three-dimensional plot of the total magnetic field over the Chicxulub crater (with a reference field removed) viewed in perspective looking towards the northwest. Vertical scale is in nanoTeslas (nT). In this plot results from a 1997 detailed survey have been merged with the 1978 regional survey results of Petróleos Méxicanos. Note roughly $90 \mathrm{~km}$-diameter subcircular zone of large amplitude anomalies that corresponds to the CDC filling at Chicxulub. Long wavelength regional anomalies interpreted as representing basement variation can also be seen.

Equally valid constraints on the extent of the CDC come from seismic reflection studies $($ e.g, 4,5$)$ which reveal the inner edge of the zone of slumping (Figure 2). Gravity modelling indicates that the position of the last resolved coherent reflectors lies within a few $\mathrm{km}$ of the inner edge of these blocks.

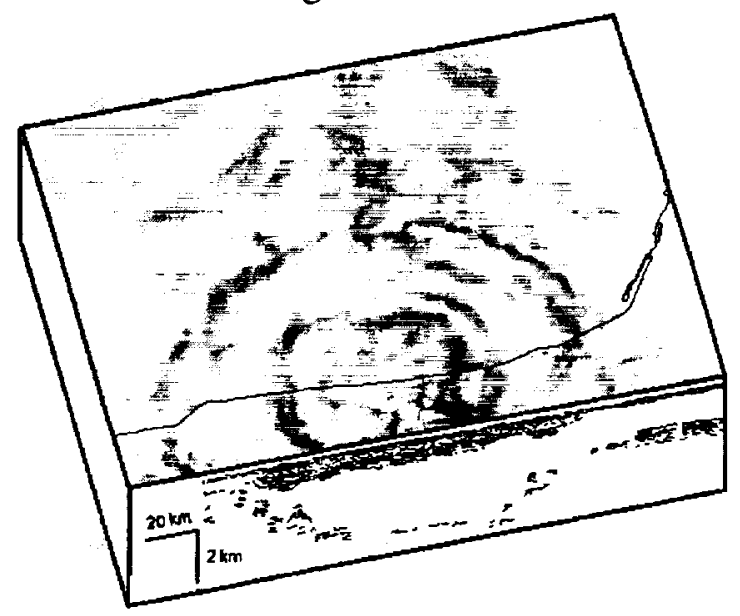

Figure 2: Perspective of horizontal gravity gradient data (2) juxtaposed with seismic reflection interpretation of (4). 
CHICXULUB CRATER STRUCTURE: A.R. Hildebrand and M. Pilkington

A CDC of this size implies an energy of $\sim 1 \mathrm{X}$ $10^{31}$ ergs for the Chicxulub impact (2) using the energy scaling relation of (6). The recognition of a possible fragment of asteroidal character of the K-T projectile (7) implies that this energy scaling relation is in need of modification or that cometary material is similar to known meteoritic material.

\section{Central Structural Uplift}

The $\sim 50 \mathrm{~km}$ diameter central structural uplift is "imaged" by 2 and 3-D modelling of magnetic field and gravity field data (e.g., 1, 2) and seismic velocity studies (8). Significant taper in the uplift may occur at relatively shallow depths, but differences exist between magnetic field and gravity models. Gravity and seismic velocity results agree on central uplift vergence towards the southwest, which together with its off centre location in the crater indicates an impact from the southwest at an $\sim 60^{\circ}$ elevation. Whole crustal seismic studies indicate that formation of the central uplift did not significantly affect the crust mantle boundary during formation of the central uplift (e.g., 5), therefore the zone of structural pinching must occur at shallower depths in the upper and lower crust.

Zone of Slumping

Gravity and seismic reflection data constrain the zone of slumping to occur between $\sim 45 \& \sim 90 \mathrm{~km}$ radius (Figs. 2 and 3 ).

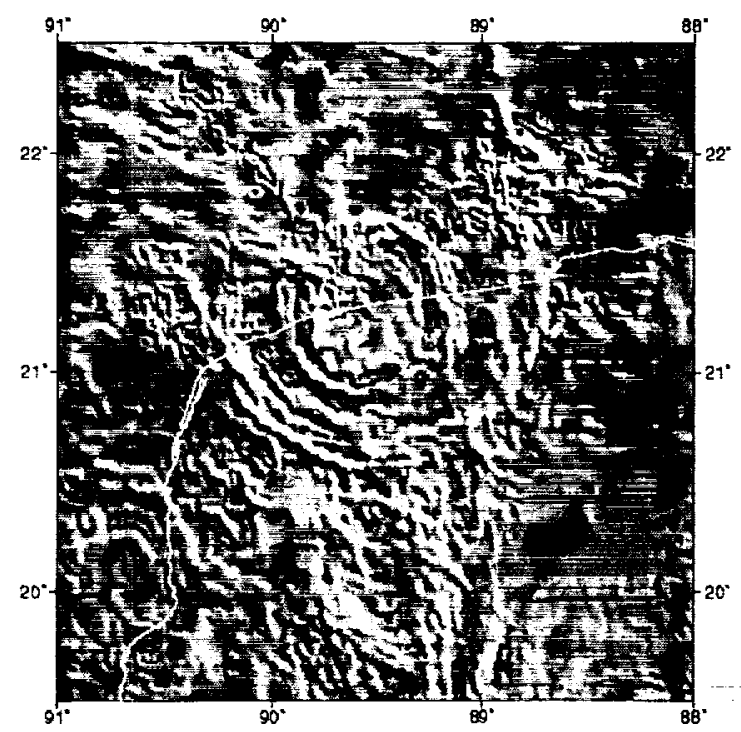

Figure 3: Horizontal Bouguer gravity anomlay gradient over the Chicxulub crater. Blurred areas indicate lack of data and numerous artifacts may be seen in marine data to the north and aerogravity data to the west (See (2) for futher description.)

The margins of the zone of slumping are delimited by the outermost concentric gradient anomaly as shown in Figure 3. The gravity gradient features may be tied to the individual faults of the zone of slumping (and margin of the basin filling) and mapped in plan (2).

Conclusions: We feel that the available evidence is consistent with Chicxulub having been a $\sim 180 \mathrm{~km}$-diameter peak-ring crater. Since 1993 a variety of significantly larger sizes (and impact energies) have been suggested for the Chicxulub crater. As some of the crater's surface expression, such as the crater rim and part of its ejecta blanket were eroded before burial, room exists for continued debate on the size and morphology of the crater. We fell that the variety of suggestions for larger sizes is indication of how weak the evidence is for morphologically expressed structure at radii $>90 \mathrm{~km}$. In any case, while the nature of the impactor remains to be established, the size of the CDC and reconstructed transient cavity are now established for modelling the enviromental perturbations of the impact.

Acknowledgments: We are grateful to Petróleos Méxicanos and Goldeneye Explorations Ltd. for providing magnetic field data, and to the latter for permission to publish survey results from a confidential study.

References: (1) Pilkington et al., 1994, JGR 99:13,147 - 13,162; (2) Hildebrand et al., 1998, Geol. Soc. Lond. Spec. Publ. 140:153-173; (3) Pilkington, M. and Hildebrand, A.R., 2000, LPS XXXI, CD format; (4) Camargo and Suárez, 1994, Bol. Asoc. Mex. Géof. Expl. 34:1-28; (5) Morgan et al., 1997, Nature 390:472476; (6) Schmidt, R.M. and Housen, K.R., 1987, Int. Jour. Impact Eng., 5:543-560; (7) Kyte, F.T., 1998, Nature, 396:237-239; (8) Christeson, et al., Geol. Soc. Am. Spec. Pap. 


\begin{abstract}
ABRUPT EXTINCTION AND SUBSEQUENT REWORKING OF CRETACEOUS PLANKTONIC FORAMINIFERA ACROSS THE K/T BOUNDARY: EVIDENCE FROM THE SUBTROPICAL ATLANTIC. B. T. Huber ${ }^{1}$ and K. G. MacLeod ${ }^{2},{ }^{1}$ Department of Paleobiology, MRC: NHB-121, Smithsonian Institution, Washington, DC 20560, USA, huber.brian@nmnh.si.edu, ${ }^{2}$ Department of Geological Sciences, University of Missouri, Columbia, MO 65211, USA, macleodk@missouri.edu.
\end{abstract}

Introduction: One of the long standing controversies in the Cretaceous-Tertiary (K/T) boundary debate is whether the terminal Cretaceous extinctions were abrupt and coincident with physical evidence for bolide impact, or gradual and linked to Earth-bound causes. Although there is abundant evidence that a large bolide impact did occur at the $\mathrm{K} / \mathrm{T}$ boundary [1] and the $\mathrm{K} / \mathrm{T}$ turnover is exceptionally sharp relative to other Phanerozoic extinctions [2], some workers continue to dispute that the impact played a significant role in the end-Cretaceous extinctions [3-5].

Differing interpretations of the planktonic foraminiferal biostratigraphic record have been the focus of much of this controversy. Some authors suggest that the gradual pattern of pre-boundary extinction among these organisms can be explained as a combination of sampling or taxonomic artifacts and low-level, background extinctions, while the post-boundary occurrences result from sediment reworking [e.g., 6-7]. On the other hand, other authors maintain that changes in sea level, temperature, and global volcanism led to prolonged extinctions before and after the $\mathrm{K} / \mathrm{T}$ boundary [e.g., 4, 8-9]. The argument for catastrophic $\mathrm{K} / \mathrm{T}$ extinction of planktonic foraminifera has recently strengthened based on strontium and carbon isotopic evidence that post-K/T occurrences of most "Cretaceous" species that originated in the Cretaceous are an artifact of sediment reworking [7, 10-11].

In this study, we focus on analysis of changes in planktonic foraminiferal population structure, stratigraphic distributions, and shell size/mass ratios across a remarkably complete and well-preserved $\mathrm{K} / \mathrm{T}$ boundary sequence from Ocean Drilling Program (ODP) Site 1049 to further evaluate evidence for post $\mathrm{K} / \mathrm{T}$ reworking of Cretaceous taxa. This site, which was located at $\sim 30^{\circ} \mathrm{N}$ paleolatitude in the western Atlantic, yielded a undisturbed, thick layer of meteorite impact ejecta precisely at the biostratigraphic boundary between the Cretaceous and Paleogene [12]. The ejecta bed was recovered at 112 meters below seafloor (mbsf) in three holes drilled within $30 \mathrm{~m}$ of each other. The lithology on both sides of the ejecta bed is nannofossilforaminifer ooze, and benthic foraminiferal assemblages indicate that this site occupied an upper bathyal paleodepth throughout the Late Cretaceous [13].

Stratigraphy: The studied samples are all from Hole $1049 \mathrm{C}$, which contains a $10 \mathrm{~cm}$ thick ejecta bed that is in sharp contact with the underlying upper Maastrichtian chalk (Fig. 1). The ejecta bed is predominantly composed of green smectite spherules that range from $1.3 \mathrm{~mm}$ in size and show no size sorting. These are accompanied by large Cretaceous planktonic foraminifera, which are size-sorted in discrete layers within the basal $1 \mathrm{~cm}$, but randomly through the rest of teh bed. Also occurring in the ejecta bed are clasts of chalk as much as $1 \mathrm{~cm}$ in diameter, euhedral calcite grains that reach $0.1 \mathrm{~mm}$ in length, and several grains of shocked quartz, which have been identified in the middle and upper portions of this bed. Above the ejecta bed is a $3 \mathrm{~mm}$-thick orange limonitic layer that contains flat limonite concretions. This is overlain by $5 \mathrm{~cm}$ of dark, burrow-mottled ooze that contains abundant quartz, limestone chips, and minute planktonic foraminifer species characteristic of lower Danian Zone $\mathrm{P} \alpha$. Smit et al. [14] reported iridium concentrations of $1.3 \mathrm{ppb}$ within the burrow-mottled ooze, in contrast to values of $<0.06 \mathrm{ppb}$ at the base of the spherule bed and $3 \mathrm{~cm}$ above its top. The final bed in the sequence is a 3 $\mathrm{cm}$ thick, white foraminiferal-nannofossil ooze that contains a Zone $P \propto$ foraminiferal assemblage and fossils typical of Calcareous Nannofossil Biozone NPI. The base of Zone Pla is identified at $88 \mathrm{~cm}$ above the top of the ejecta bed based on the extinction of $P$. eugubina.

Absence of basal Danian Zone P0 at deep sea sites, including Site 1049, has been attributed to the temporary absence or rare occurrence in shallow marine sections of Parvulorugoglobigerina eugubina, the nominate marker for the overlying Zone $P \alpha$ [12]. Whereas the possibility of a sedimentary hiatus spanning Zone PO cannot be ruled out, thin section observation of the contact between the ejecta bed and basal Danian sediments reveals no evidence of sedimentary winnowing or development of a hardground surface, which would be expected if this contact were truly disconformable.

Material and Methods: The analyzed samples are spaced between 0.2 and $0.5 \mathrm{~m}$ apart to within $15 \mathrm{~cm}$ below the ejecta bed and between 1 and $10 \mathrm{~cm}$ apart from $15 \mathrm{~cm}$ below to $\sim 1 \mathrm{~m}$ above the ejecta bed. All samples washed over a $38 \mu \mathrm{m}$ sieve and dried at $50^{\circ} \mathrm{C}$ over a warm hotplate.

The size/mass ratio of Cretaceous species in Danian sediments was determined by weighing the mass of 
Cretaceous vs. Danian planktonic foraminifera found in $1 / 4$ phi intervals for sieve sizes of $125 \mu \mathrm{m}$ and higher.

Thin sections were prepared by embedding a $20 \mathrm{~cm}$ thick slab spanning the $\mathrm{K} / \mathrm{T}$ of Hole $1049 \mathrm{C}$ with epoxy in a vacuum chamber. Some disturbance of the ejecta bed occurred during this procedure as a result of initial swelling when the epoxy was added.

Results: Analysis of trans-K/T species distributions suggests minimal extinction below and across the boundary. Of the 43 species identified in the middle through upper Maastrichtian interval 3 species have last appearances below the $\mathrm{K} / \mathrm{T}$ boundary and 37 species occur in the overlying Danian sediments. Species that disappear below the boundary are rare and occur sporadically throughout their stratigraphic ranges. The lowermost $20 \mathrm{~cm}$ of Zone $P \alpha$ contains mostly Cretaceous taxa, but by the top of this zone the Cretaceous component of the total assemblage represents less than $1 \%$ (Fig. 1).

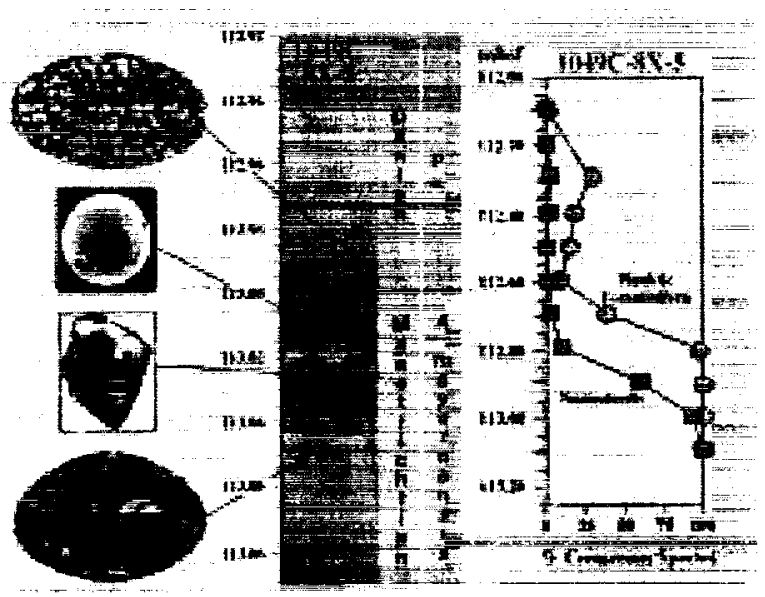

Fig. 1. Comparison of pre- and post-KT planktonic foraminiferal assemblages and examples of shocked quartz and a spherule from the K/T boundary interval of ODP Hole $1049 \mathrm{C}$. Relative abundance of planktonic foraminifera and calcareous nannofossils are based on data presented in Norris et al. [12]

Comparison of the relative mass of Cretaceous vs. Tertiary species above the ejecta bed reveals the most dramatic change in planktonic foraminiferal assemblages. Small individuals dominate typical Maastrichtian planktonic foraminifer assemblages immediately below the spherule bed whereas samples from the overlying Paleocene contain a disproportionate number of large Cretaceous foraminifera. The difference in size distribution is the opposite expected if the Cretaceous species were genuine survivors, and is also different from the expected size distribution of living populations, which tend to be dominated by small individuals [15].

Discussion: The biased size distribution is unlikely to have been produced by winnowing in the Paleocene, since small Paleocene taxa are increasingly abundant above the boundary and constitute nearly the entire $<125 \mu \mathrm{m}$ fraction above the ejecta bed. Instead, sorting of Cretaceous foraminifera probably occurred within the plume of resuspended sediment that settled out immediately following the impact event and subsequent downslope transport events. Further evidence for reworking is revealed by (1) differences in the color of sediment matrix within some shells of Cretaceous species compared to the surrounding Danian sediment, and (2) larger size and greater abundance of terrigenous clastic sediment grains above the ejecta than below.

Conclusions: Distribution analysis and thin section study of the $\mathrm{K} / \mathrm{T}$ sequence from Site 1049 indicate that the post-K/T occurrence of all but 3 planktonic foraminiferal species results from reworking. This, combined with observation of negligible change in species composition and relative abundance of assemblages during the last 3 m.y. below the $\mathrm{K} / \mathrm{T}$ ejecta bed, provide conclusive evidence that extinction of over $90 \%$ of Cretaceous species was a direct result of the $\mathrm{K} / \mathrm{T}$ bolide impact event.

References: [1] Ryder G. et al. (1996) GSA Spec. Paper, 307. [2] Ryder G. (1996) GSA Spec. Paper, 307, 31-38. [3] MacLeod N. and Keller G. (1996) The Cretaceous-Tertiary Mass Extinctions. [4] Keller G. et al. (1997) GSA Bull., 109, 410-428. [5] MacLeod et al., (1997) J. Geol. Soc. London, 154, 265-292. [6] Olsson R K. and Liu C. (1993) Palaios, 8, 127-139. [7] Huber, B.T. (1996) GSA Spec. Paper, 307, 319 334. [8] Keller G. (1989) GSA Bull., 101, 1408-1419. [9] MacLeod N. and Keller G. (1994) Paleobiol., 20, 143-177. [10] Zachos J.C. et al. [1992] Proc. ODP, Sci. Res., 120, 961-977. [11] MacLeod K.G. and Huber B.T. (1996) Geology, 24, 463-466. [12] Norris R.D. et al. (1999) Geology, 27, 419-422. [13] Norris R.D. et al. (1998) Proc. ODP, Init. Rpts., 171B, 1-749. [14] Smit J. et al. (1997) GSA Ann. Mtg., 29, A-141. [15] Berger W.H. (1971) Mar. Geol., 11, 325-358. 
THE FORAMINIFERAL RESPONSE TO THE EARLY TOARCIAN EXTINCTION EVENT. M.D.Hylton, M.B.Hart \& G.D.Price, Department of Geological Sciences, University of Plymouth, Plymouth, PLA 8AA, United Kingdom. (email: mhylton@plymouth.ac.uk, m.hart@plymouth.ac.uk, g.price@plymouth.ac.uk)

In their initial investigation of periodic extinctions Raup \& Sepkoski [1] identified an important faunal turnover at, or about, the Pliensbachian-Toarcian boundary. Subsequent work on the palaeontology of the Lower Jurassic successions in Europe, South America and Asia has shown that the most important faunal turnover was in the early Toarcian. By comparison to some of the other events (Permo-Triassic boundary, K-T boundary, etc.) the early Toarcian is clearly of less importance and appears to be both regional (?) and at the species (rather than genus or family) level [2]. As part of our on-going research on Jurassic foraminiferal assemblages $[3,4,5,6]$ the early Toarcian extinction event has been comprehensively investigated in the U.K., Germany and France.

The Early Jurassic was a time of rapidly rising sealevel associated with the extensive spread of anoxic bottom waters. Sea-level rise across the PliensbachianToarcian boundary culminated in the falciferum zone of the Toarcian and is one of the best authenticated eustatic events in the Jurassic. This major transgressive pulse was marked by deeper water marine sequences and was associated with the deposition of organic-rich shales.

The development of anoxia coincides with a notable period of mass extinction of the marine fauna. High resolution sampling and study of the microfaunas through several sequences in the U.K. confirm that benthonic foraminiferal faunas were affected by an early Toarcian falciferum zone event. Samples were analysed from Pliensbachian-Toarcian mudstone, clay and shale sequences of the South Dorset Coast, the East Midlands and the Yorkshire Coast. The sections studied show distinct changes in assemblages across the Pliensbachian-Toarcian boundary and in the basal zones of the Toarcian Stage. Evidence for a foraminiferal extinction event includes the elimination of the important Lower Jurassic Lingulina tenera, Frondicularia terquemi and Marginulina prima plexus groups, initiating a significant period of turnover of the microfauna. A marked change also occurred in the character of associated nodosariid assemblages: the uniserial forms of Nodosaria, Frondicularia, and Lingulina, dominating the Pliensbachian assemblages, were largely replaced by coiled Lenticulina in the Early Toarcian. A reduction in test size and a decline in species diversity, compared with Hettangian to Si- nemurian foraminiferal assemblages, reflect the development of low oxygen conditions followed by a subsequent renewal of the microfauna in the Middle Toarcian.

As indicated by Hylton \& Hart [5] (fig.5) it is possible to disaggregate the succession of events recorded within the overall extinction event. At the base of the exaratum subzone (falciferum zone) at Tilton (East Midlands, UK), there appears an abundance of very small ( $\sim 100 \mathrm{~mm}$ diameter), trochospiral foraminifera. These are similar to the aragonitic genus Conorboides which is also reported from the falciferum zone of the Upper Lias at Empingham, Rutland [7]. Given their extremely low abundance before the Toarcian events and their "bloom" once the environmental conditions markedly declined, this taxon could be described as a "disaster" or "opportunist" species as described by Harries et al. [8].

This species is almost identical to the species described by Wernli [9] as Oberhauserella quadrilobata Fuchs. This was recorded (op. cit.) from the falciferum zone of the Creux de l'Ours, Teysachaux, Swiss Alps. In a recent review of early planktonic foraminifera, Simmons et al. [10] have re-illustrated some of Wernli's material (Simmons et al. [10] pl.2.2, figs $4,7,9$ ). These are virtually identical to our Conorboides and, as they are of identical age, we are certain that our material is the same taxon. Simmons et al. [10], in a lengthy discussion of the origins of the planktonic foraminifera indicate that the earliest species that can be confidently identified are those of the genus Conoglobigerina from the Bajocian of Eastern Europe. These aragonitic, benthonic forms which appear in large numbers during the transgressive event in the earliest Toarcian may, therefore, be the ancestors of the planktonic foraminifera. it is interesting to speculate on whether it was the widespread occurrence of sea floor anoxia at this level that led to the development of a planktonic mode of life.

\section{References}

[1] Raup D. M. \& Sepkoski J.J. (1982) Science, 215, 1501-1503.

[2] Hallam A. \& Wignall P.B. (1999) Earth-Science Reviews, 48, 217-250 
[3] Hylton M.D. (1998) Geoscience south-west England, 9, 203-208.

[4] Hylton M.D. \& Hart, M.B. (2000) In: Hall R.L. \& Smith P.L. (Eds), Advances in Jurassic Research GeoResearch Forum, 6, 455-462.

[5] Henderson A.S. \& Hart M.B. (2000) In: Hall R.L. \& Smith P.L. (Eds), Advances in Jurassic Research GeoResearch Forum, 6, 311-320.

[6] Oxford et al. (in press). Geoscience south-west England.

[7] Horton A. \& Coleman B.E. (1978) Bull. Geol. Surv. Great Britain, 62, 1-12.

[8] HARRIES, P.J., et al. (1996) In: Hart, M.B. (Ed.), Biotic recovery from mass extinction events, Geol. Soc. London, Spec. Publ. 102, 41-60.

[9] Wernli R. (1995) Rev. Paleobiologie, 14, 257-269. [10] Simmons M.D. et al. (1997) In: Boudagher-Fadel M.K. et al. (Eds), The Early Evolutionary History. 1751. 
THE PROPERTIES OF THE NUCLEUS OF SHORT-PERIOD COMETS DANGEROUS FOR THE EARTH. Kh.I. Ibadinov, Institute of Astrophysics of the Tajik Academy of Sciences, Bukhoro Str. 22, Dushanbe 734042, Tajikistan (ibadinov@ac.tajik.net).

A part of short-period comets is a Near Earth Objects (NEO) and be of great danger for the Earth. At time (once in 50-100 years) the Earth collide with big fragment of cometary nucleus and as is generally known this collision is catasatrophic for the Earth. Therefore it is very important to know of the orbit and the physical properties and chemical copmosition of nucleus of such Near Earth Comets (NEC) in detail.

The physical properties and the chemical composition of cometary nucleus were studied by different methods in the Institute of Astrophysics of the Tajik Academy of Sciences. This report include the new results of our investigations of the nucleus of short-period comets. These results considerable supplemented our notion about short-period comets and their relation with asteroids and meteoroids.

A dependence of the rate of the decrease of secular brightness on perihelion distance, established previously from observations for short-period comets, clearly points to the progressive growth of a refractory mantle on the nucleus surface and evolution such comets into asteroid-like body (Dobrovolsky, Ibadinov, Gerasimenko, 1984; Ibadinov, 1993; 1999).

The results of laboratory simulation of a cometary nucleus show that, if the insolation energy is constant, the mantle thickness is proportional to the square root of the insolation duration, the sublimation rate grows lineary with mantle thickness, the temperature of ice under the mantle depends very weakly on the mantle thickness, and the temperature distribution over depth is nearly linear within the mantle (Ibadinov et al., 1991).

Physical and mechanical properties of the mantle models were studied experimentally under conditions that mimic true conditions. The porosity, the density, the surface temperature, the effective thermal conductivity, the strength, and the coeffisient of gas diffusion in mantle were studied in laboratory experiments (Tbadinov, et al., 1991; Ibadinov, 1999). The results of laboratory experiments (Ibadinov, 1989; Ibadinov et al., 1991) in particular, ion bombardment of ice conglomerates (Hashimov, Ibadinov, Shoyokubov, 1994) and Vega-1 and Vega-2, and Giotto data on the nucleus of comet Halley show that the dark (albedo 0.03-0.06) and high-temperature $(320-4000 \mathrm{~K})$ portions of cometary nuclei may consist of a graphite-like substance.

The results of calculations of the evolution of short-period comets into asteroid-like bodies show that the complete mantling of cometary nucleus achieved after approximatly dozens revolutions of comet around the Sun on the subsolab part of the nucleus surface the mantle more than $20 \mathrm{~cm}$ thick formed and short-period comet turned into asteroid-like body 16-18 magnitudes (Ibadinov, 1999).

Observations support the existence of cometasteroid (Comastr) objects. First, we have asteroid Chiron and comet Harrington-Wilson. Serious arguments exist to suggest that the objects $1992 \mathrm{AD}$, 5441 Pholus, $1992 \mathrm{QB}$, and $1993 \mathrm{FW}$, recorded as asteroids, as well as near Earth asteroids of Taurid complex, 2101 Adonis, 2202 Oljato, 2212 Hephaistos, 4183 Cuno, 4179 TA, 4341 Poseidon, 4486 Mithra, 5143 Heracles, 5731 Zeus, and 6063 Jason, are extinct short-period comets. The Encke's comet is potential stort-period asteroid.

Thus, a part of Near Earth Objects dangerous for the Earth is a comet-asteroid objects. They are a icy nuclei of short-period comets covering with porous refractory mantle. The thickness of this mantle is up dozens centimetres. The mantle may consist of a graphite-like consist. The density of this mantle may be $0.1-1 \mathrm{~g} / \mathrm{cm}^{3}$, and the its thermal conductivity is $0.01-$ $0.1 \mathrm{~W} / \mathrm{mK}$, and mechanical strength of the mantle is $20-50 \mathrm{kPa}$. The dependence of mantle surface temperature on heliocentrical distance, in first approximation, may be represented as $\mathrm{T}=\mathrm{To} / \mathrm{r}^{1 / 2}$. The icy temperature under crust is low $(-200 \mathrm{~K}$ at $\mathrm{r}=1$ A.U.).

References:

Dobrovolsky, O.V., Ibadinov, Kh.I., and Gerasimenko, S.I., Secular Decrease in Brightness and Structure of Nuclei of Periodic Comets, Dokl. Akad. Nauk Tajik SSR, 1984, vol. 27, no. 4, pp. 198-200.

Ibadinov, Kh.I., Laboratoty Investigation of the Sublimation of Comet Nucleus Model, Adv. Space Res., 1989, vol. 9, no. 3, pp. 97-112, London.

Ibadinov, Kh.I., Rahmonov, A.A., Bjasso, A.Sh., Laboratory Simulation of Cometary Structures, in Comets in Post-Halley Era, Newburn, R.L., et al., Eds., Dordrecht: Kluwer, 1991, vol. 1, pp. 299-311.

Ibadinov, Kh.I., The Surface Structure of ShortPeriod Comet Nuclei, in Meteoroids and Their Parent Bodies, Stohl, J. and Williams, I.P., Eds., Bratislava, 1993, pp. 373-376.

Ibadinov, Kh.I., Growth of a Refractory Mantle on a Cometary Nucleus and the Evolution of the Nucleus into an Asteroid-like Body, Solar System Research, 1999, vol., 33, no. 4, pp. 319-323.

Hashimov, N.M., Ibadinov, Kh. I., and Shoyokubov, Sh. Sh., Laboratory Investigation of the Possibility of Formation of Refractoty Substunces in Comets, Dokl. Akad. Nauk Tajikistan, 1994, vol. 37, no. 1, pp. 16-19. 


\section{THE K/T BOUNDARY IMPACT LAYER IN CUBA: UPDATE OF AN} INTERNATIONAL PROJECT. M. Iturralde-Vinent ${ }^{1}$, D. García Delgado ${ }^{2}$, C. Díaz Otero ${ }^{2}, R$. Rojas Consuegra ${ }^{1}$, R. Tada ${ }^{3}$, H. Takayama ${ }^{3}$, and S. Kiyokawa ${ }^{3} .{ }^{1}$ Museo Nacional de Historia Natural, Obispo \#61, 10100 La Habana, Cuba (e-mail: geopal@mnhnc.inf.cu), 2 Instituto de Geología y Paleontología, Via Blanca y Linea de Ferrocarril, San Miguel de Padron, CP 11000 La Habana, Cuba (e-mail: igpcnig@ @eniai.inf.cu), ${ }^{3}$ University of Tokyo, Japan.

The Cretaceous/Tertiary Boundary (KTB) bolide impactor that allegedly created the Chixulub crater in Yucatan, should have produced a series of events that must be recorded in the sedimentary sections of the surrounding areas. Cuba is an excellent spot to study these sediments and events, as in the territory of the island, there are abundant deposits of the Latest Cretaceous and Paleocene. Especially some of these rocks have been discussed recently as probably associated with the impact and related events (Pszczolkowski, 1986; Iturralde-Vinent, 1992).

A joint Cuban-Japanese international project started in 1997, with the aim of identifying the KTB rocks, improve its dating, characterize its composition and origin, and model the sediment-producer events. Some of the initial results of this project have been published in part (Tada et al., 1998; Matsui et al., Kiyokawa et al., 1998), but many new data are still under elaboration. In this paper we would like to present some of the preliminary results, as an update report, until the analysis of the large number of samples collected and extensive field observations is completed.

Suspected KTB sediments have been located in different geological context of Cuba, as in the Guaniguanico terrain detached from the Yucatan borderland (Cacarajicara Formation and Moncada calcarenite), in the southern paleomargin of the Bahamas platform (Lutgarda and Amaro Formations), and above the extinct Cretaceous volcanic arc (Peñalver and Mícara Formations) (Pszczolkowski, 1986; Iturralde-Vinent, 1976-77, 1992). Some other units, still under study, may encompass KTB deposits, in sections above the Cretaceous arc, as the Isabel, Cantabria, Palmarito, Coco, Fomento, Vaquería and Santa Clara Formations (Kantchev ed., 1978).

The suspected KTB rocks in the Guaniguanico terrain are characterized as carbonateclastic units, containing several indicators of it relationship with the impact. The Moncada calcarenite is about $2 \mathrm{~m}$ thick, containing the KTB paleontologic cocktail, lamellar quartz, spherules, and a thin black shale on top (work on process). On the other hand, the Cacarajícara Formation is up to 400 meters thick single graded megaturbidite, which contain a lithologic cocktail of Late Jurassic through Maastrichtian clastic components, as well as spherules(?) and lamellar quartz. These rocks may have been deposited by a combination of slumping and suspended sediment deposition, triggered by the seismic shock and tsunami waves induced by the Chixulub impactor.

The KTB sections of the Amaro and Lutgarda Formations in the southern margin of Bahamas have not been yet examined by the project. According to Kantchev (1978), Pszczolkowski (1986), Iturralde-Vinent et al. (1981), and Iturralde-Vinent (1992); the Amaro Formation is also a megaturbidite, few tens of meters thick, with minimum of two grain-size gradational units, and containing spherules and the lithological cocktail of Jurassic and Cretaceous clastic elements. The Lutgarda Formation consists of marls and marly limestones with abundant allochthonous debris at the base of the section. The age of both formations have been usually identified as Maastrichtian, but this dating need to be revisited. Pszczolkowski 
(1986) and Iturralde-Vinent (1992) suggested the possibility that, at least Amaro, may be related to the impact.

Above the allochthonous Cretaceous arc there are Maastrichtian-Paleocene sections which may encompass the KTB (Iturralde-Vinent, 1976-77, 1992; Kantchev, 1978; Pszczolkowski, 1986). The best know unit is the Peñalver Formation, about $200 \mathrm{~m}$ thick carbonate clastic graded section, which contain a limited Late Cretaceous paleontological cocktail, spherules and lamellar quartz (Takayama et al., in press). Mícara Formation of eastern Cuba contain the KTB, but the lithology is that of a siliciclastic flysch (Iturralde-Vinent, 197677). The investigation of this unit is as yet in progress. Other KTB sections above the Cretaceous arc (Kantchev, 1978) are pending detailed investigations.

With the information available it is possible to conclude that the KTB layer is present in Cuba, in geological units of various allochthony, which back in the Latest Cretaceous represent the infilling of the western Caribbean basin facing the Yucatan platform. Some of these units are probably impact-related as the Moncada calcarenite, and the Cacarajícara and Peñalver Formations; but in order to understand the other units, one will have to await the end of the investigations in progress. A paleogeographic map of the basin was elaborated, to illustrate the original position of the sedimentary rocks just discussed.

\section{References}

Iturralde-Vinent, M. 1976-1977. Estratigrafía de la zona Calabazas-Achotal, Mayarí Arriba, Oriente. Rev. La Minería en Cuba. Part I: (5): 9-23; Part II: (6): 32-40.

Iturralde-Vinent, M. 1992. A short note on the Cuban late Maastrichtian megaturbidite (an impact-derived deposit?): Earth \& Planetary Science Letters, 109: 225-228.

Iturralde-Vinent, M., D. Tchounev , R. Cabrera et al. 1981. Geología del territorio de CiegoCamaguiey-Las Tunas:Resultados de las investigaciones científicas y del levantamiento geológico escala 1:250 000. Academias de Ciencias de Cuba y Bulgaria. 940 p. and maps. (unpublished report). Ministry of Basin Industries files. La Habana.

Kantchev, I. ed., 1978. Geología de la provincia de Las Villas. Resultados de las investigaciones geológicas y levantamiento geológico a escala 1:250 000 realizados durante el período 19691975(Inédito). Instituto de Geología y Paleontología. MNBAS. La Habana.

Pszczolkowski A., 1986. Megacapas del Maestrichtiano en Cuba occidental y central. Bulletin of the Polish Academy of Earth Science, 34(1): 82-94.

Takayama, H, Tada, R., Matsui, T., Iturralde-Vinent, M.A., Oji, T., Tajika, E., Kiyokawa, S.,, García Delgado, D., Okada, H., Hasegawa, T., Toyoda, K., 1999. Origin of the Peñalver formation in northwestern Cuba and its relation to $\mathrm{K} / \mathrm{T}$ boundary impact event. Sedimentary Geology (submitted) 


\section{$345 / 46$}

CRUST AND MANTLE DEFORMATION UNDER CHICXULUB: TEST FOR MODELS. B. A. Ivanov, Institute for Dynamics of Geospheres, Russian Acad. Sci., Moscow, Russia 117939, <baivanov@glasnet.ru>

Introduction: The importance of the $\mathrm{K} / \mathrm{T}$ impact event formed the Chicxulub crater for the terrestrial biosphere is widely accepted. At the same time the crater is the unique example of a large and relatively young impact structure where the subsurface structure is .well preserved in contrast to two other "big sisters" (Vredeford and Sudbury). The geophysical survey revealed the main details of the subsurface target deformations [1, 2]. However, the numerical modeling of the complex phenomena of the modified impact crater formation still meets many problems [3-5]. The presented paper reports the current status report about the continuation of the work on quantitative reproduction of impact crater morphology and subsurface structure $[6,7]$.

Numerical model: paths in the shock experiments are numerically modeled using the heavily modified ALE code [8-10]. The modified code allow to compute problems with several materials in the Eulerian mode taking into account material strength. The standard thermal profile for the continental lithosphere is used. The Tillotson EOS for granite and dunite is modified to allow compute pressure and temperature from density and internal energy for crust and mantle materials.

The thermal softening model is used to describe the strength properties for rock materials. Typical experimental data for the strength of olivine are shown on Fig. 1 in comparison with the assumed model. The strength is assumed to be proportional to the ambient pressure (dry friction regime) being limited with a HEL limit at high pressures. The calculated elastic limit in each computational cell is decreased as

$$
\mathrm{Y}=\mathrm{Y}_{0}\left(1-\mathrm{T}^{* 1 / 2}\right)
$$

where $T^{*}=\left(T-T_{0}\right) /\left(T_{m}-T_{0}\right), Y_{0}$ is the plastic limit at normal temperature, $T_{0}$, and $T_{m}$ is the melting demperature depending on pressure according to a simple Simon approximation.

Preliminary Results:: The model calculations are done for a slow projectile $\left(12 \mathrm{~km} \mathrm{~s}^{-1}\right)$ to avoid mass evaporation of rocks. The simple two-layer target simulates crust/mantle structure as $33 \mathrm{~km}$ of granite upon the dunite "mantle" at the Chicxulub site.

The size of projectile is chosen so to create the transient crater $40 \mathrm{~km}$ deep. The projectile is simulated with a crust material. No atmosphere is simulated (vacuum above the target).
First runs show a strong dependence of the final crater depth on the assumed model of a thermal softening. Variations of the melt temperature dependence on pressure and the thermal gradient resulted in the final crater depth 5 to $10 \mathrm{~km}$ (Fig. 1 and 2). The crater collapse on the "simple crater" scenario [5]: the main engine of the collapse is the sliding of transient crater walls. This is in contrast to O'Keefe and Ahrens [4] results where the "complex crater" behavior was reported for the Chicxulub size events. The "complex crater" behavior (crater floor uplift) apparently needs additional mechanisms of the friction reduction. As the result we found the residual subsidence of the crust-mantle boundary ca. $10 \mathrm{~km}$ below the preimpact level which contradicts to the geophysical data $[1,2]$ (see Figs. 2 and 3). We now work on the implementation of the acoustic fluidization model into the Eulerian code.

Previously our code in the Lagrangian version allowed to reproduce some shear localization around the collapsing transient cavity [10]. The presented Eulerian version also reproduced some shear faulting (Figs. 2 and 3). These data are ready to be compared with the fault structure in the crystalline basement observed with various geophysical techniques $[1,2]$ which is a useful supplement to the ongoing ICDP drilling in Chicxulub.

Conclusions: The new Eulerian version of the ALE hydrocode allows to simulate some important features of the Chicxulub structure. While not all model results well fit to observations, the presented approach looks useful for the future "tuning" of the cratering models.

Acknowledgements: This work is supported by RFBR. The author thanks to $\mathrm{H}$. J. Melosh for extencive and useful duscusions.

References: [1] Morgan J., Warner M. and the Chicxulub Working Group (1997) Nature, 390, 472476; [2] Snyder D. B., Hobbs R. W., and the Chicxulub Working Group (1997) JGR, 104, 10,743-10,755; [3] O'Keefe, J. D.; Ahrens, T. J. (1983) JGR 88, A799-A806; [4] O'Keefe, J. D.; Ahrens, T. J. (1999) JGR 104, No. E11, p. 27,091; [5] Melosh H. J. and Ivanov B. A. (1999) Ann. Rev. Earth Planet. Sci. 27, pp. 385-415; [6] Ivanov B.A, Kostuchenko V.N. (1997), LPSC XXVII, Abstract \#1655; [7] Ivanov B. 
A. (1998) Meteroritics and Planetary Science 33 (Suppl.): A76 599-610; [8] Amsden, A. et al.. (1980). Los Alamos National Laboratory Report LA-8095, Los Alamos, NM, 101pp.; [9] Ivanov et al. (1997) Int. J. Impact. Eng. 20, 411-430; [10] Ivanov B. A. and Deutsch A. (1998) Sudbury impact event: Cratering mechanics and thermal history. Geol. Soc. Amer. Pap. (in press), [10] Kenkmann, T.; Ivanov, B. A. (1999), LPSC XXX, \#1544.

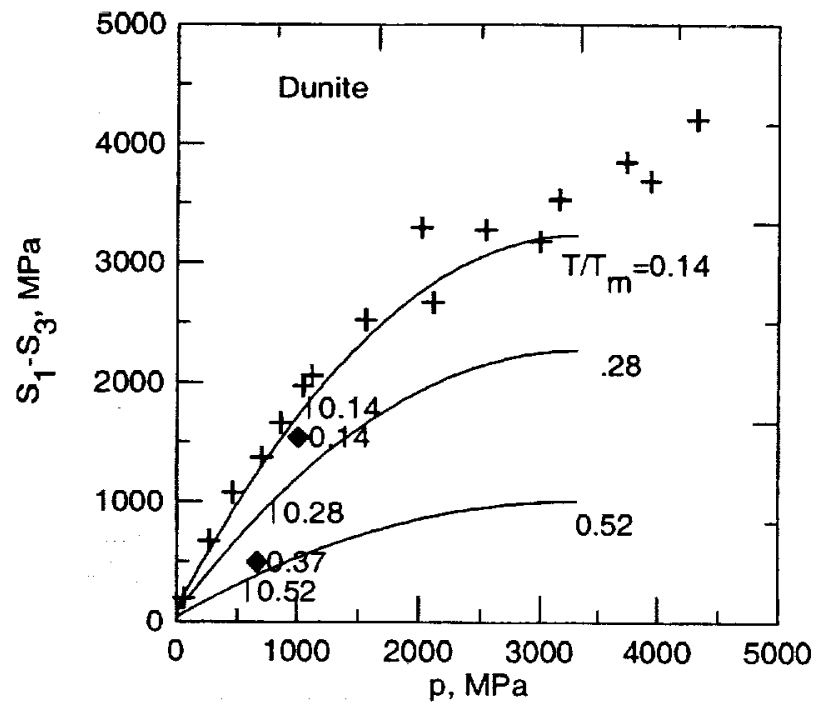

Fig. 1. The difference in maximum and minimum main stresses for dunite versus pressure at various temperatures. At elevated $T / T_{m}$ values the strength is reduced.

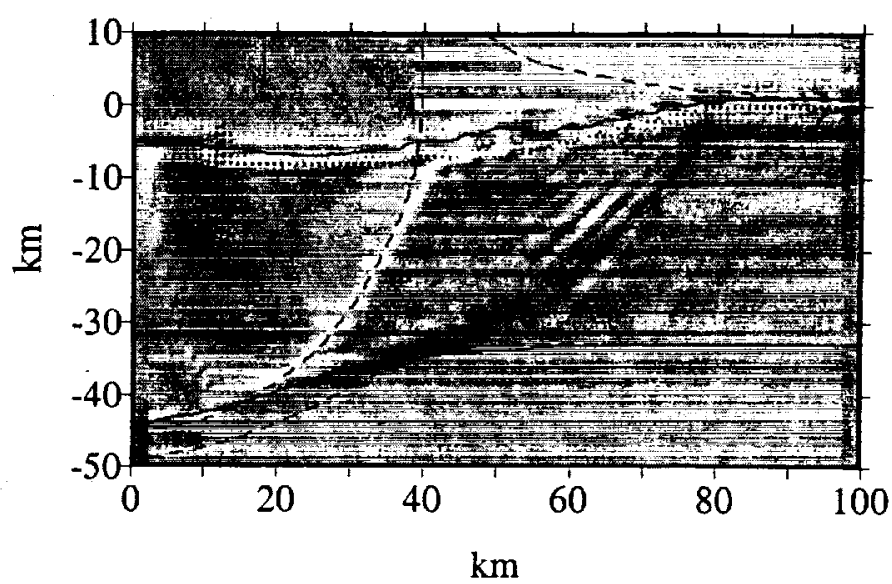

Fig. 2. The shadow relief of the field of the accumulated shear strain under the crater ( $300 \mathrm{~s}$ after impact). Dashed lines show the transient crater and Moho profiles at $20 \mathrm{~s}$ when crater reaches its maximum depth. Solid lines show the final crater and Moho profiles.

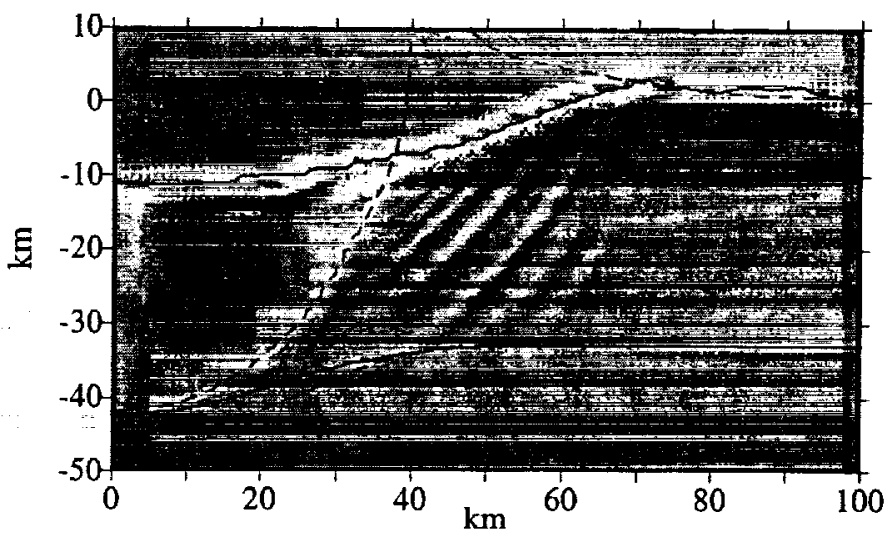

Fig. 3. The same as on Fig. 2 for the variant with reduced increase of the melting temperature with pressure. 
HOW STRONG WAS IMPACT-INDUCED $\mathrm{CO}_{2}$ DEGASSING IN THE K/T EVENT? B. A. Ivanov ${ }^{1}$, F. Langenhorst $^{2}$, A. Deutsch ${ }^{3}$, and U. Hornemann ${ }^{4},{ }^{1}$ Inst. for Dynamics of Geospheres, Russian Acad. Sci., Moscow, Russia 117939, <baivanov@glasnet.ru>; 'Bayerisches Geoinstitut (BGI), Univ. Bayreuth, D-95440 Bayreuth, Germany, <falko.langenhorst@uni-bayreuth.de>; ${ }^{3}$ Inst. f. Planetologie (IfP), Univ. Münster, D-48149 Münster, Germany, <deutsca@uni-muenster.de>; ${ }^{4}$ Ernst-Mach-Institut (EMI), Am Klingelberg 1, D-79588 EfringenKirchen, Germany

Introduction: The impact-related release of greenhouse gases is one of the potential mechanisms that could have triggered or accelerated the crisis of life at the end of the Cretaceous via drastic and fast changes of the climate. Estimates for the total input of $\mathrm{CO} 2$ into the atmosphere due to the Chicxulub impact event range from $260 \mathrm{Gton}$ [1] to $100000 \mathrm{Gton}$ [2]; the latter value is ten times the amount of $\mathrm{CO}_{2}$ in the late-Cretaceous atmosphere.

Experiments. In order to better constrain shock metamorphism of calcite, we use two experimental approaches: (1) systematic high-explosive shock experiments on single crystal calcite and compacted calcite powder (up to pressures of $100 \mathrm{GPa}$, see [3] for the general setup), and (2) fast unloading experiments in a multi-anvil apparatus (controlled quenching to ambient pT from $25 \mathrm{GPa}$ at $2700 \mathrm{~K}$ in time scales comparable to large scale natural impact events, i.e. a few $s e c)$. The recovered material is investigated with mineralogical methods, amongst them ATEM. Additionally a new design of the high-explosive setup with an open drill hole on rear side of the container was tested (Fig. 1). First data are presented in [4].

Numerical Simulations of Experiments. pT paths in the shock experiments are modeled using the heavily modified ALE code [5-7]. This code allows to compute problems with several materials in the Eulerian mode taking into account material strength. The Bobrovsky et al. equation of state for calcite [8] with constant Gruneisen parameters for each material $\left(\mathrm{CaCO}_{3}, \mathrm{CaO}\right.$, and $\left.\mathrm{CO}_{2}\right)$ is used.

The geometry of the simulations includes the ARMCO iron sample container, and the calcite sample disk that is totally enclosed in this container. The upper part of the container is treated as a flyer plate (Fig. 2). Model runs yield the p-T evolution in the experiment: during shock reverberation, mainly the first wave heats the target. For example, the first wave creates in the calcite a shock pressure of $41 \mathrm{GPa}$ and gives the shock temperature of $1128 \mathrm{~K}$. The following reverberations compress the specimen to $85 \mathrm{GPa}$ but all reverberated shocks add only $70 \mathrm{~K}$ to the shock temperature - insufficient for decomposition after pressure release. For comparison, the single $85 \mathrm{GPa}$ shock wave has a shock temperature of $2700 \mathrm{~K}$ doubtless enough to release the sample into the de- composition field. A different set-up with a hole under the sample (Fig. 1, 2) changes the situation: the lower central part of the calcite specimen is injected into the collapsing hole. The "implosion" of the injected calcite leads to a secondary heating (Fig. 3). However, due to the solid lower boundary in calculations, calcite cannot be decomposed as there is no room for the expansion.

Expand to Decompose. Already the first experiments on shock-induced calcite degassing have revealed that the degree of decomposition depends on the ambient $\mathrm{CO}_{2}$ pressure [9]. Figure 4 shows the calcite decomposition in the $\mathrm{pV}$ space at equilibrium conditions. It is important to note that at the pT decomposition boundary one need to expand $\mathrm{CO}_{2}$ dramatically to reach an observable level of decomposition. This feature explains why it is hard to observe decomposition in small-scale laboratory experiments.

Discussion. This above described, natural condition for an effective calcite degassing seems also to be important in large scale events (like the $\mathrm{K} / \mathrm{T}$ Chicxulub cratering event). The condition to separate $\mathrm{CaO}$ and $\mathrm{CO}_{2}$ in space prompts the question if the assumption of a thermodynamic equilibrium is valid in this context. Recent experiments with the reverse reaction $\left(\mathrm{CaO}+\mathrm{CO}_{2}=\mathrm{CaCO}_{3}\right)[10]$ show that diffusion of $\mathrm{CO}_{2}$ to the unreacted $\mathrm{CaO}$ grains takes ca. $100 \mathrm{sec}$. A similar time scale may be valid in direct decomposition. This kinetic effect seems to be fundamental for proper estimates of $\mathrm{CO}_{2}$ production due to the Chicxulub $(\mathrm{K} / \mathrm{T})$ impact event, decreasing previously published values.

Acknowledgments: This study is supported by grants DE 401/15, HO1446/3, and LA830/4 of the German Science Foundation. We appreciate technical assistance by $F$. Bartschat, Th. Gund, U. Heitmann, R. Thewes, H. Heying, M. Feldhaus (Münster), and H. Schulze (Bayreuth).

References. [1] B. A. Ivanov et al. (1996) Geol. Soc. Amer. Spec. Pap. 307, 125; [2] T. Takata and T. J. Ahrens (1994) LPI Contrib. 825, 125; [3] F. Langenhorst and A. Deutsch (1994) EPSL 125, 407; [4] F. Langenhorst, A. et al. (2000) LPSC 31, \#1851; [5] A. Amsden et al.. (1980). Los Alamos National Laboratory Report LA-8095, Los Alamos, NM, 101pp.; [6] B. A. Ivanov et al. (1997) Int. J. Impact. Eng. 20, 411; [7] B. A. Ivanov and A. Deutsch (2000) Sudbury impact event: Cratering mechanics and thermal history. Geol. Soc. Amer. Pap. 339, xxx;. [8] S. V. Bobrovsky et al. (1976) Physical and technical problems of mining (in Rus- 
sian) \#3, 49; [9] J. A. Tyburzcy and T. J. Ahrens (1986) JGR 91, 4730; [10] P. Agrinier et al. (1998) LPS XXIX, 1217; A. Deutsch et al. (1998) LPS XXIX, 1386.

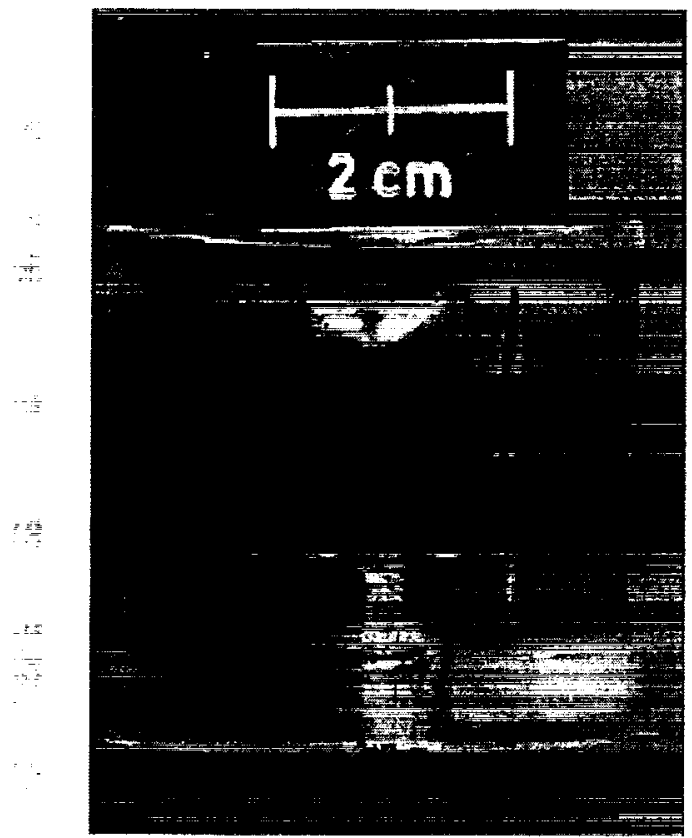

Fig. 1. Sectioned high-explosive setup with a central hole on the rear side of the container. The upper part of this hole was sealed during unloading
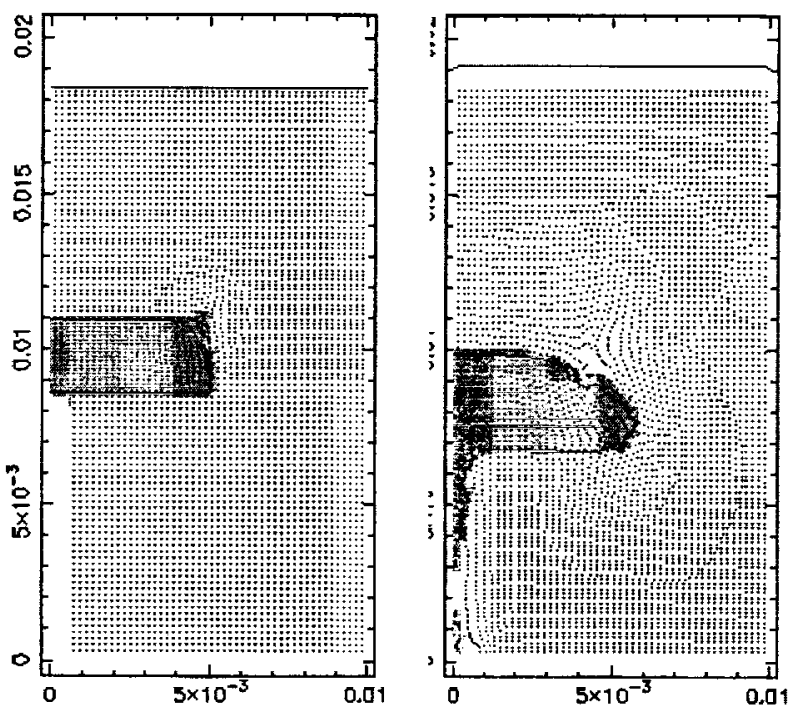

Fig. 2. Time frames of the numerical simulation of the experiment shown on Fig. 1. The calcite sample (green) is compressed inside the ARMCO iron sample holder (gray dots). The left axis is the axis of cylindrical symmetry. Note the jet in the lower part of the right drawing.

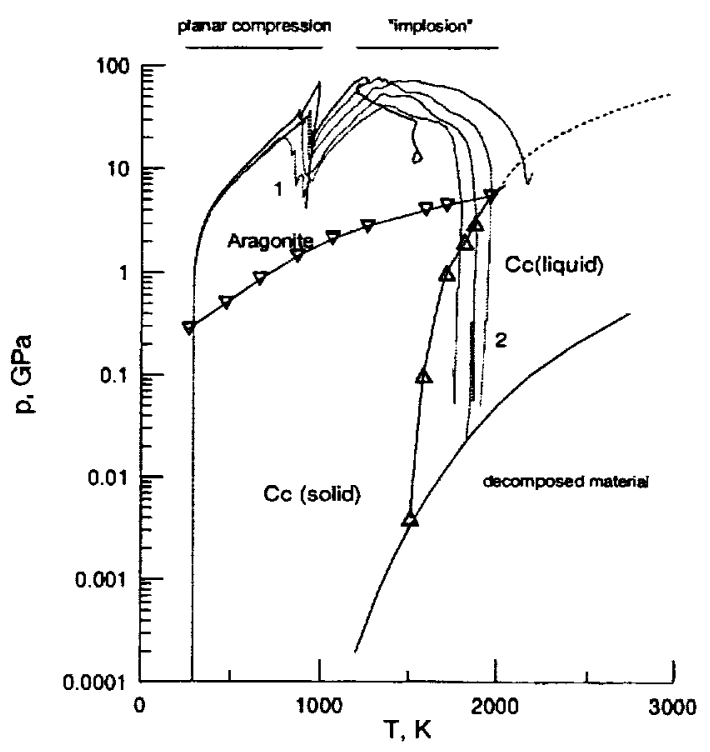

Fig. 3. Numerically calculated (Fig. 2) pT paths for selected particles in the shock experiment (Fig. 1). Main phase curves for calcite are shown for comparison.

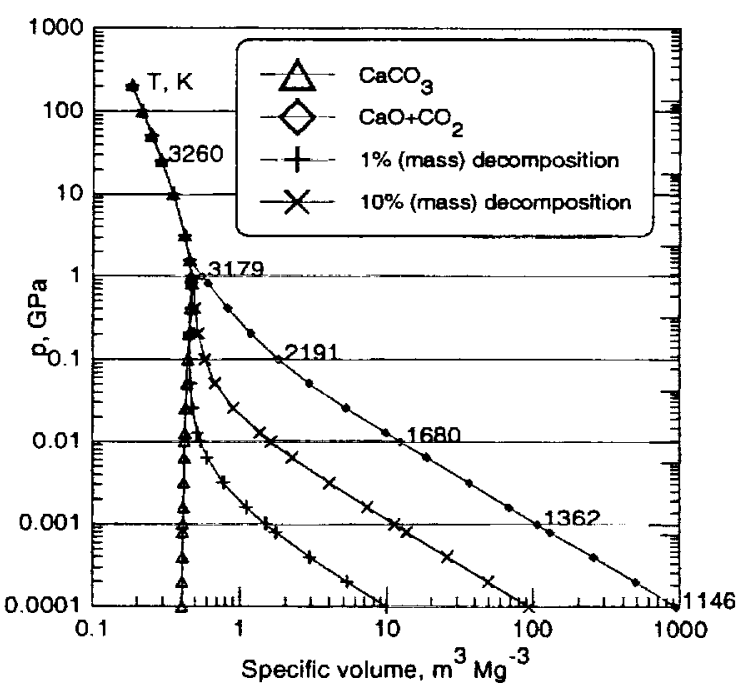

Fig. 4. The decomposition field for calcite in the presssure-volume plane. The decomposition reaction follows isotherms from zero to $100 \%$ of decomposition. To reach the given level of decomposition one should give the specimen enough volume to expand $\mathrm{CO}_{2}$ gas, otherwise the specimen will stay close to the initial calcite density. 
PATTERN OF MARINE MASS EXTINCTION NEAR THE PERMIAN-TRIASSIC BOUNDARY IN SOUTH CHINA. Y. G. Jin', Y. Wang ${ }^{1}$, W. Wang ${ }^{1}$, Q. H. Shang ${ }^{1}$, C. Q. Cao and D. H. Erwin ${ }^{2}$, 'Nanjing Institute of Geology \& Palaeontology, Academia Sinica, Nanjing 210008, China. ygjin@public1.ptt.js.cn, ${ }^{2}$ Dept. of Paleobiology, MRC-121, National Museum of Natural History, Washington, D. C. 20560, USA<Erwin.Doug@NMNH.SI.EDU>

The end-Permian mass extinction eliminated over $90 \%$ of all marine species, and had significant impact on land. However, the patterns of extinction are poorly constrained or not statistically documented and the consistency between extinction patterns and various extinction scenarios remains unclear. Geochronologic results from south China reveal the extinction occurred in less than 500,000 years (1), coincident with the eruption of the Siberian flood basalts (2) and a sharp shift in $\delta^{13} \mathrm{C}_{\text {carb }}$ (3). The cause of the extinction remains enigmatic, with claims for multiple pulses of extinction, including at least three at the classic Meishan sections in South China (4). Since abrupt extinctions can appear gradual due to sampling and preservation effects, statistical analysis of range end points is desirable (5). Analysis of the occurrences of 162 genera and 333 species at Meishan confirms a single extinction event at $251.4 \mathrm{Ma}$, coincident with a dramatic depletion of $\delta^{13} \mathrm{C}_{\text {carb }}$ and a microspherule anomaly. Although no definitive evidence for impact has been identified, this strengthens the similarity with the end-Cretaceous extinction and suggests involvement of an extra-terrestrial impact.

References: "[1] Bowring, S. A., et al. (1998) Science, 280, 1039-1045. [2] Renne, P. R. et al (1995) Science, 269, 1413. [3]. Baud, A. et al. (1989) Geologische Rundschau, 78, 649. [4]. Z. Y. Yang et al. (1993) Permo-Triassic events of South China. 153..[5]. C. R. Marshall, (1994) Paleobioology, 20, 459. 
THE LATE DEVONIAN MASS EXTINCTION - IMPACT OR EARTH-BOUND EVENT? M.M. Joachimski and W. Buggisch, University of Erlangen, Institute of Geology, Schlossgarten 5, 91054 Erlangen/Germany, joachimski@geol.uni-erlangen.de

Introduction: The Frasnian-Famennian (F-F) faunal crisis represents one of the 'Big Five Mass Extinctions' in Earth History. Studies have been published that favor either a collision with an extraterrestrial bolide [e.g. 1] or changes in the oceanographic and climatic systems [e.g. 2]. However, no unequivocal evidence on the origin of the Late Devonian faunal breakdown was reported. E.g. iridium anomalies reported from Australia [3] and Southern China [4, 5] post-date the F-F boundary by 1.5 to $2 \mathrm{Ma}$. Microtekites from Belgium boundary sections $[6,7]$ were seen in context with the $368 \pm 1$ Ma old Siljan Ring impact structure. However, the cosmic origin of these spherules has been questioned [8] and the microtektites were found above the F-F boundary and clearly post-date the extinction event. Negative carbon isotope excursions were interpreted as evidence for a sudden biomass crash hat may have been triggered by a bolide impact $[9,10]$. In contrast, two positive $\delta^{13} \mathrm{C}$ excursions measured in the late Frasnian and at the F-F boundary $[2,11]$ seem not to support the idea of a dramatic decline in primary productivity. This contribution presents a comprehensive geochemical and stable isotope data set that may help to unravel the mechanisms responsible for the Late Devonian mass extinction.

Results: Carbon isotope analysis on carbonate-rich F-F boundary sections from Nevada, Central Europe, Northern Africa and Australia reveal two $+3 \%$ excursions in the late Frasnian that can be correlated with the deposition of the Kellwasser Horizons. $\delta^{13} \mathrm{C}$ values measured on total organic carbon as well as on individual biomarkers (n-alkanes, isoprenoids and hopanes) reveal comparable $\delta^{13} \mathrm{C}$ records with two $+3 \%$ excursions. Since the amplitudes of the $\delta^{13} \mathrm{C}$ records measured in sections from different palaeogeographic units are well comparable, changes in the carbon isotopic composition of the oceanic dissolved inorganic carbon (DIC) reservoir have to be assumed. The positive shifts in $\delta^{13} \mathrm{C}$ are induced by an increase in the organic carbon burial rate during the deposition of the Kellwasser horizons. These results seem to contradict time-equivalent negative excursions in $\delta^{13} \mathrm{C}$ measured in Chinese F-F boundary sections $[9,10]$. The negative excursions are observed in organic carbon-rich and carbonate-poor sediments. Following, we favor a diagenetic orgin of these depleted signatures due the incorporation of light carbon from the oxidation of organic carbon during the recrystallisation of the car- bonates. This interpretation is supported by the fact that well-preserved brachiopod shells show no depletion in ${ }^{13} \mathrm{C}[12]$.

The increase in the organic carbon burial rate is not only documented by the positive shifts in $\delta^{13} \mathrm{C}$ but as well by the deposition of the Kellwasser Horizons in epicontinental basins and on deeper swells. In addition, the identification of biomarkers diagnostic for green sulfur bacteria in a boundary section from Poland [13] reveals that photic zone anoxia may have prevailed at least seasonally in certain areas of the Prototethys. Sulfur isotope ratios measured on sulfides and organically-bound sulfur show a $+27 \%$ excursion across the F-F boundary indicating enhanced bacterial sulfate reduction and sulfide sedimentation.

Modelling the $\delta^{13} \mathrm{C}$ record reveals that the fraction of organic carbon on total carbon burial must have increased from 20 to $30 \%$ in order to account for the $+3 \%$ shifts. The estimation of the duration of enhanced organic carbon burial resulted in a $0.4 \mathrm{Ma}$ time period for the Lower Kellwasser Horizon and a 1.0 to $1.5 \mathrm{Ma}$ period at the F-F boundary. The additional organic carbon burial was calculated as 1.4 to $1.6 \times 10^{6} \mathrm{~mol} \mathrm{C}$ for the Lower Kellwasser and 3.1 to $4.6 \times 10^{6} \mathrm{~mol} \mathrm{C}$ for the F-F boundary. It is expected that this carbon withdrawal from the Devonian ocean-atmosphere system resulted in a decrease in atmospheric $\mathrm{CO}_{2}$ concentration and culminated in global climatic cooling.

The comparison of the $\delta^{13} \mathrm{C}$ records measured on inorganic carbon and biomarkers derived from primary producers shows parallel trends [13]. However, a larger amplitude in $\delta^{13} \mathrm{C}$ of individual biomarkers is expected in case of a significant drawdown of atmospheric $\mathrm{CO}_{2}$. This assumption is based on the fact that the carbon isotopic fractionation during the photosynthetic uptake of $\mathrm{CO}_{2}$ is dependent on the $\mathrm{CO}_{2}$ concentration of ambient seawater and on the growth rate of primary producers. Assuming constant growth rate and that the enhanced organic carbon burial resulted in a drawdown of atmospheric $\mathrm{pCO}_{2}$, photosynthetic fractionation should decrease and result in a greater enrichment of ${ }^{13} \mathrm{C}$ in organic carbon relative to inorganic carbon. The fact that we do not observe a further enrichment in ${ }^{13} \mathrm{C}$ of primary organic carbon does not seem to support the conclusion that atmospheric $\mathrm{pCO}_{2}$ was reduced as consequence of an enhanced organic carbon burial. However, calculated photosynthetic fractionation is 23 to $24 \%$ which is very close to the 
expected maximum fractionation of $25 \%$ [14]. Following, we assume that photosynthetic fractionation was at a maximum level during the Upper Devonian as a consequence of high atmospheric and oceanic dissolved $\mathrm{CO}_{2}$ contents [15]. Accordingly, any superimposed change in $\mathrm{pCO}_{2}$ or growth rate was not recorded in the isotopic composition of primary organic carbon.

Climatic cooling is considered as another consequence of the enhanced organic carbon burial. Oxygen isotope analyses on conodont and fish apatite reveal an increase in $\delta^{18} \mathrm{O}$ from values around $+17.5 \%$ to $+19 \%$ (SMOW) parallel to the positive shifts in $\delta^{13} \mathrm{C}$. Assuming a $\delta^{18} \mathrm{O}$ value for Devonian sea water of $-1 \%$, the positive $\delta^{18} \mathrm{O}$ shifts translate in a decrease in sea-surface temperature from 32 to $25^{\circ} \mathrm{C}$. Although this drop in sea-surface temperature awaits confirmation by the investigation of apatite from further F-F boundary sections, a significant climatic cooling is indicated.

Conclusions: The geochemical data base for the Late Devonian extinction event shows no evidence for a bolide impact as potential cause of the mass extinction. Instead, repeated changes in the carbon cycle of the ocean-atmosphere system are indicated by positive carbon excursions. The enhanced organic carbon burial is indicated by the higher $\delta^{13} \mathrm{C}$ values, deposition of the Kellwasser horizon and a positive excursion in $\delta^{34} \mathrm{~S}$ of sulfides and organically-bound sulfur $\mathrm{A}$ decrease in atmospheric and oceanic dissolved $\mathrm{CO}_{2}$ contents is expected and may have culminated in global climatic cooling. A decrease in tropical seasurface temperature of $7^{\circ} \mathrm{C}$ is indicated by preliminary conodont and fish apatite $\delta^{18} \mathrm{O}$ data.

The paleontological data base seems to support the conclusion that climatic cooling may have represented a potential mechanism for the Late Devonian mass extinction [e.g.16]. Organisms living in the tropical to subtropical pelagic and shallow-water ecosystems were heavily decimated. Organisms thriving in higher latitudes or in deeper waters were only slightly affected. Further, late Frasnian faunal groups that were adapted to cooler temperatures migrated into tropical latitudes during the early Famennian. This pattern suggests that climatic cooling in conjunction with significant oceanographic changes may represent a powerful scenario to account for the Late Devonian mass extinction.

References: [1] McLaren D. (1970) J. Paleont. 44, 801-815. [2] Joachimski M.M. and Buggisch W. (1993) Geology 21, 675-678. [3] Playford P.E. et al. (1984) Science 226, 437-439. [4] Zheng Y. et al. (1993) Palaeogeo. Palaeoclimat. Palaeoecol. 104, 97.
104. [5] Wang K. et al. (1994) Geol. Soc. Am. Spec. Pap. 293, 111-120. [6] Claeys P. et al. (1992) Science 257, 1102-1104. [7] Claeys P. et al. (1994) Earth Planet. Sci. Lett. 122, 303-315. [8] Marini F. and Casier J.-G. (1997) Abstr. Internat. Symp. Tallinn: Impact and extraterrestrial spherules, 31-32. [9] Wang K. et al. (1991) Geology 19, 776-779. [10] Wang K. et al. (1996) Geology 24, 187-191. [11] Joachimski M.M. (1997) Palaeogeo. Palaeoclimat. Palaeoecol. 132, 133-146. [12] Hou H.F. et al. (1996) Mém. Inst. Géol. Univ. Louvain 36, 209-229. [13] Joachimski M.M. et al. (2000) Chem. Geol. in press. [14] Popp B.N. et al. (1998) Geochim. Cosmochim. Acta 62, 69 77. [15] Berner R.A. (1997) Science 276, 544-546. [16] Copper P. (1986) Geology 14, 835-839. 


\section{DEVASTATION OF TERRESTRIAL ECOSYSTEMS AT THE K-T BOUNDARY IN NORTH AMERICA:} THE FIRST CALIBRATED RECORD OF PLANT AND ANIMAL RESPONSE TO THE CHICXULUB IMPACT. Kirk Johnson', Douglas Nichols ${ }^{2}$, Conrad Labandeira ${ }^{3}$, and Dean Pearson ${ }^{4},{ }^{1}$ Denver Museum of Natural History, 2001 Colorado Blvd., Denver, Colorado 80205, kjohnson@dmnh.org, ${ }^{2}$ U.S. Geological Survey, MS 939, Box 25046 DFC, Denver, Colorado 80225, nichols@usgs.gov, ${ }^{3}$ Paleobiology Department, National Museum of Natural History, Smithsonian Institution, Washington, DC 20560, labandeira.conrad@nmnh.si.edu, ${ }^{4}$ Pioneer Trails Regional Museum, Bowman, ND 58623, pearson@bowman.ctctel.com.

Introduction: Extensive collection of leaves, many with insect damage; palynomorphs; and vertebrates from the uppermost Cretaceous (upper Maastrichtian) and lowermost Paleocene (Puercan) formations in western North America has resulted in a combined database of unparalleled density. These data are derived from sites from New Mexico to Canada with a strong focus on the excellent record of the northern Great Plains of the United States. These latter sites and samples have been correlated within a lithostratigraphic framework calibrated by magnetostratigraphy, radiometric dates, and the geochemical and physical indicators of the Cretaceous-Tertiary (K$\mathrm{T})$ boundary. This integrated record documents major devastation of terrestrial ecosystems as a direct consequence of the Chicxulub impact.

Plants: Plant fossils are studied as megafossils or palynomorphs. While both are derived from the same original vegetation, they have different taphonomic pathways and taxonomic resolution. We use both types of fossils to take advantage of their relative strengths. Leaf megafossils are suitable for extinction studies because of their high taxonomic resolution and low potential for reworking. Palynomorphs have great abundance and broad distribution allowing high stratigraphic resolution and the recognition of continentwide patterns.

The plant megafossil record. The most densely sampled K-T leaf flora in the world exists in our Great Plains research area in the Bighorn, Powder River, and Williston Basins (parts of Wyoming, Montana, and North and South Dakota) where more than 30,000 leaves from 306 localities demonstrate an 80 percent extinction across the K-T boundary. The 180 -m-thick section that spans the K-T boundary $(K=100 \mathrm{~m}, \mathrm{~T}=$ $80 \mathrm{~m}$ ) in southwestern North Dakota has yielded a diverse megaflora (based on 13,500 voucher specimens) of more than 385 morphotypes from 171 quarry sites. The uppermost Cretaceous flora is dominated by angiosperms, with ferns, fern allies, cycads, ginkgos, and conifers representing less than ten percent of total taxa and specimens. The Cretaceous sequence can be divided into three distinct floral zones. The uppermost zone begins roughly $20 \mathrm{~m}$ below the K-T boundary and corresponds approximately to the beginning of magnetic polarity subchron $\mathrm{C} 29 \mathrm{R}$. This flora is significantly more diverse than that of the lower floral zones and is characterized by leaf physiognomy that suggests a significant climate warming in the final 350,000 years of the Cretaceous. Floral extinction at the K-T boundary is extensive, effectively eliminating all dominant plant taxa in non-mire facies. The overlying depauperate Paleocene flora, preserved in a variety of facies, is dominated by taxa that were previously restricted to Cretaceous mires. We interpret this to be a post-catastrophe recovery flora that spread onto the early Paleocene landscape from mires and wetlands that, for unknown reasons, served as refugia during the terminal Cretaceous event. Recent work on more than 70 quarries spanning the K-T in the more southerly Denver Basin in Colorado is still in progress but preliminary results also suggest major floral extirpation at the K-T boundary.

The record based on palynology. Palynomorphs from $23 \mathrm{~K}-\mathrm{T}$ boundary or near-boundary sections in southwestern North Dakota indicate 30 percent extinction at the boundary. The palynological database for this area includes 110 palynomorph taxa for which relative abundance or presence/absence data were recorded in more than 230 samples based on surveys of more than 450,000 specimens. With a single exception, extinction in this area occurred exclusively among angiosperm taxa. By their nature, palynomorphs represent higher-level taxa, so this extinction involved not just species but genera or families of plants. Additional data originate from detailed investigations in five other research areas in the western United States and adjacent southern Canada (27 additional sections). Palynostratigraphy at all these localities is calibrated by the iridium anomaly and shocked minerals. Results from these areas show similar effects on palynofloras of somewhat differing compositions. On a continent-wide basis (16 study areas; 225 palynomorph taxa), about 45 percent of the late Maastrichtian palynoflora was destroyed by the terminal Cretaceous event. This regional database covers some $5000 \mathrm{~km}$ from north to south; results reflect strong variation with latest Maastrichtian and earliest Paleo- 
cene floras that was related to paleolatitude. Extinction was varied within major groups of plants continent-wide: 51 percent among angiosperms, 36 percent among gymnosperms, and 25 percent among ferns and fern allies. Because total continent-wide extinction levels are larger than local extinction levels, we suggest that locally endemic taxa were more affected by the terminal Cretaceous event than were widespread taxa. Earliest Tertiary palynofloras are characterized not by new appearances but by loss of the dominant elements of the Cretaceous vegetation. Unique palynomorph assemblages (such as fern-spore abundance anomalies) in close proximity to ejecta deposits show regional effects of impact-related devastation of terrestrial ecosystems. These short-lived plant communities consisted almost exclusively of opportunistic survivor species of ferns in most areas investigated. Repopulation of post-impact landscapes evidently was from local refugia.

Insects: Previous studies have indicated no evidence for mass extinction among insects at K-T boundary. These studies were based on global, familylevel compilations of body-fossil data that indicated no deviation from background rates of extinction. In contrast, the palynologic and megafloral evidence cited above demonstrates a major extinction of plant taxa at the K-T boundary. To test these opposite conclusions, we examined insect-mediated plant damage on 6,000 leaves in a succession of 78 of our megafloral localities in southwestern North Dakota from a section that spans a 2.0 m.y. interval of the late Maastrichtian Hell Creek Formation and earliest Puercan Ludlow Member of the Fort Union Formation. AIl characterizable leaf hosts from these floras were assigned to morphotypes and/or Linnean taxa, providing explicit recognition of plant hosts. We identified 42 types of insect damage, representing insect herbivory from four functional feeding groups: external foliage feeders, leaf miners, gallers, and piercerand-suckers. For the Hell Creek megaflora, 41 types of damage were identified, including several conspicuous examples of galls and scales on primary veins, serpentine mines, and diagnostic slot-hole feeding, each occurring monospecifically and abundantly on separate species of Lauraceae, Platanaceae, and Cannabaceae. For the Fort Union megaflora, only 17 types of damage were identified; abundance levels were found to be significantly lower; and the associations were more generalized, lacking host-specific associations. These data demonstrate that at local scales insect herbivory suffered dramatically during the terminal $\mathrm{Cre}$ taceous event, with no evidence of subsequent recovery. Levels of herbivore diversity remained depressed until pronounced vegetational shifts in the Western Interior of North America during the Early Cenozoic Thermal Maximum in latest Paleocene to early Eocene time.

Vertebrates: Recent surveys of the uppermost Cretaceous Hell Creek Formation in southwestern North Dakota have yielded a total of 10,034 identified vertebrate fossils from 42 sites and dinosaur skulls or skeletons from 41 additional sites. This Lancian fauna is composed of 67 taxa of fish (including sharks and rays), amphibians, lizards, turtles, crocodilians, champsosaurs, dinosaurs, pterosaurs, birds, and mammals. The 83 sites span the entire 100 -meter thickness of the formation. Most vertebrate sites in the lower part of the Hell Creek Formation are in channel deposits; those in the upper part of the formation are more common in floodplain deposits. Dinosaurs are found in the highest vertebrate sites in the Hell Creek Formation and one ceratopsian partial skeleton was found in the overlying Fort Union Formation $(1.4 \mathrm{~m}$ below the K-T boundary). Other significant finds include pterosaur fossils $8.4 \mathrm{~m}$ below the boundary, and sharks within $4 \mathrm{~m}$ of the boundary. The former is the world's youngest occurrence and the latter suggests that the Western Interior seaway was still present in the area near the end of the Cretaceous. Sample size, rather than stratigraphic position, appears to be the primary factor that determines the presence of taxa at these sites. All dinosaur taxa that occur at more than two sites also occur at the highest well-sampled $(>500$ specimens) site, $8.4 \mathrm{~m}$ below the K-T boundary. Dinosaurs also occur in the highest sites that preserve vertebrate fossils. Common vertebrate taxa range throughout the Hell Creek Formation and Lancian faunal extinction appears to be coincident with plant extinctions at the end of the Cretaceous.

Summary: In general, this multidisciplinary examination of K-T ecosystem change documents a dramatic loss of Cretaceous species richness. The ecological landscape of North America was fundamentally altered by the disappearance of major groups of plants and animals and the early Paleocene terrestrial biota was markedly depauperate. Twenty years ago, the Alvarez hypothesis posed the unexpectedly difficult challenge for paleontologists to evaluate abrupt extinction in the terrestrial realm. The challenge has been met for western North America using multidisciplinary methods that provide a standard for future work. A complete understanding of the global effects of the Chicxulub impact on terrestrial ecosystems awaits similar research on other continents. 
IMPACT INDUCED VOLCANISM ON EARTH; SEARCHING FOR THE EVIDENCE. CRUSTAL MAGMA CHAMBERS. A. P. Jones, Department of Geological Sciences, University College London, Gower Street, London WC1E 6BT, UK.

Large impacts can generate vast proportions of melt, as in the $200 \mathrm{~km}$ Sudbury structure where estimates suggest $\sim 12-24 \times 10^{3} \mathrm{~km}^{3}$ of impact melt and transient crater depth similar to the thickness of the crust (Stoffler et al, 1994). Simple cooling models for the Sudbury Igneous Complex (SIC) require $\sim 10^{5}$ years to crystallise to subsolidus temperatures, after which continued slow cooling and hydrothermal activity may have persisted for much longer. Even if the impact did not penetrate the mantle, it is possible that a combination of central crater uplift and/or reduction of lithostatic load would have lead to partial melting of the mantle by decompression. This may explain the mixture of crustal and mantle signatures observed in the SIC geochemistry. The massive heat capacity of this volume of melt makes the survival of any early chilled units somewhat remarkable, and the range of crystal textures and rock fabrics is expected to be exactly the same as for normal slowly cooled or coarse grained igneous rocks.

The Earth's largest known impact structure $(300 \mathrm{~km}$ ?) is probably the eroded Vredfort Dome, located within the Witwatersrand gold belt. Just to the north lies the Earth's largest known igneous intrusion, the Bushveldt Complex, which has also been proposed as an impact structure and shocked quartz has been reported from one of its roof granites. These two structures coincide in position with the only anomaly in the most recent tomographic study of the south African craton which elsewhere (apart from bounding mobile belts) is characterised by a strong uniform base at $\sim 200-300 \mathrm{~km}$ depth (James et al, 2000). In a region with little igneous activity for very long periods of time either side of the Bushveldt event $(\sim 2 \mathrm{Ga})$, it seems an amazingly unlikely coincidence that it should have exactly the same age as the Vredefort Dome ( $\sim \mathrm{Ga})$. An earlier suggestion that they represent a multiple impact event, though still speculative, should perhaps be reexamined.

Mantle Impacts

We are currently evaluating the possibility that proportionally greater amounts of melt are generated during impacts into thermally active lithosphere, due primarily to decompression melting (Jones et al 1999). In this scenario, impact craters of Sudbury dimensions into oceanic lithosphere might generate oceanic plateau type magmatism, or large igneous provinces, as suggested by several authors. Preliminary computer simulations of a 2-D symmetrical hypervelocity impact (Autodyne) which appear to support the concept of decompression melting will be presented.

Mantle Shock Indicators?

Although there is no quartz in the mantle, there are some alternative candidate mineral indicators which might record evidence of shock, though mantle xenoliths are rarely erupted from oceanic plateaus, and the ambient high mantle thermal structure generally provides ample time for annealing. One possibility might be the occurence of high pressure phases in natural diamonds, like $\mathrm{Mg}$-wustite or perovskite; these are currently taken as evidence of mass transport from the lower mantle where these phases are stable. However, this explanation has always been a logistic problem; might they not instead record ancient impact events? Similar high-P phases occur in shocked meteorites, even the grain sizes ar comparable, perhaps mantle diamond serves as a coat of armour to record the mantle 
IMPACT INDUCED VOLCANISM ON EARTH: A. P. Jones

shock event. Similarly, some mantle diamonds record dramatic internal deformation which is of unkown origin; if these deformed diamonds record the passage of giant shock waves then their geographic distribution and great ages (often $>3.5 \mathrm{Ga}$ ) will be of potentially great significance.

Meteorite Relics In Flood Lavas?

Most continental flood basalts are clearly formed by plumes, but it is also possible that some are formed by giant impacts, as suggested for the near K-T aged Deccan traps, but what evidence is there? Geochemically and isotopically the melts generated by impact and decompression of the mantle would look like any other mantle melts. A candidate for re-examination must include the famous native iron -bearing rocks near the base of the $\sim \mathrm{K} / \mathrm{T}$ aged glass-rich Disko lavas in $\mathrm{W}$ Greenland. Here the minerals schreibersite, cohenite, native nickel-bearing iron (mostly 1-3\% Ni), troilite-graphite clots (all found in iron meteorites) and other sulphides occur in large lumps (up to 25 tons) rich in PGE's which require imaginative conventional explanations (especially as the irons are coarse grained but imbedded in silicate glass). Nearby continental sediments of exactly the same age preserve spectacular Ir-rich glassy spherulite beds with similar minerals plus quenched $\mathrm{Ni}$-spinel as inclusions (P.Claeys, E.Robin pers comm.1999). Texturally and in many other respects these irons closely resemble reheated iron meteorites, yet that original idea has been discounted almost since the day it was proposed, well over a century ago (Nordenskjold, 1872). Native iron lumps have recently been reported as a new high-T form (non-sulphide) of PGE-ore in the Siberian traps.

\section{References}

James D, VanDecar J, Fouch M, et al (2000) Abstract. Jt Meeting R Astron. Soc/ Geol Soc, London Feb 10-11 2000

Jones A.P., Price G.D. and Claeys P. (1999) Abstract. ESF Impact workshop, Bremerhaven April 15 $17,1999$.

Nordenskiold A E (1872) Geol. Mag. 9, 289-306, 355-368, 409-427, 449-463, 516-524.

Stoffler, D. Deutsch, A., A Vermann, et al. (1994) In Geological Society of America Sp. Pap, 293, ,303-318. 
GEOPHYSICAL INVESTIGATION OF THE LAKE BOSUMTWI IMPACT CRATER. T. KarP', B. Milkereit $^{1}$, P. Janle ${ }^{1}$, S. Bussat ${ }^{1}$, S. Danuor ${ }^{2}$, J. Pohl ${ }^{3}$, B. Scheu ${ }^{3}$, M. Froehler ${ }^{3}$, H. Berckhemer ${ }^{4}$, B. Baier ${ }^{4}$, G. Zacher $^{4}$, C. A. Scholz ${ }^{5}$ (Lake Bosumtwi Working Group), ('Institute for Geosciences, Dept. of Geophysics, University of Kiel, Otto-Hahn-Platz 1, 24118 Kiel, Germany, e-mail: tkarp@geophysik.uni-kiel.de, ${ }^{2}$ University of Kumasi, Dept. of Physics, University Post Office, Kumasi, Ghana, ${ }^{3}$ Institute of Geophysics, University of Munich, Theresienstrasse 41, 80333 München, Germany, ${ }^{4}$ Institute of Meteorology and Geophysics, University of Frankfurt a. M., Feldbergstr. 47, 60323 Frankfurt a. M., Germany, ${ }^{5}$ Department of Earth Sciences, Syracuse University, 219 Heroy Geology Laboratory, Syracuse, New York 13244, USA).

The Lake Bosumtwi Structure is one of the largest, youngest craters on Earth. It is located in Ghana and approximately $1 \mathrm{Ma}$ old. The crater has a rim diameter of $10 \mathrm{~km}$ and is very well preserved. The structure is associated wit the Ivory Coast tektites ([1]). Remote sensing and digital topography data indicate an outer ring structure of $20 \mathrm{~km}$ diameter. The crater is almost entirely filled by Lake Bosumtwi (depth up to $\sim 75 \mathrm{~m}$ ) and post-impact sediments of unknown thickness. Little is known about the deeper structure of the crater. Aeromagnetic surveys indicate the presence of magnetized bodies, probably suevitic impact breccias or impact melts in the central area of the lake ([2], [3]). In the fall of 1999 first gravity measurements were conducted on land. Refraction seismic data were acquired in cooperation with a reflection seismic survey of the University of Syracuse, USA, using the $R N$ Kilindi, a new portable, modular research catamaran. A new platform is constructed for future geophysical work as well as for further disciplines.

In October $1999 \mathrm{ca} .160$ gravity stations were measured on land around the lake and on the shore of the lake, using differential GPS for location and elevation determination. The gravity data show the expected minimum associated with the crater structure resulting from the water in the lake, the sedimentary filling of the lake, low density impact formations, brecciated and fragmented basement and the pronounced effect of the significant morphology of the crater structure, which has yet to be determined. Additional measurements will be carried out on the lake later this year.

Refraction and wide angle reflection seismic data were collected by three Ocean-Bottom-Hydrophones (OBH) on one profile across the lake. They show good signal penetration despite pronounced 'shallow gas curtains' within in the lake's margin. Refracted and reflected arrivals are recorded to an offset of more than $6 \mathrm{~km}$, and their pattern shows a complex subsurface structure. Initial interpretation of refraction data indicate low seismic velocities (less than $2 \mathrm{kms}^{-1}$ ) in the unconsolidated shallow sediments and high basement velocities (more than $6 \mathrm{kms}^{-1}$ ). Prominent steep and wide angle reflections are also visible although partly obscured by a strong bubble pulse

We will develop a model of the crater's subsurface structure (possible uplift, thickness and distribution of breccias, fragmentation zones etc.) based on the integration of gravity, magnetic and seismic data.

References:

[1] Koeberl C. et al. (1997), Geochimica et Cosmochimica Acta, 61, 1745-1772. [2] Jones et al. (1981), Geol. Soc. Am. Bull. 92, 342-349. [3] Pesonen et al. (1998) Abstracts with programs - GSA, 30, 190. 


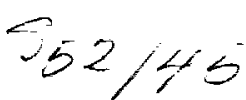

MASS EXTINCTIONS, CATASTROPHES AND ENVIRONMENTAL CHANGES. Gerta Keller, Geosciences Department, Princeton University, Princeton NJ 08544

Mass extinctions are invariably associated with major environmental changes and particularly changes in climate and sea level, which may be exacerbated by short-term catastrophes, such as extraterrestrial impacts or major volcanism. Examination of various mass extinction events in Earth's history, including the Eocene-Oligocene (E-O), Cretaceous-Tertiary (K-T) and Cenomanian-Turonian (C-T) transitions, reveal similar faunal patterns among planktic foraminifera in response to environmental changes. In each case the extinction pattern is progressive beginning with the elimination of large complex tropical and subtropical species followed by less specialized morphologies and eventually the takeover by ecologic generalists and opportunists at a time of minimum species diversity. Eventually, evolutionary diversification reverses this process beginning with the appearance of small simple morphotypes that give rise to successively more complex species and re-establishing stable high diversity faunal assemblages. Within this progressive mass extinction pattern, catastrophic events, or the attainment of threshold conditions, may hasten the demise of weakened species leading to patterns of abrupt or sometimes stepwise extinctions.

Mass extinctions, whether or not they are associated with short-term catastrophic events, are always linked to major long-term climate transitions. The clues to the demise of the planktic foraminifera lie in their ecologic requirements. The evolution, diversification and extinction of planktic foraminifera are generally associated with stratification of the water column, variations in the trophic structures, vertical temperature and density gradients and associated ecologic niche differentiation. Fundamentally important in maintaining planktic foraminiferal communities is stratification of the upper water column which is affected by seasonal changes in the thermocline that in turn affects nutrient availability, nutrient cycling, productivity, reproduction and predation (Mann and Lazier 1991). Diversity of planktic foraminifera is proportional to the watermass stratification and the highest diversity is within a stable stratified water column with normal salinity and nutrient waters and year-round temperature gradients that provide a variety of ecologic niches and a stable nutrient supply (Lipps 1979; Hallock et al. 1991).

The type of ecologic niches occupied can be inferred from the diversity and relative abundances of species, morphologies and biogeographic distributions. Complex morphotypes (e.g., keeled and highly ornamented species) generally occupy deeper oligotrophic environments, exist in assemblages with high species diversity, but generally low species abundances, have larger morphologies, and prefer low and middle latitude open marine environments. Simpler morphotypes (e.g., little surface ornamentation, thin test walls) generally occupy the surface mixed layers (above thermocline), or shallow waters with generally unstable and/or eutrophic conditions, have small test sizes, low species diversity and often high species abundances and predominate in higher latitudes, upwelling regions, shallow epicontinental seas and nearshore areas (Keller, 1996). At times of environmental extremes these regions are inhabited by ecological opportunists, such as the small thin-walled triserial Guembelitria, biserial Heterohelix and trochospiral Hedbergella morphotypes. During the K-T and C-T crises Guembelitria thrived in shallow marginal marine environments where they were most abundant in low to middle latitudes and probably tolerant of both salinity and oxygen variations. Heterohelix ranged more widely into high latitudes and thrived in well-stratified open marine settings with a welldeveloped oxygen minimum zone.

Stable isotope records, species richness and faunal abundances reveal the intricate relationships between marine ecosystems and climate-induced biotic stress that may lead to mass extinctions. At the C-T transition, biotic stress and extinctions are largely due to global cooling 
and a sea level regression which was followed by global warming, a sea level transgression and widespread ocean anoxia in low and middle latitudes. At the E-O transition, global cooling associated with Antarctic ice buildup was the primary cause for the extinctions, though multiple impact events during the late Eocene may have hastened the demise of some species.

The K-T mass extinction is unique in that at least two short-term events (one impact and one volcanic, or two impacts?) are superimposed upon the long-term late Maastrichtian climate record. The mass extinction began at the time of maximum global cooling during the late Maastrichtian which ended with a short-term warm event of $3-4^{\circ} \mathrm{C}$ between $200-400 \mathrm{ky}$ prior to the K-T boundary and may have been triggered by major volcanism or a pre-KT impact event (age of oldest of three spherule layers in new NE Mexico sections, Stinnesbeck et al., this vol.). This warm event was followed by $2-3^{\circ} \mathrm{C}$ cooling during the last $100 \mathrm{ky}$ of the Maastrichtian ( $\mathrm{Li}$ and Keller, 1998). Species extinctions accelerated during this final phase of cooling and reached a maximum at the K-T boundary with the extinction of all tropical and subtropical species coincident with an impact event (Ir anomaly). Extreme biotic stress continued through the early Danian with cool fluctuating climatic conditions, low $\partial^{13} \mathrm{C}$ values and eutrophic conditions delaying recovery of planktic foraminifera. This delayed recovery has long been an enigma, though recent studies suggest that the early Danian may have experienced an additional impact event in the middle part of the $P$. eugubina zone ( $\operatorname{lr}$ anomalies in Haiti, Bulgaria, Brazil, Guatemala, Mexico) and a major volcanic event at the end of the P. eugubina zone (see Adatte et al., this vol.).

\section{References cited:}

Hallock, P., Premoli-Silva, I. and Boersma, A., 1991. Similarities between planktonic and larger foraminiferal evolutionary trends through Paleogene paleoceanographic changes. Paleoceanography, Paleoclimatology, Paleoecology, v. 83:49-64.

Keller, G., 1996. The Cretaceous-Tertiary mass extinction in planktonic foraminifera: Biotic constraints for catastrophe theories. In: MacLeod, N. and Keller, G., eds. CretaceousTertiary mass extinctions, Biotic and Environmental changes, W. W. Norton \& Company, New York, p.49-84.

Li, L. and Keller, G., 1998. Abrupt deep-sea warming at the end of the Cretaceous. Geology 26, 995-998.

Lipps, J.H., 1979. Ecology and paleoecology of planktic foraminifera. In: Lipps, J.H. et al., eds., Foraminiferal Ecology and Paleoecology. Tulsa, Society of Economic Paleontologists and Mineralogists Short Course No. 6 (Houston), p. 62-104.

Mann, K.H. and Lazier, J.R.N., 1991. Dynamics of marine ecosystems, biological-physical interactions in the oceans. Blackwell Scientific Publications, Boston, 466p. 
COMPOSITION AND VARIABILITY OF THE CRYSTALLINE BASEMENT AT THE CHICXULUB TARGET SITE DEDUCED FROM GEOCHEMICAL-PETROGRAPHICAL DATA OF CLASTS IN IMPACTITES. B. Kettrup ${ }^{1}$ and A. Deutsch ${ }^{1}$, Inst. f. Planetologie, Wilhelm-Klemm-Str. 10, D-48149 Münster, Germany (kettrub@uni-muenster.de).

Introduction: The $65 \mathrm{Ma}$ old, $190 \cdot \mathrm{km}$ large Chicxulub structure, Yucatan peninsula, Mexico [1, refs. therein], is sealed under a thick post-impact sedimentary cover, and hence, considered as fresh and uneroded crater. Moreover, Chicxulub had a layered pre-impact target (shallow water, carbonatic-sulfatic platform sediments topping the crystalline basement). These facts, and the world-wide presence of in part pristine ejecta deposits makes the Chicxulub structure an ideal study object for all kinds of systematic studies related to impact cratering. However, while the postimpact sediments are the reason for the presumably excellent state of preservation, they also hinder access to this crater. Therefore, only geophysical methods, and drilling can help to expand our so far restricted knowledge on Chicxulub.

In general, the geochemical-petrographic investigation of lithic clasts in impact breccias as well as of melt lithologies is considered as promising approach to better constrain the target, and to determine the contribution of different pre-cursor lithologies to the impact melt. In the Chicxulub case, these rock fragments are recovered from breccias drilled by UNAM and PEMEX. Disregard further drilling (i.e., The Chicxulub Scientific Drilling Project - CSDP), these already existing core samples offer a very promising opportunity to get insight into the Yucatan basement (Maya terrane, e.g. [2]) postulated as pan-African in age [3].

Samples, Results: Here we present EMPA major element data of four crystalline clasts from the Chicxulub suevite of Y $-6 \mathrm{~N} 14$ and the impact melt breccia of Y-6 N16; corresponding Sr, Nd isotope data have been given elsewhere, e.g [4]. These breccias carry different types of target lithologies often described in this context are, besides Cretaceous platform sediments, granitic gneisses, (meta-)quartzites, quartz-mica schists, e.g. [5]. Both studied fragments of N14 (\#I and \#2) are less than $1 \mathrm{~cm}$ in diameter; they represent feldspar-rich granitic gneisses, (Table 1). The original texture of the gneiss is still preserved, the feldspars are weakly thermally annealed. Main phases are albite and anorthoclase in N14 frag. \#1, and oligoclase in N14 frag. \#2 (Figure 1). Subordinate quartz and Ti-rich phases are present only in N14 frag. \#l. From impact melt breccia Y-6 N16, two greyish, fine-grained crystalline rock fragments were selected for analysis. N16 frag. \#1 with $97 \mathrm{wt}-\% \mathrm{SiO}_{2}$ is a quartzite (Table 1 ), according to e.g. [5]. N16 frag. \#2, is strongly recrystallized due to high$T$ annealing (Figure 2). Geochemical data for this fragment indicate a rock of andesitic to trachytic composition as educt (Table 1). The modal composition of
N16 frag. \#2 is plagioclase, ranging from albite to labradorite, Na-sanidine and augite (Figure 3). The $\mathrm{fsp} / \mathrm{px}$ ratio is $11 / 2$. The mineral parageneses indicate maximal crystallization temperatures about $1350^{\circ} \mathrm{C}(1$ bar) and rapid quenching.

Table 1. Major element data for crystalline fragments in Y-6 N14 suevite and Y-6 N16 impact melt breccia.

\begin{tabular}{|l|cc|cc|}
\hline & \multicolumn{2}{|c|}{ Y-6 N14 } & \multicolumn{2}{c|}{ Y-6 N16 } \\
[wt-\%] & frag. \#1 & frag. \#2 & frag. \#1 & frag. \#2 \\
\hline $\mathrm{SiO}_{2}$ & 69.4 & 68.4 & 96.9 & 62.3 \\
$\mathrm{TiO}_{2}$ & 3.09 & n.d. & 0.08 & 0.08 \\
$\mathrm{Al}_{2} \mathrm{O}_{3}$ & 16.9 & 20.1 & 0.95 & 18.4 \\
$\mathrm{FeO}^{\mathrm{TOT}}$ & 0.13 & 0.18 & 0.69 & 2.02 \\
$\mathrm{MnO}$ & 0.01 & 0.09 & 0.03 & 0.08 \\
$\mathrm{MgO}$ & 0.01 & 0.08 & 0.30 & 2.22 \\
$\mathrm{CaO}$ & 1.28 & 1.59 & 0.51 & 6.45 \\
$\mathrm{Na}$ & 7.54 & 7.77 & 0.34 & 6.70 \\
$\mathrm{~K}_{2} \mathrm{O}$ & 1.63 & 1.99 & 0.09 & 0.85 \\
$\mathrm{P}_{2} \mathrm{O}_{5}$ & 0.02 & n.d. & 0.14 & 0.84 \\
\hline
\end{tabular}

Analytical technique: JEOL JXA- 8600 S (Inst. f.

Planetologie, normalized to $100 \mathrm{wt}-\%$; n.d.: not detected

Discussion: Together with the already published information on lithic clasts in Chicxulub impactites, our data point to a rather complex crystalline basement in the Yucatan region. We have already reached this conclusion from $\mathrm{O}, \mathrm{Sr}, \mathrm{Nd}$ isotope data of Chicxulub impact melt lithologies, where mafic to intermediate target lithologies are necessary to explain the data. Such rock types had not been described so far in the context of the Chicxulub target region. Frag. \#2 in Y-6 N16 supplies first information. We plan to recover additional target lithologies from UNAM suevitic breccias for this study. Applying the experience from systematic investigations of impact breccias of the Ries crater [e.g., 7], we will focus during this sampling on variations in the clast content. Such variations occur within one drill core, and between core samples from different wells, located at a different distance from the crater center, and in different sectors of the impact structure. Data for a more complete spectrum of basement rocks, and the different melt lithologies, known to occur in Chicxulub may yield the following information: (i) composition of the sub-crater basement, and variability of the lithologies with depth, and in radial directions; (ii) contributions of these different pre-cursor lithologies to the impact melt; (iii) mixing and homogenization of impact melts as part of the cratering process. And finally, (iv) a more detailed 
study of the clast population may help to enlighten the geological history of the Caribbean region in preCretaceous times.

References: [1] Hildebrandt A. et al. (1991) Geology, 19, 867-871; Morgan J. et al. (1997) Nature, 390, 472-476. [2] ${ }^{\circ}$ Patchett P. J. and Ruiz J. (1987) Contrib Mineral Petrol, 96, 523-528. [3] Krogh T.E. et al. (1993) EPSL, 119, 425-429. [4] Kettrup B. and Deutsch A. (1999) MAPS, 34, A62. [5] Sharpton V. L. et al. (1992) Nature, 359, 819-812. [6] ${ }^{\circ}[7]^{\circ}$ Engelhardt W. v. and Graup G. (1984) Geol. Rundschau 73, 447; Hörz F. et al. (1977) In Impact and Explosion Cratering (eds. D.J. Roddy et al.), 425-448 pp.; Pohl J. et al. (1977) In Impact and Explosion Cratering (eds. D.J. Roddy et al.), 343-404 pp.

Acknowledgements: This study is supported by grants DE401/13-1,3, and GRK 189/3 of the German Science Foundation.Y-6 samples are from P. Claeys (HU Berlin). We appreciate technical assistance by $F$. Bartschat, T. Grund, and U.Heitmann. The work is part of B.K's doctoral thesis.

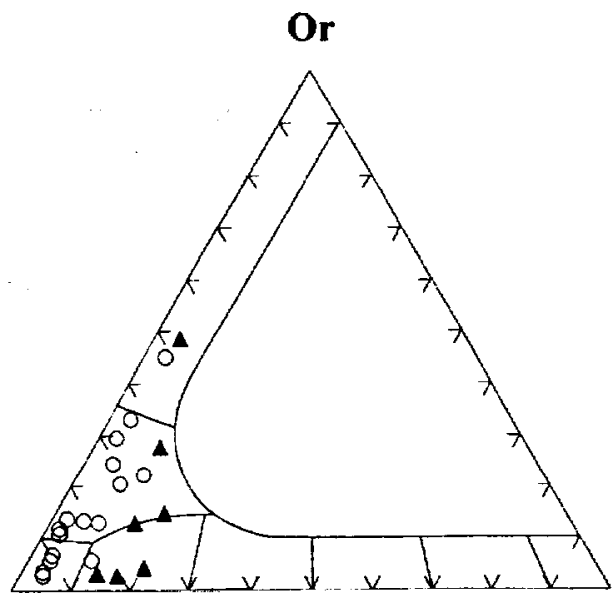

$\mathbf{A b}$

An

Figure 1 Ternary feldspar diagram of granitic gneiss fragments from $Y-6 N 14\left(T=900^{\circ} \mathrm{C} ; p=1\right.$ bar $)$. Open circles represent the feldspar composition of fragment \#1, solid triangles \#2.

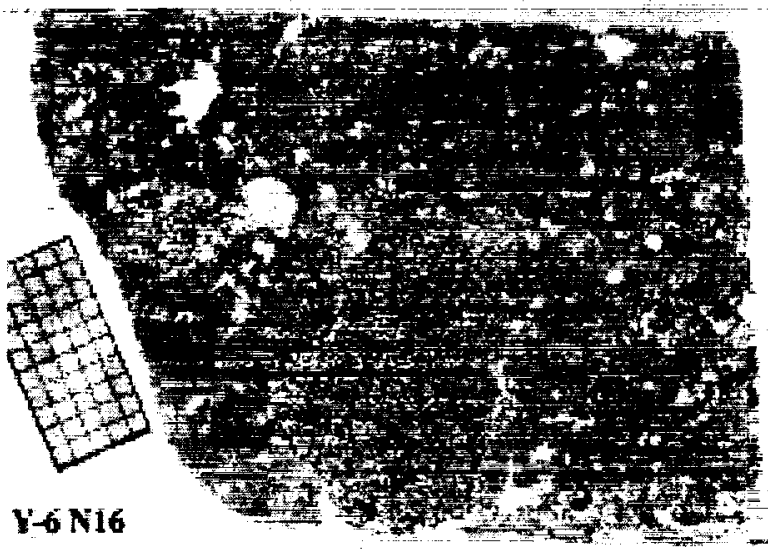

Figure 2 Photograph of fragment-rich impact melt breccia of Y-6 N16 (scale: $1 \mathrm{~cm}$ ). The big clast in the middle represents Y-6 N16 frag. \#2. Rims of the fragment are partly dissolved.

A.

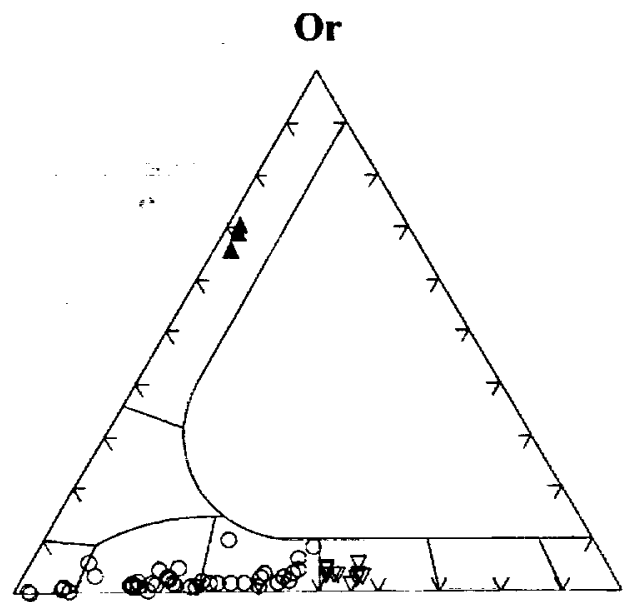

$\mathbf{A b}$

An

B.

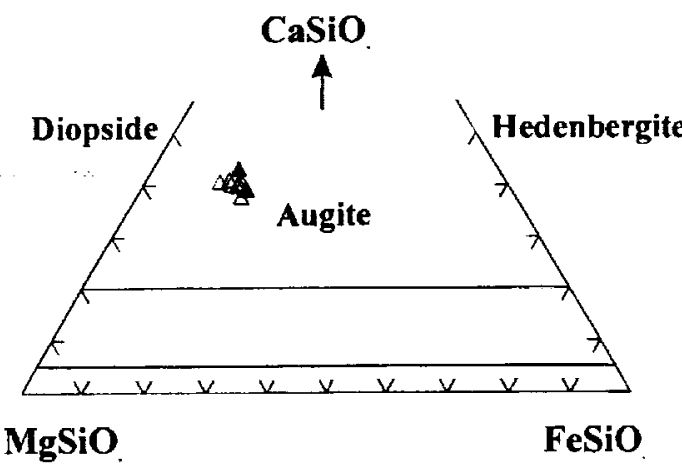

Figure $3 \mathrm{~A}$. Ternary feldspar diagram of crystalline fragment \#2 from $Y-6 N 16\left(T=900^{\circ} \mathrm{C} ; \mathrm{p}=1\right.$ bar $)$. Open circles represent a feldspar composition of $A b>50 \%$, solid triangles Or $>50 \%$, and open triangles $A n>50 \%$. B. Pyroxene composition in the system $\mathrm{CaSiO}_{3}$ $\mathrm{MgSiO}_{3}-\mathrm{FeSiO}_{3}$. Solid triangles represent augite with high $\mathrm{Al}_{2} \mathrm{O}_{3}$ of about $8 \mathrm{wt}-\%$. 
TRANSPORT AND ABRASION EXPERIMENTS WITH MICROMETEORITES - RELEVANCE FOR THE PRESERVATION OF EJECTA MATERIAL AND COSMIC DEBRIS IN THE GEOLOGICAL RECORD. D. Kettrup and $\bar{A}$. Deutsch, Inst. f. Planetologie (IfP), Univ. Münster, Wilhelm-Klemm-Str. 10, D-48149 Münster, Germany (<kettrupd@uni-muenster.de><deutsca@uni-muenster.de>).

Introduction: The total number of known layers in the terrestrial sedimentary record that contain ejecta material [1] or cosmic debris is quite low. This is especially remarkable if the rare occurrences of such materials are compared to (i) this part of the terrestrial crater population (close to 160; cf. <http://gdcinfo.agg.nrcan.gc.ca/toc.html?/crater/world_ craters.html>; [2]) which has been discovered so far, and (ii) the estimated mass of extraterrestrial input per year [e.g., 3]. For example, only three geological formations are known to contain fossil cosmic spherules, i.e., Eocene sediments [4], Jurassic hardgrounds [5] and the Mesoproterozoic Satakunta red bed formation, south-western Finland [6-8].

Several factors influence this disproportion between the events (i.e., impact, continuous and/or periodic flux of cosmic debris), and the traces of the events (i.e., tektites - microtektites, impact glass, shocked minerals, microcrystites, chemical markers [e.g., 9]; micrometeorites) in rocks and loose sediments. These are (i) biased searching - quite often fucussed to those materials (e.g., microfossils) that are expected, (ii) problems in detecting such materials due to extreme dilution by background sedimentation [e.g., 10], (iii) the generally unknown resistance of most ejecta material and/or cosmic debris to transport, weathering, diagenesis, and metamorphism. In this contribution, we report on transport simulation experiments with cosmic spherules.

Experimental set-up and results: We have constructed a simple device to simulate abrasion and cracking of micrometeorites during transportation processes in a fluviatile environment. This device consists of Plexiglas cylinders rotating at constant speed. The cylinders are filled with water, spec. pure quartz sand of a defined grain-size, and a certain number of cosmic spherules. These micrometeorites have been separated from a recent Greenland collection [see 11] and documented spherule by spherule using field-emission SEM imaging. Most of the micrometeorites belong to the barred olivine type, they all display perfect spherical forms devoid of holes or signs for weathering.

The containers were emptied in the first cycle after (a) $30 \mathrm{~min}$ (corresponding to a transport length of 790 $\mathrm{m})$, (b) $60 \mathrm{~min}(=1.583 \mathrm{~m})$, (c) $370 \mathrm{~min}(=9.764 \mathrm{~m})$, and (d) $735 \mathrm{~min}(=19.396 \mathrm{~m}$ ). After a careful cleaning, the surviving micrometeorites were recovered by magnetic methods.

In experiment (a), 5 spherules survived of 8 in the starting material. Numbers for the other runs are - (b) 4 survivors of 7, (c) 2 survivors of 8 , and (d) 3 survivors of 7 . The survivors were again documented with the FESEM, and used for a second experimental cycle with the following parameters (e) $1295 \mathrm{~min}(=34.174 \mathrm{~m})$, and (f) total time $2560 \mathrm{~min}(=67.557 \mathrm{~m}$ ). In (e), we detected 6 survivors in experiment (f) 6 micrometeorites out of 15 in the starting material.

The repeated inspection of the surface by FE-SEM indicate that abrasion plays an only minor role as ultimate cause for the destruction of the spherules. More of interest is the formation of holes, from which cracks lead into the spherules. They seem to break along these cracks, and having similar grain size as the quartz sand media, are easily destroyed.

Indications and outlook: The micrometeorites are apparently highly resistant against fluviatile transport. Sedimentological investigations have already shown [8] that an early cementation of clastic sediments by authigenic quartz is fundamental for the conservation of these delicate materials (- they have a glassy matrix [7] -) in clastic sediments. We assume that similar to micrometeorites, specific ejecta materials (e.g., melt droplets $+/$ - spinels) can survive sedimentological processes. Specific search strategies have to be developed to find both classes of materials, for example, routine screening of the non-organic content in samples prepared for micropaleontological purposes.

Acknowledgements. This work is supported by DFG grant De 401/16-1. We thank A. Bischoff for donating the Greenland sample. Skilful technical support was provided by F. Bartschat, Th. Grund, and U. Heitmann (IfP).

References: [1] Grieve R. A. F. (1997) Paleogeo. Paleoclimat. Paleoecol. 132, 5; [2] Grieve R. A. F. and Shoemaker E. M. (1994) In Hazards due to comets and asteroids (ed. T. Gehrels), Univ. of Arizona Press, 417-462pp. [3] Taylor S. et al. (1998) Nature 392, 899; [4] Taylor S. and Brownlee D. E. (1991) Meteoritics 26, 203; [5] C. Jéhanno et al. (1988) PLPSci. Conf. 18th, 623; [6] E. Marttila (1969) Lic. Phil. thesis, Univ. of Turku; [7] A. Deutsch et al. (1998) Nature 395, 146; [8] D. Kettrup et al. (2000) LPSC. XXXI, Abstract \#1350; [9] Kyte F. T. and Bohor B. F. (1995) GCA 59, 4967; Margolis S. et al. (1991) Science 251, 1594; Robin E. et al. (1992) EPSL 108, 181; Smit J. and Kyte F.T. (1984) Nature 310, 403; [10] Schmitz B. et al. (1994) Geol. Mag. 131, 361367; [11] Beckerling W. and Bischoff A. (1995) Planet. Space Sci. 43, 435 
SPATIAL PATTERNS OF THE KT EVENT. W. Kiessling ${ }^{1}$ and P. Claeys, Institut fuir Mineralogie, Museum für Naturkunde, Invalidenstr. 43, D-10115 Berlin, Germany; ${ }^{1}$ wolfgang.kiessling@rz.hu-berlin.de.

We have created a comprehensive database on the Cretaceous-Tertiary (KT) boundary. The database (KTbase) is designed to evaluate spatial patterns in data that are important to constrain the causes and mechanisms of the KT event. KTbase is a localitybased relational database that is linked to a $65 \mathrm{Ma}$ plate tectonic reconstruction and analyzed with GIS (geographic information system) software. KTbase contains paleontological, sedimentological, mineralogical, and geochemical data of currently $280 \mathrm{KT}$ sites.

Although still incomplete, KTbase can already be used to summarize global aspects of the ecological catastrophe coincident with the KT boundary and suggest some regional patterns related to the impact of an extraterrestrial body in the Gulf of Mexico. The global distribution of impact ejecta is also documented (Claeys et al., this volume).

The often cited regression at or just prior to the KT boundary [1] does not appear a globally significant event. KTbase reveals that an eustatic low is inferred in some $67 \%$ of all shallow-marine KT sections, while in $33 \%$ of the sections no evidence for a regression is evident or even a sea level rise is suggested (e.g. [2]). The most significant sea-level falls and clastic "lowstand" wedges are reported around the Gulf of Mexico area [1,3], where strong evidence exists for reworking by megatsunamis [4] or sediment gravity flows due to the Chicxulub impact [5].

The pelagic ecosystem collapse at the $\overline{\mathrm{KT}}$ boundary is exemplified by a strong decline in $\delta^{13} \mathrm{C}$ in pelagic carbonates [6]) and reduced accumulations of nutrient-type trace elements [7]. The global distribution of the $8^{13} \mathrm{C}$ event is confirmed by $\mathrm{KTb}$ ase. $\mathrm{Al}$ though less pronounced in northern high latitudes, the drop in $\delta^{13} \mathrm{C}$ is as significant in southern high latitudes as it is in low latitudes. This indicates that the bioproductivity collapse was severe in most of the Cretaceous oceans.

Global patterns in paleontological data are more difficult to achieve and KTbase is currently only able to detail the spatial patterns of a few marine invertebrate groups. However, a compilation of species level extinction data and their critical evaluation is possible (Table 1). KTbase suggests very high extinction rates for a variety of marine invertebrate fossil groups such as calcareous nannoplankton, planktonic foraminifera, larger benthic foraminifera, corals, ammonites, belemnites, bryozoans, brachiopods, and echinoderms.
But only for few of those groups, it is likely that the values reflect the real situation. The major shortcomings in the dataset of macro-invertebrates are attributed to regionally confined analyses (e.g. brachiopods and bryozoans) and problematic taxonomic concepts (e.g. corals).

The best paleontological data that can be used to unravel the environmental perturbations related to the $\mathrm{KT}$ event are given by the calcareous nannoplankton. KTbase contains species-counts for $40 \mathrm{KT}$ sections and summarizes data on three time slices around the KT boundary. The global pattern of calcisphere abundance in the first post-impact time slice (nannoplankton zone NP1) indicates a zone of strongly enhanced concentrations from the Kerguelen Plateau and the South Atlantic to northern Africa and southern Europe and further to Gulf Coast region and the northern mid Pacific (Fig. 1). The NP1 calcisphere bloom appears to be especially significant in midlatitude regions, whereas is less pronounced in the tropics and absent or delayed in the Antarctic, the Indian Ocean and Northern Europe. This example demonstrates the potential of KTbase to detect global patterns in ecological signals and extinction patterns related to the KT event. Documenting these patterns is capital to understand the biological response to the KT perturbation, and the observed selectivity of the mass extinction.

Regionally different extinction and recovery patterns were also noted for macro-invertebrate fossil groups. Gulf Coast molluscan assemblages are characterized by a rapid expansion and decline of "bloom taxa" and have lower proportions of invaders in the early recovery phase as compared to other regions [8]. There appears to be no ecological selectivity of bivalve extinction as revealed from Gulf Coast assemblages [9] or global databases that strongly refer to Gulf Coast assemblages [10]. This contrasts strongly the selective bivalve extinctions in Denmark [11]. It was also demonstrated that, although endemism per se does not enhance the extinction risk of echinoids, endemic echinoids in North America are more prone to extinction than endemic species in other regions [12]. These observations may well be related to enhanced ecosystem devastation and delayed recovery close to the Chicxulub impact site. A global database on Phanerozoic reefs [10] corroborates this view. While reef growth is apparently not affected in northern Europe and rapidly recovers in southern Europe and northern 
Africa, no Danian reefs are known from the Gulf Coast region.

The conclusions presented here must be viewed as preliminary, but clearly demonstrate the potential of a comprehensive geographic database in the discussion of the KT problems. So far, although a huge amount of data exists on the Late Cretaceous biotic crisis, there were few attemps to compile and use a multidisciplinary database to address the KT question. We encourage colleagues from all disciplines to contribute to KTbase. We are convinced that when more complete, KTbase can be used as a tool to test several of the predictions made by the impact-extinction scenario, such as selectivity of extinction, or regional patterns of biotic change.

References: [1] Keller, G. and Stinnesbeck, W. (1996) in Cretaceous-Tertiary Mass Exctinctions, eds. MacLeod, N. and Keller, G. (Norton, New York), 415-449. [2] Pardo, A. et al. (1999) Palaeo3, 154, 247-273. [3] Donovan, A. D. et al. (1988) SEPM Spec. Pub., 42, 299-308. [4] Smit, J. et al. (1996) GSA Spec. Paper, 307, 151-182. [5] Bohor, B. F. (1996) GSA Spec. Paper, 307, 183-196. [6] D'Hondt, S. et al. (1998) Science 282, 276-279. [7] Zachos, J. C. et al. (1989) Nature 337, 61-64. [8] Jablonski, D. (1998) Science 279, 1327-1330. [9] McClure, M. and Bohonak, A. J. (1995) J. Evol. Biol., 8, 779-794. [7] Jablonski, D. and Raup, D. M. (1995) Science 268, 389-391. [10] Heinberg, C. (1999) Palaeo3, 154, 87106. [11] Smith, A. B. and Jeffery, C. H. (1998) Nature 392, 69-71. [12] Kiessling, W. et al. (1999)
Table 1: Species level extinction data in KTbase and their reliability.

\begin{tabular}{|c|c|c|c|}
\hline & $\begin{array}{c}\text { Species level } \\
\text { extinction rate } \\
(\%)\end{array}$ & $\begin{array}{l}\text { Localities with } \\
\text { data }\end{array}$ & Reliability \\
\hline $\begin{array}{l}\text { Calcareous Nanno- } \\
\text { plankton }\end{array}$ & 86 & 87 & Good \\
\hline $\begin{array}{l}\text { Siliceous Phyto- } \\
\text { plankton }\end{array}$ & 15 & 5 & Poor \\
\hline $\begin{array}{l}\text { Planktonic Fora- } \\
\text { minifera }\end{array}$ & 90 & 112 & Good \\
\hline Radiolarlans & 8 & 13 & Moderate \\
\hline $\begin{array}{l}\text { Larger Foraminifera } \\
\text { (shallow) }\end{array}$ & $70^{*}$ & 44 & Poor \\
\hline $\begin{array}{l}\text { Benthonic Foraminif- } \\
\text { era (intermediate) }\end{array}$ & 11 & 15 & Good \\
\hline $\begin{array}{l}\text { Benthonic Foraminif- } \\
\text { era (deep) }\end{array}$ & 14 & 20 & Good \\
\hline Ostracodes & $50^{*}$ & 44 & Moderate \\
\hline Sponges & $50^{\circ}$ & $9^{\prime}$ & Poor \\
\hline Corals & 98 & 27 & Poor \\
\hline Bivalves & 80 & 73 & Good \\
\hline Ammonites & 100 & 36 & Good \\
\hline Bélemnites & 100 & 18 & Moderate \\
\hline Bryozoans & 74 & $18^{2}$ & Moderate \\
\hline Brachlopods & 70 & $13^{2}$ & Moderate \\
\hline Echinoids & 60 & 41 & Moderate \\
\hline Crinoids & 56 & 8 & Poor \\
\hline Asteroids & 82 & 4 & Poor \\
\hline
\end{tabular}

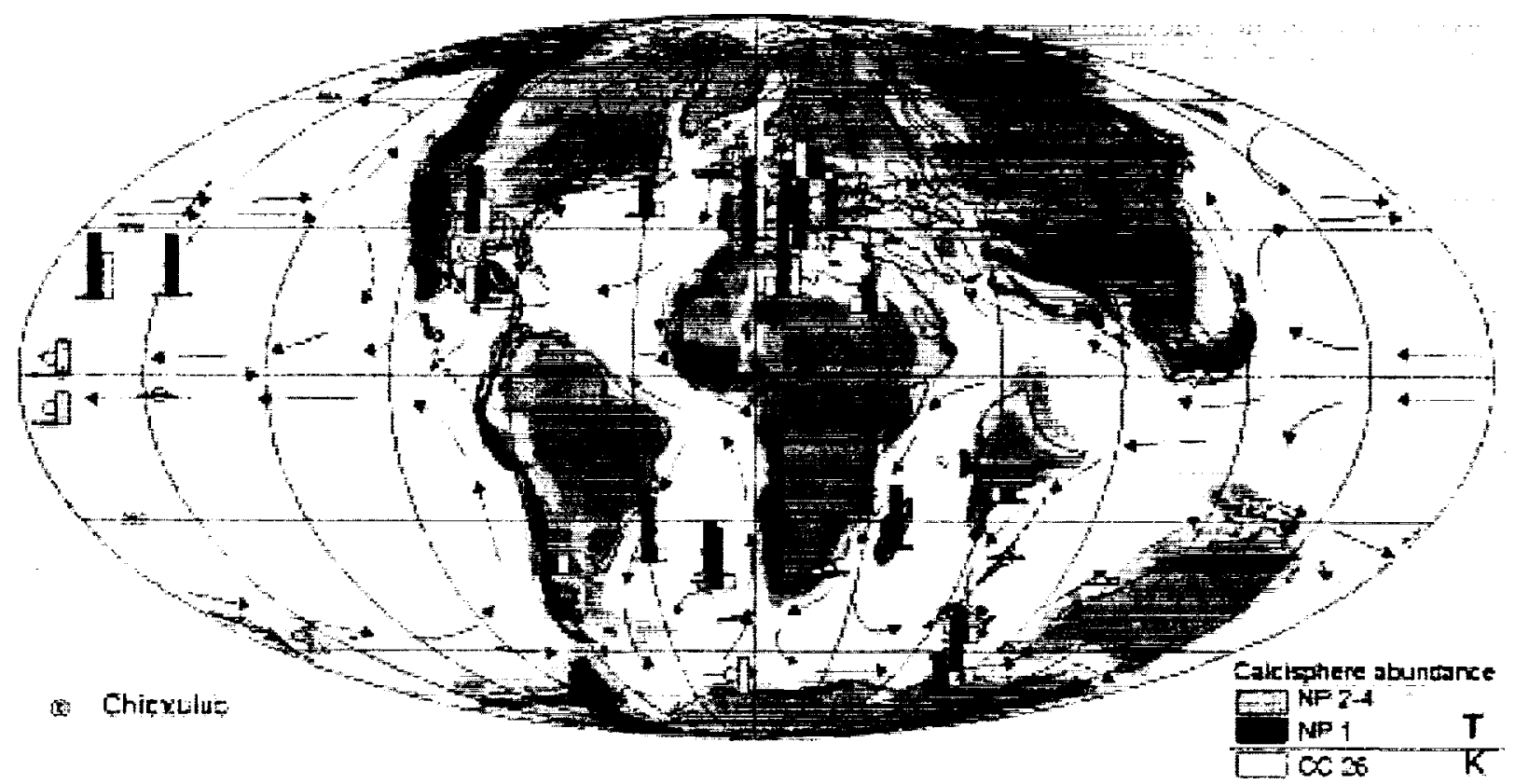

AAPG Fig. 1: Location, timing and relative magnitude of calcisphere blooms at the KT boundary 
EVIDENCE CONFIRMING METORITIC IMPACT AT WETUMPKA CRATER, ALABAMA, USA. D. T. King, Jr ${ }^{1}$, Thornton L. Neathery ${ }^{2}$, Lucille W. Petruny ${ }^{3}$, Christian Koeber ${ }^{4}$, and Willis E. Hames ${ }^{1} .{ }^{1}$ Dept. Geology, Auburn University, Auburn, AL 36849-5305 USA [kingdat@auburn.edu], ${ }^{2}$ Neathery and Associates, $1212-\mathrm{H} 15^{\text {th }}$ St. East, Tuscaloosa, AL 35404 USA, ${ }^{3}$ Dept. Curric. and Teaching, Auburn University, Auburn, AL 36849 USA, ${ }^{4}$ Institute of Geochemistry, University of Vienna, Althanstrasse 14, A-1090 Vienna, Austria.

Introduction: Wetumpka impact crater, located in Elmore County, Alabama, USA (N32 $31.5^{\prime}$, W86 ${ }^{\circ}$ $\left.10.5^{\prime}\right)$, is a prominent $6.5 \mathrm{~km}$ diameter semi-circular, rimmed structure, which formed in a target consisting of essentially unconsolidated sedimentary units overlying crystalline basement rock. At time of formation, estimated at 80 to 83 m.y. ago, this target was covered by up to $100 \mathrm{~m}$ of seawater as the area was part of a Late Cretaceous continental shelf [1,2]. Crater shape (semi-circular, open on southwest quadrant) suggests oblique impact [3] on a southwesterly trajectory [2]. Wetumpka has total gravity relief of $10 \mathrm{mGal} \mathrm{[4]} \mathrm{and}$ maximum magnetic relief of 0.015 Gauss [5].

Target stratigraphy: In this region, three soft Upper Cretaceous units lie unconformably upon crystalline pre-Cretaceous Appalachain bedrock. In age order, they are: Tuscaloosa Group $(60 \mathrm{~m})$; Eutaw Formation (30 m); and Mooreville Chalk (30 m) [3].

Surface geology: Surficial crater geology consists of two main terraines: (1) a heavily weathered, semicircular rim composed of Appalachian piedmont bedrock, which has up to $87 \mathrm{~m}$ modern relief, and (2) a highly dissected crater floor composed of contiguous tracts of slightly to highly disturbed target strata (consisting of Tuscaloosa Group and minor but significant irregularly shaped tracts of Eutaw Formation and Mooreville Chalk) [3]. Only one, small outcrop of impactite facies, which encompasses an area of a few hundred square meters, occurs within this crater. This centrally located outcrop coincides with a topographic high, which may represent Wetumpka's rebound peak.

Subsurface geology: All three stratigraphic units mentioned previously plus crystalline bedrock were involved in this impact event and contributed clastic material to Wetumpka's subsurface impactoclastic crater-filling unit [6]. Core drilling at Wetumpka's crater center reveals that disturbed target strata are only $64 \mathrm{~m}$ thick and that over $130 \mathrm{~m}$ of impactite facies occur below that level [6]. In Wetumpka's subsurface crater-filling unit, impactite facies, consisting of impactite sands and monomict and polymict impact breccias, are intercalated with 1 to $5 \mathrm{~m}$-thick blocks of target strata and crystalline basement [6].

Petrography: Polymict breccias are comprised of crystalline bedrock clasts and cataclastic matrix. In thin section, cataclastic matrix contains fine-sand sized shocked-quartz grains. These grains display two sets of PDFs, which appear to indicate shock pressures toward the lower end of the 8 to $25 \mathrm{GPa}$ range. We are currently measuring crystallographic orientation of all quartz PDFs to better understand shock-pressure effects at Wetumpka. Impact-related planar microstructures are also present in plagioclase and micas within polymict breccia matrix.

Geochemistry: Gamma-gamma coincidence spectrometry of breccia matrix shows iridium content as high as $0.21 \mathrm{ppb}$, suggesting a meteoritic component of approximately $0.04 \%$.

Conclusion: Owing to initial studies done over 25 yr ago [3], Wetumpka impact structure has been described as a "probable impact crater" on some crater lists. Now, we are reporting shocked quartz, iridium, and impactites, which provide key evidence confirming meteoritic impact at Wetumpka.

References: [1] King, Jr. D. T. et al. (1997) Alabama Geol. Soc. Guidebk., 34c, 25-56. [2] King, Jr. D. T. and Neathery T. L. (1998) Amer. Assoc. Petrol. Geol. Ann. Conv. Abst., 7, 358a-f. [3] Neathery T. L. et al. (1976) Geol. Soc. Amer. Bull., 87, 567-573. [4] Wolf L. W. et al. (1997) Alabama Geol. Soc. Guidebk., 34c, 57-68. [5] Neathery T. L. et al. (1997) Alabama Geol. Soc. Guidebk., 34c, 1-23. [6] King, Jr. D. T. et al. (1999) LPS XXX, 1634.

Acknowledgments: Drilling at Wetumpka was an in-kind gift to Auburn University from Vulcan Materials Company, Birmingham, Alabama, USA. 
ORBITAL CYCLICITIES ABOVE AND BELOW THE CRETACEOUS-TERTIARY BOUNDARY, UMBRIA-MARCHE REGION, ITALY. D. T. King, Jr. ${ }^{1}$, L. W. Petruny ${ }^{\mathrm{I}}$, M. R. Rampino ${ }^{2}$, A. Prokoph ${ }^{3}$, K. Pope $^{4}$, A. G. Fischer ${ }^{5}$, and A. Montanari ${ }^{6}$, and A. C. Ocampo ${ }^{7}$ Dept. of Geology, Auburn University, Auburn, AL 36849-5305 USA [kingdat@auburn.edu], ${ }^{2}$ Earth \& Environmental Science Program, New York University, 100 Washington Square East, New York, NY 10003, USA, ${ }^{3}$ Dept. of Earth Sciences, University of Ottawa, 365 Nicholas St., Ottawa, Ontario, K1N 6N5, Canada, ${ }^{4}$ Geo Eco Arc Research, 3220 N. Street NW, Washington, DC 20007 USA, ${ }^{5}$ Dept. of Earth Science, University of Southern California, Los Angeles, CA 90089 USA, ${ }^{6}$ Osservatorio Geologico di Coldigioco, Frontale Di Aprio, Italy, ${ }^{7}$ Jet Propulsion Laboratory, Pasadena, CA 91109 USA.

Introduction: In the Umbria-Marche region of central Italy, the deep basinal carbonate Scaglia Rossa Formation contains an important sequence of Cretaceous-Tertiary strata including a detailed paleomagnetic record [1] and the distal impactoclastic Cretaceous-Tertiary boundary clay layer [2]. In addition to this significant paleomagnetic and impactoclastic record, the Scaglia Rossa also contains potentially important stratigraphic evidence of relatively long-term oceanic and atmospheric consequences of the Cretaceous-Tertiary bolide catastrophe, which we will describe for the first time herein.

Stratigraphy: The Scaglia Rossa Formation of central Italy, Turonian-Ypresian [3], is a thinly bedded, pelagic carbonate unit, measuring up to $350 \mathrm{~m}$ thick, which displays many sizeable intervals of rhythmically layered pelagic biomicritic limestones. Scaglia Rossa limestone strata are separated by thin clay layers, which are mostly derived from beddingparallel pressure solution effects [4], and such effects reflect subtle variations in biogenic carbonate versus siliciclastic (i.e., silt plus clay) composition. Each relatively thin clay and its overlying limestone layer form a distinctive bedding couplet [4,5]. These bedding couplets comprise the whole of such Scaglia Rossa pelagic intervals except where turbiditic calcarentites and calcirudites locally punctuate the section $[1,3]$. In the region studied, the CretaceousTertiary boundary is found within such a thick interval of rhythmic clay-limestone bedding.

Field Methods: For this study, we examined several Scaglia Rossa sections, including two near Gubbio (Gola di Bottaccione and Contessa), two near Furlo (Pietralata and Bar Gostoli), and two at Monte Conero near Ancona (Fonte d'Olio and Cava delle Fornaci). Of these, the well-known and well-exposed sections along the Contessa Highway [1,3] and at Pietralata [1] (29 $\mathrm{km}$ north of Contessa) were selected for statistical analysis because of their quality and longer stratigraphic span. In the field, teams of two to four operators measured thickness of bedding couplets (by measuring both clay and limestone thickness in each couplet) over a stratigraphic interval of 8 to $9 \mathrm{~m}$, which encompassed the Cretaceous-Tertiary boundary. Bedding couplets were numbered upon the outcrop and thus consistently in each operator's notes. Separate measurements upon every couplet were made by each operator, but the operators conferred on the outcrop so as to eliminate errors that might be introduced from measuring at discontinuous, beddingparallel stylolites (i.e., stratigraphic "weak surfaces" [5]), which do not reflect original bedding surfaces. Data from all operators were averaged for each couplet prior to commencing our statistical analysis.

Statistical analysis: In our statistical analysis, continuous wavelet transforms were used to characterize thicknesses of bedding couplets (i.e., clay plus overlying limestone) as well as total thicknesses for sections Contessa and Pietralata. At Contessa, bedding rhythms are grouped in bundles of 8 to 10,25 to 30 , and about 90 couplets, and thus cycles of $1.1 \mathrm{~m}$, $2.3 \mathrm{~m}$, and $4.1 \mathrm{~m}$ were detected. Contessa's dominant cycle length reduces abruptly from $2.3 \mathrm{~m}$ to $1.1 \mathrm{~m}$ at the Cretaceous-Tertiary boundary. Contessa's cycles are bundled in sets of 4 to 5 within Maastrichtian and 9 within Danian. At Pietralata, cyclicity is less well developed than at Contessa. However, a similar weak cyclicity is present and ranges from $0.7 \mathrm{~m}$ to $1.3 \mathrm{~m}$ (from Maastrichtian to Danian), $2.3 \mathrm{~m}$ (within Maastrichtian), and about $4 \mathrm{~m}$. Pietralata's cycles are bundled in groups of 4 to 5 within Maastrichtian, and 7 within Danian.

Sedimentation rate: At Contessa, the Cretaceous portion of Chron 29R (spanning $350 \mathrm{ka}$ ) is $4.1 \mathrm{~m}$ thick [6], giving an apparent sedimentation rate of 11.7 $\mathrm{mm} / \mathrm{ka}$. Tertiary portion of C29R (spanning $230 \mathrm{ka}$ ) is $0.7 \mathrm{~m}$ thick at Contessa [6], thus giving an apparent sedimentation rate of $3.0 \mathrm{~mm} / \mathrm{ka}$. At Pietralata, the Cretaceous portion of C29R is $3.65 \mathrm{~m}$ thick [6], thus giving an apparent sedimentation rate of $10.4 \mathrm{~mm} / \mathrm{ka}$, and the Tertiary portion of C29R is $0.35 \mathrm{~m}$ thick [6], giving a rate of $1.5 \mathrm{~mm} / \mathrm{ka}$. Lower sedimentation rate at Pietralata may account for evident weaker cyclicity as noted above.

Discussion: Few studies have been able to establish good stratigraphic evidence for long-term climatic effects of the Cretaceous-Tertiary bolide catastrophe [7]. DSDP magnetic susceptibility records from sites in the South Atlantic seem to indicate an "oscillatory marine response" to the impact event, including "enhance sensitivity of the oceans to orbital forcing for almost I m.y." [8]. Statistical analysis of carbonate content within poorly bedded, hemipelagic limestonemarl successions that span the Cretaceous-Tertiary boundary sites in Spain established only that "orbital forcing was operative" during late Maastrichtian through early Paleocene [9].

We agree that orbital forcing was operative during deposition of Italian Cretaceous-Tertiary strata that we 
studied, and further conclude from our wavelettransform analysis that an apparently significant change in bedding pattern (i.e., abrupt change in dominant cycle length) across the Cretaceous-Tertiary boundary constitutes evidence of a potentially significant change in style of orbital forcing. Whereas continued study of this problem is indicated, we feel that our results are consistent with a probable sudden shift from precession-eccentricity dominated cyclicity to obliquity dominated cycles on the order of one million years, which has been proposed previously for the Cretaceous-Tertiary boundary [10].

References: [1] Alvarez W. A. and Lowrie W. (1984) Geol. Soc. Ämer. Bull., 95, 324-336. [2] Alvarez L. W. et al. (1980) Science, 208, 1095-1108. [3] Montanari A. et al. (1989) SEPM Spec. Publ. 44, 379-399. [4] Alvarez W. (1985) Jour. Sed. Petrol., 55, 720-734. [5] Schwarzacher W. and Fischer A. G. (1992) Cyclic and event stratification, 536p. [6] Chauvis H. and Le Rousseau J. (1996) Ecole de Mines de Paris thesis, 210p. [7] Crowley T. J. and North G. R. (1991) Paleoclimatology, 349p. [8] D'Hondt S. et al. (1996) Geology, 24, 611-614. [9] ten Kate W. G. H. Z. and Sprenger A. (1993) Sedimentary Geology, 87, 69-101. [10] Pope K. et al. (1997) Geol. Soc. Amer. Ann. Mtg. Abst., 29(6), A212.

Acknowledgements: We thank $M$. Petch and J. Demick for field assistance, and the Planetary Society for organizing the 1996 expedition where these field data were collected. 
MORE THAN 500M THICK K/T BOUNDARY SEQUENCE; CACARAJICARA FORMATION, WESTERN CUBA. IMPACT RELATED GIANT FLOW DEPOSIT S. Kiyokawa ${ }^{\mathrm{I}}$, R. Tada ${ }^{2}$, T. Oji ${ }^{2}$, E. Tajika ${ }^{2}$, Y. Nakano ${ }^{2}, \mathrm{~K}$. Goto ${ }^{2}$, S. Yamamoto ${ }^{2}$, H. Takayama $^{2}$, K.Toyoda ${ }^{3}$, R. Rojas ${ }^{4}$, D. Garcia ${ }^{4}$, M.A. Iturralde-Vinent ${ }^{4}$, and T. Matsui ${ }^{2}$, ('National Science Museum, Tokyo, 3-23-1 Hyakunin-cho, Shinjuku-ku, Tokyo, 169-0073, Japan, kiyokawa@kahaku.go.jp; ${ }^{2}$ Univ. of Tokyo, ryuji@geol.s.u-tokyo.ac.jp; ${ }^{3}$ Hokkaido Univ; ${ }^{4}$ National Science Museum, Cuba)

Introduction: The KT boundary sequence has been found with the Tsunami sequence and the fireball layer around the Yucatan Peninsula [1]. However, because the Yucatan Peninsula is covered with thick Tertiary carbonate sequence proximal evidence of the impact related sequence had been reported at a few places, like Belize. The western Cuba preserves a thick KT boundary sequence comprising Cretaceous to Paleogene sedimentary units [2][3][4]. These sequence was exposed as a result of arc-continent collision of Cretaceous Cuban arc and North America. Based on the plate reconstruction, western Cuba was situated less than $400 \mathrm{~km}$ to the south east of the Chicxulub impact crater of the Yucatan peninsula during the late Cretaceous time [5][6]. Thus the KT boundary of western Cuba may preserve proximal evidence of geological processes related to the impact. Here, we describe the evidence of $\mathrm{KT}$ boundary origin for a more than $500 \mathrm{~m}$ thick event deposit of the Cacarajicara Formation in western Cuba, which is the thickest KT boundary formation in the world.

Tectonic setting of the western Cuba: According to a recent study, western Cuba is tectonically divided into three belts; Los Organos, Rosario and La habana (Bahia Honda to Matanzas) belts (Fig. 1) [4]. Each belt is composed of continental shelf to oceanic slope and deep-sea sediments sediments. Oceanic crustal material, such as pillow basalt and high grade metabasite, also preserved in these belts which have been deformed by Oligocene strike-slip deformations. All of these sequences were truncated by the left-lateral Pinaer Fault [7][8]. Based on the stratigraphic and fossil fauna relationships, Los Organos and Rosario belts had been situated near the Yucatan block (North American Craton) during Jurassic time [7][8].

The Cacarajicara Formation is situated within the south subcomplex of the Rosario belt which represents a more distal facies than that of the Los Organos belt during upper Cretaceous time [8][10][11]. It unconformably overlies the upper Cretaceous deep marine sandstone-mudstone alternation. The Cacarajicara Formation is distributed over an area more than one hundred kirometer long and a few hundred meters wide. It is situated at the top-to-the north northwest fold-thrusted Rosario belt [8][10][11]. A continuous section of at least $500 \mathrm{~m}$ thick sediments, that is situated in the southeast limb of synclinal syncline, is exposed $15 \mathrm{~km}$ to the north of Soroa. Bedding dip decreased upward from $80^{\circ}$ to $30^{\circ}$ the northwest.

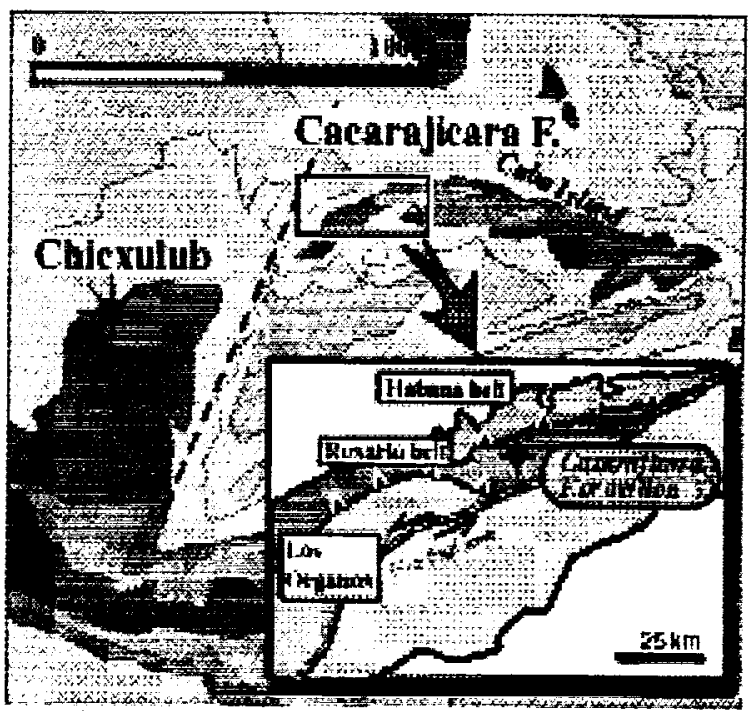

fig.1 Simplified geologic map

Stratigraphy: The Cacarajicara Formation is characterized by a upward-fining carbonate clastic sequence which is subdivided into two members. The Lower breccia member is approximately $150 \mathrm{~m}$ thick and is represented by grain-supported boulder breccia. This member disconformably overlies the middle Cretaceous Poriel Formation which is composed of carbonate-rich sandstone-shale alternations formed by a distal sequence of gravity flow. Rock components of the breccia include micritic limestone, foraminiferal limestone. rudist-bearing shallow water limestone, banded radiolarian chert and radiolarian-bearing black chert. We conducted identification, counting, and diameter measurement of the breccia. Based on diameter measurement, two modes of breccia size are identified which are grouped into two classes. The first group is pebble size class which consists of breccia with less than 20 $\mathrm{cm}$ in diameter. The second group is cobble-boulder size class which occasionally contains 1-3 m oblateshape breccia. The pebble size class is composed of more than $90 \%$ carbonate breccia and less than $10 \%$ volcanics and metamorphic rock fragment. The cobbleboulder size class contains oblate-shape radiolarian chert, black chert and chert-micritic limestone boulder which is similar to those of the underlying Middle 
Cretaceous sequence (Poriel Formation). The orientation of imbricated oblate breccia suggests that the paleoflow direction of this member is from north to south, if there was no rotation of the belt.

The breccia of this member has less than $1 \%$ of matrix that is dark brown in color. The dark brown matrix is composed mainly of siltstone that contains small amount of foraminifers, carbonate clast, volcaniclastics and spherule-like grains. A few spherule grains were extracted from the matrix using the hydrochloric acid dissolution method (Fig. 2). The spherules are gray color transluscent and approximately $150 \mathrm{Ein} \mathrm{di}$ ameter. Under the EDS electron microscope, they preserved smooth surface and very homogenous in composition.

Outcrop scale and microscopic scale matrix intrusions are preserved in this member. This evidence suggests that the lower breccia member was formed under a high pore-pressure with high-energy condition flow. Breccia size and composition changes from the Lower breccia to the Upper sandstone-slit member.

The Upper sandstone-silt member which is approximately $350 \mathrm{~m}$ thick composed mainly of a coarseto-fine massive carbonate sandstone which is composed of mainly micritic limestone, foraminifera, rudist fragments with minor amounts of quartz, serpentinite and volcanics grains. This member is homogenous and well sorted. A dewatering pipe or web structure is observed in the middle part of this member. Sedimentary structures such as cross-bed, cross- to parallellaminations and bioturbation are not observed. The lithology of this member is similar to that of the middle part of the Peñalver Formation [9]. The shocked quartz is also found in this member of this sequence. The quartz contains the Eand $\xi$ planes characteristic of the planer deformation features. According to microscopic observations, grain boundaries are partly recrystalized and low-grade metamorphic minerals were formed. Most mafic mineral has changed to the chlorite. Thus the sequence was affected by low-grade metamorphism and original sedimentary structures may have been destroyed.

The upper most part of this member consists mainly of calcareous silt and clay which contain finegrained carbonate, foraminifera and quartz grains. It contains uppermost Masstrichtian nanofossils, such as Micula murus, Mucula decussata, and does not yield any Paleocene fossils. The Paleocene micritic limestone (Ancon Formations) overlies this member. However, the boundary between them is not well exposed.

Discussion and Summary: Characteristics of the Cacarajicara Formation are summarized as follows; 1 ) more than $300 \mathrm{~m}$ thick upward-fining sequence, 2) well-sorted stratigraphic sequence, 3 ) very thick boulder zone and homogenized upper zone, 4) high waterpressure and high energy conditions during the time of deposition of the lower breccia member, 5) presence of the shocked quartz in the upper member and spherule in the lower member (analyses of these grains are now in progress). The high-energy matrix condition for the Lower breccia member may be formed by the dilatant flow and the homogenized Upper sandstone-silt member is identified as fall deposits. These two different flow pattern in a fining upward sequence suggests that the Cacarajicara Formation is formed by a hyperconcentrated flow. The existence of an extremely thick sedimentary sequence with exotic blocks and impact related materials indicates that the Cacarajicara Formation is probably an impact-related mega flow sedimentary sequence deposited on the continental slope of the Yucatan platform.

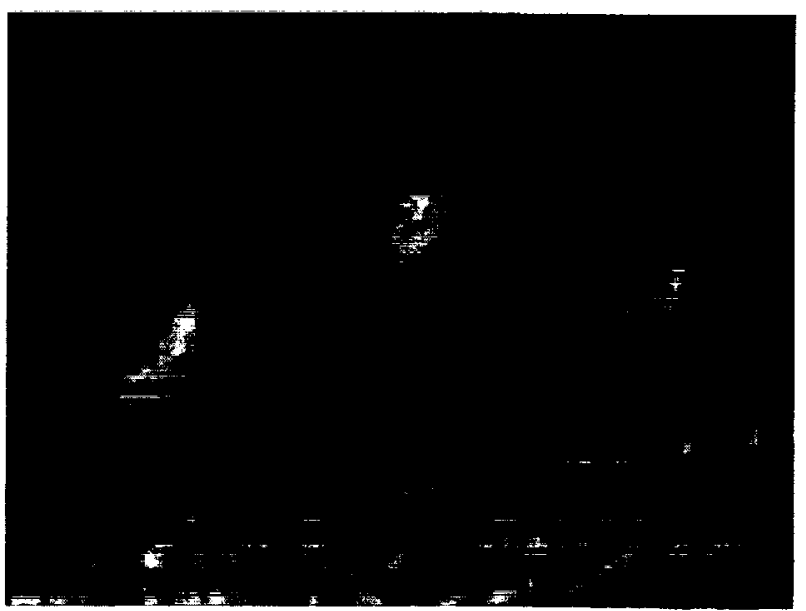

fig.2 Spherule in the Lower conglomerate unit

\section{References:}

[1] Smit et al. (1996) GSA special paper 307, 151182. [2] Plamer R. H. (1934) J. Geol., 43, 123 145. [3] Plamer R. H. (1945) J. Geol., 53, 1-34. [4] Pazczolkowski (1986) A. Bull. Pol. Acad. Sci. (Earth Sci.) 34, 81-94. [5] Pindell, J. L. and Barrett, S.F. (1990) Geology of North America, GSA 405-432. [6] Bohor, B. F. and Seitz, R. (1990), Nature, vol 344, 593. [7] Gordon et al. (1997) J. Geophys. Res. 102, 10055-10082.[8] IturraldeVinent, M. A. (1994) J. Petrolumme Geology, vol 17 (1). 39-70. [9] Takayama et al., Sedimentary Geology (axccepted). [10] Iturralde-Vinent, M. A. (1994) Tectonophysics, 234, 345-348. [11] Piotrowska K. (1978) Acta Geol. Pol., 28, 97-170. 


$$
559 / 45
$$

METEOROID FALL INTO THE OCEAN: IMPACT ON STRATOSPHERIC OZONE. Boris Klumov, Institute for Geospheres Dynamics, 117334, Leninsky prospekt, 38/6, Moscow, Russia

In the paper we discuss influence of a large cosmic body impacts on stratospheric ozone layer.It is easily to show that icy meteoroids with a size larger than about of a few hundreds meters can reach surface of the Earth. Impact of a such cosmic body into the ocean site results in ejecta of a huge amount of ocean water into the upper atmosphere, which can strongly affect on ozone layer. We focussed our attention on the next points: 1. meteoroidproduced wake impact on stratospheric ozone. 2. impact-generated ejecta impact on stratospheric ozone. We show that nitrogen oxides are generated very effectively in the wake, the oxides can almost completely destroy ozone inside the wake. We show that ozone depletion caused by the wake is local and transient, with typical life time of the order of a ten hours. In the contrary, impact-associated ejecta can produce relative long-lived ozone depletions.

Our calculations show that impact of a 1-km body creates a long-living vortex-like disturbance of the ozone concentration in the stratosphere with the spatial scale of the order of a few thousands kilometers. A significant ozone depletion is occur in the region. The depletion result in a strong increase of the oxygen photodissociation rate which in turn result in ozone production. So degenerative feedback takes place, which repair ozone in the region of the disturbance. The effect is very strongly varies with altitude: at lower stratosphere $(\mathrm{h}=20 \mathrm{~km})$ time of "ozone repair" is about of a few days, at middle stratosphere $(\mathrm{h}=30 \mathrm{~km})$ the time is about of a few months. 


\begin{abstract}
COMPARISON OF Os and $\mathrm{Cr}$ ISOTOPIC METHODS FOR THE DETECTION OF METEORITIC COMPONENTS IN IMPACT MELT ROCKS FROM THE MOROKWENG AND VREDEFORT IMPACT STRUCTURES, SOUTH AFRICA. Christian Koeberl ${ }^{1}$, Bernhard Peucker-Ehrenbrink ${ }^{2}$, Wolf Uwe Reimold ${ }^{3}$, Alex Shukolyukov ${ }^{4}$, and Günter W. Lugmair ${ }^{4.5}{ }^{1}$ Institute of Geochemistry, University of Vienna, Althanstrasse 14, A-1090 Vienna, Austria (christian.koeberl@univie.ac.at); ${ }^{2}$ Department of Marine Chemistry and Geochemistry, Woods Hole Oceanographic Institution, Woods Hole MA 02543-1541, U.S.A. (behrenbrink@ whoi.edu); ${ }^{3}$ Impact Cratering Research Group, Department of Geology, University of the Witwatersrand, Johannesburg 2050, South Africa (065wur@cosmos.wits.ac.za); ${ }^{4}$ Scripps Institute of Oceanography, University of California, San Diego, CA 92093-0212, U.S.A (ashukolyukov@ucsd.edu); ${ }^{5}$ Max-Planck-Inst. for Chemistry, P.O. Box 3060, 55020 Mainz, Germany (lugmair@mpch-mainz.mpg.de).
\end{abstract}

Introduction. The verification of an extraterrestrial component in impact-derived melt rocks or breccias can be of diagnostic value to provide confirming evidence for an impact origin of a geological structure. Geochemical methods are used to determine the presence of the traces of such a component. In the absence of actual meteorite fragments, it is necessary to search for traces of meteoritic material that is mixed in with the target rocks in breccias and melt rocks. Meteoritic components have been identified for just over 40 impact structures (out of more than 160 known on Earth; see [1] for a listing), which reflects also the detail in which these structures were studied. The identification of a meteoritic component can be achieved by determining the concentrations and interelement ratios of siderophile elements, especially the platinum group elements, which are several orders of magnitude more abundant in meteorites than in terrestrial upper crustal rocks. The usage of platinum group element abundances and ratios avoids some of the ambiguities that may result if only common siderophile elements (e.g., $\mathrm{Cr}, \mathrm{Co}, \mathrm{Ni}$ ) are considered. However, problems may arise if the target rocks have high abundances of siderophile elements, or if the siderophile element concentrations in the impactites are very low. In such cases, the $\mathrm{Os}$ and $\mathrm{Cr}$ isotopic systems have recently been used for establishing the presence of a meteoritic component in a number of impact melt rocks and breccias (e.g., [2,3]). In the past it was attempted to use PGE data to determine the type or class of meteorite for the impactor, but these attempts were not al ways successful. It is difficult to decide between chondrite types based on PGE abundances, which has led to conflicting identifications for a number of impact structures (see [1] for details). Clearly, the identification of a meteoritic component in impactites is not a trivial problem. In this study, we are using a combination of trace element (PGE) analyses and the results from both, $\mathrm{Os}$ and $\mathrm{Cr}$ isotopic studies, to illustrate the pros and cons of each method on two case studies, namely the Vredefort and Morokweng impact structures.

Vredefort Impact Structure: Background. The Vredefort structure in South Africa, centered about $120 \mathrm{~km}$ southwest of Johannesburg, currently has a diameter of about $100 \mathrm{~km}$, which is believed to represent the central uplift of this impact structure. The whole structure could initially have been as large as $300 \mathrm{~km}$, comprising the whole Witwatersrand Basin. The origin of the structure has been debated during most of this century, but recent data confirmed the existence of impactcharacteristic shock metamorphic effects in Vredefort rocks, e.g., basal Brazil twins in quartz and planar deformation features (PDFs) in zircon, supporting an impact origin as opposed to an internal origin of the structure (see [4] for a review). The Vredefort event is well dated at $2024 \pm 5 \mathrm{Ma}$ (cf. [4]). Dikes of granophyric rock, the so-called Vredefort Granophyre, occur in the basement core of the structure and along the boundary between the core and the supracrustal rocks of the collar. Previous studies indicated that the granophyre could have formed by impact melting of granite, shale, and quartzite. A major mafic contribution is unlikely due to the scarcity of mafic clasts and because the granophyre composition can be perfectly modeled with felsic crustal and supracrustal rocks $[4,5]$.

Morokweng Impact Structure: Background. The Morokweng impact structure is centered at $23^{\circ} 32^{\prime} \mathrm{E}$ and $26^{\circ} 20^{\prime} \mathrm{S}$, close to the border with Botswana in the Northwest Province of South Africa. The structure was recognized from gravity and magnetic anomalies, which revealed the possible presence of a larger circular structure. The discovery of impact characteristic shock metamorphic effects in rocks from the Morokweng area (e.g., [6]) confirmed the presence of a large meteorite impact structure. The size of the Morokweng impact structure is still debated, but a diameter of about $80 \mathrm{~km}$ seems most likely. Melt rock was found in three boreholes from the central part of the structure. The melt rock appears fresh and homogeneous, except for a large number of lithic clasts. The clast population is dominated by gabbro fragments, but microscopic studies reveal that felsic, clearly granitoid-derived, clasts are also abundant. The granites drilled below the melt body in core MWF05 are locally brecciated and pervasively recrystallized. SHRIMP ion probe dating of zircons from the melt rock yielded an age of $146.2 \pm 1.5 \mathrm{Ma}$, which is indistinguishable from that of the Jurassic-Cretaceous boundary (e.g., [6]).

Meteoritic Component at Vredefort. A Re-Os isotopic study was undertaken by Koeberl et al. [5] in order to a) search for a meteoritic component in Vredefort Granophyre, and b) to confirm that the Granophyre represents an impact melt rock. The Os abundances in the Granophyre range from 0.11 to $1.11 \mathrm{ppb}$, which is significantly higher than the average of the source rock values, indicating a distinct enrichment of Os in most of the Granophyre samples compared to the country rocks. In addition, the ${ }^{187} \mathrm{Os} /{ }^{188}$ Os ratios of the Granophyre samples are significantly lower than those of the supracrustal country rocks. A meteoritic component in the Vredefort Granophyre is the only explanation that is in agreement with these 


\section{COMPARISON OF Os AND Cr ISOTOPIC METHODS: C. Koeberl et al.}

observations. This conclusion is supported by some enrichments in $\mathrm{Cr}, \mathrm{Co}$, and $\mathrm{Ni}$ and $\mathrm{Ir}$ in the granophyre compared to the country rocks, although these enrichments are not as unambiguous as the Re-Os data. Assuming chondritic meteorite Os abundances (about $500 \mathrm{ppb}$ ), [5] concluded that the Vredefort Granophyre contains $\leq 0.2 \%$ of a chondritic component. However, the meteoritic component is not homogeneously distributed, probably due to a nugget effect, as is evident from a spread in ${ }^{187} \mathrm{Re} /{ }^{188} \mathrm{Os}$ ratios, in agreement with observations from other impact melt rocks. Meteorites contain about ten times less Re than Os, indicating that the Re contribution from the meteoritic material to the Granophyre was $\leq 30 \%$, subordinate to the Os, which is almost exclusively of meteoritic origin. The almost constant Re abundances found in the Granophyre samples indicate homogenization during the impact. Thus, the Granophyre is a mixture of a large amount of low-Os, high-Re material (crustal rocks) with a small contribution of high-Os, low-Re meteoritic material. The Os isotope results showed that all analyzed Vredefort Granophyre samples contain some meteoritic Os, confirming that the Granophyre is an impact melt rock. In contrast, the $\mathrm{Cr}$ isotopic study did not reveal the presence of extraterrestrial $\mathrm{Cr}$ : two Vredefort Granophyre samples yielded ${ }^{53} \mathrm{Cr} /{ }^{52} \mathrm{Cr}$ ratios of $-0.01 \pm 0.06 \varepsilon$ and $+0.03 \pm 0.03 \varepsilon\left(2 \sigma_{\text {mean }}\right)$, which is indistinguishable from terrestrial normal $(\equiv 0 \mathrm{\varepsilon})$. Based on the $\mathrm{Cr}$ data, the upper limit for a chondritic component in these samples is $\sim 1.5 \%$, which is consistent with the more strict limit provided by the Os isotopes. An abundance of terrestrial $\mathrm{Cr}$ masks the cosmic $\mathrm{Cr}$ and, in this case, the sensitivity of the $\mathrm{Cr}$ isotopic method is not sufficient to return a positive answer.

Meteoritic Component at Morokweng. PGE analyses (e.g. [6]) of Morokweng impact melt rock clearly showed very high values and flat chondrite-normalized PGE patterns, indicating a significant chondritic contamination. A value of about 2 to $5 \%$ of a meteoritic component was estimated [6]. To confirm the presence of this component, Os and $\mathrm{Cr}$ isotopic studies were done. The results of the Os isotope study [8] showed high Os contents of up to about $9 \mathrm{ppb}$ in the impact melt rock samples, with correspondingly low, but remarkably uniform, isotopic ratios, with ${ }^{87} \mathrm{Os}^{188} \mathrm{Os}$ at 0.1316 to 0.1341 . The breccias show a much wider variation in both isotope ratio and Os abundance. In contrast, the mafic rock samples from a close-by deep drill core, representing the mafic contribution to the Morokweng impact melt rocks, have very low Os abundances ( 9.8 to $42 \mathrm{ppt}$ ) and high isotope ratios (up to a ${ }^{187} \mathrm{Os}^{1{ }^{188}} \mathrm{Os}$ ratio of 12 !). This result clearly indicates that the mafic target rocks of the area did not contribute measurably to the high siderophile element abundances observed in the melt rocks. Also, the Os isotope analyses confirm the presence of a meteoritic component in these melt rocks. A Cr isotopic study [7] showed that about half of the $\mathrm{Cr}$ in the melt rock is of extraterrestrial origin. It was also possible to show that only an ordinary chondritic source, rather than a carbonaceous chondritic source, can explain the $\mathrm{Cr}$ isotope data. Together with trace element analyses, [7] concluded that the Morokweng bolide was most likely of Lchondritic composition.

Conclusions. Clearly, there are advantages and disadvantages of both isotopic methods, and in comparison to PGE abundance and interelement studies. PGE abundance studies may indicate the presence of an extraterrestrial component, and the normalized patterns can give an indication of the impactor type. However, it is not possible to distinguish between terrestrial and extraterrestrial PGEs. This is, in principle, possible by both the Os and $\mathrm{Cr}$ isotopic methods. In the case of the Os isotopes, it is necessary to distinguish between a possible mantle signal and an extraterrestrial signal, as the Os isotopic ratios for mantle and meteoritic material are very similar. There is a significant difference in the total abundance of Os between mantle rocks (about $1-4 \mathrm{ppb}$ Os) and meteorites (typical chondrites have about $400-800 \mathrm{ppb}$ Os). Thus, about 100 times more mantle than meteoritic material would need to be added to normal crustal rocks (e.g., in a breccia) to result in the same Os isotopic ratio of the bulk rock. Detailed field investigations, petrographic studies, if necessary combined with trace element and $\mathrm{Rb}-\mathrm{Sr}$ and/or $\mathrm{Sm}-\mathrm{Nd}$ isotopic analyses, will easily show if significant amounts of ultramafic materials are present. On the other hand, the $\mathrm{Cr}$ isotopic composition allows the distinction between terrestrial and extraterrestrial $\mathrm{Cr}$, and there is a difference between some meteorite groups [3]. For example, ordinary chondrites (types $\mathrm{H}$ and $\mathrm{L}$ ) have isotopic characteristics that are slightly different from those of enstatite chondrites and are, even more significantly, different from those of carbonaceous chondrites. Thus, assuming that a certain (fairly significant) percentage of the chromium in an impact melt of ejecta layer is of extraterrestrial origin, it should be possible by measuring the $\mathrm{Cr}$ isotopic composition to determine not only that an extraterrestrial component is present, but also which meteorite type might have been involved. However, the differences in isotopic composition are very small, requiring extremely precise and timeconsuming measurements, which severely limits the number of samples that can be measured. Also, a substantial amount of chromium has to be of extraterrestrial origin to show an effect in the $\mathrm{Cr}$ isotopic composition that is larger than the precision of the measurement. Thus, while being more selective than the $\mathrm{Os}$ isotopic method, the $\mathrm{Cr}$ isotopic method is less sensitive.

Acknowledgements: Supported by the Austrian Fonds zur Förderung der wissenschaftlichen Forschung, Y58-GEO (C.K.), the NSF ( B.P-E.), the National Research Foundation of South Africa (W.U.R.), and NASA grant 5-8172 (A.S., G.W.)

References: [1] C. Koeberl, in M.M. Grady et al., Geol. Soc. London, Spec. Publ. 140, 133-153 (1998); [2] C. Koeberl and S.B. Shirey, Paleo3 132, $25-46$ (1997); [3] A. Shukolyukov, G.W. Lugmair, Science 282, 927-929 (1998); [4] W.U. Reimold and R.L Gibson, J. African Earth Sci. 23, 125-162 (1996); [5]C. Koeberl, W.U. Reimold, and S.B. Shirey, Geology 24, 913-916 (1996); [6] C. Koeberl, R.A. Armstrong, and W.U. Reimold, Geology 25, 731-734 (1997); [7] A. Shukolyukov, G.W. Lugmair, C. Koeberl, and W.U. Reimold, Meteoritics Planet. Sci. 34, A107-A108 (1999); [8] C. KoeberI, B. Peucker-Ehrenbrink, and W.U. Reimold, LPSC 31, \#1595 (2000). 
MULTIPLE IMPACTS AND MASS EXTINCTION. H.Koshiishi ${ }^{1}$, H.Kurosaki ${ }^{2}$, Y.Iwata ${ }^{3}$, C.Komori ${ }^{4}$, J.Terazono ${ }^{5}, \mathrm{M} \mathrm{Naka}^{6}$, H.Yamamoto ${ }^{7},{ }^{1}$ AIDS (Asteroid Interception and Deflection System) Laboratory, 4-17-2, Mejirodai, Hachiohji, Tokyo, Japan, 193-0833 (koshy@nal.go.jp), ${ }^{2}$ Keio University, 5322, Endoh, Fujisawa, Japan, 252-8520 (kurosaki@sfc.keio.ac.jp), ${ }^{3}$ Fujitu FIP Corp., Japan, ${ }^{4}$ Planetary Geology Society, Japan, ${ }^{5}$ Japan Space Forum, Japan, ${ }^{6}$ Remote Sensing Technology Center, Japan, ${ }^{7}$ National Aerospace Laboratory, 7-44-1, Jindaiji-higashimachi, Chohfu, Tokyo, Japan, 182-8522.

\begin{abstract}
In the process of mass extinction by minor body impact on Earth the surface temperature drop is most important and fundamental factor. Here the analytical model for estimation of surface temperature drop after blown up of multiple impacts dust to stratosphere is established. Propriety of the model is verified by an estimation of surface temperature drop by Tambola volcano eruption and comparison of it with the actual measurement of northern hemisphere temperature drop in that time.

For some assumed example of multiple impacts surface temperature drops are estimated using the established model. The example are impacts of two $0.5 \mathrm{~km}$ diameter asteroids, impacts of one $0.5 \mathrm{~km}$ plus one $1 \mathrm{~km}$ diameters asteroids and so on. The estimated surface temperature drops of these multiple impacts are striking and the resulted optical depths of atmosphere become very thick beyond a limit of photosynthesis. Then such a estimation of surface temperature drops were carried out for some actual multiple impacts : for example, Clear-water Lake Craters in Canada, Kara-Ustkara Craters in Russia and so on. The resulted temperature drops are terrible. The drop of surface temperature would result in some amount of mass extinction if there were creatures on Earth in that time.

The impact of $10 \mathrm{~km}$ minor body in $65 \mathrm{My}$ ago brought about the mass extinction in K-T boundary. However, some multiple impacts might cause another mass extinctions in the Earth history. On the Earth's surface only about 160 craters were found, and there might be many craters under the jungle forests in Africa and Brazil and taiga in Siberia. Remote sensing technology is very helpful for detection of such unknown craters. From the view point of mass extinction by minor body impact, it is necessary to search not only single craters but also multiple craters.
\end{abstract}

REFERENCES : [1] Koshiishi H.(1994) ASP Conference Series, 63, 265-272, [2] Rampino M.R.(1998) Celestial Mechanics and Dynamical Astronomy, 69, 49-58, [3] Koshiishi H.(1998) Annual Meeting of I.G.C.P 384, Abstracts. 58. 
IMPACT-INDUCED HYDROTHERMAL ACTIVITY AND POTENTIAL HABITATS FOR THERMOPHILIC AND HYPERTHERMOPHILIC LIFE. D. A. Kring, Department of Planetary Sciences, Lunar and Planetary Laboratory, University of Arizona, 1629 E. University Blvd., Tucson, AZ 85721 (kring@lpl.arizona.edu).

Introduction; It has become increasingly clear that impact cratering processes can affect the biologic evolution of the Earth. The principal example of this relationship is the Chicxulub impact event and its likely role in the mass extinction that occurred at the Cretaceous-Tertiary boundary [e.g., 1-4]. However, other impact events, both known [e.g., 5,6] and hypothesized [e.g., 7,8], have also been linked to a variety of local, regional, and global environmental consequences.

At the same time impact processes disrupt the habitats of some organisms, they also offer opportunities for other organisms. One straightforward way of doing this is to remove successful organisms from ecological niches, giving other organisms an opportunity to exploit them. Another way is to create new environments suitable for habitation. Common examples are impact crater lakes, both now (e.g., Bosumtwi, Clearwater East and West, Lonar, New Quebec) and in the past (e.g., Barringer, Haughton, Ries, Steinheim, Tswaing). These lakes can be long-lived (thousands to millions of years) and fossil evidence clearly indicates they can be utilized by a variety of flora and fauna [9-18]. Other environments that can be created by impact cratering events are hydrothermal systems. Similar systems generated by volcanic processes have been recognized as critical habitat for some of Earth's most deeply branching organisms [e.g., 19,20] and may have been the type of habitat first populated by life on Earth [e.g., 21-23]. The purpose of this paper is to explore the extent of impact-induced hydrothermal systems and their possible role in the evolution of life.

Evidence of Hydrothermal Systems: Most studies of impact processes have focused on the formation and modification of craters, not their subsequent evolution. Consequently, little is known about the post-impact hydrothermal processes that are produced and a complete evaluation of a hydrothermal system in a crater does not yet exist. Thus, the nature of these systems needs to be pieced together from evidence from several craters.

Chicxulub. This is an $\sim 170 \mathrm{~km}$ diameter crater produced $64.98 \pm 0.05 \mathrm{Ma}$ [24]. Anhydrite and quartz veins attributed to hydrothermal processes were found in the Yucatán- 6 borehole [25], $-50 \mathrm{~km}$ from the center of the crater, within the peak ring, and near the top of a section of impact melt at least $380 \mathrm{~m}$ thick [26]. However, little else is known about this system because there are so few samples from the buried structure. It is hoped that details will be forthcoming when a core is recovered by the Chicxulub Scientific Drilling Project in 2000.
Manson. This is a $35 \mathrm{~km}$ diameter crater produced $73.8 \pm 0.3 \mathrm{Ma}$ [24]. Evidence of hydrothermal activity is extensive. It includes quartz veins in impact melt breccias and fragmental breccias, altered granite, and altered granitic gneiss [27]. Fluid inclusions in these samples indicate the water was moderately saline $(0.2$ to $\left.12.2 \mathrm{wt} \% \mathrm{NaCl}_{\mathrm{eq}}\right)$ and contained very little $\mathrm{CO}_{2}(<0.2$ mole \%). Temperatures in the system ranged from 90 to $250^{\circ} \mathrm{C}$ [27]. The fluids altered primary mineral assemblages in the central peak and in associated impact breccias, producing andradite garnet, ferroactinolite, epidote, prehnite, wollastonite, quartz, analcime, calcite, adularia, pyrite, molybdenite, and clay minerals [28]. Based on the paragenetic sequence, temperatures seem to have peaked between 275 and $360^{\circ} \mathrm{C}$ and then cooled to ambient conditions [28]. Alteration occurs in both the central peak and in breccias in the surrounding annular trough.

Puchezh-Katunki. This is a $80 \mathrm{~km}$ diameter crater produced $175 \pm 3 \mathrm{Ma}$ [24]. The hydrothermal system extended to a depth of at least $5 \mathrm{~km}$ (the bottom of the Vorotilovskaya borehole) in the uplifted peak and overlying breccias in the center of the crater [29]. The source of the water in the system appears to be a lake that filled the annular trough [30]. Temperatures in the system were $100-200^{\circ} \mathrm{C}$ in the suevites, allogenic breccia, and upper part of the authigenic breccia down to a depth of $2.5 \mathrm{~km}$ where zeolites, apophylite, calcite, anhydrite, and pyrite were deposited in vugs and fractures, veins of calcite-nontronite were produced locally, and iron saponite pervades the basement rocks $[31,32]$. Temperatures in the fluid system were hotter at depths between 2.5 and $4.2 \mathrm{~km}$, reaching $200-300^{\circ} \mathrm{C}$. Chlorite with pyrite is common while albite, epidote, and calcite occur locally in this region [32]. Below $4.2 \mathrm{~km}$, prehnite, anhydrite, calcite, and pyrite assemblages are tentatively inferred to reflect temperatures of $150-250$ ${ }^{\circ} \mathrm{C}$ [32]. The extent of the hydrothermal system is not known, but a proposed model [30] suggests it was largely confined to the central peak region, which is $\sim 12$ $\mathrm{km}$ in diameter.

Saint Martin. This is an $\sim 40 \mathrm{~km}$ diameter complex crater that was produced $\sim 220 \pm 32 \mathrm{Ma}$ [24]. The impact melt sheet is $208 \mathrm{ft}$ thick in the LSM-1 borehole $\sim 11 \mathrm{~km}$ from the center of the crater [33]. The lower 30 $\mathrm{ft}$ of the melt sheet has a perturbed chemical composition which has been interpreted to be the result of hydrothermal circulation along the base of the melt sheet $[33,34]$.

Siljan. This is a $52 \mathrm{~km}$ diameter crater produced 
$368.0 \pm 1.1 \mathrm{Ma}[24]$. Hydrothermal activity has affected the target granite and left secondary fluid inclusions in quartz [35]. The inclusions contain water that is less saline $\left(0.2 \mathrm{wt} \% \mathrm{NaCl}_{\mathrm{eq}}\right)$ than the fluids in the Manson crater. Maximum fluid temperatures are $327-342{ }^{\circ} \mathrm{C}$ in the central peak and minimum fluid temperatures are $135-225{ }^{\circ} \mathrm{C}$ near the surrounding annular trough. Drilling and surface sampling is extensive enough to indicate the impact-induced hydrothermal system affected the entire $52 \mathrm{~km}$ diameter region down to a depth of at least $1.2 \mathrm{~km}$ [35].

Sudbury. This is an $\sim 250 \mathrm{~km}$ diameter crater produced $1850 \pm 3 \mathrm{Ma}$ [24]. Hydrothermal alteration of the impact melt sheet converted plagioclase to sericite and clinozoisite and pyroxene to uralite and chlorite [36]. The hydrothermal system is also the source of exhalative mineralization in sediments that cover the impact melt sheet and impact breccias [37].

In addition, tentative evidence of impact-induced hydrothermal systems has been reported for Roter Kamm [38] and Haughton [39].

Extent and Lifetimes of Hydrothermal Systems: These examples indicate that large hydrothermal systems can be created in and around the central uplifts of complex craters and possibly (i.e., Siljan) outward as far as the rim of the craters. The systems can also affect entire melt sheets and the overlying breccias. The heat source driving these systems is the central uplift and/or the impact melt sheet. This implies that the lifetimes of these systems correspond to the time needed for the uplift or melt sheet to cool. In the case of a Chicxulub-size event, the melt sheet may have driven a hydrothermal system for $10^{5}$ years [40]. Based on the temperatures inferred from fluid inclusions and alteration mineral assemblages, parts of these systems were clearly too hot for organisms, but other large regions would have had appropriate temperatures for thermophilic and hyperthermophilic organisms. In some cases the craters were subaerially exposed, in which case the hydrothermal systems may have vented in mud pots, hot springs, and geysers similar to those in volcanic terranes (e.g., Yellowstone and Rotorua). However, in some cases the craters were filled with freshwater lakes or marine incursions (e.g., Chicxulub and Puchezh-Katunki), in which case the hydrothermal systems may have vented subaqueously like those at Crater Lake [41].

Implications for Early Earth: Impact cratering occurred more frequently earlier in Earth's history and may have been a more important source of hydrothermal activity than volcanism. In particular, it has been inferred that the impact cratering rate in the EarthMoon system was particularly high $\sim 4 \mathrm{Ga}$ based on analyses of impact melts in the Apollo collection [4244]. Recent analyses of additional impact melt clasts in lunar meteorites, which sample a larger region of the
Moon, support this assessment [45]. At $\sim 4 \mathrm{Ga}$, or a few $100 \mathrm{Ma}$ later when liquid water was clearly present on the surface of Earth, impact-induced hydrothermal systems should have been extensive and may have provided a significant habitat on Earth. Similarly, these types of hydrothermal systems, with or without life, may have been produced on Mars, supplementing the impact crater lakes that have already been hypothesized on that planet [46].

References: [1] Alvarez L.W. et al. (1980) Science, 208, 1095-1108. [2] Kring D.A. (1993) Proc. Ist Ann. Symp. Fossils Arizona, 63-79. [3] Ryder G. (1996) GSA Sp. Pap. 307, 31-38. [4] D'Hondt S. et al. (1996) GSA Sp. Pap. 307, 303317. [5] Kring D.A. et al. (1996) EPSL, 140, 201-212. [6] Kring D.A. (1997) Meteoritics \& Planet. Sci., 32, 517-530. [7] Toon O.B. et al. (1997) Rev. Geophys., 35, 41-78. [8] Sleep N.H. and Zahnle K. (1998) JGR, 103, 28529-28544. [9] Füchtbaner H. et al. (1977) Geol. Bavarica, 75, 13-19. [10] Dehm R. et al. (1977) Geol. Bavarica, 75, 91-109. [11] Riding R. (1979) Sedimentology, 26, 645-680. [12] Reif W.-E. (1983) Paläont. Z., 57, 21-26. [13] Hickey L.J. et al. (1988) Meteoritics, 23, 219-229. [14] Grönlund T. et al. (1990) Can. J. Bot., 68, 1187-1200. [15] Saarse L. et al. (1991) Bull. Geol. Soc. Finland, 63(2), 129-139. [16] Salonen V.-P. et al. (1992) Boreas, 21, 253-269. [17] Gorthner A. (1992) Stuttgarter Beitr. Naturk., B190, 1-173. [18] Partridge T.C. et al. (1999) Investigations into the Origin, Age and Palaeoenvironments of the Pretoria Saltpan, Geological Survey of South Africa, 198 p. [19] Reysenbach A.-L. et al. (1994) Appl. \& Environ. Microbio, 60, 2113-2119. [20] Deckert G. et al. (1998) $\mathrm{Na}$ ture, 392, 353-356. [21] Woese C.R. et al. (1990) Proc. Natl. Acad. Sci. USA, 87, 4576-4579. [22] Pace N.R. (1991) Cell, 65, 531-533. [23] Pace N.R. (1997) Science, 276, 734-740. [24] Grieve R. et al. (1995) GSA Today, 5, 189 and 194-196. [25] Kring D.A. and Boynton W.V. (1992) Nature, 358, 141 . 144. [26] Hildebrand A.R. et al. (1991) Geology, 19, 867-871. [27] Boer R.H. et al. (1996) GSA Sp. Pap. 302, 377-382. [28] McCarville P. and Crossey L.J. (1996) GSA Sp. Pap. 302, 347-376. [29] Pevzner L.A. et al. (1992) LPS XXIII, 10631064. [30] Masaitis V.L. and Naumov M.V. (1993) Meteoritics, 28, 390-391. [31] Naumov M.V. (1992) LPS XXIII, 967-968. [32] Naumov M.V. (1993) Meteoritics, 28, 408-409. [33] Simonds C.H. and McGee P.E. (1979) Proc. LPSC $10^{\text {th }}$, 2493-2518. [34] Reimold W.U. et al. (1990) GCA, 54, 20932111. [35] Komor S.C. et al. (1988) Geology, 16, 711-715. [36] Therriault A.M. (1999) LPS XXX, abstract \#1801 (CD. ROM). [37] Grieve R.A.F. and Masaitis V.L. (1994) Internatl. Geol. Rev., 36, 105-154. [38] Koeberl C. et al. (1989) $G C A, 53,2113-2118$. [39] Bain J.G. and Kissin S.A. (1988) Meteoritics, 23, 256. [40] Kring D.A. (1995) JGR, 100, 16979-16986. [41] Dymond J. et al. (1989) Nature, 342, 673675. [42] Tera F. (1974) EPSL, 22, 1-21. [43] Baldwin R.B. (1974) Icarus, 23, 157-166. [44] Hartmann W.K. (1975) Icarus, 24, 181-187. [45] Cohen B.A. et al. (2000) LPS XXXI, abstract \#1922 (CD-ROM). [46] Newsom H.E. (1996) JGR, 101, 14951-14955. 
THE EXTRATERRESTRIAL COMPONENT IN SEDIMENTS AND INFERENCES ON EARTH'S ACCRETION HISTORY. Frank T. Kyte, Institute of Geophysics and Planetary Physics, University of California, Los Angeles, CA, USA 90095-1567, kyte@igpp.ucla.edu

The influx of extraterrestrial materials to the Earth is dominated by two size-fractions: sub-mm interplanetary dust and impacting asteroids and comets. This influx can be detected in sedimentary deposits as physical debris (cosmic spherules, meteorites), or as chemical or isotopic signals. The study of this extraterrestrial component in sediments began with the discovery of cosmic spherules in the magnetic fraction of deep-sea sediments collected during the expedition of the HMS Challenger (1873-1876). These were correctly interpreted to be produced by ablation of meteoritic material during atmospheric entry [1].

Over the next 100 years work on extraterrestrial sediments was largely cosmic spherule studies. A notable exception was the first detection of a chemical signal when Barker and Anders [2] found an inverse relationship between Ir concentrations (from meteoritic dust) and the accumulation rate of deep sea sediments. The first attempt to use this relationship to measure the accumulation rate of a sedimentary unit was a complete failure. Alvarez et al [3] measured Ir in the Cretaceous/Tertiary (KT) boundary from Gubbio and found far too much Ir to be consistent with the Barker and Anders results. When Alvarez et al. suggested that this Ir anomaly was a signal of ejecta from an asteroid impact, rather than the slow accumulation of interplanetary dust they set off scientific explosion and the second century of research into extraterrestrial sediments got off with a bang.

About a year after the initial Alvarez et al report, the first Snowbird Conference was convened (Oct. 1981 ), and a lot of progress was already evident. Anomalous Ir and and other platinum group elements (PGEs) been discovered at a number of new KT sites [4-7]. The first ejecta from impact target rocks (sanidine spherules) was described [8]. In Snowbird an diverse group of researchers ranging from paleontologists to impact modelers exchanged ideas on a new set of problems they all shared. The major subject was the question of whether planetary accretion played an important role in Earth history, and whether it affected biological evolution. While mass extinction at the KT boundary took center stage there was considerable interest in other extinctions, such as in the late Devonian and the late Eocene. Within few years, impact at the KT boundary was virtually confirmed with discovery of shocked quartz [9]. An observation that mass extinctions appeared to occur in periodic cycles [10] led to a number of hypotheses for astronomical mechanisms to periodically disturb the Oort Cloud of comets and fill the inner solar system with storms of comets [11-13]. This hypothesis suggested that perhaps impacts caused all major extinctions in the Phanerozoic.
In the past two decades we have made enormous strides in understanding the Earth's accretion history, but have had less success linking it to the history of other extinctions. The KT boundary is now almost universally accepted as a major impact event coincident with mass extinctions, although the causes of the extinctions remain a topic of discussion and debate. The Chicxulub structure in the Yucatan Peninsula was ground zero for the impact [14]. The sedimentology and mineralogy of proximal to distal impact deposits are described around the planet [15]. No other extinction event has been so conclusively linked to an impact event, but some tantalizing data suggest possibilites, such as multiple reports of spherules in late $\mathrm{De}$ vonian deposits [e.g., 16] or possible evidence of shocked quartz near the Permian Triassic boundary [17]. But such data lack firm evidence in the form of a strong cosmic signature, such as a significant Ir anomaly.

The most widely used tracer of extraterrestrial sediment has been Ir which is typically depleted in sediments by a factor of $\sim 10,000$ relative to cosmic abundances. But mineralogical and isotopic evidence have also played an important role. An important carrier of Ir (and other PGEs) in KT boundary sediments is a type of spheroidal debris that contains a relict high temperature phase - magnesioferrite spinel - that formed during the impact event. [18]. Robin and coworkers [e.g., 19] have shown that these spinels are similar to those found in cosmic spherules and that at least some of the KT spherules may be derived directly from meteoritic materials. They note that although Ir may chemically diffuse through sediments and not accurately reflect the original distribution of fallout, spinels are not mobile and can be used as a specific marker of impact horizons. In a recent study of a long deep-sea core they have found at least four distinct spinel-rich horizons younger than the KT boundary that may record impacts or other accretionary events [20]. Spinelbearing spherules have been associated with Ir anomalies and likely impact deposits from the late Pliocene [21], late Eocene [e.g., 22], and early Archean [23].

There are now two occurences of unmelted meteorites from deposits of large-body impacts. Sub-mm to $\mathrm{cm}$ sized fragments of basaltic breccias from a mesosiderite asteroid are abundant in deposits from the impact of a km-sized asteroid into the Bellingshausen Sea [24]. A heavily altered fragment of a $2.5 \mathrm{~mm}$ meteorite has also been recovered from KT boundary sediments in the North Pacific [25]. Most of the original minerals from this specimen have been altered to clays and iron-oxides, but saponite (a Mg-smectite) may be a relict phase. Relict texures show that this 


\section{THE EXTRATERRESTRIAL COMPONENT IN SEDIMENTS...Frank T. Kyte}

meteorite was likely composed of olivine and metal in a fine-grained, clay-rich matrix. These characteristics are typical of some groups of carbonaceous chondrites. Recent 3-D simulations of large impacts [26] have shown that meteorite survival should be expected from the relatively low-velocity impacts of asteroidal objects, particularly those with low impact angles. However, meteorite survival is unlikely for the significantly higher impact velocites of long-period comets.

The use of isotopic systems to provide unequivocal evidence of a extraterrestrial component has only recently become possible. Early work with the Re-Os system [27] successfully showed that Os-isotopes in the KT boundary were consistent with a meteoritic source, but left open the possibility that Os (and other PGEs) could be derived from mantle sources. This ambiguity has now been removed by application $\mathrm{C}_{\mathrm{T}}$ isotopic systematics. The ratios of ${ }^{53} \mathrm{Cr}{ }^{52} \mathrm{Cr}$ and ${ }^{54} \mathrm{Cr}_{\mathrm{r}} /{ }^{2} \mathrm{Cr}$ vary between different planetary objects and new high-precision measurements of these ratios provide indisputable evidence that most of the $C_{r}$ in KT boundary sediments is from an extraterrestrial source, likely a carbonaceous chondrite [28]. This method has now been used to prove a extraterrestrial component in early Archean impact deposits [29] and has a great potential for identifying the projectile type in impact deposits and craters with a significant amount of extraterrestrial $\mathrm{Cr}$. While $\mathrm{Cr}$-isotopes can resolve the extraterrestrial signature from the largest projectiles, traces of ${ }^{3} \mathrm{He}$ have been used to detect a signal from the interplanetary dust. Because of their high surface-to-mass ratio, interplanetary dust particles have extremely high concentrations of solar wind-implanted ${ }^{3} \mathrm{He}$ which surprisingly is retained in deep-sea sediments. ${ }^{3} \mathrm{He}$ fluxes in sediments exhibit a significant peak for about 3 m.y. during the late Eocene [30], a time coincident with at least two large cratering events (Popigai and Chesepeake Bay) and multiple spherule deposits. Farley et al [30] argue that the only possible source of this signal is the dust from a comet shower. Because of drag from solar wind, interplanetary dust has a dynamic lifetime of only $\sim 0.1 \mathrm{~m}$.y. so only only a prolonged shower of comets can sustain high concentrations of dust for such a long interval. Dynamic models of showers produced by disturbance of the Oort cloud indicate that $3 \mathrm{~m} . \mathrm{y}$. is a reasonable duration [31].

There are several conclusions we can draw from the data collected over the last two decades. Primary among these is that the KT boundary marks one of the most significant impact events in the Phanerozolc and this was probably largely responsible for one of the great mass extinctions in Earth history. The KT projectile had isotopic and textural properties similar to those of carbonaceous chondrites. These results are consistent with an asteroid source for the KT boundary. Since meteorites from comets might be expected to porous, with mainly anhydrous phases [32] and meteorite survival is unlikely from cometary impacts
[26], these results are inconsistent with a cometary projectile. When these data are coupled with the fact that no evidence has been found of multiple impacts at the KT boundary and sediments at that time do not have a significant ${ }^{3} \mathrm{He}$ anomaly [33], it is highly unlikely that a comet shower was responsible for this mass extinction and hypotheses of periodic comet showers still lack any supporting physical evidence. However, the random comet shower is still alive and well in the late Eocene where ${ }^{3} \mathrm{He}$ anomalies, multiple craters and Ir-poor ejecta deposits are all found over a brief geologic interval. We now have the tools with Ir, spherules, and meteoritic spinels to find new impact deposits, isotopic sytematics to prove their cosmic nature, and even an isotopic tracer of the dust produced by comet showers to develop a more complete picture of the accretion history of the Earth for much of its history.

References. [1] Murray S. and Renard A.F. (1891) Rept. Sci. Res. Voyage H.M.S. Challenger, 3. [2] Barker J.L. and Anders E. (1968) Geochim. Cosmochim. Acta 32, 627. [3] Alvarez L.W. et al (1980) Science 208, 1095. [4] Smit J. and Hertogen J. (1980) Nature 285, 198. [5] Ganapathy R. (1980) Science 209, 921. [6] KyteF.T. et al. (1980) Nature 288, 1980. [7] Orth C.J. et al. (1981) Science 214, 1341. [8] Smit J. and Klaver G. (1981) Nature 292, 47. [9] Bohor B.F. et al. (1984) Science 224, 867. [10] Raup D.M. and Sepkowski J.J. (1984) Proc. Nat. Acad. Sci. USA 81, 801. [11] Davis et al. M. (1984) Nature 308, 715. [12] Rampino M.R. and Stothers R.B. (1984) Nature 308, 709. [13] Whitmire D.P. and Jackson A. (1984) Nature 308, 713. [14] Hildebrand A.R. et al. (1981) Geology 19, 867. [15] Smit J. (1999) Ann. Rev. Earth Plan. Sci. 27, 75. [16] Claeys P. and Casier J.G. (1994) Earth Plan. Sci. Lett. 122, 303. [17] Retallack G.J. et al. (1997) Geology 26, 979. [18] Smit J. and Kyte F.T. (1984) Nature 310, 403. [19] Robin E. et al. (1993) Nature 363, 615. [20] Robin E. (1999) GSA Abs. Prog 31, A63. [21] Margolis S.V. et al. (1991) Science 251, 1594. [22] Vonhof H.B. and Smit J. (1999) Meteoritics Plan. Sci. 34, 735. [23] Byerly G.R. and Lowe D.R. (1994) Geochim. Cosmochim. Acta 58, 3469. [24] Kyte F.T. and Brownlee D.E. (1985) . Geochim. Cosmochim. Acta 49, 1095. [25] Kyte F.T. (1998) Nature 396, 237. [26] Pierazzo E. and Melosh H.J. (2000) Meteoritics Plan. Sci. 35, 117. [27] Luck J.M. and Turekian K.K. (1983) Science 222, 613. [28] Shukolyukov A. and Lugmair G.W. (1998) Science 282, 927. [29] Shukolyukov A. et al., Workshop Impacts Early Earth, in press. [30] Farley A.K. et al. (1998) Science 280, 1250. [31] Hut P. et al. (1987) Nature 329, 118. [32] Campins H. and Swindle T.D. (1998) Meteoritics Plan. Sci. 33, 1201. [33] Farley K.A. (1999) GSA Abs. Prog. 31, A63. 
BIODIVERSITY OF LATE MAASTRICHTIAN DINOSAURS. J. Le Loeuff' and Y. Laurent', 'Musée des Dinosaures, GIS Paléontologie et Sédimentologie continentales, 11260 Espéraza, France (jean.leloeuff@wanadoo.fr).

Introduction: A review of the available literature suggests that few dinosaur species went extinct at the Cretaceous Tertiary Boundary $[1,2]$. This is not consistent with a catastrophic extinction. However, these data are mostly based on apparent biodiversity in Montana, which is a little part of Western North America. At the end of the Cretaceous, Western North America was a distinct paleobioprovince of the Laurasiatic paleorealm. Four realms and at least 10 provinces (fig. 1) existed in the Late Maastrichtian. Their area was comprised between 0.3 and 28 million square kilometers. Late Maastrichtian dinosaurs have been discovered in several of these areas, and it is clear that different families or genera occupied the same ecological niches on the different landmasses.

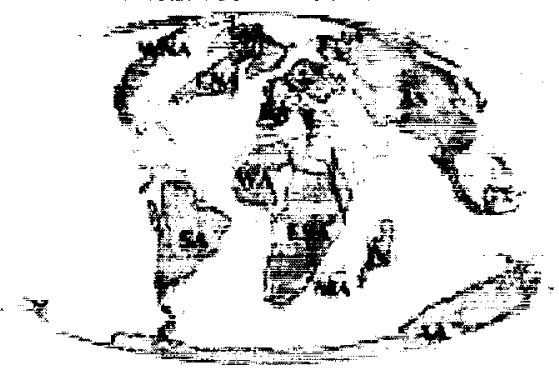

Fig 1 : Maastrichtian paleogeography (after Smith et al. [3]

The fossil record is very different for these different Late Maastrichtian landmasses : in some places, a very few or even no dinosaur bone have been unearthed for different reasons (lack of Late Maastrichtian continental strata, unexplored levels). Only five provinces have yielded Late Maastrichtian dinosaurs in 2000 , totalizing 65 species belonging to 59 genera and 17 families. This is the apparent global dinosaur biodiversity at the end of the Maastrichtian.

\section{Apparent biodiversity and real biodiversity:}

Signor and Lipps [4] have emphasized the disparity between real and apparent biodiversity in the fossil record [5]. In the case of land vertebrates, taphonomic biases are so important that most of the time the apparent biodiversity will be much lower than the real biodiversity. Several methods have been used to estimate paleobiodiversity. They are based on the relationship between the area of a land mass and the number of medium to large animals species that live upon it. Russell [6] obtained the following relationship for Late Pleistocene mammals :

Generic diversity $=0.1386\left(\text { area } \mathrm{km}^{2}\right)^{0.36}$
We applied Russell's equation to two hypotheses of the real biodiversity of West Northern America, so far the best known area for Late Maastrichtian dinosaurs (table 1). As proposed by Russell, we employed the exponent $(0.36)$ to calculate two intercepts postulated to be representative of Late Maastrichtian dinosaur assemblages.

H1. The apparent biodiversity of Western North America (28 genera) equals the real biodiversity, which means that all dinosaurs living in this area during the Late Maastrichtian have been discovered. Intercept is thus calculated to be 0.0999 .

$\mathrm{Ge}$ (generic dinosaur diversity) $=0.0999$ (area in $\mathrm{km} 2)^{0.36}$

This gives a global dinosaur diversity of 294 genera.

H2. The real biodiversity of Western North America equals that for the Campanian ( 39 genera according to Russell, 1995). The calculated intercept is nearly identical to that for Late Pleistocene mammals.

$\mathrm{Ge}=0.1392(\text { area in } \mathrm{km} 2)^{0.36}$

This yields to a global dinosaur diversity of 416 genera

\section{Conclusions.}

Real dinosaur biodiversity in the Late Maastrichtian (ie in a time intervall between 69.5 and $65 \mathrm{ma}$ ) would be situated between 294 and 416 genera. Future field work should allow to refine this estimate. This does not prove that all these genera went extinct at the KT boundary, but sometime in this time interval. However, all speculations about dinosaur extinction should be based on this estimated real biodiversity and not on the apparent biodiversity of eastern Montana ( 21 genera).

\section{References:}

[1] Archibald, J. D. (1996) Columbia Univ. Press, 1237. [2] Taquet, P. (1993) La Vie des Sciences, comptes-rendus, série générale, 10, 265-284. [3] Smith, A. G. et al. (1994) Atlas of Mesozoic and Cenozoic landmasses, Cambridge University Press, 1-99. [4] Signor, P. W. III and Lipps J. H. (1982) Geol. Soc. America, Spec. Pap., 190, 291-296. [5] Jablonski, D. (1997) Nature, 387, 354-355. [6] Russell, D. A. (1995) Hist. Biol., 10, 3-12. 
ESTIMATIONS OF PHYSICAL EFFECTS OF AN TERRESTRICAL 1 KM SIZE ASTEROID IMPACT. S. LenZner, Institute of Space Sensor Technology and Planetary Exploration, German Aerospace Center, Germany, (stephan.lenzner@ dlr.de).

An impact of an asteroid with a size of $1 \mathrm{~km}$ or larger on earth occurs within a average time intervall of 300.000 years [1]. As the effects of an impact of this magnitude already might cause global devasations and impacts of larger magnitude, as the KTimpact event 65 Mio years ago, are believed to be responsible for some of the great mass extinctions in the history of earth [2], theoretical investigations of these events are helpful to understand geological and biological evolutionary processes on earth and to predict the consequences of such an event on human civilisation. The presented study intends to review some of the most significant physical effects. The analytic and numeric methods used allow to perform the investigations on high-performance personal computers. These investigations are:

- The atmospheric entry, the trajectory during the entry, the energy release into the atmosphere during the entry and the flowfield of the atmospheric gas affected by the speeding asteroid.

- The expansion of the vapour-plume in the atmosphere, in which the asteroid is converted after impacting on the ground.

- Global range effects as earthquake, the impact orcan and tsunami-propagation.

- Tsunami-generation at the impact site and the creation of the impact-crater.

Atmospheric Entry: For a 45 degree entry of a stony asteroid with $1 \mathrm{~km}$ diameter in an altitude of $100 \mathrm{~km}$ the equations of motions for hypersonic velocities are solved to compute the trajectory and the energy release into the atmosphere during the entry. The entry velocity is set to $15 \mathrm{~km} / \mathrm{s}$. During the 9.3 seconds lasting entry only less than $1 \%$ of the impactors energy is released into the atmosphere, creating a bow-shock of high energetic gas around the impactor. The velocity components in horizontal and vertical direction are only affected by some tens of meters per second. To compute the hypersonic flowfield quantities around the impactor, a flowsolver based on Mc. Cormac's technique [3] is applied on a structured grid containing 3600 knots. In the frame of reference of the moving impactor, which is assumed to retain it's size and shape during the entry, the flow enters the computational domain with ambient conditions in pressure and density and velocity equal to the speed of the impactor. As expected for hypersonic motions, the atmospheric gas is heated and compressed in the shape of a bow-shock around the impactor.

Expansion of the Vapour-Plume: After colliding with the surface of the planet, the impactor is converted into high compressed, high energetic vapour-plume which expands into the atmosphere. To simplify the investigation of this process, the initial vapour-plume is hemispherically with the radius equal to the radius of the former impactor, while the energy of the plume is set equal to $50 \%$ of the impactors energy. The planet's surface is assumed to be ideal reflecting. This assumptions lead to the initial flow quantities as energy-density and pressure of the flowfield in the atmosphere. The atmosphere is taken as isothermal with an exponentially decay in density and pressure. Similar assumptions for modelling this process are made by Newman et. al. [4], where the atmospheric blow-off of the KT-impact event is investigated. As the released energy of an $1 \mathrm{~km}$ size asteroid impact event into the atmosphere exeeds the treshold to balance with the ambient pressure, the vapour-plume expands above the characteristic scale height of the atmosphere through the stratosphere into space. To simulate this process numerically which covers a large variation in length- and time scales, the numerical scheme is equipped with a grid-stretching technique sensitive on arrival of the shock-wave at the upper outflow boundary.

Effects on Global Scales: Portions of the released energy of the impact propagate on global distances, significant are the global earthquake, impact-orcan and tsunamis if the impact takes place on sea where the depth of the water is sufficient large at the impact site. As numeric modelling of this global effects has to face difficulties due to huge variations in lengthand time scales, analytical estimations are used to predict the amplitudes of these effects. Fundamental parameters in these estimations are the energy-partitions of these phenomenons, which are only rhoughly estimated at present and are subject to further research.

Tsunami- and Impact-Crater Creation: Specializing the flowsolver described above on quasi incompressible fluids, the creation and propagation of tsunami-waves can be studied at the impact site. For this purpose, in a quasi incompressible fluid with a given depth a transient cavity is taken as initial condition and the process of filling under the influence of gravity is investigated with respect to time. The size of this transient cavity is taken from Crawford [5]. It is visible, that the fluid forms a huge fountain after filling the cavity, which collapses and generates a series of tsunami-waves. The two-dimensional, radial symmetric model is also equipped with a profile of the ocean floor which rises to a shallow-water region at the radial boundary of the domain. This allows to observe the increase of the wave-heigth as they reach the shallow-water region.

The interaction of the impactor with the planet's surface is investigated using a two-fluid hydrodynamic code. The upper atmosphere and the impactor are described by species 1 , the material of the surfaces by species 2 . For species 1 a ideal gas equation including cold pressure effects (when the impactor is compressed above it's normal density) is used, while for the species 2 the tillotson equation of state is applied [6]. Also in this case the grid-stretching method is applied to cover the wide range of length-scales from the initial size of the impactor to the final size of the crater. The shape of the impactor and the surface material is marked with tracer-particles [7] 
which allow to observe the deformation of the impactor and the excavation flow created by the impact. The method is capable to compute more than 150 characteristic times. As this method also is based on the Mc. Cormac's technique where artifical viscosity is needed in the presence of shocks, the interface of impactor and planet's surface becomes smeared out in the density distribution during the computation. Either an upwind technique applied in the flowsolver or a density reconstruction based on volume cells defined by the tracer-particles positions are planned to sustain a sharp interface.

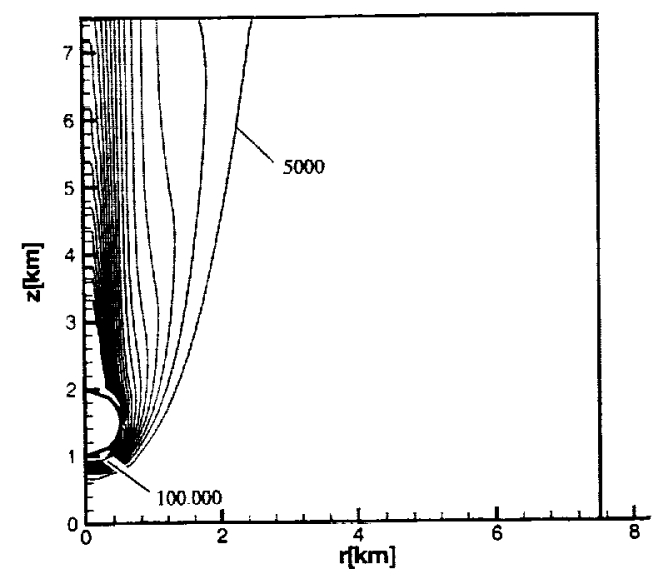

Figure 1: Temperature profile around impactor, $T_{\min }=$ $5000 K, \Delta T=5000 K$

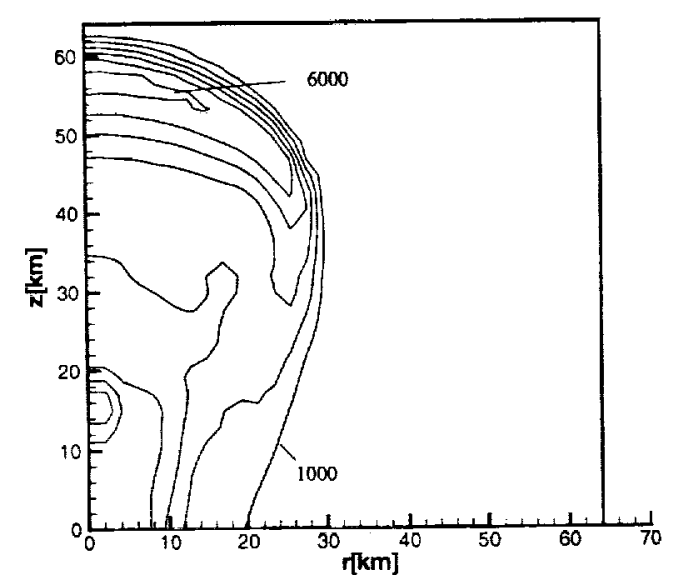

Figure 2: Temperature in vapour-plume after $9.22 \mathrm{~s}, T_{\min }=$ $1000 K, \Delta T=1000 K$

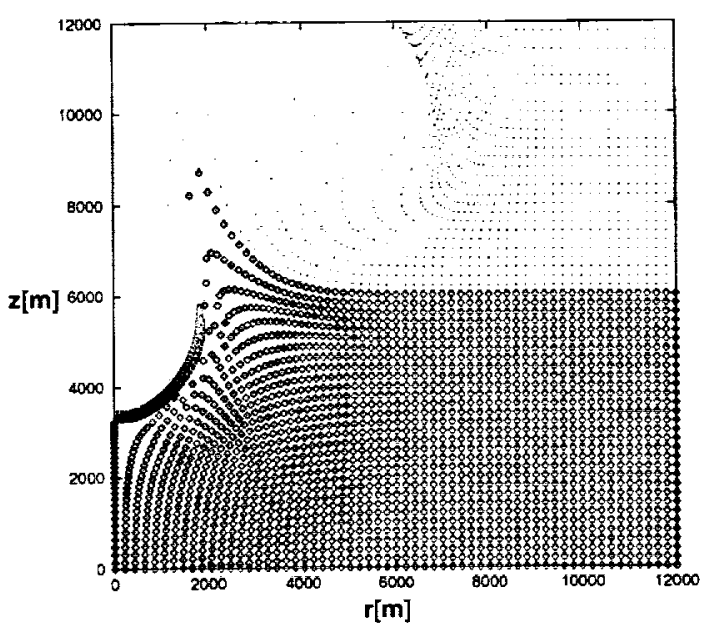

Figure 3: Position of the tracer-particles at $t=1 \mathrm{~s}$

Figure 1 illustrates the temperature distribution around the moving impactor in the lower part of the atmosphere. In figure 2 the temperature distribution in the expanding vapourplume $9.22 \mathrm{sec}$ after the begin of the expansion is shown. The deformation of the projectile as the created transient cavity in the surface, consisting of water-ice, is illustrated in figure 3. Aslo visible in figure 3 is the outgoing shock-wave in the atmosphere.

\section{References:}

2) Alvarez, L. W., F. Asaro, H. V. Michel, and Alvarez, W.: Extraterrestrial cause for the Cretaceous-Tertiary extinction, Experimental results and theoretical interpretation. Science 208,1095-1108.

3) Anderson, J. D.: Computional Fluid Dynamics, Mc Graw-Hill Int, 1995.

1) Bergh van den, S. : Life and death in the inner solar system, Astronomic Society of the Pacific, 101, p 500509. 1989.

5) Crawford, D.A. and Mader, C. L.: Modelling Asteroid Impact and Tsunami. Science of Tsunami Hazards, $16,1,17-21,1988$.

6) Melosh, H. J.: Impact Cratering. A Geological Process. Oxford University Press, 1989.

4) Newman, W. 1., Symbalisty, E. M. D., Ahrens, T. J., and Johnes, E. M. 1999: Impact Erosion of Planetary Atmospheres: Some Surprising Results. Icarus 138, 224-240.

7) Rider, W.J. and Kothe, D.B.: Stretching and tearing inrerface tracking methods, AIAA paper 95-1717, 1995. 
PRODUCTION, ACCELERATION AND DISTRIBUTION OF MICROTEKTITES ON EARTH, MARS, VENUS AND TITAN R. D. Lorenz, Lunar and Planetary Lab, University of Arizona, Tucson, AZ 85721-0092, USA (rlorenz@|pl.arizona.edu)

Introduction: Microtektites, formed by melt dispuption and condensation of rock vapor in the expanding impact fireball can only be distributed widely by events energetic enough to punch through the atmosphere and distribute ejecta on ballistic trajectories. I compare the formation and distribution environment for microtektites on Mars, Venus and Titan with that of Earth. Typical impact velocity, gravity and atmospheric parameters are all controlling factors. Mars' thin atmosphere means that this process can occur for smaller, and therefore more frequent, impact events [1].

Atmosphere-Piercing Impacts: Part of the energy of an impact event is deposited in a fireball of gas, whose volume relates to the energy [2]. This fireball will expand, nominally to a size at which its pressure will have fallen to the ambient surface pressure of the planet and any material in it ('fallout') is deposited around, or in a streak downwind of, the source crater. However, if the fireball is energetic enough that its diameter is comparable to an atmospheric scale height, it keeps expanding upwards, accelerating entrained material into space. This 'blowout' has been observed in a highaltitude nuclear test ('Teak', 3.8MT) as well as in the SL-9 impact plumes on Jupiter. The phenomenon is also responsible for the distribution of of microtektites on Earth (which are dispersed far too widely to have transported within the atmosphere) and is also believed to lead to the formation of the parabolic features around impact craters on Venus [3] - in these features the ejecta is dispersed with a circular symmetry by ballistic transport above the atmosphere, and then the material is winnowed by East-West winds in Venus' thick atmosphere.

On Earth, an event needs to be energetic enough to form a $10 \mathrm{~km}$ crater to pierce the atmosphere (e.g. the Ivory Coast microtektite field is associated with the $12 \mathrm{~km}$ Bosumtwi crater). In Mars' thin atmosphere, the corresponding threshold size is only about $2.5 \mathrm{~km}$, thus atmosphere-piercing events are relatively common on Mars, while less so on Venus and Titan, with thicker atmospheres. The volume of material available for tektites and microtektites is limited by the melt and melt+vapor fraction of material produced by the impact - this depends somewhat on impact velocity as well as the crater size [4]: the fine ejecta volume for terrestrial craters appears to be around $5 \times 10^{-5} \mathrm{D}_{c}{ }^{3.84}$, where, where $D_{c}$ is the crater diameter.
Global Ejecta Transport: On Earth, a velocity of around $10 \mathrm{~km} / \mathrm{s}$ is needed to transport material half-way around the planet. Mars is both smaller in diameter, and has a lower gravity, so the corresponding speeds are lower. Trajectory simulations (fig.1) show that particle trajectories are appreciably affected by planetary rotation, and only 4.5 $\mathrm{km} / \mathrm{s}$ is needed to carry particles half-way around the planet. On Earth, microtektites are distributed with a surface number density (or equivalently, a layer thickness $t$ ) that varies with crater radius $R_{c}$ and distance $d$ as $t=k R_{c}{ }^{x}\left(R_{d} / d\right)^{n}$, with $x=0.74, n=3$ and $k=0.14$ For Bosumtwi [5], there are around 100 particles (100 $\mu \mathrm{m}$ or larger) per square $\mathrm{cm}$, at a distance of about $2000 \mathrm{~km}$.

Since dispersal velocities are typically $\sim 1 / 2$ of the impact velocity, and the altitude at which atmospheric density becomes negligible $\left(\sim 10^{-10} \mathrm{kgm}^{\text {- }}\right.$ ${ }^{3}$ ) is about the same for Venus as for Earth, the dispersal kinematics are similar. For Mars, the impact velocities are about half of those typical for Earth, commensurate with the global transport velocities above, so again (fortuitously) the same relations may hold.

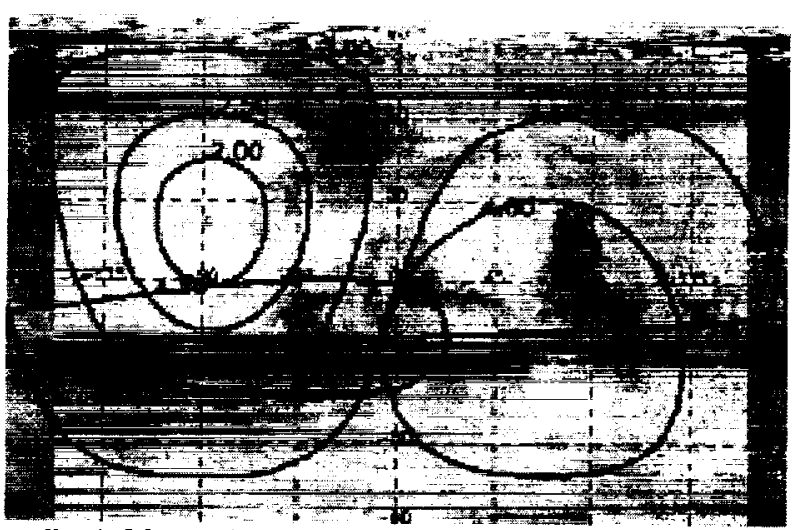

fig. 1 Map of the Martian surface : diamond indicates example crater (Fesenkov, 86km dia - same lat/long as Chicxulub on Earth) contours (launch velocity $\mathrm{km} / \mathrm{s}$ ) show regions reached by particles launched at $45^{\circ}$. The poles are reached with about $3 \mathrm{~km} / \mathrm{s}$, and antipodes with $4.5 \mathrm{~km} / \mathrm{s}$. Note lateral displacement of contours, an dstretched tadpole shape of $4.5 \mathrm{~km} / \mathrm{s}$ contour, due to planetary rotation.

Spherules and Heating: Material melted in or condensing from the vapor plume of an impact will 
tend to condense as small spheres whose size is limited by surface tension's ability to overcome aerodynamic stress [6] and the spherules can be deposited as thick, uniform beds. More energetic events (higher velocity impact) produce smaller spheres : for Mars, with lower escape velocity and further from the sun, such velocities are lower than for Earth, and so spherules are larger. For the $2.5 \mathrm{~km}$ crater event discussed above, the corresponding particle diameter would be $300 \mu \mathrm{m}$ [1]. These and smaller particles, having condensed from melt or vapor, will have a molten texture.

Micrometeoroids, if large enough, can melt. But while for the Earth the temperatures experienced as a function of size and entry velocity [7] are such that cosmic spherules (i.e. melted micrometeoroids) of the same size as microtektites would appear melted, on Mars most meteoroids of that size would not due to the lower entry velocity, so a molten texture on a $\mathbf{3 0 0}$ micron (or smaller) particle on Mars discriminates against most micrometeorites and points to an impact crater origin [1].

Future Prospects for Space Missions:

Venus - distant plans only for balloon and/or sample return missions.

Mars - the present 2001 Mars lander is equipped (as was the ill-fated Mars Polar Lander) with a sampling arm, and a robotic arm camera with the ability to image the soil with $\sim 20 \mu \mathrm{m}$ pixels. With such a resolution, it should be possible to recognize $300 \mu \mathrm{m}$ diameter particles as spherical and uniform, and with appropriate lighting a glassy texture might be apparent - this instrument may therefore be able to find preserved microtektite deposits. Analysis of returned samples in the next decade is likely to yield further insights.

Titan - RADAR imaging by Cassini in 20042008 may reveal ejecta deposits, and allow texture/thickness to be determined, as for Venus with Magellan, but Cassini will also have near-IR imaging, perhaps allowing particle sizes to be constrained.

\section{Summary: Comparisons with Earth}

Venus: high $P$, so only large impacts are atmosphere-piercing. High $T$ and Vimp give $\sim 2 x$ larger melt+vapor fraction. Zonal winds cause near-field ejecta to be swept into parabolae. Planetary radius, vertical extent of atmosphere and gravity are same as earth, Vimp only modestly larger, so $t$ vs d relationships for Earth still hold.

Moon : very low P so melt/vapor droplets distributed ballistically on essentially all impacts. But Vimp $\gg$ Vesc, so large fraction of ejecta escapes. Ejecta that is retained itself impacts surface at high speed.
Mars : low $P$, so even small impacts make microtektites. Vimp $50 \%$ of Earth, but gravity and planetary radius are also lower by a similar factor, so t vs d relationships for Earth probably still applicable.

Titan : moderate P. Similar atmospheric rotation to Venus, but atmosphere very vertically extended, so parabolae impossible - only eejecta streaks. Icy surface rather than rock, so melt production different : Vimp is poorly constrained, $t$ vs $d$ likely to be different.

\section{Areas for Future Work}

This abstract has qualitatively discussed the planetary settings for microtektite dispersal. The next step is a detailed, and probably numerical, investigation of the interaction of the fireball, its entrained particles, and the atmosphere. Size/distance relationships (which the terrestrial community could usefully document) may help constrain these processes.

\section{References:}

[1] Lorenz, R. D. 2000 Microtektites on Mars: Volume and Texture of Distal Ejecta deposits, Icarus, in press [2] Melosh, H. J. 1989. Impact Cratering A Geologic Process. Oxford University Press [3] Vervack, R. J. Jr., and H. J.Melosh, 1992, Wind Interaction with Falling Ejecta: Origin of the Parabolic Features on Venus, Geophysics Research Letters, 19, 525-528 [4] Grieve, R. A. F. and Cintala, M. J. 1992 An Analysis of Differential Impact Melt-Crater Scaling and Implications for the Terrestrial Impact Record, Meteoritics 27, 526-538 [5] Glass, B. P. and J. E. Pizzuto 1994. Geographic Variation in Australian Microtektite Concentrations: Implications concerning the location and size of the source crater Joumal of Geophysical Research, 99, 19075-19081 [6] Melosh H. J. and Vickery A. M. 1991. Melt droplet formation in energetic impact events Nature , 350, 494-496 [7] Flynn, G. J. 1989. Atmospheric Entry Heating : A criterion to distinguish between asteroidal and Cometary sources of Interplanetary Dust. Icarus 77, 287-310 
CONTRIBUTIONS TO THE MINERALOGY OF CHICXULUB: IN SITU RAMAN SPECTROSCOPY EVIDENCE OF COESITE IN SUEVITE. Elena Lounejeva ${ }^{1}$, Mikjail Ostroumov ${ }^{2}$ and Gerardo Sánchez-Rubio ${ }^{1}$, ${ }^{1}$ Instituto de Geología, Universidad Nacional Autónoma de México, Ciudad Universitaria, Delegación Coyoacán, 04510 D.F. e-mail: elenal@servidor.unam.mx , ${ }^{2}$ UMSNH, IIM,Depto. De Geología y Mineralogía, Ciudad universtaria, A.P. 52-B, C.P. 58000, Morelia, Michoacán

The occurrence of high pressure polymorphism of silica, i.e. coesite and especially stishovite, is widely accepted as a hard evidence that an impact of a cosmic body took place some time in the past. Evidence for such event in the case of Chicxulub structure has been growing (1-3), but reports on the occurrence of coesite and/or stishovite are scarce $(4,5)$. During the last decade the traditional material consuming XRD identification of high-pressure mineral phases have given way to the non-destructive methods such as magic angle solid state nuclear magnetic resonance and Raman spectroscopy.

Here we report the Raman spectroscopy unambiguous evidence of coesite in suevite from Chicxulub. The study was carried out on sample Y6N14 described elsewhere $(1,6,7)$ as a polymict suevite breccia with up to 50 vol.\% clasts less than $1 \mathrm{~cm}$ in size embedded in a microcrystalline matrix of complex mineralogy. Previously the half-polished slab and then polished thin sections were examined under the stereoscopic and polarising microscope and promising areas, such as fragments of crystalline basement and quartz with shock metamorphic features, were selected for micro-Raman spectroscopy study. This was accomplished with a Jobin-Yvon T64000 ( $\lambda=514.5 \mathrm{~nm})$ and a Bruker instrument $(\lambda=1064 \mathrm{~nm})$ to obtain simple and Fourier transform Raman spectra respectively. In both cases a microscope giving $2 \mu \mathrm{m}$ spatial resolution was used, the beam diameter was about 10-20 $\mu \mathrm{m}$ and the beam power was about $200-250 \mathrm{~mW}$. The spectral slit width was $2.5 \mathrm{~cm}^{-1}$, the wave number accuracy was $1 \mathrm{~cm}^{-1}$. The program GRAMS 386c was used to present the results. Our results were checked with spectra obtained from synthetic standard minerals as well as from the shock metamorphosed sandstone from the Arizona impact crater where the coesite presence were additionally confirmed by $\mathrm{X}$-ray diffraction.

Despite the spectra of common alpha quartz in most of selected fragments, the Raman bands about 119,178 and $272 \mathrm{~cm}^{-1}$ corresponding to coesite were obtained from two aplitic-like clasts where quartz displays more than three decorated PDF sets. This rock looks quite unlike the high-P metamorphic rocks such as eclogites from regions with strong tectonic disturbance or grospydites from kimberlite pipes where coesite has occasionally been found.

We believe that coesite in the Chicxulub rocks confirmed by Raman spectra was shock-induced and that objections to the impact origin of Chicxulub are now poorly supported.

References: (1) Hildebrand,A.R., et al. (1991). Geology 19, 867-871; (2) Sharpton, V.L. et al., (1992) Nature 359, 819-821.(3) Schuraytz B. C. et al., (1994) Geology 22(10), 868-872; (4) Gómez, R., et al., (1997). Abstracts of the Material Research Society Fall Meeting, Boston, U.S.A, p.583; (5) Lounejeva et al. (in press) Revista Mexicana de Ciencias Geológicas; (6) Quezada Muñeton, J.M. et al (1992) LPSC XXIII, 1121-1122. (7) Heuschkel,S. et al. (submitted) Meteoritics and Planetary Science. 
$568 \%, 5$

116 Catastrophic Events Conference

TOWARDS MODELING LONG TERM CLIMATIC EFFECTS OF IMPACTS. T. Luder, W. Benz, Physics Institute, Space Research \& Planetary Sciences, Sidlerstr. 5, 3012 Bem, Switzerland, (luder@phim.unibe.ch,willy.benz@phim.unibe.ch), T. F. Stocker, Physics Institute, Climate and Environmental Physics, Sidlerstr. 5, 3012 Bem, Switzerland, (stocker@climate.unibe.ch).

Numerical models of present oceans and of radiative transfer through a dust loaded atmosphere are used to explore the long term response of our climate system to the impact of an asteroid.

It is acknowledged that an impact on a planet like our Earth hurls large amounts of dust-like aerosols into the global atmosphere, where sub-micrometer particles may reside for years. Dust loading values up to $1 \mathrm{~kg} / \mathrm{m}^{2}$ are well conceivable for a $10 \mathrm{~km}$ asteroid (figure 1). As a consequence radiation, in particular solar light and infrared radiation, is inhibited from passing freely through the atmosphere, which can push climate away from its present state within tens of years. Possible effects are changes in the pattern of global ocean and heat flows, leading for instance to displacement of deserts or growth of glaciers and ice sheets. One example can be the interruption of the Gulf Stream, which provides Europe with thermal energy and keeps large areas free from ice.

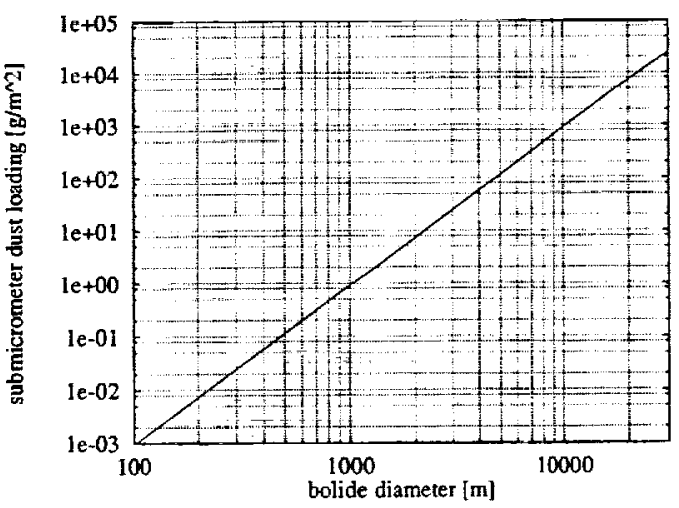

Figure 1: Global dust loading due to a bolide impact. It is supposed that the total sub micrometer dust mass is proportional to the impactor mass: $m_{s u b \mu m}=0.3 \cdot m_{b a l i d e}$. Here we used $\rho=3000 \mathrm{~kg} / \mathrm{m}^{3}$ for the mass density of the bolide.

Current results infer that the extent of longterm change is not a monotonic increasing function of the quantity of dust, i.e. a larger asteroid does not imply a more severe perturbation of climate. Rather, there seems to exist a critical amount of loading which maximizes the outcome. The reason behind it is the fact that if more dust is spread into the atmosphere not only does less sunlight reach the ground but conversely, less radiation is allowed to leak out to space. The point is that the Sun darking effect works already at relatively small wavelength, whereas the isolation requires larger quantities of dust, just because of wavelength dependence of optical properties of the dust particles.

The procedure of the modeling consists of two components. The climate in the long run is dominated by the state of

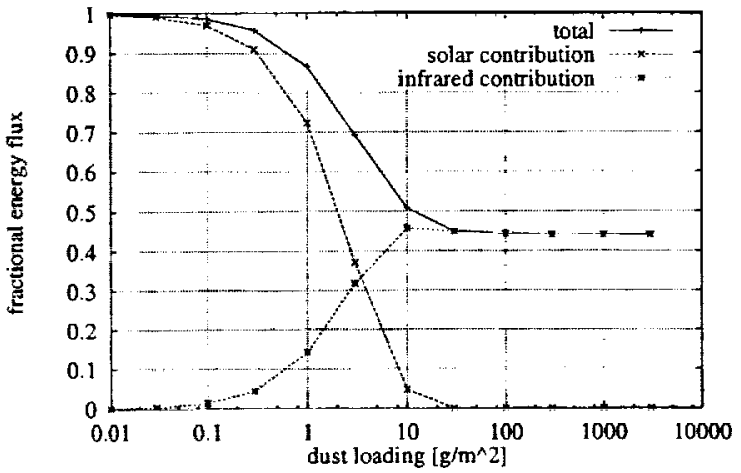

Figure 2: Calculated downwards energy fluxes of sunlight and infrared radiation from the dust layer at ground level for different dust loadings $\left(0.01 \mathrm{~g} / \mathrm{m}^{2}\right.$ to $\left.3000 \mathrm{~g} / \mathrm{m}^{2}\right)$. The fluxes are given as fractions of the flux in the situation where no dust is present. The position of the sun is $40^{\circ}$ above horizon. The ground albedo is 0.2 . The dust layer and the ground are in radiative equilibrium.

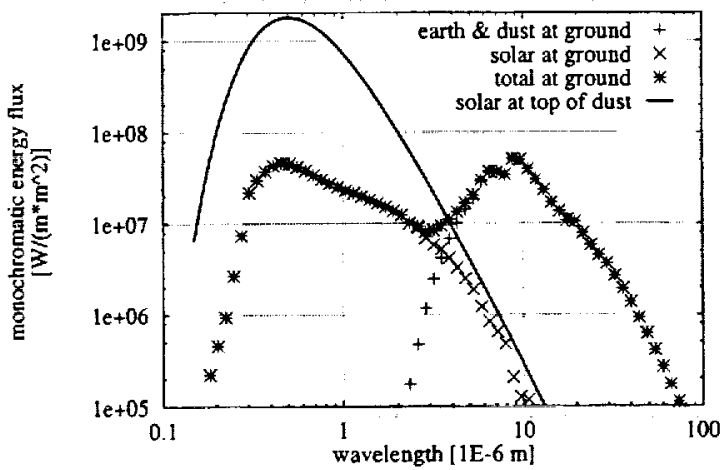

Figure 3: Wavelenght spectra calculated by the dust model for a $10 \mathrm{~g} / \mathrm{m}^{2}$ loading. The single points represent the downwelling spectral fluxes at the lower boundary of the dust layer. The solid line is the solar spectra at the top of the dust layer. At the ground the solar radiation is attenuated by a factor of about 40. Clearly the radiation from the dust and the ground dominates. The sun is positioned at $5^{\circ}$ below the zenith. Ground albedo is 0.2 for visible and 0.05 for infrared radiation. The model uses 63 discrete wavelengths that are equally spaced on a logarithmic axis. 
Modeling Climatic Effects of Impacts, T. Luder et al.

the oceans, because of their large heat capacity. Thus the first component is a model of the thermohaline circulation in the Pacific, Atlantic and Indian oceans, connected by the Southern ocean. A simple thermodynamic sea ice model is included.

Besides the driving solar energy the important quantities are the temperature, salinity and mass density fields in the water. With present-day conditions this model shows deep water formation in the Northern Atlantic and in the Southern Oceans and up-welling in the Pacific and the Indian Oceans. Observed temperature and salinity patterns just as meridional fluxes of heat and freshwater are well reproduced.

Since each basin is zonally averaged, the model is two dimensional. This restriction allows us to run the code with much less computational effort than a fully three dimensional model of the glcbal oceans. Therefore, integrations of the order of $10^{4}$ years and extensive sensitivity studies are possible.

The other component handles the interplay of a dust layer with the Sun as a black body on the one side and the ground of the Earth as a grey body on the other side. The model determines the radiative fluxes in the layer and at its boundaries under the constraint of being in a radiative equilibrium with Sun and Earth.

Input parameters of the simulation are the amount of dust, its size distribution at different altitudes above ground, the position of the Sun with respect to the zenith, the solar spectra, the temperature as well as albedo of the ground in the visible and infrared wavelength range, the complex refraction index of the dust material as a function of wavelength, and the discretization of wavelength.
Of prime importance for the transfer of radiation are the multiple scattering processes. A photon may be scattered many times in a field of dust particles, because the absorption cross sections are smaller than the scattering cross sections for a series of wavelengths. In this regard dust is similar to tiny water droplets but very different from soot particles, where absorption dominates. Therefore, significant parts of solar energy can penetrate a layer even if the sun is not visible anymore. In order to consider such effects a technique called 'Doubling and Adding' is used. It bases on the possibility to calculate the angular dependence of reflectance and transmission of radiation through a compound of two layers, if the transmission and reflection properties of the single layers are known. Thus starting with an infinitesimally thin layer and 'doubling' it sev. eral times, it is possible to compute the radiative properties of a thick layer. The interaction of radiation with a thin layer can be traced to the process of single scattering of plane waves at one particle, which is described by Mie theory.

Figure 2 shows how downward energy fluxes are attenuated by the presence of different amounts of dust. In these setups the temperature of the ground is not a fixed parameter but free to evolve until the net energy flux at the ground vanishes.

Figure 3 shows the contribution to the spectra of the downward directed flux for a specified quantity of dust.

As long as there is dust present at the beginning of a simulation both oceanic and dust components are coupled. The ocean model hands over current parameters of each of its cells to the dust model, which hereupon gives the radiative energy flow at the boundary. The exchanged parameters are current solar position, temperature and albedo. 
PHYSICAL PROPERTIES OF NEAR-EARTH ASTEROIDS AS PRINCIPAL IMPACTORS ONTO THE EARTH. D.F.Lupishko, Astronomical Observatory of Kharkiv National University, Sumskaya str. 35, Kharkiv 61022, Ukraine. lupishko@astron.kharkov.ua

INTRODUCTION. Besides the main-belt asteroids, which rotate around the Sun in stable orbits located between the orbits of Mars and Jupiter, there is a population of asteroids in unstable eccentric orbits which can approach and cross the Earth's orbit. This population is called "near-Earth asteroids" (NEAs). More than 800 NEAs have been discovered to-date. They are the objects of a special interest from the point of view not only of fundamental science but of the applied science as well (NEAs as the potential sources of raw materials in the nearest to the Earth space, the problem of asteroid hazard, etc.). There is no doubt that Earth-crossing asteroids are the principal bodies who strike our planet ocasionally and therefore they are a real threat to the Earth civilization.

\section{TAXONOMY AND MINERALOGY} Taxonomic classification of the discovered near-Earth asteroids shows that among the classified NEAs practically all taxonomic classes are represented with the exception of one or two low-albedo classes which are located in the outer part of the main belt. The main question of the NEA taxonomy is a relative abundance of the two most numerous $\mathrm{C}$ (carbon) and $\mathrm{S}$ (silicate) classes. About a half of the classified near-Earth objects belong to class $S$, and the observed number of S-types exceeds the number of low-albedo types (C and others) as much as a factor of three. Using the results of the selection effects modelling [1] it was obtained [2] that the relative number of $\mathrm{C}$ and other low-albedo objects among NEA population is approximately 2.5 times less than in the main asteroid belt. This could be an important constraint for the possible sources of NEA replenishment. The simplest explanation could be that NEAs are coming preferentially from the inner regions of asteroid main beit, where the relative abundance of $\mathrm{C}$ and other lowalbedo asteroids is much lower.

Most of the NEAs for which mineralogical information exists, represent differentiated assemblages. Among them there are objects with monomineral silicate composition and purely metalic ones. For example, small asteroid 1915 Quetzalcoatle appears to have little or no olivine, and diogenitic meteorites (Mg-pyroxenes) are the best analogs of it. 3199 Nefertity has the same content of pyroxene and its composition corresponds to that of stony-iron meteorites - pallasites. The object of A-class 1951 Lick also appears to have a composition indentical to olivine achondrites or pallasites. There are two $\mathrm{M}$ objects, one of which, $61781986 \mathrm{DA}$, has radar albedo clearly indicating the real metalic composition of this asteroid. 3109 Eger with very high albedo (0.64) corresponds to assemblages of iron-free silicate minerals, such as enstatite. Five NEAs classified as Vclass, have spectra indentical to those of main-belt asteroid 4 Vesta, which is known to have a differentiated structure. The variety of taxonomic classes among NEAs reflects the diversity of their surface mineralogy and an overall analogy with the MBAs. Taking into account their small sizes, one might infer that they are the products of much larger differentiated bodies which were later injected into the present orbits.

SIZES AND SHAPES. NEAs are much smaller in sizes in comparison with main-belt asteroids (MBAs), the largest of which is I Ceres (about $950 \mathrm{~km}$ in diameter). Asteroid 1036 Ganymed $(D=38.5 \mathrm{~km})$ remains to be the largest among NEAs, two other asteroids 433 Eros and 3552 Don Quixote are about $20 \mathrm{~km}$ in diameter, all others are about or less than $10 \mathrm{~km}$ and approximately $3 / 4$ of them are less than $3 \mathrm{~km}$. The smallest known NEAs are about 6-9 $\mathrm{m}$ across. The population of NEAs can be approximated by a power law, which reflects a general exponential increase of the number of asteroids as we go to smaller sizes:

$$
n=k D^{-b}
$$

where: $n$ is a number of asteroids larger than a given diameter $D, k$ is the constant and $b$ is the power law exponent.

According to the availble estimates, Earth-crossing population contains about 2100 objects larger than 1 $\mathrm{km}$ in diameter and about 300000 objects larger than $100 \mathrm{~m}$. Among ECAs 1866 Sisyphus is the largest object with diameter of about $8 \mathrm{~km}$. The absence of NEA-objects larger than $40 \mathrm{~km}$ in diameter is usually interpreted as an indication that near-Earth asteroids are not primordial objects, but they are collisional fragments of larger main-belt asteroids.

The data of ground-based observations and space missions show that NEAs have irregular and elongated shapes. The NEAs on the average are elongated to the same extent as those of MBAs of corresponding sizes. But radar observations showed a striking diversity of NEAs shapes from nearly spherical (1566 Icarus) to very elongated (1620 Geographos, 1865 Cerberus) and to bifurcated and contact-binary ones (4179 Toutatis and 4769 Castalia). The most elongated asteroid among observed NEAs is 1865 Cerberus $(D=1.2 \mathrm{~km})$, the axis ratio $a: b$ of its figure is estimated to be equal to 3.2. The opinion that NEAs have more exotic shapes than MABs may belong only to the large MBAs, be- 
cause we know practically nothing about the shapes of kilometer-sized main-belt objects.

AXIS ROTATION. The distributions of the rotation rates of Earth-approaching asteroids in comparison with that for MBAs of comparative sizes show that both asteroid samples have very similar means equal to $4.85 \pm 0.30$ and $4.50 \pm 0.24 \mathrm{rev} / \mathrm{day}$, respectively, similar dispersions and similar maxima of their distributions. At the same time the mean rotation rate of the large MBAs is equal to $2.90 \pm 0.12$ rev/day. Thus, one can conclude that on the average NEAs rotate practically in the same manner as the small MBAs and considerably faster than large MBAs. The fastest rotators among NEAs have the rotation periods equal to 2-2.5 hrs, but the slowest one (3102 Krok) rotates with the period equal to $147.8 \mathrm{hrs}$. The main peculiarity of NEA rotation is that among this population there are objects with very complex and non-principal axis rotation (so-called "tumbling" asteroids).

OPTICAL PROPERTIES AND SURFACE STRUCTURE. The analysis of photometric, polarimetric, radiometric and other observing data clearly demonstrates that the surfaces of NEAs display the same optical properties as the surfaces of MBAs, and most likely they have the same microstructure. The whole range of NEA albedos $(0.04 \div 0.60)$ is basically the same as that of MBAs and it corresponds to the same distribution of taxonomic classes and mineralogy within these two populations. But at the same albedo, colors and similar surface composition, the strict similarity of the other photometric and polarimetrical parameters gives evidence of the same surface textures at submicron scale.

Most of NEAs are covered with regolith of low thermal inertia. But the conditions of formation, accumulation and evolution of regolith on NEAs are different from those on MBAs because of the much smaller gravity of the former ones, the higher flux of impactors in main belt than in the region of NEA orbits (1-3 orders of magnitude), and the difference in intensity of Solar wind. As a result, the regolith of NEAs tends to be more coarse-grained than that of MBAs and still more coarse-grained than the lunar regolith. Asteroidal regoliths should be less mature than the lunar ones due to a more global distribution of crater ejecta and a lower magnitude of thermal effects to provide agglutinate formation.

Finally, radar data evidence that NEA surfaces are rougher than surfaces of large MBAs at the scale length of decimeters and meters and the porosity of NEA surface matter corresponds to porosity of the top 5 to $10 \mathrm{~cm}$ of lunar regolith $(30-60 \%)$. Besides that data of radiometric measurements evidence that about $30 \%$ of NEAs of $0.5-5 \mathrm{~km}$ in sizes satisfy a thermophysical model of asteroid with high-thermal-inertia surface, such as bare rock without developed regolith.

The images of one of the largest NEA 433 Eros obtained by the NEAR-spacecraft in February 2000 showed a surface covered with large number of craters of different sizes. Ground-based radar observations also showed that even the relatively small NEA 4179 Toutatis $(D=3 \mathrm{~km})$ is cratered at about the same extent as MBAs 951 Gaspra and 243 Ida [3].

CONCLUSION. The new results of NEA studies allow us to better understand their nature, origin and relation to the comets and meteors. Indeed, small sizes of NEAs, almost the same variety of taxonomic classes, the same mineralogy and predominance of differentiated assemblages among them, approximately the same shapes and rotation, optical properties and surface structure as compared to those of MBAs, all these clearly indicate that the main asteroid belt is the principal source of NEA origin. It means that most of the NEAs are the fragments of main-belt asteroids ejected on their current orbits by processes of collisions and chaotic dynamics [4]. This conclusion does not contradict the recent results of dynamic considerations, according to which the main asteroid belt can supply a few hundred $\mathrm{km}$-sized NEAs per 1 Myr, well enough to sustain the current NEA population [5]. On the other hand, the identification of a few asteroids with extinct or dormant comets does not exclude the cometary origin of some of them. Hence, the main problem of NEAs' origin now is the relative contributions of both sources.

The discovery rate of NEAs increases greatly over the last years and the organization of new programs for their discovery and investigation in the USA, Europe, Japan and Australia gives good reasons to hope that a new era of NEA studies is coming and active groundbased and space-mission (like Galileo and NEAR) investigations will give us all information necessary for the solution of fundamental and applied problems connected with NEAs.

[1] Luu J. and Jewitt D. (1989) Astron. J., 98, 1905-1911. [2] Lupishko D.F. and Di Martino M. (1998) Planet. Space Sci., 46, 47-74. [3] Ostro S.J. et al. (1995) Science, 270, 80-83. [4] Farinella P. et all (1993) Icarus, 101, 174-187. [5] Menichella et al. (1996) Earth, Moon, and Planets, 72, 133-149. 


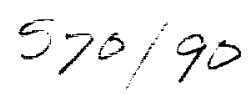

ASTEROID HAZARD: CORE OF THE PROBLEM. D.F.Lupishko' and T.A.Lupishko', 'Astronomical Observatory of Kharkiv National University, Sumskaya str. 35, Kharkiv 61022, Ukraine. lupishko@astron.kharkov.ua

In the last decade the asteroid or comet impact hazard have come to be "discovered" by the human society in parallel with many other problems that might threaten the future of civilization. The new data about small bodies of the Solar system, discovery of more and more of the geological structures on the Earth associated with catastrophic impacts of large asteroids, Shoemaker-Levy comet's crash into Jupiter in July 1994 , all these provide dramatic evidence of the potential danger to humanity if a large cosmic body strikes the Earth. The problem of asteroid hazard has been transformed from a theoretical curiosity into very distinct reality and therefore the awareness of the threat to civilization from asteroid/comet impacts has increased. It is becoming more clear that collisions of large asteroids or comets with the Earth played a very important role in the evolution of life in the past, and perhaps such impact events would become a turningpoint in the evolutional history of the Earth's life in the future. The major role in this process belongs to the population of near-Earth asteroids (NEAs) in unstable orbits which can approach or cross the Earth's orbit.

More than 800 Earth-approaching and Earthcrossing asteroids (ECAs) have been discovered so far. Physical characteristics of these objects are on the average identical to those of the main-belt asteroids of comparable sizes [1]. They have similar compositions, the same optical properties, similar shapes and the axis rotation. The principal differences of NEAs from main-belt asteroids are in their orbits and relatively small sizes. The largest NEA 1036 Ganymed is about $38 \mathrm{~km}$ in diameter though it belongs to the Amorgroup asteroids which only approach the Earth's orbit. The largest among Earth-crossers is 1866 Sisyphus with diameter of $8 \mathrm{~km}$.

In the last years the NEAs are the subject of particular interest of scientists. From the point of view of fundamental science the problem of the NEAs origin, the mechanisms of transformation of their orbits into the Earth-approaching ones, their life-time, relationships with other small bodies of the Solar system (comets and meteors) etc., are very important for the solution of the basic problem of the nearest space studies, that is the origin and evolution of our planetary system.

On the other hand, during the recent years the studies of NEOs have also acquired important applied significance. These objects are believed to be the potential sources of metals and other raw materials in the near-Earth space. Finally, the problem of asteroid impact hazard arouses the increasing interest in studies of these objects nowadays. This danger has existed over all period of the Earth history, however the realizing of it is coming only now.

According to the available estimates [2], there are about 2,000 Earth-crossers larger than $1 \mathrm{~km}$ in size, and about 300,000 ones with diameter more than 100 $\mathrm{m}$. The collision of each of these objects with the Earth is a real hazard for humanity. However at present the orbital characteristics are known for only about $7 \%$ of Earth-approaching asteroids with diameter $D \geq 1 \mathrm{~km}$, and for only about $0.2 \%$ Earth-approachers with $\mathrm{D} \geq 100 \mathrm{~m}$. The smallest of these objects could cause the local or regional environmental catastrophe, while the $\mathrm{km}$-sized objects could cause a global one.

The probability of collision of any of these numerous asteroids with the Earth is extremely low but due to a very large number of them the estimated collision frequency (a product of probability by the asteroid numbers) is one chance per one million years for 1-2 $\mathrm{km}$ diameter objects, and one chance per every 100 years for an asteroid of about $30 \mathrm{~m}$ in size. The frequency of the collisions of the bodies like the Tunguska phenomenon of 1908 (about $60 \mathrm{~m}$ in size) is equal to one chance in every 300 years.

The calculations and the results of nuclear weapon testing have shown [3] that the minimum mass of an asteroid which can cause the global catastrophic changes of climate, flora and fauna on the Earth is equal to a few tens of billion tons. The threshold size of this body is estimated to be $1-2 \mathrm{~km}$ in diameter. If the Earth met such a mass, the horrifying explosion equal to one million megaton of TNT (50 million of the Hiroshima-class atomic bombs) would occur. The amount of material ejected from a crater formed by this explosion would be about 1,000 times that of the impacting asteroid volume, as the result the so-called "nuclear winter" over the entire planet could cause the deaths of the considerable part of the Earth's population.

The cosmic bodies of a few hundreds meters in size (but not those of the comet nature) pass through the terrestrial atmosphere without significant fragmentation. The greatest part of energy is released when the impacting body hits the solid surface or the ocean of the Earth. The diameter of the formed crater is 15-20 times larger than the size of the impacting body, and the area of the destruction $S$ (in hectares) can be estimated as:

$$
S=10,000 \cdot E^{2 / 3},
$$

where $\mathrm{E}$ is the kinetic energy in megatons. For example, when a 250 -meter-sized body $(E=1,000 \mathrm{Mt})$ falls 
onto the Earth (it happens once per ten thousand years), the area of the destruction is equal to $10^{6} \mathrm{hec}$ tares.

The body less than 100 meters in size would be entirely fractured in the atmosphere, and tens of square kilometers of the surface would be covered by its fragments. The explosion of this impactor in the upper atmosphere would generate the intense shock wave combined with the light and heat energy release, thereby more than half of the energy of the explosion would be lost at heights of $5-10 \mathrm{~km}$. The size of the area of the destruction will depend on the original size and velocity of the impactor. For example, if the size of a stony impacting body is approximately $80 \mathrm{~m}$ in diameter and its original relative velocity is $20 \mathrm{~km} / \mathrm{sec}$, this impactor causes a havoc area of $25 \mathrm{~km}$ in radius.

American scientists estimated the degree of risk to be killed due to an asteroid impact event and other causes for an average person during his life [4]. At first sight, they obtained the paradoxical result: a plane crash, a global cosmic catastrophe and a flood give approximately the same degrees of the risk.. But it is more or less true, since the degree of the risk is a product of the event probability by the number of victims, and the impact of a cosmic body could kill millions of people.

The question arises: have there already been any collisions of large cosmic bodies (asteroids or comets) with the Earth? Yes, such events happened before and, certainly, they will occur in the future. Many of circular geological anomalies on the Earth surface were recognized as meteor craters with the help of artificial satellites of the Earth. Now on the surface of our planet there exist more than 130 impact craters with sizes up to $250 \mathrm{~km}$ in diameter. The crater's age ranges from relatively young to very old (hundreds of millions years).

In recent years there is a widespread acceptance of the hypothesis that the collision of a 5-10 kilometersized asteroid with the Earth about 65 million years ago caused the sudden extinction of the gigantic dinosaurs and some other pre-historic animals and plant species on the Earth. The fall of such a cosmic body was to produce a $150-200 \mathrm{~km}$ wide crater on the surface of our planet. It is worth noting that such crater of $180 \mathrm{~km}$ in diameter was found in the northern Yucatan (Mexico). The name of this immense crater is Chicxulub and its age was estimated to be equal to $64.98 \pm 0.04$ million years. It is believed that this asteroid impact also led to the evolutional burst of mammals and the eventual emergence of homo sapiens. The second global catastrophe seemed to have happened about 10,000 years ago and as a result, the so-called "mammoth" fauna became extinct.

The famous Meteor Crater in Arizona (USA), the Tunguska event of 1908 in Siberia (Russia), the great number of impact craters on the Moon, Mercury, Mars and its moons Phobos and Deimos and even on the small asteroids - all of these is the direct evidence of cosmic catastrophes not far from our planet. The unique event of July 1994 - Shoemaker-Levy comet's crash into Jupiter, a beautiful spectacle of nature that was successfully predicted one year in advance by astronomers was like serious warning that such catastrophes are to-day's reality. Nature attempted to let us understand the objective aspects of impact hazard.

The asteroid hazard problem was officially recognized in July 1981 when NASA held the first Workshop devoted to collisions of asteroids with the Earth and their physical consequences for humanity. The great interest in the impact threat has been expressed by the scientists of many countries. Since then about 20 international meetings and workshops on this problem have taken place in the USA, Italy, Russia. Telescopic observational programs to survey Earthapproaching and Earth-crossing objects and their catalogization are primary problems that are to be solved. Therefore, astronomers in the USA, Europe, Australia and Japan undertake maximum efforts to launch the NEO search programs. The possibility of asteroid or comet collisions with the Earth and probable consequences of them are now being discussed at the level of governments, national and international institutions and agencies.

The problem of the potential cosmic hazard is international in its nature. The significant issue is that the realization of the potential danger that can be caused by an asteroid hitting the Earth coincided with the time when the level of science and technology is already high enough and human civilization is capable to protect itself from the asteroid/comet hazard. In other words, there is hope for our civilization to survive the threat from cosmos, that is, we have a chance to protect ourselves from a collision with dangerous space bodies. Whether or not we will use this chance depends not only on scientists but also on politicians.

[1] Lupishko D.F. and Di Martino M. (1998) Planet. Space Sci., 46, 47-74. [2] Morrison D. (1992) Report of the NASA Intern. NEO Detection Workshop, JPL, Pasadena, 66 p. [3] Toon O.B..et all (1994) In: Hazard due to comets and asteroids, Univ. Arizona Press, Tucson, 791-826. [4] Chapman C.R. and Morrison D. (1994) Nature, 367, 33-40. 
EVIDENCE FOR A SMALL ( $\mathbf{0 . 0 0 0 0 3 0 )}$ BUT RESOLVABLE INCREASE IN SEAWATER ${ }^{87} \mathrm{Sr}^{86}$ Sr RATIOS ACROSS THE K/T BOUNDARY. K. G. MacLeod', B. T. Huber ${ }^{2}$ and P. D. Fullagar ${ }^{3}$, ${ }^{1}$ Department of Geological Sciences, University of Missouri, Columbia, MO 65211, USA, macleodk@missouri.edu, ${ }^{2}$ Department of Paleobiology, MRC: NHB-121, Smithsonian Institution, Washington, DC 20560, USA, huber.brian@nmnh.si.edu, ${ }^{3}$ Department of Geological Sciences CB\# 3315, University of North Carolina, Chapel Hill, NC, 27599, USA, fullagar@unc.edu.

Introduction: Possible changes in ${ }^{87} \mathrm{Sr} /{ }^{86} \mathrm{Sr}$ ratios of microfossils across the Cretaceous/Tertiary $(K / T)$ boundary have been used to infer the nature of the $\mathrm{K} / \mathrm{T}$ event $[e . g ., 1,2,3] .{ }^{87} \mathrm{Sr} /{ }^{86} \mathrm{Sr}$ analyses have also been used to provide an independent test of reworking vs. survivorship of Cretaceous fossils occurring in Tertiary strata [4]. However, inferring the nature of $\mathrm{K} / \mathrm{T}$ perturbation(s) based on ${ }^{87} \mathrm{Sr} /{ }^{86} \mathrm{Sr}$ values has been hampered by inconsistent results among different studies. A recent study suggested that purported steps or spikes in ${ }^{87} \mathrm{Sr} /{ }^{86} \mathrm{Sr}$ values at the boundary are analytical or diagenetic artifacts [5]. Tests of reworking require resolvable differences in seawater ${ }^{87} \mathrm{Sr} /{ }^{86} \mathrm{Sr}$ ratios between the time a fossil lived and the time at which it is finally buried; so far reworking has been tested in this manner at only a single locality $[4,6]$. In short, despite potential contributions to $\mathrm{K} / \mathrm{T}$ discussions, ${ }^{87} \mathrm{Sr} /{ }^{86} \mathrm{Sr}$ patterns across the $\mathrm{K} / \mathrm{T}$ boundary are not well established.

Ocean Drilling Program (ODP) Site 1049 provides excellent samples to both examine the evolution of seawater ${ }^{87} \mathrm{Sr} /{ }^{86} \mathrm{Sr}$ across the $\mathrm{K} / \mathrm{T}$ boundary and to use ${ }^{87} \mathrm{Sr} /{ }^{86} \mathrm{Sr}$ ratios to test for reworking in the lowest Tertiary. ODP Site 1049 is located in the western Atlantic $\sim 500 \mathrm{~km}$ east of Florida. The $\mathrm{K} / \mathrm{T}$ boundary was recovered in three holes. We studied Hole 1049C in which the boundary is represented by $10 \mathrm{~cm}$ of green, spherulitic clay capped by a mm-scale limonitic layer. The Maastrichtian and Danian sediments on either side of the boundary clay are generally composed of homogeneous hemipelagic nannofossil oozes with common, well preserved foraminifera. The basal $7 \mathrm{~cm}$ of the Danian ooze, though, contains distinct mottling. Foraminifera below the boundary clay are typical of late Maastrichtian Tethyan sites, whereas Danian samples contain both Danian and Maastrichtian taxa. Paleodepths are estimated at 1000-2000 m.

Materials and Methods: Cretaceous foraminifera were isolated from 5 samples in the top $2.5 \mathrm{~m}$ of the Maastrichtian and from 9 samples in the bottom $90 \mathrm{~cm}$ of the Danian. Danian foraminifera were isolated from all but the lowest Tertiary sample with two separates collected from independent samples at one horizon. In addition, two bulk sediment samples from the clay and one separate of dolomite rhombs from the mottled interval were collected. Carbonate samples were placed in centrifuge tubes with $0.2 \mathrm{ml}$ of $\sim 1.7 \mathrm{M}$ acetic acid. Foraminiferal tests dissolved in 1-2 hours. The samples were centrifuged and the supernatant was separated from undissolved material. Two splits of each bulk sample were leached with $\sim 1.7 \mathrm{M}$ acetic acid. The leachate was collected and assumed to represent bulk carbonate. The remaining sample was then dissolved in HF and was assumed to represent the silicate fraction. All samples were dried and then redissolved in $3 \mathrm{M} \mathrm{HNO}_{3}$. Strontium was separated using EiChrom $\mathrm{SrSpec}$ resin. Samples were loaded on a Re filament in $4 \mu \mathrm{l}$ of $\mathrm{H}_{3} \mathrm{PO}_{4}$ and $\mathrm{TaCl}_{5}$ and analyzed on the VG Sector 54 thermal ionization mass spectrometer at the University of North Carolina, Chapel Hill.

Results: Cretaceous foraminifera exhibit remarkably consistent values (avg. $0.707856 \quad+$ /$0.000002,1 \sigma$ standard error) across the interval studied (Figure 1). The five separates of Tertiary foraminifera

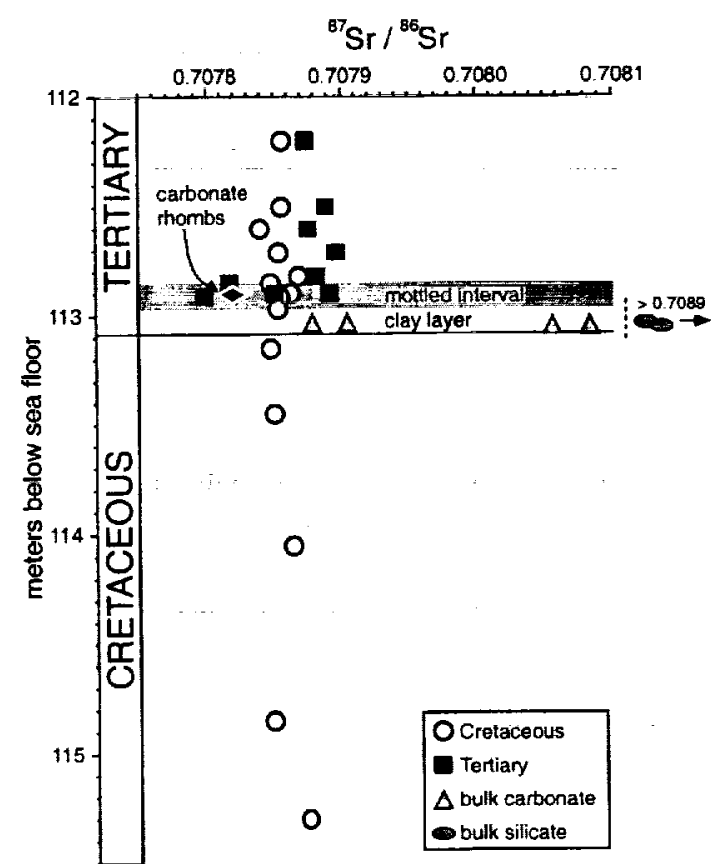

Figure 1 - Strontium isotopic results of various components from the KT boundary interval in ODP Hole 1049C.

from above the mottled interval also exhibit very consistent values (avg. $0.707884,+/-0.0000041 \sigma$ stan- 
dard error). The average of those values is $\sim 0.000030$ higher than the average for Cretaceous foraminifera and the difference is highly significant $(p<0.001, \mathrm{t}$-test).

Within the mottled interval, the separates of Tertiary foraminifera exhibit variable ${ }^{87} \mathrm{Sr} /{ }^{86} \mathrm{Sr}$ results. SEM images of broken tests show small carbonate rhombs $(\sim 1 \mu \mathrm{m})$ on the inner walls of many foraminifera. These overgrowths are rare to absent both higher and lower in the section. Dolomite rhombs from the mottled interval yield a ${ }^{87} \mathrm{Sr} /{ }^{86} \mathrm{Sr}$ value lower than the values in Cretaceous foraminifera, but similar to the lowest Tertiary values. Carbonate values from within the boundary clay are slightly to markedly higher than values in Cretaceous foraminifera. Two silicate analyses failed, but the other two were both $\sim 0.709$, much higher than other values seen in this study.

Discussion: Low Tertiary ${ }^{87} \mathrm{Sr} /{ }^{86} \mathrm{Sr}$ values in the mottled interval are attributed to diagenetic overprinting likely hosted in the carbonate overgrowths observed on the inner walls of many foraminifera. Both Tertiary and Cretaceous taxa show these overgrowths, but Tertiary individuals in this interval are much smaller and thinner walled than co-occurring Cretaceous individuals. Thus, the thin veneer of secondary carbonate is proportionally more important in the Tertiary taxa. Mottling suggests bioturbation-induced heterogeneity at the scale of samples. Mixing of individuals from less and more altered levels could explain the variability in ${ }^{87} \mathrm{Sr} /{ }^{86} \mathrm{Sr}$ ratios observed among Tertiary foraminifera in this interval. Regardless, results for the dolomite rhombs confirm the presence of diagenetic carbonate with a relatively low ${ }^{87} \mathrm{Sr} /{ }^{86} \mathrm{Sr}$ ratio (similar to low values observed among Tertiary foraminifera). Alteration of some component of the spherulitic clay is a logical source for diagenetic strontium with low ${ }^{87} \mathrm{Sr} /{ }^{86} \mathrm{Sr}$ ratios, but bulk analyses within that interval suggest that this hypothetical source material is not a dominant phase in the boundary layer today.

Differences between Cretaceous and Tertiary taxa from above the mottled layer, on the other hand, are attributed to a small step increase in seawater ${ }^{87} \mathrm{Sr} /{ }^{86} \mathrm{Sr}$ across the boundary and reworking of Cretaceous individuals (with lower ${ }^{87} \mathrm{Sr}{ }^{86} \mathrm{Sr}$ ratios) into Tertiary strata. Diagenesis is not considered a likely explanation for difference in ${ }^{87} \mathrm{Sr} /{ }^{86} \mathrm{Sr}$ ratios of Cretaceous and Tertiary taxa above the mottled interval because 1) SEM images show minor to absent overgrowths in this interval, 2) Tertiary and Cretaceous taxa are of similar dimensions but exhibit different values, and 3) diagenetic fluids appear to have had low ${ }^{87} \mathrm{Sr} /{ }^{86} \mathrm{Sr}$ ratios. Constant values in Cretaceous taxa across the boundary are predicted in a reworking scenario. In the absence of significant diagenetic alteration, results for Tertiary taxa suggest that earliest Danian seawater had ${ }^{87} \mathrm{Sr} /{ }^{86} \mathrm{Sr}$ ratios $\sim 0.000030$ higher than latest Maastrichtian seawater.

Conclusions: Parallel ${ }^{87} \mathrm{Sr} /{ }^{86} \mathrm{Sr}$ analyses of Cretaceous and Tertiary foraminifera from ODP Hole 1049C provide taphonomic and diagenetic control and suggest there was a small, but resolvable, increase in seawater ${ }^{87} \mathrm{Sr} /{ }^{86} \mathrm{Sr}$ across the $\mathrm{K} / \mathrm{T}$ boundary. Occurrences of Cretaceous taxa in the boundary clay and in the lower Danian are attributed to reworking. Finally, ${ }^{87} \mathrm{Sr} /{ }^{86} \mathrm{Sr}$ ratios in both isolated diagenetic rhombs and small Tertiary foraminifera from the basal $7 \mathrm{~cm}$ of the Danian suggest diagenetic alteration affects this interval; paleoenvironmental interpretation based on geochemical analyses of samples from the mottled zone should only be made with caution.

\section{References:}

[1] Macdougall J. D. (1988) Science, 239, $485-$ 487. [2] Martin E. E. and Macdougall J. D. (1991) Earth Planet. Sci. Lett., 104, 166-180. [3] Vonhof H. B. and Smit J. (1997) Geology, 25, 347-350. [4] MacLeod K. G. and Huber B. T. (1996) Geology, 24, 463466. [5] McArthur J. M. et al. (1998) Earth Planet. Sci. Lett., 160, 179-192. [6] Pardo A. (1999) Palaeogeogr. Palaeoclimatol. Palaeoecol., 154, 247-273. 
RAUP'S DICTUM AND THE ROLE OF PALEONTOLOGICAL DATA IN IDENTIFYING CONTROLS ON PHANEROZOIC BACKGROUND AND "MASS" EXTINCTION PATTERNS. Norman MacLeod, Department of Palaeontology, The Natural History Museum, Cromwell Road, London SW7 5BD, UK. N.MacLeod@nhm.ac.uk

Although the fossil record forms the primary object of extinction-based studies, it is no longer the case that investigations addressed solely to that record can hope to test realistic cause-effect hypotheses in a convincing manner. Rather, patterns of taxic richness over defined time intervals must be compared to the physical record of long-term environmental change in order establish the necessary connection between physical causes and biotic effects. While this juxtaposition between physical and biological investigations has been both stimulating and fruitful, it has also brought differences between the investigative styles characteristic of these two scientific fields into sharp relief; particularly with reference to the concepts of logical reductionism, time, and the problems of hypothesis-testing with historical data.

As an antidote to the increasingly tight focus with which many have come to view the phenomenon of extinction in general and "mass extinction" in particular I would point to the following observation by Dave Raup (1991, p. 151), "There is no way of assessing cause and effect [in extinction studies] except to look for patterns of coincidence-and this requires multiple examinations of each cause-and-effect pair. If all extinction events are different the dechipering of any one of them will be next to impossible." Thus, any general model of stage-level extinctions in earth history must account for (1) the decline in Phanerozoic "background" extinction-intensity gradient and (2) the timing and magnitude of extinction-intensity peaks, as well as being sensitive to the idea that biotic data themselves can be used to probe aspects of the Earth's history of physical change; especially the timing of those changes. Moreover, in line with Raup's dictum (above), an understanding of the nature of controls on these patterns can only be gained by examining patterns of common and repeated associations between particular physical and biotic variables over the couse of long time intervals containing mutliple extinction events.

In this regard it is particularly striking that a number of isotopic proxies for paleo-oceanographic and productivity factors exhibit statistically significant, first-order patterns of variation that strongly resemble the overall extinction-intensity gradient. These results suggest that secular changes in the continentderived nutrient flux to the oceans exerted a dominant control on "background" extinction patterns throughout the Phanerozoic. Furthermore, the pattern of second-order deviations from this general trend suggest that contingent evolutionary developments in phytoplankton and terrestrial plant clades represent the proximate mechanism through which these abiotic changes are first expressed in the biotic realm and by which macro-evolutionary changes in marine an terrestrial animal clades have been directed.

On the larger end of the extinction spectrum, new statistical results show that the Phanerozoic, stagelevel, "mass" extinction record does not exhibit significant periodicity, but, does show significant correspondence to the record of flood-basalt volcanism (Mesozoic and Cenozoic) and eustatic sea-level change (Paleozoic). Over the last 250 m.y. differences in the relative magnitudes of stage-level "mass" extinction events seem to be best explained by a multi-factor model involving independent inputs from tectonic (eustatic sea level, hot-spot volcanism) and, in the case of the Late Maastrichtian event, possibly by extraterrestrial (bolide impact) processes.

\section{Reference:}

Raup, D. M., 1991, Extinction: bad genes or bad luck: New York, W. W. Norton and Co., 210 p. 
Deep-sea is typically considered as low energy environment, where basinal sediments have very good preservation potential. However, we frequently see evidence of very high-energy events in deep-sea sequences, in form of exceptionally thick beds commonly referred to as megabeds or megaturbidites. These were obviously induced by exceptional causes, because the rest of the sequence is composed of much thiner beds. The number of such thick beds differs from one basin to the other, as well as the criteria for their definition; some authors define certain minimal thickness, whereas some other define a set of several criteria amongst which is thickness which should exceed that of the thickest normal bed in succession studied [1]. In some basins megabeds (MB's) account for significant part of the succession, but sometimes there occur rare beds which are exceptionally thick, even by criteria of megabeds, and these will be referred to as giant beds (GB's). The giant beds commonly exceed $100 \mathrm{~m}$ in thickness, have basin-wide extent and dry volume of 100 $\mathrm{km}^{3}$, or more. Their internal composition is typically complex, with olistolite-bearing debrite in the lower part, and megaturbidite in the upper. It is not uncommon to see textural evidence of flow reversals (reflections) [2] which document large flow volume and momentum. Initiation of MB's is commonly attributed to seismic shocks with M7 - M7.5 magnitude [3], and their recurrence is estimated in span of $5 \times 10^{5}$ to $1 \times 10^{6} \mathrm{y}$. However, GB's are even more infrequent, since during the life-span of a basin there may have deposited just one or two, making their initiation even more challenging issue.

The following key characteristics of GB's should be kept in mind: a) they are the thickest singleevent deposits in the basin-fill, b) they comprise huge extraclasts (olistolithes) $\left(>200.000 \mathrm{~m}^{3}\right)$ which sometimes show evidence of subaerial weathering such as karstification, c) they also comprise large "intrabasinal" rip-up clasts and very abundant skeletal debris, d) they occur randomly within the succession. The initiation process must have been strong enough to initiate not only collapse of a shelf-margin, but also large-scale collapse of emergent land (!), so the magnitude of triggering earthquake estimated for "ordinary" megabeds does not seem sufficient.

Being exceptional basinal events, the dating of GB's is often very interesting, although not easy for several reasons: a) the abundance of resedimented skeletal debris may mislead researchers for indigenous fauna, b) fine-grained part of the bed which was deposited from ponded suspension is commonly fossilfree, d) biostratigraphic data available refer to the whole basin-fill, with no finer-scale control.

GB's, as defined herein, occur in various parts of the world and in basinal successions of various stratigraphic ages, but I will focus on the Eocene of circum-Mediterranean region; Hecho Group of South Pyrenean Basin, Flysch of the Friuli Basin, and Flysch of Eastern Adriatic basins, in particular (Fig 1). The GB's in all of the above cases share common characteristics,

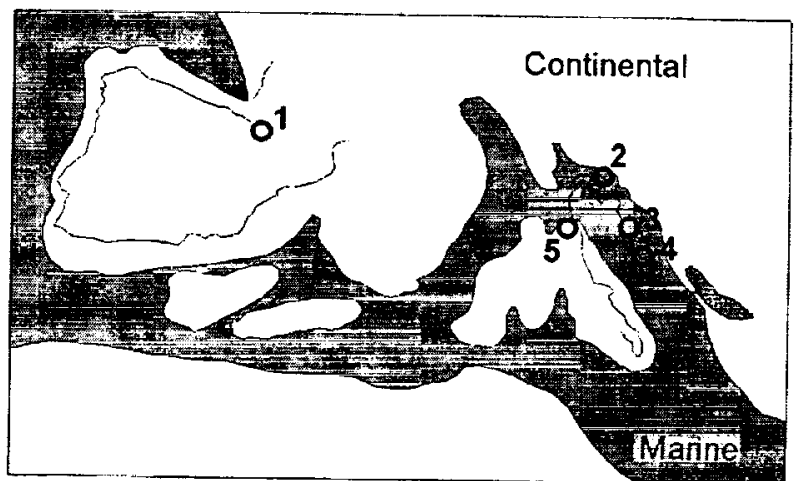

Fig 1. Paleogeographic map of Mediterranean in Rupelian, after Dercourt 1993, very simplified, as proxy for Priabonian paleogeography. Key: 1) South Pyrenean Basin, 2) Friuli Basin, 3) Northem Dalmatia Basin, 4) Central Dalmatia Basin, 5) Macigno.

regardless of their different ages and geotectonical position.

Fig. 2 shows that Ypresian and BartonianPriabonian were the times with relatively frequent impacts, whereas Lutetian was a period apparently without one. These periods are also characterized by deposition of clastics in circum-Mediterranean basins. Ypresian was the time when flysch with MB's and GB's was deposited in northern Spain, northern Italy and south Slovenia, whereas Bartonian and Priabonian of Dalmatia are characterized by successions with thick MB's and one GB. So, it seems that MB's and GB's bearing successions correlate well with known impacts. Priabonian Chakespeake Bay impact structure (of P15/P16 age) (11 in Fig. 2) correlates well with occurrence of microtektites, clynopyroxene nodules, and Ir-anomaly found in DSDP cores [4][5][6] and outcrops in Northern Italy [7] (5 in Fig 2), and giant bed K-S of Central Dalmatia (4 in Fig. 2).

The K-S bed [8] is $175 \mathrm{~m}$ thick, and comprises karstified extraclasts with volume up to $500.000 \mathrm{~m}^{3}$. The 


\section{GIANT BEDS: T. Marjanac}

lower half of megaturbidite part of the bed is composed almost entirely of resedimented nummulites, but the upper half is faunistically sterile. Attempts to find indigenous nannofossils in the upper part of megaturbidite (where contemporaneous pelagic forms were expected) usually failed. Only very scarce and poorly preserved planktonic forams were found in the uppermost part of the bed, but nevertheless, they allowed attribution to P15-16 planktonic zone. Abundant skeletal debris below was preserved due to rapid burial, whereas the lack of calcareous nannofossils is most likely caused by carbonate dissolution which is typical at depths below CCD, but was also recognized by Keller [5] in zones enriched with microtektites, which may also account for scarcity and poor preservation of planktonic foraminifers. Contemporaneous correlative MB's are

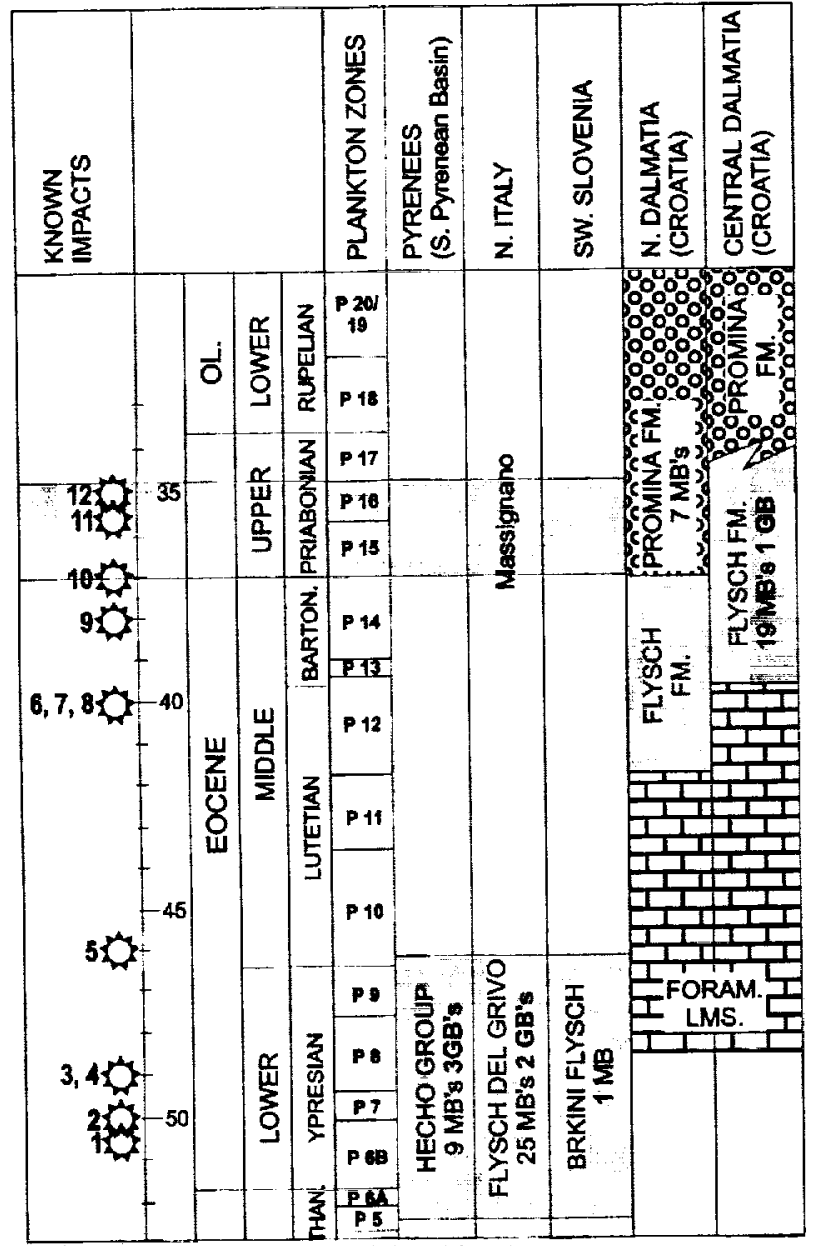

Fig. 2. Stratigraphic distribution of impact structures, GB's and MB's in several circum-Mediterranean basins. Impacts: $1=$ Montagnais (N. Scotia), 2= Goat Paddock (W. Australia), 3= Gusev (Russia), 4= Kamensk (Russia), 5= Chyli (Kazahastan), $6=$ Bee Bluff, $7=$ Azuara (Spain), $8=$ Logoisk (Belarus), 9= Mistastin (Labrador), 10= Wanapitei (Ontario), $11=$ Chakespeake Bay (Virginia), 12= Popigai (Siberia). somewhat thinner; SV megabed of Central Dalmatia (4 in Fig. 1), and DD-2 megabed in Central Dalmatian hinterland reach thickness of $46 \mathrm{~m}$ and $65 \mathrm{~m}$, respectively [9], whereas Tintor-bed in Northern Dalmatia ( 3 in Fig. 1) attains thickness of about $30 \mathrm{~m}$ [10]. I strongly believe all of these beds were initiated by a common trigger, which must have been of very high magnitude, since the area of their occurrence is presently $120 \mathrm{~km}$ long, and about $20-45 \mathrm{~km}$ wide. An impact trigger is preferred in this case because it can create sufficient high-magnitude and high-acceleration tremor, which will affect very wide area. Despite good stratigraphic correlation, it is unlikely that trigger was Chakespeake Bay impact, due to its large distance from Eastern Mediterranean which was well protected from possible megatsunamis in Atlantic (Fig. 1) as indicated by paleogeographic maps [11]. Thus, it seems most likely that the trigger was one, so far undiscovered impact, which may be located somewhere close to Dalmatia.

\section{References}

[1] Bouma A.H. (1987) Megaturbidite: an Acceptable Term? Geo-Marine Letters, 7/2, 63-67, [2] Marjanac T. (1990) Reflected sediment gravity flows and their deposits in flysch of Middle Dalmatia, Yugoslavia. Sedimentology, 37/5, 921-929, [3] Séguret M.\& al. (1984) Eocene seismicity in the Pyrenees from megaturbidites of the South Pyrenean Basin (Spain). Marine Geology, 55, 117-131, [4] Keller (1986a) Eocene-Oligocene boundary reference sections in the Pacific. Dev. in Paleont. And Strat., 9, 209-212. [5] Keller (1986b) Late Eocene impact events and stepwise mass extinctions. Dev. in Paleont. And Strat., 9, 403412. [6] Müller-Merz \& Saunders (1986) The EoceneOligocene boundary in the Bath Cliff section, Barbados, West Indies. Dev. in Paleont. And Strat., 9, 193-198. [7] Pierrard \& al. (1998) Extraterrestrial Ni-rich spinel in upper Eocene sediments from Massignano, Italy. Geology, 26/4, 307-310. [8] Marjanac T. (1989) Ponded megabeds and some characteristics of the Eocene Adriatic basin (middle Dalmatia, Yugoslavia). Mem. Soc. Geol. It. 40, 241-249 [9] Marjanac T. (1991) Importance of megabeds for reconstruction of Paleogene flysch basin in Split hinterland (Middle Dalmatia). Geol. vjesnik, 44, 201-213, [10] Babic Lj. \& Zupanic J. (1983) Paleogene Clastic Formations in Northern Dalmatia. Excursion Guide Book, 4. I.A.S. Reg. Meet. Split, 37-61, [11] Dercourt \& al. (1993) Atlas Tethys Paleoenvironmental Maps. Gauthiers-Villars. Paris, 1-307. 
THE CRETACEOUS-TERTIARY BOUNDARY IMPACT EJECTA AT BLAKE NOSE (ODP LEG 171B) AS RECORD OF THE CHICXULUB IMPACT. F. Martinez-Ruiz ${ }^{1}$; M. Ortega-Huertas ${ }^{2}$; I. Palomo ${ }^{2}$ and J. Smit ${ }^{3}$, ${ }^{1}$ Instituto Andaluz de Ciencias de la Tierra (CSIC-UGR). Facultad de Ciencias. Campus Fuentenueva. 18002 Granada, Spain, e-mail:fmruiz@goliat.ugr.es; ${ }^{2}$ Departamento de Mineralogia y Petrologia. Facultad de Ciencias. campus Fuentenueva. 18002 Granada, Spain, e-mail: mortega@goliat.ugr.es; ${ }^{2}$ Department of Sedimentary Geology, Vrije Universiteit, 1081HV Amsterdam, Netherlands, e-mail: smit@geo.vu.nl.

Introduction: The ODP Leg 171B recovered an excellent Cretaceous-Tertiary (K/T) boundary interval in ODP Site 1049. This site is located on the eastern margin of Blake Nose (NW Atlantic) at a present depth of $2671 \mathrm{~m}$ below sea level. The K/T boundary sediments were recovered from three adjacent holes: $1049 \mathrm{~A}\left(30^{\circ} 08.5436^{\prime} \mathrm{N}\right.$, $\left.76^{\circ} 06.7312^{\prime} \mathrm{W}\right), \quad 1049 \mathrm{~B} \quad\left(30^{\circ} 08.5423^{\prime} \mathrm{N}, \quad 76^{\circ} 06.7264^{\prime} \mathrm{W}\right)$ and $1049 \mathrm{C}\left(30^{\circ} 08.5370^{\prime} \mathrm{N}, 76^{\circ} 06.7271^{\prime} \mathrm{W}\right)$. A single $17-$, 7 - and 9-cm thick bed of green spherules, capped by a red layer, is respectively marking the $\mathrm{K} / \mathrm{T}$ boundary at the three holes. This bed occurs at the biostratigraphic boundary between the Cretaceous and the Paleocene. It sharply overlies slumped uppermost-Cretaceous foraminiferal-nannofossil ooze and is overlain by Tertiary clay-rich ooze with planktonic foraminiferal assemblages indicative of Early Danian Foraminiferal Zone P-alpha [1]. The variable thickness of the spherule bed at the three holes drilled suggests reworking of the ejecta material down slope. The green spherules are nonetheless a record of the Chicxulub impact-generated material.

Samples and methods: The spherule bed and sediments above and below were taken in continuous sampling every $2 \mathrm{~cm}$. Spherules were hand-picked under a stereomicroscope. Bulk samples and representative handpicked spherules were subjected to mineralogical and geochemical analyses using X-ray Diffraction (XRD), Scanning Electron Microscopy (SEM) and Transmission Electron Microscopy (TEM) for mineralogical analyses. Quantitative microanalyses of clay minerals were obtained by transmission electron microscopy in scanning TEM mode only from edge particles using $\propto 70 \AA$ diameter beam and $200 \times 1000 \AA$ scanning area and a short counting time to avoid alkali loss [2]. Atomic Absorption (AA) and Inductively Coupled Plasma-Mass Spectrometry (ICP-MS) were used for geochemical analyses.

Results: The spherule bed at Blake Nose consists of a coarse and poorly cemented unit. Mineralogical analyses reveal it is mostly composed of clays and minor proportions of carbonates, mainly derived from the presence of Cretaceous clasts within the spherule bed. Other minerals also present in lower proportions are quartz, zeolites and minor amounts of rutile, biotite and some lithic fragments. Clays are mostly smectites since spherules are diagenetically altered to smectite. Sediments above and below the spherule bed are mostly composed of calcite, clays and minor amounts of quartz. Clay mineral assemblages in Cretaceous and Tertiary sediments are mostly composed of smectite and lower proportions of illite and kaolinite. The contact of the spherule bed with sediments above and below is very sharp. The contact surface of the Cretaceous sediments contains some spherical impressions that seem to be bubbles or deformations by deposition of spherules in soft sediments. Cretaceous sediments are slump-folded, however, the overlying stratigraphy is undisturbed. Deformation of Cretaceous sediments is a general feature at proximal ejecta sites. Deformation and large-scale slope failures were related to the seismic energy input from Chicxulub impact [3].

SEM observations revealed that the morphologies of the Blake Nose spherules are tektite-like and they mainly correspond to perfect spheres (Fig. 1) and lesser proportions of oval spherules. Size usually ranges from $100 \mu \mathrm{m}$ to $1000 \mu \mathrm{m}$. Some hollow spherules and spherical voids are filled with smaller spherules that may represent diagenetic infills of original bubbles. The surface of the spherules is nodular, smooth or rough and color is darkgreen pale-yellow or light-green. The XRD scans on oriented samples revealed that spherules are mainly composed of smectite, and TEM microanalyses revealed that the smectite corresponds to a dioctahedral type. Some compositional variations were observed between dark green spherules and pale yellow spherules. Dark green spherules are richer in $\mathrm{Fe}$ and pale yellow ones are richer in $\mathrm{Ca}$. TEM microanalyses on pale yellow spherules also revealed that they contain a very rich-Ca matrix altering to smectite, and some calcite crystals are observed in this matrix.

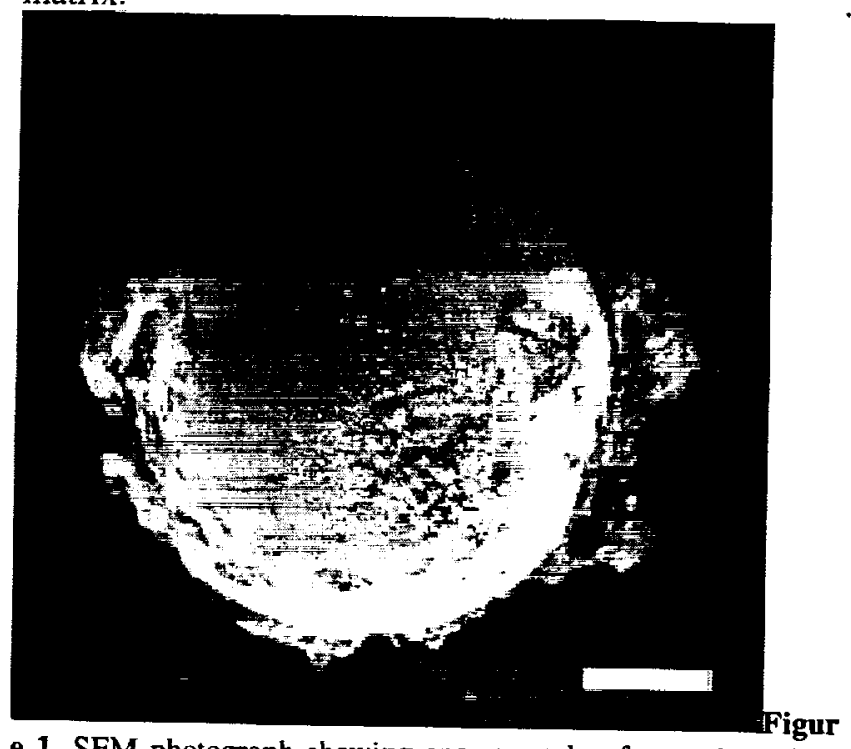

e 1. SEM photograph showing one example of smectite spherules from Blake Nose (ODP Leg 171B). Scale bar $=200 \mu \mathrm{m}$.

This suggests that Ca-rich material could have been 


\section{THE K/T BOUNDARY AT BLAKE NOSE (ODP LEG 171B): F. Martinez-Ruiz et al..}

the precursor. Such observations on dark-green spherules revealed instead very high silica areas that do not correspond to a real smectite composition, suggesting Si-rich glass could have been the precursor in this type of spherules and that smectite directly replaced the original precursor [4].

The data from chemical analyses performed on samples from the $\mathrm{K} / \mathrm{T}$ boundary interval at Blake Nose revealed that the boundary bed is depleted in $\mathrm{Ca}$, as can be expected from the decrease in biogenic calcite. $\mathrm{Fe}$ and $\mathrm{Mn}$ profiles from the $\mathrm{K} / \mathrm{T}$ boundary interval are mainly governed by diagenetic remobilization. The top of the spherule bed (the red layer) is marked by a significant Fe increase, and $\mathrm{Mn}$ also increase just above the red layer, while lower $\mathrm{Fe}$ and $\mathrm{Mn}$ concentrations are present within the spherule bed, these peaks indicate diagenetic remobilization of both elements. The Ir concentration is very low at Blake Nose [5] reaching the highest concentration above the spherule bed. Regarding other possible extraterrestrial elements, $\mathrm{Cr}, \mathrm{Co}$ and $\mathrm{Ni}$ also present low concentrations at Blake Nose [6]. $\mathrm{Cr}$ decreases considerably in the spherule bed, which points to the absence of a significant extraterrestrial $\mathrm{Cr}$ contribution. Although Co and $\mathrm{Ni}$ concentrations are not as high as in distal sections, both elements are enriched in the upper part of the spherule bed, suggesting a possible extraterrestrial contamination. Nevertheless, no clear evidence for significant extraterrestrial contribution is observed at Blake Nose, suggesting that the spherule bed material mainly originated from the alteration of target rock derived-material. REE C1-normalized patterns also suggest that spherule bed material derive from upper crustal rocks.

Discussion and conclusion: The $\mathrm{K} / \mathrm{T}$ material from Blake Nose derives from the fallout of the material generated by the Chicxulub impact. The spherules from Blake Nose are similar to spherules from different locations on the North America Atlantic margin, such as Bass River [7] and DSDP 603B [8], and all of them represent the same diagenetically altered impact ejecta. Spherules from the El Mimbral and La Lajilla sections in Mexico are also similar but often contain a preserved impact glass core [9, 10]. In Haiti, exposures of the ejecta deposits also reveal spherules are not completely altered, consisting of impact glasses and glass spherules. Two types of glass have been recognized at Haitian sections: black andesitic glass and honey color $\mathrm{CaO}$-rich glass $[11,12]$. At Blake Nose, the original material has been altered to smectite, however, compositional differences in the analyzed spherules suggest that they may derive from different precursor glass types. Mineralogical and geochemical evidence indicate that the smectites derive from the alteration of Si-rich and $\mathrm{Ca}$-rich materials. In fact, the precursor of the Blake Nose spherules could have been compositionally similar to those impact glasses reported at Haitian sections. The geochemical composition of the boundary bed support that the impact-generated material mainly derived from melted target rocks. As occurs for tektites or impactgenerated material derived from the inner ejecta, Ir and other extraterrestrial elements show lower concentrations than at distal locations. Only Ni and Co have higher concentrations within the upper part of the spherule bed, however, these concentrations are not high enough to support significant extraterrestrial contribution. On the other hand, original concentrations have been severely modified after deposition. Low Eh conditions led to traceelement remobilization. Fe and Mn mobilized, diffusing upward and precipitating upon encountering the oxygenated pore waters required for their precipitation. As different oxygen conditions are required for precipitation of these elements, they became decoupled showing peaks at different depths. Major chemical changes also accompanied the diagenetic alteration of glass to smectite. REE, and possibly other associated elements, where significantly depleted during this alteration. Eh and alteration of glass are therefore the main factor controlling the geochemical profiles across the $\mathrm{K} / \mathrm{T}$ boundary at Blake.

Acknowledgments. We thank the ODP Leg 171B Shipboard Scientific Party and the crew of the Joides Resolution for assistance with the samples and data, the Bremen ODP Core Repository for assistance during the sampling party and the C.I.C. (University of Granada, Spain) for the use of the analytical facilities. This work was supported by Project PB96-1429 (DGES, MEC, Spain) and Research Group RNM0179 (Junta de Andalucia, Spain)

\section{References:}

[1] Norris, R.D., Kroon, D., Klaus, A., et al. (1998). Proc. ODP, Init. Repts., 171B: College Station, TX, 4791. [2] Nieto, F., Ortega-Huertas, M., Peacor, D.R. and Arostegui, J. (1996). Clays and Clay Minerals, 44, 304323. [3] Smit, J. (1999). Annu. Rev. Earth Planet. Sci., 27, 75-113. [4] Martinez-Ruiz, F., Ortega-Huertas, M., Kroon, D., Smit, J., Palomo, I. and Rocchia, R. (in press). Geol. Soc. Sp. Pub. [5] Smit, J., Rocchia, R., Robin, E., and ODP Leg 171B Shipboard Party. (1997). Geol. Soc. of Am. Annual Meeting, 29, A-141. [6] Martinez-Ruiz, F., Ortega-Huertas, M., Palomo, I and Smit, J. (in lit.). Geol. Soc. Sp. Pub. [7] Olsson, R.K., Miller, K.G., Browning, J.V., Habib, D. and Sugarman, P.J. (1997). Geology, 25, 759-762. [8] Klaver, G.T., van Kempen, T.M.G., Bianchi, F.R. and van der Gaast, S.J. (1987). Init.Rrep.DSDP, 93, 1039-1056. [9] Smit, J., Montanari, A., Swinburne, N.H.S., Alvarez, W., Hildebrand, A.R., Margolis, S.V., Claeys, P., Lowrie, W. and Asaro, F. (1992). Geology, 20, 99-103. [10] Keller, G., Stinnesbeck, W. and LópezOliva, J.G. 1994. Palaios, 9, 144-157. [11] Izett, G.A. (1991). J. Geophys. Res., 96, 20879-20905. [12] Koeberl, C. and Sigurdsson, H. (1992). Geochim. et Cosmochim. Acta, 56, 2113-2129. 
SULFUR ISOTOPIC COMPOSITIONS ACROSS TERRESTRIAL K-T BOUNDARY SUCCESSIONS. Teruyuki Maruoka ${ }^{1}$, Christian Koeberl ${ }^{1}$, Jason Newton ${ }^{1,2}$, Iain Gilmour ${ }^{3}$, and Bruce F. Bohor ${ }^{4}$, ${ }^{1}$ Institute of Geochemistry, University of Vienna, Althanstrasse 14, A-1090 Vienna, Austria (christian.koeberl@univie.ac.at); ${ }^{2}$ Dept. of Earth and Planetary Physics, Univ. of Tokyo, Japan. ${ }^{3}$ Planetary Science Research Institute, Open University, Milton Keynes MK7 6AA, U.K. ${ }^{4}$ U.S. Geological Survey, Denver, CO, USA.

Introduction: Most sulfides present in sediments originate from $\mathrm{H}_{2} \mathrm{~S}$ produced by sulfate-reducing bacteria. This process is accompanied by a fractionation of the sulfur isotopes that results in the sulfide being ${ }^{34} \mathrm{~S}$-depleted with respect to the parent sulfate. The degree of isotopic fractionation between sulfate and sulfide is dependent on the kinetics of the reduction reaction [1] that, in turn, is affected by the environment of deposition. Consequently, the isotopic composition of sulfide can be used as a proxy for environmental conditions such as the temperature of water, sulfate abundance, abundance and types of electron source, etc. In this study, we have used $\mathrm{C} / \mathrm{S}$ ratios as well as $\delta^{34} S$ values to examine paleo-environmental conditions of terrestrial successions across the K-T boundary from the Western Interior of the United States. Previous sulfur isotope studies have encompassed one terrestrial [2] and two marine successions $[3,4]$.

Samples: Dogie Creek, Wyoming: A series of 17 samples from $26 \mathrm{~cm}$ below the boundary to $28 \mathrm{~cm}$ above were analyzed. They include Upper Cretaceous carbonaceous shale, boundary claystone, fireball layer, and Lower Tertiary clay-shale and lignite [5]. Brownie Butte, Montana: A series of 11 samples in $2 \mathrm{~cm}$ intervals from $9 \mathrm{~cm}$ below the boundary to $12 \mathrm{~cm}$ above were analyzed. At the time of the terminal Cretaceous event, this locality was part of a large area consisting of floodplains and backswamps, allowing the deposition of sandstones interlayered with coal, mudstone, carbonaceous shale and siltstone [6]. Berwind Canyon, Colorado: A series of 7 samples from fireball layer, and coal layers above fireball layer were analyzed.

Experimental: We measured the concentrations and isotopic compositions of sulfur by using a continuous flow isotopic ratio mass spectrometer (CF-IRMS) and the concentration of carbon by using a thermal conductivity detector (TCD) with a combustion furnace, followed by measurement in a mass spectrometer (Micromass Optima). With our system it is possible to simultaneously obtain both the $\delta^{34} S$ value and the $\mathrm{C} / \mathrm{S}$ ratio for a single sample.

Results and Discussion: Concentrations of carbon and sulfur together with isotopic compositions of sulfur for Dogie Creek sediments are given in Table 1 and are plotted in Figure 1. At the boundary (fireball layer and melt ejecta layer), $\delta^{34} \mathrm{~S}$ values decrease markedly. This negative (i.e., more ${ }^{34} \mathrm{~S}$-depleted) excursion at the boundary was also observed in samples from Brownie Butte, Montana (this study). In contrast, a positive (i.e., more ${ }^{34} S$-enriched) excursion has previously been reported at the Sugarite K-T site [2]. This suggests that the boundary $\delta^{34} \mathrm{~S}$ excursion may be influenced primarily by localized depositional conditions.

The data reveal some interesting differences in the $\mathrm{C}$ and $\mathrm{S}$ record across the boundary. In the uppermost Cretaceous, $\delta^{34} S$ values display a negative correlation with $\mathrm{C} / \mathrm{S}$ ratio (solid arrows in Fig. 1), whereas, in the lowermost Tertiary a positive correlation is apparent (dotted arrows in Fig. 1). One explanation for these trends is that they reflect changes in the relative abundance of nutrient sources and sulfate concentrations across the boundary. Under normal conditions in which the system contains sufficient sulfate and an electron source, the production rates of sulfide are independent of the abundance of sulfate and an electron source. In this situation, an increase in the production rate of sulfide results in a decrease in the $\mathrm{C} / \mathrm{S}$ ratio and the isotopic fractionation associated with bacterial sulfate reduction is decreased. This would result in $\delta^{34} S$ values becoming more positive with a decreasing $\mathrm{C} / \mathrm{S}$ ratio, as is observed in the sediments just below the boundary. As the temperature of system will also affect the production rate, the $\delta^{34} \mathrm{~S}$ and $\mathrm{C} / \mathrm{S}$ ratios may also be a proxy for temperature.

However, under conditions in which the concentrations of nutrients and/or sulfate are limited because of the existence of a higher number of sulfatereducing bacteria, the production rate of sulfide may be affected by the concentrations of organics (and sulfate). Such a situation may arise if the environment of deposition were to become more anoxic with a concomitant increase in deposition of organic carbon. Such conditions may also result in an increase in the production rate of sulfide with increasing $\delta^{34} S$ values. This process could also cause an increase in the C/S ratio with an increase of the $\delta^{34} \mathrm{~S}$ values, although the balance between the organic input and sulfide production would determine the $\mathrm{C} / \mathrm{S}$ ratios. This may explain the fluctuations of the $\mathrm{C} / \mathrm{S}$ ratios and the $\delta^{34} \mathrm{~S}$ values 
immediately above the $\mathrm{K} / \mathrm{T}$ boundary. Biomarker analysis of samples from Brownie Butte and Berwind Canyon reveal the presence of ${ }^{13} \mathrm{C}$-depleted hopanes, further evidence for the onset of anoxic conditions [7].

The $\delta^{34} S$ values above the boundary therefore appear to have been controlled primarily by an increase in organic input reflecting a marked change in environmental conditions immediately after the Chicxulub impact. Apparently, the onset of anoxic conditions in freshwater ecosystems may have resulted in a sudden increase in sulfate-reducing bacteria.

Acknowledgments: This work was supported by the Austrian Science Foundation, FWF project Y58GEO (to C.K.).

References: [1] Kaplan I. R. and Rittenbeg S. C. (1964) J. Gen. Microbiol., 34, 195-212; [2] Holmes C. W. and Bohor B. F. (1994) ICOG8, U.S. Geol. Survey Circular 1107, p. 141; [3] Schmitz B. et al. (1988) GCA, 52, 229-236; [4] Kajiwara Y. and Kaiho K. (1992) PPP, 99, 151-162; [5] Bohor B. F. et al. (1987) Geology, 14, 896-899; [6] Bohor B. F. et al. (1984) Science, 224, 867-869; [7] Gilmour 1. and Sephton M.A. (2000) This volume.

Table 1. Concentrations of sulfur and carbon and isotopic compositions of sulfur in K-T boundary sediments at Dogie Creek, Wyoming.

\begin{tabular}{lrcrrr}
\hline Sample Name & \multicolumn{2}{c}{$\begin{array}{c}\text { Depth (cm) } \\
\text { Bottom }\end{array}$} & $\begin{array}{c}\text { Top } \\
\text { (wt\%) }\end{array}$ & $\begin{array}{c}\delta^{34} \mathrm{~S} \\
(\%)\end{array}$ & $\begin{array}{c}\mathrm{C} \\
\text { (wt\%) }\end{array}$ \\
\hline LC 86-1A & -26 & -24 & 0.08 & -1.64 & 0.50 \\
LC 86-1B & -22 & -20 & 0.17 & -0.38 & 0.65 \\
LC 86-1C & -18 & -16 & 0.10 & -3.39 & 0.72 \\
LC 86-1D & -14 & -12 & 0.42 & -2.32 & 1.71 \\
LC 86-1E & -10 & -8 & 0.09 & -2.10 & 0.64 \\
LC 86-1F & -6 & -4 & 0.06 & -2.61 & 0.56 \\
LC 86-1G & -4 & -2 & 0.21 & -2.53 & 0.60 \\
LC 86-1H & -2 & 0 & 0.05 & -2.85 & 0.50 \\
LC 86-1K & 0 & 2 & 0.05 & -0.30 & 0.99 \\
LC 86-1L & 2 & 4 & 0.05 & 0.57 & 1.15 \\
LC 86-1M & 4 & 6 & 2.62 & -3.80 & 5.43 \\
LC 86-1N & 8 & 11 & 0.63 & 0.49 & 23.17 \\
LC 86-1O & 14 & 16 & 0.22 & -3.87 & 2.54 \\
LC 86-1P & 18 & 20 & 0.05 & -3.60 & 2.43 \\
\hline Fireball Layer & & & 1.46 & -4.60 & 4.57 \\
Melt Ejecta Layer & & & 1.32 & -3.33 & 2.92 \\
\hline
\end{tabular}

* relative to Canyon Diablo Troilite.

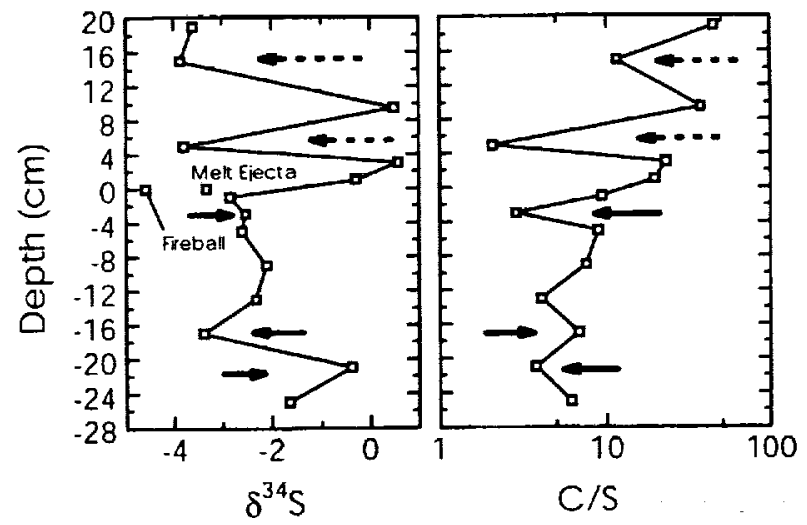

Fig. 1. $\delta^{34} \mathrm{~S}$ values and $\mathrm{C} / \mathrm{S}$ ratios of Dogie Creek samples. Depths of each sample are represent by the center of sampling depth. 


\begin{abstract}
THE IMPACT CRATERING RECORD OF AFRICA: AN UPDATED INVENTORY OF PROVEN, PROBABLE, POSSIBLE, AND DISCREDITED IMPACT STRUCTURES ON THE AFRICAN CONTINENT. S. Master ${ }^{1} \&$ W. U. Reimold'. 'Impact Cratering Research Group, Dept. of Geology, University of the Witwatersrand, P. Bag 3, Wits 2050, Johannesburg, Republic of South Africa. (065sha@ cosmos.wits.ac.za, 065wur@ cosmos.wits.ac.)
\end{abstract}

Introduction: The last inventory of African impact craters, by Koeberl (1994) [1], showed 15 proven impact structures on the continent. Since then, a number of new proven and probable impact structures have been discovered in Africa. Several new possible impact structures, which are still awaiting investigation, have been found using remote sensing techniques (Landsat imagery, aerial photography, airborne and satellite radar, and airborne geophysics). Some of the new discoveries include large impact structures that may have a bearing on the terrestrial record of mass extinctions. New studies have shown that some structures, previously suggested to be of impact origin, must now be discounted as impact structures. We have compiled an updated inventory (to the year 2000) of confirmed, probable, possible and discredited impact structures in Africa (Table 1).

Confirmed Impact Structures: In addition to the 15 impact structures known in 1995 [1], three new structures (Gweni-Fada [2], Morokweng [5] and Kgagodi [4]) have been proven on the basis of the occurrence of shock metamorphic effects diagnostic of impact processes. The 70-80 km-diameter Morokweng structure [5] is dated at $145 \mathrm{Ma}$, which coincides with the terminal Jurassic mass extinction and the Jurassic-Cretaceous boundary.

Probable Impact Structures: In addition to the well-known $750 \mathrm{~m}$ Temimichat Ghallaman crater in Mauritania [1], two newly discovered structures, Sinamwenda [6-8] and Velingara [9], are strong contenders as probable impact structures (which have many attributes of impact structures, but in which diagnostic shock features have not yet been recognised). Sinamwenda, in Zimbabwe, is only 220 $m$ in diameter [7], and although the overturned crater rim shows multiply-striated joint surfaces and microbrecciation, TEM examination of the few examples of possible planar deformation features (PDF's) reported [7] show that they are deformation bands [25]. A possible iron meteorite with Widmanstätten lamellae was reported from near the crater [8], but this has not yet been confirmed. The $48 \mathrm{~km}$-diameter multiring Velingara structure in Senegal and Gambia [9] is probably a buried complex impact structure, formed on Mid-Eocene carbonate rocks, and buried by Neogene continental sediments, in which a central uplift of metamorphic Neoproterozoic/ Paleozoic basement schists has been delineated by drilling and geophysical studies. This structure may be related to other Late Eocene impact structures (Chesapeake Bay, Popigai), or to the terminal Eocene mass extinction [9].

Possible Impact Structures: Numerous possible impact structures found with remote sensing techniques have not yet been investigated on the ground. The main reasons for this are remoteness and inaccessibility in deserts (El-Baz [12], Ntwetwe [18], Aorounga 2,3,4 [10]) or in dense tropical jungles (Kogo [13], Minkebe, Mekambo [17]). Some structures, though less remote, are inaccessible because of ongoing wars (Luizi [15]), or lack of infrastructure such as roads. Lack of funding is probably the main constraint in the investigation of possible impact structures in Africa. Other factors include restrictive policies imposed by governments and by private mining companies, and the legacies from past conflicts, such as minefields.

Discredited Structures: Several circular structures in the Sahara (Richat, Semisiyat, El Mouilah, Aflou, Foum Teguentour, Mazoula) have been discounted as impact structures [1]. The Bangui anomaly of the Central African Republic [19] is part of a continental-scale magnetic anomaly, and is not of impact origin [14,20]. No macroscopic or microscopic evidence of shock metamorphism has been found in the Bushveld Complex of South Africa [21]. The "Nyika Plateau structure" [22] was rediscovered, and shown to have formed by a mudslide, not a meteorite impact [23]. The "Meteor Strike" of Maputaland, South Africa, has also been discredited [24].

References: [1] Koeberl, C. (1994). J. Afr. Earth Sci., 18(4), 263-295. [2] Vincent, P. and Beauvilain, A. (1996). CRAS, 323(II), 987-997. [3] Master, S. et al. (1995). LPS, $X X V I, 903-904$. [4] Paya, B. K. et al. (1999). Late Abstr., 62 ${ }^{\text {nd }}$ Ann. Metsoc Meeting, Johannesburg. NB: Extensive shock metamorphic effects covering the range of shock pressures of 10 to $>30 \mathrm{GPa}$ have been found in Kgagodi drillcore samples (W.U.R., work in progress). [5] Corner, B. et al. (1997). EPSL, 146, 351-364. [6] Master, S. et al. (1995). LPS, $X X V I$, 905-906. [7] Master, S. et al. 
(1996). LPS, XXVII, 827-828. [8] Master, S. (1999). Zimbabwe Excursion Field Guide. $62^{\text {nd }}$ Ann. Metsoc Meeting, Johannesburg. [9] Master, S. et al. (1999). LPS, XXX, Abstr. \# 1926. [10] Ocampo, A. C. and Pope, K. O. (1996). LPS, XXVII, 977-978. [11] Master, S. (1993). Meteoritics, 28, 392. [12] El-Baz, F. (1981). Science, 213, 439-440. [13] MartinezTorres, L. M. (1995). Africa Geosci. Rev., 2(2), 215217. [14] Master, S. (1998). Meteoritics \& Planet. Sci., 33(Suppl.). [15] Dumont, P. (1990). Bull. Soc. belge Géol., 99(1), 57-65. [16] Vrana, S. (1985). Meteoritics, 20, 125-139. [17] Antoine, L. et al.
(2000). LPS, XXXI. [18] Master, S. (1994). Botswana J. Earth Sci., 2, 33-34. [19] Girdler, R. W. et al. (1992). Tectonophysics, 212, 45-58. [20] Antoine, L. et al. (1999). Meteoritics \& Planet. Sci., 34 (Suppl.), A9. [21] Buchanan, P. C. and Reimold, W. U. (1998). EPSL, 155, 149-165. [22] Mossman, D. J. (1972). Meteoritics, 7, 71-74. [23] Master, S. and Duane, M. J. (1998). LPS, XXIX, Abstr. \# 1057. [24] Brandt, D. et al. (1999). Meteoritics \& Planet. Sci., 34 (Suppl.), A17-A18. [25] Langenhorst, F. (1998). Personal communication.

Table 1: List of confirmed, probable and possible impact craters in Africa.

\begin{tabular}{|c|c|c|c|c|c|c|}
\hline Name & Country & Latitude & Longitude & $\begin{array}{l}\text { Diameter } \\
(\mathbf{k m})\end{array}$ & $\begin{array}{l}\text { Age } \\
\text { (Ma) }\end{array}$ & Ref. \\
\hline \multicolumn{7}{|c|}{ Confirmed Impact Structures } \\
\hline Amguid & Algeria & $26^{\circ} 05^{\prime} \mathrm{N}$ & $04^{\circ} 23^{\prime} \mathrm{E}$ & 0.45 & $\leq 0.1$ & {$[1]$} \\
\hline Aorounga & Chad & $19^{\circ} 06^{\prime} \mathrm{N}$ & $19^{\circ} 15^{\prime} \mathrm{E}$ & 12.6 & 0.01 & [1] \\
\hline Aouelloul & Mauritania & $20^{\circ} 15^{\prime} \mathrm{N}$ & $12^{\circ} 41^{\prime} \mathrm{W}$ & 0.36 & $3.1 \pm 0.3$ & [1] \\
\hline B.P. Structure & Libya & $25^{\circ} 19^{\prime} \mathrm{N}$ & $24^{\circ} 20^{\prime} \mathrm{E}$ & 2.8 & $<120$ & [1] \\
\hline Bosumtwi & Ghana & $06^{\circ} 32^{\prime} \mathrm{N}$ & $01^{\circ} 25^{\prime} \mathrm{W}$ & 10.5 & $1.1 \pm 0.2$ & [1] \\
\hline Gweni-Fada & Chad & $17^{\circ} 25^{\prime} \mathrm{N}$ & $21^{\circ} 45^{\prime} \mathrm{E}$ & 14 & $<345$ & {$[2]$} \\
\hline Highbury & Zimbabwe & $17^{\circ} 04^{\prime} \mathrm{S}$ & $30^{\circ} 07^{\prime} \mathrm{E}$ & 20 & $1034 \pm 13^{*}$ & [3] \\
\hline Kalkkop & South Africa & $32^{\circ} 43^{\prime} \mathrm{S}$ & $24^{\circ} 26^{\prime} \mathrm{E}$ & 0.64 & $<1.8$ & {$[1]$} \\
\hline Kgagodi & Botswana & $22^{\circ} 29^{\prime} \mathrm{S}$ & $27^{\circ} 35^{\prime} \mathrm{E}$ & 3.5 & $<2000$ & [4] \\
\hline Morokweng & South Africa & $26^{\circ} 28^{\prime} \mathrm{S}$ & $23^{\circ} 32^{\prime} \mathrm{E}$ & $70-80$ & $145 \pm 0.8$ & [5] \\
\hline Oasis & Libya & $24^{\circ} 35^{\prime} \mathrm{N}$ & $24^{\circ} 24^{\prime} \mathrm{E}$ & 11.5 & $<120$ & [1] \\
\hline Ouarkziz & Algeria & $29^{\circ} 00^{\prime} \mathrm{N}$ & $07^{\circ} 33^{\prime} \mathrm{W}$ & 3.5 & $<70$ & [1] \\
\hline Roter Kamm & Namibia & $27^{\circ} 46^{\prime} \mathrm{S}$ & $16^{\circ} 18^{\prime} \mathrm{E}$ & 2.5 & $3.7 \pm 0.3$ & [1] \\
\hline Talemzane & Algeria & $33^{\circ} 19^{\prime} \mathrm{N}$ & $04^{\circ} 02^{\prime} \mathrm{E}$ & 1.75 & $<3$ & [1] \\
\hline Tenoumer & Mauritania & $22^{\circ} 55^{\prime} \mathrm{N}$ & $10^{\circ} 24^{\prime} \mathrm{W}$ & 1.9 & $2.5 \pm 0.5$ & [1] \\
\hline Tin Bider & Algeria & $27^{\circ} 36^{\prime} \mathrm{N}$ & $05^{\circ} 07^{\prime} \mathrm{E}$ & 6 & $<70$ & [1] \\
\hline Tswaing ** & South Africa & $25^{\circ} 24^{\prime} \mathrm{S}$ & $28^{\circ} 05^{\prime} \mathrm{E}$ & 1.13 & 0.2 & [1] \\
\hline Vredefort & South Africa & $27^{\circ} 00^{\prime} \mathrm{S}$ & $27^{\circ} 30^{\prime} \mathrm{E}$ & $250->300$ & $2023 \pm 4$ & {$[5]$} \\
\hline \multicolumn{7}{|c|}{ Probable Impact Structures } \\
\hline Sinamwenda & Zimbabwe & $17^{\circ} 11.7^{\prime} \mathrm{S}$ & $27^{\circ} 47.5^{\prime} \mathrm{E}$ & 0.22 & $<220$ & [6-8] \\
\hline \multicolumn{7}{|l|}{ Temimichat- } \\
\hline Ghallaman & Mauritania & $24^{\circ} 15^{\prime} \mathrm{N}$ & $09^{\circ} 39^{\prime} \mathrm{W}$ & 0.75 & & [1] \\
\hline Velingara & Senegal/Gambia & $13^{\circ} 0.2 .2^{\prime} \mathrm{N}$ & $14^{\circ} 07.7^{\prime} \mathrm{W}$ & 48 & $>24,<42$ & [9] \\
\hline \multicolumn{7}{|c|}{ Possible Structures, not yet fully investigated } \\
\hline Aorounga $2,3,4$ & Chad & $19^{\circ} 15^{\prime}-19^{\circ} 30^{\prime} \mathrm{N}$ & $19^{\circ} 15^{\prime}-19^{\circ} 30^{\prime} \mathrm{E}$ & $11.6,12,11.7$ & & {$[10]$} \\
\hline Bangweulu & Zambia & $11^{\circ} 32.3^{\prime} \mathrm{S}$ & $30^{\circ} 08.3^{\prime} \mathrm{E}$ & 150 & $<620$ & [11] \\
\hline El-Baz & Egypt & $24^{\circ} 12^{\prime} \mathrm{N}$ & $26^{\circ} 24^{\prime} \mathrm{E}$ & 4 & & {$[12]$} \\
\hline Kogo & Equat. Guinea & $01^{\circ} 11^{\prime} \mathrm{N}$ & $10^{\circ} 01 ' \mathrm{E}$ & 4.67 & $>145$ & {$[13,14]$} \\
\hline Luizi & D.R. Congo & $10^{\circ} 10^{\prime} \mathrm{S}$ & $27^{\circ} 55^{\prime} \mathrm{E}$ & 12.6 & $<620$ & [15] \\
\hline Lukanga Swamp & Zambia & $14^{\circ} 24^{\prime} \mathrm{S}$ & $27^{\circ} 45^{\prime} \mathrm{E}$ & 52 & $<450$ & [16] \\
\hline Mekambo & Gabon/Congo & $00^{\circ} 55.7^{\prime} \mathrm{N}$ & $13^{\circ} 40.4^{\prime} \mathrm{E}$ & 50 & $>2100,<2800$ & {$[17]$} \\
\hline Minkebe & Gabon & $01^{\circ} 21.2^{\prime} \mathrm{N}$ & $12^{\circ} 24.5^{\prime} \mathrm{E}$ & 90 & $>2100,<2800$ & [17] \\
\hline Ntwetwe & Botswana & $20^{\circ} 55^{\prime} \mathrm{S}$ & $24^{\circ} 50^{\prime} \mathrm{E}$ & 7 & $<200$ & [18] \\
\hline
\end{tabular}

\footnotetext{
* to be confirmed $\quad * *$ formerly known as Pretoria Saltpan
} 
EXTRAORDINARY VARIATION OF LANTHANIDE' TETRAD PHENOMENON RECORDED IN CONODONTS: MASS EXTINCTION AT LATE DEVONIAN. A. Masuda ${ }^{1}$, J. Shimoda ${ }^{2}, \mathrm{~S}$. K. Sahoo ${ }^{3}$ and $\mathrm{H}$. Goto ${ }^{4},{ }^{1}$ Dept. of Chem., Univ. of Tokyo (Hongo 7-3-1, Tokyo, Japan 113-0033; masfield@green.ocn.ne.jp), ${ }^{2}$ Univ. of Electro-Communications (Chofu, Tokyo, 182-8585; yaruki@ fa2.so-net.ne.jp), ${ }^{3}$ National Institute of Radiological Sciences (Inage, Chiba, Japan 263-8555), ${ }^{4}$ Kobe Women's Univ. (Suma, Kobe, Japan 654-8585).

Introduction: A drastic change of fossil species occurred between the uppermost Frasnian zone and the lowermost Fammenian zone, which form the Late Devonian limestone layers near Coumiac in the Montagne Noire area of southern France [1], [2]. GrandjeanLecuyer et al. [3] determined REE in old biogenic apatites (conodonts) separated from these conodontrich limestones, with SIMS ion probe. They reported that any particular REE anomaly was not detected in connection with the Frasnian-Fammenian mass extinction. According to our mathematical analysis of their data, however, we can recognize an obvious and peculiar discontinuity of REE tetrad effect at the mass extinction in question.

REE Tetrad Phenomenon: Masuda and Ikeuchi [4] found out the lanthanide tetrad phenomenon in the chondrite-normalized lanthanide patterns for samples from the marine environments. Further, it was found [5] that there are two types of lanthanide tetrad effect, $\mathrm{W}$ and $\mathrm{M}$ types, which are conjugate to each other, i.e., downward concave and upward convex. Usually, the seawaters [4], [5] exhibit W-type tetrad effect, while the hydroxide precipitates [6] and residues from the hydrous reaction show the M-type tetrad effect. (As a result of tetrad effect, lanthanides are divided to four subgroups, La-Nd, Pm-Gd, Gd-Ho and Er-Lu, which correspond to four smooth curves for stable lanthanides with discontinuities between $\mathrm{Nd}$ and $\mathrm{Pm}$, at Gd and between Ho and Er.)

Quantification of Lanthanide Tetrad Effect: Masuda et al. [7-9] developed a mathematical method to quantify the lanthanide tetrad effect. If the "necessary" data are available, one can obtain four nemerical values corresponding to four subgroups. Note that the $\mathrm{W}$-type tetrad effect is given by negative values, while the M-type effect is given by the positive ones. For conodonts from Coumiac, the abundances for $\mathrm{La}, \mathrm{Ce}$, $\mathrm{Nd}, \mathrm{Sm}, \mathrm{Eu}, \mathrm{Gd}, \mathrm{Dy}, \mathrm{Er}$ and $\mathrm{Yb}$ are determined, but the abundance for $\mathrm{Lu}$ is lacking. As a result, we cannot evaluate [7] degrees (AE3 and AE4) of tetrad effect for the third and fourth subgroups, but the degree(s) for light lanthanides (AELL) can be estimated (see Appendix). However, provided that there are abundance data for "stable" light lanthanides, La, Nd, Sm and Gd, we have to assume [7] that the quantified values for Ist and 2nd subgroups are identical to each other, which are designated as AELL. From the mathematically defined parabola, the "theoretically" normal abundances (see Appendix) for potentially irregular light lanthanides, $\mathrm{Ce}$ and $\mathrm{Eu}$, can be evaluated independently of observed abundances.

Light Lanthanide Tetrad Effects for Conodonts from Coumiac Limestones and their Characteris-

tics: The results are shown in Fig. 1.

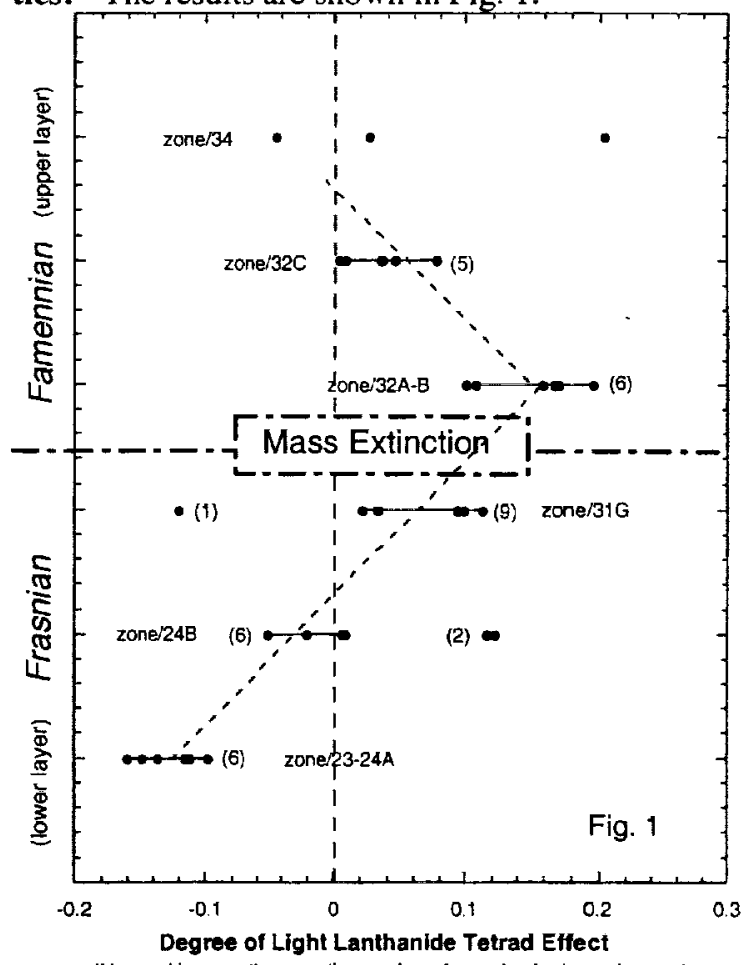

\{Numeral in parentheses = the number of samptes for barred range \}

Uncertainties due to experimental errors. The averaged uncertainties of AELL for determination with individual experimental errors of $7 \%$ is \pm 0.05 [10]. (The experimental errors are not given in the original paper.) Thus the range indicated by a bar might be substantially represented by a very small circle if the determination was very precise.

Unusual event. The average AELL value for zone 23-24A is -0.130 . AELL for Western North Pacific [12] ranges from -0.18 to -0.13 . That for Gulf of Oman [12] ranges from -0.17 to -0.11 . Lanthanides $(\mathrm{Ln})$ contained in connodonts of $23-24 \mathrm{~A}$ are judged to reflect the oceanic or marine Ln. Contrastingly, AELL for conodonts of zone $31 \mathrm{G}$ averages +0.074 , with 0.021 for intermediate zone 24B. The change from 0.130 (negative) to +0.074 (positive) reveals a dramatic reversal of hydrological environments. Subsequent to formation of $31 \mathrm{G}$, zone $32 \mathrm{~A}-\mathrm{B}$ reaches an abnormal AELL maximum of +0.149 . Prior to 32A-B, a mass extinction occurred. Positive AELL value im- 
LANTHANIDE TETRAD EFFECT IN CONODONT: A. Masuda, J. Shimoda, S. K. Sahoo and H. Goto

plies that $\mathrm{Ln}$ for this zone were derived by desoprtion from fresh-water and/or estuarine sediments $[6,13]$.

Change of Ce (obs.)/Ce (cal.): Here, obs. and cal. indicate observed and calculated, respectively. Calculation was made based on our assumption of parabolic curve related with the tetrad phenomenon. The features in Fig. 2 can be interpreted in terms of preferential adsorption of $\mathrm{Ce}$ on calcium phosphate from seawater and of the preferential

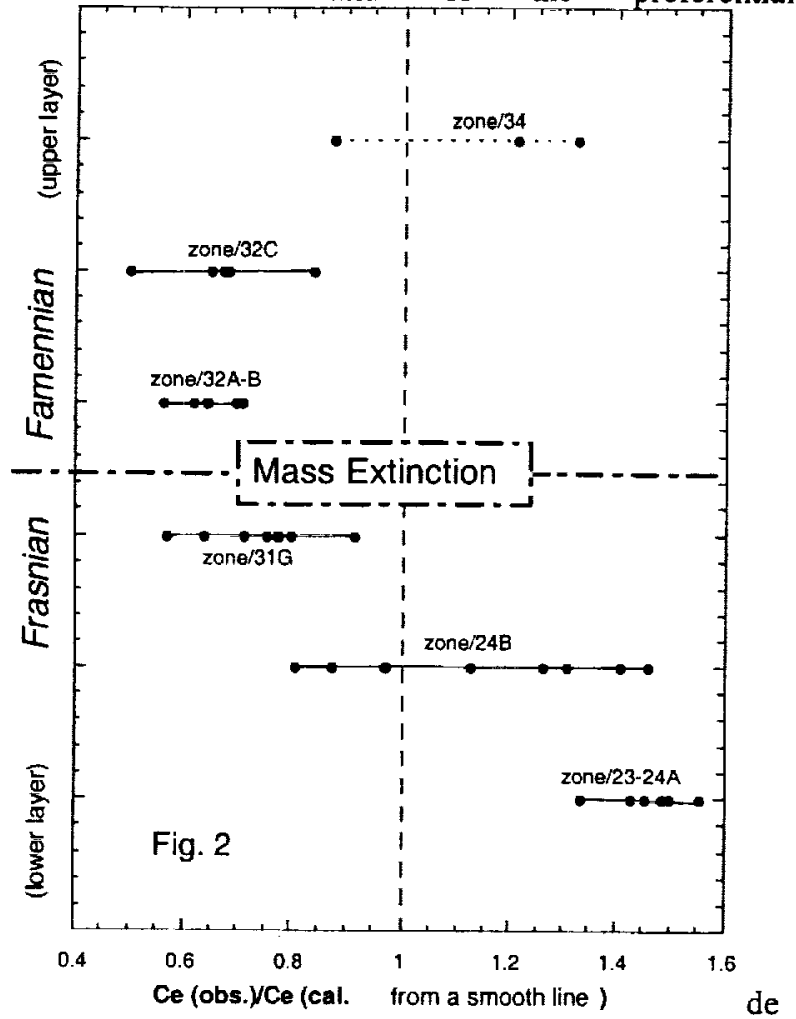

sorption of normal Ln from fresh-water or estuarine sediments, with insolubility of $\mathrm{CeO}_{2}$ into the aqueous phase. It merits attention that $23-24 \mathrm{~A}$ shows relatively narrow variation range, while $24 \mathrm{~B}$ a wider variation. It may suggest a chemical (especially, valency) unstability of $\mathrm{Ce}$ for "intermediate" zone 24B. The $\mathrm{Ce}$ (obs.)/Ce(cal.) is much less sensitive to the experimental errors than AELL.

Mass Extinction and Geological Processes: In view of Figs. 1 and 2 (especially Fig. 1), the following scenario is conceivable: (1) Presence of shallow marginal sea or shallow big bay wholly or partially surrounded by a chain of islets; (2) Isolation of marine water area from ocean, by formation of bank, due to connection of islets; (3) Formation of separate lakes and ponds; (4) Replacement of seawater by nearly fresh water by activity of freshet; (5) Break of dam and re-inflow of the seawater.

"Rapid" freshening process in almost closed area caused the mass extinction at the period of its high activity. Lowering and rise of sea level, the elevation and sinking of sea bottom, and/or change of freshet activity would have had something to do with this unusual event. It is likely that the chemical and salinity change from oceanic to nearly fresh water must be accompanied by lowering of $\mathrm{pH}$ of water and variation of oxidation potential, which also must have prompted the chemical reactions and the mass extinction. Temperature may have changed then.

References: [1] Feist R. (1985) Cour. Forsch. Inst. Senckenberg, 75, 331-352. [2] Becker R. T., Feist R., Flajs G., House M. R. and Klapper G. (1989) CRAS, 309, 259-266. [3] Grandjean-Lecuyer P., Feist R. and Albarede F. (1993) GCA, 57, 2507-2514. [4] Masuda A. and Ikeuchi Y. (1979) Geochem. J., 13, 1922. [5] Masuda A., Kawakami O., Dohmoto Y. and Takenaka T. (1987) Geochem. J., 21, 119-124. [6] Bau M. (1999) GCA, 63, 67-77. [7] Masuda A., Matsuda N., Minami M. and Yamamoto H. (1994) Proc. Jpn. Acad., 70B, 169-174. [8] Masuda A., Shimoda J. and Yamamoto H. (1995) Proc. Jpn. Acad., 71B, 208-213. [9] Masuda A., Shimoda J. and Ikeuchi Y. (1998) Geochem. J., 32, 275-280. [10] Shimoda J. and Masuda A. (1998) Proc. Jpn. Acad., 74B, 185-187. [11] Masuda A. and Shimoda J. (1996) Proc. Jpn. Acad.., 72B, 202207. [12] Masuda A. and Shimoda J. (1997) Proc. Jpn. Acad., 73B, 187-191. [13] Liu C.-Q., Masuda A., Okada A., Yabuki S., Zhang J. and Fan Z.-L. (1993) Chem. Geol., 106, 359-374. [14] Shiokawa T., Shimoda J. and Masuda A. (1999) Proc. Jpn. Acad., 75B, 112-116.

Appendix: Example of calculation of AELL, defined as length of two-headed bold arrow, for W-type tetrad effect [14]

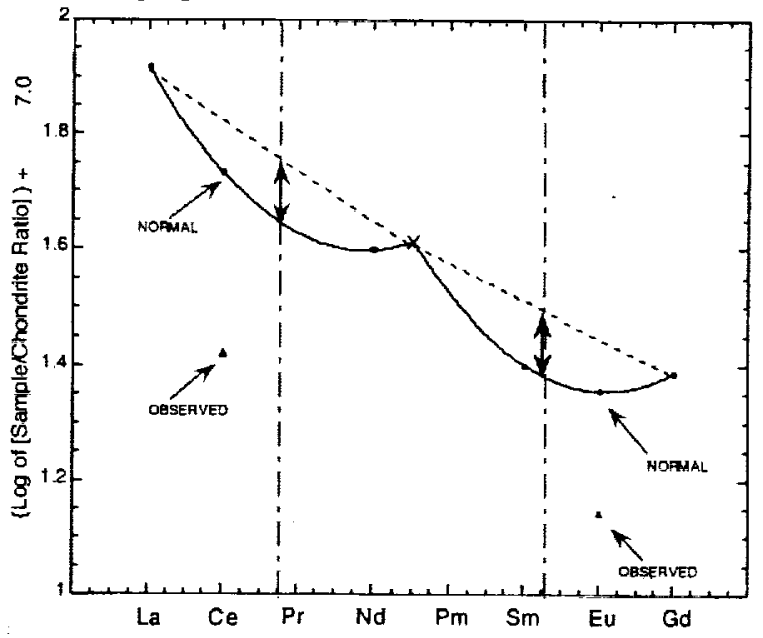




\section{NOBLE GASES IN A LARGE BUBBLE IN MOLLDAVITE: A COMPARISON WITH PHILIPPINITE.} J. Matsuda, T. Matsumoto, A. Seta, A. Tsuchiyama 1 , Y. Nakashima ${ }^{2}$ and S. Yoneda ${ }^{3}$

1. Department of Earth Sciences, Graduate School of Science, Osaka University, Osaka 560-0043, Japan. (J. Matsuda's e-mail address: matsuda@ess. sci.osaka-u.ac.jp)

2. Geological Survey of Japan, 1-1-3 Higashi, Tsukuba 305-8567, Japan.

3. Department of Science and Engineering, National Science Museum, Tokyo, 3-23-1 Hyakunin-cho, Shinjuku-ku, Tokyol 690073 , Japan.

We previously crushed the philippinite with an unusually large bubble, and found that the concentrations of $\mathrm{He}$ and $\mathrm{Ne}$ were more enriched than those of heavy noble gases of $\mathrm{Ar}, \mathrm{Kr}$ and $\mathrm{Xe}$ in the bubble, in comparison with the terrestrial atmosphere [1]. The ${ }^{20} \mathrm{Ne}{ }^{22} \mathrm{Ne}$ and ${ }^{21} \mathrm{Ne}{ }^{22} \mathrm{Ne}$ ratios were higher than the values expected from steady state process, and were interpreted to reflect very fast nonsteady state diffusion in the early stages of tektite formation.

In this study, we again had a chance to obtain a moldavite which has comparatively large bubble and could compare the noble gas feature in it with the data in the philippinite in our previous study. The moldavite is a typical tear-drop fluidal shape of $50 \times 22 \mathrm{~mm}$ and weighing $22.70 \mathrm{~g}$. The existence of a large internal bubble could be seen from the outside with the transparent thin color of its portion and was confirmed by an X-ray CT scanner equipped at the Geological Survey of Japan. The three-dimensional structure was reconstructed from successive imaging by the $\mathrm{X}$ ray $C T$ scanner, and the volume of the large bubble was estimated to be $0.16 \mathrm{~cm}^{3}$. There were several small bubbles of which volume are less than $0.002 \mathrm{~cm}^{3}$. The total volume of the moldavite itself including bubbles was $9.6 \mathrm{~cm}^{3}$. If bubble was formed due to the gas expansion inside the glass, the bubble should be spherical shaped. However, the largest bubble in the moldavite is not spherical and is rather prolonged shaped to the long axis of the tektite, suggesting that the deformation of tektite to the tear-drop shape was after the bubble formation.

The elemental abundances and isotopic compositions of noble gases have been measured by crushing the moldavite sample in the crushing device in Osaka University. The large crushing device is the same one as that we used for the crushing experiment of the philippinite [1]. The sample chamber of the device is cylindrical, with a diameter of $10 \mathrm{~cm}$ and a height of $10 \mathrm{~cm}$, which was connected to a purification line and a VG 5400 noble gas mass spectrometer. A piston goes slowly down to crush the sample by turning a handle. The experimental procedures of measuring noble gases are given in our previous works [ 1 , 2]. The procedural blanks of noble gases were measured using the same experimental setup without crushing the sample before the measurement.

The moldavite sample was crushed with a violent sound in the crushing device. Our results of noble gas analyses are listed in Table 1. As the isotopic ratios of all noble gases are atmospheric, we do not list them for $\mathrm{Ar}, \mathrm{Kr}$ and $\mathrm{Xe}$. The elemental abundances are enriched in $\mathrm{He}$ and $\mathrm{Ne}$ compared to those in the ter restrial atmosphere, which is compatible with the previous works for tektites $[1,3-5]$ and for impact glasses [2]. The He/Ar and Ne/Ar ratios are higher than those in air by three orders of magnitude although $\mathrm{Kr} / \mathrm{Ar}$ and Xe/Arratios are almost identical to the air values (Fig. 1). The isotopic ratio of $\mathrm{He}$ is identical to the air value, which is identical to our previous work for a large bubble in philippinite [1]. The isotopic ratio of $\mathrm{Ne}$ is also identical to the air value, which is compatible with the data of previous observations for many tektites [3-5], but is different from that for a large bubble in the philippinite [1]. The Ne isotopic ratios in philippinite were fractionated from the air value and were higher than the latter values.

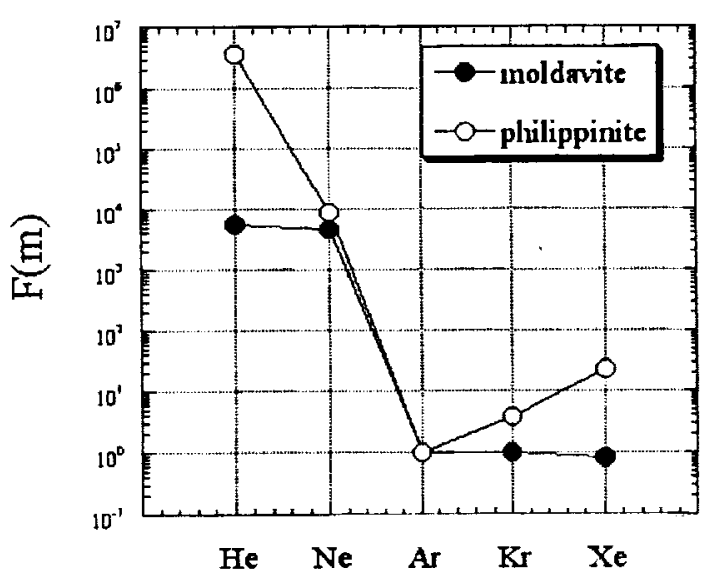

Fig. 1. The elemental abundance patterns of noble gases in the moldavite and the philippinite [1] displayed by the fractionation factor $\mathrm{F}(\mathrm{m})$.

$$
\mathrm{F}(\mathrm{m})=\left(\mathrm{m}_{\mathrm{X}} /{ }^{36} \mathrm{Ar}\right)_{\mathrm{sampk}} /\left(\mathrm{m}_{\mathrm{X} /} / 6_{\mathrm{Ar}}\right)_{\mathrm{ar}}
$$


Table 1. Noble gas contents (in $\mathrm{cm}^{3} \mathrm{STP}$ ) and their isotopic ratios of the bubble gases in the moldavite in this study and the philippinite [1].

\begin{tabular}{cccc}
\hline & moldavite & philippinite & air \\
\hline${ }^{4} \mathrm{He}$ & $8.3 \times 10^{-7}$ & $3.0 \times 10^{-5}$ & \\
${ }^{3} \mathrm{He} / \mathrm{He}$ & $1.33(12) \times 10^{-6}$ & $1.30(17) \times 10^{-6}$ & $1.40 \times 10^{-6}$ \\
${ }^{22} \mathrm{Ne}$ & $2.2 \times 10^{-7}$ & $2.4 \times 10^{-8}$ & \\
${ }^{20} \mathrm{Ne}{ }^{22} \mathrm{Ne}$ & $9.89(12)$ & $10.52(52)$ & 9.80 \\
${ }^{21} \mathrm{Ne} /{ }^{22} \mathrm{Ne}$ & $0.0290(3)$ & $0.0299(3)$ & 0.0290 \\
${ }^{36} \mathrm{Ar}$ & $8.7 \times 10^{-10}$ & $5.0 \times 10^{-11}$ & \\
${ }^{84} \mathrm{Kr}$ & $1.8 \times 10^{-11}$ & $4.0 \times 10^{-12}$ & \\
${ }^{130} \mathrm{Xe}$ & $8.3 \times 10^{-14}$ & $1.3 \times 10^{-13}$ & \\
\hline
\end{tabular}

Numbers in parentheses are uncertainties (1 s.d.) in isotopic ratios and corres ponding to the last digits.

We looked for the cause of the difference of $\mathrm{Ne}$ isotopic ratios between the philippinite and the moldavite. We calculated the ${ }^{22} \mathrm{Ne}$ partial volume ratio in the bubble of the moldavite by assuming that the whole amount of ${ }^{22} \mathrm{Ne}$ was derived from the large bubble. The calculated ratio is $1.4 \times 10^{-6}$ which is almost identical to the value $\left(1.6 \times 10^{-6}\right)$ in the terrestrial atmosphere. Thus, the Ne partial pressure in the bubble in the moldavite was almost reached to the air value. This is not the case for the big bubble in the philippinite where the partial volume ratio was $4.5 \times 10^{-9}$, much lower than the atmospheric value and that in the moldavite. This is probably due to the difference of the ages for the philippinite and the moldavite. The age of philippinite is estimated to be $0.7 \mathrm{my}$, but that of moldavite is $15 \mathrm{my}$ and much older. As the moldavite has been exposed to the atmosphere for a longer time, $\mathrm{Ne}$ could be fully diffused into the tektite and reached to the partial pressure in the bubble as same as that in the terrestrial atmosphere. Thus, it is compatible with the model that a very high ${ }^{20} \mathrm{Ne} P^{2} \mathrm{Ne}$ ratio was obtained in a very short time by nonsteady state diffusion during melting stage of the tektite formation and was lowered later by slow diffusion from the atmosphere [1]. On the contrary, the partial pressures in heavy noble gases in the bubble of the moldavite still show the values at the formation. They are much lower than the atmospheric values under one atmospheric pressure, suggesting that the tektite was formed at high altitude of the atmosphere as indicated by our previous works $[1,5]$.

\section{References:}

[1] Matsuda J., Maruoka T., Pinti D.L., and Koeberl C. (1996) Meteoritics \&Planet. Sci., 31, 273-277.

[2] Matsuda J., Matsubara K., Yaj̈ma H., and Yamamoto K. (1989) Geochim. Cosmochim Acta 53, 30253033.

[3] Hennecke E.W., Manuel O.K., and Sabu O.K. (1975) J. Geophys. Res., 80, 2931-2934.

[4] Matsubara K. and Matsuda J. (1991) Meteoritics, 26 217-220.

[5] Matsuda J. and Matsubara K. and Koeberl C. (1993) Meteoritics, 28, 586-599. 
CATASTROPHIC GLOBAL TSUNAMI INDUCED BY K/T IMPACT. T. Matsui ${ }^{1}$, F. Imamura ${ }^{2}$, E. Tajika ${ }^{3}$, Y. Nakano $^{3}$ and Y. Fujisawa ${ }^{4}$, 'Dept. of Complexity Science and Engineering, Graduate School of Frontier Science, Univ. of Tokyo (7-3-1 Hongo, Bunkyo-ku, Tokyo 113-0031, Japan, matsui@geoph.s.u-tokyo.ac.jp), ${ }^{2}$ Disaster Control Research Institute, School of Engineering, Tohoku Univ. (Aoba 06, Sendai 980-8579, Japan, imamura@tsunami2.civil.tohoku.ac.jp), ${ }^{3}$ Department of Earth and Planetary Science, Graduate School of Science, Univ. of Tokyo (7-3-1 Hongo, Bunkyo-ku, Tokyo 113-0031, Japan, tajika@geol.s.u-tokyo.ac.jp, nakano@geoph.s.u-tokyo.ac.jp), ${ }^{4}$ Technical Research Institute, Obayashi Corporation (Shimo-kiyose 4-640, Kiyose 204-0011, Tokyo, Japan. Fujisawa@tri.obayashi.co.jp)

Introduction: There occurred a gigantic meteorite impact in Yukatan peninsula at $65 \mathrm{Ma}$, which resulted in the formation of Chicxulub crater [1]. Hereafter we call this impact as the $\mathrm{K} / \mathrm{T}$ impact. Since Yucatan peninsula was covered with shallow water at that time [2], a gigantic tsunami may have been generated in association with this impact. Many geologic features supporting this view have been found so far at the $\mathrm{K} / \mathrm{T}$ boundaries in and around the gulf of Mexico [3]. Recently Takayama et al. [4] found the homogenite in the $\mathrm{K} / \mathrm{T}$ boundary in Cuba, which gives more clear geological evidence supporting tsunami generation by the $\mathrm{K} / \mathrm{T}$ impact. It is therefore very important to study whether or not the $\mathrm{K} / \mathrm{T}$ impact could generate tsunami. In this paper we report the results of numerical simulation on generation and propagation of tsunami due to the $\mathrm{K} / \mathrm{T}$ impact.

Background: Since the discovery of Chicxulub crater in Yucatan peninsula [1] focus of studies on $\mathrm{K} / \mathrm{T}$ impact phenomena seems to shift toward more environmental consequences due to this gigantic meteorite impact . One of examples of such studies is concerning the $\mathrm{K} / \mathrm{T}$ boundary tsunami deposits found in and aroud the Gulf of Mexico [3] although their origin is still controversial. Recently Japan-Cuban joint research group reported the discovery of thick deposit layer (thickness is about $180 \mathrm{~m}$ ) consisted of the lower grain flow unit overlain by the upper homogenite unit whose age is tightly constrained at the K/T boundary [4]. The homogenite is a thick, normal graded, structureless deposit formed by tsunami in deep sea environment [5]. This discovery may give a first strong evidence supporting for $\mathrm{K} / \mathrm{T}$ impact tsunami generation. It is, however, uncertain how a gigantic tsunami is generated by the $\mathrm{K} / \mathrm{T}$ impact.

Tsunami generation: The $10 \mathrm{~km}$-sized meteorite impact on the earth at $65 \mathrm{Ma}$ with the impact velocity of several tens $\mathrm{km} / \mathrm{s}$ (the $\mathrm{K} / \mathrm{T}$ impact case) released the impcat energy corresponding to the TNT explosion energy of 1 to $10 \mathrm{Mt}$ and resulted in the formation of Chicxulub crater. The diameter and depth of the crater are about $180 \mathrm{~km}$ and several $\mathrm{km}$, respectively [6]. In association with this impact the seawater and sea floor would have vaporized instantaneously and the shock waves generated by the impact would have propagated in the atmosphere. Shock waves caused by the entry of the meteorite into the atmoshere could have induced tsunamis. As a more gradual process, the surrounding seawater may have flowed into the crater, and as the crater overfilled with water, elevated tsunamis could eventually have propagated outward from the crater site. We can consider three stages of tsunami generations caused by the impact of meteorite on the earth: (1) the wave coupled with high air pressure and wind generated by the entry of the meteorite into the atmosphere, (2) the "rim wave" formed at the front of the ejecta curtain and (3) the wave caused by movement of water to fill and flow out of the crater cavity after the crater formation (hereafter called "receding" and "rushing" waves, respectively). The wave generation at the first stage is considered to be negligible because the waves generated by strong winds are dispersive and rapidly damped during propagation over a long distance. The waves generated by the second stage was modelled as the initial condition of the "rim wave" with wave height and length estimated by the hydraulic experimental results of Gault and Sonett [7]. The wave generated by the third stage might have been the most devastating, and is simulated based on the nonlinear long wave theory.

Paleobathymetry: In order to simulate the tsunami generation and propagation due to the $\mathrm{K} / \mathrm{T}$ impact, we need to assume the probable conditions of the earth at the time of the K/T impact. As will be shown later, the shape of crater does not affect the generation and propagation of tsunami significantly. Hence we simply assume the crater shape just after the impact as the present shape of the Chicxulub crater [6]. We also assume the Yucatan peninsula was covered with shallw water (less than $200 \mathrm{~m}$ deep) at the time of the $\mathrm{K} / \mathrm{T}$ impact [2]. For the reconstruction of paleobathymetry of the Gulf of Mexico and Caribbean region, we adopted the tectonic reconstruction model proposed by Ross and Scotesse [8], modified slightly based on the fieldwork in cuba by Takayama et al. [4]. We also reconstructed the continental distribution, paleobathymetry and sea level of $65 \mathrm{Ma}$, using the plate motion and cooling models of the plate. For this purpose we used the ETOPO-5 as the topographic data of the present earth and a digital age map of the ocean floor. 
Numerical results: We summarize the results on (1) tsunami genertion at first, and secondary on (2) tsunami propagation.

(1a) Behavior of the rim wave: According to breaking wave criteria in the field of coastal engineering [9], the amplitude of rim wave is estimated to be on the same order as the mean depth. In the near field for a centered wave system, the higher frequency components will be dispersed backwards and due to turbulence and bottom friction the wave amplitude will damp in accordance with traveling distance. In addition to that the wave aplitude would also decrease as a function of $1 / \mathrm{r}(\mathrm{r}$ is the radius from the center of the crater). We can estimate the effect of non-linearity by using the Ursell parameter which represents the relative importance of non-linearity to dispersion effects. This estimation implies that the effect of non-linearity is dominant on the platform whereas the dispersion effect becomes significant in the deep water after passing the shallow region. The Ursell parameters are $\mathrm{O}(10)$ at the edge of the platform and $O(1 / 10)$ in the deep water. The amplitude of the rim wave would be of the order of $10 \mathrm{~m}$ at the edge of platform and several meters in the deep water at a distance of $500 \mathrm{~km}$ from the center.

(1b) The receding and rushing waves: We used the non-linear shallow water theory with dispersion effect to simulate the movement of water on the Yucatan platform. Since the water depth of the Yucatan platform around the crater is much shallower (less than $200 \mathrm{~m}$ ) than the crater depth (approximately $3 \mathrm{~km}$ ), a detailed crater shape is not important to tsunami generation, that is, the flow rate into crater cavity is independent of the depth of the crater. The numerical simulation demonstrates the water movement that generates the receding and rushing waves. The water that flowed into the crater cavity accumulates and the crater cavity overfilled, thus, generating the rushing wave outward. We found that the wave going out of the crater is controlled by the depth of the shallow water region surrounding the crater. It is shown that the smaller the flow velocity in the shallow water region, the smaller is the wave height of the rushing wave with the longer oscillation period. When the water depth of the Yucatan platform is $200 \mathrm{~m}$ at the end of the Maastrichtian, the wave height and period at the rim of the crater are estimated to be about $50 \mathrm{~m}$ and 10 hours, respectively.

(2) Tsunami propagation: We can obtain the wave amplitude and period of receding and rushing waves as a function of the crater size and the water depth around the crater from the above numerical simulation. Using these results as the initial conditions we can simulate oceanic propagation of tsunami based on the linearized long-wave theory in the spherical coordinates; one is for tsunami propagation in the Gulf of Mexico with a detailed coastal run-up condition. The second is for oce- anic propagation over the entire globe. For the spherical coordinate system, the $20 \mathrm{~min}$. spatial grid size was used together with the time interval adjusted to satisfy the CFL condition at all times. Details of the model such as numerical scheme and stability condition are referred to the work by Imamura and Shuto [10]. There are two types of tsunamis that attacked the coast near the impact crater; one is the receding wave and the other is the rushing wave. No measurable wave was found ahead of the receding wave. This means that the rim wave must have quickly dispersed during the propagation to the shore. The receding wave covers the entire Gulf over 10 hours after the imact. The positive wave flows with a height of more than 200 meter, reaching the coastal area of North America. It runs up over the lands and passes the Mississippi embayment, a distance of over $300 \mathrm{~km}$. The maximum run-up height of $300 \mathrm{~m}$ is found near the Rio Grande embayment with an average value of more than $150 \mathrm{~m}$. The numerical results of oceanic propagation show that some of the wave energy (with the wave periods of 1 to 2 hours) is trapped in the Gulf of Mexico and then propagated mostly towards Europe and North Africa, but less to the Pacific ocean. The simulation suggests that, besides the North American coasts, the impact must have also caused significant tsunami runup in South America: for example, approximately $200-250 \mathrm{~m}$ high runup in what is now Venezuela. Furthermore, the simulation shows the runup height of approximately $100-150 \mathrm{~m}$ in Northwest African coasts and $100 \mathrm{~m}$ along Northern Europe coasts. Two separate waves, one propagated across the Atlantic ocean and the other across the Pacific ocean, met at the eastern part of the Indian ocean at about 28 hours after the impact. The wave height in the Indian ocean was found to be approximately $10 \mathrm{~m}$ with the wave period of 10 hours.

References: [1] Hildebrand A. R. et al. (1991) Geology 19, 867-871. [2] Sohl N. F. et al. (1991) In The Geology of North America, Vol. J, 205-244. [3] Smit J. et al. (1996) Geol. Soc. Am. Spec. Pap. 307, 151-182. [4] Takayama H. et al. (2000) Sediment. Geol. in press. [5] Cita M. B. et al. (1996) Sediment. Geol. 104, 155173. [6] Morgan J. V. et al. (1997) Nature 390, $472-$ 476. [7] Gault D. E. and Sonett C. P. (1982) Geol. Soc. Am. Spec. Pap. 190, 69- [8] Ross M. J. and Scotese C. R. (1988) Tectonophysics 155, 139-168. [9] Dean R. G. and Dalrymple R. A. (1991) Water Wave Mechanics for Engineers and Scientists, World Scientific pp. 353. [10] Imamura F. and Shuto N. (1990) Proc. of Int. Sym. Comp. Fluid Dynamics, Nagoya, 390. 
PLATINUM-GROUP ELEMENTS IN THE MOROKWENG IMPACT MELT SHEET: EVIDENCE FOR AN L-CHONDRITE GIANT IMPACTOR AT THE J/K BOUNDARY. I. McDonald ${ }^{1}$, M.A.G. Andreoli ${ }^{2.3}$, R.J. Hart $^{3.4}$, and M. Tredoux ${ }^{5}$, ${ }^{1}$ School of Earth \& Environmental Sciences, University of Greenwich, Chatham Maritime, ME4 4TB, U.K. (mi08@gre.ac.uk), ${ }^{2}$ AEC, P.O. Box 582, Pretoria 0001, South Africa, ${ }^{3}$ Schonland Centre, University of the Witwatersrand, Wits 2050, South Africa, ${ }^{4}$ Council for Geoscience, Private Bag X112, Pretoria 0001, South Africa, ${ }^{5}$ Dept. of Geological Sciences, University of Cape Town, Rondebosch 7700, South Africa.

Introduction: The discovery that the giant $(>170 \mathrm{~km})$ diameter Chixculub impact structure formed 65 million years ago $(\mathrm{Ma})$, coincident with the Cretaceous-Tertiary (K/T) boundary [1], provided clear evidence for an overlap in time between a giant impact crater and a major geological boundary. Recent discoveries have shown that the Jurassic-Cretaceous $(\mathrm{J} / \mathrm{K})$ boundary may also overlap with a large impact event. The melt sheet of the $>90 \mathrm{~km}$ diameter Morokweng impact structure in southern Africa gives precise U-Pb ages of $145 \pm 1 \mathrm{Ma}$ within error of the currently estimated $\mathrm{J} / \mathrm{K}$ boundary age [2-4]. While the age overlap between large craters and some boundaries is now clear, the types of objects involved in giant impacts and the frequency with which they strike Earth is much less so. This kind of information is central to understanding the sources of different projectiles and how collisions between the Earth and different large-scale objects have influenced geological history.

The signature of an impactor is imparted via the fraction of the projectile retained in the crater into the final melt sheet and the platinum-group elements (PGE) have been used as tracers for meteoritic components at many impact craters [5-7]. However, while it is often possible to distinguish silicate and iron meteorites, fingerprinting different chondrites in impact rocks has been less successful. $\mathrm{Cr}$ isotope analyses and PGE data from $\mathrm{K} / \mathrm{T}$ boundary sites suggest that the $\mathrm{K} / \mathrm{T}$ impactor was a carbonaceous chondrite $[5,8]$. Such a reliable classification has not yet been made at Morokweng. Existing data $[3,9]$ indicate broadly "chondritic" relative concentrations of PGE but insufficient data to perform meaningful statistical analysis against known meteorite PGE compositions has prevented more detailed identification. The aim of this work has been to test whether a more precise classification can be made. This will be compared with an independent study [10] which, on the basis of $\mathrm{Cr}$ isotope and $\mathrm{Ir}$ data, proposed that impact of an ordinary chondrite (most probably an L-chondrite) formed the Morokweng structure.

Methods: Samples were recovered from a series of diamond drill boreholes sunk into the structure. Some of this core has been described previously [2,3]. 17 samples ( 0.35 to 1.5 meters in length) of continuous core through the Morokweng melt sheet were selected for PGE analysis. 14 of these samples were sulphidefree quartz norite, two were sulphide-bearing norite and one was a sample of granite. PGE data were obtained using NiS fire assay followed by ICP-MS [11]. Impactor PGE ratios and estimates of the target rock input were determined together using analysis of regressions between Ir and the other PGE $[5,6]$.

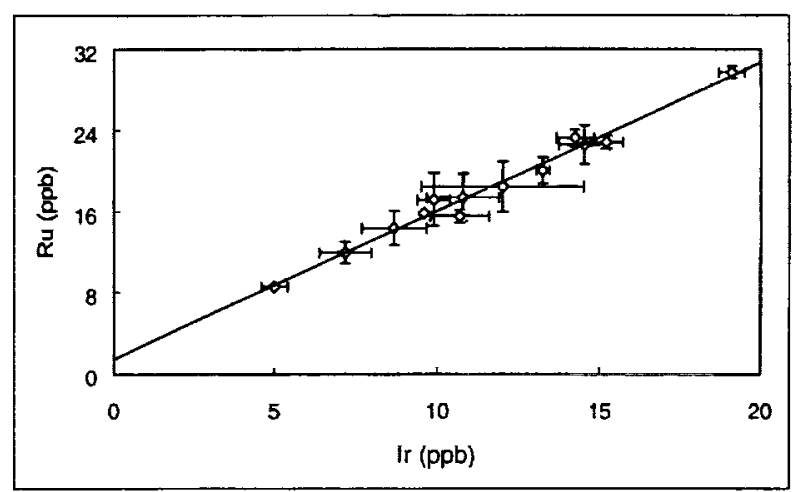

Figure 1: Regression between Ru and Ir for sulphidepoor Morokweng melt samples. Error bars show one standard deviation of the mean concentration [11].

Results: All of the melt rocks produce Ir concentrations which are at least 25 times those found in the granite and the Archean metasediments and Karoo strata which comprise the bulk of the target rock suite $[11,12]$. Ir concentrations in the melt rocks are also at least 2-6 times those found in greenstones (komatiites) which comprise a poorly known proportion of the target rocks. When the melt sheet data are normalised to Ir and $\mathrm{CI}$ chondrite $\left([\mathrm{X} / \mathrm{Ir}]_{\mathrm{N}}\right)$ the ratios are only slightly fractionated from unity and fall in narrow populations with low standard deviations. $[\mathrm{Pt} / \mathrm{Ir}]_{\mathrm{N}}$ and $[\mathrm{Pd} / \mathrm{Ir}]_{\mathrm{N}}$, are consistently less than 2.00 - beneath the lower limit for most mafic terrestrial melts but within the range shown by meteorites. The only terrestrial melt rocks with similar PGE characteristics are Fe-rich massive sulphides from the Strathcona and Falconbridge mines at Sudbury [13]. These giant ore bodies formed during the fractional crystallisation of $\mathrm{Pt}$ and $\mathrm{Pd}$-poor $\mathrm{Fe}$ sulphide and $\mathrm{Cu}, \mathrm{Pt}$ and $\mathrm{Pd}$-rich sulphide melt. As a result, bimodal distributions of sulphide types and PGE ratios are evident at Sudbury [13]. Sulphides are scattered minor constituents at Morokweng and our bulk analyses of 
sulphide-rich lithologies (excluding late-stage $\mathrm{Ni}-\mathrm{S}$ oxide segregations) indicate that they show the same PGE signatures as the barren quartz norites. There is no bimodal distribution in the bulk rock PGE ratios to support a sulphide fractionation mechanism for generating the low $[\mathrm{Pt} / \mathrm{Ir}]_{\mathrm{N}}$ and $[\mathrm{Pd} / \mathrm{Ir}]_{\mathrm{N}}$ ratios and we feel that they most probably reflect a primary (meteoritic) signature.

Regression analysis reveals that correlation between Ir and the other PGE is very strong for all samples (see Figure 1) and is consistent with metal fractionation controlled by varying absolute amounts of a homogenous PGE-rich component such as a meteorite. In regression analysis, the slope of the line represents the PGE/Ir ratio of the impactor and by extrapolation to low concentrations, the target PGE concentration can also be estimated if the target Ir concentration is known or assumed. The advantage of this method for determining the PGE signature is that it is based on the impact melt alone. There is no reliance on successful modelling of the exact mix of target lithologies in order to estimate a correction for target PGE input.

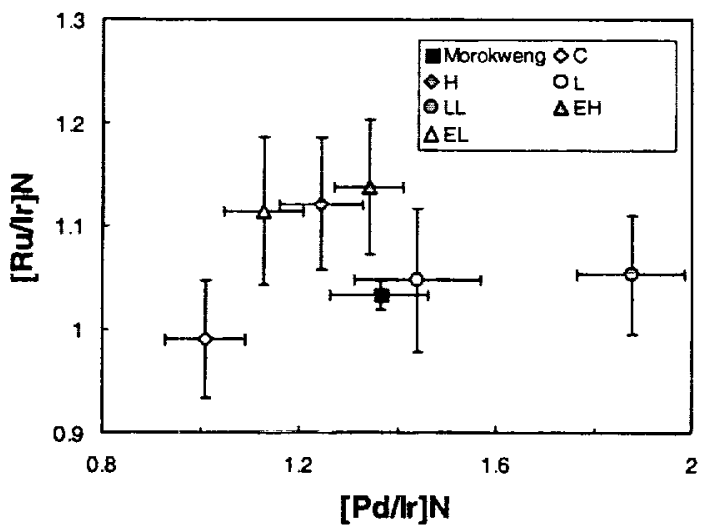

Figure 2: Ru and Pd data from Morokweng and various chondrites normalised to $\mathrm{Ir}$ and $\mathrm{CI}$ chondrite. Data sources: carbonaceous chondrites [16], ordinary chondrites [17], enstatite chondrites [16].

When the PGE/Ir ratios obtained by regression are normalised and compared with various types of chondrite, a striking pattern emerges (see Figure 2). The signatures of C, H, LL, EL and EH chondrites consistently fall at least two standard errors of the mean from Morokweng, suggesting that they are unlikely PGE candidates. However, Morokweng falls consistently within one standard error of the PGE signature of ordinary (L) chondrites. This strongly suggests that the impactor was Lchondrite and offers independent support for the conclusions of an earlier study [7] that reached a similar con- clusion, using ${ }^{53} \mathrm{Cr} /{ }^{52} \mathrm{Cr}$ isotope analyses and the $\mathrm{Cr} / \mathrm{Ir}$ ratio.

Implications: These results provide clear evidence that Chixculub and Morokweng, the two largest known craters at $\mathrm{K} / \mathrm{T}$ and $\mathrm{J} / \mathrm{K}$ times, were formed by the impact of different objects - a carbonaceous and an ordinary chondrite respectively. Reflectance spectra indicate that subtype S(IV) asteroids are likely candidates for ordinary chondrite parent bodies whereas class $\mathrm{C}$ asteroids are probable parents bodies for carbonaceous chondrites [14]. Class $C$ asteroids are $>40$ times more abundant than S(IV) asteroids so carbonaceous chondrites should strongly dominate over ordinary chondrites in the terrestrial cratering record if selection processes are random. However, S(IV) asteroids are concentrated adjacent to the Jovian 3:1 orbital resonance - a highly favourable position from which to perturb objects into Earth-crossing orbits $[14,15]$. This position was probably just as favourable in the late Jurassic and it is possible that the Morokweng impactor originated from here. Current knowledge of impactor types at different craters is very limited ( $\sim 6$ are known with any real certainty) and clearly many more impactor classifications are needed. Ultimately, these will help reveal how frequently different types of objects have struck Earth over geological time and how closely this pattern compares with asteroid populations or not.

References: [1] Sharpton V.L. et al. (1997) Nature, 359, 819-821. [2] Hart R.J. et al. (1997) EPSL, 147, 2535. [3] Koeberl C. et al. (1996) Geology, 25, 731-734. [4] Andreoli M.A.G. et al. (1999) Geol. Soc. Am. Spec. Paper, 339, 1-18. [5] Evans N.J. et al. (1993), GCA, 57, 3737-3748. [6] Schmidt G. (1997), Meteoritics, 32, 761-767. [7] Schmidt et al. (1997), GCA, 61, 29772987. [8] Shukolyukov A. \& Lugmair G.W. (1998), Science, 282, 927-929. [9] McDonald I. et al. (1998), (astract) in Impacts \& the Early Earth, Cambridge, 18. [10] Shukolyukov A. et al. (1999), MAPS, 34, A107. 108. [11] Koeberl C. et al. (2000), in (1. Gilmour \& $C$. Koeberl eds.) Impacts \& the Early Earth, Springer Verlag, Lecture Notes in Earth Sciences, 92, 73-96. [12] Huber H. et al. (2000), J. Rad. Nucl. Chem, (in press) [13] Naldrett A.J. et al. (1982), Econ. Geol., 77, 15191534. [14] Gaffey M.J. et al. (1993), Meteoritics, 28, 161-187. [15] Farinella P. et al. (1993), Icarus, IOI, 174-187. [16] Wasson J. \& Kallemeyn (1989), Phil T. R. Soc, A352, 535-544. [17] Kong P \& Ebihara M. (1997), GCA, 61, 2317-2329. 
CAN IMPACTS INDUCE VOLCANIC ERUPTIONS? by H. J. Melosh, Lunar and Planetary Lab, University of Arizona, Tucson, AZ 85721. jmelosh@lpl.arizona.edu

Introduction: A theme that runs through hundreds of papers on meteorite impacts is the idea that large impacts can induce volcanic eruptions [one of the first was 1]. This idea probably got its start in preApollo days when early observers of the moon noted the common occurrence of dark material-usually supposed to be lava - filling the nearside impact basins. A logical inference is that this is a genetic association: The impacts caused lava to upwell in the biggest craters after they had formed, eventually filling them. This view should have collapsed in 1965, when the Russian probe Zond 3 made good photos of the lunar farside that showed that the farside basins are not filled with basalt. Moreover, the samples returned from the moon by the Apollo missions showed that the mare basalts are considerably younger (up to about $1 \mathrm{Gyr})$ than the basins in which they lie [2]. Any presumption of a genetic association of impacts and volcanism on the moon must thus be deemed questionable. It seems more likely that the large nearside basins were merely the lowest spots on the moon's surface at the time that the lunar interior warmed to the point where basaltic partial melts formed in its mantle, and that the rising lava simply flowed to the lowest points. At most, this rising lava might have flowed up impact-induced fractures in the lunar crust.

Sources of Magma: To examine this problem further, consider the sources of melt on the Earth. Terrestrial magmas originate in one of two settings: Arc magmas are produced by volatile (mainly water) fluxing of the mantle overlying subducting slabs. Pressure-relief melting induced by mantle convection produces the most voluminous lavas on Earth. The first setting has little relevance for meteorite impacts: Impacts do not inject material deep into the target. During an impact the projectile material forms a liner to the growing crater cavity. Even as the crater collapses, these materials are always near the surface and do not get injected deep into the underlying rocks. At large craters such as Sudbury, Manicouagan and Chicxulub the melt sheet lies on top of the brecciated unmelted target rocks. Even a slow impact of a large comet would thus not introduce substantial quantities of water into the crust deep beneath the impact site.

Pressure relief melting by impacts is a more plausible alternative. Terrestrial mid-ocean ridge basalts originate over upwellings where the peridotitic mantle has risen nearly $1000 \mathrm{~km}$ from mid- or even lowermantle sources. Similarly, mantle plumes represent places where especially hot mantle material rises large distances (perhaps even from the core-mantle boundary). Since the slope of the peridotite melting curve is $15-17 \mathrm{~K} / \mathrm{kbar}$ near the surface, it is clear that uplifts of hundreds of $\mathrm{km}$ can easily result in the production of basaltic melt.

Uplift in Craters: The crucial question is, how much uplift do impacts induce in the target rocks beneath them? A number of investigators [e.g. 3] have noted that depth of the transient crater formed by an impact is $1 / 3$ to $1 / 4$ its diameter. Assuming that material is uplifted by a distance equal to the depth of the crater ( 25 to $30 \mathrm{~km}$ for a $100 \mathrm{~km}$ diameter crater), it is possible that the ca. $8 \mathrm{kbar}$ pressure change could bring mantle material previously below the solidus more than $100 \mathrm{~K}$ closer to melting. Whether melting occurs or not depends on the local geotherm, but if the impacted region is already hot it is possible that melting might occur. However, this scenario overestimates the actual uplift by a factor of 3 or more. Detailed studies of impact craters show that during the impact event material is first pushed downward as the transient cavity opens, then rebounds upward. For most target material this excursion is adiabatic, so the amount of uplift effective for pressure melting is only that remaining after the collapse of the transient crater. Numerous field and numerical studies of crater collapse show that the maximum uplift is only about $1 / 10$ of the transient crater diameter [4]. Furthermore, this maximum uplift occurs only beneath the center of the crater and it dies out rapidly beneath the crater. Even in the 100-km (transient) diameter Chicxulub crater the Moho beneath it is barely disturbed, with less than a few $\mathrm{km}$ uplift beneath the center [5]. Under these circumstances pressure relief melting seems very unlikely, even in the largest known terrestrial craters.

Impact Melt: Melt is, of course, very common near large impact craters. This melt is created by the strong shock waves that emanate from the site of the impact. These shocks first compress the underlying target rock, doing irreversible work on this material, then release it adiabatically to low pressure. If the shock is strong enough (typically $50 \mathrm{GPa}$ or more) the released material may be in a molten, or even vapor state. However, since the shock waves are strong only very close to the impact site, the melt remains on the floor of the crater as it opens and later collapses. Shock heating dies off very quickly with increasing distance away from the impact site [6]. The melt thus forms a near-surface sheet throughout the crater formation process. In large craters this melt volume may be considerable. The differential scaling of melt volume (proportional mainly to the projectile volume) and crater volume shows that as crater size increases the ratio of melt volume to crater volume increases [7] until a point is reached when the melt volume equals the crater volume. This probably does not happen for 
terrestrial craters until the transient crater diameter exceeds about $1000 \mathrm{~km}$. Even for the ca. $200 \mathrm{~km}$ diameter Sudbury impact crater, where the entire Sudbury Igneous Complex is now interpreted as a differentiated impact melt sheet [8], the melt layer is only a few $\mathrm{km}$ thick although more than $100 \mathrm{~km}$ wide. Shortly after the Sudbury impact there may have been many igneous phenomena associated with the melt sheet, but nothing like the extended period of magma extrusion that is characteristic of normal terrestrial volcanism.

Cleopatra: The best possible example of volcanism associated with an impact is the crater Cleopatra on the regional slope of Maxwell Montes, Venus. This enigmatic crater [9] is clearly of impact origin at Magellan resolution. However, it is deeper than most Venusian craters and possesses a channel leading from the crater center to lower-lying plains, where it is associated with a large lava flow. Although an attempt was made to explain its form as impact-induced volcanism (B. Ivanov, unpublished 1992 lecture notes), these models required such high thermal gradients (up to $50 \mathrm{~K} / \mathrm{km}$ ) in the pre-impact surface that it seems more likely that the melt near Cleopatra is similar to the observed outflow sheets [10], modified by the strong regional slope (B. Ivanov, 2000 personal communication).

Volcanic Triggering at a Distance: Although there is no evidence that impacts can induce volcanism near the site of the impact (I know of no single example of such an association on any body in the solar system), some authors have opted for the idea that impacts can induce volcanism at very distant locations. The most widely discussed association is that between the $\mathrm{K} / \mathrm{T}$ impact and the Deccan Traps in India [3], which are nearly antipodal to the impact site. Although the $\mathrm{K} / \mathrm{T}$ impact does nearly coincide with the beginning of the Deccan volcanic episode, recent evidence suggests that the volcanism actually pre-dated the impact by a few million years [11]. Another problem with such an association is the sheer amount of energy involved. The volume of the Deccan traps is at least $500,000 \mathrm{~km}^{3}$ (which does not take into account material now eroded). Using a latent heat of fusion of $330 \mathrm{~kJ} / \mathrm{kg}$ [12], production of this volume of basalt from a source assumed to be at its melting point would require an energy of $5 \times 10^{23} \mathrm{~J}$. This is about two times larger than the entire kinetic energy of the $K / T$ impactor (assumed to be a $10 \mathrm{~km}$ diameter asteroid striking at $20 \mathrm{~km} / \mathrm{sec}$ )! Clearly, the impact cannot be the direct cause of the basalt but must act as a "trigger" of some kind. What kind of trigger this could be has never been explained satisfactorily. However, one might suppose that a short pulse of intense heat at the antipode might be sufficient to start an eruptive episode of some material nearly ready to erupt anyway.
Boslough et al. [13] have suggested that antipodal focusing of seismic waves from the impact might cause large material motions and heat dissipation sufficient to begin an eruption. However, studies of impacts using the Apollo Lunar Seismic Network indicate that the total amount of energy radiated from an impact in the form of seismic waves is only about $10^{-4}$ of the total impact energy [7]. The simulations of [13] show the seismic energy is concentrated in the asthenosphere at the antipode in a volume several hundred $\mathrm{km}$ deep and at least this much in radius. Thus, presuming that the entire seismic energy of $3 \times 10^{19} \mathrm{~J}$ is concentrated in this volume, the energy deposited comes out to be about $2500 \mathrm{~J} / \mathrm{m}^{3}$, or about $1 \mathrm{~J} / \mathrm{kg}$ of the mantle. Using a typical heat capacity of $1 \mathrm{~kJ} / \mathrm{kg}$, we get a thermal "pulse" from this mechanism of about 1 milliKelvin! Even using a much higher seismic efficiency of 5\% derived from Russian explosion tests (B. Ivanov, 2000 personal communication), the temperature rise is only $0.5 \mathrm{~K}$. This seems utterly inadequate to trigger anything.

Conclusions: The bottom line of this discussion is that there is not a single clear instance of volcanism induced by impacts, either in the near vicinity of an impact or at the antipodes of the planet. This accords well with theoretical expectation from our current understanding of the impact cratering process. The possibility of impact-induced volcanism must thus be regarded with extreme skepticism.

\section{References:}

[1] Ronca, L.B. (1966) Icarus 5, 515. [2] Taylor, S.R. Planetary Science: A Lunar Perspective 1-481 (Lunar and Planetary Institute, Houston, TX, 1982). [3] Rampino, M.R. (1987) Nature 327, 468. [4] Melosh, H.J. \& Ivanov, B.A. (1999) Ann. Rev. Earth Planet. Sci. 27, 385. [5] Morgan, J. \& Warner, M. (1999) Geology 27, 407. [6] Pierazzo, E., Vickery, A.M. \& Melosh, H.J. (1997) Icarus 127, 408. [7] Melosh, H.J. Impact Cratering: A Geologic Process 1-245 ( Oxford University Press, New York, 1989). [8] Grieve, R.A.F., Stöffler, D. \& Deutsch, A. (1991) $J$. Geophys. Res 96, 22. [9] Basilevsky, A.T. \& Ivanov, B.A. (1990) Geophys. Res. Lett. 17, 175 . [10] Asimov, P.D. \& Wood, J.A. (1992) J. Geophys. Rev. 97, 13. [11] Bhandari, N., Shukla, P.N., Ghevariya, Z.B. \& Sundaram, S.M. (1995) Geophys. Res. Lett. 22, 433. [12] Yoder, H.S. Generation of Basaltic Magma 1-265 (National Academy of Sciences, Washington, D. C., 1976). [13] Boslough, M.B., Chael, E.P., Trucano, T.G., Crawford, D.A. \& Campbell, D.L. in The Cretaceous-Tertiary Event (eds. Ryder, G., Fastovsky, D. \& Gartner, S.) 541 (Geol. Soc. Amer., Boulder, Co, 1996). 
EVIDENCE FROM IBERIA AND THE CENTRAL ATLANTIC OCEAN FOR AN OCEANIC IMPACT NEAR THE CENOMANIAN-TURONIAN BOUNDARY. J.F. Monteiro', M. R. Rampino ${ }^{2}, A$. Ribeiro $^{1}$, and J. Munha ${ }^{1},{ }^{1}$ Departamento de Geologia, Faculdade de Ciencias da Universidade de Lisboa, Edificio C-2, Campo Grande, 1700 Lisboa, Portugal (jf.monteiro@teleweb.pt) ${ }^{2}$ Earth \& Environmental Sciences Program, New York University, New York, NY 10003, USA (mrr1@nyu.edu).

The Cenomanian/Turonian $(\mathrm{C} / \mathrm{T})$ boundary $(93 \pm 1$ Myr) was marked by stepwise extinctions in an interval of major oceanic perturbations [1]. Two closelyspaced iridium peaks with values up to $560 \mathrm{ppt}$, coinciding with extinction steps, were reported in North and South America, and western Europe [2], and a $\mathrm{C} / \mathrm{T}$ comet impact shower has been suggested [3]. Thus far, however, shocked quartz has not been found at the $\mathrm{C} / \mathrm{T}$ boundary, suggesting that if impacts occurred they may have been in the oceans.

We present evidence, including brecciated limestone with evidence of shock metamorphism and possible tsunamites from near Nazaré (Portugal) $[4,5]$, and unconformities, disturbances, and unusual deposits at the boundary in Europe and the Central Atlantic Ocean [6] that may be related to an impact in the eastern Atlantic, possibly involved in forming the Tore "Seamount" [7,8].

The upper Cenomanian brecciated limestone contains ejecta clasts of various lithologies. The ejecta is a polymictic breccia that includes suevite-type clasts, microscopic spherules (some with shapes typical of microtektites), and irregular shard-like structures. Quartz grains with one or two PDF directions occur in the matrix of the polymictic breccia. The breccia is composed largely of pyrite, hematite, devitrified glass, quartz, and calcite; solid hydrocarbons occur as surface accumulations and impregnations. Geochemical anomalies were detected in the ejecta and in an overlying green mudstone layer (up to $50 \mathrm{~cm}$ thick), with anomalous elemental concentrations about 5 to 10 times average continental crustal abundances, including $\sim 200 \mathrm{ppt}$ iridium and other PGEs. The ejecta occurs along a corridor aligned $N 80^{\circ} \mathrm{E}$, in line with the Tore "Seamount".

At Nazaré, a sharp stratigraphic discontinuity exists between the brecciated Cenomanian limestone and superposed Turonian siliciclastic sandstones. These sandy deposits are interpreted here as the product of a series of events resulting from tsunami related to the impact event [8]. The sandstones display several characteristics typical of tempestites (lamination, cross bedding, layers with fossil debris, and sedimentloading and collapse structures).

In the Eastern Ațantic region, a number of unusual deposits, indicating disturbances and highenergy flows, are found in the uppermost Cenomanian. For example: South Pyrenees (Spain)-the Santa Fe Breccia (boulders up to $12 \mathrm{~m}$ across), with blocks of cemented platform sediments mixed with slope and basin facies, possibly related to margin slumping and collapse [9]; SE France-major slumping [10]; Northern Europe-erosion, chalk conglomerates [11]. In the Central Atlantic Ocean, the boundary is commonly marked by an unconformity, poor fossil preservation, and significant sediment disturbances [6].

A genetic link between the Tore "Seamount" and an oceanic impact event near the Cenomanian/Turonian boundary responsible for the Nazare ejecta layer and tsunami deposits remains to be tested by direct evidence for an impact at the seamount. However, the existing chronological constraints are not incompatible with this link; the Tore "Seamount" must be younger than anomaly Mo (118 My) and older than $80 \mathrm{My}$

References: [1] Kauffman, E. and Hart, M. (1995) In: O. Walliser (Ed), Global Events and Event Stratigraphy, Springer, Berlin, 285-312. [2] Orth, C.J. et al. (1993) Earth \& Planet. Sci. Lett., 117, 189-204. [3] Hut, P. et al. (1987) Nature, 329, 118-126. [4] Monteiro, J.F. et al. (1997) LPS XXIX II, 967. [5] Monteiro, J.F. et al. (1998 Meteoritics \& Planet. Sci., 33, A112-A113. [6] Huber, B.T. et al. (1999) J. Foram. Res., 29, 392-417. [7] Laughton, A. et al. (1975) Deep Sea Res., 791-810. [8] Monteiro, J.F. et al. (1999) Reports on Polar Res., 343, 64-66. [9] Caus, E. et al. (1993) Cretaceous Res., 14, 531-551. [10] Tronchetti, G. and Grosheny, D. (1990) Geobios, 24, 13-31. [11] Hart, M.B. and Leary, P.N. (1991) Terra Nova, 3, 142-147. 
GEOPHYSICAL CONSTRAINTS ON THE SIZE AND STRUCTURE OF THE CHICXULUB IMPACT CRATER. J. Morgan' and M. Warner ${ }^{1}$, 'T.H.Huxley School, Imperial College, Prince Consort Road, London SW7 2BP, UK. j.morgan@ic.ac.uk, m.warner@ic.ac.uk

Introduction: The Chicxulub structure in Mexico is now widely accepted as the site of a K-T meteorite impact that was, at least in part, responsible for mass extinctions 65 million years ago. The crater is buried several hundred meters beneath surface, with the $\mathrm{Yu}$ catan coastline passing approximately through the center of the crater. The crater floor and impactgenerated deposits have been penetrated with several deep and shallow boreholes. In September 1996, 650 $\mathrm{km}$ of BIRPS deep seismic reflection profile (Chicx-A, $\mathrm{A} 1, \mathrm{~B}$ and $\mathrm{C})$ were acquired across the offshore portion of the crater; the 13,000 airgun shots that generated the reflection data were recorded at wide-angle on 35 ocean-bottom and 90 land seismometers (figure 1). Magnetic, gravity and magnetotelluric data have also been collected across the crater. These datasets enable us to estimate the size of the crater, determine the morphology of the impact basin, the nature of the peak ring and central uplift, and the thickness and extent of the impact melt sheet.

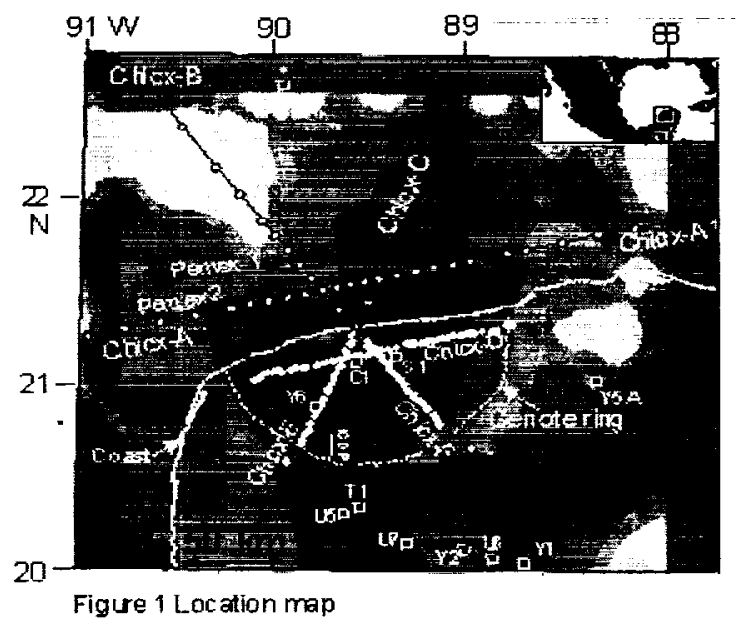

Size and morphology: Early estimates of the crater diameter varied by a factor of two, and of impact energy by an order of magnitude, but recent estimates are much closer. The most important parameter, in terms of quantifying impact size and energy, is the diameter of the excavation and transient cavities. Estimates for this parameter, based on the magnetic gravity and seismic reflection data, lie within the range of $80-110 \mathrm{~km}(1-4)$. A more precise figure for the size of the transient cavity may be obtained when we have a better understanding of the dynamics of crater collapse. The size of the final crater is less clear. We observe multiple concentric anticlinal and

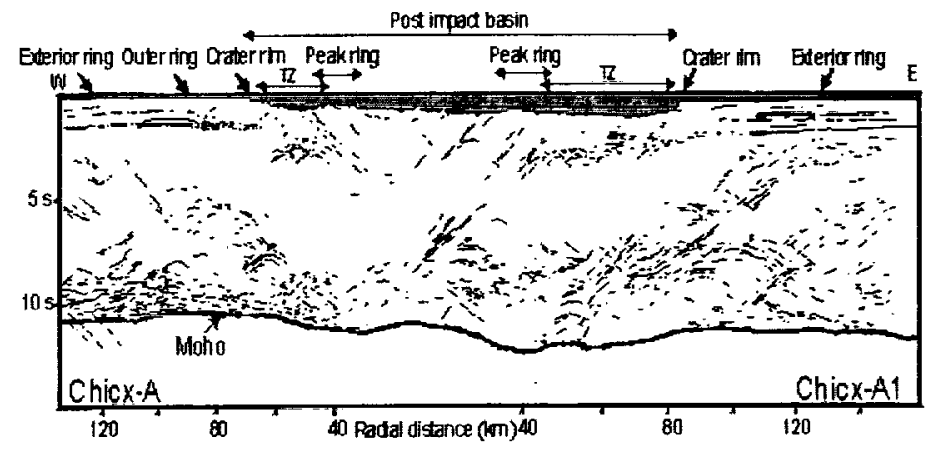

Figure 2 Line drawing of seismic reflection data along Chicx-A and A1

synclinal structures in the land topography (5), rings in the gravity data (6), and, in the seismic reflection data we observe offsets in the target stratigraphy (7). The offshore seismic data and onshore topographic data both show topographic highs at distances of around 75,95 and $120 \mathrm{~km}$ from the crater centre; the two inner rings (the crater rim and outer ring in figures 2 and 4) are inward-facing asymmetric scarps, the outermost (the exterior ring) is outward facing. The ring at $75 \mathrm{~km}$ radius is labelled as a crater rim because it corresponds to the head scarp of a terrace zone (TZ in figure 2) and is directly analogous to the crater rim of a peak ring crater. If Chicxulub were on another planet and these three rings were expressed at surface, then Chicxulub would be a multi-ring basin with a final crater size equivalent to the diameter of the outer ring (190-195 km). Although these structural rings do appear to be analogous to those observed on other planetary bodies, it remains to be shown definitively (8), and Hildebrand et al. (9) prefer the interpretation that Chicxulub is a peak-ring crater.

Peak ring: Pilkington et al. (10) suggested that the peak ring at Chicxulub lay directly on the melt sheet, and consisted of breccia material that had been sloughed off a rebounding central uplift. Observations of rings of uplifted basement rocks at the Ries and Popigai craters, led Sharpton et al. (6) to propose that the peak ring was produced by sub-vertically uplifted basement rocks. In the reflection data we observe a $\sim 145 \mathrm{~km}$ post-impact basin (shaded grey in figure 2), and within the basin we observe an $\sim 80-\mathrm{km}$ diameter topographic ring that appears directly analogous to peak rings observed on other planetary bodies. The seismic data also reveal that, on some profiles, the peak ring lies directly above the slumped blocks, as illustrated in figure 4 . Bright inward dipping reflectors run from the outer edge of the peak ring to the 
inner edge of the slumped blocks. Brittan et al. (11) proposed that the peak ring was formed by the interaction between the outwardly collapsing central uplift and the inwardly collapsing uplifted rim, and that the dipping reflectors represented the boundary between the two collapse regimes (dashed line in figure 4). Numerical modelling of the collapse of the transient cavity has been reasonably successful in producing final craters with the expected topographic features $(12-14)$, by allowing the target rocks to be temporarily weakened by the impact process. There is an ODP proposal to drill the peak ring at Chicxulub, one objective is to verify the nature of the peak ring.

Central uplift: The wide-angle data reveal a central velocity high about $40 \mathrm{~km}$ wide, offset to the

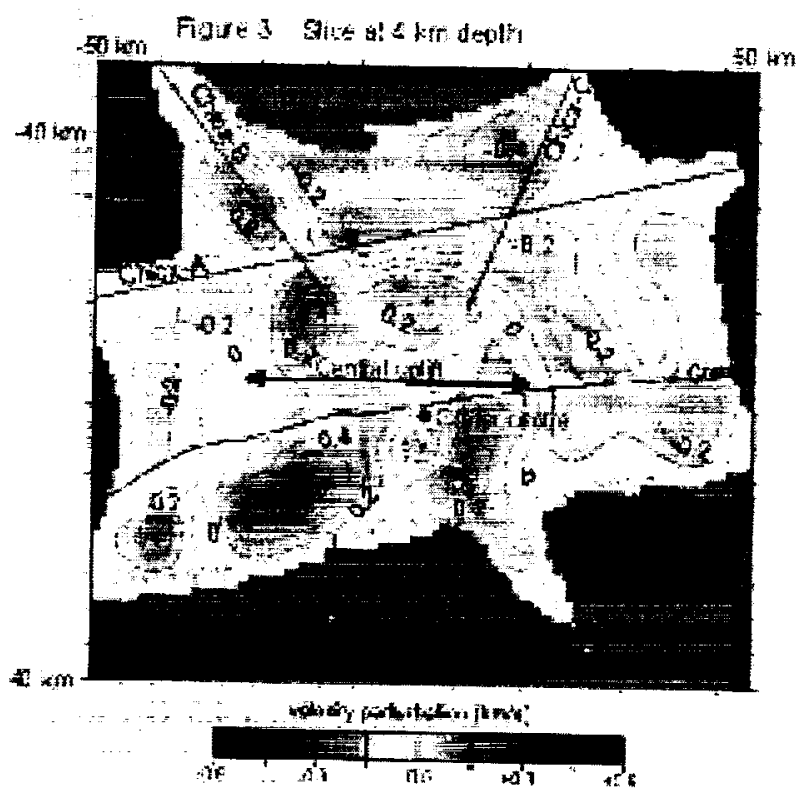

southwest, and imaged by a strong $\mathrm{p}$-wave velocity contrast of $\sim 0.5 \mathrm{kms}^{-1}$ (see figure 3 ). Its location coincides in position with the gravity high previously interpreted as representing the central uplift by Pilkington et al. (10). Interestingly, the central uplift has a concave upward top (illustrated in figure 4); this appears to be a genuine feature and is not an artifact generated by poor data coverage or parameterization. The models also indicate that the central uplift is widest at its top, and narrows with depth. This geometry is consistent with a model for uplift that involves both vertical and outward flow in the central region during crater collapse.

In a recent $3 \mathrm{D}$ inversion of magnetic data (15) the central uplift was determined to be $40 \mathrm{~km}$ in diameter, in agreement with the velocity data.

Melt sheet: We do not appear to be able to clearly image the melt sheet using p-wave seismic velocity data, although further work may yet do so. Prelimi- nary results from velocity modeling suggest that the melt sheet has a diameter of $65 \mathrm{~km}$ or less. If our identification of the central uplift (using velocities) is correct, then the melt sheet cannot be thicker than about $3.5 \mathrm{~km}$, and is more likely $<3 \mathrm{~km}$ thick in the central part of the crater (see figure 4). We expect that shear-wave velocity measurements will help to constrain the melt sheet thickness more tightly. Results from inversion of the magnetic data suggest that

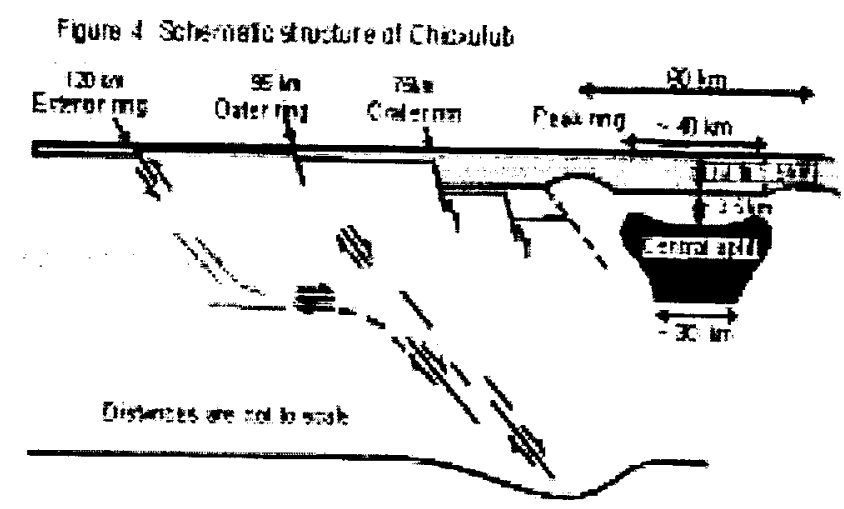

the thick melt sheet has a diameter of about $45 \mathrm{~km}$ (15).

Base of the Crust: At Chicxulub, the outer and exterior topographic rings seen outside the postimpact basin are associated with deeper crustal reflectors. The crustal reflectors have a predominant dip of $30-40$ degrees toward the centre of the crater; the outer ring penetrates the whole crust and offsets the Moho at a radial distance of $35-55 \mathrm{~km}$ (see figures 2 and 4). The observed offsets in the target stratigraphy and Moho suggest that these reflectors represent large displacement faults, potentially analagous to rings of pseudotachylyte observed at Sudbury crater [2]. The crust thickens from west to east, from about 33 to 36 $\mathrm{km}$, and the Moho does not appear to be uplifted in the center of the crater.

References: [1] Kring, D.A. (1995) JGR, 100, 16979-16986. [2] Morgan et al., (1997) Nature, 390, 472-476. [3] Hildebrand et al., (1998) Geol. Soc. London, 140, 177-193. [4] Marin et al., (1999) CSDP proposal. [5] Pope et al., (1996) Geology, 24, 527. 530. [6] Sharpton, et al., (1996) Geol. Soc. Am. 307, 55-74. [7] Morgan \& Warner, (1999), Geology, 27, 407-410. [8] Grieve \& Therrialt, 2000, Ann. Rev. Earth Planet. Sci., in press. [9] Hildebrand et al. (1998), LPSC XXIX, 1821-1822. [10] Pilkington et al., [1994] JGR, 99, 13147-13162. [11] Brittan et al., (1999) Geol. Soc. Am., 339, 269-279. [12] Melosh \& Ivanov, (1999) Ann. Rev. Earth Planet. Sci., 27, 385 415. [13] O'Keefe \& Ahrens, (1999) JGR, 104, 27091-27104. [14] Collins et al., (2000) LPSC XXX1, CD. [15] Pilkington \& Hildebrand, (2000) LPSC $\mathrm{XXX1,CD.}$ 
A 3.5 BILLION YEAR RECORD OF SOLAR SYSTEM IMPACTS, AND THE RECENT (0.4 GYR) INCREASE. Richard A. Muller, Dept. of Physics and Lawrence Berkeley Laboratory, 50-5032 LBL, University of California, Berkeley California 94720 USA. email: muller@physics.berkeley.edu web: http://muller.lbl.gov

Introduction: When an extraterrestrial impact takes place on the Moon, some of the target rock vaporizes and recondenses into small droplets of glass called spherules. These land from a few meters to thousands of kilometers from the impact site. As a consequence, every gram of lunar soil contains spherules from a hundred or more impacts. These spherules are only 150 to $250 \mu \mathrm{m}$ in diameter, but modern methods of ${ }^{40} \mathrm{Ar} r^{39} \mathrm{Ar}$ dating can be used to determine their ages. In 1993 we speculated that most of these spherules would come from different craters [1], a result that was later confirmed. Thus, even though we don't know which crater was the source of each spherule, the distribution of the ages of the spherules from a single lunar site reflects the age distribution of craters on the Moon.

We have measured the ages of 155 spherules from the Apollo-14 site [2], and from these determined the time variation of cratering on the Moon - and presumably also on the Earth. The results show a gradual decrease in the cratering rate from $3 \mathrm{Gyr}$ until about $0.4 \mathrm{Gyr}$, when the rate increased by a factor of $3.7 \pm$ 1.2 , back to the level that it had been 3 billion years earlier. Statistical analysis indicates that approximately $94 \%$ of the spherules come from different craters [3], a result that is confirmed by chemical analysis [4]. Potential biases from lunar gardening and nearby craters have been analyzed, and appear to be negligible. We will discuss the results, the possible biases and systematic errors, and potential implications for our understanding of the solar system and for the evolution of life.

Experimental method: Approximately 1 gram samples of lunar soil were obtained from NASA, from each of three lunar sites: Apollo-11, 12, and 14. The spherule ages were measured at the Berkeley Geochronology Center using the ${ }^{40} \mathrm{Ar} /{ }^{39} \mathrm{Ar}$ isochron technique. Measurements of the spherule ages from Apollo-11 and 12 yielded inaccurate dates, due to low potassium content. Based on a chemical analysis of these spherules, we concluded that most of the spherules came from local impacts [4]. To improve the accuracy, we obtained lunar soil samples from the Apollo-14 site which was known to have high potassium content. This was indeed reflected in the spherules chemical composition, and led to improved age accuracy. The median age uncertainty for our 155 spherules had a one standard-deviation error of $0.15 \mathrm{Gyr}$.

Age distribution: The distribution of ages for these spherules is shown in the figure. The histogram shows the number of spherules with ages in each 0.4 Gyr bin. The number of spherules in each bin is printed above the histogram. At the bottom of the plot we have drawn 155 Gaussian curves, one for each spherule. Each Gaussian has unit area, but the width (RMS deviation) for each is set to the 1 standard deviation error in the age uncertainty for that spherule. The sum of the individual Gaussians is shown as the smooth curve. This curve represents the best estimate that we have, in a statistical sense, for the cratering rate. Note, however, that the sharp peaks are artifacts of several highly-accurate ages.

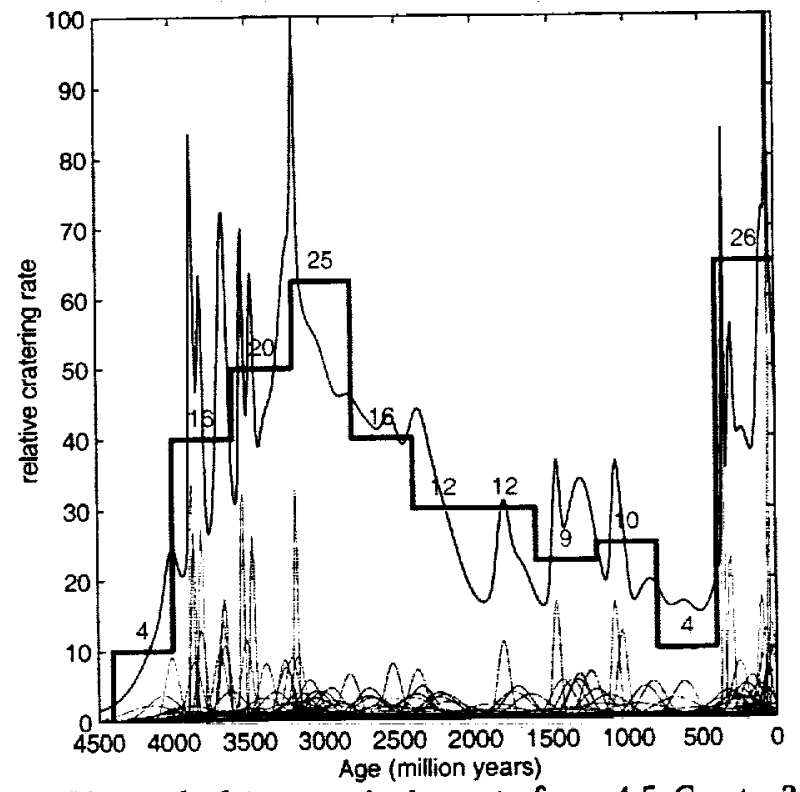

The gradual increase in impacts from $4.5 \mathrm{Gyr}$ to 3 Gyr does not imply an increasing impact rate, but is instead a result of the age of the Apollo-14 site, estimated at 3.85 Gyr. The spherules older than this were probably first deposited at distant sites and then transported to the Apollo-14 site by subsequent impacts.

The decrease from $3 \mathrm{Gyr}$ to $0.4 \mathrm{Gyr}$ probably reflects a decrease in the density of potential impactors (comets and asteroids) in the solar system. The observed decrease is consistent with previously reported estimates. [5]

The most surprising result is the increase seen in the most recent bin, representing the last $0.4 \mathrm{Gyr}$. We estimate that the rate increased (compared to the previous $1 \mathrm{Gyr}$ ) by a factor of $3.7 \pm 1.2$, to a level comparable to the highest it had reached in the previous 3 Gyr. A similar increase of a factor of two had previously been suggested based on measurements on the Earth and crater counting on the moon. [6-9]

Systematics and biases: To test if the recent increase is due to an experimental bias, we analyzed several possible systematic errors. The increase can not be accounted for as an excess due to the nearby Cone crater, both because of the diversity of chemical com- 
position, and the incompatibility of ages. [2] Of the 11 spherules compatible with the Cone crater age (25 Myr), 3 are black, 3 are yellow, 3 are orange, 1 is green, and $\bar{I}$ is white. A statistical analysis of the spherule ages [3] shows that we expect $94 \%$ of the spherules to be from different craters, i.e. a total of 9 spherules in the entire distribution come from the same craters as others. It is even less likely that all nine would be in the same bin.

Lunar gardening could, in principle, distort the distribution. However the sample was collected from the ejecta blanket of Cone crater, and represents a wellmixed sample of lunar soil. Removal of all 11 recent spherules (0-25 Myr) would completely eliminate this systematic effect, if it were there. That is probably an overcompensation for the bias, and it leaves 15 spherules in the bin, still a significant increase.

Implications for evolution: The increase in cratering was roughly coincident with the Cambrian explosion of complex life on Earth. As Darwin originally conceived evolution, survival of the fittest meant superiority in conflict with other species. But an increased crater rate also increases the stress on species to be able to survive catastrophe. It is conceivable that this increased stress helped drive evolution towards species with greater adaptability and flexibility, away from instinct and towards greater intelligence.

Implications for the Solar System: The lunar spherule project was originally conceived [1] as a method to search for periodicities in comet showers, a prediction of the Nemesis theory [10]. This theory postulates that there is a companion star to the Sun. orbiting at a distance of about 3 light years, with a period of 26 million years. There has been a great deal of speculation that the orbit is insufficiently stable for the theory, but a detailed analysis by Hut has shown that the stability is adequate [11]. The strongest argument against the Nemesis idea is the fact that it predicts that most of the mass extinctions of Raup and Sepkoski $[12,13]$ should have been caused by impacts, and little evidence has been adduced since 1984 in favor of this conclusion. Unfortunately, the age accuracy achieved thus far in the lunar spherule project is insufficient to see a 26 Myr cycle.

Nevertheless, the Nemesis hypothesis provides a ready explanation for the $0.4 \mathrm{Gyr}$ increase in cratering rate. If the orbit of Nemesis were nearly circular prior to this time (eccentricity $<0.5$ ), then its orbit would not bring it sufficiently close to the inner Oort comet cloud to trigger periodic comet showers. But in its large orbit, perturbations from passing stars are frequent. We speculate that Nemesis was perturbed into a more eccentric orbit (eccentricity $>0.7$ ) at 0.4 Gyr. This would be adequate to cause it to trigger comet showers at every subsequent perihelion, and that could account for the recent increase in impact rate. Ultimately, of course, the existence of Nemesis must be confirmed by its direct observation. In the original theory, we assumed that Nemesis is a red dwarf star, and should be readily visible from the Earth. The Hipparcos satellite, unfortunately, surveyed only about $1 / 4$ of the known candidates. Future parallax surveys, if they reach stars as dim as $10^{\text {th }}$ magnitude, should find the star if it is there, or prove (by lack of discovery) that it is not there.

Implications for future measurements: The spherule method has proven extremely successful. The increase in the last $0.4 \mathrm{Gyr}$ has important implications, so it is important that it be confirmed at a different lunar site. This requires either another high-potassium site, or the use of larger spherules. Use of such spherules may also allow the detection of comet showers and a search for periodicity in impacts. Measurements in the lunar highlands could potentially determine older cratering rates, and answer lingering questions about the existence and intensity of the late heavy bombardment.

References:

[1] Muller, R. A., (1993), Cratering rates from Junar spherules, Lawrence Berkeley Laboratory Report LBL-34168.

[2] Culler, T. S., T. A. Becker, R. A. Muller, and P. R. Renne, (2000), Lunar impact history from ${ }^{40} \mathrm{Ar}$ ${ }^{39}$ Ar dating of glass spherules, Science, issue of March 10.

[3] Muller, R. A., T. A. Becker., T. S. Culler, P. R. Renne (2000), Solar System impact rates measured from lunar spherule ages, in Accretion of Extraterrestrial Matter Throughout Earth's History, edited by B. Peucker-Ehrenbrink and B. Schmitz, Kluwer Publishers, in press.

[4] Culler, T. S., and R. A. Muller (1999), Use of surface features and chemistry to determine the origin of fourteen Apollo 11 glass spherules, Meteoritics and Planetary Science (submitted).

[5] BVSP (1981), Basaltic Volcanism on the Terrestrial Planets (Pergamon, New York).

[6] McEwen, A.S. et al. (1997) JGR 102, 9231-9241.

[7] Grieve, R., and E. M. Shoemaker, (1994), in Hazards due to Comets and Asteroids, T. Gehrels ed., Univ Arizona Press, pp 417-462.

[8] Shoemaker, E. M., et al. (1990), in Spec. Pap. Geol. Soc. Am., L. Sharpton and P. Ward eds, vol 247, pp 155-170.

[9] Shoemaker, E. M. et al. (1997), in Hazards due to Comets and Asteroids, T. Gehrels ed., Univ Arizona Press, pp. 313-336.

[10] Davis, M., P. Hut, and R. A. Muller (1984), Extinction of Species by Periodic Comet Showers, $\mathrm{Na}$ ture 308, pp 715-717.

[11] Hut, P. (1984). Nature, vol 311, pp. 636-640

[12] Raup, D., J. Sepkoski (1984) Proc. Nat. Acad. Sci. USA, vol 81, pp 801-805.

[13] Sepkoski, J., J. (1989) Geol. Soc. London, vol 146, pp 7-19. 
ORIGIN OF CRETACEOUS TERTIARY BOUNDARY IN MONCADA, WESTERN CUBA AND ITS RELATION TO K/T EVENT. Y. Nakano', R. Tada ${ }^{2}$, T. Kamata ${ }^{1}$, E. Tajika ${ }^{2}$, T. Oji ${ }^{2}$, S. Kiyokawa ${ }^{4}, \mathrm{H}_{\text {. Takayama }}{ }^{2}$, K. Goto ${ }^{2}$, S. Yamamoto ${ }^{2}$, K. Toyoda ${ }^{5}$, D. Garcia ${ }^{3}$, R. Rojas ${ }^{3}$, M. Itturalde-Vinent ${ }^{3}$ and T. Matsui ${ }^{1}{ }^{1}$ Dept. of Earth and Planet. Phys., University of Tokyo, JAPAN (Hongo 7-3-1, Bunkyu-ku, Tokyo 113-0033, Japan, nakano@geoph.s.utokyo.ac.jp, matsui@geoph.s.u-tokyo.ac.jp, tomoka@geoph.s.u-topkyo.ac.jp), ${ }^{2}$ Geological Institude, University of Tokyo, JAPAN (Hongo 7-3-1, Bunkyu-ku, Tokyo 113-0033, Japan, ryuji@geol.s.u-tokyo.ac.jp, tajika@geol.s.u-tokyo.ac.jp, oji@geol.s.u-topkyo.ac.jp), ${ }^{3}$ Museo Nacional de Historia Natural, Cuba ( Capitolio Nacional, Habana CH-10200, Cuba, Iturralde@mnhnc.inf.cu), ${ }^{4}$ Department of Geology , National Science Museum, JAPAN (Hyakunin-cho 3-23-1, Shinjyuku-ku, Tokyo 164-0078, kiyokawa@kahaku.go.jp), ${ }^{5}$ Division of Material Science, Graduate School of Environmental Earth Science, Hokkaido Univeresity, JAPAN (N10, W5, Sapporo 060-0810, Japan, kazuhiro@ high.hokudai.ac.jp)

Abstract: In contrast with a thin boundary clay (KTB) in Europe [1], KTB in the Gulf of Mexico and Caribbean regions are characterized by a thick sandstone with abundant impact derived materials [2][3]. However, total amount and distribution of ejecta from Chicxulub crater is not well understood. Ejecta blanket of crater is observable on Moon and Mars, but hardly on Earth because of rarity of large crater and erosion after formation on Earth. Therefore, it is important to investigate distribution of ejecta from Chicxulub crater for understanding the mechanism of terrestrial impact.

We found a $2 \mathrm{~m}$ thick KTB layer in Moncada, western Cuba. The locality belongs to Guaniguanico Terrain, that is considered to have been located on the slope along the southeastern margin of Yucatan Peninsula during the latest Cretaceous[4], and later scraped off from the margin and accreted to the $\mathrm{Cu}$ ban Island in association with northeastward migration of the Caribbean arc in Paleogene time [5]. Thus, the locality is the one of the closest sites from the Chicxulub crater at the time of the impact. In addition, KTB from the southeast side of Yucatan Peninsula has not been reported. Therefore, KTB in Moncada offers good opportunity for understanding the distribution of ejecta from Chicxulub crater.

The KTB layer in Moncada overlies dark gray bedded limestone of Maastrichtian Pons Formation, and consists of a $185 \mathrm{~cm}$ thick sandstone unit that is overlain by a $4 \mathrm{~cm}$ thick siltstone to claystone unit. The sandstone unit is normal graded as a whole, and consists of alternations of coarse to medium grained, thicker $(22$ to $76 \mathrm{~cm})$, olive gray sandstone layers and medium to fine grained, thinner $(9$ to $17 \mathrm{~cm}$ ) light to dark gray, calcareous sandstone layers. The olive gray sandstone layers are either massive or parallel laminated, whereas dark and light gray calcareous sandstone layers are generally cross laminated. Rip-up clasts of cherts and limestones are occasionally found near the base of a $76 \mathrm{~cm}$ thick olive gray layer, which develops at the base of the unit. The 4 $\mathrm{cm}$ thick siltstone to claystone unit consists of a $2 \mathrm{~cm}$ thick purplish brown claystone with thin fine sandstone lenzes, a $1 \mathrm{~cm}$ thick light brownish claystone layer, a $1 \mathrm{~cm}$ thick olive gray fine sandstone layer, and a $1 \mathrm{~cm}$ thick yellowish brown clay layer in ascending order. The upper siltstone to claystone unit grades upward into gray fissile limestone (marly limestone), which is $35 \mathrm{~cm}$ thick, and then to dark gray bedded limestone of Paleocene Ancon Formation. (Figure 1)

Ir and $\mathrm{Ni}$ anomaly was found in the clay layers of the upper unit. Peak concentration of Ir is 0.89 [ppb] (Figure 1), approximately equal to the value at Mimbral, Mexico (0.92 [ppb]) [6] and 10 times higher than average concentration in crust [7]. Maximum Ni anomaly was estimated as approximately 30 [ppm]. Quartz grains with planar deformation feature (PDF) were found throughout the formation (figure 2). We measured the angle between the c-axis and the pole to PDFs using universal stage. Figure 3 show that these features correspond to the crystallographic orientations characteristic of shock produced lamellae. The $\omega, \pi$ and $\xi$ crystallographic orientation of these feature were prominent. This indicates our quartz grains were derived from several pressure zones. The strata of Guaniguanico Terrain are moderately deformed and weakly metamorphosed. Moderately sheared spherule-like grains are found at 30 to $70 \mathrm{~cm}$ level from the bottom. We measured chemical composition of the spherule-like grains, but different from the spherules of Beloc and Mimbral. Especially $\mathrm{Si}$ concentration of our sample is much lower. We consider it to be because of diagenetic alteration. These evidences, such as $\mathrm{Ir}$ and $\mathrm{Ni}$ anomaly, quartz with PDF, and spherule-like grains, support the relation with the $\mathrm{K} / \mathrm{T}$ impact.

We analyzed major element composition of the bulk samples and conducted Q-mode factor analysis using it to identify possible source materials. Three factors can explain $97.9 \%$ of the variance. Factor 1 is characterized with higher $\mathrm{Al}, \mathrm{Fe}, \mathrm{Si}, \mathrm{Ti}, \mathrm{K}$ and $\mathrm{Mg}$, Factor 2 with higher $\mathrm{Ca}, \mathrm{P}$ and $\mathrm{Mn}$, and Factor 3 with higher $\mathrm{Na}$, respectively. Bulk mineral composition is also analyzed to characterize the factors. Factor 1 has strong positive correlation with smectite and illite, Factor 2 has positive correlation with calcite, and Factor 3 has positive correlation with plagioclase, respectively. Since loading of Factor 1 are higher in olive gray sandstone layers that are characterized 
with abundant spherule-like grains, whereas loading of Factor 3 are higher in light and dark gray calcareous sandstone layers that are characterized with abundant quartz and feldspar grains, and since quartz grains in the sandstone unit are dominantly of shocked quartz origin, we consider Factor 1 and 3 as representing impact ejecta dominated by tektite and shocked quartz, respectively. On the other hand, Factor 2 probably represents limestone fragments whose origin is currently under investigation.

\section{References:}

[1] L. W. Alvarez et al. (1980) Science, 208, 1095-1108.

[2] J. Smit et al. (1996) G.S.A. Spec. Pap., 307, 151-182.

[3] B. F. Bohr (1996) G.S.A Spec. Pap., 307, 183-195.

[4] M. Iturralde-Vinent (1994) J. Petrol. Geol., 17, 39-70.

[5] F. Futson et al. (1998) Geology, 26, 83-86.

[6] J. Smit et al. (1992) Geology, 20, 99-103.

[7] S. R. Taylor and S. M. Mclennan (1985) The Continental Crust: its Composition and Evolution. Blackwell Scientific Publications, 312 pp.

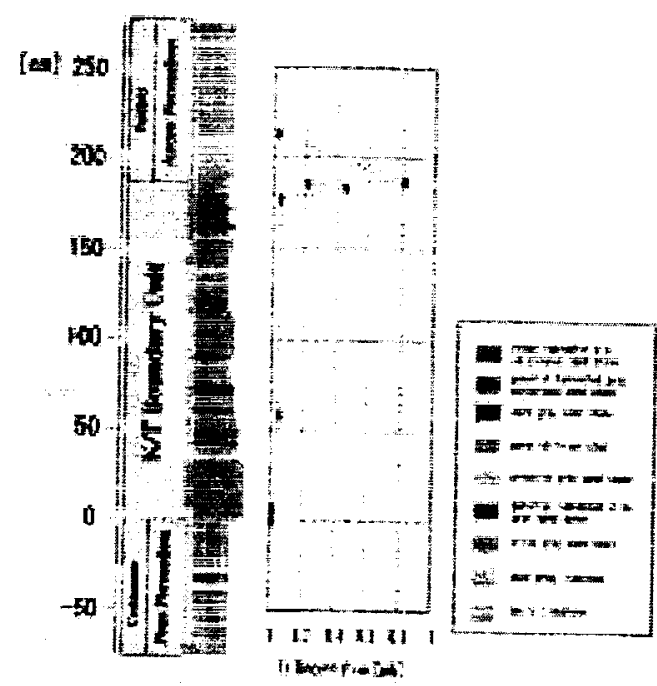

Figure 1

Columnar section of KTB in Moncada and stratigraphy of Ir concentration.

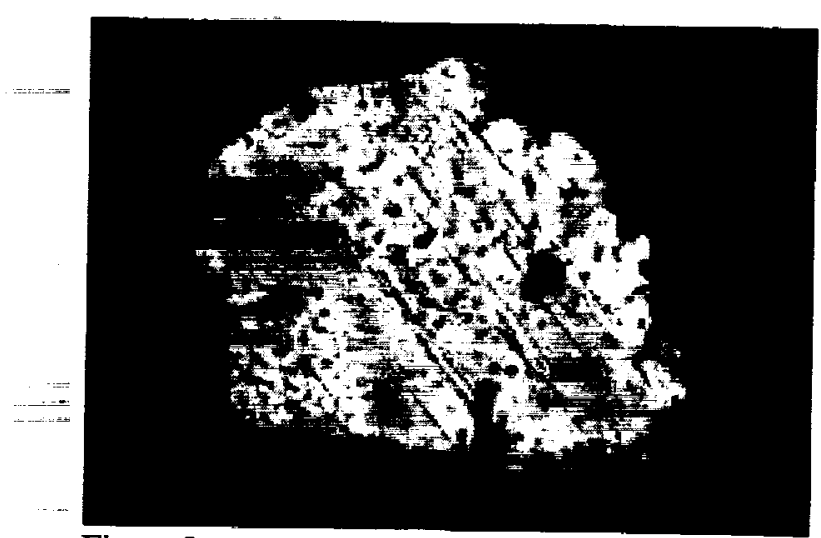

Figure 2

A quartz grain showing at least 3 sets of PDFs. (Cross-polarized light)

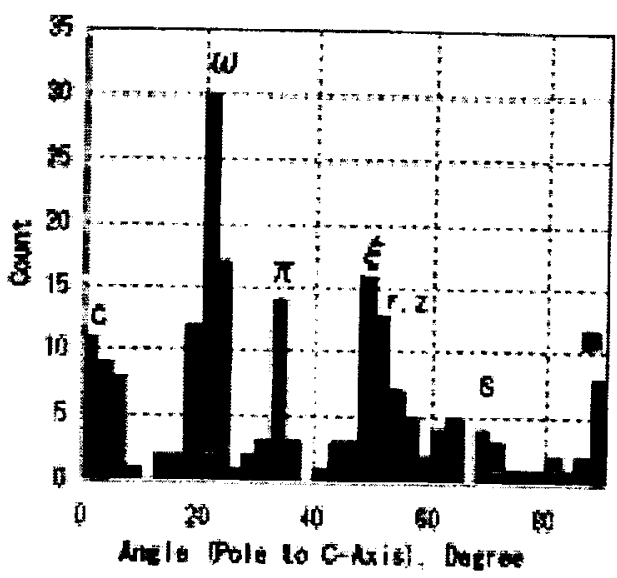

Figure 3

Histgram shows variations in the angle between the $c$-axis and the pole of PDF. The pattern strongly suggests shocked origin of the quartz grains. The angle of 196 sets of PDFs are measured. 
PALYNOLOGY OF THE K-T BOUNDARY IN THE RATON BASIN, COLORADO AND NEW MEXICO-NEW DATA AND INTERPRETATIONS FROM THE BIRTHPLACE OF K-T PLANT MICROFOSSIL STUDIES IN NONMARINE ROCKS. D. J. Nichols', and C. L. Pillmore', 'U.S. Geological Survey, M.S. 939, Box 25046, Denver, CO 80225 nichols@usgs.gov, ${ }^{2}$ U.S. Geological Survey, M.S. 913, Box 25046, Denver, CO 80225 cpillmor@usgs.gov.

Introduction: Palynological studies of effects of the terminal Cretaceous impact event on terrestrial vegetation in the Raton basin of southern Colorado and northern New Mexico began about 20 years ago with the work of the late R. H. Tschudy of the U. S. Geological Survey and the late C. J. Orth of Los Alamos National Laboratory and their collaborators [1]. The earliest work was directed at precisely locating the K-T boundary in nonmarine rocks, immediately following the introduction of the Alvarez impact theory [2]. Tschudy did the palynological analyses in conjunction with Orth, who did neutron-activation analyses. In subsequent years, research by the present authors and collaborators continued intermittently in this area, and 15 localities documented with both palynological and iridium anomalies are now known. More recent emphasis has been on detailing the plant microfossil record of major ecosystem changes associated with the extraterrestrial impact. The most recent research has led to new interpretations based on previously unpublished data. Some of these interpretations put into perspective recently published reinterpretations of the origin of the K-T boundary layer and of vegetational changes from latest Cretaceous to earliest Tertiary time [3, 4].

New Data: At Long Canyon, a new locality in southern Colorado, the rocks are typical of the mudstone, siltstone, and thin coal beds of the lower part of the Raton Formation. Beneath a sandstone ledge near the top of the section, the K-T boundary claystone bed is underlain by $17-20 \mathrm{~cm}$ of carbonaceous shale and shaly coal and overlain by a coal bed $2.5-5 \mathrm{~cm}$ thick. In accordance with the latest interpretations of the origin of the boundary layer [5], this sequence suggests that the ejecta cloud from the impact deposited a thin layer of glassy debris in large coal-forming mires across western North America where it was preserved and eventually altered to kaolinitic clay. A peak iridium anomaly of 8.2 parts per billion (ppb) is present in a $2-\mathrm{mm}$-thick layer of flaky shale at the top of the 1- to 2-cm-thick boundary bed (new Ir analyses provided by F. Asaro, Lawrence Berkeley Laboratory). Palynologic analysis of this sequence defines the K-T boundary by extinction of key palynomorph taxa and reveals the presence of a fern-spore abundance anomaly (fern-spore "spike") in the thin coal bed just above the boundary bed. Nearly monospecific assemblages of fern spores have a relative abundance to 75 percent in the lower part of the coal and 82 percent near the top. The numerically dominant fern spore in the lower of these two samples is a species of the genus Cyathidites, but the dominant species in the upper sample is of the genus Laevigatosporites. This pattern could be regarded as the "classic" fern-spore spike for the Raton basin because it closely resembles that reported previously $[6,7]$ if all fern spores are considered, but it is even more similar to that recently reported from certain localities in southern Saskatchewan [3] in the presence of a two-phase fern-spore spike that consists of assemblages in stratigraphic succession that are numerically dominated by two different species of fern spores.

In contrast, at Dawson North, a new locality in a similar sedimentologic setting about $60 \mathrm{~km}$ to the south in the New Mexico part of the basin, millimeterscale sampling reveals a different pattern. Here the K$\mathrm{T}$ boundary claystone layer was stratigraphically subdivided and analyzed in four parts, including three sub-units within the kaolinite-rich ejecta layer and one distinguished as a shaly fireball layer (terminology from [8]). A peak Ir anomaly of $9.0 \mathrm{ppb}$ was measured in a 1-cm-thick carbonaceous shale that overlies the boundary claystone; this anomaly results from migration of Ir up from the underlying 2- to 3-mm-thick fireball layer, which contains $6.2 \mathrm{ppb}$ Ir (previously unpublished data of Orth). The palynologic extinction level is placed between the ejecta layer and the fireball layer. Microstratigraphic palynologic analysis of this succession shows that the fern-spore spike originates within the ejecta layer and persists into overlying coal, shale, and shaly coal above it. The palynologic assemblage from a shaly coal $6-12 \mathrm{~mm}$ below the boundary layer contains only 11 percent fern spores, but in the lowermost subunit of the ejecta layer, the relative abundance abruptly rises to 96 percent. Abundance of fern spores is 99 percent in the middle subunit of the ejecta layer, 96 percent in the upper subunit of the ejecta layer, and 100 percent in the fireball layer. In shaly coal $4-5 \mathrm{~cm}$ above the boundary layer the abundance of fern spores remains as high as 93 percent. The dominant fern spore in all these samples is the 
same species of Cyathidites as at the Long Canyon locality. Spores of Laevigatosporites are absent.

At the third new locality, the Crow Creek Canyon site in New Mexico, similar microstratigraphic sampling and analyses were conducted on 18 samples from an interval consisting of carbonaceous shale, siltstone, and sandstone. This boundary interval lacks coal beds; thus, the paleoenvironmental setting of this locality differed from the others in the absence of mire deposits. The palynologic extinction horizon is between the ejecta and fireball layers, as at Dawson North. The expected anomalous concentrations of Ir are present (previously unpublished data of Orth); however, here a 2 -m-thick sandstone bed rests directly on the boundary layer and no fern-spore abundance anomaly was observed. Spores of both Cyathidites and Laevigatosporites are present in this section, but only in low percentage abundance in all samples where they occur. No fern-spore spike is present in the boundary layer in this section, which is only $1.5 \mathrm{~km}$ from the Dawson North locality.

We also reviewed unpublished palynologic analyses by Tschudy from the Clear Creek South locality in the Colorado part of the basin. What we now interpret to be the fireball layer at this locality yielded an Ir anomaly of $27 \mathrm{ppb}$ [6]. At this locality Tschudy recorded that the K-T claystone (ejecta) layer contains 45 percent fern spores in the lower part and 86 percent in the upper part. A 2-cm-thick coal bed just above the boundary layer contains 91 percent fern spores, and the peak fern-spore spike is 100 percent in carbonaceous shale $10 \mathrm{~cm}$ above the boundary layer. Tschudy did not record which species are present except to note that the peak fern-spore abundance anomaly consists predominantly of a single species. Thus, here also the boundary interval in a coal-bearing section shows that the fern-spore spike originates in the ejecta layer.

New Interpretations: These new data lead to interpretations that contrast somewhat with those recently published $[3,4]$, which propose a complex microstratigraphy of the K-T boundary layer at Canadian localities and redefine it elsewhere in North America, including the Raton basin. The authors referenced also reinterpreted the implications of the fern-spore or its equivalent (which may include angiosperm pollen in Canada) with regard to timing of deposition of subunits of the boundary layer. Our new data verify some of their interpretations but show that others are effects of local paleoenvironment and sedimentology, specifically the presence or absence of coal-forming mires. The palynological evidence suggests that Cyathidites ferns were present in local mires at the time of impact but were rare or absent in other paleoenvironments, and Laevigatosporites ferns became prominent later. Data from the Raton basin reaffirm the view [8] that the K-T boundary claystone is composed of two distinct units-the kaolinitic ejecta layer and the shaly fireball layer; they do not support the interpretation [3, 4] of it being composed of three units. That interpretation may be valid for Canadian localities, but it cannot be considered a general model for all nonmarine $\mathrm{K}-\mathrm{T}$ boundary settings in North America.

References: [1] Orth, C. J. et al. (1981) Science 214, 1341-1343. [2] Alvarez, L. W. et al. (1980) Science 208, 1095-1108. [3] Sweet, A. R. et al. (1999) Can. J. Earth Sci. 36, 743-768. [4] Lerbekmo et al. (1999) Can. J. Earth Sci. 36, 717-724. [5] Alvarez, W. et al. (1995) Science 269, p. 930-935. [6] Pillmore, C. L. et al. (1984) Science 223, 1180-1183. [7] Tschudy, R. H. et al. (1984) Science 225, 1030-1032. [8] Pollastro, R. M., and Bohor, B. F. (1993) Clays and Clay Minerals 41, 7-25.
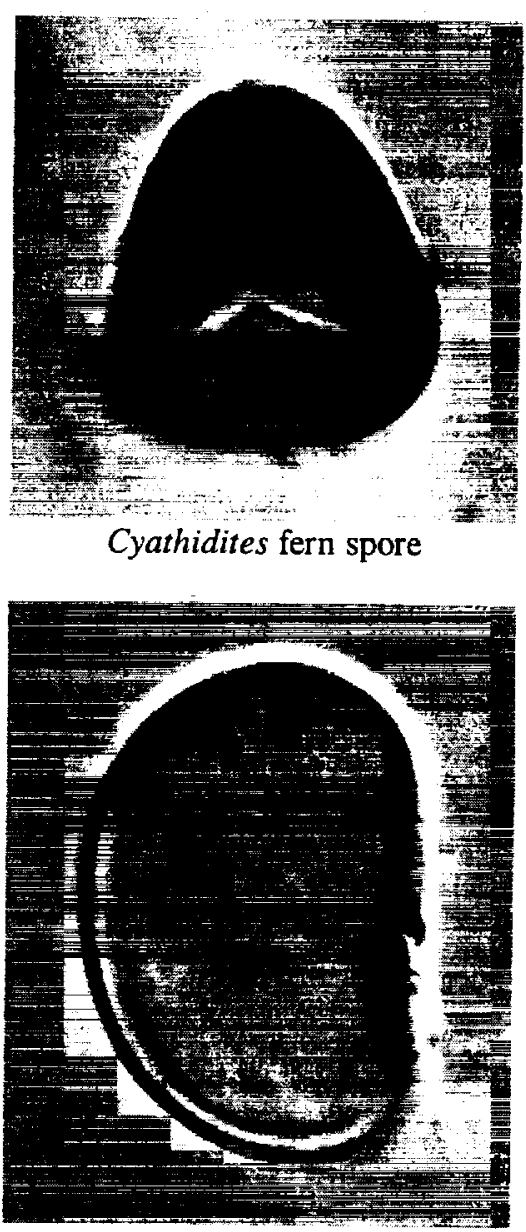

Laevigatosporites fern spore 


\title{
MASS FAILURE OF THE NORTH ATLANTIC MARGIN TRIGGERED BY THE CRETACEOUS/PALEOGENE
}

\author{
BOLIDE IMPACT. Norris ${ }^{1}$, R. D., Firth ${ }^{2}$, J., Blusztajn ${ }^{1}$, J. S., and Ravizza ${ }^{1}$, G, ${ }^{1}$ Woods Hole Oceanographic Institution,
}

Woods Hole, MA 02543-1541, Rnorris@whoi.edu; ²Ocean Drilling Program, 1000 Discovery Drive, College Station TX

Introduction: The Chicxulub impact 65 million years ago is known to have triggered large submarine slope failures near the crater in the Gulf of Mexico and Caribbean. Here we show that the impact also precipitated massive submarine failure of the continental margin around the North Atlantic. We have identified a mass flow deposit containing impact ejecta of Cretaceous/Paleogene (K/P) boundary age in two deep sea cores over $700 \mathrm{~km}$ from the continental margin and a third deep sea site off Portugal. The mass flow in the western North Atlantic must have originated from the continental margin since it contains microfossils typical of shallow water environments and sedimentary features indicative of deposition by gravity currents. We can trace part of the deposit in geophysical data over the entire western North Atlantic from Puerto Rico to the Grand Banks of Canada and demonstrate that it represents one of the largest mass wasting deposits on Earth. Mass failure of the eastern margin of North America may account for elevated extinction rates of North American invertebrates compared to other places. The biotic recovery from the extinction may have been further complicated by climatic changes produced the massive release of methane from sedimentary reservoirs disturbed by slope failure.

Western Atlantic Slope Failure: The K/P boundary is preserved at Deep Sea Drilling Project (DSDP) sites 387 and 386 on the Bermuda Rise (Fig. 1) which are 700 and $1200 \mathrm{~km}$ offshore of the continental escarpment, and 2560 and $2830 \mathrm{~km}$ from the Chicxulub Crater, respectively. Both sites contain a chalk bed sandwiched between red and brown pelagic clay; the chalk has been previously interpreted as a normal pelagic deposit laid down during a brief drop in the calcium carbonate compensation depth. However, the chalk at both sites contains impact ejecta, sedimentary structures indicative of turbidity current deposition, and an uppermost Maastrichtian microflora and fauna. In addition, the chalk at DSDP 387 contains a dinoflagellate assemblage similar in species content, diversity, and abundance to those found in eastern North American continental shelf environments. The sedimentary structures, fossil content and geochemistry show that the chalk represents a mass wasting deposit derived from the North American margin.

The K/P chalk beds on the Bermuda Rise have been previously correlated with a distinctive acoustic reflector, Horizon $\mathrm{A}^{*}$ (Fig 1). Horizon $\mathrm{A}^{*}$ is found throughout the western North Atlantic and is particularly prominent south and west of Bermuda. Horizon $A^{*}$ is also present in the subsurface of the New England Seamount chain and in the Sohlm Abyssal Plain south of the Grand Banks. The reflector is recognizable as far east as $1300 \mathrm{~km}$ from the continental slope of eastern North America and 1400-1500 km from the present shoreline. The distribution of Horizon $A^{*}$ suggests the K/P boundary turbidites cover an area of $\sim 3.9$ million $\mathrm{km}^{2}$, rendering these mass wasting deposits by far the most widespread on the Earth.

Eastern Atlantic Slope Failure: DSDP Hole 398D has a well preserved K/P boundary sequence from the Iberian Abyssal Plain about $80 \mathrm{~km}$ from the continental rise off Portugal. A $1 \mathrm{~mm}$ thick layer of green spherules is associated with the biostratigraphic $\mathrm{K} / \mathrm{P}$ Boundary. An interval $70 \mathrm{~cm}$ thick below the boundary is slumped into a series of recumbent folds that pass upward into $-10 \mathrm{~cm}$ of structureless chalk penetrated by occasional burrows filled with Paleocene sediment. This is the only slump deposit within the upper Maastrichtian at this site.

We interpret the record at DSDP 398D to reflect a single mass failure event immediately predating the arrival of impact ejecta on the seafloor. Our data suggest that the impact caused slope failures along the Portuguese coast whether by the direct effects of ground motion or the secondary effects of tsunamies crossing the Atlantic. The slump preserved below the K/P boundary at DSDP Hole 398D must have been locally derived since it contains microfossils and sediment typical of that preserved below the slump and does not have uniquely shallow water species. The folded sediment did not travel long distances unlike the deposits at DSDP 386 and 387 since it did not become size-graded or develop sedimentary structures indicative of a fluidized gravity flow. The structureless white chalk overlying the slump probably represents material that was suspended during slope failure and settled out before arrival of impact ejecta on the sea floor. Sediment failure must have stopped within a day or two after the impact because the spherule layer, interpreted as impact ejecta, rests undeformed on top of the slump deposit.

Biotic effects of Slope Failure: Slope failures associated with the impact may have had substantial effects on the marine biota. Devastation wrought by 
slope failure may account for the delayed recovery of North American molluscan assemblages compared to faunas elsewhere in the world. The combination of slumping on the slope and continental rise coupled with extensive erosion of the shelf by tsunamies should have been particularly severe around the North American margin. Indeed, endemic North American species and those without pelagic larvae suffered particularly high extinction rates compared to plankton feeding species during the end-Cretaceous mass extinction. Biotic recovery may have been further complicated by climatic changes produced the hypothesized massive release of methane from sedimentary reservoirs disturbed by slope failure.

Our results show that large impact events such as the Chicxulub impact leave a distinctive sedimentary record in the deep sea that includes the widespread, massive deposition of shallow marine, calcareous sediments below the CCD, geochemical signatures of the impacting bolide, and climate changes produced by the impact events. In the North Atlantic, large impacts in the Chesapeake Bay at $\sim 35 \mathrm{Ma}$, and on the Canadian Margin at $49 \mathrm{Ma}$ are likely to have precipitated large scale slope collapse. Unfortunately present drill holes from the deep western North Atlantic contain large gaps in core recovery from these time periods that prevent a definitive test of this idea. Still, the deep sea record may have been sculpted by impact events more than is generally appreciated. 


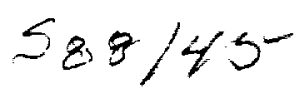

IMPACT MECHANICS AND IMPLICATIONS FOR EXTINCTION; John D. O'Keefe James R. Lyons and Thomas J. Ahrens, Lindhurst Laboratory of Experimental Geophysics, Seismological Laboratory 252-21, California Institute of Technology, Pasadena, CA 91125.

The acceptance of the Alvarez hypothesis [1] that impact is a source of biologic extinction has grown since the discovery of the Chicxulub crater [2]. Here we will review the mechanics of large scale impacts (diameter $>10 \mathrm{~km}$ ) and the associated extinction processes.

Large scale impactors punch a hole in the Earth's atmosphere which does not close until the impactor reaches the surface of the Earth and starts to penetrate it [3]. The passage through the atmosphere produces a wake along side and behind the impactor which moves downward at a velocity of $\sim 5 \mathrm{~km} / \mathrm{s}$. As the impactor penetrates the Earth, the wake stagnates on the surface produces a high temperature region that propagates around the impactor and evolves into a hemi-spherical shock that propagates radially outward from the impact site (the associated flash has been observed in laboratory experiments [4]). This initial flow field occurs prior to the initiation of the ejecta curtain and vapor expansion and thus would not entrain material but would significantly reduce the density of the atmosphere above the impact site. The strong shock heating of the atmosphere would be a source of NOx (Table 1) .

The impactor would propagate through the atmosphere unimpeded and strike the Earth at velocities ranging from 20 to $60 \mathrm{~km} / \mathrm{s}$, and produce a shock wave sufficient to melt and vaporize large masses of material [ 5 ]. The shock wave would decay to an elastic wave with an equivalent energy to magnitude 14 earthquake [5]. The shock wave profile is approximately hemispherical [6], however the profile of the vaporized/devolatilized (V/DV) material is driven by the stratigraphy because the materials are sensitive to the thermodynamics, porosity and degree of water saturation of a given layer. As an example the Chicxulub stratigraphy has been modeled as water ( $100 \mathrm{~m})$, porous water saturated carbonates and anhydrites $(2.9 \mathrm{~km})$, and granite base $(30 \mathrm{~km})$, and a dunite mantle [6]. The V/DV material expands outward from the impact site (hot fireball in Fig. 1). The central area of the VIDV region expands upward for global distribution [7]. The upward near normal sequence consists of highly shocked atmosphere, V/DV impactor and Earth material (Fig.1). This shock wave regime is the primary source of greenhouse gasses $\left(\mathrm{H}_{2} \mathrm{O}, \mathrm{CO}_{2}\right)$ and acid precursors and ozone depletors $\left(\mathrm{SO}_{2}, \mathrm{NOx}\right)$ [ $8,9,10]$ ( Table 1) .

The ejected material state and associated phenomena change with the angle away from the normal to the impact site, because of the decay of the shock wave. The VIDV material decreases and dust ejection begins. This former region called the warm fireball [7] is the source of carbonate and anhydrite precipitates and is near the interface of the region V/DV and the atmosphere (Fig. 1). The distribution of the warm fireball V/DV material is less than global. The velocity of solid ejecta decreases radially away from the impact sites and is dependant upon porosity, water saturation, damage and bulking. The angle of ejection varies because of material damage (weakening) [11] and ranges from 0 deg from the normal close to the impact site to $\sim 45 \mathrm{deg}$. further out. This ejecta angle variation supports the Alvarez et al explanation of the ejecta sequence reversal [12]. Fine dust is produced near the impact site, however the efficiency of the process for particles sizes $<20 \mu \mathrm{m}$ is poor [13].

Large impactors drive the material along the centerline of impact down to depths of $45 \mathrm{~km}$ and excavate material to depths of $\sim 5 \mathrm{~km}$. The collapse of the transient cavity (diameter $\sim 80 \mathrm{~km}$ ) is driven by gravity and produces the observed surface ring structure and stratatigraphy. A model of the Chicxulub crater inferred from field data [14] and a comparison with an impact simulation is given in Fig. 2 [15]. This simulation forms the basis for estimates of the diameters of asteroid and comet impactors.

A large impact event produces many effects that greatly stress the environment. Table 1 gives a brief synopsis of the various impact processes, resulting physical effects, and which portions of the food chain were most vulnerable. Given the extensive and diverse degree of extinction apparently produced by the $\mathrm{K} / \mathrm{T}$ impact, it is sensible to assume that life was severely stressed at or close to the base of the food chain both in terrestrial and surficial marine environments. Although all the effects listed in Table 1, and undoubtedly many others, contributed to global extinctions, the most obvious candidate to greatly perturb the base of the food chain is the cessation of photosynthesis, as orignally suggested by Alvarez et al [1]. However, the original mechanism of dust shielding probably would not interupt photosynthesis for greater than one month. Instead, a stratospheric sulfuric acid aerosol haze contaminated by silicate or pyrolized organic material [7] could easily provide sufficient opacity to turn off photosynthesis for perhaps as much as 6 months. Whether an interuption of photosynthesis for this period of time would cause the observed global extinctions is unknown, but there is little doubt that life on Earth, almost exclusively driven by the energy of the sun, would have been greatly affected. Moreover, there is a possibility that either the atmosphere and/or ocean circulations could have been altered and the changes persisted for time scales greater than a decade. 
REFERENCES: [1] Alvarez et al., (1980) Science 208, 1095-1108. [2] Hildebrand,A.R. et al (1991), Gelogy, 19,867870. [3] O'Keefe,J.D. and T.J. Ahrens (1988), Lunar Plan. Sci.Conf.. XIX, 887-888. [4] Schultz, P.H. and D. Gault (1982) Geo. Soc. Spec. Paper, 153-174. [5] O'Keefe,J.D. and T.J. Ahrens (1982) Geo. Soc. Spec. Paper, 190, 103-121. [6] Pierazzo, E. et al (1997), Icarus. 127, 408-423. [7] Pope, K.O. et al(1997), J.Geophy.Res. 102, 21645-21664. [8] O'Keefe,J.D. and T.J. Ahrens(1999), Nature 338, 247-249. [9] Pierrazzo, E. et al (1998), J.Geophy. Res. 103, 28,20628,625. [10] Brett, R., Geochim. Cosmochim. A. 56, 3603-3606, 1992. [11] O'Keefe,J.D. and T.J. Ahrens (1999), Lunar Plan. Sci.Conf. XXX,abst.1304.[12] Alvarez. et al (1995), 269, 930-935. [13] O'Keefe,J.D. and T.J. Ahrens(1987), Int. J. Impact Eng., 5, 493-499. [14] Hildebrand et al (1998) In Grady, M. M., et al Meteorites: Flux with Time and Impact Effects. Geological Soc. Special Publications, 140, 153-173. [15] O'Keefe J. D. and Ahrens, T. J. (1999) J. Geophys. Res .104,27091-27104. [16] Melosh et al., Nature 343, 251-254, 1990. [17] Wolbach et al (1985), Science 230, 167-170. [18] Retallack, G.(1996), GSA Today 6(5), 1-7.

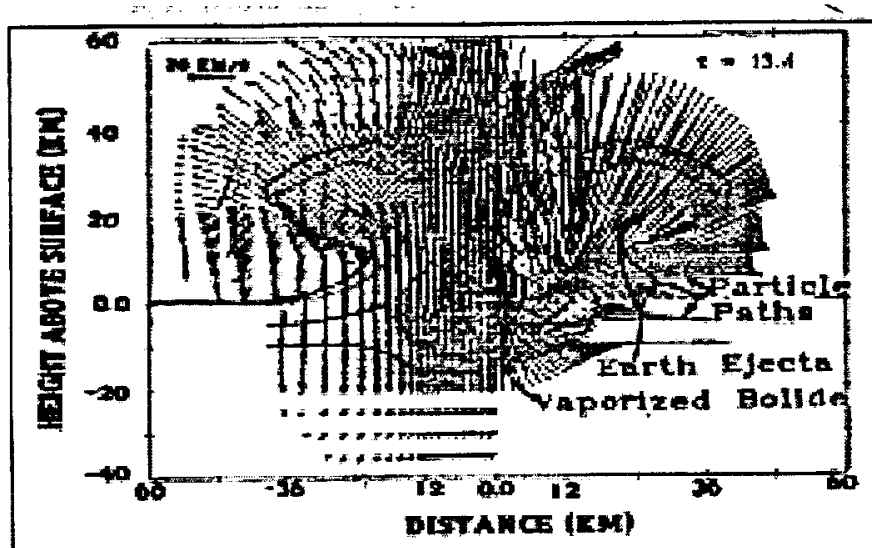

Figure 1. Crater profile and atmospheric interaction [3].

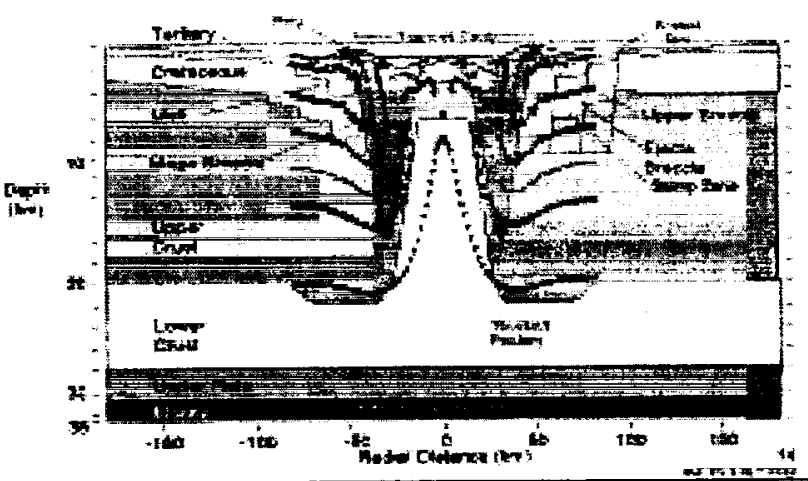

Figure 2. Chicxulub crater profile [14] and simulation results [15]

\begin{tabular}{|c|c|c|c|c|c|}
\hline Impact Process & Effect & Timescale & $\begin{array}{l}\text { Geographic } \\
\text { scale }\end{array}$ & $\begin{array}{l}\text { Geological } \\
\text { evidence }\end{array}$ & $\begin{array}{l}\text { Affect on global } \\
\text { food chain }\end{array}$ \\
\hline $\begin{array}{l}\text { Ejecta reentry } \\
{[16]}\end{array}$ & $\begin{array}{l}\sim 10 \times \text { solar } \\
\text { insolation }\end{array}$ & $\begin{array}{l}\sim 20 \text { minutes; } \\
\text { global fires } \sim \\
\text { days }\end{array}$ & Global & $\begin{array}{l}\text { Global soot layer } \\
\text { at KTB [17] }\end{array}$ & $\begin{array}{l}\text { Destruction of } \\
\text { significant } \\
\text { fraction of } \\
\text { terrestrial } \\
\text { vegetation }\end{array}$ \\
\hline Dust loading [1] & $\begin{array}{l}\text { - Cessation of } \\
\text { photosynthesis } \\
\text {-Cooling }\end{array}$ & $\sim 1$ month & Global & $\begin{array}{l}\text { Fine ejecta layer } \\
\text { at KTB }\end{array}$ & $\begin{array}{l}\text { Cessation of } \\
\text { photosynthesis }\end{array}$ \\
\hline $\begin{array}{l}\mathrm{SO}_{2} \\
\text { devolatilized } \\
\text { from target } \\
\text { anhydrite [10]; } \\
\text { stratospheric } \\
\text { aerosol layer [7] }\end{array}$ & $\begin{array}{l}\text { - Cessation of } \\
\text { photosynthesis; } \\
\text { - Cooling } \\
\text { - Surface water } \\
\text { acidification } \\
\text { - Ozone } \\
\text { depletion }\end{array}$ & $\begin{array}{l}-1-6 \text { months } \\
\text { - years } \\
\text { - days }\end{array}$ & $\begin{array}{l}\text { - Global } \\
\text { - Global } \\
\text { - Regional }\end{array}$ & $\begin{array}{l}\text { Acid leaching in } \\
\text { North America } \\
\text { [18] }\end{array}$ & $\begin{array}{l}\text { - Cessation of } \\
\text { photosynthesis } \\
\text { for up to } 6 \\
\text { months } \\
\text {-pH-susceptible } \\
\text { organisms in } \\
\text { some surface } \\
\text { waters }\end{array}$ \\
\hline $\begin{array}{l}\text { Noxious gases } \\
\left(\mathrm{SO}_{2}, \mathrm{NOx}, \mathrm{CO}\right)\end{array}$ & $\begin{array}{l}\text { Poisonous levels } \\
\text { of gases }\end{array}$ & Days & $\begin{array}{l}\text { Regional - } \\
\text { global }\end{array}$ & Inferred & $\begin{array}{l}\text { Higher animals, } \\
\text { some plants } \\
\text { poisoned }\end{array}$ \\
\hline $\begin{array}{l}\text { Tsunamis, } \\
\text { earthquakes, } \\
\text { shock waves }\end{array}$ & $\begin{array}{l}\text { Drowning, } \\
\text { shaking, high } \\
\text { winds }\end{array}$ & Hours & Regional & $\begin{array}{l}\text { Tsunami in Gulf } \\
\text { coast }\end{array}$ & Minimal \\
\hline $\begin{array}{l}\text { Water, } \mathrm{CO}_{2} \\
\text { injection [13] }\end{array}$ & Global warming & Years - decades & Global & Inferred & Minimal \\
\hline
\end{tabular}


THE SOLAR SYSTEM LINKEED TO A GIGANTIC INTERSTELLAR CLOUD, DURING 500 MYR: IMPLICATIONS FOR A GALACTIC THEORY OF TERRESTRIAL CATASTROPHISM. C.A. Olano, Instituto Argentino de Radioastronomía, C.C. Nº5, 1894 Villa Elisa, Argentina.

The local galactic environment within $1 \mathrm{Kpc}$ of the Sun comprises a massive, expanding ring of interstellar matter [1] associated with star-forming molecular clouds and a group of relatively young $O B$ stars known as Gould's Belt. This structure is likely the result of the disintegration of a formerly bound supercloud. Gould's belt is a discrete system that forms part of the so-called Orion or local arm, which is thought to be a material interarm branch or spur. Another characteristic of the solar neighborhood is the existence of at least three superclusters near the Sun : Sirius, Pleiades and Hyades [2].

The central thesis of this paper is that Gould's Belt, the local arm and the superclusters were formed in different epochs within a supercloud of $\approx 2 \times 10^{7}$ solar masses and $\approx 500 \mathrm{pc}$ of radius that has been being decelerated for a long period of time. The stars of the older generations, i.e. the Sirius supercluster whose age is around $500 \mathrm{Myr}$, tend to conserve the kinematics of the pre-braking phase of the supercloud, while the gas and early stars complexes reflect the recent kinematics, resulting from the braking process. We calculated back in time the epicyclic galactic orbits of the Sirius supercluster and the supercloud, starting from their current state as initial conditions and having into account the action of a friction force on the gas. From the condition that the Sirius supercluster and the supercloud shared the same orbits before the separation of gas and stars due to the braking of the gas, we determined the model's free parameters. The main evidence supporting our hypothesis is that the supercloud's track derived from the model coincides with a large "tunnel" in the distribution of local interstellar matter, toward the galactic longitude of $\approx 240^{\circ}[3]$.

An interesting prediction of the model is that the Sun has been gravitationally bound to the supercloud, rotating in sense contrary to the supercloud's rotation. With the values obtained for the model's parameters, we calculated the Sun's orbit with respect to the supercloud's gravitational center, for the last $100 \mathrm{Myr}$; time in which the braking force acted on the supercloud. A plausible explanation for the capture of the Sun by the supercloud is that while the Sun was passing through an extended concentration of gas, around $500 \mathrm{Myr}$ ago, this gas was suddenly accelerated and organized into a supercloud, making the difference between the supercloud's barycentre velocity and the Sun velocity relative to Regional Standard of Rest lower than the escape velocity. This explains why the Sun current velocity of about $11 \mathrm{~km} / \mathrm{s}$ with respect to LSR is signifi- cantly lower than the average of $60 \mathrm{~km} / \mathrm{s}$ typical for similar G-type stars in the Galaxy [4], [5].

The fact that the Sun was linked strongly for a long time to a gigantic interstellar cloud fortifies the idea that the Sun's galactic history is relevant to the geological and biological history [6],[7], [8]. The Oort cloud was the bridge between the solar system and the supercloud and was surely disturbed repeatedly during 500 Myr by the Sun's encounters with substructures of the supercloud and the tidal forces caused by the supercloud disk, incrementing the flux of comets at the Earth [9]. The collision of Comet Shoemaker-Levy 9 on Jupiter has shown vividly the phenomenon of cometary impacts (e.g. [10]). The periodical passages of the Sun through the midplane of the supercloud, where the probability of an encounter with a dense substructure is higher, could explain the 26 Myr periodicity found in the cratering and palaeontological records [11], [12]. This is the mechanism proposed by Rampino and Stothers [13], except the galactic plane is here replaced by the supercloud's plane. However, the amplitude of the Sun's oscillation in $\mathrm{Z}$, direction perpendicular to galactic plane, is not enough large compared with the probable thickness of the supercloud's disk, to modulate the comet flux. On the other hand, according to our model, the times in which the Sun crossed the supercloud's midplane do not coincide with the dates of the main mass extinction episodes. Though the period of these crossing times is similar to that of the extinctions $(P \approx 26 \mathrm{Myr}$ ), there is a phase difference of $1 / 2 \mathrm{P}$. The great episodes of extinction during the last $100 \mathrm{Myr}$ have occurred in Middle Miocene (11 Myr), late Eocene (36 Myr), Maestrichtian(65Myr) and Cenomanian(91 Myr) ( [12] and references therein). But our model shows that the dates of these extinctions are in approximate correspondence with the times corresponding to the $\mathrm{Z}$ extremes of the Sun's vertical oscillation, where the tidal forces due to the supercloud disk are maximal. This could indicate that the tidal forces have played a dominant role in governing the comet flux at the Earth. The effects of the tidal forces on the Oort cloud have been discussed in detail by Bailey et al .[2].

[1]Olano,C.A. (1982), A\&A,112,195. [2]Palouš, J. (1986), *.[3]Heiles,C. (1998), ApJ,498,689. [4]Bailey,M.E. (1983), MNRAS,204,603. [5]Clube,S.V.M., and Napier, W.M. (1982),QJRAS, 23,45. [6]Bailey,M.E., Clube,S.V.M.,Napier,W.M. (1990), in "The Origen of 
Comets", Pergamon Press. [7]Clube,S.V.M. (1988), **. [8]Napier,W.M. (1988), **. [9]Clube,S.V.M., and Napier, W.M. (1986), *. [10]Olano,C.A. (1999), Ap\&SS,266,347.[11]Raup,D.M., and Sepkoski, J.J.Jr. (1968),Science,231,836. [12]Shoemaker,E.M., and Wolfe, R.F. (1986), *.

[13]Rampino,M.R., and Stothers, R.B. (1986), *.

*in "The Galaxy and The Solar System", Smoluchowski,R., Bahcall, J.N. and Matthews,M.S.(eds)The University Of Arizona Press

**in "Catastrophes and Evolution", Clube ,S.V.M (ed)

Cambridge University Press 
PROGRESS IN THE SEARCH FOR AN IMPACT LAYER AT THE TRIASSIC-JURASSIC BOUNDARY IN EASTERN NORTH AMERICA. P. E. Olsen', C. Koeberl', H. Huber ${ }^{2}$, and A. Montanari ${ }^{3},{ }^{1}$ Lamont-Doherty Earth Observatory or Columbia University, Rt. 9W, Palisades, NY 10964 (polsen@ldeo.columbia.edu), USA, ${ }^{2}$ Institute of Geochemistry, University of Vienna, Althanstrasse 14, A-1090 Vienna, AUSTRIA (koeberc3@mailbox.univie.ac.at), ${ }^{3}$ Osservatorio Geologico do Coldigioco, I-62020 Frontale di Apiro, Italy (sandro.ogc@fastnet.it).

Introduction: The Triassic-Jurassic (Tr-J) boundary marks one of the "big five" mass extinctions in the last half billion years. In many of the exposed rift basins of the Atlantic passive margin of eastern North America and Morocco the boundary is identified as an interval of stratigraphically abrupt floral and faunal change within cyclical lacustrine sequences [1]. A comparatively thin interval of Jurassic age strata separate the boundary from extensive overlying basalt flows, the "best" dates of which (201 Ma) are practically indistinguishable from recent dates on tuffs from marine boundary sequences $[2,3]$. Milanlkovitch cyclostratigraphy of these boundary sections suggests that the oldest basalts in these rifts postdate the TriassicJurassic boundary by about $40 \mathrm{Ky}$ [4].

The biological pattern and magnitude the Triassic boundary is remarkably similar to that at the K-T boundary, which has sparked much debate on the cause of the Tr-J extinctions. As with the K-T debate, hypotheses have largely focused on bollide impacts $[5,6]$ and greenhouse warming from a $\mathrm{CO}_{2}$ increase driven by massive flood basalt volcanism $[6,7]$. There have been four prior unsuccessful attempts at find evidence of impacts at the Tr-J boundary in these rifts, in the Newark $[6,8]$ and Fundy basins $[5,8]$.

Here we present the results of a much more detailed geochemical and mineralogical sampling at four sections that cross the Tr-J boundary in the Newark rift basin (NY, NJ, PA: USA), where is has been most tightly constrained (Fig. 1). The strategy has been to focus first on constraining the interval of faunal and floral change [1] and only then focusing in on associated geochemical and geophysical properties.

The overall microstratigraphy of the sampled sequences is remarkably like that of the K-T boundary in the Raton basin of Colorado and New Mexico, although most of the surrounding sequence is dominated by red clastic rocks as is typical for the Newark basin. In this part of the Newark basin, the boundary section consists of several meters of gray claystone, siltstone, sandstone, and minor limestone and coal that are part of the generally cyclical lacustrine sequence. At most locations, the basal gray beds consist of gray siltstone and fine sandstone with coalified roots and thin gray limestone lenses, with a Triassic-type palynoflora [1], overlain by several to tens of centimeters of whiteweathering smectitic [6] claystone with abundant coalified roots. This is generally overlain by a few centimeters of coal or carbonaceous shale containingvirtually only spores [1]. The shale is overlain by a blue to buff or brownish sandstone and siltstone contain plant debris including abundant charcoal.

Above and below this gray sequence are mostly red shaly mudstones and subordinate gray mudstones and sandstones. Thin gray beds in the overlying sequence, below the basalt. produce a typical Jurassic-type palynoflora, dominated by Corollina and lacking all Triassic forms [1], while gray beds in the underlying sequence produce typical Late Triassic-type palynofloras with abundant Patinasporites [1]. This part of the ba$\sin$ is unusual in that reptile footprints and bones occur in many beds through the sequence allowing unusually tight constraints on the pace of faunal change. Perhaps not surprisingly Triassic-type faunal remains are restricted to below the spore-dominated zone.

The samples discussed here were collected continuously in 3 to $12 \mathrm{~cm}$ intervals across the boundary as defined palynologically by the spore-rich bed $[1,6]$. Major and trace elements have been assayed by XRF, and Ir was measured by gamma-gamma coincidence spectrometry after neutron activation. The latter has a detection limit of about $0.02 \mathrm{ppb}$ Ir. A search for shocked quartz after dissolution of the non-silicate portions of the samples is now underway.

Results: The results obtained thus far (Fig. 2), show at least a small Ir anomaly [1] at the boundary at the three sections analyzed at this writing (maximum of $285 \mathrm{ppt}$ ). The elevated levels of Ir are mostly associated with higher levels of $\mathrm{Al}$ in a white smectitic claystone, directly adjacent to the thin coaly layer. It is especially suggestive that the anomaly is directly associated with the previously identified spore spike [1] in these sections (Fig. 2), recalling the similar pattern at the K-T boundary in the western US [9]. It is possible the relatively weak Ir anomaly seen thus far is a consequence of dilution by the rather coarse sampling level (ca. $3 \mathrm{~cm} /$ per sample) required by the very high accumulation rates (ca. $1 \mathrm{~m} / 2000 \mathrm{yr}$ ) in the sampled part of the Newark basin.

Implications: While tantalizing, the observed anomaly requires much additional geochemical and mineralogical analysis for its significance to be understood for testing hypotheses of the origin of the Tr-J boundary. Although the microstratigraphy is very similar to continental K-T boundary sections, and this lithological similarity is matched by a similar biotic pattern, we cannot rule out volcanic or even a diagenetic hypotheses for that data we have thus far.

References: [1] Fowell, S. J. et al. (1994) GSA Spec. Pap. 288, 197-206; Olsen, P. E. et al. (1997 
PROGRESS IN THE SEARCH FOR AN IMPACT LAYER: P. E. Olsen et al.

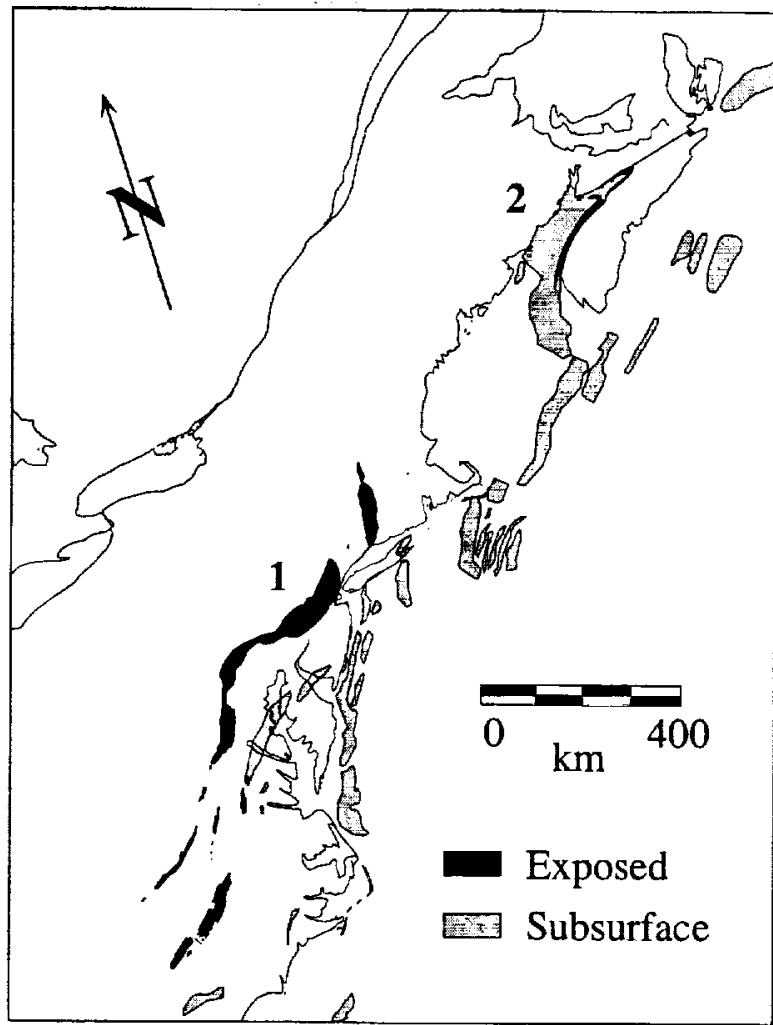

Figure 1. Above. Triassic-Jurassic rift basins of the Newark Supergroup (black) and related subsurface basins, showing the Newark (1) and Fundy (2) basins. Modified from [36].
Eos, Trans., AGU 78, Suppl., 721; Olsen, P. E.. et al. (1999) Eos, Trans., AGU 808, Suppl., F50. [2] Sutter, J. F. (1988) USGS Bull. B1776, 194-200; Dunning, G. R. and Hodych, J. P. (1990) Geology 18, 795-798; Hodych, J. P. and Dunning, G. R. (1992) Geology 20 , 51-54. [3] Palfy, J., et al. (2000) Geology 28, 39-42. [4] Olsen P. E. et al. (1996) Mus. North. Ariz. Bull. 60, 11-22. [5] Olsen, P.E. et al. (1987) Science 237, 1025-1029; Spray. J. G. et al. (1998) Nature 392, 171-173. [6] Olsen, P. E. (1999) Science 284, 604605. [7] Courtillot, V. et al. (1994) LPI Contrib. 825 , 27-28; Marzoli, A. (1999) Science 284, 616-618; McElwain, J.C. et al. (1999) Science 285, 1386-1390. [8] Smith, R.C. et al. (1989) PA Geol. 19, 8-13; Mossman, D. et al. (1998) Can. Jour. Earth Sci. 35, 101-10. [9] Tschudy, R.H. et al. (1984) Science 225 , 1030-1032. [10] Olsen, P. E. (1997) Ann. Rev. Earth Planet. Sci. 25, 337-401.

Figure 2. Below. Data for $\mathrm{Al} 2 \mathrm{O} 3$ and Ir from three sections in the Newark basin. Sectionll 1 is about 15 $\mathrm{m}$ east of Section I, and Section III is located about $330 \mathrm{~m}$ east of Section II. Abbreviations are: ssp. "spore spike" described by [1]; cly, claystone, md, mudstone; sit, siltstone; fss, fine sandstone; mss, medium sandstone.

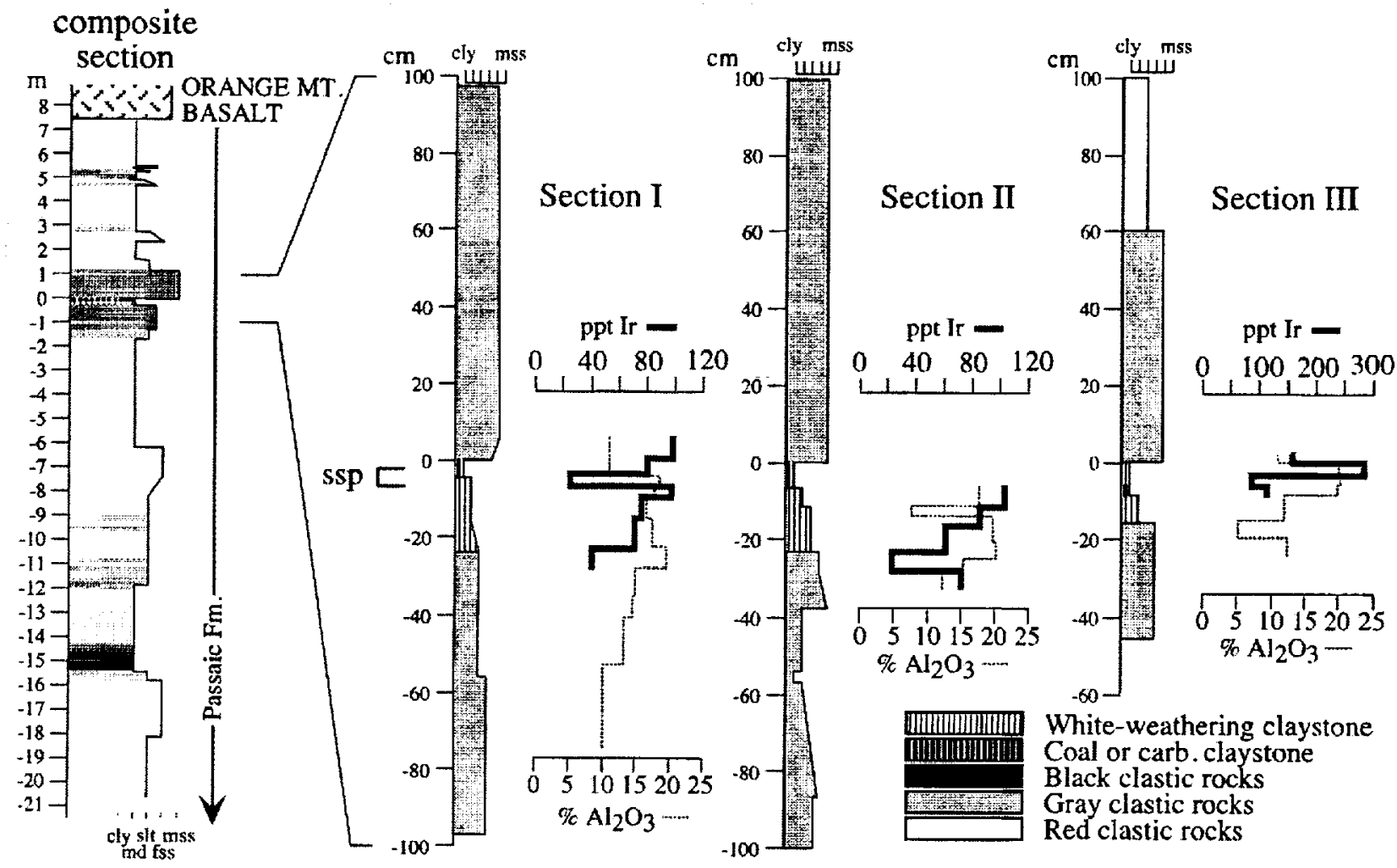


CRETACEOUS-TERTIARY BOUNDARY EVENTS ON THE NEW JERSEY CONTINENTAL MARGIN. OIsSON, R.K., Wright, J.D., Miller, K.G., Browning, J.V., and Cramer, B.S.

Boreholes drilled by the New Jersey Coastal Plain Drilling Project (ODP Leg 150AX and ODP Leg 174AX) recovered 11 $\mathrm{m}$ thick sections of Danian and Maastrichtian strata. A 6-cm-thick spherule layer abruptly separates latest Maastrichtian (calcareous nannofossil Micula prinsii Zone) from earliest Danian (Guembelitria cretacea, Zone P0) strata in the Bass River Borehole. Impressions of tectites in glauconitic clays at the top of the Maastrichtian indicate an abrupt interruption of sedimentation by a rain of tectites that were condensed from a vapor-ejecta cloud formed by the asteroid impact at Chicxulub, Yucatán. A well-defined iridium anomaly, shocked quartz, and shocked $\mathrm{K}$ feldspar are associated with the spherule layer. Internal globular shapes of gas bubbles characterize the Bass River spherules as they do in the spherules that occur in the K T boundary sections in the Gulf of Mexico. At Bass River, except for Hedbergella and Guembelitria cretacea, all Cretaceous planktonic foraminiferal species appear to have their last occurrences below the spherule layer.

Above the spherule layer small clay clasts, containing calcite-replaced tectites and Cretaceous foraminifera and dinoflagellates, occur in the lower $10 \mathrm{~cm}$ of the Danian. Cretaceous planktonic foraminifera are absent above the interval containing clay clasts. The clasts are surrounded by Danian sediments which contain typical early Danian planktonic species (ie. Parvularugoglobigerina eugubina, Eoglobigerina eobulloides, Woodringina claytonensis, and others). The clay clast interval is a marker for the K/T boundary in other New Jersey Coastal Plain boreholes and in outcrops where a spherule layer is absent. The clasts are interpreted as ripups that were transported shoreward from a deeper part of the Maastrichtian sea floor. The most likely mechanism for the transport and deposition of the clasts is by tsunami activity. Although a tsunami generated by the asteroid impact in the Gulf of Mexico may have traveled into the Atlantic Ocean and affected the New Jersey margin, tsunamis may have also been triggered by earthquake induced slumping along Atlantic continental slopes as has been recently suggested by Norris and Firth (1999) at ODP Site 1049 off eastern Florida. Olsson and Wise (1987) showed that a huge hiatus with missing Maastrichtian and upper Campanian strata was encountered in exploration and stratigraphic test wells in the Baltimore Canyon Trough beneath the New Jersey continental margin. DSDP Site 605 located east of the Baltimore Canyon Trough at the foot of the New Jersey continental slope terminated in the upper Maastrichtian (Abathomphalus mayaroensis Zone) indicating that the hiatus is confined to the shelf margin. The area of the hiatus encompasses at least $30,000 \mathrm{~km} 2$ of the Maastrichtian outer continental shelf and upper slope and may represent a giant slump scar. A tsunami generated at this area would have reached the New Jersey Coastal Plain in probably less than $1 / 2$ hour. Surface seismic waves generated from the impact at Chicxulub, Yucatan would have arrived in a little less than 10 minutes, about the time of the arrival of the ejecta-vapor cloud. The fact that the Bass River clay clasts contain replaced tectites indicates that the tsunami took place after deposition of the tectites and that the two events closely followed one another.

An decrease of up to 1 per mil in oxygen 18 values on shells of the Cretaceous planktonic foraminifer Rugoglobigerina from Bass River and Ancora Boreholes indicates a significant warming trend in near sea surface temperatures that lasted about 425,000 years and ended ca 22,000 years before the $\mathrm{K} / \mathrm{T}$. This warming trend is coincident with a 16-18 degree latitude poleward shift in the North and South Atlantic Oceans of the Maastrichtian subtropical planktonic species Pseudotextularia elegans. The warming trend which starts near the lower boundary of Chron C29R is believed related to the main outpouring of the Deccan Traps in India. Carbon 13 values of benthic and planktonic foraminifera also show the wellknown carbon isotopic shift across the $\mathrm{K} / \mathrm{T}$ that indicates a substantial reduction in oceanic primary productivity, the "Strangelove" ocean. Carbon 13 values of Danian benthic and planktonic foraminifera in the New Jersey boreholes corroborates the data of D'Hondt et al. (1998) at DSDP Sites 528 and 577 that indicates the structure of the open-ocean productivity did not fully recover for over 3 million years after the $\mathrm{K} / \mathrm{T}$.

Analysis of water depth variations using foraminifera indicates that the $\mathrm{K} / \mathrm{T}$ lies within a cycle of sea level change that began ca 4 million years before the K/T and ended ca 2 million years after the K/T. From an initial rise of $\sim 200 \mathrm{~m}$, sea level had fallen slowly over ca 4 million years with a sharper lowering of sea level to $\sim 75 \mathrm{~m}$ just below the boundary (ca $22 \mathrm{~K} / \mathrm{yrs}$ before $\mathrm{K} / \mathrm{T}$ boundary time). This lowering of sea level is associated with the appearance of typical Danian benthic species, e.g. Alabamina midwayensis, Anomalinoides acuta. Sea level remained low after the $\mathrm{K} / \mathrm{T}$ before the next cycle of sea level rise began ca 2 million years after the $\mathrm{K} / \mathrm{T}$.

References:

D'Hondt, S., et al., 1998, Science, v. 282, p. 276-279.

Norris, R. D. and J. Firth, 1999, Annual meetings of the Geological Society of America, Denver, Abstracts with Programs, p. A123.

Olsson, R.K. and S.W. Wise, Jr., 1987, Initial Reports of the Deep Sea Drilling Project, v. 92, p. 1343-1365. 
TIMING THE END-TRIASSIC AND EARLY JURASSIC MASS EXTINCTIONS. J. Pálfy ${ }^{1}$, P. L. Smith ${ }^{2}$, and J. K. Mortensen', ' Hungarian Natural History Museum, Department of Paleontology (PO Box 137, Budapest, H1431, Hungary; e-mail: palfy@paleo.nhmus.hu), ${ }^{2}$ Department of Earth and Ocean Sciences, University of British Columbia (6339 Stores Road, Vancouver, BC, V6T 1Z4, Canada).

The end-Triassic marks one of the five biggest mass extinctions, which was followed by a minor extinction event in the Early Jurassic. We obtained highprecision $\mathrm{U}-\mathrm{Pb}$ ages integrated with biostratigraphy from volcanosedimentary sequences in western North America [1]. Together with other recent U-Pb and ${ }^{40} \mathrm{Ar}-{ }^{39} \mathrm{Ar}$ ages, these dates help provide a temporal framework for the extinctions and place constraints on their possible causes.

A tuff layer in marine sedimentary rocks encompassing the Triassic-Jurassic transition yielded a U-Pb age of $199.6 \pm 0.3 \mathrm{Ma} \mathrm{[2]}$. The dated level lies immediately below a prominent change in radiolarian faunas and the last occurrence of conodonts. Additional recently obtained $\mathrm{U}-\mathrm{Pb}$ ages integrated with ammonoid biochronology confirm that the Triassic Period ended ca. $200 \mathrm{Ma}$, several million years later than suggested by previous time scales. Published dating of continental sections suggests that the extinction peak of terrestrial plants and vertebrates occurred before $200.6 \mathrm{Ma}$ $[3,4]$. The end-Triassic biotic crisis on land therefore appears to have preceded that in the sea by at least several hundred thousand years. Such temporal pattern is not compatible with causation by bolide impact. Recently published ${ }^{40} \mathrm{Ar}-{ }^{39} \mathrm{Ar}$ dating suggests that activity of the short-lived Central Atlantic Magmatic Province peaked around $199 \pm 2.4$ Ma [5]. Therefore environmental change triggered by voluminous volcanism may have played a key role in the end-Triassic extinction.
A well-known second-order mass extinction was first recognized as a minor Pliensbachian peak in the global extinction rate, but it has alternatively been interpreted as a regional response to the Early Toarcian oceanic anoxic event. Detailed studies established it as a global long-term event spanning five successive ammonoid zones [6]. Our revised time scale, based on high-precision $\mathrm{U}-\mathrm{Pb}$ ages resolved to the zone level, suggests that elevated extinction rates were sustained for about 4 million years and peak extinction occurred at $183 \mathrm{Ma}$. Recently published isotopic dating of flood basalts from the southern Gondwanan Karoo and Ferrar provinces documents a culmination in volcanic activity also around $183 \mathrm{Ma}[7,8]$ The onset of volcanism is recorded as an iflection and start of a rapid rise of the seawater ${ }^{87} \mathrm{Sr} /{ }^{86} \mathrm{Sr}$ curve. Again, the synchrony of voluminous flood basalt eruptions and the biotic crisis permits their causal relationship, which in this case may be mediated by widespread oceanic anoxia.

References: [1] Pálfy J. et al. (in press) Can. J. Earth Sci., 37. [2] Pálfy J. et al. (2000) Geology, 28, 39-42. [3] Hodych J. P. and Dunning G. R. (1992) Geology, 20, 51-54. [4] Dunning G. R. Hodych J. P. (1990) Geology, 18, 795-798. [5] Marzoli A. et al. (1999) Science, 284, 616-618. [6] Little C.T.S. and Benton M. J. (1995) Geology, 23, 495-498. [7] Duncan R. A. et al. (1997) JGR, 102, 18127-18138. [8] Encarnación J. et al. (1996) Geology, 24, 535-538. 
NATURAL FULLERENES FROM THE KTT BOUNDARY LAYER AT ANJAR, KUTCH, INDIA. G. Parthasarathy ${ }^{1}$, N. Bhandari ${ }^{2}$, M. Vairamani ${ }^{3}$, A.C. Kunwar ${ }^{3}$ and B. Narasaiah ${ }^{3}$; ${ }^{1}$ National Geophysical Research Institute, Hyderabad $500 \quad 007,{ }^{2}$ Physical Research Laboratory, Ahmedabad 380009 (bhandari@prl.ernet.in), ${ }^{3}$ Indian Institute of Chemical Technology, Hyderabad 500 007, India.

We report here the presence of fullerenes in the iridium-rich Cretaceous-Tertiary boundary (KTB) layer in the intertrappean beds of Anjar within the Deccan Volcanic Province. Fullerenes $\left(C_{60}\right)$ have been identified in or near the two iridium rich horizons from this section by high-resolution electron-impact ionization mass spectrometry and ${ }^{13} \mathrm{C}-\mathrm{NMR}$ studies. Fullerenes are absent in four other iridium-poor horizons of the same section.

Introduction: Fullerenes have been synthesized in the laboratory by gas-phase chemistry at high-temperatures over $1300^{\circ} \mathrm{K}$. However, Buseck et al [1] reported the occurrence of natural fullerenes in $\sim 2 \mathrm{Ga}$ old Precambrian carbon-rich rocks of Shunga (Russia) called shungite. Subsequently other workers found them in rocks which had witnessed singular geological events like lightning strikes [2], wild fires at the Cretaceous-Tertiary boundary [3,4] and shockproduced impact generated breccias from Sudbury Meteorite crater [5]. Fullerenes from Karelia (Russia) from a low pressure metamorphic terrain [6] and from the samples of Permo-Triassic boundary sections [7] have been reported recently. We have studied the properties of the carbonaceous matter in a sediment bed from Anjar, which is believed to be a continental $\mathrm{K} / \mathrm{T}$ boundary within the Deccan [8] and find that fullerenes are present at two horizons in this section.

Geological Setting: The Anjar volcanosedimentary sequence is located in the western periphery of Deccan flood basalt province and consists of nine lava flows and at least four intertrappean beds $[9,10]$. The third intertrappean bed is well developed (about $6 \mathrm{~m}$ thick) and consists of cherty limestone, shale and mudstone. Three thin limonitic layers are present in the lower 1.5 meters of the intertrappean which was exposed in pit BG-1 [8]. The limonitic layers have high concentration of iridium (650 to $1333 \mathrm{pg} / \mathrm{g}$ ) and osmium(650 to 2230 $\mathrm{pg} / \mathrm{g}$ ), compared to less than $100 \mathrm{pg} / \mathrm{g}$ measured in other horizons of this pit. Based on the geochronological, geochemical, paleomagnetic and paleontological data $[11,12]$, it is believed that the limonitic layers were deposited during the $\mathrm{K} / \mathrm{T}$ boundary event.

Experimental methods and Results: Six samples from the $3^{\text {rd }}$ intertrappean bed, collected from pit BG1 during 1994 were analyzed in this study. Their stratigraphic location with respect to the three iridium-rich layers $(\mathrm{Br} 1,2,3)$ are shown in
Fig.1 [8]. The carbonaceous matter was extracted from the powdered samples by using a standard acid-digestion method [13]. The resulting residue was analyzed by mass spectroscopic, powder X-ray diffraction, and ${ }^{13} \mathrm{C}-\mathrm{NMR}$ spectroscopic methods. Only two samples L (Ir layer,Br-2) and 964 (just below Ir layer $\mathrm{Br}-1$ ) yielded some extractable fullerenes. The content of the carbonaceous matter extracted from these two rock samples are about $1.5-1.9 \%$. The other samples yielded only neo formed fluoride residues as fluorite crystals and sample 965 showed noticeable amount of pyrite.

The electron impact ionization mass spectra were run on a VG autospec-mass spectrometer with Opus.V3.IX data system under the following conditions: source temperature $250^{\circ} \mathrm{C}$; electron energy: $70 \mathrm{eV}$; trap current: $200 \mu \mathrm{A}$; resolution: 1000; mass range scanned: $300-900 \mathrm{amu}$; scan speed: $5 \mathrm{~s} /$ decade; Interscan delay: $0.5 \mathrm{~s}$. Samples were loaded in a quart $z$ cup, introduced through direct inlet probe and instantly heated to $250^{\circ} \mathrm{C}$. The mass spectrometer was calibrated up to 900 amu with a reference sample of high-purity perfluorokerosene. The samples were scanned between 300 and 900 amu to improve the sensitivity of detection of $\mathrm{C}_{60}$ and $\mathrm{C}_{70}$. However, no ions corresponding to $\mathrm{C}_{70}{ }^{+}$could be detected. Although a single scan gave enough signal to identify $\mathrm{C}_{60}$, the average of 20 scans was used for analysis. The mass spectrum of the carbonaceous matter from Anjar samples shows peaks corresponding to $\mathrm{C}_{60}{ }^{++}$and $\mathrm{C}_{60}{ }^{+}$at 360 and $720 \mathrm{amu}$, respectively. $\mathrm{C}_{60}$ was resolved into four peaks at $720,721,722$ and 723 amu, corresponding respectively, to ${ }^{12} \mathrm{C}_{60}{ }^{+},{ }^{12} \mathrm{C}_{59}$ ${ }^{13} \mathrm{C}^{+},{ }^{12} \mathrm{C}_{58}{ }^{13} \mathrm{C}_{2}^{+}$, and ${ }^{12} \mathrm{C}_{57}{ }^{13} \mathrm{C}_{3}{ }^{+}$. It is interesting to note that peaks corresponding to the addition of up to three oxygen atoms (m/z 736,752 and 768 ) are observed in both the samples. Their origin is being investigated. The highest concentration of fullerenes was found in sample $L$ having the highest average concentration of iridium $(1287 \mathrm{pg} / \mathrm{g})$.

We also carried out ${ }^{13} \mathrm{C}$ NMR spectroscopic studies on the powdered carbonaceous material to confirm the presence of fullerenes. ${ }^{13} \mathrm{C} N M R$ spectrum was recorded in benzene- $\mathrm{d}_{6}$ at $125 \mathrm{MHz}$ on a Varian Inova 500 NMR spectrometer. 3200 free induction decays were collected using $30^{\circ}$ pulse width and $15 \mathrm{~s}$ relaxation delay. ${ }^{13} \mathrm{C}$ - NMR spectrum (with an acceptable signal-to-noise ratio), exhibits clearly the presence of a single NMR line at 143.28 ppm for sample L and 143.24 ppm for sample 964 
NATURAL FULLERENES FROM THE KJT BOUNDARY LAYER: G. Parthasarthy et al.

corresponding to the $s p_{2}$ carbons of the fullerene $\mathrm{C}_{60}$. The other peaks expected for $C_{70}$ at 130.9 , $145.4,147.4,148.1$ and $150.7 \mathrm{ppm}$ [14] are not observed in any of the samples, corroborating the results obtained by mass spectroscopic studies. The concentration of fullerene $\mathrm{C}_{60}$ given in Fig. 1 is approximate but appears to be comparable to the values found in woodside creek and flaxbourne River sections [3,4]. The absence of $C_{70}$ is also noticed in $\mathrm{K} / \mathrm{T}$ boundary clay from some sections, e.g. at Wood side Creek [4], Shungites of Karelia [6] and in P/T boundary [7]. The absence of $C_{70}$ is attributed to weathering and differential oxidation as suggested by the results of Chibante et al [15]. Becker et al [5] have suggested that the survival of Fullerenes in the Sudbury crater is due to the presence of diagenetic sulfides, as the fullerenes degrade quickly at fairly low temperatures. The

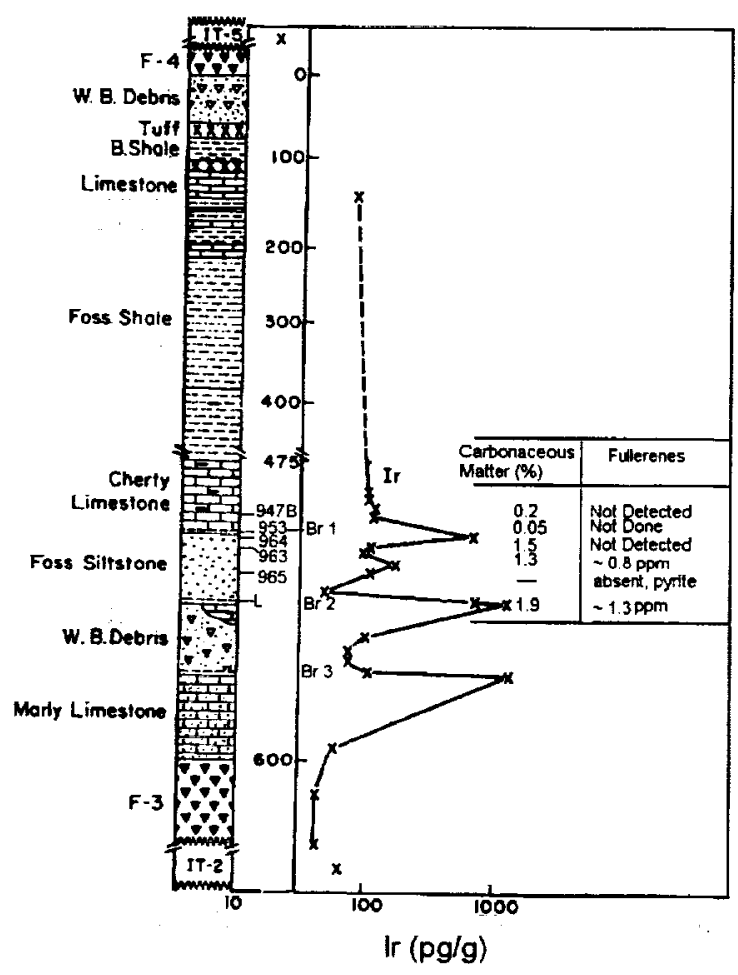

Fig.1. Stratigraphic locations of samples analyzed for fullerenes with respect to the iridiumrich layers $(\mathrm{Brl}$,2, and 3). Content of carbonaceous matter and approximate concentration of fullerenes in various horizons is also given. presence of sulfides indicated that the environment under which the impact breccias at Sudbury were deposited had low oxygen and high sulfur concentrations. They also suggested that the fullerenes were protected from oxidation by the surrounding sulfide-silicate matrix in which they are contained. However in the Anjar samples, despite the noticeable sulfur content, in samples 965, just above L (Fig. 1) $C_{70}$ is not present. Hence we believe that absence of $\mathrm{C}_{70}$ in Anjar is not due to its oxidation.

In view of the association of fullerenes with iridium and their absence in other horizons which definitely have volcanic components, it appears that the origin of fullerenes is related to impact rather than volcanism. This is consistent with the recent finding of high ${ }^{3} \mathrm{He} /{ }^{4} \mathrm{He}$ in fullerenes in other KTB layers [16].

Acknowledgements: We are grateful to Professor Govardhan Mehta, Dr. K.V.Raghavan, and Dr. H.K. Gupta for providing facilities and support for this work. We thank A.D.Shukla for his help in preparation of the samples.

References: [1] Buseck P.R. et al. (1992) Science, 257, 215-217. [2] Daly T.K. et al. (1993) Science, 259, 1599-1601. [3] Heymann D. et al. (1994) Science, 265, 645-647. [4] Heymann D. (1996) Geol. Soc. Am. Spl. Pap. 307, 453-464. [5] Becker L. et al. (1994) Science, 265, 642-645. [6] Parthasarathy G. et al (1998). Geochim. Cosmochim. Acta, 3541-3544. [7] Chijiwa T. et al. (1999) Geophys. Res. Lett., 26, 767-770. [8] Shukla P.N. et al. (1997) Palaeobotanist, 46, 127-132. [9] Ghevariya Z.G. (1988) Curr. Sci., 57, 248-251. [10] Bhandari, N. et al (1995) Geophys. Res. Lett., 22, 433-436. [11] Bhandari, N. (1998) Proc. Indian Acad. Sci. [12] Venkatesan T.R. et al. (1996) Curr. Sci., 70, 990-996. [13] Wedekind et al. (1983) In Earth's Earliest Biosphere: Its origin and Evolution (ed. J.W. Schopf) pp 428-441, Princeton Univ. Press. [14] Ajie et al (1990) J. Phys. Chem., 94, 8630-8633. [15] Chibante et al (1993) Carbon, 31, 185-193. [16] Becker et al (2000) Lunar and Planert. Sci, XXXI, 1832. 


\section{CHICXULUB AND CLIMATE: ASSESSING THE CLIMATE FORCING OF THE SULFATE}

\section{AEROSOLS. E. Pierazzo, Lunar \& Planetary Lab, University of Arizona (1040 E. $4^{\text {th }}$ St., 85721 Tucson, Ari-} zona, U.S.A.; betty@lpl.arizona.edu)

Introduction: The occurrence of a large impact on the Yucatán Peninsula, Mexico, apparently coinciding with the Cretaceous/Tertiary (K/T) boundary extinction, $65 \mathrm{Myr}$ ago, has led speculations that the extinction may have been caused by an impact-related climate shift, in addition to short-term effects directly associated with the impact (e.g., see [1]). In particular, important climate changes have been attributed to $\mathrm{CO}_{2}$, water vapor, and S-bearing gases released from the sedimentary layer at the impact location. However, modeling studies [2] seem to indicate that the $\mathrm{CO}_{2}$ released in the impact is not enough to produce a strong effect on the climate. On the other hand, the release of large amounts of S-bearing gases is responsible for a large climate forcing, as suggested by [3]. This work assesses the climate forcing caused by the stratospheric production of sulfate aerosols (injection of small dust particles is not included here) from the reaction of impact-produced S-bearing gases and water vapor.

The Chicxulub impact: The Chicxulub impact event occurred on a partially submerged carbonate/evaporite platform [4]. Several oil exploration wells drilled in the region indicate that a thick sequence $(-3 \mathrm{~km})$ of carbonates and evaporites underlies the top of the Cretaceous. A climatically conservative estimate of $30 \%$ evaporites and $70 \%$ carbonates [5] was chosen for this study, although up to $50 \%$ evaporites have been inferred for the region [6]. A shallow sea (few tens of meters) was probably covering the region $65 \mathrm{Myr}$ ago. The impactor could have been a comet or an asteroid; currently, the asteroidtheory seems to be favored [7]. The impact produced a multiring structure, whose transient cavity diameter is estimated to be around $100 \mathrm{~km}$ [8]. Hydrocode simulations $[3,9]$ indicate that the amount of $S$ injected into the stratosphere ranged between about 75 and $160 \mathrm{Gt}$, depending on projectile type and impact speed (the effect of the angle of impact, investigated in [10], suggests an uncertainty of about a factor of two for the estimates). For this work I conservatively chose a loading of $80 \mathrm{Gt}$ of sulfur and $650 \mathrm{Gt}$ of $\mathrm{H}_{2} \mathrm{O}$ (i.e., similar to the case of an asteroid $15 \mathrm{~km}$ in diameter impacting at $20 \mathrm{~km} / \mathrm{s}$ in [3]).

Model: The model couples a Sulfate Aerosol Model to the Column Radiation Model (CRM) developed at the Nat. Center for Atmosph. Res. (Boulder, $\mathrm{CO}$ ). Given the initial loading of impact-produced gases and aerosols, the model calculates the mean aerosol size, concentration and optical properties over time, as well as the short- and long-wave radiation balance, and the heating rates at various atmospheric levels. These values can then be compared to those for the unperturbed atmosphere, to determine the climate forcing due to the stratospheric aerosols.
Column Radiation Model. The CRM is a standalone version of the radiation model used in the latest version of the NCAR Community Climate Model CCM3 [11]. It can be used to study the Earth's energy budget and the radiative forcing of greenhouse gases and aerosols. Climate forcing is defined as the change in the Earth's radiative balance and is measured in

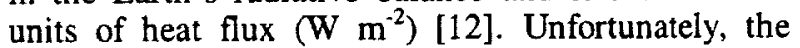
responses of the climate to the forcing, like surface temperature, is not a simple function of the forcing, and can only be modeled by a 3D General Circulation Model. The atmosphere is modeled by 18 levels, ranging from the surface to $\sim 48 \mathrm{~km}$ (the radiation balance is determined at each atmospheric level). The top 7 levels represent the stratosphere. The radiation balance is obtained by treating separately the incoming Short-Wave (solar) and outgoing Long Wave (terrestrial) radiation. The SW radiation is resolved by 19 spectral bands covering the range $0.2-5 \mu$, while the $\mathrm{LW}$ radiation is resolved by 8 bands in the $6.5-20 \mu$ region.

Aerosol Model. The one-dimensional microphysical model for the formation and evolution of the stratospheric aerosols follows that described in [13]. The aerosols are continuously formed by the reaction of $\mathrm{SO}_{2}$ with $\mathrm{H}_{2} \mathrm{O}$, and their evolution is described by processes like coagulation and growth, gravitational settling and diffusion, for various particle sizes. The model starts from the impact-produced gases, namely $\mathrm{SO}_{2}, \mathrm{SO}_{3}$, and $\mathrm{H}_{2} \mathrm{O}$, injected in the stratosphere by the impact event. The $\mathrm{SO}_{3}$ is assumed to immediately react with water vapor to form sulfate aerosols (to account for an initial aerosol formation in the expansion plume, as suggested in [8]). As $\mathrm{H}_{2} \mathrm{O}$ and $\mathrm{SO}_{2}$ react, small sulfate aerosol $\left(\mathrm{H}_{2} \mathrm{SO}_{4} \times 2 \mathrm{H}_{2} \mathrm{O}\right)$ particles are formed, which then grow in size by coagulation with other particles of the same size, while settling through the stratosphere. The smallest particle radius modeled is $0.315 \mu$, and the aerosol growth is followed up to 4 $\mu$ radius. As the aerosol particles leave the lowermost stratospheric layer and enter the troposphere, they are removed from the model (they are probably rained out from the troposphere in a matter of days).

To a first approximation it is assumed that the sulfate aerosols and the gases are distributed uniformly over the globe. This assumption is justified by the fast expansion (well beyond the stratosphere) of the impact plume, that carries within the forming sulfate aerosols. Models of the ballistic distribution of impact ejecta [14] suggest that impact-produced material would be distributed all over the globe in a matter of few hours. Since impact products re-enter the stratosphere from above, the gases and sulfate aerosols are initially distributed in the uppermost 3 stratospheric layers. 
Model Validation. The model was tested for historically recorded volcanic eruptions. In particular the well-recorded and studied Pinatubo eruption, in 1991, is an important benchmark for testing the model. The climate forcing associated with the Pinatubo eruption is shown in Figure 1, together with the forcing inferred from observations [15], and proves the good agreement of the model with the observations. Figure 1 also shows the forcing associated with the Toba eruption (for a $1 \mathrm{Gt}$ loading of $\mathrm{SO}_{2}$ ). Measurements from Greenland ice cores [16] indicate a significant deposition of Toba sulfate aerosols for about 6 to 7.5 years. The model suggests a significant deposition for only about 3 years. However, this discrepancy is only apparent. Indeed [16] suggests that the longevity of the Toba sulfate loading is probably the result of a series of explosive eruptions that lasted several years (for a total $\mathrm{SO}_{2}$ loading larger than the modeled $1 \mathrm{Gt}$ ), while the model only deals with one episode.

Climate Forcing: The aerosol's absorptivity, emissivity, and transmissivity depend on the product of the absorption coefficient with the aerosol concentration. Different concentrations are associated with different aerosol sizes, while the aerosol's type affects the absorption coefficient.

Aerosol's Optical Properties. Figure 2 shows how the introduction of small amounts of impurities can affect the absorption coefficient for pure sulfate aerosols. In particular, even a tiny amount of soot in the expansion plume, would dramatically change the optical properties of the aerosol layer. The effect is strongest in the visible part of the spectrum, therefore affecting the SW component of the radiation balance, and is negligible in the LW. The net result is a sensible increase in the aerosol's climate forcing. This is particularly important for impact-generated aerosols, where large amounts of mineral particles are entrained in the expansion plume.

Initial Aerosol's Concentration. The amount of aerosols initially injected into the stratosphere depends on the amount of $\mathrm{SO}_{3}$ present in the expansion plume. Experimental studies $[8,16]$ suggest that about $20 \%$ of the sulfur is released as $\mathrm{SO}_{3}$, and quickly reacts with water vapor in the expansion plume to form $\mathrm{H}_{2} \mathrm{SO}_{4}$. Therefore, the model input consists of $128 \mathrm{Gt}$ of $\mathrm{SO}_{2}$ $\left(80 \times\left(\mathrm{M}_{\mathrm{SO}_{2}} / \mathrm{M}_{\mathrm{S}}\right) \times 0.8\right)$ and $40 \mathrm{Gt}$ of $\mathrm{SO}_{3}$. The initial aerosol concentration strongly affects the magnitude and duration of the climate forcing.

Aerosol's sizes. According to [17] the size of the forcing depends on the area-weighted radius, $R_{a}$, of the aerosols. For $R_{a}<2 \mu$ the net effect at the Earth's surface is negative and cooling occurs. For $R_{a}>2 \mu$ the net effect is positive, suggesting warming. Significant concentrations of the larger sizes, however, are rarely achieved for sulfate aerosols evolving from an initial cloud of water vapor and S-bearing gases. The aerosol model follows the aerosol's growth to a size of about $4 \mu$, but concentrations of aerosols larger than $2 \mu$ in radius are negligible even for Chicxulub-type loading.
Conclusions: Figure 1 shows the climate forcing ( $\triangle F>0$ implies cooling) of the modeled stratospheric loading for a Chicxulub-type impact event. A forcing of about $220 \mathrm{~W} \mathrm{~m}^{-2}$, about one order of magnitude stronger than the Toba volcanic eruption, persists globally for about two years after the impact. For comparison, the climate forcing associated with the largest $\mathrm{CO}_{2}$ injection (for a $100 \mathrm{~km}$ transient crater) modeled by [3] is only around $-2 \mathrm{~W} \mathrm{~m}^{-2}$ (i.e., warming with the adopted convention). Significant aerosol formation, and therefore deposition, occurs for about 5 years. This time interval is shorter by about a factor of two than the estimates of [4]. When compared to the timescale for cooling of the ocean mixed layer, this difference can be important. The results of [4] suggest a major cooling of the mixed ocean layer following the impact, and a long lasting climate change. This study, however, suggests that the climate change associated with the impact was of short duration, followed by a complete recovery of the climate to pre-impact conditions.

References: [1] Toon O.B. et al. (1997) Rev. Geophys. 35, 41. [2] Pierazzo E. et al. (1998) JGR, 103, 28607. [3] Pope K.O. et al. (1997) JGR 102, 21645. [4] Hildebrand A.R. et al. (1991) Geol. 19, 867. [5] Ward P.D. et al. (1995) Geology 23, 873. [6] López-Ramos E. (1975) in The Ocean Basins and Margins Vol. 3 (Nairn-Stehli eds.), 257. [7] Kyte F.T. (1998) Nature 396, 237. [8] Ivanov B.A. et al. (1996) Geol. Soc. Am. Spec. Paper 307, 125. [9] Morgan J. et al. (1997) Nature 390, 472. [10] Pierazzo E. \& Melosh H.J. (1999) Earth Plan. Sci. Lett., 165, 163. [11] Kiehl J.T. et al. (1996) $N C A R T N-420+S T R, 152$ pp. [12] Seinfeld J.H. and Pandis S.N. (1998) Atmospheric Chemistry and Physics (Wiley \& Sons) 1326 pp. [13] Turco R.P. et al. (1979) J. Atmo. Sci., 36, 699. [14] Durda D.D. et al. (1997) LPSC XXVIII, 315. [15] McCormick M.P. et al. (1995) Nature 373, 399. [16] Zielinski G.A. et al. (1996) GRL 23, 837. [17] Gerasimov M.V. et al. (1995) LPSC XXVI, 451. [18] Lacis A. et al. (1992) GRL 19, 1607.
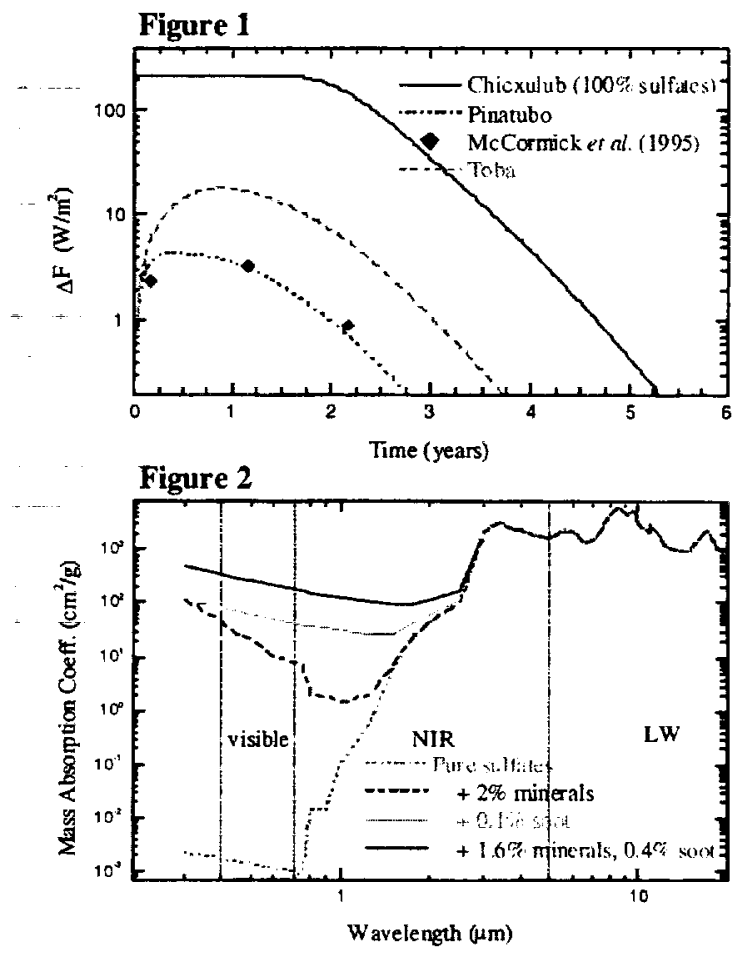


\section{A NEW ${ }^{40} A R^{39}$ AR AGE DETERMINATION ON THE K/T BOUNDARY INTERVAL: POSSIBLE} CONSTRAINTS ON THE TIMING OF THE K/T EVENT AND SEDIMENTATION RATES OF THE K/T SEQUENCE. C. L. Pillmore', and D. P. Miggins ${ }^{2}$, ${ }^{1}$ U.S. Geological Survey, M.S. 913, Box 25046, Denver, CO 80225, cpillmor@usgs.gov, ${ }^{2}$ U.S. Geological Survey, M.S. 963, Box 25046, Denver, CO 80225, dmiggins@usgs.gov.

Cretaceous-Tertiary $(\mathrm{K} / \mathrm{T})$ boundary sites in the Raton basin, Colorado and New Mexico, present a considerable variation in physical appearance, chemistry, and palynology, but they also demonstrate an amazing consistency in that they all contain basic evidence of the terminal Cretaceous asteroid impact: anomalously high concentrations of Ir and the presence of shocked quartz at the palynologically-defined $\mathrm{K} / \mathrm{T}$ boundary $[1,2]$.

Much has been written on the age of the $\mathrm{K} / \mathrm{T}$ boundary asteroid impact at Chicxulub on the northern tip of the Yucatan Peninsula, Mexico [e.g., 3, 4, 5]. An age of $64.6 \pm 0.1 \mathrm{Ma}$ (using a standard age for Fish Canyon Tuff sanidine of $27.55 \pm 0.12 \mathrm{Ma}$ ) for tektite glass resulting from the event has been reported [5], in essence concurring with an earlier age determination [3]. Most recently, this age has been revised to $65.5 \pm$ $0.1 \mathrm{Ma}$, based on the monitor ages of the Taylor Creek Rhyolite at $28.32 \mathrm{Ma}$ and the Fish Canyon Tuff at 28.02 Ma [6].

We have calculated a new minimum age for the $\mathrm{K} / \mathrm{T}$ boundary event on the basis of a high-purity sanidine separate obtained from a kaolinitic tonstein parting that lies in a coal bed beneath the $\mathrm{K} / \mathrm{T}$ boundary. This tonstein was collected at a site in the Canadian River valley west of Raton, New Mexico. The K/T boundary interval is beneath a 1 -m-thick sandstone bed that lies on a thin bed of flaky carbonaceous shale, $0.5 \mathrm{~cm}$ thick. This bed constitutes the fireball layer and contains the peak Ir anomaly of 13.7 ppb (previously unpublished neutron activation analyses by the late Carl Orth). Beneath the fireball layer is the $2-\mathrm{cm}$-thick kaolinitic claystone of the ejecta layer, which contains only $0.3 \mathrm{ppb}$ Ir. It is in direct contact with an underlying carbonaceous shale bed $10 \mathrm{~cm}$ thick that contains $0.45 \mathrm{ppb}$ Ir at the top, receding to values of $0.080 \mathrm{ppb}$ Ir or less in the lower part. Below the shale is a $26-\mathrm{cm}-$ thick bed of coal that contains a $1.5-\mathrm{cm}$-thick bed of tonstein $15 \mathrm{~cm}$ below the top. Tonsteins are considered to result from the alteration of volcanic ash layers in coal swamps. It is from this tonstein bed that we extracted the sanidine separate considered to be of high purity for age determination. The 40Ar/39Ar age determination made on sanidine from this tonstein is $65.45 \pm 0.11$, using a standard age for Fish Canyon Tuff sanidine of $27.84 \mathrm{Ma}$.

The tonstein also occurs $0.5 \mathrm{~km}$ to the southwest where it is contained in the same coal bed, but at this locality the interval between the tonstein and the $\mathrm{K} / \mathrm{T}$ boundary bed has thickened to one meter. We intend to redate sanidine from the tonstein beds at both sites along with tektite glass from Haiti and Mimbral, Mexico using the Fish Canyon tuff monitor. The resulting age determinations should contribute to the ongoing study of the age of the K/T event and contribute to knowledge on the rate of accumulation of coal and rates of deposition of carbonaceous shale and mudstone in the $\mathrm{K} / \mathrm{T}$ boundary sequences in the Raton ba$\sin$.

References: [1] Orth, C. J. et al. (1981) Science 214, 1341-1343. [2] Pillmore, C. L. et al. (1984) Science 223, 1180-1183. [3] Izett, G. A. et al. (1991) Science 252, 1539-1542. [4] Swisher, C. C., III et al. (1992) Science 257, 954-958. [5] Dalrymple, G. B. et al., (1993) USGS Bull. 2065, 20 p. [6] Obradovich, J. D., and Hicks J. F. (1999) Geol. Soc. Amer. Abstracts with Programs 31 (7), A71. 


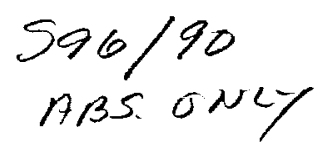

CAN SOHO COMETS BE EARTHCROSSERS? E. M. Pittich, Astronomical Institute, Slovak Academy of Sciences, 84228 Bratislava, Slovak Republic (pittich@savba.sk), N. A. Solovaya, Celestial Mechanics Department, Sternberg State Astronomical Institute, 119899 Moscow, Russia(solov@sai.msu.ru).

The paper presents the results of investigation of dynamical behaviour of 102 known SOHO comets, assuming their orbits to be near-parabolic. Their parabolic orbits derived from the coronographs data covering short near perihelion part of the orbits are not precisely determined and it is possible to make assumption about their near parabolic eccentricities. Sungrazing comets discovered from the Earth with better determined orbits support this idea, too. The equation of motion of these bodies were numerically integrated from the epoch March 25, 1991 forward within the interval of 200,000 years, using a dynamical model of the solar system consisting of all planets.

The long term numerical integrations of the SOHO comets with the near parabolic eccentricities show periodical changes of their eccentricities, inclinations and perihelion distances. These bodies are dynamically stable at least during the investigated interval. Majority of their revolution around the Sun pass within the space behind the Mars orbit. Some of these bodies come periodically to the Earth vicinity and can be candidates for collisions with the Earth.

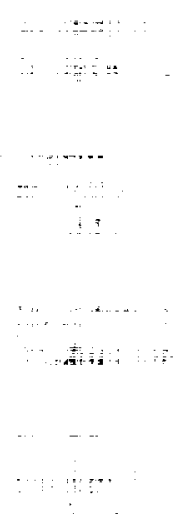


CRETACEOUS/TERTIARY (K/T) PROFILE, RHYTHMIC DEPOSITION AND GEOMAGNETIC POLARITY REVERSALS OF MARINE SEDIMENTS NEAR BJALA, BULGARIA. A. Preisinger', $S$. Aslanian $^{1,2}$, F. Brandstätter', F. Grass ${ }^{4}$, H. Stradner ${ }^{5}$, H. Summesberger. ${ }^{3}$, 'Techn. Univ.of Vienna, Inst. 171, Austria (e-amil:apreisin@mail.zserv.tuwien.ac.at), ${ }^{2}$ Bulg.Acad.Sciences, Varna, Bulgaria, ${ }^{3}$ Natural History Museum, Vienna, Austria, ${ }^{4}$ Atomic Institute of the Austrian Universities, Vienna, Austria, ${ }^{5}$ Geological Survey, Vienna, Austria.

In 1991 the $\mathrm{K} / \mathrm{T}$ boundary was discovered in Bulgaria in marine sediments on the coast of the Black Sea near the city of Bjala, $35 \mathrm{~km}$ south of Varna [1], This K/T boundary section $\left(42^{\circ} 52^{\prime} 40^{\prime \prime} \mathrm{N}\right.$, $27^{\circ} 53^{\prime} 58^{\prime \prime} \mathrm{E}$ ) is located in the Luda Kamchiya tectonic unit, lying between the Balkan chain in the south and the Moesian platform in the north within a distance of about $10000 \mathrm{~km}$ from the impact crater at Chicxulub, Mexico. Rhythmic sedimentation over a vertical range of $100 \mathrm{~m}$ resulted in the deposition of limestone with intercalated marl under hemipelagic conditions from the Late Cretaceous $(\mathrm{C}-30 \mathrm{~m})$ to the Early Paleogene $(\mathrm{T}+70 \mathrm{~m})$. Two hundred limestone beds correspond to precessional Milankovitch cycles of an average duration of $22.5 \mathrm{kyr}$ [2]. An absolute geological time-scale over five million years is obtained from the combination of the numbers of beds with the measured magnetic polarity changes (Chron 29R to Chron 26R). The reference age $(65.0 \mathrm{Myr})$ corresponds to the level of the maximum iridium content in the $\mathrm{K} / \mathrm{T}$ profile $(\mathrm{T}=0)$

The K/T profile reflects 3 different events:

1. "Fallout" is a direct consequence of the $\mathrm{K} / \mathrm{T}$ impact. The "fallout" is characterized by a maximum amount of extraterrestrial iridium and chromium as well as other siderophile elements, $\mathrm{K} / \mathrm{T}$ spinels (nickel rich magnesioferrites with variable chromium contents and iridium inclusions) with etched pits on spinel faces resulting from reaction with sulfuric acid aerosols; small amount of shocked quartzes and feldspars of unmolten material derived from the original impact site.

2. "Boundary clay" is a consequence of the megatsunami. The about $3 \mathrm{~cm}$ thick "boundary clay" is composed of sheet silicates, quartz and feldspar transported mainly from the flooded coastal area, small amounts of $\mathrm{Mg}$-calcite crystals, framboidal iron sulfides, as well as surviving nannoplankton like Thoracosphera operculata.

3. "Reworked sediments" are a consequence of the sea level changes. They consist of transported marine sediments, including "fallout" ( $\mathrm{Ir}$ and $\mathrm{Cr}$ ) and reworked Cretaceous fossils.
The process of a geomagnetic polarity reversal is relatively short (5-10 kyrs) compared with the constant polarity intervals between the reversals (2001200 kyrs). The polarity reversals show $\mathrm{CaCO}_{3}$ minima of the limestone beds and maxima of magnetic susceptibility [3]. In addition to magnetic minerals ferrimagnetic spinels composed of Ni-rich magnesioferrites with high $\mathrm{Cr}$-contents were found at the polarity reversals These spinels are similar in their composition to the cosmic $\mathrm{K} / \mathrm{T}$ spinels of the Cretaceous/Tertiary impact at Chicxulub but without etch pits on the octahedral faces of the crystals.

It is known that the intensity of the Earth's magnetic field decreases significantly during polarity reversals [4]. Therefore, the screening against cosmic radiation and particles is reduced. The magnesioferrites of the polarity reversal zones indicate a correlation between the weak Earth's magnetic field and a high influx of cosmic particles during the polarity reversals. The higher influx of cosmic particles could have caused a higher mutation rate of organisms. Therefore, the polarity reversals could have enhanced the evolution of new species. At the $\mathrm{K} / \mathrm{T}$ boundary of Bjala only 6 nannoplankton genera and 3 out of 15 genera of planktonic foraminifera survived.

References: [1] Preisinger, A. et al. (1993) Palaeogeogr., Palaeoclimat., Palaeoecol., 104, 219229. [2] Preisinger, A.\& Aslanian, S. (1999) LPS $X X X, 1660$. [3] Preisinger, A. et al. (2000) LPS XXXI. [4] Glatzmaier, G.A.\& Roberts, P.H.(1995) Nature, 377, 203-209. 
BIOSPHERIC TRAUMAS CAUSED BY GREAT IMPACTS. Ronald G. Prinn, Massachusetts Institute of Technology, Building 54-1312, 77 Massachusetts Avenue, Cambridge, MA 02139-4307, rprinn@ @it.edu

\section{INVITED PAPER}

Introduction: Impacts of large bolides on Earth over geologic time were one of a number of episodic regional- to global-scale traumas experienced by the Earth's evolving biosphere. Depending on the oxidation state (e.g. C/O ratio) of the atmosphere, shockheating of air during a collision produces copious amounts of chemically and biologically important trace gases (e.g. $\mathrm{HCN}$ when $\mathrm{C} / \mathrm{O}>1$; $\mathrm{NO}$ (then $\mathrm{NO}_{2}$ and $\mathrm{HNO}_{3}$ ) when $\mathrm{C} / \mathrm{O}<1$ ). This input can be augmented by gases evading from the shocked target rock (e.g. $\mathrm{SO}_{x}$ from $\mathrm{CaSO}_{4}$ ); and from shock-initiated wildfires and hydrate $\mathrm{CH}_{4}$ releases. The resultant combination of acid rain, soot, ash, and the ejecta dust cloud would have had a major impact on the biosphere in an oxygen-rich atmosphere. The potential biospheric traumas include inhibition of photosynthesis, foliage damage, respiratory damage, toxicosis by trace metals, acidification of the oceanic mixed layer, $\mathrm{CO}_{2}$ exhalation, and annihilation of carbonate-shelled organisms. Possible relics in the sedimentary record include selective extinctions in the mixed layer, terrestrial biosphere, and neritic zone, nitrate and sulfate anomalies, dissolution of normally insoluble metals, and disruption of the global carbon cycle. In contrast $\mathrm{HCN}$ production by collisions in an earlier reducing atmosphere may have enabled complex organic syntheses to occur.

\section{References:}

[1] Prinn, R. and B. Fegley, (1987) Bolide impacts, acid rain, and biospheric traumas at the Cretaceous-Tertiary boundary, Earth Planet. Sci. Lett., 83, $1-15$.

(2) Fegley, F. and R. Prinn, (2000) Chemical reprocessing of the earth's present and primordial atmosphere by large impacts. In The Barringer Lec. tures, in press. 
KNOWN AND UNKNOWN METEORITE IMPACT EVENTS, AS RECORDED IN THE EPICONTINENTAL LOWER PALAEOZOIC SEDIMENTARY SEQUENCE OF THE BALTIC REGION. V. Puura ${ }^{1}$, L. Ainsaar', M. Eriksson $^{2}$, T. Flodén ${ }^{2}$, K. Kirsimäe ${ }^{1}$, A. Kleesment ${ }^{3}$, M. Konsa ${ }^{3} \&$ K. Suuroja ${ }^{4},{ }^{1}$ Institute of Geology, University of Tartu, Vanemuise 46, 51014 Tartu, Estonia, e-mails: Väino.Puura puura@ut.ee; Kalle.Kirsimäe arps@ut.ee, ${ }^{2}$ Department of Geology and Geochemistry, Stockholm University, 10691 Stockholm, Sweden, e-mails: Tom.Flodén tom@geo.su.se, ${ }^{3}$ Institute of Geology at Tallinn Technical University, Estonia Ave 7, 10143 Tallinn, Estonia, e-mails: Anne.Kleesment kleesmen@gi.ee, Mare.Konsa mare@gi.ee, ${ }^{4}$ Geological Survey of Estonia, Kadaka Ave 80/82, 12618 Tallinn, Estonia, email: Kalle.Suuroja k.suuroja @egk.ee.

In ancient sedimentary deposits, the survival of impactrelated cosmic material with different characteristic signatures depends on the rate of diagenetic and metamorphic changes. In the Baltic Palaeozoic sedimentary basin, and especially in its northern part, the deposits have never been loaded under a cover more than $1 \mathrm{~km}$ thick. The groundwaters that have percolated the sedimentary sequence have been of considerably unaggressive nature. Thus, the mineralogical and geochemical evidences of past impacts, namely their signatures in the sediments, have survived remarkably well. However, the Palaeozoic sedimentary sequence of the Baltic region is dissected by a number of sedimentary breaks and erosional unconformities. Impacts during those intermedia might by recorded by some secondary signatures only.

The variety of signatures caused by impacts of nebular bodies into the regional environment of the Baltic Early Palaeozoic sedimentary basin is considerably large (Fig. 1).

Cosmic material has been found in the form of small meteorites, small particles and spherules, and as an admixture of indicative Platina-Group-Elements (PGE) in cosmic material and impacted target rocks (Fig 1, column I).

Structural forms in layered formations caused by, or related to, impacts are craters but also surrounding and distant impact deformations (Fig. 1, column II). The deformations consist of faults, folds, fractures, and mainly clastic sedimentary and injection dikes. Specific sharp asperities in the seafloor depositional environment, namely anticlines, synclines, flexures, homoclines etc., may also be attributed to impact events.

Due to impact-related modifications of the depositional environment, specific facies zonations, which resulted in local sedimentary breaks and the erosion of pre-existing layers, occurred around the crater sites (Fig. 1 , column III).

Post-impact compaction of the secular crater sediments caused synclinal downwarping of the respective layers (Fig. 1, column IV). Compaction of the impact-deformed, and impact-rarefactured, formations surrounding the crater caused fracturing and uneven layering of the subsequent post-impact sediments .

Influx of impact ejecta, as well as crater- and ejecta-provenanced material, forms distinctive clasticenriched layers in the sediments surrounding the craters (Fig. 1, column V). Primary impact ejecta is typical for the surroundings of the crater rim. In the distant area, redeposited material derived from the ejecta, and from uplifted crater elements, occurs. Clastic admixtures, mainly sand and gravel, derived from the erosion of crater rims that were subjected to post-impact synsedimentary erosion, may occur in deposits that formed during tens of million years after the impact. Even in the distant areas well sorted sands may form interlayers at different post-impact levels. Findings of impact metamorphic signatures in mineralsof ejected and redeposited material may be highly indicative.

Erosional re-exposition of crater structures after thin burial under sediments may form sources of craterderived clastic sediments (Fig. 1, column VI). Many previously buried craters are re-exposed under the recent sediments at the present earth surface.

Craters, as well as surrounding primary impactinduced, and secondary crater-derived, elements in the sedimentary sequences can be identified or at least indicated using geophysical techniques. Marine seismic profiling, gravity- and magnetic surveys, among other methods, are most informative.

Structures and lithologies out of the ordinary which are found in the sedimentary sequence of a region, as well as other findings which point directly towards suspected impact structures, may be either of primary or of secondary origin. Thus, the dating and nature of these layers would be of a special value for identification of possible events. Research of different impact- and crater-related signatures in a geological sequence mutually enriches the perspectives in finding new craters as well as for the interpretation of the complex environmental consequences of the meteorite explosions and the craters formed by them. At present, the multiple reflection of the Kärdla and Neugrund impacts, and their respective structures in the geological record, is rather well distinguished. On the other side, findings of cosmic material in the Upper Vendian of north-eastern Estonia (the Viru-Roela borehole), in the Lower Cambrian of Ruhnu Island in south-western Estonia (the Ruhnu borehole at $500 \mathrm{~m}$ depth), in the Upper Silurian, Pridolian, in the Baltic Sea southeast of Gotland Island, and other places, may predict the discovery of new impact structures in the region. Recording of specific geophysical signatures may furthermore lead to new discoveries, or deeper structural studies of known impact structures as e.g. the Tvären, Hummeln, Neugrund and Ivar craters. 
Fig. 1. Stratigraphy of lower and middle Palaeozoic in Baltoscandia with extraterrestial flux and influence of it on the sedimentary sequence.

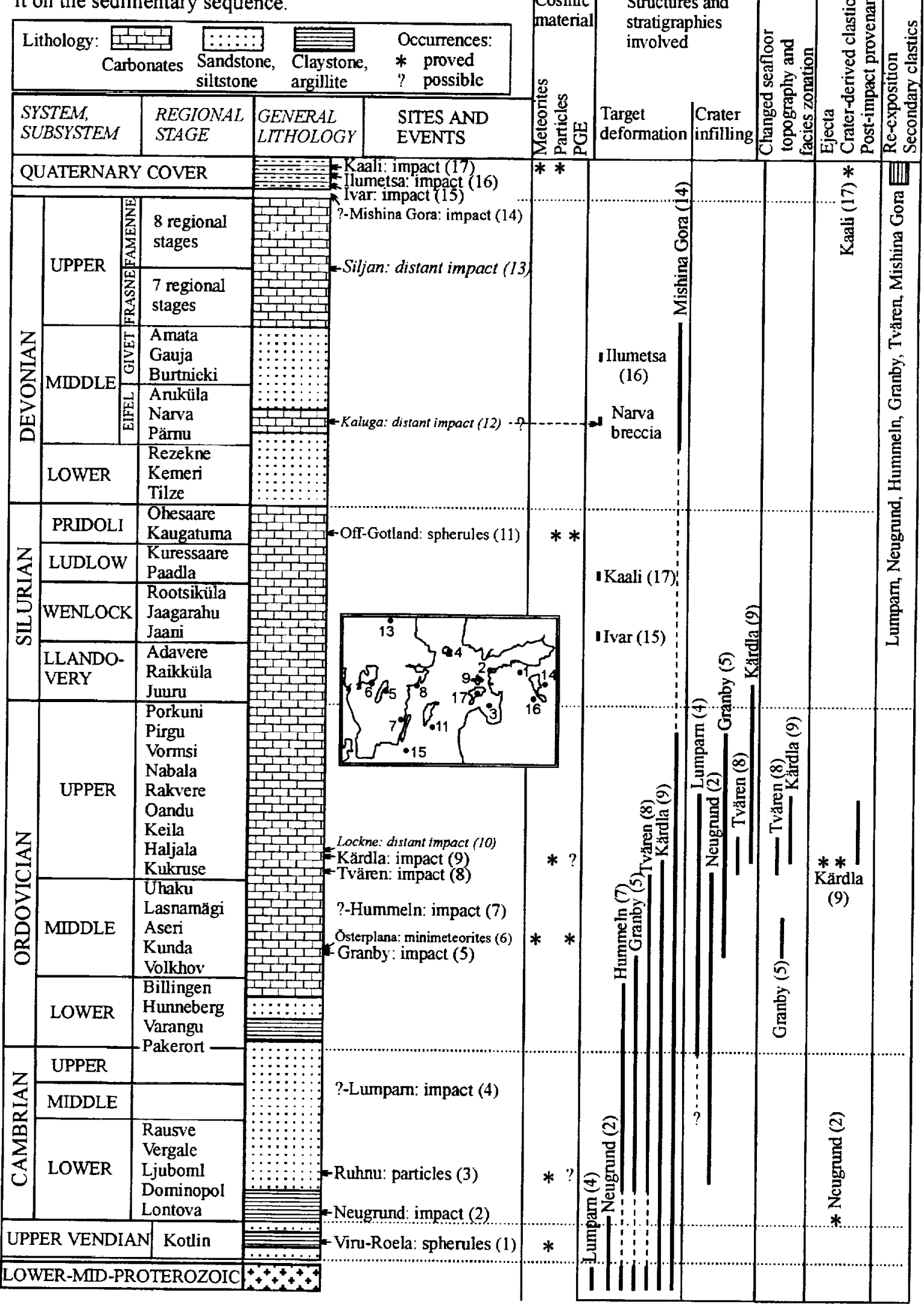


ALTERATION OF CRATER SILICATE ROCKS: EXAMPLES OF DISSIMILAR ENVIRONMENTS FROM KÄRDLA AND MANSON STRUCTURES. V. Puura ${ }^{1}$ A. Kärki ${ }^{2}$, J. Kirs ${ }^{1}, K$. Kirsimäe', A. Kleesment ${ }^{3}$, M. Konsa ${ }^{3}, K$. Suuroja ${ }^{4},{ }^{1}$ Institute of Geology, University of Tartu, Vanemuise 46, 51014 Tartu, Estonia, e-mails: Väino.Puura puura@ut.ee; Juho.Kirs juho@ut.ee, Kalle.Kirsimäe arps@ut.ee, ²Department of Geosciences, Oulu University, P.O Box 333, FIN-90571 Oulu, Finland, e-mail: Aulis.Kärki aulis.karki@oulu.fi, ${ }^{3}$ Institute of Geology at Tallinn Technical University, Estonia Ave 7, 10143 Tallinn, Estonia, e-mails: Anne.Kleesment kleesmen@gi.ee, Mare.Konsa mare@gi.ee, ${ }^{4}$ Geological Survey of Estonia, Kadaka Ave 80/82, 12618 Tallinn, Estonia, e-mail: Kalle.Suuroja k.suuroja@egk.ee.

Impact-induced hydrothermal systems are supposed to cause extensive secondary changes of rocks involved into impact-related evolution. The impact breccias of the carefully studied Manson crater, Iowa, USA (1) offer a good example of a sequence in which hydrothermal minerals gradually fill fractures, vugs and pores along conduits of fluids (2, and others). The Kärdla structure yields an example of environment where extensive metasomatic enrichment of potassium in the country rock took place but almost without any mineral growth in fractures and pores (3). So far, this process is poorly understood. A mineralogicalchemical comparison of Kärdla and Manson rocks (Table 1) gives a possibility to make some constraints in the mineral formation processes.

In both structures, the characteristic impact-induced alterations occurred in rocks derived from the subcrater basement, built up of Precambrian felsic and mafic rocks. During the impact, the basement at both places was covered with vineers of black shale and limestones-sandstones dominated sedimentary deposits under the shallow water environment.

The mineralogical alterations in Manson is interpreted as a result of post-impact hydrothermal system induced by heat stored in the central uplift of the crater during the impact. In Kärdla, there is no evidences of mineralisation (excepted calcite), precipitated from solutions into pores and fissures in breccias and subcrater rocks. Contrary, the macropores in rocks as well as micropores in mineral grains show up dissolution features.

Samples of the basement-derived crystalline clasts and fine-clastic breccia matrix from both allochthonous and autochthonous position of the Kärdla structure were subjected to deatailed investigation. Optical microscopy in thin and polished sections and immersion, XRD, SEM+EDS, FESEM and EPMA studies were used.

In Kärdla, maximum chemical alteration - depletion in $\mathrm{Na}$ and $\mathrm{Ca}$ and enrichment with $\mathrm{K}$, occurs in granitic and amphibolitic clasts from allochthonous tuffitic and parautochthonous shock-metamorphic breccias. Depletion of rocks in $\mathrm{Ca}$ and $\mathrm{Na}$ is in good correlation with the decomposition of plagioclase and hornblende. Also, enrichment in $\mathrm{K}$ associates with the replacement of plagioclase by orthoclase and enrichment in $\mathrm{Mg}$ with the chlorite replacement of hornblende and biotite. For these rocks 1-3 sets of PDF-s in quartz, 1-3 sets PDF-s in K-feldspar and kink-banding of biotite are inherent. The same kind of chemical-mineralogical alterations occur also in the subcrater autochthonous breccias and basement rocks, which are void of shock metamorphic features.

Our preliminary conclusion is, that the major mineral alteration process in Kärdla structure was induced by chemical interactions between impact fluids and hard rocks within the impact cloud (breccia clasts and matrix) as well as in the subcrater basement where the impact fluids were injected to (3). Formation of orthoclase-type K-Fsp characterizes the pneumatolytic stage and formation of chlorite, calcite and smectite-type clay minerals the hydrothermal stage of the process. 
Table 1. Alteration of silicate rock fragments in impact breccias from Kärdla and Manson structures

Kärdla crater, 4 km-wide

Hiiumaa island, Estonia

Puura et al, 2000; new unpublished data
Manson impact structure, 38 km-wide Iowa, USA

Koeberl et al. 1996, McCarville \&Crossey 1996, Short \& Gold 1996

\section{Shock metamorphic features}

Tuffitic breccia. Quartz (Qz): PDF-s (up to 3-4 systems), mosaicism; Microcline (Mi): PDF-s; Biotite (Bi): kinkbanded

Parautochthonous breccias. Bi: kinkbanded Brecciated subcrater basement: No PDF-s nor other features

Suevites. Qz: diaplectic, 3 and more PDF-s sets; Feldspar (Fsp): PDF-s; Lithic and mineral melts

Central Peak Breccias. Qz: "toasting", polygonalization, 2-6 PDF-s sets (commonly decorated); Mi: PDF-s; Plagioclase (PI): separate PDF-s in twinning pairs, isotropization, melting, recrystallization; Micas: kink-banding, Bi degradation into formless mass; Amphibole: shock fracturing, degradation

\section{Features of secondary mineralization (alteration)}

Mainly metasomatic mineral replacement

Pl $\rightarrow$ orthoclase (Or)

$\mathrm{Mi} \rightarrow \mathrm{Or}$, rarely, in breccia matrix

Hornblende $(\mathrm{Hbl}) \rightarrow$ chlorite $(\mathrm{Chl})$

$\mathrm{Bi} \rightarrow \mathrm{Chl}$

In pores of breccia matrix very rare submicroscopic

Or and smectite-type clay minerals.

Fractures, vugs and pores are almost void of macroand microscopic authigenic minerals, cavity walls with traces of dissolution. Calcite cement and veins only in upper part of the tuffitic breccia body.
Autigenic minerals in vugs, pores and veins, minor metasomatic replacement

Garnet, ferroactinolite, prehnite, epidote, wollastonite, quartz, laumontite, pyrite, calcite, clay minerals, goethite, Ksp (adularia), a.o.

\section{Geochemical changes of rocks bulk composition as a result of alteration}

Enrichment with $\mathrm{K}$ and $\mathrm{Mg}$, depletion of $\mathrm{Na}$ and $\mathrm{Ca} \quad$ No essential changes reported

References: (1)Koeberl C. \& Anderson R.R. 1996. : GSA Spec. Paper 302, 1-468. (2) McCarville P. \& Crossey L. 1996. In: GSA Spec. Paper 302, 347-376. (3) Puura V., Kärki A., Kirs J., Kirsimäe K., Kleesment A., Konsa M., Niin M., Plado J., Suuroja K. \& Suuroja S. 2000 (in press). In:. Impacts and the Early Earth. Springer, manu s 22 pp. (4) Short N.M. \& Gold D.P. 1996. : GSA Spec. Paper 302, 245-264. 
The prime causation of the mid-late Devonian mass extinction near the Frasnian-Famennian (F-F) boundary remains uncertain (McGhee, 1996). The goal of this study was a detailed analysis of geochemical signatures (mostly trace element contents, including REE) across the F-F boundary interval, and their interpretation in terms of environmental processes responsible for the turnover in Late Devonian marine ecosystems. The high-resolution analysis based on three continuous carbonate sequences (Kowala, Plucki, Debnik) in the Holy Cross Mts and Cracow region, belonging to the South Polish-Moravian part of the Laurussian shelf (Racki, 1998). The inorganic geochemical data supplement previous studies of isotopic signatures (Halas et al., 1992; Joachimski et al., in press)

Firm evidence of an extraterrestrial impact has not been found. Among terrestrial factors, the main role in the South Polish shelf habitats is ascribed to fluctuating anoxia and/or productivity, best recorded in a radiolariansponge acme (Racki, 1999a). However, the key F-F boundary interval was marked by improving oxygen conditions of near-bottom waters and increased biological production, as indicated earlier for other Laurussian shelves (Schindler, 1990; Bratton et al., 1999). Geochemical and mineralogical evidences for episodic volcanic and/or hydrothermal influences have been provided. Therefore, catastrophic eutrophication, probably stimulated by various hydrothermal and volcanic phenomena (see Bai et al., 1994; Racki, 1998), should be seen as one of the major biogeochemical processes during the Late Devonian biotic crisis.

In general terms, sedimentological (mega-tsunami), physical (craters, microtektites), and geochemicalmineralogical records remain either elusive in many aspects, or incompatible with the predicted F-F impact crisis pattern. The available evidence is still in contrast to the well-documented early Frasnian Alamo extraterrestrial event (see discussion in Racki, 1999b). Thus, the underestimated role of early Variscan tectonism [?related to episodic (super)plume activity], as possible prime controls of many F-F aspects, is suggested (e.g., Wilson \& Lyashkevich, 1996; Racki, 1998). Tectonically triggered changes climaxed in thermal and nutrification pulses, and induced the stepdown destabilization of the ocean-atmosphere system observed in the F-F bio-crisis. In particular, the worldwide biosiliceous signal is mostly explained by a large-scale increase in volcano-hydrothermal activity during major plateboundary re-arrangements; siliceous communities, adapted to more eutrophic conditions, have thrived in the stressed niches (Racki, 1999a). Minor cometary strike(s) might have eventually participated in this prolonged multicausal environmental stress, mainly due to additional thermal shocks, but perhaps effective on a regional scale only.

\section{REFERENCES}

Bai, S.L., Bai, Z.Q., Ma, X.P., Wang, D.R., Sun, Y.L., 1994. Devonian Events and Biostratigraphy of South China. Peking Univ. Press, Pekin, 303 p.

Bratton, J.F., Berry, W.B.N., Morrow, J.R., 1999. Anoxia pre-dates Frasnian-Famennian boundary mass extinction horizon in the Great Basin, USA. Palaeogeogr. Palaeoclimatol. Palaeoecol. 154, 275-292.

Halas, S., Balinski, A., Gruszczynski, M. ., Hoffman, A., Malkowski, K., Narkiewicz, M., 1992. Stable isotope record at the Frasnian/Famennian boundary in southern Poland. N. Jb. Geol. Paläont. Mh. 3, 129-138.

Joachimski, M.M., Ostertag-Henning, C., Pancost, R.D., Strauss, H., Freeman, K.H., Littke, R., Damsté, J.S., Racki, G., in pres. Water column anoxia, enhanced productivity and concomitant changes in $\delta^{13} \mathrm{C}$ and $\delta^{34} \mathrm{~S}$ across the FrasnianFamennian boundary (Kowala-Holy Cross Mountains/Poland). Chem. Geol.

McGhee, G.R., 1996. The Late Devonian Mass Extinction: The Frasnian/Famennian Crisis. Columbia Univ. Press, New York, $303 \mathrm{p}$.

Racki, G., 1998. Frasnian-Famennian biotic crisis: undervalued tectonic control? Palaeogeogr., Palaeoclimatol., Palaeoecol. 141, 177-198.

Racki, G., 1999a. Silica-secreting biota and mass extinctions: survival patterns and processes Palaeogeogr., Palaeoclimatol., Palaeoecol. 154, 107-132.

Racki, G., 1999b. The Frasnian-Famennian biotic crisis: how many (if any) bolide impacts? Geol. Rundsch. 87 (4), $617-$ 632.

Schindler, E., 1990. The Late Frasnian (Upper Devonian) Kellwasser Crisis. In: Kauffman, E.G., Walliser, O.H. (eds.), Extinction Events in Earth History. Springer, Berlin, p. 151-159.

Wilson, M., Lyashkevich, Z.M., 1996. Magmatism and the geodynamics of rifting of the Pripyat-Dnieper-Donets rift, East European Platform. Tectonophysics 268, 65-81. 
PERIODIC COMET SHOWERS, MASS EXTINCTIONS, AND THE GALAXY. M.R. Rampino ${ }^{1,2}$ and R.B. Stothers ${ }^{2}$, 'Earth \& Environmental Science Program, New York University, 100 Washington Square East, New York, NY, 10003 USA (mrr1@nyu.edu). ${ }^{2}$ NASA, Goddard Institute for Space Studies, 2880 Broadway, New York, NY, 10025 USA

Geologic data on mass extinctions of life and evidence of large impacts on the Earth are thus far consistent with a quasi-periodic modulation of the flux of Oort cloud comets. Impacts of large comets and asteroids are capable of causing mass extinction of species, and the records of large impact craters and mass extinctions show a correlation. Impacts and extinctions display periods in the range of $-31 \pm 5$ m.y., depending on dating methods, published time scales, length of record, and number of events analyzed. Statistical studies show that observed differences in the formal periodicity of extinctions and craters are to be expected, taking into consideration problems in dating and the likelihood that both records would be mixtures of periodic and random events.

These results could be explained by quasi-periodic showers of Oort Cloud comets with a similar cycle. The best candidate for a pacemaker for comet showers is the Sun's vertical oscillation through the plane of the Galaxy (Fig. 2), with a $1 / 2$-period over the last 250 million years in the same range. We originally suggested that the probability of encounters with molecular clouds that could perturb the Oort comet cloud and cause comet showers is modulated by the Sun's vertical motion through the galactic disk (1). Tidal forces produced by the overall gravitational field of the Galaxy can also cause perturbations of cometary orbits. Since these forces vary with the changing position of the solar system in the Galaxy, they provide a mechanism for the periodic variation in the flux of Oort cloud comets into the inner solar system (2). The cycle time and degree of modulation depend critically on the mass distribution in the galactic disk.

The time between plane crossings (the half-period of vertical oscillations) is given by:

$$
\mathrm{P}_{1 / 2}=(\pi / 4 \mathrm{G} \rho)^{1 / 2}
$$

Where $\rho$ is the mean volume density of matter near the galactic plane. Stothers (3) estimated a total of $\sim 0.15$ $\mathrm{M}_{\mathrm{Opc}}{ }^{-3}$; since the density of the known visible matter in the plane is only $\sim 0.10 \mathrm{M}_{\mathrm{oPc}}{ }^{-3}$, the result implies $\sim 30 \%$ dark matter (probably cold interstellar clouds). This gives a half-period of $34 \pm 3$ m.y.; more extreme estimates of dark matter lead to half-periods as short as 27 to $28 \mathrm{~m}$.y. [3]. The three most severe mass extinctions (Late Ordovician, $\sim 435 \mathrm{Myr}$; Late Permian, $\sim 250$ Myr; and Late Cretaceous, $65 \mathrm{Myr}$ ) are separated by $\sim 180 \mathrm{~m} . y$. The solar system also undergoes a revolution cycle with a period of $\sim 170 \pm 10$ m.y., from perigalactic to apogalactic position, and this cycle might also modulate the flux of Oort cloud comets.

Thus, major evolutionary changes in the history of life on the Earth may be related to simple galactic dynamics; the name Shiva Hypothesis has been applied to the galactic comet shower hypothesis in reference to the Hindu deity of cyclical destruction and renewal (4). Discovery and accurate age-dating of large impact craters, and better determination of the dark-matter component of galactic disk mass should help to clarify and refine both the expected astronomical cycle times and the periodicities detectable in the geologic record. The results could be a new synthesis of astrophysics and the earth sciences.

References: [1] Rampino M.R. and Stothers R.B. (1984) Nature, 308,709-712. [2] Matese J.J. et al. (1995) Icarus, 116, 255-268. [3] Stothers R.B. (1998) Monthly Not. Royal Astron. Soc, 300, 1098-1104. [4] Rampino M.R. and Haggerty, B.M. (1996) Earth, Moon \& Planets, 72, 441-460. 


\begin{abstract}
ABRUPT CHANGES AT THE PERMIAN/TRIASSIC BOUNDARY: TEMPO OF EVENTS FROM HIGH-RESOLUTION CYCLOSTRATIGRAPHY. M.R. Rampino', A. Prokoph ${ }^{2}$ and A.C. Adler $^{3}$, 'Earth \& Environmental Science Program, New York University, New York, NY 10003 USA, and NASA, Goddard Institute for Space Studies, New York, NY 10025 USA, (mrr1@is3.nyu.edu), ${ }^{2}$ Dept. of Earth Sciences, University of Ottawa, 365 Nicholas St., Ottawa, Ontario, K1N 6N5, Canada, ${ }^{3}$ Dept. of Physics, New York University, New York, NY 10003 USA
\end{abstract}

The Permian/Triassic (P/Tr) boundary $(251.4 \pm 0.3 \mathrm{Myr})$ is marked by the most severe mass extinction in the geologic record [1]. Recently, precise absolute dating has bracketed the marine extinctions and associated carbon-isotope anomaly within <1 Myr [2]. We improve this resolution through high-resolution stratigraphy across the P/Tr boundary in the 331-m Gartnerkofel-1 core and nearby Reppwand outcrop section (Carnic Alps, Austria) utilizing FFT and wavelet timeseries analyses of cyclic components in down-hole core logs of density and natural gamma-ray intensity, and carbon-isotopic ratios of bulk samples.

The wavelet analysis indicates continuity of deposition across the P/Tr boundary interval, and the timeseries analyses show evidence for persistent cycles in the ratio of $\sim 40: 10: 4.7: 2.3$ meters, correlated with Milankovitch-band orbital cycles of $\sim 412$ : 100: 40: 20 kyr (eccentricity 1 and 2 , obliquity, and precession), and giving a consistent average sedimentation rate of $-10 \mathrm{~cm} / 1,000 \mathrm{yr}$.

Milankovitch periods in $\delta^{13} \mathrm{C}$ and density in these shallow-water carbonates were most likely the result of climatically induced oscillations of sea level and climate, coupled with changes in ocean circulation and productivity, that affected sedimentation. Fluctuations in gamma radiation reflect varying input of clay minerals and the presence of shaly interbeds. Throughout the $\mathrm{P} / \mathrm{Tr}$ boundary interval in the core, the 100,000 -year eccentricity cycle seems to be dominant. Weaker obliquity and precession cycles are in line with the location of the Austrian section in the latest Permian, close to the Equator in the western bight of the Tethys, where obliquity and precessional effects on seasonal contrast might be subdued.

Using the improved resolution provided by cycle analysis in the GK-1 core, we find that the dramatic change in the faunal record that marks the P/Tr boundary takes place over $\leq 6 \mathrm{~m}$, or less than 60,000 years. In the nearby Reppwand outcrop section, the same faunal changes occurs over only $0.8 \mathrm{~m}$ or about 8,000 years, close to the limit of time-resolution induced by bioturbation and reworking in these sediments. The sharp negative global carbon-isotope shift took place within $\leq 40,000 \mathrm{yr}$, and the isotope excursions persisted for $\sim 480,000 \mathrm{yr}$ into the Early Triassic.
The results indicate that the severe marine faunal event that marks the $P / T r$ boundary was very sudden, perhaps less than the resolution window in the GK-1 core, and suggest a catastrophic cause [3]. The wavelet-analysis approach to high-resolution cyclostratigraphy can be applied to other $\mathrm{P} / \mathrm{Tr}$ boundary sections, and when combined with precise absolute dating and magnetostratigraphic methods promises a significant increase in resolution in determining the correlation and tempo of the end-Permian extinctions and related events worldwide.

References: [1] Erwin D.A. (1993) The Great Paleozoic Crisis (Columbia Univ. Press, New York). [2] Bowring S.A. et al. (1998) Science, 280, 1039-1045. [3] Rampino M.R. and Adler, A.C. (1998) Geology, 26, 415-418. 


\section{IMPACT EVENTS IN ESTONIA AND THEIR POSSIBLE ENVIRONMENTAL CONSEQUENCES. Anto Raukas, Institute of Geology at Tallinn Technical University, 7 Estonia Avenue Tallinn 10143, Estonia Phone +372-6454659 Fax +372-6312074 Mail: Raukas@gi.ee}

The first scientifically registered meteorite fall in Estonia was on July 4, 1821, when a stony meteorite as large as a man's head fell to the earth near the village of Kaiavere (Fig.). Since then, several meteorites and meteorite falls (in $1855,1863,1872$, etc.) have been recorded.

Up to now, Kaali and Ilumetsa groups of craters and four single forms - Kärdla, Tsõõrikmäe, Simuna and Neugrund with a total of 15 depressions have been distinguished in Estonia. A giant meteorite crater of Kärdla on the Island of Hiiumaa, $4 \mathrm{~km}$ in diameter and $400 \mathrm{~m}$ in depth, was formed in the middle of the Ordovician, approximately $455 \mathrm{Ma}$ ago and is buried under Ordovician sediments.

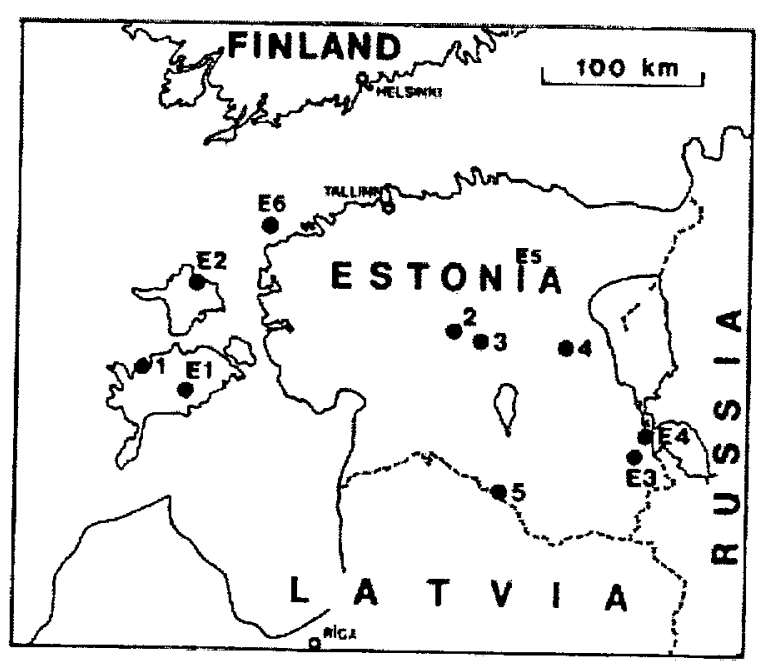

Distribution of impact craters and meteorite falls in Estonia. I - Craters: E1 - Kaali; E2 Kärdla; E3 - Ilumetsa; E4 - Tsõõrikmäe; E5 Simuna; E6 - Neugrund. II - Meteorite falls: 1 - Kaande (Oesel); 2 - Tännasilma; 3 - Pilistvere; 4 - Kaiavere; 5 - Iigaste.

The Neugrund crater, about $5 \mathrm{~km}$ in diameter, is located between the islands of Osmussaar and Suur-Pakri and is about $474 \mathrm{Ma}$ old. The environmental consequences of Kärdla and Neugrund impacts have not yet been precisely studied, but can only be guessed drawing comparisons with analogous structures in other regions.

Nine hollows of Holocene age have been registered at Kaali and five at Ilumetsa. The biggest craters are the Kaali main crater (diameter $110 \mathrm{~m}$, depth $22 \mathrm{~m}$, crater wall 4-7 $\mathrm{m}$ ) and Ilumetsa Põrguhaud (diameter 75-80 m, depth $12.5 \mathrm{~m}$, crater wall several metres). Lennart Meri, President of Estonia and a well-known writer, analysed in 1976 the Kaali catastrophe and concluded, that the striking impression this catastrophic event produced was long preserved in the minds of islanders. Since the appearance of a crater lake and a new landform with uplifted and destroyed dolomite blocks was somewhat mystical and unexpected, people started to use the site as a place of sacrifice. It may well be that tales about the dreadful event passed from generation to generation and it has found reflection even in the Nordic mythology and folklore ("Kalevala", "Edda").

To solve the problem, we should know the age and energy of the impact. According to different authors, the energy needed for the formation of the Kaali main crater must have been up to $10^{19}$ ergs. The initial velocity of the meteorite with an initial mass of $400-10000$ tonnes (most probably about 1000 tonnes upon entering the atmosphere) was 15 to $45 \mathrm{~km} / \mathrm{sec}$. At the time of impact its weight was probably $20-80$ tonnes and velocity $10-20 \mathrm{~km} / \mathrm{sec}$. The meteorite broke into pieces in the air and fell to the earth from NE or SE under an angle of $35-40^{\circ}$.

Based on the archaeological evidence from the burning of ancient strongholds at Asva and Ri- 
dala, and dendrochronological data, archaeologists reached the conclusion that the Kaali meteorite could not have fallen before the turm of the $7^{\text {th }}-8^{\text {th }}$ centuries BC, i.e. about 2600 years ago. In 1961, the idea was supported by the geologist Aaloe. His conclusion was based on the radiocarbon dates obtained on charcoal from the craters $(2530 \pm 130,2660 \pm 200$ and $2920 \pm 240$ years). Based on the results of pollen analyses and radiocarbon dating of peat from the lake bottom, Saarse placed the age of the craters at 3500 to 3900 years. However, it was not certain that the sediments studied originated from the bottom of the section. There is also a general disturbance of sediments in the lake of the main crater caused by the rammed-down timber (for a former pavilion in the middle of the lake) and slumping of sediments. The length of the time interval between the crater formation event and the age of the lowermost radiocarbon-dated sample from the crater lake deposit is also uncertain. In consideration of the above, we reached the conclusion that the craters should be much older than believed earlier.

During our study, detailed geological and geophysical mapping and complex studies of meteorite debris and micrometeorites in the Kaali crater field were carried out, and microimpactites were searched for in surrounding lakes and bogs. In all the four mires studied, microimpactites - mainly glassy spherules formed on the melting and vaporisation of meteoritic matter and target rocks during the impact of crater-producing meteorites - were identified only in one layer dated by palynological and radiocarbon methods at about 7500 years BP. Based on these dates, it may be concluded that the Kaali craters were formed in the Early Atlantic. At that time, the Northern Baltic area was already inhabited and it is conceivable that the large craterproducing meteorite impact, releasing an amount of energy comparable to that of the $\mathrm{Hi}$ - roshima bomb, produced a striking and longlasting impression on people.

Using the same method, we obtained an age of ca. 6600 years BP for Ilumetsa impact in SE Estonia. There are traces of different types of settlements in the vicinity of the Ilumetsa craters, which means that this part of Estonia was inhabited before and after the time of impact. The biggest crater at Ilumetsa is called Põrguhaud (The Hell's Grave). It is difficult to say whether the name is derived from the meteorite fall or from the morphology of the hollow ("leading to the hell"). As a conclusion, it may be said that even medium-size meteorite bodies could induce remarkable environmental consequences (forest fires, etc.) and became fixed in the memories of ancient people. 


\section{SEAWATER ${ }^{187}$ OS $/{ }^{188}$ OS VARIATIONS ACROSS THE CRETACEOUS- TERTIARY BOUNDARY. G. Ravizza, B. Peucker-Ehrenbrink, J. Blusztajn. And R. Norris.}

Although it is well documented by several studies that ${ }^{187} \mathrm{Os} /{ }^{188} \mathrm{Os}$ ratios at the K-T boundary are close to meteoritic values, relatively few Os isotope studies across K-T boundary sections have been conducted (Meisel et al.1995; Peucker Ehrenbrink et al. 1995; Pegram and Turekian 1999). We have measured ${ }^{187} \mathrm{Os} /{ }^{188} \mathrm{Os}$ and platinum group element (PGE) concentrations across DSDP 577 in the western Pacific and DSDP 386 in the Western North Atlantic. The specific objective of our study was to establish in detail the Os isotopic evolution of seawater across the $\mathrm{K}-\mathrm{T}$ boundary. The primary impediments to reconstructing such a record are the ubiquity of impact debris, rich in meteoritic Os, throughout most K-T boundary sections and the potential for diagentic redistribution of this Os during the intervening 65 million years. By concentrating on boundary sections with PGE patterns indicative of a seawater source and by employing selective leaching methods we have largely circumvented these impediments and obtained an coherent record of ${ }^{187} \mathrm{Os} /{ }^{188} \mathrm{Os}$ variations across the K-T boundary. The significant features of the record are summarized below.

The ${ }^{187} \mathrm{Os} /{ }^{188} \mathrm{Os}$ of latest Cretaceous seawater was approximately 0.45 , consistent with the early work of Geissbuhler (1990). The ${ }^{187} \mathrm{Os} /{ }^{188} \mathrm{Os}$ of leachable Os at the K-T boundary ranged from 0.290 at DSDP 386 to 0.167 at DSDP 577 . These values are distinctly higher than meteoritic values and are similar to or more radiogenic than existing Os isotope data from other K-T boundary sections. Simple mixing calculations which assume a chondritic ${ }^{187} \mathrm{Os} /{ }^{188} \mathrm{Os}$ ratio for the impactor and a seawater Os concentration equivalent to present day seawater imply dissolution of all Os supplied by the K-T impactor would shift seawater ${ }^{187} \mathrm{Os} /{ }^{188} \mathrm{Os}$ to approximately 0.136 . The higher ratios determined in this study require significant Os be derived from target rocks and/or incomplete dissolution of meteoritic Os. Complete recovery to pre-impact ${ }^{187} \mathrm{Os} /{ }^{188} \mathrm{Os}$ ratios occurs on the order on 200,000 years or less, consistent with the short marine residence time of Os and limited recycling of meteoritic Os in the surficial environment. These results imply that although much smaller impacts could produce excursions in the marine Os isotope record detecting such excursions would require sampling the sediment record at extremely high temporal resolution. 
PHYSICAL CHARACTERISTICS OF DEPOSITION OF IMPACT BRECCIAS AND PAN-AFRICAN BASEMENT AFFINITIES OF CHICXULUB CRATER. Rebolledo-Vieyra, Mario ${ }^{1,2}$, P. Vera-Sánchez ${ }^{1,3}$, J. Urrutia-Fucugauchi ${ }^{1,4}$, and L. E. Marin ${ }^{1,5}$, 'Instituto de Geofísica, UNAM, Circuito Exterior S/N, Cd. Universitaria, Coyoacán, D.F., 04310, México. ${ }^{2}$ marior@tonatiuh.igeofcu.unam.mx, ${ }^{3}$ pvera@quetzalcoatl.igeofcu.unam.mx, ${ }^{4}$ juf@tonatiuh.igeofcu.unam.mx, , ${ }^{5}$ Imarin@tonatiuh.igeofcu.unam.mx.

Introduction: A scientific drilling program was carried out by the National Autonomous University of Mexico (UNAM) at the Chicxulub impact crater, during 1994 and 1995. Eight boreholes, ranging in depth from $60 \mathrm{~m}$ to $702 \mathrm{~m}$, with a total of $2.62 \mathrm{~km}$ of continuos core, were recovered. The high recovery rate, the average recovery rate is $87 \%$, permits to investigate on the stratigraphy of the impact lithologies and Tertiary carbonate sequence. Three of the boreholes (UNAM-5, UNAM-6 and UNAM-7) sampled the impact breccias that were classified in two units, the upper breccia sequence rich in basement clasts, impact glass and fragments of melt (suevite-like breccia) and the lower breccia sequence rich in carbonate and evaporite clasts (bunte-like breccia). The rest of the boreholes only sampled part of the Tertiary lithologies, composed, mainly of carbonate, dolomitized carbonates and calcarenite, with some fossiliferous horizons.

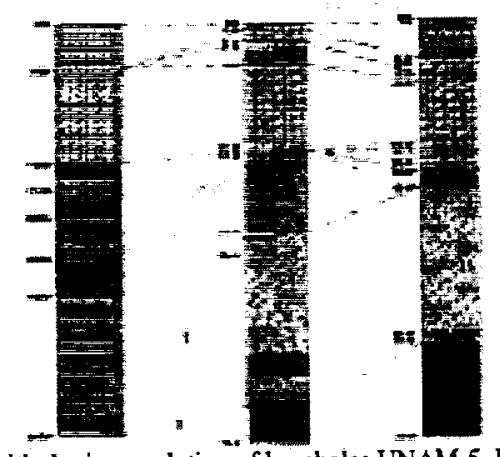

Figure 1.- Lithologic correlation of boreholes UNAM-5, UNAM-7 and UNAM-6. Main correlating units are the impacts breccias.

Investigations on the behavior of the magnetic susceptibility within the impact breccias sampled by UNAM's boreholes, UNAM-5, UNAM-6 and UNAM-7 (fig.- 2), revealed that the spatial arrange of the magnetic minerals within the upper breccia unit (suevite-like) in the Chicxulub crater, are sorted, susceptibility values increase towards the base. The investigations also revealed the absence of the upper breccia unit within borehole UNAM-6. The fractal behavior of the magnetic susceptibility, show scale invariant or self-similar properties, with a power spectrum proportional to the 1.6 power, for UNAM-5, and -1.1 power, for UNAM-7, of the spatial frequency (fig.-3).

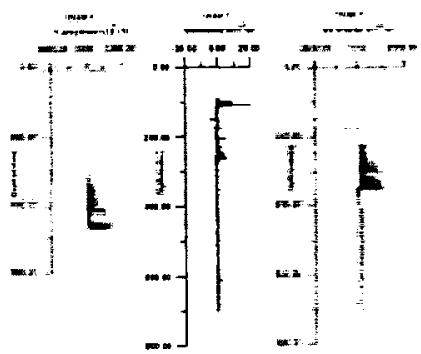

Figure 2.- Susceptibility record of UNAM-5, UNAM-7 and UNAM-6. Data taken every $10 \mathrm{~cm}$. Susceptibiliy units are $10^{-6} \mathrm{SI}$

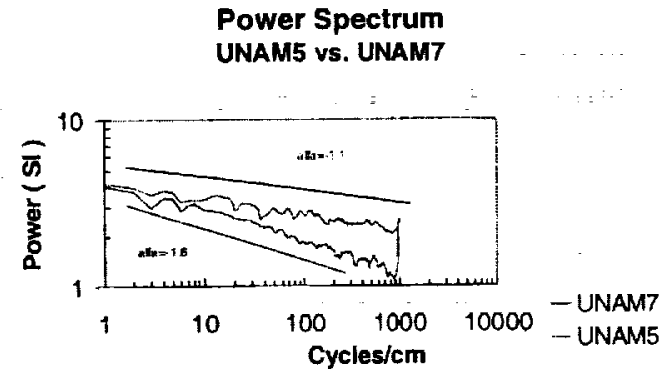

Figure 3.- Power spectrum of boreholes UNAM-5 and UNAM-7, lines showed for slope comparison. Power is $\mathrm{SI}^{2}$.

Geochemistry. The petrologic and tectonic nature of the basement of the Yucatan Block [10], can be inferred from major and trace element chemistry of granitic (14) and extrusive (4) samples which come from the Maya Mountains $[4,7,17]$, and ten samples from the UNAM 7 well [20]. Five of the samples correspond to granites and five correspond to extrusive samples. They come from a depth of $226.99-341.83 \mathrm{~m}$ in the suevitic-like portion of the impact breccia. The ages from the Yucatan samples are $545 \pm 5$ and $418 \pm 6 \mathrm{U}-\mathrm{Pb}$ date from zircons of the suevitic portion of the impact breccia [8], we considered this zircons to be magmatic by their characteristics, according to lithologic nature of the basement of Yucatan, in general we can classified this as granitic-metamorphic $[3,9,16,21]$; and this is also the source of the zircons [8]. So, the youngest age might be associated with the intrusion event at the Maya Mountains and the oldest age with the hosted rock. This last age coincides with the Osceola Granite and St. Lucie metamorphic Complex, both form the Suwannee Terrane Basement at the Florida Peninsula, the paleogeographic models at this time show Yucatan and Florida peninsulas joined. We considered only the granitic rocks, in agreement with the petrographic and normative results, we found that the rocks of Yucatan 
Physical characteristic of impact breccias and basement affinities, Rebolledo-Vieyra, et al.

are granodiorite, quartzmonzonite and granite. The $\mathrm{SiO}_{2}$ ranges are 48.5-67.4, 63.3-73.92 and 74.13-75.8 ppm for Yucatan, LGmMPR and LGbMPR respectively, in agreement [6] this ranges suggest a sub alkaline composition from intermediate to acidic with $\mathrm{K}_{2} \mathrm{O}$ > $\mathrm{Na}_{2} \mathrm{O}$ (Calco - alkaline), agree with the petrographic determinations. With the help of Harker diagrams, we noticed linear trends with smooth and negative slope for: $\mathrm{Al}_{2} \mathrm{O}_{3}, \mathrm{Fe}_{2} \mathrm{O}_{3}, \mathrm{TiO}_{2}$ and $\mathrm{MgO}$; trends not very clear but visible for $\mathrm{MnO}, \mathrm{P}_{2} \mathrm{O}_{5}$ and $\mathrm{CaO}$; but not for $\mathrm{K}_{2} \mathrm{O}$ and $\mathrm{Na}_{2} \mathrm{O}$. We used the same procedure for the trace elements, plotting those vs. $\mathrm{SiO}_{2}$. The Th, $\mathrm{Y}, \mathrm{Hf}, \mathrm{Nb}$ and $\mathrm{Zr}$, graphics show a clear separation into two groups . One group is the LGbMPR [7] with almost constant $\mathrm{SiO}_{2}$ content, but high variation in trace elements than the second group (Yucatan and LGmMPR), this last group has a lager $\mathrm{SiO}_{2}$ range $(48.48-73.92)$ because it has three types of rocks (granodiorite, quartzdiorite and granite), other factor is that the Yucatan samples are altered, the intensity and kind of alteration produced lost of $\mathrm{SiO}_{2}$. Other plot that support this separation is bulk alkali vs. $\mathrm{Y}+\mathrm{Th}+\mathrm{Nb}$, the importance in this case are the trace elements because the differences were produced by petrogenetic process and not by post plutonic emplacement history. The Yucatan samples, show a minor rare earth elements (REE) total contents (16.96116.26) those samples come from Belize (73.11144.09). The $(\mathrm{La} / \mathrm{Lu})^{*}$ ratio is coincident just for three of the four samples of Yucatan (1.06- 5.22) with the Belize samples (5.23-17.9), those differences of slope are attributable to post impact alterations for Yucatan samples, that produced lost of general REE, as well as $\mathrm{SiO}_{2}$ mobilization. Cloritization, seritization and fenitization are the types of alterations in those samples [1, $5]$, this type agree with the post impact hydrothermal alterations $[2,11,12,15,16]$. The Eu anomaly is other parameter modified by alteration process, in Yucatan samples those anomaly is negative but too small $\left(\mathrm{Eu} / \mathrm{Eu}^{*}=0.67-0.98\right)[18]$. The tectonic emplacement environment of the plutonic bodies that conform part of basement, might be inferred from [13], [14], [19]. Diagrams of those authors pointed to syn collisional granites and post collisional. The whole samples (Yucatan and LGmMPR) allow us to establish a clear sequence of emplacements related to a collision event $418 \mathrm{~m}$. y. ago (Late Silurian), period between Taconian and Acadian orogenies.

\section{References}

I. Alderton D. H. M. Perce J. A. and Potts P. J. (1980) Earth and Planetary Science Letters, 49, p. 149-165.

2. Allen, Gooding, Keil. (1982). JGR. Vol. 87. pp 10083 - 10101

3. Bass y Zartman, (1969. Abs (EOS) Trans Act. AGU V. 50 p 313

4. Bateson, J. H. (1972) Over seas memoir 3. Inst. Geol. Sc. Oxford Univ. Press.

5. Humphris S. E. (1984) in Rare Earth elements Geochemistry. edt. Henderson Cap 9, p. 317-342.
6. Irvine $y$ Baragar (1971) Canadial Journal of the Earth Sciences. Vol. 8, p. 523-548.

7. Jackson T. A., Duke M: J. M., Scott P. W. Smith F., Wilkinson F. C. F. (1995). International Geology Review, vol. 37, p. 26-38.

8. Krogh, T. E., Kamo, S. L., Bohor, B. F. (1993) "Nature. Vol. 366. p $731-734$.

9. López-Ramos, E (1975) The Ocean Basins and Margins, Vol. 3, The Golf of Mexico an the Caribbean. V. 3, p. 257-282.

10. Marton y Buffler, (1994) International Geology Review, Vol. 36. p. 545-586.

11. Masaitis V. L. and Naumov M. V. (1993), The Meteoritical Society $56^{\text {th }}$ Annual Meeting Abstract

12. Naumov M. V. (1993) The Meteoritical Society $56^{\text {th }}$ Annual Meeting Abstract

13. Paerce, Harris y Tindle (1984). Journal Petrology, Vol. 25, p 956-983.

14. Paerce, (1996). Episodes. Vol. 19 No. 4. pp 120 - 125

15. Schuraytz B. C. and Sharpton V. L (1993) Nature, vol. 362 p 503-504.

16. Sharpton V. L., Dalrymple G. B., Marín L. E., Ryder G., Schuraytz B. C., Urrutia-Fucugauchi J. (1992). Nature, vol. 359 p 819-821.

17. Steiner, M. B. y Walker, J. D. (1996) Journal of Geophysical Research, Vol. 101, No. B8, p. 17, 727-17,735

18. Taylor (1988). Handbook of rare earth elements. vol. 1

19. Thiéblemont D. et Tégyey M. (1994) Académie des Sciences. p. 87-94.

20. Urrutia - Fucugauchi, Marin, Trejo. (1996). Geofisica Internacional. Vol. 35. No. 2 ppl25 - 133.

21. Vera - Sánchez. (1996). Tesis degree ..Fac. Ingenieria, UNAM. 
EXTRATERRESTRIAL SPINEL IN MARINE SEDIMENTS : AN OVERVIEW. E. Robin, I. Lefevre, and R. Rocchia, Laboratoire C.E.A./C.N.R.S. des Sciences du Climat et de l'Environnement, 91198 Gifsur-Yvette, France, Eric.Robin@lsce.cnrs-gif.fr

Extraterrestrial spinel is a magnetic mineral formed by hypervelocity interaction of meteoroids with the Earth's atmosphere [1]. It is found in melted micrometeorites (the socalled cosmic spherules) [2-5], in the fusion crust of meteorites [6-7] and in various cosmic debris more or less preserved in marine sediments [8-12]. This mineral is distinguishable from terrestrial spinel on the basis of a high Ni content, due to the high abundance of this element in meteorites, and a high fer$\mathrm{ric} /$ ferrous ratio resulting from the crystallization in an $\mathrm{O}_{2}$-rich environment, i.e. the Earth's atmosphere [1, 13-14]. Such chemical characteristics are unknown among volcanic spinels as terrestrial magma are strongly depleted in $\mathrm{Ni}$ relative to meteorites and evolved under relatively low oxygen fugacities. Oxidized Ni-rich spinel is therefore a specific marker of extraterrestrial material and can be used as a tracer of impact events in the sedimentary record.

Previous investigations have shown that this mineral is present in impact debris found associated with iridium and other impact markers in a lower-middle Jurassic hardground $(-180 \mathrm{Ma})$ [8], at the CretaceousTertiary boundary $(-65 \mathrm{Ma})[1,10,13-25]$, and in sediments of late Eocene (-35 Ma) [12, 26], middle Oligocene (-30/-28 Ma) [11, 27], late Pliocene (- 2.4 Ma) [9] and Pleistocene (1.3/-1.1/0.8 Ma) ages [27]. We will present an overview of these various impact horizons showing the different physical and chemical characteristics of Ni-rich spinel and will discuss its potential in the field of impact research in marine sediments.
References: [1] Robin E. et al. (1992) EPSL, 108, 181-190. [2] Blanchard M.B. et al., (1980) EPSL, 46, 178-190. [3] Brownlee D.E. (1981) In: The sea 7, C. Emiliani ed., Wiley N.Y., 733-762. [4] Robin E. (1988), PhD Thesis Univers. Paris XI, Orsay. [5] Koeberl C. and Hagen E.H. (1989) GCA, 53, 937-944. [6] Brownlee D.E. (1975) JGR, 80, 4917-4924. [7] Robin E. et al. (1992) LPSC, 23, 1159-1160 (abstract). [8] Jéhanno C. et al. (1988) Proc. LPSC, 18, 623-630. [9] Margolis S. et al. (1991) Science, 251, 1594-1597. [10] Robin E. (1993) Nature, 363, 615-617. [11] Kyte F.T. and Bostwick J.A. (1995) EPSL, 132, 113-127. [12] Pierrard O. et al. (1998) Geology, 26, 307. [13] Gayraud J. (1995) PhD Thesis, University of Paris XI, Orsay. [14] Gayraud J. et al. (1996) GSA sp. Paper, 307, 425-443. [15] Smit J. and Kyte F.T. (1984) Nature, 310, 403-405. [16] Kyte F.T. and Smit J. (1986) Geology, 14, 485487. [17] Bohor B.F. et al. (1986) EPSL, 81, 57-66. [18] Jéhanno C. et al. (1987) Mém. Soc. Géol. France, 150, 81-94. [19] Bohor B.F. and Foord E.E. (1987) LPS, 18, 101-102 (abs). [20] Robin E. et al. (1991) EPSL, 107, 715-721. [21] Jéhanno C. et al. (1992) EPSL, 109, 229-241. [22] Rocchia R. et al. (1992) Proc. ODP leg 122, 753-762. [23] Kyte F.T. and Bohor B.F. (1995) GCA, 59, 4967-4974. [24] Kyte F.T. et al. (1996) GSA sp. Paper, 307, 389-415. [25] Robin E. and Rocchia R. (1998) Bull. Soc. Géol. France, 169, 365372. [26] Pierrard O. (1999) PhD thesis Univers. Paris XI, Orsay [27] Robin E. et al. (1999) ESF abstract program, Espéraza/Quillan, 61. 
TAPHONOMIC AND PALAEOECOLOGICAL OBSERVATIONS ON THE PEÑALVER FORMATION, WESTERN CUBA. Reinaldo Rojas-Consuegra. Museo Nacional de Historia Natural. Obispo \# 61, Plaza de Armas. La Habana. C.P.10100. Cuba. E-mail: (geopal@mnhnc.inf.cu)

The megabreccia of the Peñalver Formation was characterized by Pszczolkowski (1986) and Iturralde-Vinent (1992) as a calcareous clastic deposits probably related with the KTB impact. Some other suspected KTB sediments have been located in different geological context of Cuba (Iturralde-Vinent et al., 2000). The Peñalver Formation is one of the best studied unit. It is about $200 \mathrm{~m}$ thick carbonate clastic graded deposit, which contain a limited Late Cretaceous paleontological cocktail, sphaerules and lamellar quartz (Takayama et al., in press). The larger amount of reworked microfossils belong to the Campanian-Maastrichtian interval, probably eroded from the Vía Blanca Formation; but also contain older Cretaceous fossils of different ages (Díaz-Otero et al., 2000).

The Peñalver Formation was subdivided in five members (Kiyokawa et al., 1998). The lower member in some places consists in $20-40 \mathrm{~m}$ thick coarse grain-supported deposit, composed by bioclastic calcirudite to breccia, containing large intraclasts from the Cretaceous Cuban Arc. Fragments of rudists and equinoids meanly represent the bioclastic material. More rarely coral fragments, as well as abundant biodetritic limestone lithoclasts. The composition of litho- and bioclasts suggest that the most probably source of these sediments was the shallow water carbonate platform, which covered the extint volcanic arc.

The macrofossils reported for the western region of Cuba are mainly represented by different rudists species (Rojas et al., 1995). Evidently the most part of those specimens were redeposited from the Maastrichtian sediments (Titanosarcolites giganteus, Macgillavryia nicholasi and Praebarrettia porosa), but some of them could be eroded from the volcanoclastic units within volcanic arc and resedimented in the Peñalver formation. Late Campanian-Maastrichtian rudists cover all three palaeoecological morphotypes (Skelton and Gilli, 1991). They lived forming thickets, clusters, associations or individually at the overlapped extinct volcanic arc basins. They occupied different facies of the sedimentary environment; zones of internal lagoons, banks and bioherms at the calcareous platforms, and also colonized the coarse siliciclastic sediments at open basins.

Some species may range from Santonian (?) to Campanian in age (Parastroma sanchezi and ?Praebarrettia corrali). Besides, some other genera which represents Campanian - Maatrichtian age are known from the region (Barrettia; Radiolites; Biradiolites and Tampsia). These fauna are presented by clingers, elevators and recumbents. They lived in associations, clusters and also individually. They widely proliferate at shallow water areas, in the vulcanogenic-sedimentary basins of the mature volcanic arc. From palaeocological point of view, the listed taxa are representing different environments and sedimentary facies. They are indicators of at least four biofacies and the environment that existed on the destroyed overlapped Maastrichtian carbonate platform (F1, F2, F3, F4): 
TAPHONOMIC AND PALAEOCOLOGICAL OBSERVATIONS: R. Rojas-Consuegra

F1 - T. giganteus (recumbent Antilocaprinid) represents highest energetic conditions, situated on very shallow water submittal environment, nearly from emerged lands (Rojas, 1996, 1998), may be on the bypassing zone.

F2 - M. nicholasi (semiclinger! Radiolitid) was an inhabitant of probably high (seasonally) to moderate energy shallow water, on the subtidal environment, situated transitionally to seaward from the $\mathrm{F} 1$, with low deposition of sediment.

F3 - P. porosa (elevator Hippurritid) represents the moderate to low energy environment, but with very high depositional rate. More or less the same situation should be represented by Parastroma and Barrettia genera.

F4 - Any others facies and environments are suggested by the presence of some others Radiolitids: Radiolites, Tampsia and Biradiolites.

In many regions of the Cuban volcanic terrain the carbonate platform is partially preserved, providing very useful palaeogeographical information about the territory that was destroyed by supposed K/T tsunamis. The most western outcrop of Maastrichtian carbonate platform, containing macrobentonic fauna in situ, is at Las Cochinatas town, located some kilometers away from Bahia Honda, in Pinar del Río province. And the most eastern carbonate outcrop belongs to Real Campiña region, in the Cienfuegos province. Both localities are separated for more than $300 \mathrm{~km}$. This fact and previous information, suggests that this was the strongliest hitted (by the K/T sunamis) segment of the Cuban Cretaceous volcanic arc and the Maastritchian carbonate platform that covers it. Is in this region where precisely the Peñalver formation is distributed.

References: 1. Díaz Otero, C.; M. Iturralde-Vinent and D.García Delgado, 2000. (Abstract, this event); 2. Iturralde-Vinent, M.; D. García Delgado, C. Díaz Otero, R. Rojas Consuegra, R. Tada, H. Takayama, S. Kiyokawa, 2000. (Abstract, this event); 3. Iturralde-Vinent, M. 1992. Earth \& Planetary Science Letters, 109: 225-228; 4. Psczczlkowski, A., 1986. Bulletin of the Polish Academy of Earth Science, 34(1): 82-94; 5. Rojas, R., 1996. Proceedings IV International Conference on Rudists. Marcella, Francia.: p.43; 6. Rojas, R., 1998. Geología y Minería, Memorias I (III Congreso de Geología y Minería), La Habana.: 263-266; 7. Rojas, R., M. IturraldeVinent and P. Skelton, 1995. Revista Mexicana de Ciencias Geológicas, 12 (2): 272-291; 8. Takayama, H, Tada, R., Matsui, T., Iturralde-Vinent, M.A., Oji, T., Tajika, E., Kiyokawa, S., García Delgado, D., Okada, H., Hasegawa, T., Toyoda, K., 1999. Sedimentary Geology (submitted); 9. Skelton, P. W. y E. Gilli, 1991. First International Conference on Rudists, October 1988. Proceedings (Ed. M. Sadid - Trifunovic) : 71-86. Serbian Geological Society, Belgrade. 
THE ANCIENT LUNAR IMPACT RECORD, THE ANCIENT TERRESTRIAL IMPACT RECORD, AND POSSIBLE ENVIRONMENTS FOR THE ORIGIN OF LIFE. G. Ryder, Lunar and Planetary Institute, Center for Advanced Space Studies, 3600 Bay Area Boulevard, HOUSTON, TX 77058-1113. [zryder@lpi.usra.edu]

Introduction: Modern concepts for the origin of life most commonly accept continual ocean-evaporating, Earth-sterilizing impact events [1]. This is true even of the latest discussions, e.g., [2]. These sterilizations have a negative effect, while the cargos of impacting of water, carbon compounds, and other chemicals required for life have a positive effect. Sterilizing impacts required large impactors, hundreds of kilometers [3]. In contrast, the valuable cargos were potentially present on any size of impactor.

The large, sterilizing impacts are assumed to have occurred continually from the completion of Earth's essential accretion $\sim 4.5 \mathrm{Ga}$ until $\sim 3.8 \mathrm{Ga}$. This latter age is based on the end of the period of impact basin formation as preserved on the Moon. In the following, I address the nature of the lunar impact record at and before about $3.8 \mathrm{Ga}$, and briefly that of the Earth. More detailed discussions of these records are in $[4,5]$. I suggest that the basin-forming period was short ("the lunar cataclysm") such that older continual sterilizing impacts did not occur or were rare. The basin-forming period quite possibly had a positive, not negative, effect, on the origin of life. While this is speculative, it is no more so than that of scenarios that include continual sterilization events for which there is no record.

The lunar record at $\sim 3.85 \mathrm{Ga}:$ Photogeological mapping shows the presence of numerous ( $>40)$ impact basins on the Moon that precede the age of mare basalt floods (many of which were into those basins) [6,7].

The stratigraphic basin record. The relative stratigraphy and relationships of at least the later of the basins are reasonably understood. Their relationships are established by superposition and by the counting of craters (with careful evaluation of which might be secondaries rather than primaries) on their own basin debris and ejecta blankets. The Orientale basin $(930 \mathrm{~km}$ diameter; for definition of diameters, see [6]), the youngest, is well preserved and its features are the model for comparison for other basins. No extant mare plains predate the Orientale basin (although mare volcanism was active, according to sample data, and cryptomare - blanketed by ejecta - have been inferred). The ejecta of the Orientale basin has crater densities about 3 or $4 x$ higher than those of the oldest mare plains. The Imbrium basin $(1160 \mathrm{~km})$ has crater counts on its ejecta similar to that of Orientale, and the Schrödinger basin $(320 \mathrm{~km})$ event took place in between the formation of the Imbrium and Orientale basins.

The stratigraphically older Nectaris basin $(860 \mathrm{~km})$ ejecta has crater counts about $4 \times$ higher than Imbrium/Orientale ejecta. A dozen basin-forming events took place between those of Imbrium and Nectaris, including Serenitatis $(920 \mathrm{~km})$ and Crisium $(740 \mathrm{~km})$. Thus about $1 / 3$ of the recognized basin forming events occurred after Nectaris; their sizes are as large or larger on average than those older. The stratigraphic age of Serenitatis is least well-defined because it has been badly degraded by being adjacent to Imbrium; it is permissively rather older stratigraphically than most other Nectarian basins, although it is unlikely to be stratigraphically older than Nectaris itself.

The oldest and largest of the pre-Nectarian basins is the far-side South Pole-Aitken basin $(2600 \mathrm{~km})$. It is very degraded, but clearly mappable as a depression $\sim 9$ $\mathrm{km}$ deep. The oldest of these basins, and the interba$\sin /$ crater plains, have crater counts on the order of 3 or $4 \mathrm{x}$ those on Nectaris. No other older basin is as large as the "young" Nectaris, Serenitatis, Imbrium, or Orientale basins.

The absolute age of basins. The Imbrium basin has been bracketed in age using Apollo 15 samples: the superposed Apennine Bench Formation (KREEP volcanics) and the impact melt fragments on the Apennine Front. These latter fragments must mainly pre-date or be contemporaneous with Imbrium. This gives an age of $3.85+/ 0.01 \mathrm{Ga}[8,9]$. consistent with data from the Apollo 14 landing site. Crater counts suggest a similar age for Orientale and Schrödinger, and this is consistent with the oldest mare basalts $(\sim 3.80 \mathrm{Ga})$ and the cratercount difference between these basins and the mare plains. Alternatively, there was virtually NO impacting between the Imbrium $(3.85 \mathrm{Ga})$ and an Orientale event at $3.80 \mathrm{Ga}$ that was immediately followed by a massive impacting and then a precipitous drop before the oldest mare plains were formed. This does not seem to be a reasonable alternative.

The Nectaris event is more difficult to date absolutely. The Apollo 16 mission collected relevant samples, but none absolutely certain to be actual melt from that basin. Geological considerations combined with sample data however suggest that the 3.89-3.91 Ga ages for feldspathic melt material at the site correlate with the age of Nectaris $[6,7,11]$. This is consistent with a well-defined of $3.893+/-0.009 \mathrm{Ga}$ age for the Nectarian basin Serenitatis [12] and a tenuous $\sim 3.9$ Ga for Crisium [13]. Absolute ages for any specific older basins cannot as yet be obtained because of a lack of relevant samples.

The lunar record prior to $\sim 3.9 \mathrm{Ga}$ : Impacts are heating events which reset radiogenic clocks mainly in the impact melt, not in the dominant masses of cooler ejecta. The lunar highland sample collections contain 
samples of impact melt that have diverse compositions but cannot be ascribed to any particular event. However, if the Moon had been subjected to a continuous declining bombardment, impact melts would have been produced. They would only have been removed, or their ages reset, if they were subsequently reconverted to a younger impact melt. Thus, unless most of the Moon's upper crust has been converted to impact melt, most of the highland melt samples should be old, of the order of $4.2 \mathrm{Ga}$ or older.

The lunar crust and the samples collected are dominantly NOT impact melt, and those collected are NOT old. At present we have no evidence for impact melt samples older than $4.2 \mathrm{Ga}$, and even this old is rare. Virtually all samples of impact melt are less than 3.95 $\mathrm{Ga}$. These are not from a single event, such as Imbrium, but from a large variety of events. Thus both the dating of specific basins and the general population of impact melts is strongly consistent with the concept that most of the highlands cratering of the Moon took place after $3.95 \mathrm{Ga}$, and this might well included even the very oldest visible basin. This conclusion is also most consistent with the evident preservation of general crustal stratigraphy and the low abundance of siderophile elements in the crust prior to the $-3.9 \mathrm{Ga}$ additions.

The ancient lunar cratering record: It is evident that the Moon was severely battered during the period from $3.95 \mathrm{Ga}$ to about $3.85 \mathrm{Ga}$. However, the evidence suggests that very little was bombarding the Moon in the period for several hundred million years before that. How intense was this bombardment? From the point of view concerned here, the decline is most important, and the evidence suggests that between 3.90 and $3.85 \mathrm{Ga}$ the flux was a factor of about a 1,000 higher than the average since $3.80 \mathrm{Ga}$. The flux might have dropped precipitously at 3.85 to be almost negligible at $3.83 \mathrm{Ga}$; the Apennine Bench formation is well preserved, though certainly not as well as many mare plains.

The terrestrial record at $\sim 3.85 \mathrm{Ga}$ : Searches of the Earth's oldest sedimentary rocks for signatures of impact has so far turned up negative, e.g. [5]. These possible signatures would include meteoritic siderophiles, sedimentary breccia deposits, and shock features. The rocks in question include the Isua belt as well as the even older Akilia enclaves in Greenland. Some of these have been inferred from cross-cutting relationships of igneous rocks and geochronology of their zircons to have formed before or equal to $3.85 \mathrm{Ga}$. The lack of impact features possibly results from a lack of preservation or from a high rate of deposition (these ancient sediments are dominated by banded iron formations). They equally might result from a lack of impacts. If so, they suggest that the rocks are actually about $3.85 \mathrm{Ga}$ (which is quite likely) and that the rate of impacting declined extremely rapidly from the high lunar Nec- tarian rate to a rate within a few factors of the presentday rate. This is probably the best way to reconcile the lunar and terrestrial records.

Impacts and the origin of life on Earth: The inferred rapid decline of the impacting record of the Earth and Moon from 3.95 to $3.85 \mathrm{Ga}$ is not compatible with a continuous intense impacting of the Moon prior to 3.95 $\mathrm{Ga}$. An extrapolation back in time of such increasingly high rates is not consistent with either the siderophiles in the crust or the size of the Moon. Thus the conclusion to be made is that the Earth was NOT subject to continual sterilizing events from $4.5 \mathrm{Ga}$ to $3.8 \mathrm{Ga}$. The record of around $3.85-3.90 \mathrm{Ga}$ is compatible with a few such events at around that time. However, it is equally possible that the impacting of the Earth-Moon system during this time period was benign, and even the cause of the origin of life on Earth. The Earth's surface may have been too cold prior to that time because of a lack of insolation, and the intense peaked impacting could have been responsible either for a general warming. Alternatively, impacting could have provided specific environments, such as near-surface hydrothermal systems, in craters or even just one specific large basin, conducive to the origin of life. Earth's own internallydriven systems, such as volcanic hydrothermal systems, might have been unsuitable or by themselves inadequate. Such a concept is speculative, but so are those invoking the continual sterilization for which there is no record.

References: [1] Sleep N.H. et al. (1989) Nature, 342, 139-142. [2] Ward P.D. and Brownlee D. (2000) Rare Earth. Copernicus/Springer-Verlag. 333 pp. [3] Zahnle K.J. and Sleep N.H. (1997) In Comets and the Evolution of Life, 175-208. Springer-Verlag. [4] Hartmann W.K. et al. (2000). In Origin of the Earth and Moon. U. Arizona Press. (in press). [5] Ryder G. et al. (2000) In Origin of the Earth and Moon. U. Arizona Press. (in press). [6] Spudis P.D. (1993) The Geology of Multi-ring Basins. Cambridge. 263 pp. [7] Wilhelms D. E. (1987) The Geologic History of the Moon. USGS Prof. Paper 1348, 302 pp. [9] Ryder G. (1994) In Large Meteorite Impacts and Planetary Evolution. GSA Spec. Paper 293, 11-18. [10] Dalrymple G.B. and Ryder G. (1993) J. Geophys. Res., 98, 13085-13095. [11] James O.B. (1981) Proc. Lunar Planet. Sci. Conf., 12B, 209 233. [12] Dalrymple G.B. and Ryder G. (1996) J. Geophys. Res., 101, 26069-26084. [13] Swindle T.D. et al. (1991) Proc. Lunar Planet. Sci. Conf., 21, 167-181. 
POSSIBLE IMPACT ORIGIN OF THE ENIGMATIC EARLY LATE DEVONIAN AMÖNAU BRECCIA, RHEINISCHES SCHIEFERGEBIRGE, GERMANY. C. A. Sandberg ${ }^{1}, \mathrm{~J}$. R. Morrow ${ }^{2}$, and W. Ziegler, ${ }^{1}$ U.S. Geological Survey, Box 25046, MS 939, Federal Center, Denver, CO 80225, U.S.A., sandberg@usgs.gov, ${ }^{2}$ Dept. of Earth Sciences, University of Northern Colorado, Greeley, CO 80639, U.S.A., jrmorro@bentley.unco.edu, and ${ }^{3}$ Forschungsinstitut Senckenberg, D-60325 Frankfurt am Main, Germany, wziegler@sngkw.uni-frankfurt.de.

Introduction: The Amönau Breccia, containing large blocks derived from Devonian reefs mixed with basalt clasts and glass shards and cropping out in two quarries in the village of Amönau, near Wetter, Germany, was originally interpreted to have resulted from "erosional destruction of a reef during a period of volcanic activity" [1]. We restudied this breccia to determine if it had been instantaneously emplaced by a single volcanic explosion, and if so, was the timing of this event the same as that of the Alamo impact breccia, which was emplaced in southern Nevada within the middle part of the punctata Zone [2,3].

Amönau Breccia: Re-collection of conodonts from the Amönau Breccia and adjacent strata confirms its emplacement as an instantaneous event. However, we found that this Amönau Event occurred well before the Alamo Event and within the early Frasnian, late part of the Early falsiovalis Zone, at or close to the first occurrence of Ancyrodella rotundiloba. This timing coincides with a eustatic rise marking the start of the Late Devonian.

Related German localities: At Donsbach, $38 \mathrm{~km}$ WSW of Amönau, a limestone bed below a similar tuff breccia containing atrypid brachiopods was dated by conodonts as Lower asymmetricus Zone (= transitans Zone of current usage) [4]. Our re-study of the original collection shows that this bed and hence the overlying tuff breccia were misdated and are actually slightly older and thus the same age as the Amönau Breccia.

At Blauer Bruch, on the outskirts of Bad Wildungen and $40 \mathrm{~km}$ ENE of Amönau, the only bentonite within a thinly interbedded slope sequence of shales and limestone turbidites has precisely the same conodont dating as the volcaniclastic breccias at Amönau and Donsbach [5]. Thus, the Amönau Event coincides with the onset of volcanism along an ENEtrending transect, $78 \mathrm{~km}$ long, of the Rheinisches Schiefergebirge in central Germany.

Further evidence of the widespread instantaneous onset of volcanism is provided by the classic stratotype section at Martenberg, near Diemelsee and $40 \mathrm{~km} \mathrm{NW}$ of Blauer Bruch. There, in a sequence of hematitic micrites deposited during nearby submarine exhalations, the time of the Amönau Event is represented by a 95 -cm-thick bed of sedimentary hematite, the only thick hematite interbed in the sequence [5].

Conclusions: The Amönau Event is documented not only by volcanic explosions at two localities, $38 \mathrm{~km}$ apart, but also by the simultaneous start of volcanism across a wide expanse of the Rheinisches Schiefergebirge. This coincidence was not recognized previously because of the lack of information due to the scarcity of exposures, except in a few quarries and stream cuts, in this region of predominantly highly weathered slate hills. We are now re-investigating other localities in the region to determine if the Amönau Event was strictly a volcanic event or whether the widespread volcanism might have been triggered by an early Frasnian subcritical, oceanic impact coincident with a eustatic rise.

References: [1] Bender, P., Hühner, G., Kupfahl, H.G. and Voutta, U. (1984) GJH 112, 31-65. [2] Morrow, J. R., Sandberg, C. A. and Ziegler W. (1999) $A W I B P$ 343, 66-69. [3] Morrow, J. R., Sandberg, C. A. and Ziegler W. (1999), GSAAP 31-7, A-64. [4] Krebs, W. and Rabien, A. (1964) NHLAB 92, 75-119. [5] Sandberg, C. A., Ziegler, W. and Bultynck, P. (1989) CFS 110, 195-230.

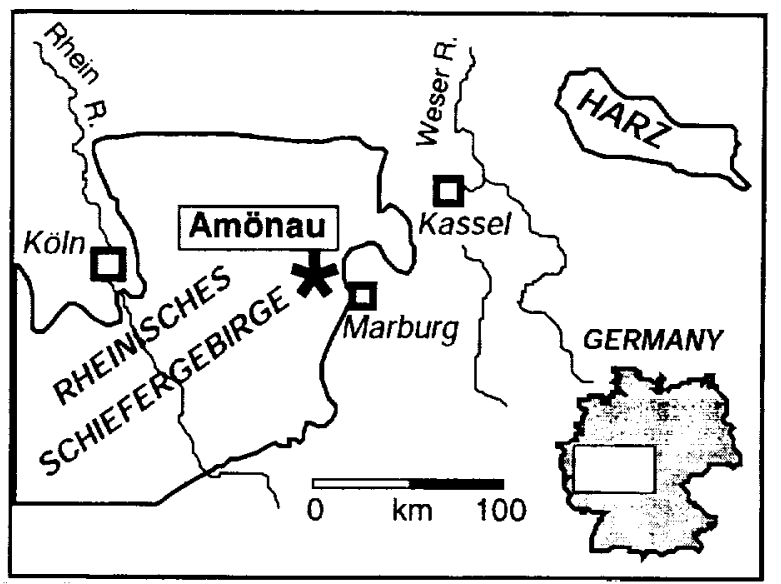




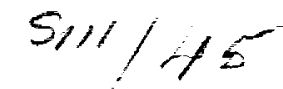

LATE DEVONIAN EVENTS AND MASS EXTINCTIONS. C. A. Sandberg', W. Ziegler', and J. R. Morrow ${ }^{3}$, ${ }^{1}$ U.S. Geological Survey, Box 25046, MS 939, Federal Center, Denver, CO 80225, U.S.A., sandberg@usgs.gov; ${ }^{2}$ Forschungsinstitut Senckenberg, D-60325 Frankfurt am Main, Germany; ${ }^{3}$ Department of Earth Sciences, University of Northem Colorado, Greeley, CO 80639, U.S.A.

Introduction: The Late Devonian Epoch, one of the most intensively studied of all the Paleozoic Epochs, was a time of major sea-level changes, catastrophic events, some of which were impact related, and two mass extinctions, one of which was impact related. These many events are plotted herein against the generally accepted sea-level curve $[1,2]$. Detailed knowledge and dating of Late Devonian events resulted from a high-resolution biochronology, based primarily on conodont zonations, but supported in part by ammonoid, ostracod, and spore zonations. This detailed knowledge was gained by intensive biostratigraphic studies during the past two decades, inspired by the IUGS Subcommission of Devonian Stratigraphy and by IGCP Projects on Bio-Events and Mass Extinctions. Many Late Devonian events produced changes in the environmentally sensitive mudmound levels in Belgium [3].

The initial Late Devonian Stage, the Frasnian, was a time of general transgression during the Taghanic onlap that began in the late Middle Devonian. The final Famennian Stage was a time of general regression, probably due to Southern Hemisphere glaciation, interrupted by four major transgressions, probably related to interglacial episodes. Both the late Frasnian and late Famennian mass extinctions occurred during, not at the start of, rapid regressions that closely followed rapid transgressions. The stepwise late Frasnian mass extinction, one of the five greatest in Earth's history [4], is believed to have occurred as a result of environmental stresses that were related to not just one but to a series of multiple, non-critical impacts. The late Famennian mass extinction, on the other hand, is believed to have occurred at the culmination of stresses produced by alternating glacial and interglacial episodes.

Frasnian: Some Frasnian events are closely related to or even may have produced significant transgressions. The enigmatic Amönau Event, which locally produced a megabreccia, can now be tied to the onset of volcanism across a $75-\mathrm{km}$ transect of the Rheinisches Schiefergebirge in Germany and to a eustatic rise in sea level. It is dated as occurring within the Early falsiovalis conodont Zone at the first occurrence of Ancyrodella rotundiloba, the conodont used to define the start of the Frasnian. We are now trying to determine whether this volcanism resulted from an oceanic impact. The oceanic, subcritical Alamo Impact in southern Nevada is at present the best evidenced Late Devonian impact, even though its crater is now buried or obliterated. Evidence of its $\sim 1.5-\mathrm{km}$-deep crater derives from Middle Ordovician to possibly Late Cambrian conodonts that were blasted from the crater depths and redeposited in the resulting chaotic megabreccia and tsunami-related turbidites [5], along with carbonate impact spherules, shocked-quartz grains, and a locally high iridium concentration $[6,7]$. This impact occurred in the middle of the punctata Zone and coincides with a major transgression and the demise of the first mudmound level in Belgium. Because of the current controversy in methodology for radiometric dating, we are now uncertain whether the Siljan Impact in southern Sweden coincides with the Alamo Impact, with the late Frasnian mass extinction, or was part of an intervening comet shower.

The late Frasnian mass extinction, commonly known as the Kellwasser Event, occurred not at the highstand of transgression [8] but within the regressive part of a thin transgressive-regressive black shale bed. Where well developed, this shale contains a detailed record of several stepped extinctions and introductions of shallow-water biota, culminating in an abiotic layer at its top. Researchers are still trying to locate an impact exactly coincident with this position. Possibly the Siljan Impact was the source of microtektites found within the extinction shale in Belgium. However, it seems more likely that the extinction occurred as a result of a series of sub-critical impacts or comet showers during the Frasnian. This scenario is supported by the stepwise extinction of several animal groups [9] and by the decreasing size and biotic diversity of the first three Belgian mudmound levels.

Famennian: To date, no direct evidence of any impacts has been found in Euramerica during the less turbulent Famennian Stage. A possible, closely postextinction time of impact, however, is within the late part of the earliest Famennian Early triangularis Zone, when normal sedimentation was interrupted globally by deposition of coarse tsunami-related breccias. This event has been attributed, alternatively, to collapse of platform margins during continuing regression [2]. Only one local Famennian mudmound level, the Baelen [10] is known in Belgium, and this lacks the stromatoporoids and corals that were important to Frasnian mudmound construction. The Baelen mudmound was constructed during the later part of the second major Famennian interglacial? transgression. The late Famennian mass extinction, commonly known as the Hangenberg Event, occurred during a severe sea-level drop within the Middle praesulcata Zone, near the end of the Devonian. 
LATE DEVONIAN EVENTS AND MASS EXTINCTIONS. C. A. Sandberg, W. Ziegler, and J. R. Morrow

References: [1] Johnson, J. G., Klapper, G. and Sandberg, C. A. (1985) GSAB 96, 567-587. [2] Sandberg, C. A., Ziegler, W., Dreesen, R. and Butler, J. L. (1988) CFS 102, 263-307. [3] Sandberg, C. A., Ziegler, W., Dreesen, R., and Butler, J. L. (1992) CFS 150, 1-87. [4] McGhee, G. R. (1996) CUP, 1-303. [5] Morrow, J. R., Sandberg, C. A., Warme, J. E. and Kuehner, H.-C. (1998) JBIS
51, 451-460. [6] Warme, J. E. and Sandberg, C. A. (1995) CFS 188, 31-57. [7] Warme, J. E. and Kuehner, H.-C. (1998) IGR 40, 189-216. [8] Hallam, A., and Wignall, P. B. (1999), ESR 48, 217-250. [9] Schindler, E. (1990) GAGP 46, 1-115. [10] Dreesen, R., Bless, M. J. M., Conil, R., Flajs, G. and Laschet, C. (1985) $A S G B$ 108, 311-359.

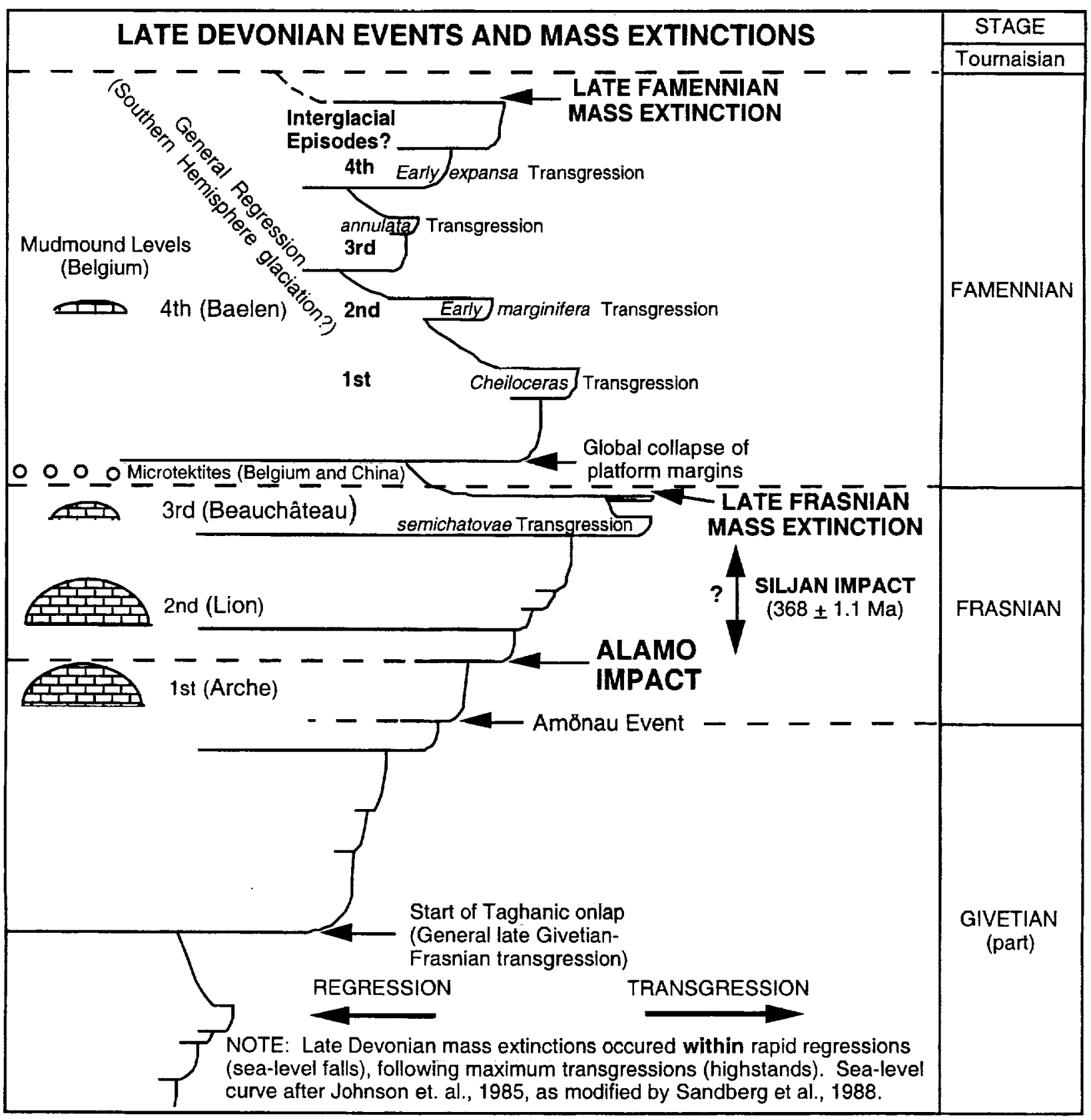


$9 / 2 / 51$

\section{LATE CRETACEOUS THEROPOD DINOSAUR DIVERSITY: LATITUDINAL DIFFERENCES IN NORTH AMERICA AND IMPLICATIONS FOR THE K/T EXTINCTIONS. J.T. Sankey, Museum of Geology, South Dakota School of Mines and Technology, 501 E. Saint Joseph Ave., Rapid City, SD, 57701, U.S.A. Julia.Sankey@ sdsmt.edu}

Although the evidence for an impact at the end of the Cretaceous no longer makes this event controversial, the link between an impact and the terrestrial vertebrate extinctions is still controversial among some paleontologists. The proposed ecosystem collapse as a result of impact does not fit with the selective nature for these extinctions. This paper reports on the differences in theropod dinosaur diversity between southern and northern North America during the last 10 million years of the Cretaceous, and suggests that climatic and environmental changes were important factors in the dinosaur extinctions.

Temperature and rainfall differences along a northsouth latitudinal gradient in the Western Interior of North America resulted in distinct terrestrial faunal and floral provinces during the late Campanian. The "Corythosaurus" dinosaur fauna was from Wyoming to the north and the "Kritosaurus" fauna occurred to the south. These faunas correspond approximately to the Aquillapollenites and Normapolles palynofloral provinces. More temperate and humid climates, with more closed-canopy forests occurred to the north and warm, dry, and non-seasonal climates, with more opencanopy woodlands occurred to the south [1].

Late Cretaceous southern theropods are not as well known, especially from west Texas (Aguja and Javelina Formations, Big Bend National Park), where deposits have received less attention, have less outcrop area, and are generally less fossil-rich. Northern Late Cretaceous theropods are better known, especially from Alberta (Judith River and Edmonton Groups), due to more intense collection, more outcrop area, and richer deposits.

Fossils studied are teeth collected by various workers by screening microvertebrate sites and by surface collecting. Fossils from Alberta are in the Royal Tyrrell Museum of Paleontology (Drumheller, Alberta) and those from Big Bend, at Louisiana State University (Baton Rouge) and University of Texas at Austin. There are only five theropods from Big Bend:

Saurornitholestes, Richardoestesia cf. $\underline{\mathrm{R}}$ gilmorei, Richardoestesia sp. nov., Paronychodon lacustris, and tyrannosaurid $[2,3,4]$. However, there are at more taxa from Albertan deposits, including Troodon,

Dromaeosaurus, "Saurornithoides", and several tyrannosaurids $[5,6,7]$.

Paleoecologically, the Aguja and Javelina (late Campanian to latest Maastrichtian) of Big Bend may have been more similar to the lower Scollard Formation (latest Maastrichtian) of Alberta: both had warm, dry, open environments producing lower theropod diversity and abundance. This connection between climate, environment, and theropod diversity suggests that these factors were important in their extinctions.

\section{References}

[1] Lehman T.M. (1997) Dinofest Intl, Phila. Acad. Nat. Sci., 223-240. [2] Standhardt B. R. (1986) Ph.D. Diss., Louisiana State Univ., 1-298. [3] Rowe T. et al. (1992) J. Vert. Paleo, 12, 472-493. [4] Sankey J.T. (1998) Ph.D. Diss., Louisiana State Univ, 1-263. [5] Currie P. J. et al. (1990) in Dinosaur Systematics: Perspectives and Approaches (eds, Carpenter, K. \& Currie, P.J.) 107-125 (Cambridge Univ. Press). [6] Baszio, S. (1997b) Courier Forschungsinstitut Senckenberg, 196, 33-77. [7] Sankey, J.T. et al. (in prep). [8] Baszio, S. (1997a) Courier Forschungsinstitut Senckenberg, 196, 1-31. 
A NEOPROTEROZOIC SNOWBALL EARTH. D. P. Schrag ${ }^{1}$ and P. F. Hoffman ${ }^{2}$, 'Dept. of Earth and Planetary Sciences, Harvard University, Cambridge, MA 02138, USA, schrag@eps.harvard.edu.

Introduction: The Snowball Earth hypothesis proposes that Neoproterozoic glacial deposits and associated "cap" carbonates represent a series of global glaciations followed by extreme greenhouse conditions (Hoffman et al., 1998). In the context of the hypothesis, a runaway icealbedo feedback causes a global glaciation, with nearcomplete sea-ice cover, and a greatly reduced hydrologic cycle dominated by sublimation. Escape from this frozen state requires several to several 10 's of millions of years for carbon dioxide, released by magmatic outgassing, to build up in the ocean/atmosphere system, providing adequate radiative forcing to overcome the high planetary albedo. Meltback would be extremely rapid (i.e., hundreds of years), transforming the earth from frozen to ultra-greenhouse conditions.

The hypothesis predicts that the cap carbonates were rapidly deposited, with alkalinity supplied by intense carbonate and silicate weathering. Banded iron formations, associated with the glacial deposits, represent chemical precipitates that formed as the ocean, anoxic from millions of years of ice cover, mixed with the atmosphere as the ice melted away. An important question is whether carbonate dissolution during the glaciation was sufficient to maintain carbonate saturation. If the ocean were undersaturated at the termination, intense dissolution of shelf carbonate, exposed by low sea level from continental ice, would quickly bring the surface ocean to calcite (and dolomite) saturation, causing rapid deposition of very pure carbonate. The carbon isotopic compositions of the cap carbonates are consistent with this hypothesis. Values immediately on top of the glacial deposit are approximately -2 per mil, consistent with dissolved inorganic carbon in isotopic equilibrium with a $\mathrm{CO} 2$-rich atmosphere. This value implies approximately equal partitioning of carbon between the atmosphere and the ocean. With this constraint, assuming a range of alkalinities, the $\mathrm{pCO} 2$ can then be calculated for the glacial termination. Values within the cap carbonate rapidly decrease to -5 per mil, consistent with Rayleigh distillation of the atmosphere as carbonate is deposited, and mass balance considerations. The basal unit of the cap exhibits a "tube" texture, with evidence for shallow water deposition, followed by a transgressive sequence of carbonate all within the cap sequence. This suggests that the basal unit of the cap precipitated over a very short time interval before continental glaciers had melted causing the eustatic sea level rise. The basal unit, predominantly dolomite, may represent the unusual conditions in the aftermath of the snowball earth, with dolomite saturation enhanced by addition of fresh water to the surface ocean from melting of sea ice.

Elevated $87 \mathrm{Sr} / 86 \mathrm{Sr}$ values above the basal carbonate unit are biased by in-situ $\mathrm{Rb}$ decay. They are consistent with very intense weathering of silicate rock flour after an initial sequence of carbonate deposition due to degassing of seawater during ocean warming and/or intense carbonate weathering prior to eustatic sea-level rise from melting continental glaciers.

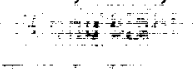

The reasons why the Earth was susceptible to such glaciations in the Neoproterozoic remain a mystery. The convergence of continents at low-latitudes may have been a contributing factor. When all the continents move to tropical latitudes, there are at least two interesting perturbations of the carbon cycle that result. First, most of the ocean area would exist in the polar regions, with no land mass available to supply dust (the atmosphere is inefficient at transporting dust from the tropics to higher latitudes). This condition would make biological productivity in the high latitude oceans extremely iron-limited, focusing most of the productivity into low latitudes ocean basins which would be smaller and more removed from global circulation. In essence, this would yield a world with multiple basins like the Black Sea, more prone to suboxic or anoxic conditions. In these oceans, organic matter burial would dramatically increase due to more efficient recycling of phosphate. This can explain the high carbon isotope values observed in the millions of years of sediment preceding each of the snowball glaciations. In addition, the low latitude continents would allow for lower carbon dioxide levels by removing the glacial barrier to chemical weathering. In the current continental configuration, as carbon dioxide emissions from volcanic sources decrease, ice caps on high latitude continents would decrease the rate of chemical weathering, stabilizing the amount of carbon dioxide in the atmosphere. If all the continents were at low latitudes, no such "safety switch" would exist, and carbon dioxide could reach lower levels for the same rate of volcanic emissions. This may explain why the snowball glaciations occurred at this time, and not in the Phanerozoic, and not in the 1.5 billion years preceding. The possibility that an early Proterozoic snowball occurred is an interesting new hypothesis that deserves additional consideration.

References: Hoffman, P.F., A.J. Kaufman, G.P. Galverson and D.P. Schrag, A Neoproterozoic snowball earth, Science, 281, 1342-1346, 1998. 


\section{BIOSTRATIGRAPHIC AND GEOCHEMICAL ANALYSES ACROSS THE K/T BOUNDARY IN THE} SINAI, EGYPT: RELATION TO A BOLIDE? Iknur Korhan Senguler ${ }^{1}$, Ahmed Dakrory $y^{1,2}$, Christian Koeber $^{3}$ and Muharrem Satir', ${ }^{1}$ Institut und Museum für Geologie und Paläontologie der Universität Tübingen, Sigwartstr.10, D-72076 Tübingen, Germany (ilknur@ uni-tuebingen.de) ${ }^{2}$ Department of Geology, Faculty of Science, El-Minia University, El-Minia, Egypt, ${ }^{3}$ Institut für Geochemie der Universität Wien, Althanstra.14, A-1090 Wien, Austria (christian.koeber1@univie.ac.at), ${ }^{4}$ Institut für Mineralogie, Petrologie und Geochemie der Universität Tübingen., Wilhelmstr.56, D-72074 Tübingen, Germany (Satir@uni-tuebingen.de)

The numerous papers dealing with the $\mathrm{K} / \mathrm{T}$ boundary in Egypt concentrated until now mainly on lithostratigraphic and biostratigraphic aspects, whereas detailed geochemical investigations are still lacking. In the six sections ( $4 \mathrm{~m}$ below to $2 \mathrm{~m}$ above the K/T boundary, with in general $0,5-0,3 \mathrm{~m}$ sample spacing) studied in the western part of the Central Sinai, the distribution of the benthic and planktic foraminifera, stable isotopes in bulk samples, but also in a few selected plankic and benthic species as well as the oxides of main-elements, trace elements and the platinum-group elements have been analysed.

The following planktonic and benthic foraminiferal zones have been recognized:

\begin{tabular}{lll}
\multicolumn{1}{c}{ planktic foraminifera } & \multicolumn{1}{c}{ benthic foraminifera } & Paleocene \\
Parasubbotina pseudobulloìdes & Gavelinella danica & \\
Parvularugoglobigerina eugubina & & \\
Abathomphalus mayaroensis & Bolivinoides draco draco Maastrichtian \\
Globotruncana gansseri &
\end{tabular}

Some species of planktic foraminifera survived the mass extinction at the $\mathrm{K} / \mathrm{T}$ boundary, which affected mainly the globotruncanids, the biserial pseudotextulariids and pseudoguembelinids, and became gradually extinct in the basal Paleocene. $15 \%$ of the benthic foraminiferal species disappear at the $\mathrm{K} / \mathrm{T}$ boundary. The P0 Zone (Guembelitria cretacea Zone) could not be recognized all the studied sections. The assemblage of the Pla Zone (Parvularugoglobigerina eugubina Zone) is composed by Cretaceous survivors (mainly dwarfed forms) and the first appearance of new Paleogene species. Most of surviving Cretaceous species disappear progresively through Parvularugoglobigerina eugubina biozone.

An upper Maastrichtian positive $\delta^{13} \mathrm{C}$ excursion is followed by a negative $\delta^{13} \mathrm{C}$ anomaly $(-0.5$ to $-1.0 \%$ ) at or near the $\mathrm{K} / \mathrm{T}$ boundary. These changes are observed in the bulk samples as well as in the selected planktic and benthic foraminiferal species. This negative excursion could be caused by a lower sea level or other paleoceanographic changes, but also by an impact event of extraterrestrial origin.

In all studied sections, the $\mathrm{K} / \mathrm{T}$ boundary interval is marked by an enrichment in $\mathrm{Co}$, Ni and Cr. Preliminary neutron activation data also indicate an Ir anomaly. Measurements and data reduction are currently in progress. 


\section{EXPLORING" THE CHICXULUB IMPACT BASIN THROUGH SCIENTIFIC DRILL-CORING:} HISTORICAL PERSPECTIVE AND CURRENT PLANS. Sharpton, Geophysical Institute, University of Alaska, Fairbanks, 903 Koyukuk Drive, Fairbanks, AK 99775; buck.sharpton @ gi.alaska.edu

Background: The buried Chicxulub structure in northernmost Yucatan (Figure 1) was first recognized as a zone of concentric anomalies in gravity surveys circa 1948 [1], prompting an exploratory drilling program by Petróleos Mexicanos (Pemex) consisting of 8 intermittently cored wells penetrating through the Mesozoic platform sequence. While the amount of coring was small (only $2 \%$ of intervals were cored) these samples provided the evidence required to demonstrate that the Chicxulub structure is a large meteorite impact crater and to link it with mass extinctions

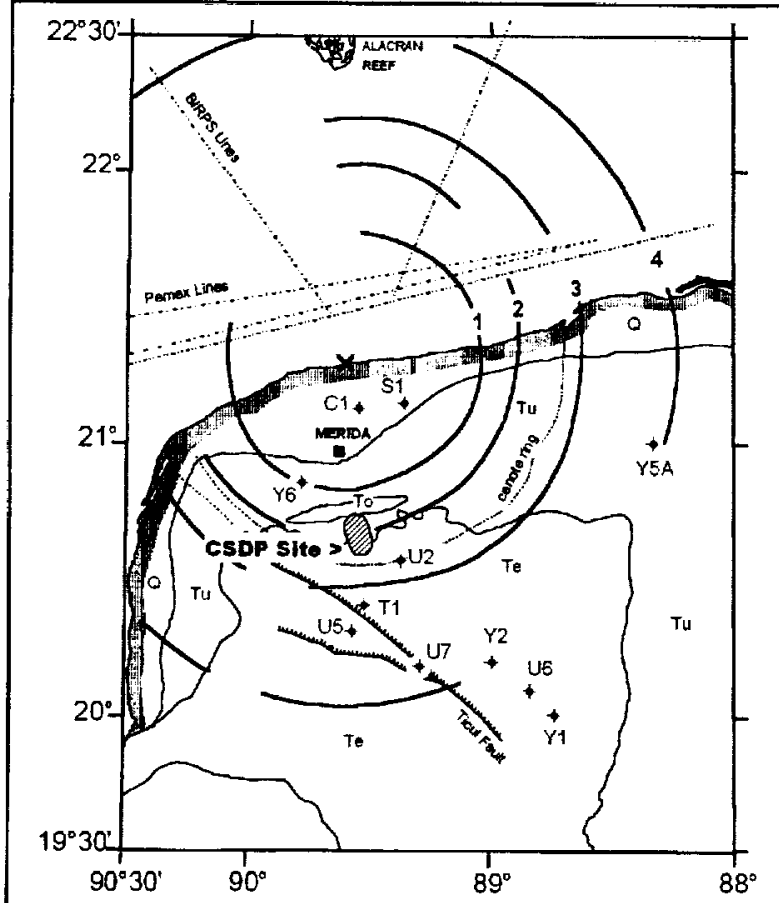

Figure 1: Surface geology, ring locations from gravity data, and wells in the vicinity of the Chicxulub multiring impact basin. The three wells that penetrated impact melt rocks and breccias beneath the carbonate cover rocks are $\mathrm{Cl}$ (Chicxulub 1), S1 (Sacapuc 1), and Y6 (Yucatan 6). Other Pemex well sites shown are Yuca$\tan 1$ (Y1), Yucatan 2 (Y2), Yucatan 5A (Y5A), and Ticul 1 (T1). The Yucatan 4 (Y4) well site is located off the map, $-65 \mathrm{~km}$ east of Y5A. Important sites of shallow drill-coring, led by UNAM scientists, are denoted by $\mathrm{U} 2$ through $\mathrm{U} 7$. Carbonate units at the surface are Q (Quaternary; <1.6 Ma), Tu (Upper Tertiary; $~ 1.6$ to $38 \mathrm{Ma}$ ), To (Oligocene; -24 to $\sim 38 \mathrm{Ma}$ ), Te (Eocene; $\sim 38$ to $\sim 55 \mathrm{Ma}$ ), and Tpal (Paleocene; $\sim 55$ to $\sim 66.0$ Ma). Hatchured lines represent the Ticul fault system. Dashed lines indicate trends of ringlike zones of cenotes or sinkholes. Existing (Pemex) and (BIRPS) offshore seismic lines are shown by broken line pattems. at the KT boundary [2-11]. By the mid-1990s, this evidence was accepted widely, albeit not universally [e.g., 12]. Consequently, exploration goals shifted toward refining our understanding of the feature, the nature of such large impact events, and, in particular, how this one could have initiated a global environmental crisis that resulted in such a dramatic turnover in Earth's biosphere.

In 1994, under the direction of Dr. Luis E. Marín, Universidad Nacional Autónoma de México (UNAM) began a privately sponsored campaign of shallow drill-coring along the southern flank of the Chicxulub basin (Table 1). The four primary sites are shown in Figure 1. Of particular significance was the discovery of thick sequences of ejected melt rocks overlying suevitic breccias at U5, suevite over a weakly shocked, carbonate-evaporite-rich breccia at $\mathrm{U} 7$ and $\mathrm{U} 6$, and the existence of anhydrite megablocks in the U7 cores. Notably, this effort represents the only scientific drilling accomplished to date in or around the Chicxulub impact basin.

Why Continue to Study Chicxulub? The Chicxulub impact basin is at least $200 \mathrm{~km}$ in diameter. There are only two other terrestrial impact craters that approach this size: the Sudbury structure in Ontario [e.g., 13] and the Vredefort structure in South Africa [e.g., 14]. Both are Proterozoic and both are heavily eroded; Sudbury, in addition, has suffered considerable deformation associated with the Penokean orogeny. Consequently, the upper several kilometers of these structures have been severely modified and their original morphology and near-surface geology is, therefore, a mystery.

Due to its young age and the shallow marine setting prior to impact, Chicxulub is remarkably well preserved. The crater, extending several hundred meters below KT sea level, was shielded from the effects of erosion throughout the Tertiary. Only the high-standing rim and ejecta blanket would have been subjected to extensive impact-generated wave action and long-term exposure to reworking. Furthermore, the target assemblage is composed of three primary components: silicates, sulfates, and carbonates, that (roughly) correlate with stratigraphic depth and age. Major oxides and volatiles, therefore, can be used to (roughly) track the original stratigraphic position of various lithological components even when they are finely disseminated in ejected materials. Thus it may 
DRILL-CORING THE CHICXULUB IMPACT BASIN: V. L. Sharpton

\begin{tabular}{|c|c|c|}
\hline Well Site & Depth Surface Geology & Obiectives, Comments \\
\hline $\begin{array}{l}\text { UNAM 1; southeast of center on innermost } \\
\text { prominent gravity ring }[7] ; \sim 50 \mathrm{~km} \text { from basin }\end{array}$ & $\begin{array}{l}155 \mathrm{~m} \text { T.D. Eocene-Oligocene carbon- } \\
\text { ates; }-85 \% \text { core recovery. }\end{array}$ & $\begin{array}{l}\text { Drilling terminated when loss of circulation and } \\
\text { continued caving could not be remedied }\end{array}$ \\
\hline $\begin{array}{l}\text { UNAM 2.; } 85 \mathrm{~km} \text { southeast of center on 'ring } \\
\text { of cenotes' [3]. Corresponds to proposed rim } \\
\text { in [2] }\end{array}$ & $\begin{array}{l}559 \text { m T.D. Eocene carbonates; } \sim 85 \% \\
\text { core recovery. }\end{array}$ & $\begin{array}{l}\text { Assess origin of ring of cenotes and link with } \\
\text { crater. T.D. did not reach crater at this site. }\end{array}$ \\
\hline $\begin{array}{l}\text { UNAM 3; southeast of center just inside grav- } \\
\text { ity ning } 4 \sim 150 \mathrm{~km} \text { from center }\end{array}$ & $\begin{array}{l}138 \mathrm{~m} \text { T.D. Eocene carbonates; } \sim 65 \% \\
\text { core recovery. }\end{array}$ & Lost circulation, caving; terminated coring. \\
\hline UNAM $4 ; \sim 10 \mathrm{~km}$ south of U3. & $\begin{array}{l}63 \mathrm{~m} \text { T.D. Eocene carbonates. } \sim 70 \% \\
\text { core recovery }\end{array}$ & Lost circulation, caving; terminated coring. \\
\hline $\begin{array}{l}\text { UNAM } 5 ; \sim 110 \mathrm{~km} \text { south of center on ring } 3 \text { at } \\
\text { Santa Elena. }\end{array}$ & $\begin{array}{l}503 \mathrm{~m} \text { T.D. } 91 \% \text { recovery. Impact melt } \\
\text { encountered at } 330 \mathrm{~m} \text {; suevitic crystal- } \\
\text { line rock clast breccia at }-360 \mathrm{~m} \text { to T.D. }\end{array}$ & $\begin{array}{l}\text { Evaluate depth to, thickness of, and lithological } \\
\text { characteristics of ejecta at this distance. }\end{array}$ \\
\hline $\begin{array}{l}\text { UNAM } 6 ; \sim 150 \mathrm{~km} \text { SSE of center on ring } 4 \\
\text { near Peto. }\end{array}$ & $\begin{array}{l}702 \mathrm{~m} \text { T.D.; carbonate-anhydrite-rich } \\
\text { breccia } 257-520 \mathrm{~m} \text {; disturbed evaporitic } \\
\text { rock to T.D. }\end{array}$ & $\begin{array}{l}\text { Evaluate depth to, thickness of, and lithological } \\
\text { characteristics of ejecta at this distance. }\end{array}$ \\
\hline $\begin{array}{l}\text { UNAM } 7 ;-125 \mathrm{~km} \text { south of center between } \\
\text { rings } 3 \text { and } 4 \text { near Tekax. }\end{array}$ & $\begin{array}{l}-700 \mathrm{~m} \text { T.D. Suevite breccia ( } 211- \\
345 \mathrm{~m} \text { ); underlying carbonate-anhydrite- } \\
\text { rich impact breccia to T.D. }\end{array}$ & $\begin{array}{l}\text { Evaluate depth to, thickness of, and lithological } \\
\text { characteristics of ejecta at this distance. }\end{array}$ \\
\hline
\end{tabular}

be possible to estimate the proportions of each rock type contained in the ejected material around the Chicxulub excavation zone thereby constraining fundamental impact parameters such as the shape of the excavation cavity, and the efficacy of target mixing during excavation and ejecta emplacement. Consequently, Chicxulub offers a unique opportunity to study the morphological, lithological, and structural effects of large body impact - a rare but extremely energetic and poorly understood geological process

The Chicxulub Scientific Drilling Project: In October, 1999, the Continental Scientific Drilling Program accepted a proposal by Drs. L.E. Marín, V.L. Sharpton, and J. Urrutia (UNAM) to conduct an intermediate-depth $(2-3 \mathrm{~km})$ drill-coring project designed to recover a complete sequence of impactgenerated rocks from within the Chicxulub crater. This effort would provide the first complete section through the sequence of melt-rocks and breccias within any large $(>50 \mathrm{~km})$ impact crater. These samples, therefore, will be of immeasurable importance in: (1) assessing the nature of the target rocks (relevant to constraining the KT kill mechanism and understanding the evolution of the Yucatan Platform)

(2) understanding how those target materials were shocked, comminuted, mixed, and emplaced onto the crater floor during the impact process (relevant to understanding the nature of large-body impact).

(3) enhancing interpretations of seismic reflection data used to constrain the large-scale configuration of the impact basin.

Another goal is to recover a continuous section through the Tertiary cover rocks above the impactites, from which information about post-impact faunal recovery and long-term modification of the crater can be gleaned. Finally, we hope to penetrate into the upper part of the disturbed Cretaceous-Jurassic platform rocks below the breccias, in order to provide additional constraints on target-rock compositions and deformation styles characteristic of the regions flanking the collapsed central excavation cavity.

Existing geophysical and well-log data, along with a consideration of the scale and symmetry of this extremely large impact feature, indicate that these coring goals can be achieved at a distance of $60-80 \mathrm{~km}$ from the basin center. The well will be located in the southern part of the crater (CSDP, Figure 1) to promote correlations with the existing oil-exploration wells and to facilitate a prospective onshore seismic line that would tie this well to others in the vicinity. The main hole may be preceded by one or two 700-m deep 'pilot holes', commencing as soon as early March 2000.

It will not be possible to adequately understand the Chicxulub crater by drilling alone. CSDP is simply the next step in a decadal-scale exploration program that includes additional drill-coring, seismic profiling, and potential field studies.

References: [1] Comejo-Toledo, A., and HernandezOsuna, A. (1950) Boletín de la Asociación Mexicana de Geólogos Petroleros, 2, 453-460.. [2] Hildebrand, A.R. et al. (1991) Geology, 19, 867-871. [3] Pope, K.O. et al. (1991) Nature, 351, 105. [4] Pope K.O.et al. (1993) Earth, Moon and Planets, 63, 93-104. [5] Kring, D.A. and Boynton, W.V. (1992) Nature, 358, 141-144. [6] Sharpton, V.L. et al. (1992) Nature, 359, 819-821. [7] Sharpton, V.L. et al. (1993) Science, 261, 1564-1567. [8] Koeberl, C. et al. (1994) Geochim. Cosmochim. Acta, 58, 1679-1684. [9] Krogh, T. E. et al. (1993) Nature, 366, 731-734. [10] Swisher et al., 1992. [11] Blum, J.D. et al. (1993) Nature, 364, 325-327. [12] Keller, G., et al. (1997) Geol. Soc. Am. Bull., 109, 410-428. [13] Dressler, B. O. (1984) in Pye, E. G. et al., eds. Ontario Geol. Surv. Sp. Vol. 1, 57-82. [14] Nicolaysen, L. O., and Reimold, W. U., eds. (1990), Tectonophysics, $171,422 \mathrm{p}$. 


\section{PERMIAN-TRIASSIC TRANSITIONAL ENVIRONMENT IN SPITI VALLEY, HIMALAYAS, INDIA A.D.Shukla, N. Bhandari and P.N. Shukla, Physical Research Laboratory, Navvrangpura, Ahmedabad - 380 009, Gujarat, India (bhandari@ prl.ernet.in ).}

Introduction : The Permian-Triassic mass extinction event has been attributed wholly or partly to climatic stress due to Siberian volcanism [1,2], regression of sea [3], oceanic anoxia $[4,5]$, overturning of deep anoxic oceans [6] and impact $[7,8]$ or combination of all these factors [9]. Their relative roles in causing mass extinction, however, have not been evaluated. The impact hypotheses has received some support from the work of Retallack [10] who reported occurrence of planer defects in quartz in the Permian-Triassic sections from some localities of Antarctica and Australia. India was a part of the old Gondwanaland in which Antarctica, Australia, Africa etc. were located close together during Permian-Triassic time. If impact really took place at Falkland, as proposed by Rampino [8], then Indian sections, because of their proximity, are in a better position to record these events compared to the Northern Hemispheric sections e.g. Carnic Alps and China.

It has been observed that a thin $(\sim 2 \mathrm{~cm})$ limonitic band separates the Permian and Triassic succession in the Spiti valley and should represent the Permian-Triassic Boundary. The absence of high iridium and presence of a large positive Eu-anomaly in Guling and Lalung $\mathrm{P}-\mathrm{Tr}$ sections of Spiti valley of Himalayas would indicate a eucritic or anorthositic bolide in an impact scenario [7].

Limonitic Layer : To understand the extent of the limonitic layer, its mineralogical and chemical characteristics and geological context, we have carried out study of several sites in Lahaul and Spiti valley. Field observations indicate that the limonitic band separating the Permian grey-black shale and Triassic limestone is present throughout the Spiti valley and also in Lahaul valley. From the macroscopic and physical examination and $\mathrm{X}$-ray diffraction studies of this limonitic material which is well developed near Attargoo village in Spiti valley, we find that it consists of goethite, quartz, gypsum and feldspar. Maganese in form of oxide with minor iron has also been observed by SEM studies, indicating a marine component in this clay whereas presence of gypsum shows components of sub-aerial origin. A large drop in the sea level and aerial exposure of sediments can probably result in the mixed mineral assemblages seen here but it can not easily explain the high europium anomaly observed in dark nodules found at the base of the limonitic layer. The presence of multiple components of diverse origin in the limonitic layer could also be ascribed to an impact ejecta [7].

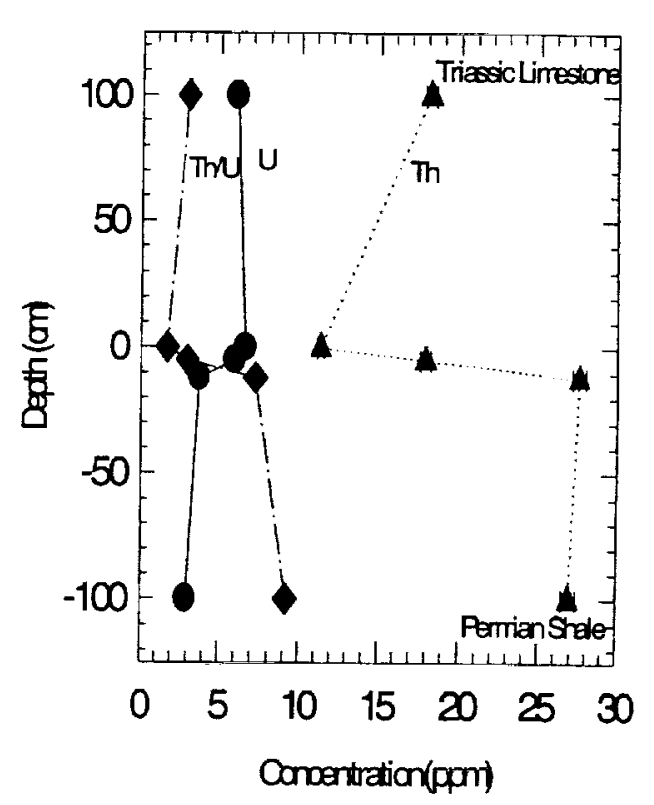

Fig.1. Profile of $U$, Th and $T h / U$ ratios in the Attargoo section.

Trace element composition: To characterize the samples in detail we have carried out geochemical studies of samples of P. $\operatorname{Tr}$ sections in Spiti valley as well as from Kashmir (Guryul) using neutron activation analyses. $\mathrm{U}, \mathrm{Th}$ and $\mathrm{K}$ measurements were made using gamma-ray spectrometry. Some major elements have also been measured using ICPAES and AAS techniques.

Th, $U$ and $T h / U$ ratios show a drastic variation in the section as shown in Fig.1. Generally $\mathrm{Th} / \mathrm{U}$ is considered as an indicator of redox conditions prevailing at the time of 
PERMIAN-TRAISSIC TRANSITIONAL ENVIRONMENT: A. D. Shukla et al.

sediment deposition, since under anoxic conditions $U$ is tetravalent and forms insoluble compounds which remain in the sediments while in oxic environment, $U$ changes to hexavalent state and forms the soluble uranyl carbonate. In the Attargoo section, we find that $\mathrm{Th} / \mathrm{U}$ ratio starts decreasing from $5 \mathrm{~cm}(7.27)$ below the limonitic layer and attains a minimum value in the limonitic layer (1.72). Thereafter it increases during Triassic (to 3.0). This variation suggests that much before the deposition of the layer the oxygen in the sea started depleting, although the concomitant variation in Th

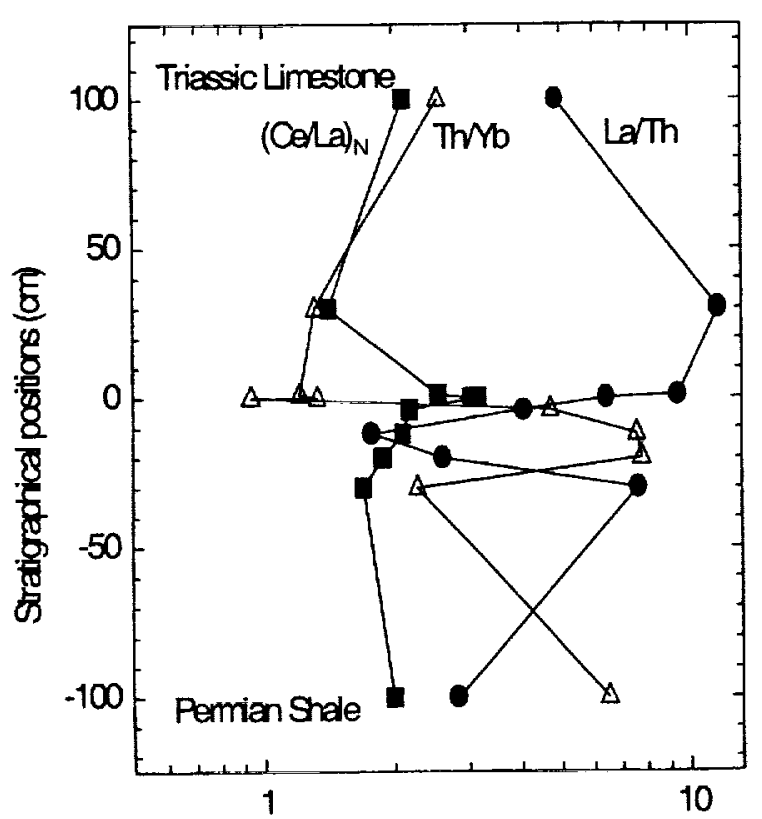

Bemental Ratios

Fig 2. Profile of diagnostic elemental ratios in the Attargoo P/Tr section.

concentration suggests simultaneous chânges due to lithological variations. The anoxic condition at the time of deposition of the limonitic layer can also be inferred from the high $(\mathrm{Ce} / \mathrm{La})_{\mathrm{N}}$, which is similar to those occurring in Austrian sections [11]. Thus the anoxia starts building up before the deposition of this limonitic layer. This decrease in oxygen also reflects in the colour of shales which change from grey to black [11]. The duration and extent of anoxia seems to vary from place to place as can be inferred by comparing $\mathrm{Th} / \mathrm{U}$ and $[\mathrm{Ce} / \mathrm{La}]_{\mathrm{N}}$ in Attargoo section with austrian and chinese (Meishan and Shangsi) sections [12]

The boundary samples from four localities (Lalung, Guling, Attargoo and Ganmachidam) show parallel trends in REE. The REE content is high in the limonitic layer compared to the adjacent samples above and below it. La/Th and $\mathrm{Th} / \mathrm{Yb}$ also show similar depth profiles in these sections. The Permian shales have low $\mathrm{La} / \mathrm{Th}$ and high $\mathrm{Th} / \mathrm{Yb}$, similar to granites whereas the Triassic limestone have high $\mathrm{La} / \mathrm{Th}$ (4.9 to 11.6) and low $\mathrm{Th} / \mathrm{Y}(1.2-2.5)$ respectively, similar to basalts. This could possibly be due to Panjal and Phe volcanism which occupied large areas in the adjoining Kashmir and Zanskar basins in the Tethyan realm of north-western Himalayas.

We thank Harald Strauss for conducting a very useful field trip in the Spiti Valley under IGCP 386, which allowed us to collect samples used in this study.

References : [1] A.R. Basu, et al. (1995) Science, 269, 822-825. [2] Campbell I.H. (1992) Science, 258, 1760-1763. [3] Erwin D.H (1994) Nature, 367, 231-236. [4] Wignall P. and Twitchett (1996) Science, 272, 1155. [5] Isozaki Y. (1997) Science, 276, 235-238. [6] Knoll A.H. et al., (1996) Science, 273, 452-457. [7] Bhandari N. et al. (1992) Geophys. Res. Lett., 19, 1531-1534. [8] Rampino M. R. (1992) EOS: Trans. $A G U, 73,49-52$. [9] Shukla, P.N. and Bhandari, N., Palaeobotanist, 46, 41-62. [10] Retallack G.J. et al. (1998) Geology, 26, 979982. [11] Holser W.T. et al. (1989) Nature, 337, 39-44. [12] Wang et al., (1986) Geochim. Cosmochim Acta, 50, 1337-1355. 
EXTRATERRESTRIAL MATTER ON EARTH: EVIDENCE FROM THE CR ISOTOPES. Shukolyukov' and G.W. Lugmair ${ }^{1,2}$. 'Scripps Institute of Oceanography, Univ. of California, San Diego, La Jolla CA 92093 0212, ${ }^{2}$ Max-Planck-Inst. for Chemistry, Cosmochem., PO 3060, 55020 Mainz, Germany.

The recent studies of the ${ }^{53} \mathrm{Mn}-{ }^{53} \mathrm{Cr}$ isotope systematic in various solar system objects [1] has provided a method for unequivocally demonstrating the existence of an extraterrestrial component (ETC) in impact ejecta with high concentrations of meteoritic $\mathrm{Cr}$. The method is based on the study of the relative abundances of ${ }^{53} \mathrm{Cr}$, daughter product of the extinct radionuclide ${ }^{53} \mathrm{Mn}\left(\mathrm{T}_{1 / 2}=3.7 \mathrm{Ma}\right)$. The isotopic variations are measured as the deviations of the ${ }^{53} \mathrm{Cr} /{ }^{52} \mathrm{Cr}$ ratios from the standard terrestrial ${ }^{53} \mathrm{Cr} /{ }^{52} \mathrm{Cr}$ ratio, which are usually expressed in $\varepsilon$-units ( $1 \varepsilon$ is 1 part in $10^{4}$, or $0.01 \%$ ). We developed a technique for high precision mass spectrometric analysis of the $\mathrm{Cr}$ isotopic composition in rocks and minerals, which allows measurement of ${ }^{53} \mathrm{Cr} /{ }^{52} \mathrm{Cr}$ variations of less than $1 \varepsilon$ with an uncertainty of 0.05 to $0.10 \varepsilon$-units [1].

Because Earth homogenized long after ${ }^{53} \mathrm{Mn}$ had fully decayed, no variation of ${ }^{53} \mathrm{Cr} /{ }^{52} \mathrm{Cr}$ ratios is expected for any terrestrial samples. Indeed, all examined terrestrial samples exhibit the same ${ }^{53} \mathrm{Cr} /{ }^{52} \mathrm{Cr}$ ratio $\left(\equiv \begin{array}{lll}0 & \varepsilon\end{array}\right)$ (Fig. 1). In contrast, most meteorite classes studied so far, including ordinary and enstatite chondrites, primitive achondrites, and various differentiated meteorites are characterized by a variable excess of ${ }^{53} \mathrm{Cr}$ relative to terrestrial samples (Fig. 1), reflecting a heterogeneous distribution of ${ }^{53} \mathrm{Mn}$ in the early solar system [1]. The ${ }^{53} \mathrm{Cr} /{ }^{52} \mathrm{Cr}$ variations in the bulk samples of differentiated meteorites are due to processes of an early $\mathrm{Mn} / \mathrm{Cr}$ fractionation within their parent bodies. The carbonaceous chondrites show an apparent deficit of ${ }^{53} \mathrm{Cr}$ of $\sim-0.40 \varepsilon$ [2]. However, due to the presence of a pre-solar component the bulk carbonaceous chondrites have an excess of ${ }^{54} \mathrm{Cr}$. Since in our method the ${ }^{54} \mathrm{Cr} /{ }^{52} \mathrm{Cr}$ ratio is used for a second order fractionation correction [1] and, for this purpose, is assumed to be normal, the elevated ${ }^{54} \mathrm{Cr} /{ }^{52} \mathrm{Cr}$ ratio translates into apparent deficit of ${ }^{53} \mathrm{Cr}$. The measured "raw" ${ }^{53} \mathrm{Cr} /{ }^{52} \mathrm{Cr}$ and ${ }^{54} \mathrm{Cr} /{ }^{52} \mathrm{Cr}$ ratios of the bulk CV meteorite Allende (that is, without application of the second order fractionation correction) are $+0.1 \pm 0.1 \varepsilon$ and $+0.9 \pm 0.2 \varepsilon$. Preliminary data for bulk Orgueil show that the actual ${ }^{53} \mathrm{Cr} /{ }^{52} \mathrm{Cr}$ ratio is comparable with that for the other undifferentiated asteroid belt meteorites (i.e., an excess of ${ }^{53} \mathrm{Cr}$ ) and the ${ }^{54} \mathrm{Cr} /{ }^{52} \mathrm{Cr}$ ratio is elevated up to $\sim+1.5 \varepsilon$. Thus, an apparent deficit of ${ }^{53} \mathrm{Cr}$ in the carbonaceous chondrites (when the "normalized" ${ }^{53} \mathrm{Cr} /{ }^{52} \mathrm{Cr}$ ratios are used) is actually due to an excess of ${ }^{54} \mathrm{Cr}$. Nevertheless, be- cause the use of the "raw" ${ }^{53} \mathrm{Cr} /{ }^{52} \mathrm{Cr}$ ratio would drastically decrease the precision, and thus the resolution of our measurements, we prefer to apply the second order fractionation correction, even for the samples with an elevated ${ }^{54} \mathrm{Cr} /{ }^{52} \mathrm{Cr}$ ratio.

The observed difference in ${ }^{53} \mathrm{Cr} /{ }^{52} \mathrm{Cr}$ ratios between Earth and meteorites represents a direct experimental fact that does not involve any models or assumptions. This allows us to unequivocally demonstrate an extraterrestrial component in geological samples on Earth that contain a significant proportion of meteoritic $\mathrm{Cr}$, based on measurements of the $\mathrm{Cr}$ isotopic composition.

The Cretaceous/Tertiary (K/T) boundary. The K/T boundary sediments from Stevns Klint, Denmark, and Caravaca, Spain, were found to have a $\mathrm{Cr}$ isotopic signature which is very similar to that of the carbonaceous chondrites: from -0.33 to $-0.40 \varepsilon$, while the background clays were found to have a normal $\mathrm{Cr}$ isotopic composition (Fig. 1) [2]. The "raw" ${ }^{53} \mathrm{Cr} /{ }^{52} \mathrm{Cr}$ and ${ }^{54} \mathrm{Cr} /{ }^{52} \mathrm{Cr}$ ratios of the carbonaceous chondrites and the $\mathrm{K} / \mathrm{T}$ sediments were also found to be similar. These results indicate that more than $80 \%$ of $\mathrm{Cr}$ in the $\mathrm{K} / \mathrm{T}$ sediments originated from a carbonaceous chondrite type impactor. This is the first isotopic evidence for the cosmic origin of the $\mathrm{K} / \mathrm{T}$ layer and the type of the impactor.

Archean impact deposits in Barberton, South Africa. Criteria that distinguish these beds from typical volcanic and clastic sediments include wide geographic distribution in a variety of depositional environments, relict quench textures, absence of juvenile volcaniclasitc debris, and extreme enrichment of Ir and other platinum group elements [3]. However, some workers argued for terrestrial origin, possibly related to volcanism or gold mineralization [4]. This controversy has been solved based on the recent studies of the $\mathrm{Cr}$ isotopes [5]. The $\mathrm{Cr}$ isotopic compositions of samples from spherule bed $\mathrm{S} 4$ are unquestionably non-terrestrial (Fig. 1). Samples D-4 and C were found to have a clearly anomalous "normalized" ${ }^{53} \mathrm{Cr} /{ }^{52} \mathrm{Cr}$ ratios of $-0.32 \pm 0.06 \varepsilon$ and $-0.26 \pm 0.11 \varepsilon$, respectively. The less precise "raw" data for the ${ }^{54} \mathrm{Cr}$ abundances in bed $\mathrm{S} 4$ indicate only a small enrichment in this isotope, a result most consistent with a $\mathrm{CV}$-type chondrite source. The background sediments yield normal terrestrial ${ }^{53} \mathrm{Cr} /{ }^{52} \mathrm{Cr}$ ratios. The "normalized" ${ }^{53} \mathrm{Cr} /{ }^{52} \mathrm{Cr}$ ratios in samples $10 \mathrm{~B}$ and $10 \mathrm{G}$ (- 
$0.37 \pm 0.07 \varepsilon$ and $-0.41 \pm 0.08 \varepsilon$, respectively) from another Archean bed from the Sheba Mine (probably bed S3, northern location) also clearly indicate the presence of abundant ETC from a carbonaceous chondrite type source (Fig. 1). The background sample $(3 \mathrm{~m}$ below the bed) yields normal terrestrial ${ }^{53} \mathrm{Cr} /{ }^{52} \mathrm{Cr}$ ratio of $+0.01 \pm 0.06 \varepsilon$. These results imply that essentially all $\mathrm{Cr}$ in samples $10 \mathrm{~B}$ and $10 \mathrm{G}$ is extraterrestrial. The "raw" ${ }^{53} \mathrm{Cr} /{ }^{52} \mathrm{Cr}$ and ${ }^{54} \mathrm{Cr} /{ }^{52} \mathrm{Cr}$ ratios in sample $10 \mathrm{G}$ $(+0.08 \pm 0.18 \varepsilon$ and $+0.89 \pm 0.23 \varepsilon)$ are consistent with this conclusion and suggest a $\mathrm{CV}$ type projectile. The sample $5 \mathrm{~B}$ from the southern part of bed $\mathrm{S} 3$ indicates a similar "normalized" ${ }^{53} \mathrm{Cr} /{ }^{52} \mathrm{Cr}$ ratio of

$-0.41 \pm 0.10 \varepsilon$. Thus, the $\mathrm{Cr}$ isotope signature in the samples from beds $\mathrm{S} 4$ and $\mathrm{S} 3$ provide unequivocal evidence of at least two major accretion events at -3.24 Ga. These deposits are considerably thicker than the $\mathrm{K} / \mathrm{T}$ deposits and a simple interpretation of the data leads to the conclusion that the projectiles that formed them were at least $20 \mathrm{~km}$ in diameter and possibly considerably larger.

ETC in impactites. We have studied impact melt samples from the Morokweng, Clearwater East, Lappajärvi, and Rochechouart impact structures. Based on the chemical analysis [6-8] the projectiles of all these craters are of chondritic origin. The ${ }^{53} \mathrm{Cr}$ excesses (from $\sim+0.2 \varepsilon$ for Lappajarvi up to -+0.3 for Rochechouart ) indicate the presence of an ETC . Using the $\mathrm{Cr}$ isotope data and the correlations in the siderophile element concentrations, the type of the Morokweng projectile was recently determined to be an L-chondrite [9]. Similarly, the Clearwater East and
Lappajärvi projectiles were found to be a H-chondrite type objects. In the Rochechouart melts the interelement ratios among the siderophile elements are heavily disturbed [7]. This makes the assignment to a specific class difficult. However, based on the measured ${ }^{53} \mathrm{Cr} /{ }^{52} \mathrm{Cr}$ ratio the enstatite and carbonaceous chondrites can be excluded and, thus, the most likely candidate for the projectile is an ordinary chondrite.

Acknowledgement. We thank Ch. MacIsaac for his help in the lab.

References. [1] Shukolyukov and Lugmair (1998) Science 282, 927. [2] Lugmair and Shukolyukov (1998) GCA 62, 2863. [3] Lowe et al. (1989) Science 245, 959; Kyte et al. (1992) GCA 56, 1365. [4] Koeberl and Reimold (1995) Precambrian Research 74, 1. [5] Shukolyukov et aI. (1999) Proceedings of $1^{\text {st }}$ Workshop of the ESF-Impact Scientific Programme (in press). [6] Koeberl et. al. (1997)Geology 25, 731. [7] Palme et al. (1980) LPSC XI, 848. [8] Reimold (1982) GCA 46, 1203. [9] Shukolyukov et al. (1999), Met. Planet. Sci. 34, A107.

Fig. 1. Chromium isotope systematics in terrestrial samples, various meteorites, $\mathrm{K} / \mathrm{T}$ boundary samples, Archean impact deposits, and impactites.

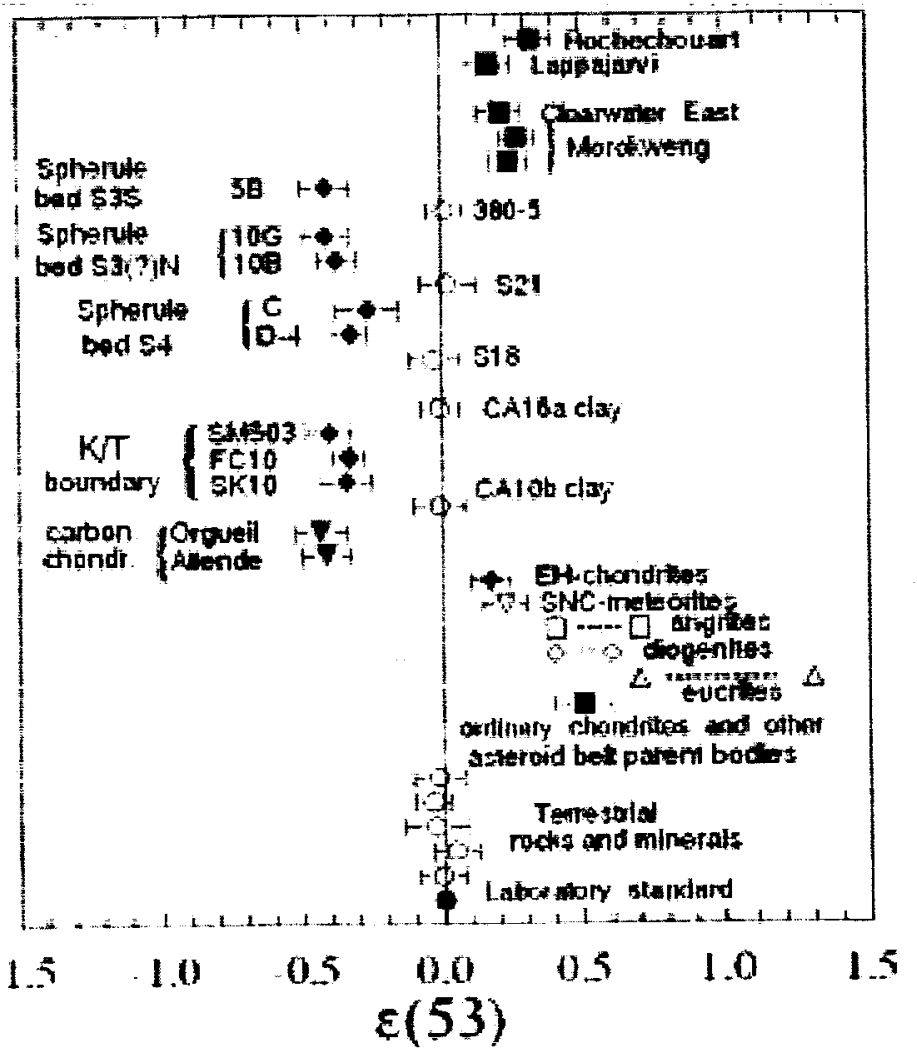


ATMOSPHERIC EROSION AND RADIATION IMPULSE INDUCED BY IMPACTS. V.V.Shuvalov and N.A. Artemieva, Institute for Dynamics of Geospheres, Leninsky pr., 38, bld.6, Moscow, 117979, Russia. valery@vshuvalov.mccme.ru

Introduction: The impacts of large cosmic bodies (with the size exceeding some $100 \mathrm{~m}$ ) could substantially influence the evolution of planetary atmospheres [1-4]. The growth of the atmospheric mass was defined by a release of volatiles in the impact process. At the same time some portion of the atmospheric gas could accelerate and escape from the Earth. The main results concerning impact induced atmospheric erosion were obtained with the use of a simplified sector model [2]. However, this model does not take into account an influence of the atmospheric perturbations created during impactor flight through the atmosphere and the influence of the cratering process on the air ejection. The significance of these factors was justified in [5-6]. The purpose of this paper is to study the impact induced atmospheric erosion with the use of detailed numerical simulations. One more objective is to calculate the impact generated radiation impulse, which is considered as a possible reason for mass extinction.

Numerical simulations are performed for a range of impact velocity $\mathrm{V}=20-50 \mathrm{~km} / \mathrm{s}$ and impactor sizes $\mathrm{D}=1-30 \mathrm{~km}$, both for comets and asteroids. ANEOS for granite [7] is used to describe thermodynamics of asteroid substance and soil, Tillotson EOS for water [8] is applied for the comet material, and table equation of state [9] is used to determine the air pressure. The nonuniform detailed grid $300 \times 1000$ with 20 cells across impactor radius is exploited to model a flight through the atmosphere from the altitude of $400 \mathrm{~km}$, crater growth and plume evolution with the use of the SOVA multi-material hydrocode [10].

Results of simulations. In the case under consideration the total mass ejected from the crater is much greater than the mass of air within the cone of ejection. Therefore, the main part of ejecta is not exposed to atmospheric drag. However, a leading (very hot, rarefied and fast) portion of vapor experiences considerable drag and expands within the rarefied wake preferably. In some sense the wake looks like an empty tube through which the hot rarefied vapor moves to high altitudes. In case of impacts of 3-10 km projectiles the main part of the fast ejecta moves through the rarefied wake and can accelerate only a small mass of the air filling the wake. This leads to the decrease of the atmospheric erosion. As the impact energy increases the mass of hot and fast part of the plume also increases and atmospheric drag becomes too small to influence the plume evolution. In this case atmospheric erosion does not depend on the presence of the wake. In the case of smaller impactors (about
$1 \mathrm{~km}$ ) the atmospheric erosion is possible only due to the wake, otherwise, the hot vapor cloud would simply decelerate to the velocity below the escape one.

Some results of numerical simulation are summarized in the table:

\begin{tabular}{|l|c|c|l|}
\hline impactor & $\begin{array}{l}\text { diameter, } \\
\mathrm{km}\end{array}$ & $\begin{array}{l}\text { velocity, } \\
\mathrm{km} / \mathrm{s}\end{array}$ & $\mathrm{m}_{\mathrm{esc}} / \mathrm{m}_{\mathrm{imp}}$ \\
\hline asteroid & 30 & 20 & $4.7 \times 10^{-5}$ \\
asteroid & 10 & 20 & $1.6 \times 10^{-4}$ \\
asteroid & 10 & 30 & $2.5 \times 10^{-4}$ \\
asteroid & 10 & 50 & $8.8 \times 10^{-4}$ \\
asteroid * & 10 & 20 & $2.5 \times 10^{-4}$ \\
asteroid ** & 10 & 20 & $1.8 \times 10^{-4}$ \\
asteroid & 3 & 20 & $7.1 \times 10^{-4}$ \\
asteroid & 3 & 50 & $1.7 \times 10^{-3}$ \\
asteroid * & 3 & 50 & $1.2 \times 10^{-2}$ \\
asteroid & 1 & 20 & $1.3 \times 10^{-3}$ \\
asteroid & 1 & 50 & $4.5 \times 10^{-3}$ \\
comet & 30 & 50 & $6.5 \times 10^{-3}$ \\
comet & 10 & 20 & $1.3 \times 10^{-3}$ \\
comet & 10 & 30 & $9.7 \times 10^{-3}$ \\
comet & 10 & 50 & $2.6 \times 10^{-2}$ \\
comet & 3 & 20 & $1.9 \times 10^{-3}$ \\
comet & 3 & 50 & $7.0 \times 10^{-3}$ \\
comet & 1 & 20 & $4.0 \times 10^{-3}$ \\
comet & 1 & 50 & $1.0 \times 10^{-2}$ \\
\hline
\end{tabular}

Hear $m_{\text {esc }}$ is the air mass reaching the velocity exceeding $11 \mathrm{~km} / \mathrm{s}$ in $20 \mathrm{~s}$ after the impact, $m_{\text {imp }}$ is the impactor mass, * marks the runs without the wake. In the run marked by $* *$ the asteroid hits against an ocean $4 \mathrm{~km}$ deep. Several runs were continued to the time of $60 \mathrm{~s}$. This did not lead to increase of the escaping mass.

As expected, the atmospheric erosion increases with the increase of impact velocity, and the comet impacts are more effective than the asteroid ones. The influence of the target (water or rocks) is found to be small. The presence of the wake leads to a decrease of the value of $m_{\text {esc }}$ for the 3 and $10 \mathrm{~km}$ impactors and increase - for the kilometer sized bodies with small velocity.

Apart from the total escaping mass it is interesting to know how much air is removed from each altitude. It is important from the viewpoint of possible changes in the chemical composition of the atmosphere, because the relative concentrations of different components change with the altitude. 15,000 tracer particles were initially distributed below $100 \mathrm{~km}$ to follow the motion of different atmospheric layers and to deter mine the initial distribution of the escaping air. 
Several typical distributions are shown in Fig.l. At very high impact energies $D=10-30 \mathrm{~km}, V=50 \mathrm{~km} / \mathrm{s}$ the atmospheric escape region really looks like a cone. However, the air from the bottom part of this cone (which has the highest density and contains the most part of cone air mass) does not escape from the Earth. Just before meteoroid strikes the ground surface this air mass is contained in the shock compressed layer surrounding the projectile. Some portion of this gas is forced into the target, mixes with melt and is further ejected with rather small velocity (less than the escape one). The other part of the air surrounding the impactor spreads along the ground surface. The dense curtain of ejecta separates this air from the wake and upward expanding plume. These peculiarities of the flow (typical for all the impacts under consideration) considerably decrease the atmospheric erosion.
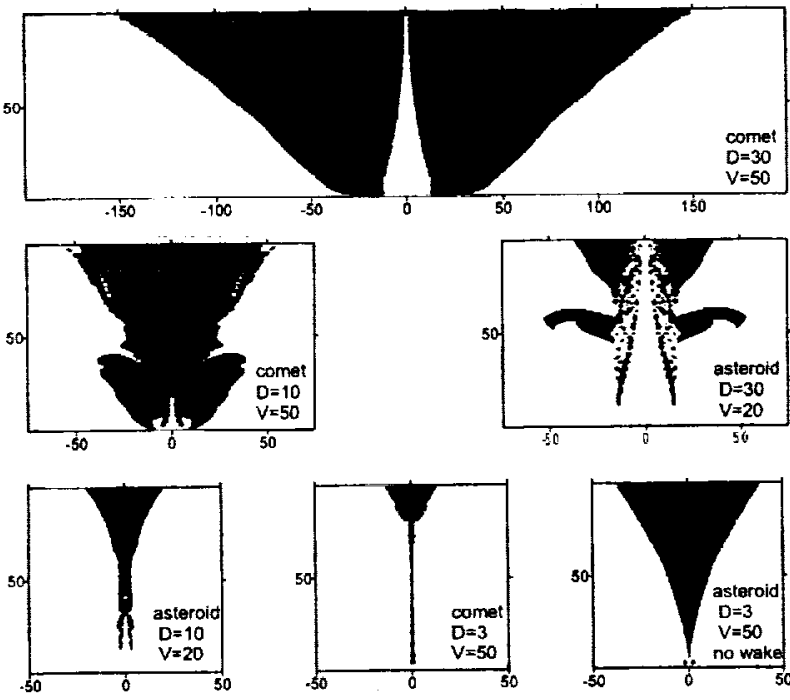

Fig.1.Volumes occupied by escaping air before the impact.

In the case of smaller impactor and lower velocity the region of escaping air does not look like a cone, but resembles a cylinder which radius is approximately equals the impactor radius. The bottom boundary of the cylinder is located at the altitude of several impactor sizes. In the run without wake the air is thrown out from the volume which looks like a cone with gradually increasing angle.

A rough estimate of atmospheric erosion induced by an oblique impacts can be derived from the modeling of the vertical impacts without the wake. It was shown in [11] that the oblique impact at large distances (about several atmospheric scales) from the impact site looks like a vertical impact without the wake. 3D simulations are used to justify this estimate.

Conclusions. First of all we can conclude that the impacts apparently could not decrease the mass of the
Earth's atmosphere. The ratio of escaping air mass to the impactor mass does not exceed the value of $2-3 \%$, which is considerably less than the mass of volatiles released during the impact.

Most likely the atmospheric erosion could not result in the deficit of xenon [12], because the relative escaping mass increases with the altitude.

A rough estimate of the erosion of the hypothetical primitive 1-bar Martian atmosphere [5] can be obtained by replacing the Earth's escape velocity $11 \mathrm{~km} / \mathrm{s}$ by the Martian one, which equals $5 \mathrm{~km} / \mathrm{s}$. The ratio of $m_{\text {esd }} / m_{\text {imp }}$ increases by 3-10 times.

The conclusion can be derived from the numerical simulations that direct radiation induced by the Chicxulub-like impact could be responsible for fire origin at an area of about $5-10 \%$ of the total Earth's surface.

Numerical simulations show that the value of highvelocity ejecta mass given in [13] is strongly overestimated and, hence, the process of ejecta reentry apparently could not be responsible for the global wildfires, or at least this problem needs more detailed investigation.

Another scenario seems to be more probable. The impact itself and local wildfires could result in the «impact winter». This in turn could lead to a global mortality of forests and other plants. The dead forests are known to be much more subjected to ignition than the living forests are. Moreover a fraction of totally burned mass of wood considerably (several times) increases in the dry mortal forests, which leads to the increase of the total mass of soot. The ignition of dead forests could result from the natural thunderstorm activity enhanced by strong atmospheric perturbations induced due to the impact. There is no evidence of instant fires and extinction - a period (or periods) of global wildfires could continue for several tens years (or even much longer).

References: [1] Melosh H.J. and Vickery A.M. (1989) Nature, 338, 487-489. [2] Vickery A.M. and Melosh H.J. (1990) in: Global Catastrophes in Earth history (eds.) GSA Spesial Paper 247, 289-300. [3] Zahnle K. et al. (1992) Icarus 95, 1-23. [4] Chyba c. (1990) Nature 343, 129-133. [5] Vickery A.M. (1994) LPSC XXV, 1437-1438. [6] Svetsov V.V. (1996) ESF Workshop, Postojna, abstract 91-92. [7] Thompson S.L. and H.S.Lauson (1972). Sandia National Laboratory Report SC-RR-71 0714.[8] Tillotson J.H. (1962) General Atomic Report GA-3216. [9] Kuznetsov N.M. (1965) Thermodynamic Functions and Shock Adiabats for air at High Temperatures, Moscow (in Russian). [10] Shuvalov V.V. (1999) Shock Waves 9, 6, 381-390. [11] Artem'eva N.A. and Shuvalov V.V. (1994) LPSC XXV, 3940. [12] Zahnle K.J. (1993) J. Geophys. Res. 98 e6, $10899-$ 10913. [13] Melosh H.J. et al., (1990) Nature 343, 251-254. 


\begin{abstract}
CONDENSATION IN AN IMPACT VAPOR PLUME : ESTIMATES OF GAS AND AEROSOL EMISSIONS GENERATED BY THE CHICXULUB IMPACT. D. Siret ${ }^{1}, \mathrm{E}$. Robin $^{1}$, F. Le Guem ${ }^{1}$ and B. Cheynet ${ }^{2}$, ${ }^{1}$ Laboratoire C.E.A./C.N.R.S. des Sciences du Climat et de l'Environnement, 91198 Gif-sur-Yvette cedex, France, Delphine.Siret@lsce.cnrs-gif.fr, ${ }^{2}$ Grenoble campus, 1001 avenue Centrale, B.P. 66, 38402 Saint Martin d'Hères cedex, France.
\end{abstract}

An extraterrestrial body impacted the Earth, in Mexico, 65 millions years ago, causing the mass extinction at the end of the Cretaceous [1]. Previous works described high emissions of $\mathrm{CO}_{2}(500 \mathrm{Gt}), \mathrm{H}_{2} \mathrm{O}(200 \mathrm{Gt})$ and $\mathrm{SO}_{2}(200 \mathrm{Gt})$. The injection of $\mathrm{SO}_{2}$ in the atmosphere is supposed to have caused an important climate cooling, followed by a greenhouse warming induced by the long residence time of $\mathrm{CO}_{2}[2,3]$. However, these works do not take into account the thermodynamic and kinetic reactions that occur during cooling. Such reactions must be considered since they are able to modify the mass balance of gaseous emissions [4].

The purpose of this study is to predict the condensation sequences in an impact vapor cloud, using a thermodynamic model, in order to estimate the nature and amount of gas and aerosol emissions in the atmosphere. Our calculations have been performed considering an impact vapor plume composed of i) projectile material only and ii) a mixture of projectile and target materials. In both cases, we have performed three calculations: 1) assuming thermodynamic equilibrium between condensates and gases during the whole cooling; 2) and 3) assuming thermodynamic equilibrium down to $1000 \mathrm{~K}$ and $2000 \mathrm{~K}$, respectively, and quenching below these temperatures.

All the results indicate the predominance of aerosol emissions, these latter representing about $70 \mathrm{wt} \%$ of the total emissions. The condensates are mainly silicate and ironrich phases, as diopside, anorthite, magnet- ite... The model also predict that the nature and amount of aerosol and gas emissions are strongly dependent on the initial composition of the vapor plume and on the thermodynamic and kinetic reactions that occur during cooling. For example, the sulfur emissions are restricted to $\mathrm{SO}_{2}$ ones if the kinetic of the solidgas reactions are slow below $2000 \mathrm{~K}$ (cases 2 and 3). At the contrary, they are restricted to aerosol emissions in case 1 (anhydrite, troilite, pyrite, ...).

Our calculations underline the importance and the necessity to take into account the condensation reactions and their kinetic of formation to estimate, in a qualitative and a quantitative way, the total atmospheric emissions generated by a huge asteroid impact, especially the aerosol ones whose optical properties may have produced a major radiative effect at the end of the Cretaceous.

References: [1] Alvarez W. et al. (1980) Science, 208, 1095-1108. [2] Pope K.O. et al. (1994) EPSL, 128, 719-725. [3] Pope K.O. et al. (1997) JGR, 102, 21,645-21,664. [4] Grossman, L. (1972) GCA, 36, 597-619. 
MINERALOGICAL STUDIES OF EXPERIMENTALLY SHOCKED DOLOMITE : IMPLICATIONS FOR THE OUTGASSING OF CARBONATES. R. Skála ${ }^{1}$ and F. Hörz ${ }^{2},{ }^{1}$ Czech Geological Survey, Geologická 6, CZ15200 Praha 5, Czech Republic, e-mail: skala@cgu.cz, ${ }^{2}$ NASA Johnson Space Center, Houston, TX 77058, USA.

Introduction: Common rock-forming rhombohedral carbonates - calcite and dolomite - constitute a considerable fraction of terrestrial sediments that may be shocked during hypervelocity impacts, such as during the KT event or at the Haughton structure. The relatively modest temperatures needed to decompose carbonates and to release their $\mathrm{CO}_{2}$ are easily attained during such impacts. However, detailed and quantitative understanding of the $\mathrm{CO}_{2}$ release of carbonates as a function of shock stress is still the subject of controversy, as are a number of other reactions and phase transitions that were suggested for carbonates.

The first devolatilization studies of carbonates in the early 80ties suggested that incipient devolatilization of calcite and/or dolomite commences at modest pressures, in the range $<10$ to $18 \mathrm{GPa}$ (amounting to $0.03-0.3 \%$ $\mathrm{CO}_{2}$ loss), with massive decarbonation (30-40\% $\mathrm{CO}_{2}$ loss) occurring at shock pressure of $20 \mathrm{GPa}$ and above [e.g. 1-3]. However, most later studies revealed that both calcite and dolomite are unexpectedly stable under shock conditions and no significant outgassing has been observed at pressures as high as $40 \mathrm{GPa}$ for calcite and $60 \mathrm{GPa}$ for dolomite [e.g. 4-10]. Despite these uncertainties, the calculations of O'Keefe and Ahrens [11] (and others) serve to illustrate that the $\mathrm{K} / \mathrm{T}$ bolide liberated sufficient $\mathrm{CO}_{2}$ that a substantial temperature increase of the global atmosphere is possible due to $\mathrm{CO}_{2}$ triggered greenhouse effects. The quantitative understanding of the devolatilization of carbonates as a function of shock stress is obviously critical to refine such calculations.

Additional proposals of shock effects in carbonates relate to the possibility of complex oxidation-reduction reactions involving formation of elemental carbon from shocked carbonates as detailed by [12-14]. Also, Martinez et al. [15] observed during static compression experiments the following reaction:

$$
\underset{\text { dolomite }}{\mathrm{CaMg}\left(\mathrm{CO}_{3}\right)_{2}} \rightarrow \underset{\text { aragonite magnesite }}{\mathrm{CaCO}_{3}}+\mathrm{MgCO}_{3}
$$

and they postulated that such mineral assemblages should also be found in shocked carbonates from terrestrial impact structures.

The mineral portlandite $-\mathrm{Ca}(\mathrm{OH})_{2}$ - was reported from shocked carbonates of the Haughton impact structure, presumably a weathering product of devolatilized carbonates [16]. However, this observation has never been confirmed by later studies [17]. Other observations indicate the reaction of carbonates with silicates, associated with highly shocked, vesicular, carbonate rich materials at Haughton, or the incorporation and solution of
$\mathrm{CaO}$ and $\mathrm{MgO}$ into silicate-based impact melts [e.g. 1821].

Shock Recovery Experiments: Sample disks of 8 $\mathrm{mm}$ diameter and $0.6 \mathrm{~mm}$ thickness were manufactured from a non-porous, massive, polycrystalline dolomiterock and shock-loaded following the methods of [22]. The peak shock pressures were (in GPa): 4.6, 8.2, 16.9, 17.0, 17.6, 19.2, 20.0, 24.1, 26.0, 29.8, 41.0, 55.2, 65.2, and 68.0. Pressures above $70 \mathrm{GPa}$ led to the reproducible, catastrophic disintegration of the metal containers that accommodate the target disks. These containers remain intact when silicates are being shocked at otherwise identical conditions, suggesting that the containers fail due to excessive vapor production of the carbonate targets.

Electron Probe Analyses: Microprobe investigations confirmed that the starting material consists of $\mathrm{Ca}^{-}$ rich dolomite (with the $\mathrm{Ca} / \mathrm{Mg}$ ratio ranging from 1.02 to 1.17) and subordinate K-feldspar, quartz and pyrite. No other, much less new, minerals were indicated by microprobe investigations of both unshocked and shocked materials, excepting rare droplets of tungsten from the tungsten-alloy ("Fansteel 77") sample container for samples shocked above $40 \mathrm{GPa}$. BSE images reveal increasing degrees of fracturing with increasing shock pressure.

X-ray diffraction: XRD reveals the presence of dolomite, quartz, and $\mathrm{K}$-feldspar in agreement with the microprobe observations. Diffraction peaks of quartz and feldspar broaden gradually at modest pressures and disappear completely at about $30 \mathrm{GPa}$ [23]. Specimens shocked above $40 \mathrm{GPa}$ contain variable, yet small amounts of tungsten, tungsten carbide, and sheelite representing artifacts due to shock-induced melting of the sample containers. In dolomites shocked above $60 \mathrm{GPa}$, periclase and pure calcite have been detected as well.

Raman Spectroscopy: None of the micro-Raman spectra displayed spectral bands other than those of dolomite. For each sample, three individual spectra have been collected over a spectral region from about 20 to 30 $\mu \mathrm{m}$. On this scale, all samples except those with the lowest degree of shock exhibit considerable data scatter. Most spectra display two shock induced effects: 1) systematic peak broadening with increasing peak pressure and 2) systematic decrease in absolute amplitude of the spectral bands [24].

Interpretations: The gradual decrease in amplitude/intensity of the XRD reflections and Raman spectral bands indicates a progressive decrease of the absolute fraction of crystalline dolomite that remains in the samples. This suggests that progressively larger fractions are 
rendered amorphous or have decomposed, i.e. lost their $\mathrm{CO}_{2}$. The intensity loss in the XRD data of the 104 reflection suggests only $50 \%$ of the sample remains crystalline at the highest experimental shock pressures. The amplitude decrease is not linear with pressure, however. A polynomial dependence best fits the observations with a relatively steep portion between about 15 and $40 \mathrm{GPa}$ accounting for some 15 to $35 \%$ absolute intensity lost. Neither XRD data nor Raman spectra confirmed the presence of magnesite + calcite due to the breakdown reaction proposed by [15].

Calcite and periclase were found, however, in samples shocked above $60 \mathrm{GPa}$. They most likely are the result of thermally induced breakdown of dolomite according to the following chemical reaction.

$\mathrm{CaMg}\left(\mathrm{CO}_{3}\right)_{2} \rightarrow \mathrm{CaCO}_{3}+\mathrm{MgO}+\mathrm{CO}_{2} \uparrow$ dolomite calcite periclase gaseous $\mathrm{CO}_{2}$

Obviously, shock induced temperatures increase with increasing pressure and will enable this reaction above some threshold pressure, which we found to be $60 \mathrm{GPa}$. The amount of periclase is estimated from measured intensities of XRD reflections using RIR to reach about 3.5 $\%$ at $68 \mathrm{GPa}$ and about $2.5 \%$ at $65.2 \mathrm{GPa}$. The percentage of calcite can not be calculated directly because of very poor resolution of the calcite 104 reflections; it is expected to be complementary to that of periclase, however.

The scatter in Raman peak widths and amplitudes among individual measurements on a single sample reveals that the shock deformation of dolomite was rather heterogeneous on scales of tens of microns. This probably applies to outgassing processes as well, yet the general trend in amplitudes indicates that outgassing increases systematically and maximum outgassing was indeed achieved at highest experimental pressures.

Discussion: Results achieved with various techniques indicate variable amounts of carbon dioxide being released during shock loading and associated post-shock heating. Our observations indicate that dolomite outgasses massively during laboratory impacts at peak pressures of about $70 \mathrm{GPa}$. Destruction of the sample containers at these pressures prevented the recovery and characterization of the solid residues, however. Nevertheless, it is reasonable to expect that these materials are similar to those found at lower pressures, i.e. mixture of calcite and periclase, the dominant decomposition products of dolomite. We cannot positively exclude, however, that the aragonite + magnesite assemblage postulated by [15] initially forms during dynamic compression and that - subsequently - the aragonite undergoes a temperature-induced phase transition to calcite, and the magnesite decomposes to periclase and $\mathrm{CO}_{2}$.

Conclusions: The results on experimentally shocked dolomite show that the amount of $\mathrm{CO}_{2}$ released during hypervelocity impact into a carbonate-rich target was probably overestimated in the past. Shock effects are distributed very heterogeneously in the polycrystalline dolomite on the scale of tens of microns and associated outgassing could be substantially localized. This is consistent with the concept of thermally induced shear bands as the dominant deformation mechanism of shocked carbonates [e.g. 3, 25, 26]. The search for solid products of this outgassing process in natural impact structures may be largely obscured by post-impact geological processes, as there is no evidence in naturally shocked samples for the phase assemblage found in the experimentally shocked samples. Most probably the major products like $\mathrm{MgO}$ and $\mathrm{CaO}$ easily dissolved in silicate melts or in watery solutions at elevated temperatures, the latter forming secondary minerals, including carbonates, that contain no clues for any shock-produced prescursors.

References: [1] Boslough M. B. et al. (1982) EPSL, 61, 166-170. [2] Lange M. A. and Ahrens T. J. (1986) EPSL, 77, 409-418. [3] Tyburczy J. A. and Ahrens T. J. (1986) JGR, 91, 4730-4744. [4] Love S. L. and Ahrens T. J. (1998) LPS XXIX, \#1206. [5] Kotra R. K. et al. (1983) LPS XIV, 401-402. [6] Martinez I. et al. (1995) JGR, 100, 15,465-15,476. [7] Bell M. S. (1997) Meteoritics \& Planet. Sci., 32, A11. [8] Bell M. S. et al. (1998) LPS XXIX, \#1422. [9] Langenhorst F. et al. (1998) Meteoritics \& Planet. Sci., 33, A90. [10] Langenhorst $\mathrm{F}$. et al. (2000) LPS XXXI, \#1851. [11] O'Keefe J. D. and Ahrens T. J. (1989) Nature, 338, 247249. [12] Miura Y. and Okamoto M. (1997) Excursion Guide and Abstracts, pp. 38-40, IGCP Project \#384, Tallinn. [13] Miura Y. et al. (1999) LPS XXIX, \#1522. [14] Rietmeijer F. J. M. et al. (1999) LPS XXIX, \#1051. [15] Martinez I. et al. (1996) Am. Mineral., 81, 611-624. [16] Ostertag R. et al. (1985) LPS, XVI, 633-634. [17] Metzler et al. (1988) Meteoritics, 23, 197-207. [18] Martinez I. et al. (1994) EPSL, 121, 559- [19] Hörz F. et al. (1998) LPS XXIX, \# . [20] Mittlefehldt D. and Hörz F. (1998) LPS XXIX, \# . [21] Kenkmann T. et al. (1999) LPS XXX, \#1561. [22] Gibbons, R. V. et al. (1975) Lunar Sci. Conf., 6th, 3143-3171. [23] Skála R. et al. (1999) LPS XXX, \#1327. [24] Skála R. et al. (2000) LPS $X X X I$, \#1567. [25] Grady D. E. (1980) JGR, 85, 913924. [26] Kondo K.-I. and Ahrens T. J. (1983) Phys. Chem. Minerals, 9, 173-181. 


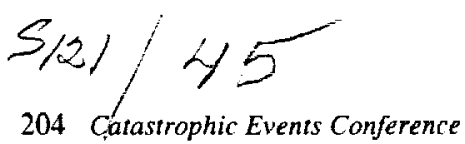

THE FATE OF PLANKTIC FORAMINIFERS CROSSING THE KT BOUNDARY (OR NOT): A REVIEW. J. Smit ${ }^{1}$. 'Institute of Earth Sciences, Vrije Universiteit, de Boelelaan 1085, 1081HV Amsterdam, the Netherlands, smit@geo.vu.nl.

Introduction: Planktic foraminifers appear to suffer an almost complete annihilation directly at the KT boundary or, in particular at higher latitudes, a few thousand years later. Their extinction i.e. the disappearance of the last surviving representative, is still a matter of debate. Which lineage (or more) that crossed the K/T boundary and becomes the founder of modern planktic faunas is also still unclear. The extinction process can be monitored in three periods $1-3$, tied to the global chronostratigraphic marker, the KT boundary ejecta layer of the Chicxulub impact (fig. 1): 1) The period preceding the Chicxulub impact ejecta emplacement, 2) The boundary clay (BCL. P0 zone) (Strangelove ocean) marked by a strongly negative - 13C isotope anomaly, and 3) The period following the boundary clay deposition, marked by a rapid diversification ( $\mathrm{P} \alpha$-eugubina zone)

Period 1: Planktic foraminifers are sensitive indicators of paleoceanographic changes. Temperature,

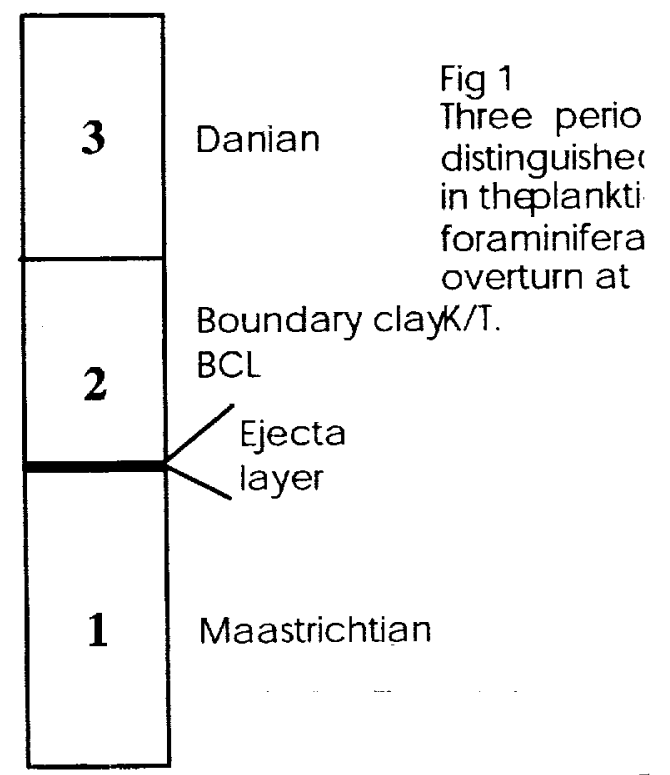

salinity, watermass, thermocline changes are reflected in relative abundance changes of the planktic population. Planktic foraminiferal populations do change very little in the Late Maastrichtian, whereas the diversity remains very high. The traditional Late Maastrichtian biozone, the Abathomphalus mayaroensis Zone, has duration of $2.6 \mathrm{Ma}$, during which period almost no species appear or disappear. Recently, the top part of the A. mayaroensis zone has been subdivided into three subzones, as consequence of the disappearance of the marker species $G$. gansseri, and the
FAD of $\mathrm{P}$. hariaensis and $P$. hantkeninoides (fig 2), leading to a further diversity increase towards the KT boundary. It is still a debate whether the uppermost part of the Maastrichtian shows a significant increase in extinction rate, as suggested by [1, 2] or a normal background variation in species composition and diversity. A blind test effort to settle this debate has led to further confusion rather than a solution [3, 4]. A detailed quantitative analysis of samples spaced at $10 \mathrm{~cm}$ intervals of the top 3.3 meters of the Kef section shows typical background variations on a $1.5 \mathrm{~m}$ cycle, consistent with orbital precession cycles. The analysis also demonstrates (\% Fragments) the increased influence of dissolution approaching the KT boundary, that may have eliminated rare species from statistical counting, suggesting a decrease in diversity [1].

Period 2: Specimen abundance drops by more than an order of magnitude, exactly at the ejecta layer. It is not clear what sedimentation rates prevailed in the BCL, but most sedimentological evidence suggests a decrease in sedimentation rate, bringing down the specimen flux another factor 2 to 3 . Whatever the final extinction mechanism, this indicates a truly catastrophic reduction event, reducing the planktic population to a global minimum. This is supported by the 2.5 permil $-13 \mathrm{C}$ decrease measured in surface dwelling nannofossils, that strongly suggests a reduction of primary production during deposition of the $\mathrm{BCL}$. Originally [5], the P0 zone was thought to contain only relicts of the Maastrichtian mayaroensis fauna. However, recently [6], some rare lowermost Paleocene specimens of $P$. eugubina were encountered in the P0 zone. It is not clear whether these specimens are contaminants from burrows, or truly indigenous.

Period 3: Fairly rapid, over a few $\mathrm{cm}$ in the most expanded sections, the new Paleocene fauna radiates and the number of specimens increases to Maastrichtian levels. The lowermost fauna already contains of a number of species; thus the initial radiation must have taken place somewhere in P0 Zone. Characteristic for this period is the development of unstable associations. Successively different species dominate at different levels, at different environments. The first 'bloom' usually is of $G$. cretacea, in particular at near-shore environments, followed by $P$. eugubina in both deep and shallow-water seas.

Ancestor-descendant. The question of ancestordescendant is not resolved. [6] Smit speculates that the 
clear survivor species $G$. cretacea is the only ancestral species of modern planktic faunas, Liu and Olsson [7] indicate three species, $G$. cretacea, $H$. monmouthensis and $H$. holmdelensis as ancestral to the early Paleocene stock, that soon diversifies to cancellate-spinose and non-spinose premuricate lineage's. However, wall structures between these species and earliest Paleocene cancellate species differ significantly, and require some morphological jumps not observed yet among KT planktic faunas.

References: [1] Pardo, A., Ortiz, N. \& Keller, G. (1996) in Cretaceous-Tertiary Mass Extintions 139172 (W. W. Norton, New York,. [2] Keller, G. (1988) Marine Micropaleontology 13, 239-263 . [3] Ginsburg, R. (1997). Marine Micropaleontology 29, 101103. [4] Aubry, M. P. (1999) Marine Micropaleontology 36, 65-66 . [5]Smit, J. (1982)Geological Society of America Special Paper 190, 329-352. [6] Norris, R. D., et al (1999) Geology 27, 419-422. [7] Liu, C. and Olsson, (1992) Joumal of Foraminiferal Research 22, 328-346.

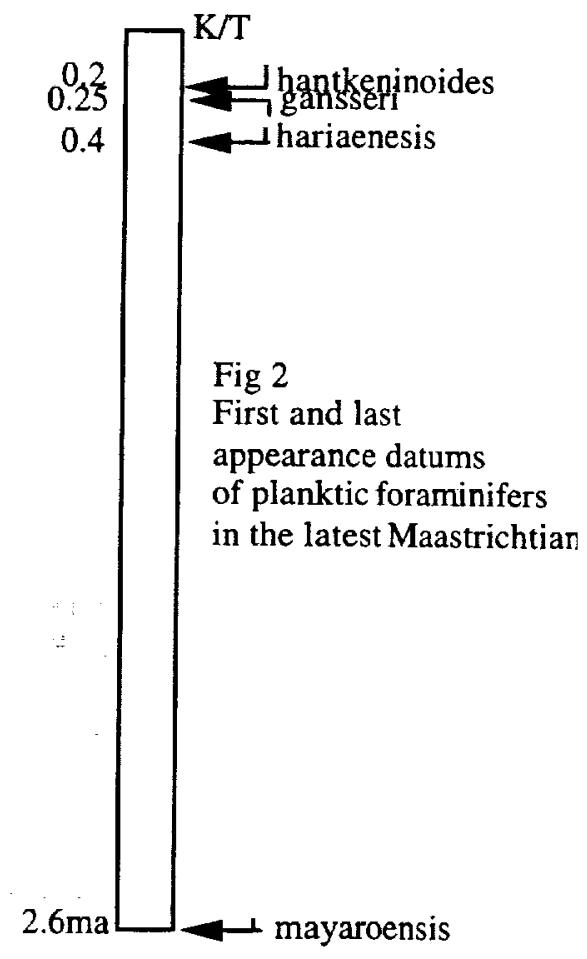


MINERALOGY AND TRACE ELEMENTS GEOCHEMISTRY OF THE CRETACEOUS/TERTIARY BOUNDARY (K/T) AT GABAL QREIYA SECTION, NILE VALLEY, EGYPT: EVIDENCE FOR A PREK/T IMPACT. M. F. Soliman ${ }^{1,2}$, H. Palme ${ }^{3}$, A. El Goresy ${ }^{4}$ and B. Spettel $\left.{ }^{4}, 1\right)$ Max-Planck- Institut für Kernphysik, D- 69117 Heidelberg - Germany, 2) Present adress: Geology Department, Assiut University, Assiut- Egypt, 3) Institut für Mineralogie und Geochemie - Universität Köln, D- 50674 Köln - Germany, 4) Max-Planck Institut für Chemie, Saarstrasse 23, D-55122 Mainz - Germany.

1. Introduction: The discovery of a large iridium anomaly at the $\mathrm{K} / \mathrm{T}$ boundary in marine shales at Gubbio (Italy), Stevens Klint (Denmark), and Woodside Creek (New Zealand) lead Alvarez et al. [1] to propose that an asteriod struck the earth 65 million years ago, raising an earth-girdling dust cloud and causing major extinctions of the plant and animal life at the end of the Cretaceous period.

The mineralogy has played an important role in testing the hypothsis of Alvarez et al. The discovery of magnesioferrite [2], spinel [3], shocked quartz grains [4], platinum grains, $\mathrm{Fe}-\mathrm{Cr}-\mathrm{Ni}$-rich particles and $\mathrm{Ni}$-rich minerals $(\mathrm{NiO})[5]$ in the Ir-rich layer provides evidence that an asteriod or a comet impact was the main cause of the extincion at the end of the Cretaceous time.

2. Site location and sampling: Gabal Qreiya (Abu Had) crops out $50 \mathrm{~km} \mathrm{NE}$ Qena town in Wadi Qena region ( long. $32^{\circ} 57^{\prime}$ and lat. $26^{\circ} 31^{\prime}$ ). Within the framework of a mineralogical and geochemical studies, in a vertical cross section, continuous sampling was conducted at the surface outcrop of the transitional sediments across the K/T boundary zone at Gabal Qreiya (Nile Valley/Egypt).

3. Stratigraphy and sea level change: Lithologically, the $\mathrm{K} / \mathrm{T}$ boundary in Gabal Qreiya section can be traced on the surface which separates the lower (1) shaley marl from the upper (2) marly shale. Paleontologically, it is found to be above the shaley marl with about $7 \mathrm{~cm}$. No $\mathrm{K} / \mathrm{T}$ clay layer was found in Gabal Qreiya. The sequence of the $\mathrm{K} / \mathrm{T}$ boundary at Gabal Abu Had consists the following zones of planktonic foraminifera arranged from base to top: Abathomphalus mayaroensis zone, Pseudoguembelitria deformis zone (103 cm thick), PO zone (10 cm thick) and Globigrina triloculinoides zone. The section of Qreiya is still more on innershelf position as El Kef within a very large area of Southern Tethys Shelf. This area showed specially shallowing events of regional environments with hypersaline and $\mathrm{O}_{2}$ declining positions (Herm pers. com.). Based on its microfossils analyses, a regression can be traced from 1.2 Ma. before the $\mathrm{K} / \mathrm{T}$ to 850,000 years above the $\mathrm{K} / \mathrm{TB}$. The paleoecological conditions are changing a little, perhaps very regionally, in temperature as a result of water movement. Depths could be analyzed from $150 \mathrm{~m}$ (1.2 Ma. before the $\mathrm{K} / \mathrm{T}$ ) to $20-60 \mathrm{~m}$ round about $\mathrm{K} / \mathrm{T}$ boundary. Later (1 Ma. above The $\mathrm{K} / \mathrm{T}$ ), deeper water conditions $(100 \mathrm{~m}$ ) could be reached (Herm, pers. com.) The INAA indicated that during the deeper marine deposition (depth $=100-150 \mathrm{~m})$, the $\mathrm{Cl} / \mathrm{Br}$ ratio was very high (1856). During the deposition of the $\mathrm{K} / \mathrm{T}$ boundary, at shallower depth $(20-60 \mathrm{~m})$, the $\mathrm{Cl} / \mathrm{Br}$ ratio drooped to 162 indicating high salinity and very probably high temperature. When transgression occurred, the depth increased to $100 \mathrm{~m}$, and the $\mathrm{Cl} / \mathrm{Br}$ ratio raised to 264 .

4. Elemental patterns: About 15 samples represent the $\mathrm{K} / \mathrm{T}$ boundary zone in Gabal Qreiya were analysed by INAA for iridium and more than 25 elements. The Ir abundance is found to be below the detection limit in all samples $(<1.2$ to $<4.5 \mathrm{ppb})$.

Although, the $\mathrm{K} / \mathrm{T}$ clay layer and frequently Ir anomaly are missing at this sequence, the distribution patterns of the trace elements, $\mathrm{Co}, \mathrm{Ni}, \mathrm{Cr}, \mathrm{Sc}, \mathrm{Re}, \mathrm{Zn}, \mathrm{Sb}$, and $\mathrm{Se}$ are very similar of those of Stevns Klint, Caravaca and Flaxbourne River (New Zealand) where these elements are well correlated with one another. The correlation among these elements at Gabal Qreiya was found only within $22 \mathrm{~cm}$ bracketing the boundary in the middle.

5. Mineralogy: The mineralogical characteristics of the Cretaceous/Tertiary boundary layers are compared with the lithologies at Woodside Creek and Stevns Klint. The sediments of the $\mathrm{K} / \mathrm{T}$ boundary zone at Gabal Qreiya section contain different concentrations of pyrite, sphalerite, marcasite and detrital grains of ilmenite, magnetite, pyroxenes and feldspars. The abundance of pyrite and sphalerite increases gradually upward from the upper $10 \mathrm{~cm}$ of the upper Cretaceous shaley marl. The abundance of detrital minerals culminates $7 \mathrm{~cm}$ below the lithological boundary. The pyroxenes compositions from the K/T boundary samples of Gabal Qreiya and Woodside Creek are plotted in the pyroxene quadrilateral. It is evident that both pyroxenes have similar composition. The data points of both localities lie in the fields of augite, ferroaugite and rarely salite.

5.1. Possible Meteoritic Particles: One of the most remarkable findings at Qreiya $7 \mathrm{~cm}$ below the lithological $\mathrm{K} / \mathrm{T}$ boundary is the discovery of micron-sized $\mathrm{Fe}-\mathrm{Cr}-\mathrm{Ni}$ - oxide particles impergnated in potassium feldspar grains. The particles are aligned as microveins up to $100 \mu \mathrm{m}$ in length and $5 \mu \mathrm{m}$ in width. The particles were found in chemically and mineralogically untreated grains (unpolished grains) of feldspars. EDX energy dispersive analysis of 
these particles at the SEM shows they consist of an oxidized alloy consisting on the average $66 \mathrm{wt} . \% \mathrm{FeO}, 20.78$ wt. $\% \mathrm{Cr}_{2} \mathrm{O}_{3}$ and $11.48 \mathrm{wt} . \% \mathrm{NiO}$.

Metalic particles with a typical composition like these particles were found injected into fractured rocks at the floor of the Ries crater in Germany [6], Rochechouart in France [7], Terny in Russia [8], and in the basal K/T boundary layer at Zumaya-Spain enclosed within a feldspathic spherules [5]. The similarity on chemical composition, mode of occurrence, and sizes with metallic alloy particles injected into rocks beneath two known impact craters led us to suggest that, these $\mathrm{Fe}-\mathrm{Cr}-\mathrm{Ni}$ particles probably represent metal condensates from the vapour cloud at the $\mathrm{K} / \mathrm{T}$ event(s) during a meteorite impact. We suggest that the impacting body was a stony meteorite.

The enrichment of biogenic sulphides around the $\mathrm{K} / \mathrm{T}$ boundary started immediately above the particles-bearing sample with a large anomaly exactly at the K/T boundary. Thus Strongly indicates that reducing conditions directly followed the impact and was associated with the extinction of the Cretaceous phytoplankton and perhaps resulted globally from the excess of sudden death of organisms. This reducing event occurred globally, as evidenced from observations ([9-13]) in Stevns Klint K/T boundary; [14] in Woodside Creek K/T boundary clay;[15] in El Kef K/T boundary; and [16] in Agost, Spain K/T boundary. This work extends their presence to four different Egyptian K/T
sites [17].

References: [1] L.W. Alvarez, Alvarez, W. , Asaro, f. , and Michel, H. V., Sceince 208, 1095-1108, 1980. [2] B.F. Bohor, and Izett, G. A ., LPSC 17, 68-69, 1986. [3] E. Robin, Bonté, Froget, L. Jehanno, C. , and Rocchia R., Earth and Planetary Science Letters 108, 181-190, 1992. [4] B.F. Bohor, Foord, E. E. , Modreski, P. J. , Triplehom, D. M., Science 224, 867-869, 1984. [5] E. Doehne, and Margolis, S. V., Geological Soceity of America Special Paper 247, 367-382, 1990. [6] A. El Goresy, and Chao, E. C. T., Earth and Planetary Sceince Letters 31, 330-340, 1976. [7] W. Horn, and El Goresy, A., Bull. Minéral. 104, 587-593, 1981. [8] A.A. Valter, Burmistrova, V. V. , and Sharkin, O. P., LPSC XVIII, 1032-1033, 1982. [9] F.T. Kyte, Zhou, Z. and Wasson J. T., Nature 288, 651-656, 1980. [10] F.T. Kyte, Smit, J. , and Wasson, J. T., Earth and Planetary Science Letters 73, 183-195, 1985. [11] J.C. Varenkamp, and Thomas, E., Geological Society of America, special paper 190, 461-467, 1982. [12] B. Schmitz, Geochimica Cosmochimica Acta 49, 2361-2370, 1985. [13] B. Schmitz, Geology 16, 1068-1072, 1988. [14] R.R. Brooks, Hoek, P. L., Reevs, R. D., Wallace, R. C., Johnston J. H., Ryan, D. E., Holzbecher, J., and Collen, J. D., Geology 13, 738-740, 1985. [15] M. Lindinger, Ph.D. thesis, ETH Nr.8638, Zurich, 253 P., 1988. [16] F.M. Ruiz, Huertas, M.O. , Palomo, I. , and Barbieri, M., Chemical Geology 95, 265-281, 1992. [17] M.F. Soliman, Ph.D. thesis, MPI für Kernphysik, Heidelberg-Germany 
208 Catastrophic Events Conferęnce

EARTH COLLISION WITH HIGH INCLINATION ASTEROIDS. N. A. Solovaya, Celestial Mechanics Department, Sternberg State Astronomical Institute, 119899 Moscow, Russia (solov@sai.msu.ru), E. M. Pittich, Astronomical Institute, Slovak Academy of Sciences, 84228 Bratislava, Slovak Republic (pittich@savba.sk).

The orbital evolution of fictitious high inclination main belt asteroids with movement corresponding to the conditions of the Tisserand invariant for $\mathrm{C}=\mathrm{C}(\mathrm{L} 1)$ in the restricted three body problem has been investigated. The obtained results showed that the bodies with inclinations within $40^{\circ}-80^{\circ}$ and $100^{\circ}-140^{\circ}$ and eccentricities within $0-0.4$ are dynamically stable at least during the 200,000 years investigated period, and periodically change their inclinations, eccentricities and perihelion distances. In some time, they can reach the vicinity of the Sun and during their orbital evolution they cross the
Earth orbits many times. The bodies belong to the potential candidates dangerous for the Earth in that they may bring about catastrophic events on its surface.

The discoveries of some tents retrograde sungrazers with LASCO coronographs of the SOHO spacecraft and MMC and SOLWIN space equipments lead to the idea that bodies with the studied orbital parameters exist, whereby majority of their revolution around the Sun occur in the space outside the Mars orbit. 
THE THEORY OF BREAKAGE AND ASTEROID SIZE DISTRIBUTION. D. H. Speidel, Queens College, City University of New York, Flushing, NY 11367-1597, USA; David_Speidel@qc.edu.

The Theory of Breakage: The last decade has seen an increasing interest by both scientists and the public in hazards associated with asteroid/cometary impacts. The degree of hazard depends not only on the frequency of impacts, but also on the size distribution of the impactors. Because of sampling difficulties caused by the relative shortness of sampling time and the vastness of space, it is necessary to make assumptions about the general size relationship among asteroids. This paper presents an argument for a modification in the present operating assumption of a power law for such size distributions.

The size distribution of asteroids -- both Main Belt and Near Earth (NEAs) -- can be described as the result of a cascade produced by successive impacts and fragmentations. The results extend over 12 orders of magnitude -- from over $1000 \mathrm{~km}$ in diameter to micrometer dust. With even partial conservation of mass from generation to generation of fragments, the overall effect of the cascade is that of a power law with a steadily increasing number of smaller and smaller particles. A parallel exists in Jonathan Swift's verse: a flea hath smaller fleas that on him prey; and these have smaller yet to bite 'em, and so on ad infinitum.

The products of a single fragmentation event by the single nature of the event can not be a power law; there has to be maximum and minimum cut-offs in the size of the products. A.N. Kolmorgorov [1] took time off from his work on probability theory and the analysis of turbulence to explain the occurrence of two-parameter log normal distribution in ores crushed by natural or artificial processes. Aitchison and Brown [2] point out that this distribution pattern is essentially a restatement of the theory of proportional effect in terms of distribution function and apply the term a theory of breakage, crediting Kolmorogov. Such log normal fragment size patterns have been known for a long time in sedimentological analyses from the work of Krumbein and Pettijohn [eg., 3].

Observations about asteroid size frequency and related experiments: It is believed that NEAs come from a fragmentation process in the Main Belt asteroids with subsequent injection into Earth orbit [eg, 4]. Careful work by Binzel [5] discovered small Main Belt asteroids whose size is consistent with NEAs. Rabinowitz et al. [6] reported a second NEA population, one that was several orders of magnitude smaller that the NEAs previously observed. Thus, one might be looking at asteroid populations that represent three levels of the fragmentation cascade: large and small in the Main Belt; small and smaller as NEAs. The problem is defining those populations.

The analysis of finite mixture distributions depends initially on being able to approximately define how many and what characteristics (mean, standard deviation, \% of total) each population has [7]. One such graphical way of indicating the presence, proportion, and two-value characterizations of individual populations present in a mixture is that of probability graphs, a technique used widely in exploration geochemistry [8]. Speidel has used this to cluster first 153 NEAs [9], and subsequently, over 600 NEAs [10] into two NEA populations with respective means of $\mathrm{H}=17.8$ and $\mathrm{H}=25.5$, roughly corresponding in size to 1.0 and $0.03 \mathrm{~km}$ in diameter. The relative proportions of the two populations is clearly a function of measurement sensitivity. However, the two populations have significant enough difference in visual magnitude within the sensitivity range to allow discrimination and separation into multiple log normal populations. Because of the shape of the curves, size frequency distribution of normally distributed samples above the mean of $\mathrm{d}>1 \mathrm{~km}$ would not significantly differ from a power law model. Significant variation would occur between the two models for the estimated number of asteroids $<1 \mathrm{~km}$ with the $\log$ normal model having much lower numbers. This would also lower the natural hazard for Earth from asteroids < $1 \mathrm{~km}$ diameter from that presumed from a power law distribution.

In addition to the $\mathrm{H}=17.8$ population represented by the small asteroid population recognized in the Main Belt, more than $80 \%$ of the Main Belt size distribution can be described as a single population with a mean visual magnitude of $\mathrm{H}=11.2$ (a logarithmic mean diameter of about $40 \mathrm{~km}$ ). Eros and Ganymed, the largest of the NEAs, may be representatives of this larger Main Belt population.

Laboratory experiments on ballistic impacts designed to retain and analyze fragment size frequency lend support to the log normal pattern [11] with in some cases, two log normal populations able to be discriminated $[12,13]$. The general description (and a replot of their data) for fragments as core, fine fragments, and fragments other than core fits a log normal population and does not force the use of multiple power law populations - a logical contradiction in the applicability of power laws presently favored [14] to describe experimental results.

Associated crater size frequencies: Craters should also follow a log normal size distribution based on the assumed cause-effect relationship with asteroids. The microsized particles appear to be log normal based on measurement of microcraters on the Long Duration Exposure Facility [15]. These results showed a log normal distribution with a peak near 220 micrometers.

Speidel [10] has shown that terrestrial craters younger than $1000 \mathrm{My}$ and older than $1 \mathrm{My}$ fit a log normal population with a $10 \mathrm{~km}$ mean diameter. Craters younger than 1 My appear to be a mixture of the $10 \mathrm{~km}$ population and a smaller crater diameter population with a $\log$ normal mean diameter of $0.12 \mathrm{~km}$.

Summaries of lunar crater frequencies show increases 
in frequency of over 30 orders of magnitude in going from $1000 \mathrm{~km}$-sized craters to submicrometer ones [16, $17,18]$. The undulating pattern in lunar relative frequency plots can be a natural outgrowth of the overlap of individual log normal populations from the various steps in the size cascade. In spite of complications from secondary craters, uneven distributions, and other sampling problems, analysis of lunar compilations supplemented by the author [19] can define at least two of the crater populations (mean diameters of $18 \mathrm{~km}$ and $1.2 \mathrm{~km}$ ) and two other unconstrained populations on either side (mean diameter $<0.1 \mathrm{~km}$ ? and $>300 \mathrm{~km}$ ?). Crater patterns support the concept of individual asteroid populations with diameters with log normal distributions even though the overall effect of size distribution approximates a power law [20]

The size frequency distributions of both asteroids and associated craters can be interpreted as a set of individual $\log$ normal populations that together form a cascade that appears as a power law. This is consistent with Kolomogorov's theory of breakage. The apparent slope of the power law and/or changes in the slope of the curve would be a direct effect of the relative proportions of each population making up the sample of interest.

Finally, the recent reduced estimate for the number of kilometer-sized near-Earth asteroids [21] based on 45 detections by the Near Earth Asteroid Tracking program is totally consistent with the two log normal NEA populations discussed herein and previously [10]

References: [1] Kolmogorov A.N. (1941) Dokl. Akad. Nauk. SSSR, 31, 99-101. [2] Aitchison J. and Brown J.A.C. (1957) The Lognormal Distribution, Cambridge Univ Press. [3] Krumbein W.C. and Pettijohn F.J. (1938) Manual of Sedimentary Petrography, Appleton-Century. [4] Morbidelli A. and Froeschle C (1998) 113-136 in Impacts on Earth, Benest D. and Froeschle C. eds., Springer-Verlag. [5] Binzel R. P. et al. (1992) Icarus, 99, 225-237. [6] Rabinowitz D. L. et al. (1993) Nature, 363, 704-706. [7] Titterington D. M. et al. (1985) Statistical Analysis of Finite Mixture Distributions, Wiley. [8] Sinclair A. J. (1957) Applications of Probability Graphs in Mineral Exploration Sp.V. 4, Assoc. Explor. Geochem. [9] Speidel D. H. (1994) LPS XXV, 1319. [10] Speidel D. H. (1999) Asteroids, Comets, Meteors Comell, 124. [11] Nakamura A and Fujiwara A. (1991) Icarus, 92, 132146. [12] Evans N. J. et al. (1993) LPS XXIN, 457-458. [13] Evans N. J. et al. (1994) GSA Sp. Pa 293, 93-101. [14] Davis D. R. (1998), 113-136 in Impacts on Earth op. cit. [15] Love S. G. and Brownlees D. E. (1993) Science, 262 550-553. [16] Grieve R. A. F. (1994) Episodes, 17 9-17. [17] Neukum G. and Ivanov B. A.(1994), 359-416 in Hazards Due to Comets and
Asteroids Gehrels T. (Ed), U. Arizona Press. [18] Heiken G. H. et al. (eds) (1990) Lunar Sourcebook, Cambridge. [19] Speidel D. H. (1991) Geol Soc Am Abst 23, A474-A475. [20] Dohnanyi J. S. (1969) J. Geophys. Res., 74, 2531-2554. [21] Rabinowitz D. et al. (2000) Nature 403, 165-166. 
PALEOENVIRONMENTS OF THE LATE CRETACEOUS - EARLY PALEOGENE TETHYS; BUILDING A BASELINE FOR ASSESSING PAST GLOBAL CHANGE. R. P. Speijer, Department of Geosciences, Bremen University, P.O. Box 330440, 28334 Bremen, Germany (speijer@uni-bremen.de).

Introduction: Research on major biotic events and global change in earth history has grown explosively during the last two decades. In their initial stages of development, hypotheses forwarded to explain these phenomena are commonly based on a limited number of widely separated sections. Through hypothesis testing the global pattern of an event gradually emerges. However, following this procedure regional context and background conditions and variability during relative stasis prior to a big event tend to be neglected.

Background conditions and anomalies: In order to appreciate the systematics and significance of apparent anomalies observed in individual sections, there is a need for better knowledge of background conditions and variability. Not only the "best" sections spanning a certain event demand intensive investigations; numerous sections - also those which are not as complete or well exposed - covering a whole range of paleoenvironments basin-wide require detailed research. This approach could lead to a baseline of background conditions, distributions of taxa or sedimentary facies, etc., against which any biotic, geochemical or sedimentary change should be evaluated prior to and independent of any comparison with the "global" record. In this way, true anomalies with unique characteristics can be distinguished from more ordinary lateral shifts of bio- or sedimentary facies, climate belts, etc.

Global events - expression in the Tethys: The Maastrichtian to early Eocene spans an interval comprising at least three major events of global significance: Mid-Maastrichtian deep ocean circulation reversals, the $\overline{\mathrm{K}} / \mathrm{T}$ boundary mass-extinction and the late Paleocene thermal maximum (LPTM). In this time in terval, the Tethys was a narrowing ocean within the subtropical belt between Eurasia and Äfrica/India. Remnants of extensive epicontinental seas on the passive southern Tethyan margin (north Africa, Middle East) provide excellent opportunities to study the paleoenvironments on a basin-wide scale. Since also some of the world's "best" sections spanning the $\mathrm{K} / \mathrm{T}$ boundary and the LPTM are found in this region (particularly in Egypt, Italy, Spain, and Tunisia), it is of timely importance to provide an integrated paleoenvironmental baseline for this time interval and region. Furthermore this baseline could provide critical tests of climatic and oceanographic modeling results. This presentation will delineate the present status and current activities towards achieving this goal and an evaluation of future research needed. Focus will be on a quantification and statistic evaluation of microbiotic data (e.g. foraminif- era, dinoflagellates, ostracoda) and integration with geochemical data (e.g. stable isotopes, clay minerals, TOC) and sedimentary facies. This will be exemplified by results from epicontinental basins in the Middle East.

Example of need for a baseline: A good example of the practice described in the introduction provides the case of the K/T-boundary. Soon after the proposition of an asteroid impact and its possible relationship to the extinctions from planktic microbiota to dinosaurs at $\mathrm{K} / \mathrm{T}$-boundary time [1], numerous detailed studies were presented either against or in favor of the impact or the impact-extinction coupling hypothesis. Only rarely, the observed phenomena of individual sections were evaluated intensively in a local to regional context prior to confirming or refuting any of these hypotheses. For my own field, for instance, it has been suggested that benthic foraminifera assemblages from Tethyan margins indicate large sea-level fluctuations at or prior to the $\mathrm{K} / \mathrm{T}$ boundary $[2,3]$. Sea-level may well have fluctuated considerably during the $\mathrm{K} / \mathrm{T}$ - boundary transition. However, to date there is no sound paleobathymetric distribution model of taxa for the Maastrichtian Tethys, based on a quantified record across the Tethyan paleoslope, against which any benthic foraminiferal changes can be properly evaluated. There are such models for the Paleocene Tethys $[4,5]$ and for the lower Maastrichtian east coast of the US [6]. However, because of endemism, extinctions and evolutionary turnover, community restructuring, and different oceanographic conditions, application of these models, assuming fixed depth limits for certain taxa is unwarranted. Without a benthic foraminiferal paleoslope model for the Tethys, it is not possible to solve the question to what extent - if any - sea-level change contributed to the turnover observed in Tethyan successions in this microbiotic group - and others - across the $\mathrm{K} / \mathrm{T}$ boundary.

References: [1] Alvarez L. W. et al. (1980) Science, 208, 671-690. [2] Keller G. (1988) Palaeogeogr., Palaeoclimatol., Palaeoecol., 66, 153-171. [3] Pardo A. et al. (1996) The Cretaceous-Tertiary Mass Extinction: Biotic and Environmental Events, Norton and Company, 155-176. [4] Saint-Marc P. and Berggren W. A. (1988) J. Foram. Res., 18, 97-113. [5] Speijer R. P. and Schmitz B. (1998) Palaeogeogr., Palaeoclimatol., Palaeoecol., 137, 79-101. [6] Nyong E. E. and Olsson R. K. (1984) Mar. Micropaleontol., 8, 437-477. 
BURSTS OF METHANE FROM THE DEEP SEA AND THE SPREAD OF ANOXIA INTO EPICONTINENTAL BASINS AT THE END OF THE PALEOCENE - A CAUSAL RELATIONSHIP INVOLVING SEA-LEVEL CHANGE? R. P. Speijer and T. Wagner, Department of Geosciences, Bremen University, P.O. Box 330440, 28334 Bremen, Germany (speijer@uni-bremen.de; tw@mail.sedpal.uni-bremen.de).

Introduction: The late Paleocene thermal maximum (LPTM; [1]) involved the most severe perturbation of the global carbon cycle during the Cenozoic and coincides with major evolutionary turnovers in various biotic groups, such as the mammals, foraminifera, and calcareous nannofossils [2]. A $-20 \mathrm{kyr}$ period comprising possibly three discrete methane hydrate melting events from deep-sea sediments is thought to have caused the $3 \%$ negative $\delta^{13} \mathrm{C}$ excursion recorded in marine and terrestrial carbonates worldwide $[3,4]$. Methane hydrates are stable within sediments under high pressure and low temperatures. In the late Paleocene ocean, the stability zone would have been below $\sim 1000 \mathrm{~m}$ depth. Warming of intermediate and deep waters during the LPTM may have disrupted the methane-hydrate stability zone, thus leading to injection of methane into the ocean and atmosphere [5]. A direct consequence of methane release into the water column, would be an increase in oxygen consumption where the methane is injected. During the LPTM, this would have been most notable at intermediate depths (middle to lower bathyal) where methane-hydrate melting is thought to have occurred. Reduced oxygen concentrations on the sea-floor and within the water column are indeed indicated by sedimentologic and biotic data from a number of cores and localities from this depth range. Oxygen deficiency is also regarded as one of the main players causing the largest extinction $(40 \%)$ of deep-sea benthic foraminifera since the early late Cretaceous [6].

Oxygen deficiency on Tethyan margins: The development of a sea-floor oxygen minimum at the onset of the LPTM is also a prominent feature of extensive epicontinental basins bordering both sides of the Tethys. We studied sedimentology, microbiota, and organic petrography and geochemistry of a number of sections in Egypt (Fig. 1), which are considered to represent a relatively complete coverage of the sequence of events (see [7], this abstract volume) across the LPTM in a low latitude setting. The successions generally consist of monotonous gray to brown marls and shales with low $(0.5 \%)$ TOC values. Their planktic foraminifera assemblages are rich and diverse, indicating fully marine conditions and good connections with the open ocean. Diverse benthic assemblages display a distinct paleobathymetric arrangement $(-100-500 \mathrm{~m}$ paleodepth) and indicate well to moderately oxygenated bottom conditions. An inconspicuous lithologic couplet, consisting of a dark brown laminated marl bed of $-50 \mathrm{~cm}$ thickness, mostly overlain by a paler calcarenitic bed, interrupts the monotonous successions. The dark bed shows a very fine wavy-laminated texture containing abundant fish remains, phosphatic peloids, amorphous organic matter, planktic foraminifera (mostly Acarinina spp.) and calcareous nannofossils. TOC concentrations in this bed reach up to $2.7 \%$, whereas benthic foraminifera are exceptionally rare, being represented by a few opportunistic species only. These characteristics resemble those of many Cenozoic sapropelic and Mesozoic black shale beds and point to anomalous envi-

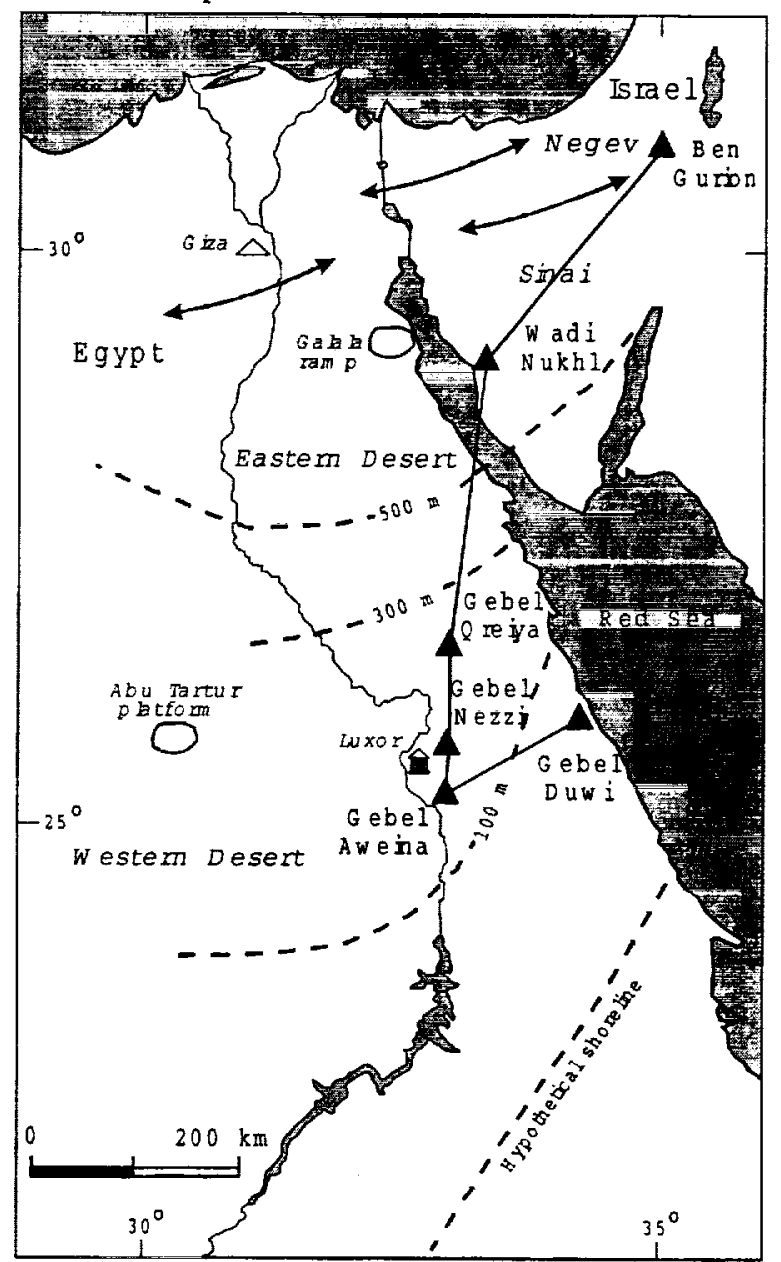

Fig. 1. Studied profiles on paleoslope transect. Nukhl, Qreiya and Nezzi yield the dark and laminated TOC-rich bed indicative of oxygen deficiency at the onset of the LPTM. Arrows represent general direction of fold axes (a region of submarine and perhaps emerged swells) of the Sinai-Negev fold belt (modified from [11]). 
ronmental conditions at the sea-floor and in the water column. Detailed chemo- and biostratigraphic studies indicate that this interval correlates with the onset and early part of the $\delta^{13} \mathrm{C}$ excursion and the LPTM as observed in the finest ODP sequences (see [7], this abstract volume). The overlying calcarenitic bed $(-50 \mathrm{~cm})$ represents the interval with the return to stable $\delta^{13} \mathrm{C}$ values. The bed is well bioturbated, its TOC levels are low and it contains extremely abundant planktic foraminifera. Benthic foraminifera assemblages are relatively rich and diverse. This bed signals a return to normal or more stable conditions with respect to oxygenation, and community structure of both planktic and benthic foraminifera. The lithological couplet with its peculiar features is unique in Paleogene successions of the region.

- On the opposite side of the Tethys over a vast area between the Crimea and Uzbekistan, a similarly developed "sapropelite unit" has been recorded. There, an up to 1 -m-thick TOC-rich bed in the same stratigraphic position as in Egypt contains phosphatic concentrations and enrichments of a suite of elements typical for deposition under suboxic to anoxic conditions [8]. Apparently, the onset of suboxic to anoxic conditions in epicontinental basins bordering the Tethys at the onset of the LPTM was widespread. The spread of oxygen deficiency correlates accurately with the initiation of the $\delta^{13} \mathrm{C}$ excursion and thus with the hypothesized methane injection into the ocean. Both in Egypt on the southern Tethyan margin and on the northern Tethyan margin, this occurred basin-wide, involving even middle neritic parts of the basins.

What caused this sudden oxygen deficiency remains unclear. It was suggested earlier that productivity in these basins may have increased considerably leading to increased oxygen consumption from organic carbon raining down on the seabed and thus forming a redox front at or just above the sediment-water interface $[8,9]$. However, typical indicators of enhanced productivity like diatoms and radiolarians are generally absent in this bed, which potentially weakens the case for this scenario.

Sea-level change: Sedimentologic observations and new benthic foraminiferal data from Egypt indicate fluctuations in relative sea level in association with the LPTM. Benthic foraminiferal data from neritic sections indicate shallowing through the upper Paleocene up to the level of the onset of the LPTM. The top of the pre-LPTM succession in some cases is eroded and also the early part of the LPTM (represented by the dark laminated bed) is lost in a hiatus as indicated by an omission surface (e.g. Aweina and Ben Gurion). In Nezzi, this bed appears as an incised channel fill. Thus, the discontinuity may be considered as a sequence boundary. In the more complete sections, the lithological couplet with abundant peloids and countless planktic foraminifera - the latter particularly in the calcarenitic bed - has the characteristics of a condensed sequence. Condensed sequences typically represent transgressive times and/or maximum flooding surfaces. The laminated bed may thus reflect the transgressive phase and the calcarenitic bed the maximum flooding surface of a short-term relative sealevel cycle. Benthic foraminiferal data support largest paleodepths within the calcarenitic bed. In short, sedimentologic and biotic data strongly suggest a falling relative sea-level up to the onset of the LPTM followed by rapid rise, reaching highstand before $\delta^{13} \mathrm{C}$ values stabilized (i.e. within $120 \mathrm{kyr}$ [3]).

Also in the northern Tethys the "sapropelite unit" appears to coincide with a major transgression [8], suggesting that the sea-level rise may be of eustatic origin. If correct, it seems plausible that this rise is causally related to the onset of the LPTM.

Hypothesis: We hypothesize that an extensive oxygen minimum zone at intermediate depths encroached upon the epicontinental basin floors during rapid sea-level rise of perhaps some 10 s of meters. This rise could have resulted from thermal expansion of oceanic water masses and through the reduction of high altitude ice, particularly at high latitudes during the LPTM. Possibly, elevated primary production on the shelves, resulting from the redistribution of nutrients and climatic change further intensified oxygen consumption at the seafloor. Many aspects remain yet uncertain for this critical period in Cenozoic earth history. Questions to be solved for this scenario include: How much and how fast did sea level rise? Was sea-level rise instrumental anyway in raising the OMZ into epicontinental basins or was it merely a side effect of global warming? This aspect needs to be investigated in the light of other main extinction events that signify a systematic coupling between sea-level rise and spread of anoxia into epicontinental basins [10].

References: [1] Zachos J. C. et al. (1993) J. Geol., 101, 191-213. [2] Aubry M.-P. et al. (1998) Late Paleocene - Early Eocene Climatic and Biotic Events in the Marine and Terrestrial Records, Columbia Univ. Press. [3] Norris R. D. and Röhl U. (1999) Nature, 401, 775-778. [4] Bains S. et al. (1999) Science, 285, 724-727. [5] Dickens G. R. et al. (1995) Paleoceanogr., 10, 965-971. [6] Kennett J. P. and Stott L. D. (1991) Nature, 353, 225-229. [7] Speijer R. P. et al. (2000) this abstract volume. [8] Gavrilov Y. O. et al. (1997) Lithol. Mineral. Resour., 32, 427-450. [9] Speijer R. P. et al. (1997) Geology, 25, 683-686. [10] Hallam A. and Wignall P. B. (1997) Mass Extinctions and Their Aftermath, Oxford Univ. Press. [11] Speijer R. P. et al. (2000) J. Geol. Soc., London, 157, 37-47. 
MULTIPARAMETER STRATIGRAPHY OF THE LATE PALEOCENE THERMAL MAXIMUM ALONG A SOUTHERN TETHYAN PALEOSLOPE TRANSECT. R. P. Speijer ${ }^{1}$, S. Monechi ${ }^{2}$, A. M. Morsi ${ }^{3}$ and B. Schmitz ${ }^{4}$, 'Department of Geosciences, Bremen University, P.O. Box 330440, 28334 Bremen, Germany (speijer@unibremen.de), ${ }^{2}$ Department of Earth Sciences, Florence University, via la Pira 4, 50121 Florence, Italy (monechi @unifi.it), ${ }^{3}$ Geology Department, Faculty of Science, Ain Shams University, 11566 Cairo, Egypt (ammorsi@asunet.shams.eun.eg), ${ }^{4}$ Department of Marine Geology, Göteborg University, P.O. Box 460, 40530 Göteborg, Sweden (birger@gvc.gu.se).

Introduction: Lower Paleogene marine deposits cover extensive areas of Egypt and Israel, usually in a sub-horizontal or slightly tilted position. In combination with a near absence of vegetation, this setting provides unique opportunities to study events associated with the late Paleocene thermal maximum (LPTM; [1]) basinwide and in full detail. This paper details a compilation of the stratigraphy of six upper Paleocene successions, wherein we focus on lithology, planktic and benthic foraminifera, calcareous nannofossils, ostracoda and stable isotopes. The sections are arranged on a generally northwest dipping paleoslope of an epicontinental basin, which in its northern part was interrupted by - predominantly submarine - highs and lows of the Syrian Arc. Benthic foraminifera assemblages indicate overall deposition at $\sim 500 \mathrm{~m}$ at Ben Gurion and Wadi Nukhl, $\sim 200 \mathrm{~m}$ at Gebel Aweina, Gebel Nezzi and Gebel Qreiya, and $\sim 75 \mathrm{~m}$ at Gebel Duwi (see [2], this abstract volume, for paleobathymetric map).

Lithology: Monotonous gray to brown marls prevail within the studied interval (Biozones P4-P6a). The short stratigraphic interval of global biotic and environmental change, however, is marked by a foraminifera-rich calcarenitic bed, overlying - in the more complete sections a 20-50-cm-thick fissile (Duwi) or TOC-rich (1-3\%) laminated (Nukhl, Nezzi, Qreiya) marl bed. The Aweina and Ben Gurion sections do not show the latter bed, but instead a discontinuity (omission surface) at the base of the calcarenitic bed.

$\delta^{13} \mathrm{C}$ isotopes: The global negative carbon-isotope trend and the superimposed negative $\delta^{13} \mathrm{C}$ excursion (CIE; [3]) have been recorded in whole-rock samples from all sections within Zone P5. The CIE coincides with the anomalous beds and terminates above the calcarenitic bed. In Aweina and Ben Gurion, the base of the $\mathrm{CIE}$ coincides with the discontinuity, indicating that in these sections at least the lower part of the excursion is truncated. Whereas whole-rock isotopic records from this region are suitable for stratigraphic purposes, specimen-based paleoenvironmental studies are generally not reliable. Thin-shelled foraminifera (e.g., planktic or benthic like Nuttallides truempyi) from this region and time interval are morphologically well preserved, but mostly recrystallized and infilled with calcite, making them unsuitable for isotopic analysis. Reliable results can only be obtained from well-preserved, thick-shelled genera like Frondicularia and Lenticulina, from which the infillings can be removed [4].
Calcareous nannofossils: Calcareous nannofossils of three sections containing the TOC-rich bed (Nukhl, Nezzi, Qreiya) were analyzed, leading to the recognition of many well known nannofossil events. The Nukhl section represents the most detailed and best preserved nannofloral succession. A turnover in calcareous nannofossils has been recognized around the CIE and BEE and it is characterized by a succession of bio-events. The lowest occurrence of Rhomboaster coincides with the TOCrich bed and other markers, but the genus is generally rare and not well preserved. Gebel Qreiya and Gebel Nezzi show similar successions of events as Nukhl, even if few discrepancies exist, which are most likely resulting from the low sample resolution and the poorer preservation of the nannofossil assemblages. The range of Tribrachiatus digitalis, the zonal marker of Subzone NP10b [5] is poorly constrained due to preservational and taxonomic problems.

Planktic foraminifera: In all sections, the lowest common occurrence of Globanomalina luxorensis is found just above the base of the CIE. In addition, the fissile or laminated marl beds in the Nukhl, Qreiya, Nezzi and Duwi sections contain a unique planktic assemblage (P/B ratios up to $99.9 \%$ ), largely consisting of Acarinina (e.g. A. sibaiyaensis) and with a minor but distinct component of Morozovella allisonensis. To date, the latter species has only been recorded within lower part of the CIE interval in ODP holes from the equatorial Pacific [6] and western Atlantic [7,8], and thus has a very short stratigraphic range. These biostratigraphic data enable a threefold subdivision of Zone P5 (Morozovella velascoensis Zone), with Subzone P5b being the total range zone of $M$. allisonensis. In Middle-East profiles where this subzone is missing (e.g. Aweina and Ben Gurion), Subzone P5a can be distinguished from Subzone P5c by the common presence of $G$. luxorensis in the latter. We consider this subzonation applicable in open marine low-to-middle latitude regions [9].

Benthic foraminifera: The benthic extinction event (BEE) marks the most important global turnover in deepsea benthic foraminifera during the Iast 90 m.y. About $30-50 \%$ of all species became extinct within a few kyr [3]. Along the entire paleoslope transect, the equivalent to the deep-sea extinction is evident (Fig. 1). The largest turnover (40\% extinction of Gavelinella beccariformis c.s.) occurred at bathyal depths, decreasing towards neritic depths. In the localities at $-200 \mathrm{~m}$ depth the extinction of Angulogavelinella avnimelechi and some 
other taxa is most prominent. At the shallower Duwi the large Frondicularia phosphatica became extinct. In all localities new taxa appear: Anomalinoides zitteli at all localities, Turrilina brevispira in all but the shallowest site. The dark laminated or fissile bed, displaying evidence of oxygen deficiency [2], [10] contains in all sections a peculiar oligotaxic assemblage dominated by opportunistic and tolerant taxa like Anomalinoides aegyptiacus, Valvulineria sp. and Stainforthia farafraensis.

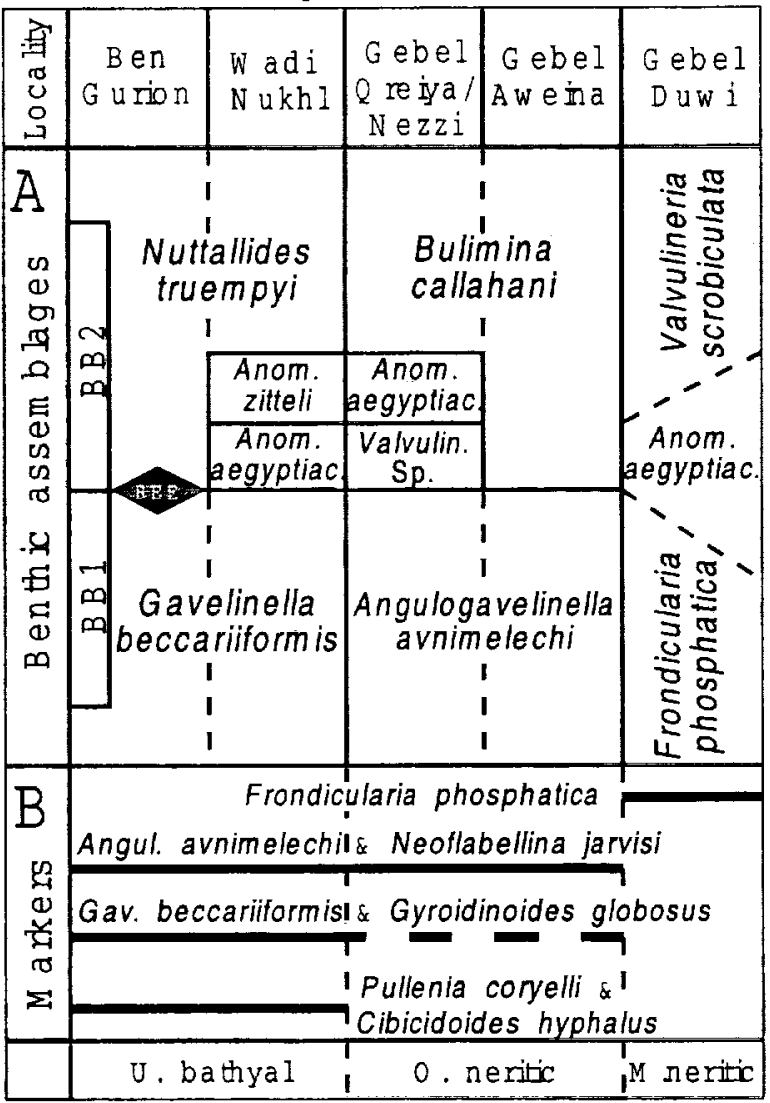

Fig. 1. (A) Schematic representation of the stratigraphic and geographic distribution of the main benthic foraminiferal assemblages on the paleoslope transect. BB1 and $\mathrm{BB} 2$ indicate corresponding bathyal benthic foraminiferal zones [11]. (B) Selected taxa that became extinct during the $\mathrm{BEE}$, ordered by bathymetric range (from [9]).

Ostracoda: The response of ostracoda assemblages to the events associated with the LPTM has received very little attention yet and is thus poorly known. Rich ostracoda assemblages occur at Duwi, but abundance decreases strongly with increasing paleodepth. Assemblage compositions, like for the benthic foraminifera, are paleobathymetrically controlled. Pre- and post-LPTM assemblages differ significantly within each succession, with many species appearing (e.g. Protobuntonia aegyptiaca) or disappearing (e.g. Alocopocythere? ramalia) close to the laminated bed. Very few ostracoda could be retrieved from the laminated bed. Yet, there appears to have occurred no major extinction at this level, but rather an ecological restructuring, possibly in response to longterm changes in the basin.

Conclusions: In all Middle-East sections studied, the level of late Paleocene global change can readily be monitored by distinct changes in the lithologic, biotic and carbon-isotopic composition.

The Nukhl, Qreiya, Nezzi and Duwi sections yield some of the finest records of this interval known worldwide. These sections show a laminated TOC-rich or fissile bed with unique benthic and planktic foram assemblages within the critical interval.

Calcareous nannofossils, planktic foraminifera and ostracoda show striking evolutionary innovations, but unlike the benthic foraminifera no major extinction event coinciding with the LPTM.

The short stratigraphic and wide geographic range of $M$. allisonensis enables a threefold subzonation of planktic foraminifera Zone P5 and world-wide correlation. Absence of this species in low-to-middle latitude successions indicates discontinuities which otherwise might easily be overlooked.

A well-expressed $\delta^{13} \mathrm{C}$ excursion does not necessarily indicate a good coverage of the CIE: at Aweina and Ben Gurion, like in other sections world-wide, the lowermost part of the CIE is truncated.

References: [1] Zachos J. C. et al. (1993) J. Geol., 101, 191-213. [2] Speijer R. P. and Wagner T. (2000) this abstract volume. [3] Thomas E. and Shackleton N. J. (1996) Geol. Soc. Lond. Spec. Publ., 101, 401-441.[4] Schmitz B. et al. (1996) Geology, 24, 347-350. [5] Aubry M.-P. (1995) Isr. J. Earth Sci., 44, 239-253. [6] Kelly D. C. et al. (1998) Palaeogeogr., Palaeoclimatol., Palaeoecol., 141, 139-161. [7] Cramer B. S. et al. (1999) Bull. Soc. Géol. France, 170, 883-897. [8] Norris R. D. and Röhl, U. (1999) Nature, 401, 775-778. [9] Speijer R. P. et al. (2000) J. Geol. Soc., London, 157, 37-47. [10] Speijer R. P. et al. (1997) Geology, 25, 683-686. [11] Berggren W. A. and Miller K. G. (1989) Micropaleontol., 35, 308-320. 


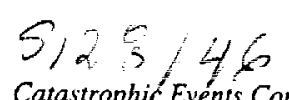

216 Catastrophic Evénis Conference

TERRESTRIAL MULTIPLE IMPACT EVENTS John G. Spray ${ }^{1}$ and Simon P. Kelley ${ }^{2}$, 'Planetary and Space Science Centre, Department of Geology, University of New Brunswick, 2 Bailey Drive, Fredericton, NB E3B 5A3, Canada; igs@unb.ca; Simon P. Kelley, Department of Earth Sciences, The Open University, Walton Hall, Milton Keynes, MK7 6AA, U.K. S.P.Kelley@open.ac.uk

Evidence for multiple impact events affecting Earth is limited. However, we only know of a small fraction (currently about 160) of the craters that have been generated through geological time. This is due to the relatively rapid destruction of craters by erosion or subduction on our tectonically active planet. A more pertinent question concerns the plausibility of Earth being bombarded by disaggregated asteroidal or cometary bodies, given Earth's relatively small size compared to Jupiter, and the complex orbital dynamics required to bring in such bodies to produce a crater chain. From our current understanding of orbital dynamics and other considerations, it appears that the probability of multiple impact on Earth remains very low.

However, two purported crater chains have received attention in the last few years. The first is the $700-\mathrm{km}$ long linear array of eight circular structures located in the southern midcontintent United States, extending from Kansas, through Missouri to Illinois [1]. There is good evidence for some of these structures being impact generated: Decaturville and Crooked Creek. But, until further detailed mapping, sampling and radiometric dating are performed on the remaining structures, it is difficult to assess the possibility of their being a true crater chain.

The second multiple impact candidate concerns at least four craters that span central North America and Eurasia [2]. Redating of the Rochechouart impact structure of France [3] has drawn attention to the similarity in ages of four impact structures: Manicouagan, Canada (214 \pm 1 Ma) [4], Obolon, Ukraine $(215 \pm 25 \mathrm{Ma})$ [5], Rochechouart $(214 \pm 8 \mathrm{Ma})$ [3], and Saint Martin, Canada $(219 \pm 32 \mathrm{Ma})$ [6]. A fifth structure, Red Wing, U.S.A. $(200 \pm 25 \mathrm{Ma})$ [7], is also close in age. If the continents are repositioned for Late Triassic times at $214 \mathrm{Ma}$, the three largest impact structures (from east to west), Rochechouart (25 km diameter); Manicouagan $(100 \mathrm{~km})$ and Saint Martin $(40 \mathrm{~km})$, are co-latitudinal at a mean paleolatitude of $22.8^{\circ}$, with a root mean squared deviation of 0.88 , and a latitudinal width of about $1.2^{\circ}$. This is a remarkably good fit to a small circle path about the Earth's spin axis. The spread in paleolongitude is $42.8^{\circ}(4462 \mathrm{~km})$.

The two smallest impact structures, Obolon $(15 \mathrm{~km})$ and Red Wing $(9 \mathrm{~km})$, have essentially identical trajectories with respect to the latitude-parallel trajectory of the other three. Obolon and Rochechouart (easternmost pair) define (by definition) a great circle that has a declination of $37.5^{\circ}$, while Red Wing and Saint Martin (westernmost pair) define (by definition) a great circle that has a declination of $42.8^{\circ}$. They thus have the same sense and essentially the same magnitude of rotation with respect to the small circle trajectory. If the longitudinal offset of $42.8^{\circ}$ is removed for Red Wing and Saint Martin, while maintaining their latitudes, and a best fit great circle is computed for the four "end" craters (Red Wing, Saint Martin, Rochechouart and Obolon), the best fitting great circle has a pole at $37.21^{\circ} \mathrm{N}, 92.35^{\circ} \mathrm{W}$, and hence a declination of $37.21^{\circ}$. Deviations of these data from the best fit great circle are remarkably small $\left(<0.4^{\circ}\right)$.

From the age and spatial constraints, we conclude that Saint Martin, Manicouagan and Rochechouart were generated by projectiles that were probably co-axial with respect to each other (like Shoemaker-Levy 9 [8,9]). The projectile that generated Obolon probably impacted at the same time as, and co-linearly with, the projectile that generated Rochechouart. Similarly, the projectile that generated Red Wing probably impacted at the same time as, and co-linearly with, the projectile that generated Saint Martin.

Lack of unequivocal projectile 
signatures in impact melt rocks associated with the five impact structures do not allow determination of projectile composition, and whether comet or asteroid. Rochechouart shows some evidence for a chondritic projectile [10]. Interestingly, the largest impact structure (Manicouagan) is at the centre of the five, while the smaller craters (Red Wing and Obolon) are peripheral - a feature noted for the Shoemaker-Levy 9 crater chain distribution on Jupiter $[11,12]$. However, we consider it probable that there were more than five impact structures generated by the fragmented bolide. Those fragments that hit the Tethys ocean rather than Pangea, however, would have been subsequently destroyed by subduction.

Using ${ }^{40} \mathrm{Ar}^{-39} \mathrm{Ar}$ laser spot dating of melt sheet and fault-related pseudotachylyte samples, we present new age data on the Saint Martin impact structure of Manitoba in an attempt to improve on the existing age of $219 \pm 32 \mathrm{Ma}$ [6] and so further test the likelihood of Saint Martin being part of a late Triassic crater chain.

[1] Rampino, M.R. and Volk, 1996. Geophysical Research Letters, 23, 49-52.

[2] Spray, J.G., Kelley, S.P. and Rowley, D.B. 1998. Nature 392, 171-173.

[3] Kelley, S.P. and Spray, J.G. (1997). Meteoritics and Planetary Science, 32, 629636.

[4] Hodych, J.P. and Dunning, G.R. (1992). Geology, 20, 51-54.

[5] Masaitis, V.L., Danilin, A.I., Mashchak, M.S., Raikhlin, A.I., Selivanovskaya, T.V. and Shadenkov, E.M. (1980). The Geology of Astroblemes. 231 pp. (Nedra Press, Leningrad).

[6] Reimold, W.U., Barr, J.M., Grieve, R.A.F. and Durrheim, R.J. (1990). Geochim. Cosmochim. Acta, 54, 2093-2111.

[7] Gerhard, L.C., Anderson, S.B., Lefever, J.A. and Carlson, C.G. (1982). Amer. Assoc.
Petrol. Geol. Bull. 66, 989-1020.

[8] Hammel, H.B. et al. (1995). Science, 267, 1288-1296.

[9] Weaver, H.A. et al. (1995). Science, 267, 1282-1288.

[10Reimold, W.U. and Oskierski, W. (1987) In: Research in Terrestrial Impact Structures (ed. J. Pohl), p. 94-114. Vieweg, Braunschweig/Wiesbaden, Germany. [11Melosh, H.J. and Schenk P. (1993). Nature, 365, 731-733.

[12] Schenk, P., Asphaug, F., McKinnon, W.B., Benner, L.A.M., and Melosh, H.J. (1995). LPS XXIV, 1233-1234. 
THE AGE OF THE CHICXULUB IMPACT AND OTHER EVENTS IN THE KT TRANSITION: NEW DATA FROM NE MEXICO

STINNESBECK, W., SCHULTE, P., Geologisches Institut, Universität Karlsruhe, 76128 Karlsruhe, Germany; KELLER, G., Department of Geosciences, Princeton University, Princeton, NJ 08544, USA; ADATTE, T. Institut de Géologie, Université de Neuchâtel, 2007 Neuchâtel, Switzerland; STÜBEN, D., KRAMAR, U. Institut für Petrographie und Geochemie, Universität Karlsruhe, 76128 Karlsruhe, Germany

The circular Chicxulub structure in the subsurface of Yucatan is generally interpreted as an impact crater caused by an asteroid that struck the Earth at the $\mathrm{K} / \mathrm{T}$ boundary $65 \mathrm{Ma}$ ago. So far, however, the precise age of this impact is difficult to constrain from the data in Yucatan. Consequently, the timing is frequently based on supposed impact ejecta and megatsunami deposits in neighboring regions of Yucatan. These deposits consist of complex siliciclastic sediments often containing diagenetically altered glass spherules in New Jersey, Texas, Alabama, Haiti, the Gulf of Mexico and NE Mexico. In other localities such as southern Mexico, Belize, Guatemala and Cuba, these so-called megatsunami deposits consist of limestone breccias which sometimes also contain spherules at the top (e.g., Belize and Guatemala). These breccias and spherule-rich deposits are all assumed to be of $\mathrm{K} / \mathrm{T}$ boundary age, deposited within hours or days of the Chicxulub impact.

Detailed biostratigraphical analysis of new sections in Haiti and NE Mexico indicate, however, that deposition of the oldest spherule deposits occurred during the late Maastrichtian and may have been re-deposited in the early Danian. We report here on the stratigraphy, lithology and the depositional environment of over a dozen new sections in the La Sierrita region of NE Mexico. The La Sierrita sections reveal the presence of up to three spherule-rich deposits (SRD) interbedded with hemipelagic marls of latest Maastrichtian age (Plummerita hantkeninoides, Zone CF1, or the last 300 ky of the Maastrichtian). The marls are deposited under normal pelagic conditions with no significant evidence for reworking. The original deposition of the spherule layer is stratigraphically below the siliciclastic deposits. In NE Mexico these siliciclastic deposits contain several bioturbated horizons which indicate that deposition occurred over a long time period, could not have resulted from a megatsunami (Ekdale and Stinnesbeck, 1998) and was not associated with the underlying spherule event. The $\mathrm{K} / \mathrm{T}$ boundary, as characterized by an Ir anomaly and mass extinction of tropical Cretaceous planktic foraminifera, is stratigraphically above the SRDs and the siliciclastic deposits in the Mexican sections. These data suggest a multi-event scenario across the $\mathrm{K} / \mathrm{T}$ transition consistent with impacts 
THE AGE OF THE CHICXULUB IMPACT: W. Stinnesbeck et al.

in the latest Maastrichtian Zone CF1, assuming that the spherules are of impact origin, and at the $\mathrm{K} / \mathrm{T}$ boundary marked by the Ir anomaly.

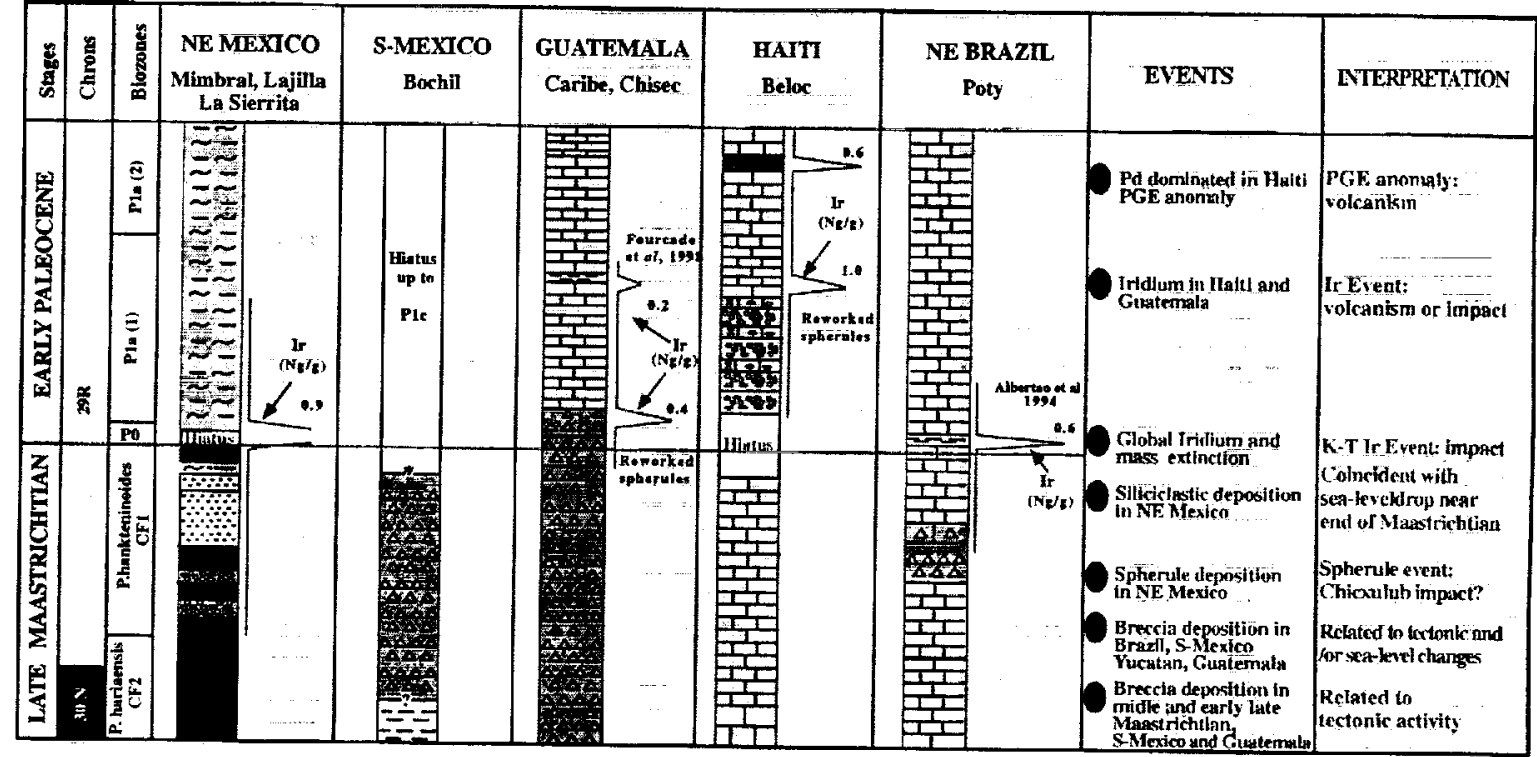

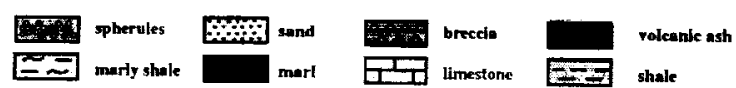


HIGH RESOLUTION CARBON AND OXYGEN ISOTOPE PROFILES OF FORAMINIFERA AND THE CA-NORMALIZED SR CURVE FROM LATE MAASTRICHTIAN ACROSS THE KTB AT ELLES, TUNISIA. D.Stüben ${ }^{1}$, U.Kramar ${ }^{1}$, Z. Berner ${ }^{1}$, M. Leosson ${ }^{1}$,G. Keller ${ }^{2}$, W. Stinnesbeck ${ }^{3}$ and Th. Adatte ${ }^{4},{ }^{1}$ Institut für Petrographie und Geochemie, Universität Karlsruhe, Kaiserstr. 12, 76128 Karlsruhe, Germany (Doris.Stueben@bio-geo.uni-karlsruhe.de), ${ }^{2}$ Department of Geosciences, Princeton University, NJ 08544, USA, ${ }^{3}$ Geologisches Institut, Universität Karlsruhe, Postfach 6980, D-76128 Karlsruhe, Germany, ${ }^{4}$ Institute de Géologie, 11 Rue Emile Argand, 2007 Neuchâtel, SwitzerTand.

Introduction: Due to the discussion of global catastrophic events at the Cretaceous-Tertiary (KT) boundary based on various reason e.g. [1], [2], [3], [4] and to controversial discussion on the faunal extinction based on high-resolution biostratigraphic investigations e.g. [5], [6] studies to investigate the climate record of the last million years of the Maastrichtian became important.

Stable isotope studies of deep sea sites in the Pacific and South Atlantic reveal a terminal Cretaceous warm event as a distinct $2-3^{\circ} \mathrm{C}$ warming of intermediate waters across latitudes and a $2-3^{\circ} \mathrm{C}$ warming in surface waters in middle and high southern latitudes [7]. The well documented long-term cooling trend that characterizes the late Cretaceous was terminated by a shortterm warming followed by a rapid cooling near the end of the Maastrichtian 100-200 kyr before the KT boundary [8], [9].

However, different sample resolution, condensed or erosional sedimentation, short-term hiatuses, bioturbation, diagenetic alteration etc. makes a high-resolution chemostratigraphy necessary to determine the nature of this terminal Cretaceous warm event and the cooling shortly below the KT boundary.

Climate and depositional variations during the last 570000 years of Late Maastrichtian are presented for a $26 \mathrm{~m}$ long ELLES section on the base of a highresolution chemostratigraphy $\left(\delta^{13} \mathrm{C}, \delta^{18} \mathrm{O}\right.$ isotopes and Ca-normalized Sr gradients)..

Material and Methods: High resolution chemistratigraphy was undertaken for a Late Maastrichtian section, at Elles, Tunisia. The section comprises a $26 \mathrm{~m}$ long sedimentation record of almost $600 \mathrm{Kyrs}$. The sedimentation is dominated by dark grey sandy to silty marl. Biostratigraphic zonation is based on the zonal scheme by [7] with zones CF1, 2 and CF4 marking the upper part of the Abathomphalus mayaroensis zone.

The sample interval of this study is every $20 \mathrm{~cm}$. From each subsample benthic (Anomalinoides acuta) and planktic formaminifera (Rugoglobigerina rugosa) were hand-picked under microscope in Princeton for further detailed geochemical studies. Samples revealed well preseved foraminiferal tests with little evidence of alteration.

Stable carbon and oxygen isotope data for fora- minifera were obtained from several species usings a fully automated preparation system (MultiCarb) connected on-line to an Optima Isotope Ratio Mass Spectrometer (Micromass Limited UK).

Strontium, Ca concentrations in foraminiferes were determined by using total reflection $\mathrm{X}$-ray fluorescence (TXRF, Atomika EXTRA II ).

Time series: To determine periodicities in the sediment column time series analysis was performed for the sediment profile from $1.2 \mathrm{~m}$ to $18 \mathrm{~m}$ below $\mathrm{KT}$. A hiatus of several hundred kyr at $18 \mathrm{~m}$ below KT (Keller et al. in prep.) hinders the applicabitity of time series techniques to the complete profile. Time series analysis was applied to the $\mathrm{Sr} / \mathrm{Ca}$ ratio data and to $\delta^{18} \mathrm{O}$ - values of both benthics (Cibicides) and planktics (Rugo Rugosa).

Results and interpretation: Due to $\delta^{18} \mathrm{O}$ excursions three cooling periods at around $22 \mathrm{~m}, 10 \mathrm{~m}$ and 2 $\mathrm{m}$ and two warm periods at around $15 \mathrm{~m}$ and $6 \mathrm{~m}$ can be distinguished. The cool periods are characterized by a small surface-to-deep $\mathrm{T}$ gradient reflecting intense mixing of the water column. The surface-to-deep $\mathrm{Sr} / \mathrm{Ca}$ gradient correlates to the oszillating $\Delta \mathrm{T}$ trend but is more pronounced reflecting corresponding dissolution rates of $\mathrm{Sr}$ from carbonate shells during sealevel changes. Carbon-isotope composition of foraminifers show upsection a general trend towards a progressive decrease in values of planktic foraminifers accompanied by a corresponding increase of $\delta{ }^{13} \mathrm{C}$ of benthic foraminifers which suggests a continuous decrease in surface bioproductivity over late Maastrichtian period (Fig. 1).

At the onset of warming at $65.5 \mathrm{Myrs}$ the decrase in $\Delta{ }^{\circ} \mathrm{C}$ and the decrease in surface $\delta^{13} \mathrm{C}$ reflects a reduction in surface productivity as a result of decreasing upwelling that accompanied global warming and increased $\mathrm{CO}_{2}$ possible related to Deccan Trap volcanic degassing.

The isotope and $\mathrm{Sr} / \mathrm{Ca}$ records of planctic and benthic foraminifera suggests that Maastrichtian oceanclimate evolution was tectonically driven and caused changes in seawater masses. 
ELLES : LATE MAASTRICHTIAN (ES)

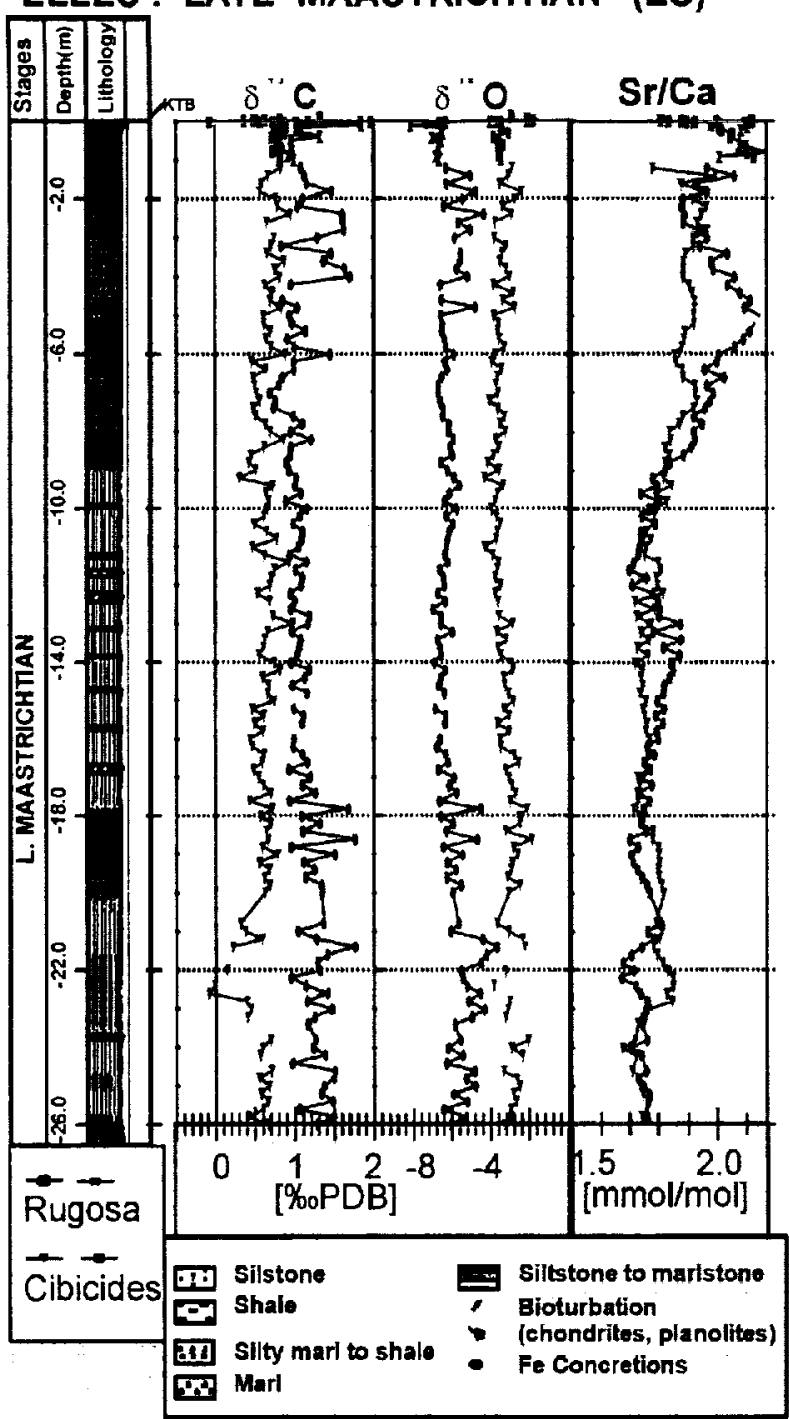

Fig. 1: Carbon and oxygen isotope values and $\mathrm{Sr} / \mathrm{Ca}-$ ratios in benthic and planktic formaminiferes of the Maastrichtian section at ELLES/ Tunisia.

The KT boundary represents an abrupt increase and adjustment of $\delta^{18} \mathrm{O}$ in benthic and planktic foramininfers supposing a drastic change in the water regime to cooler conditions and reduced differences between the $\delta^{18} \mathrm{O}$ values of benthic and planktic foraminiferes as a result of short term intense mixing of the water column (Fig. 2).

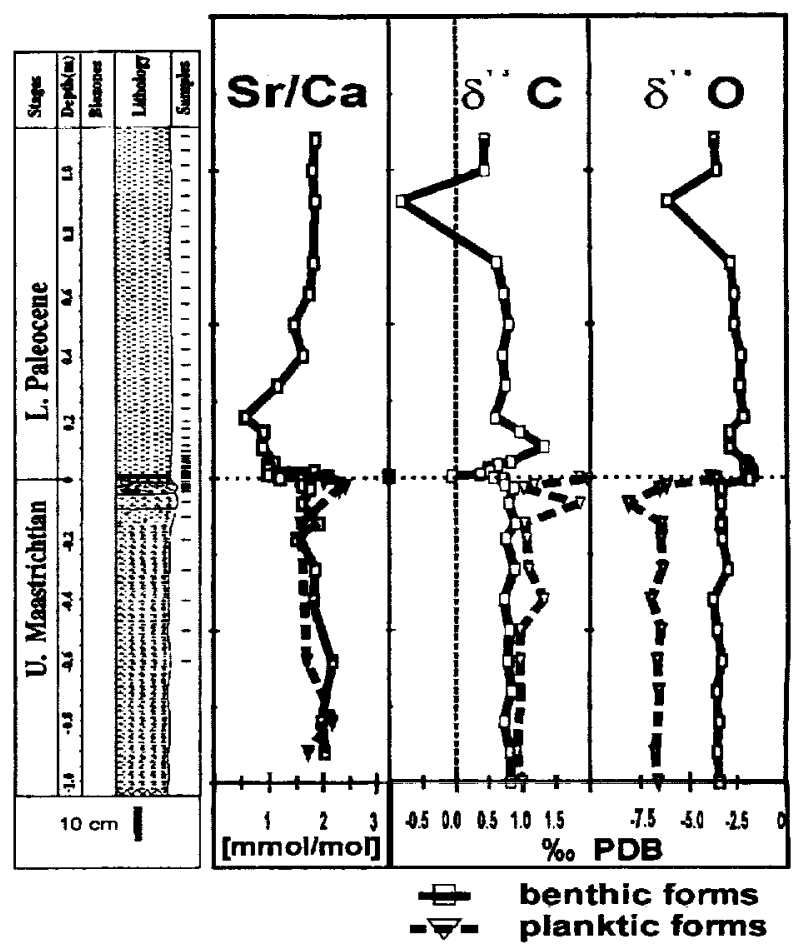

Fig. 2: Carbon and oxygen isotope values and $\mathrm{Sr} / \mathrm{Ca}$ ratios in benthic and planktic formaminiferes across the KTB at ELLES/ Tunisia.

\section{References:}

[1] Alvarez, L.W., Alvarez, W., Asaro, F. and Michel, H.V. (1980) Sience, 208, 1095-1108. [2] PerchNielsen, K., McKenzie, J. and He, Q.(1982) Geol. Soc. Am. Spec. Pap., 190, 353-371.[3] Izett, G.A. (1990) Geol. Soc. Am. Spec. Pap., 249, 100. [4] Rocchia, R., Froget, L., Robin, E. and Gayraud, J., (1994) Lunar and Planetary Institute Contribution, Houston, Texas, 825, 97-99. [5] Johnson, C.C. and Kauffman, E.G. (1993) Geol. Soc. Am., Abstracts with Programm, 25, A363. [6] Keller, G., and Lindinger, M. (1989) Palaeogeogr. Palaeoclimatol. Palaeoecol., 73, 243-265. [7] Li, L., and Keller, G.(1997) Mar Micropaleontol., 33,55-86. [8] D'Hondt, S., and Lindinger, M.(1994) Palaeogeogr. Palaeoclimatol. Palaeoecol., 112, 363378. [9] Barrera, E. (1994) Geology, 22, 877-880. 


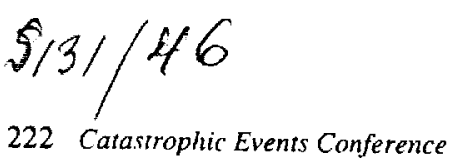

THE EARLY ORDOVICIAN CATASTROPHIC EVENT ON OSMUSSAAR ISLAND(ESTONIA) - RESULT OF AN IMPACT OR EARTHQUAKE? Kalle Suuroja and Sten Suuroja, Geological Survey of Estonia, Kadaka tee 80/82, 12618 Tallinn, Estonia, e-mail: k.suuroja@egk.ee

The Osmussaar (Odensholm in Swedish) Island (Estonia) is situated in the southern part of the entrance to the Gulf of Finland $\left(59^{\circ} 18^{\prime} \mathrm{N} ; 23^{\circ} 28^{\prime} \mathrm{E}\right)$. It is a relict island of the ca $1200 \mathrm{~km}$ long Baltic Klint, extending from the Oland Island (Sweden) to Lake Ladoga (Russia). The up to $8 \mathrm{~m}$ high island emerged from the Baltic Sea ca 3000 years ago. In the coastal cliff of the island Ordovician limestones crop out within ca $5 \mathrm{~km}$. The most intriguing part of the Osmussaar bedrock section is related to the 1.0-1.5 m thick layer of rocks of the Billigen, Volkhov and Kunda stages at the foot of the coastal escarpment, where the limestones are split into blocks and penetrated by veins and bodies of strongly cemented breccia-like limy sandstones. The rocks above (limestones of the Lasnamägi Stage) and below this level (glauconitic sandstones of the Hunneberg Stage) are undisturbed.

Since the middle of the 19th century, several hypotheses concerning the origin of the described disturbed level have been proposed. Several terms have been used in geological literature to designate this formation: earthquake cracks (Opik 1927), sedimetary veins (Orviku 1960), clastic dykes (Puura and Tuuling 1988) and sediment-intrusions (Suuroja et al 1999). By opinion of the majority of authors the catastrophic earthquake is proposed to be the main cause of this phenomenon.

In connection with discovering of the submarine Neugrund impact structure a short way off (some miles to northeast) from the island in 1996, the authors (Suuroja et al 1996) proposed that the traces of destruction observed on Osmussaar Island and to a lesser degree on Pakri isalands are connected with the Neugrund impact. However, later investigations (1997-1999) showed that these two appearances have not nothing in common. The study of the crater filling rocks in the Neugrund impact structure and target rocks in the surrounding area has shown that the Neugrund impact took place in the Early Cambrian time (ca $535 \mathrm{Ma}$ ago), while the Osmussaar event (splitting sea floor and penetrating sediment-intrusions) happened considerably later (ca $475 \mathrm{Ma}$ ago). Likewise it was proved that distribution of the split sea floor is not restricted only to coastal outcrops of Osmussaar Island but can be followed in Northwestern Estonia on several thousands square kilometers. Inside the Neugrund impact crater the complex of rocks with sedimentintrusions (limestones of the Pakri and Toila Formations) is undisturbed and forms an unusually thick layer (ca $8 \mathrm{~m}$ in contrast to ca $1-2 \mathrm{~m}$ in the surrounding area). The differences in lithological composition are also noticeable. The chemical, lithological and mineralogical composition of the breccia-like sediment intrusions has been studied as well. In this strongly cemented rock two types of limy sandstone (light and dark) both bearing evident signs of mudflow can be distinguished. Alongside with these traces, angular pieces of one rock type (usually dark) occur in the other (light) one. The sharp-edged pieces and blocks of pre-event limestones (the Pakri and Toila Formations) make up 0-50\% (average $15 \%$ ) of this three-component breccia-like limy sandstone. The dark (brownish) component differs from the light one mainly by its limy substance, cementing the clastic material only. In the light component the cementing material is finegrained calcite, in the dark one the latter contains also a slight admixture of kerogene and diffused pyrite. In the thin (1-20 $\mathrm{cm}$ ) veins injected into the surrounding rocks the dark modification prevails. At some distance from the Osmussaar Island (on the Suur-and Väike-Pakri islands ) the veins occur rarely, are thinner $(1-10 \mathrm{~cm})$ and grey in colour. On Osmussaar Island the veins and bodies of sediment-intrusions make up ca $10 \%$ of the host layer, but on the Suur-Pakri Island the content of the intrusions is less than $1 \%$ (one vein to every ten meters). In the aforesaid veins is found shocked quartz (with planar features)! By the authors opinion it does not refer directly to the impact origin of these veins. The grains of shocked quartz are derived from the pre-impact (target) sandstones which had been subjected to the Neugrund impact in the Early Cambrian time (ca $535 \mathrm{Ma}$ ago). To the sediment-intrusions they have been carried from the slopes of the Neugrund impact crater by the mudflow accompanying the catastrophic earthquake ca 60 Ma latter during the Middle Ordovician erosion in Upper Kunda time (ca $475 \mathrm{Ma}$ ago). Analogous processes that caused the formation of the sediment-intrusions on Osmussaar Island and its surroundings embraced a great deal of the shallow part of the basin at this time. The about $50 \mathrm{~km}$ wide and several hundred kilometers long zone extended from Pakri Peninsula via Hiiumaa Island (Estonia) to the Öland Island (Sweden). In different parts of this area the results of the described processes connected with global tectonic movements (forming the Kaledonites) and of uplifting the aforesaid zone, have also been different. 
THE IMPACT-RELATED SEDIMENTS OF THE KÄRDLA CRATER (HIIUMAA ISLAND, ESTONIA). Sten Suuroja and Kalle Suuroja, Geological Survey of Estonia, Kadaka tee 80/82, ee12618, Tallinn, Estonia. (s.suuroja@ egk.ee)

The Kärdla crater was formed in the Middle Ordovician, at early Caradoc time (ca $455 \mathrm{Ma}$ ) in the shallow epicontinental sea, not far $(<100 \mathrm{~km})$ from the shore and erosion area on the Baltic Shield. The Baltic Shield in a body of the Baltic Continent at that time located at $30^{\circ}$ latitudes at the Southern Hemisphere. The projectile (meteorite) apporached from SE (at the present notion) by angle $30-45^{\circ}$. It penetrated relatively thin $(<100 \mathrm{~m})$ water layer and sedimentary cover consisting mainly of ca $140 \mathrm{~m}$ thick Lower Cambrian water-saturated friable terrigenous rocks) and exploded in the top of the Precambrian (Svecofennian) crystalline basement metamorphic rocks (granitoids, gneisses, amphibolites). $4 \mathrm{~km}$ rim-to-rim diameter and more than $500 \mathrm{~m}$ deep complex crater with central uplift (ca $130 \mathrm{~m}$ high and ca $800 \mathrm{~m}$ in diameter) was generated by the impact. The inner crater is surrounded by the elliptic ring fault, up to $15 \mathrm{~km}$ in diameter, delimiting the area where the sedimentary target rocks are strongly disturbed (outer crater) from the area where they are not.

Due to the shallow marine environment almost all the structures of the impact crater and impact-related deposits were buried after the impact and therefore preserved well both in the crater proper and surrounding area. The 160 drill holes penetrating this succession and several geophysical methods (gravimetric, magnetometric and seismometric studies) have enabled its ivestigation both areally and spatially. Abundant information about the lithology, petrography and biostratigraphy of the horizontally bedded target rocks of the Kärdla crater has enabled reconstruction of the spatial movements of the substance during the marine impact and hundreds of million years after it. As the Kärdla impact occurred in the shallow sea environment, some specific rock types (resurge or tsunami breccias, turbitides) were formed, missing in land impacts. Complex section of directly impact-related inner crater sediments (rocks) has been reached by drilling in the crater proper in three sites: above the central uplift (d.h. K-18, depth $431.4 \mathrm{~m}$ ), the ring depression (d.h. K-1, $815.2 \mathrm{~m}$ ) and in front of the inner slope $(\mathrm{d} . \mathrm{h} . \mathrm{K}-12,464.0 \mathrm{~m})$. There are 68 drill holes reacing the impact-related sediments out of crater proper.

In the above-mentioned sections the following complexes of impact-related rocks have been distinguished (from bottom to top):

1. Authigenic monomict impact breccias of the crater floor with dikes of suevite-like breccias - more than $292 \mathrm{~m}$.

2. Allogenic suevite-like polymict impact breccias - up to $52 \mathrm{~m}$.

3. Slumped breccias -up to $140 \mathrm{~m}$. They consist mainly of blocks of the Cambrian terrigenous rocks (silt- and sandstones, clays) and contain clasts and blocks of the crystalline basement rocks and suevite-like impact breccias. This layer is thinner $(42 \mathrm{~m})$ above the central uplift and thicker further away from it.

4. Fallback impact breccias -up to $14 \mathrm{~m}$. They consist of clasts of the crystalline basement rocks with suevitelike matrix and have been formed on the account of material ejected by almost vertical trajectory. The above-mentioned breccias formed the lens-like layer in the crater proper approximately on the same level ($305 \mathrm{~m})$ in all three sections. The thickness of this layer is the biggest $(14 \mathrm{~m})$ above the central uplift.

5. Ejecta layer -up to $16 \mathrm{~m}$. Consists mainly of clastic material of (gravel to silty fraction) and is distributed up to $50 \mathrm{~km}$ from the impact site.

6. Ejected megablock -the biggest discovered block consist of brecciated crystaline basement metamorphic rocks is $34 \mathrm{~m}$ in diameter and is situated ca $1 \mathrm{~km}$ outer from the crater rim.

7. Resurge or tsunami breccias are the last complex of sediments directly related to the impact. The contacts between slumped, fallback and tsunami breccias cannot unambiguously determined in all sections. The thickness of this layer is $30 \mathrm{~m}$ in the drill core $\mathrm{K}-1$, while in the drill cores $\mathrm{K}-12$ and $\mathrm{K}-18$ - only ca $10 \mathrm{~m}$.

8. Turbitites are indirectly related to the impact. Thickness of this layer, consisting of conglomerates to clays and deposited immediatelly after the impact, is enough sustained $(25-30 \mathrm{~m})$ in the crater proper. 
GRAZING IMPACTS AS A CAUSE OF THE GLOBAL CATASTROPHES. V. V. Svetsov, Institute for Dynamics of Geospheres, Russian Academy of Sciences (Leninskiy prospekt 38-6, 117939 Moscow, Russia, svetsov@idg1.chph.ras.ru).

Introduction: Large impacts giving rise to a number of environmental stresses have had dramatic effects on the Earth's biosphere [1]. A 10-15 km impactor that produced the Chixulub crater seems to be the most important factor of the mass extinction at the K/T boundary. Four other major mass extinctions and about 20 smaller extinction pulses have happened in the past 540 Myr but only some of them may be linked to recorded impact craters [2]. This suggests to study events different from the crater forming impacts.

The size and energy of impactors are commonly accepted as critical parameters of impact induced mass extinctions. Large impactors, however, are not very effective in the energy partition from the viewpoint of the maximum effect on the environment. Much of their preentry kinetic energy goes to the planetary surface [3] and only a small portion of this energy is converted to the radiation of a fireball and to the kinetic energy of high-velocity re-entering ejecta. The ejecta is recognized as a major ignitor of the global wildfires [4]. The fires can release amounts of heat, soot, and aerosols that by far exceed those produced by the impactor.

Were an impactor severely dispersed over the globe it could produce a stronger effect on the environment setting fires and killing plants and animals almost simultaneously at many places on the Earth's surface. A large impactor can be dispersed if its trajectory goes beyond the solid Earth and grazes the atmosphere. Then the meteoroid intercepts some atmospheric mass, loses some fraction of the energy under aerodynamic load, and its fragments can start motion along another Earthbounded trajectory ending at a distant point at the Earth surface. Some possible effects on the environment from $0.5-1.5 \mathrm{~km}$ grazers are considered here.

Grazing Impactors: A relevant question is that the grazing encounters are only a small fraction of all meteoroids striking the Earth. Assuming that the grazers are meteoroids with theoretical perigee from 0 to $50 \mathrm{~km}$ above the Earth surface (in the absence of any atmospheric dissipation) we get that they are from 1 to 2 per cent of all impactors (the percentage is higher for higher velocities). The grazing impact of a comet was considered in [5] as a probable mechanism of organic delivery to the Earth by soft atmospheric deceleration of comets in the period of heavy bombardment in the solar system. Grazing impacts of relatively small, 2 to $40 \mathrm{~m}$, highstrength impactors have been studied in [6] for the probability to be captured into elliptical orbits about the Earth. Here I regard the grazers as a possible cause of the mass extinctions.
The chance that a $10 \mathrm{~km}$ impactor approached the Earth along the grazing trajectory is negligibly small for the recent geological time. Smaller $1 \mathrm{~km}$ asteroids or comets have typical intervals between the impacts of about $0.3 \mathrm{Myr}$ and, therefore, some 20 of such grazers collided with the Earth during the Phanerozoic Eon. Comets are usually considered as very weak bodies. Large asteroids also have much lower strength than that of meteorite samples and, moreover, they are likely to be gravitationally bound rubble piles rather than solid bodies [7], [8]. So these impactors may be treated in numerical simulations as strengthless fluid-like or granular objects.

Numerical Models: The motion of grazing impactors is governed by the Earth's gravitational field and is determined by the standard equations of mechanics. The atmospheric drag and dispersion of fragments are taken into account when the meteoroid height above the Earth's surface is smaller than $100 \mathrm{~km}$ The atmosphere is assumed to be spherical with a tabulated density in the vertical direction. To compute the motion and dispersion of strengthless meteoroids in the atmosphere I used the pancake model [9] that is known to be well applicable to large meteoroids. However, the pancake model allows an infinite enlargement of the meteoroid cross-section that is unreal. Numerical simulations based on hydrocodes show that the object cannot become flattened as a genuine pancake [10]. In computations, I restricted the radius of the flying dispersed object, not allowing it to be larger than its five pre-entry radii. Variations of this maximum radius only moderately influenced the main results

The size of fragmented impactors in our case turns out to be very large and comparable with the characteristic scale height of the atmosphere when the meteoroid cross-section is substantially enlarged. This presents a problem for numerical simulations and suggests modification of the model. I have done this in the following way. The lateral expansion of the fragmented meteoroid is allowed to be different at its edges. The velocity of lateral expansion in a given direction is assumed to be equal to $\mathrm{V}\left(\rho / \rho_{\mathrm{m}}\right)^{1 / 2}$, where $\mathrm{V}$ is the meteoroid velocity, $\rho_{\mathrm{m}}$ is the meteoroid density, and $\rho$ is the atmospheric density at the edge of the flattened meteoroid in the given direction. Then the shape of a meteoroid crosssection is distorted being elongated or flattened in the vertical direction. The meteoroid is assumed to move as a whole and the drag force is calculated by the integration of the stagnation pressure $\left(\rho \mathrm{V}^{2}\right)$ over the meteoroid surface at every time step. 
Results: Fig. 1 demonstrates the fates of $1 \mathrm{~km}$ in diameter asteroids $\left(\rho_{\mathrm{m}}=2.2 \mathrm{~g} / \mathrm{cm}^{3}\right)$ against their velocity at infinity $\mathrm{V}_{\mathrm{o}}$ and the closest theoretical approach to the Earth's surface $h_{0}$ (in the absence of any atmospheric drag). The impactors with parameters lying above the upper curve leave the Earth moving along hyperbolic orbits. The region below the lower curve corresponds to asteroids impacting the Earth surface after a relatively short (on the global scale) passage in the atmosphere. If the parameters fall between the curves the asteroid makes from half a loop to several revolutions around the planet before the full deceleration. Almost all of its energy is released in the atmosphere. It is improbable for an asteroid to be thrown to elliptical orbits and spend there a considerable time.

The meteoroid moving through the atmosphere releases its energy heating the air in the shock wave. A significant portion of the thermal energy (roughly a half) is converted to radiation. The radiation flux at the Earth surface is inversely proportional to the squared distance from the source. When the flux is high (as in the nuclear tests and in our case) forests can be ignited if a specific radiative energy at the surface is above $\mathbf{5 0}$ $\mathrm{J} / \mathrm{cm}^{2}$. I computed the surface area where meteoroids set fire assuming that point radiation sources of appropriate energy are spread along the trajectory. The atmosphere was assumed to be transparent.

A fraction of the global surface that is subjected to the radiation flux sufficient for the forest ignition is shown in Fig. 2 as a function of $h_{o}$ for two velocities of a $1 \mathrm{~km}$ asteroid (velocity at infinity $V_{0}=15 \mathrm{~km} / \mathrm{s}$ corresponds to the rms impact velocity for asteroids). The grazing asteroids set fires along a surface strip with a typical width from some hundred kilometers to about $1000 \mathrm{~km}$. The strip length depends on the impactor parameters. The largest area is ignited by the objects persisting in orbiting the Earth. To provide the global effect comets and asteroids must be aimed at a very narrow (some kilometers in size) gap of $h_{0}$. However, it is not improbable that one or two of $1 \mathrm{~km}$ impactors and several of $0.5 \mathrm{~km}$ grazers were aimed there and produced global effects during the Phanerozoic.

The total area ignited by a successful $1 \mathrm{~km}$ grazer is comparable to the area that can be ignited by the expanding fireball of a $10 \mathrm{~km}$ impactor. The fireball of a $10 \mathrm{~km}$ asteroid produces fires on a continental scale. The grazing impactors can set wildfires along half an equator. The igniting effect of a $1 \mathrm{~km}$ impactor may be quite competitive with the effect from re-entering ejecta of a $10 \mathrm{~km}$ asteroid. This ejecta produces a modest radiation flux at the surface equivalent only to about ten solar constants for an hour or two [11]. This may be insufficient for the ignition because thermal conductivity and air convection cool the objects exposed to the radiation when the time is so long. The radiation flux and concentration of the radiation energy are much higher below a large flying meteoroid. The computations show that typical values of the radiation energy in the middle of the ignition band are from 10 to 100 $\mathrm{MJ} / \mathrm{cm}^{2}$ for a $1 \mathrm{~km}$ grazer. Thus, we get the conclusion that, without cratering, some grazers might be a cause of global environmental stresses.

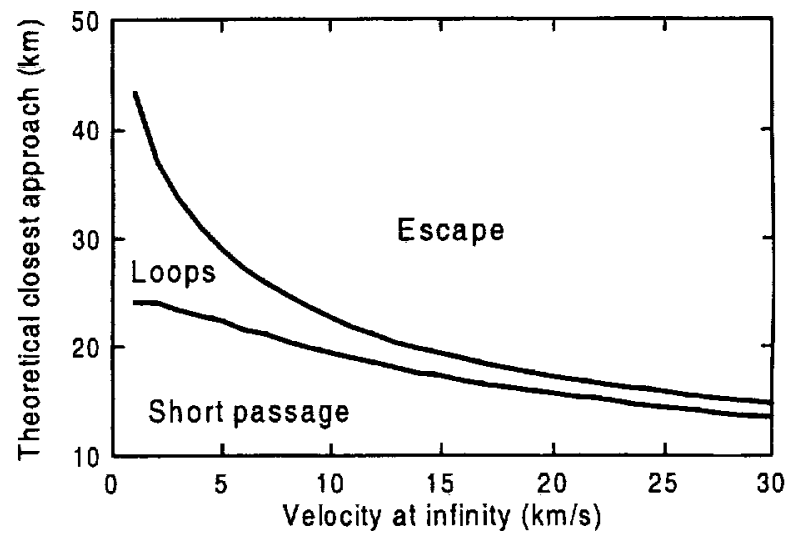

Fig. 1. The fate of grazing asteroids

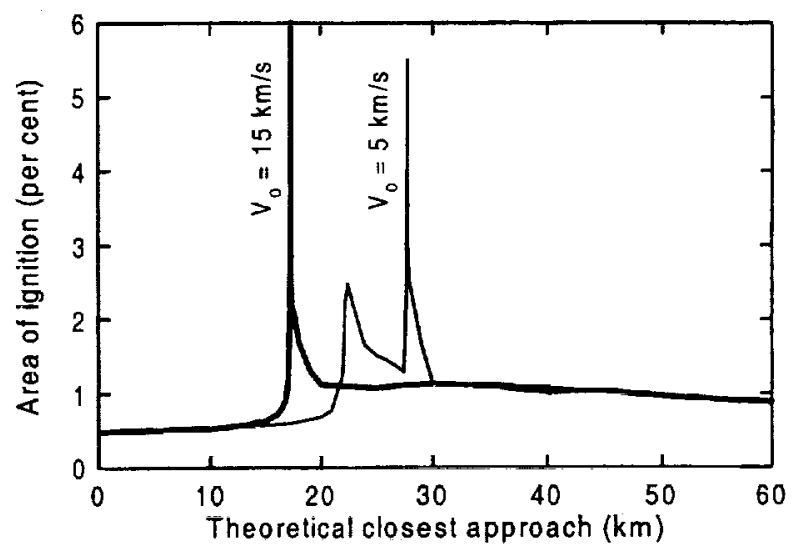

Fig. 2. The effect of ignition

\section{References:}

[1] O'Keef J. D. and Ahrens T. J. (1989) Nature, 338, 247-249. [2] Rampino M. R. et al. (1997) In: Near-Earth Object, New York, 403-431. [3] O'Keef J. D. and Ahrens T. J. (1982) JGR, 87, 6668-6680. [4] Melosh H. J. et. al. (1990) Nature, 343, 251-254. [5] Svetsov V. V. (1995) In: Abstr. 4th Int. Workshop on Impact Cratering and Evolution of Planet Earth, Ancona, 152-153. [6] Hills J. G. and Goda M. P. (1997) Planet. Space Sci., 45, 595-602. [7] Love S. G. and Ahrens T. J. (1996) Icarus, 124, 141-155. [8] Melosh H. J. and Ryan E. V. (1997) Icarus, 129, 562-564. [9] Hills J. G. and Goda M.P. (1994) Astron. J.., 105, 1114-1144. [10] Svetsov et al. (1995) Icarus, 116, 131153. [11] Zahnle K. (1990) Geol. Soc. Amer. Spec. Pap., 247, 271-288. 
A GIANT TSUNAMI DEPOSIT AT CRETACEOUS-TERTIARY BOUNDARY IN CUBA. R. Tada ${ }^{1}, \mathrm{H}$. Takayama $^{1}$, T. Matsui ${ }^{1}$, M. Iturralde Vinent ${ }^{2}$, E. Tajika ${ }^{1}$, T. Oji ${ }^{1}$, S. Kiyokawa ${ }^{3}$, D. Garcia ${ }^{4}$, H. Okada ${ }^{5}$, K. Toyoda ${ }^{6}$, T. Hasagawa, ${ }^{1}$ Department of Earth and Planetary Science, Graduate School of Science, University of Tokyo, 7-3-1 Hongo, Tokyo 113-0033, Japan, ${ }^{2}$ Museo Nacional de Historia Natural, Obispo no. 61, Plaza de Armas, La Habana 10100 , Cuba, ${ }^{3}$ National Science Museum, Department of Geology, 3-23-1 Hyakuninn-cho, Shinjuku-ku, Tokyo 169-0073, Japan, ${ }^{4}$ Instituto de Geologia y Paleontologia Via Blanca y Linea del Ferrocarril San Miguel del Padron, La Habana 11 000, Cuba, ${ }^{5}$ Department of Earth and Planetary Sciences, Hokkaido University, N10 W8, Sapporo 060-0810, Japan, ${ }^{6}$ Graduate School of Environmental Earth Science, Hokkaido University, N17 W8, Sapporo 060-0810, Japan, ${ }^{7}$ Department of Earth Sciences, Faculty of Science, Kanazawa University, Kakuma-machi, Kanazawa 920-1 192, Japan.

Introduction: A giant tsunami is one of the probable consequences of the impact, and possible tsunami deposits have been reported at the $\mathrm{K} / \mathrm{T}$ boundary (KTB) from around the margins of the Gulf of Mexico [1, 2]. However, their origin is still controversial, and an alternate impact shock-induced megaturbidite origin has been advocated [3]. One of the arguments against a tsunami origin is the lack of "homogenite", a thick, normal graded, structureless deposit formed by tsunami in deep sea environment $[4,5]$.

Cretaceous to early Tertiary deposits were widely distributed on Cuba and the presence of a giant KTB event deposit was proposed based on presence of upper Maastrichtian coarse clastic rocks with thickness in excess of $400 \mathrm{~m} \mathrm{[6]}$. However, no convincing evidence is found on its relation to the impact, and its depositional mechanism has not been investigated in detail.

Geological Setting: Cuba is formed by several different terranes including the Cretaceous Cuban Arc and Southern Terranes detached from the southeastern margin of Yucatan Peninsula, which were accreted to the southern margin of Bahamas platform during the early Tertiary [7]. At the time of KTB impact, the Cretaceous Cuban Arc was probably located approximately $500 \mathrm{~km}$ to the south of its present position [8], and a deep oceanic basin existed between the Bahamas platform and the Cretaceous Cuban Arc. The Peñalver Formation was deposited on the northern slope of the Cretaceous Cuban Arc. The formation disconformably overlies the Campanian to uppermost Maastrichtian Via Blanca Formation whose depositional paleodepth is estimated at 600 to $2000 \mathrm{~m}$ [9]. The formation is conformably overlain by the Danian to Thanetian formations [7].

Lithology of the Peñalver Formation: The Peñalver Formation is divided into two lithological units. The lower unit overlies the Via Blanca Formation with an irregular erosional surface and consists of $25 \mathrm{~m}$ thick granular bioclastic calcirudite with large intraclasts from the Via Blanca Formation. The bioclastic calcirudite is poorly-sorted, homogeneous with grain-supported fabric, and dominantly composed of fragments of shallow water macrofossils as well as shallow water limestone probably derived from the carbonate platform on the Cretaceous Cuban Arc. Size grading is not obvious throughout the unit.

The upper unit is more than $155 \mathrm{~m}$ thick and is subdivided into subunits $A$ and $B$ in ascending order. Subunit $\mathrm{A}$ is composed of a coarse- to fine-grained, normally graded calcarenite with frequent intercalations of thin conglomerate layers in its lower part. A few large mudstone intraclasts also occur in the lower part. The middle part is massive with abundant largescale water-escape structures, whereas the upper part is faintly thick-bedded with very rare water-escape structures. Fragments of shallow-water macrofossils drastically decrease in the basal part, and they are absent in the middle and upper parts. The middle and upper parts are characterized by significant increase in planktonic foraminifers, decrease in benthic foraminifers, and dominance of serpentine fragments (within non-calcareous fraction). The grain composition of subunit $A$ is distinctly different from the lower unit, suggesting that the source of the two units are different. Bioturbation is absent throughout subunit A. Subunit B is composed of massive, homogeneous calcilutite without bioturbation. The calcilutite is composed of coarse silt grains including planktonic foraminiferal skeletons and fine silt- to clay-size calcareous matrix with nannofossils. The abundance of serpentine fragments decreases drastically in this subunit.

The upper unit shows a single normal size-grading with upward increase in sorting. More importantly, the grain size distribution shows a rapid upward decrease in the coarsest grain-size components and a consequent increase in skewness. This is known as coarse-tail grading suggestive of settling from a dense sediment cloud [10].

Relation with the $K / T$ Boundary Impact: Macro- and microfossil assemblages in the Peñalver Formation are examined to constrain the timing of deposition, confirm reworking, and specify the source of the reworked materials. The lower unit contains 
only shallow water macrofossils derived from carbonate platform of the Cretaceous Cuban Arc. The upper unit, on the other hand, contains abundant microfossils. Various species of planktonic foraminifers and nannofossils with different diagnostic ages are found from the upper unit, whereas no Tertiary species are found. Dominance and the assemblage of Campanian to late Maastrichtian species suggest that the upper unit is mostly composed of the materials reworked from the underlying Via Blanca Formation. The occurrence of the nannofossil Micula prinsii within a large intraclast in the lower unit suggests that the age of the Peñalver Formation is younger than the latest Maastrichtian $(<65.4 \mathrm{Ma})$, whereas the absence of Tertiary microfossils throughout the formation suggests the age older than the earliest Danian (> 65.0 Ma). Thus, the age of the Penalver Formation is tightly constrained between 65.4 and $65.0 \mathrm{Ma}$.

Examination of thin sections revealed that altered vesicular glass of up to $2 \mathrm{~mm}$ in diameter, now replaced by heulandite, smectite and calcite, are present in small amount in the lower unit. Their concentration is highest near the bottom of the unit, decreases upward, and disappears near the top of the unit. These vesicular glass grains are similar in texture and size to those described from probable KTB deposits in Belize [11]. Glass spherule is almost absent.

We also examined $>60 \mu \mathrm{m}$ acid-insoluble residue, and found small amount of shocked quartz from the upper unit but it is absent in the lower unit. Concentration of shocked quartz in the Peñalver Formation is very low because of dilution by resuspended sediments. However, the flux of $>60 \mu \mathrm{m}$ shocked quartz to the Penalver Formation amounts to $15000-20000$ grains $/ \mathrm{cm}^{2}$, which is slightly larger than the flux estimated at Beloc [12]. The combination of its tight stratigraphic age constraint, and presence of altered vesicular glass and shocked quartz strongly suggest the KTB impact origin of the Peñalver Formation.

Depositional Mechanisms: Significant basal erosion, granule-size poorly-sorted grains with grainsupported fabric, homogeneous lithology without size grading, common occurrence of large intraclasts, and abundant bioclasts from shallow platform together suggest a grain flow origin of the lower unit. The probable source for these sediments is the carbonate platform on the Cretaceous Cuban Arc. On the other hand, single normal coarse-tail grading, abundant water escape structures, and the lack of sedimentary structures indicative of current influence in the calcarenite of the upper unit suggest rapid deposition from dense sediment suspension [10]. Finer grain sizes, homogeneous appearance without bioturbation, and mixed microfossil assemblages probably reworked from the underlying Via Blanca Formation within the calcilutite of the upper unit suggest late stage deposition from the suspension. These characteristics of the upper unit are consistent with those of homogenite[5]. Thus, the upper unit is interpreted as a giant homogenite [13]. Thin conglomerate layers intercalated in the basal part of the upper unit, whose characteristics are similar to those of a storm-wave induced deposits [14], could represent down-slope transported materials eroded by repeated tsunamis that hit the carbonate platform on the Cretaceous Cuban Arc.

Discussion and Summary: It is demonstrated that the Penalver Formation is the KTB deposit formed by grain flow and subsequent tsunamis. It is possible that the grain flow was triggered either by the impact-generated seismic wave or by the tsunami wave generated by the impact. Alternatively, the tsunami could have been induced by the grain flow. However, the distinctly different grain composition between the lower and upper units suggests different source. Namely, shallow platform of the Cretaceous Cuban Arc for the grain flow and deeper slope sediments for the homogenite. This may further suggests that homogenite of the upper unit does not have genetic relation with the grain flow deposit of the lower unit. If true, it is most likely that the grain flow was triggered by the impact-generated seismic wave within a few minutes after the impact, whereas the homogenite was formed by the subsequent tsunamis generated by the KTB impact and reached the site after the grain flow deposit was emplaced.

References: [1] Bourgeoris, J. et al. (1988) Science, 241, 567-570. [2] Smit, J. et al. (1992) Geology, 20, 99-103. [3] Smit, J. et al. (1996) GSA Spec. Pap., 307, 151-182. [4] Bohor, B.F. (1996) GSA Spec. Pap., 307, 183-195. [5] Kastens, K.A. and Cita, M.B. (1981) GSA Bull.,92, 845-857. [6] Pszczolkowski, A. (1986) Bull. Pol. Acad. Sci., Earth Sci., 34, 8193. [7] Bralower, T.J. and Iturralde-Vinent, M.A. (1997) Palaios, 12, 133-150. [8] Rosencrantz, E. (1990) Tectonics, 9, 1037-1059. [9] Bronnimann, P. and Rigassi, D. (1963) Eclogae Geol. Helv., 56, 193480. [10] Allen, J.R.L. (1982) Sedimentary Structures, Their Character and Physical Basis, vol. II. Amsterdam, Elsevier, 643 p. [11] Ocampo, A.C. et al. (1996) GSA Spec. Pap., 307, 75-88. [12] Leroux, H. et al. (1995) EPSL, 131, 255-268. [13] Takayama, H. et al. (2000) Sed. Geol., (in press). [14] Einsele, G. and Seilacher, A. (1991) in Einsele, G. et al. eds., Cycles and Events in Stratigraphy, Berlin, Springer-Verlag, 377-382. 
PHYSICAL AND GEOCHEMICAL PROCESSES IN THE GLOBAL GLACIATION: IMPLICATION FOR SNOWBALL EARTH. E. Tajika, Department of Earth and Planetary Science, School of Science, University of Tokyo, 7-3-1 Hongo, Bunkyo-ku, Tokyo 113-0033, Japan. tajika@geol.s.u-tokyo.ac.jp

Introduction: Low-latitude glaciations during the Late Proterozoic might be interpreted as global glaciations [1, 2]. Such a "snowball Earth" hypothesis is supported by results of energy balance climate models: analysis of the energy balance climate models suggests that low-latitude glaciation should be unstable, and so it falls into a globally ice-covered state owing to a large ice cap instability [3, 4]. The globally icecovered state is known as one of the stable climate states of the Earth [3, 4], although it has not been known whether the Earth has really fallen into this state during the Late Proterozoic.

- The globally ice-covered state may be caused by a decrease in the effective solar constant $[3,4]$, or, more likely, by a decrease in the atmospheric $\mathrm{CO}_{2}$ level $[5$, 6]. On geological timescale, the atmospheric $\mathrm{CO}_{2}$ level decreases because of a decrease in a net $\mathrm{CO}_{2}$ release rate to the atmosphere-ocean system [7]. Decrease in the net $\mathrm{CO}_{2}$ release rate corresponds to a decrease in the $\mathrm{CO}_{2}$ degassing rate via volcanism and metamorphism of carbonate and organic carbon, and also to an increase in a growth rate of organic carbon reservoir [7]. In this respect, snowball Earth phenomena during the Late Proterozoic could have been caused by fluctuations within the carbon cycle system. -In this study, physical and geochemical processes concerning the snowball Earth and their timescale are investigated by using a one-dimensional energy balance climate model combined with a carbon geochemical cycle model.

Models: A one-dimensional energy balance climate model (1-D EBM) with $\mathrm{CO}_{2}$-dependent outgoing radiation is employed in this study $[5,6]$. This model can estimate latitudinal temperature distribution as functions of the partial pressure of atmospheric $\mathrm{CO}_{2}$, when the effective solar constant and the thermal diffusion coefficient for latitudinal heat transport are given. Therefore, if the partial pressure of $\mathrm{CO}_{2}$ in the atmosphere is given by a carbon cycle model, temporal variation of the latitudinal temperature distribution can be estimated from the 1-D EBM.

As a carbon cycle model, a simple box-type model with geochemical processes such as a net $\mathrm{CO}_{2}$ release to the atmosphere-ocean system (that represents $\mathrm{CO}_{2}$ degassing via volcanism, metamorphism of carbonate and organic carbon, and a net budget of organic carbon reservoir), chemical weathering of silicate and carbonate, chemical equilibrium among carbon-related species in the ocean, dissolution of atmospheric $\mathrm{CO}_{2}$ into the ocean, and carbonate precipitation are considered [e.g., 8, 9]. Chemical weathering rate is assumed to be functions of temperature and the $\mathrm{CO}_{2}$ partial pressure [e.g., 8-10].

Results and Discussion: Snowball Earth phenomenon would be divided into four stages.

Runaway cooling stage: Runaway glaciation is expected to occur as the atmospheric $\mathrm{CO}_{2}$ level decreases owing to a considerable decrease in a net $\mathrm{CO}_{2}$ release rate to the atmosphere-ocean system. Timescale for this stage is estimated to be on the order of 100 thousands years. In order to decrease the atmospheric $\mathrm{CO}_{2}$ level to reach a critical condition to cause a large ice cap instability (about $10 \mathrm{ppm}$ under the condition of the present solar constant; See Figure 1), the net $\mathrm{CO}_{2}$ release rate should decrease to less than $1 / 10$ of the present rate. This may be caused by a decrease in volcanic activity and/or by an increase in organic carbon burial rate.

In this stage, ocean will freeze owing to cooling from the sea surface. Ocean freezes with releasing latent heat, which should prolong a time to freeze the ocean (so-called the Stefan problem). However, geothermal heating from the interior of the Earth prevents the ocean from freezing completely. As a result, about $1000 \mathrm{~m}$ of the surface ocean should freeze from the pole to the equator, and the deep ocean would not freeze. Timescale for this process is about 100 thousands years. Therefore, if the net $\mathrm{CO}_{2}$ release rate remains to be low for more than this timescale, the Earth will fall into the globally ice-covered state, and the $1000 \mathrm{~m}$ of the surface ocean will freeze.

Snowball Earth stage: Once the entire surface of the Earth is covered with ice and snow, it is quite difficult to escape from this state. This is because planetary albedo becomes very high, so most of the solar incident flux should be reflected to space. Consequently, globally-averaged surface temperature would be below $230 \mathrm{~K}$. In order to escape from this state, it is necessary for the partial pressure of $\mathrm{CO}_{2}$ in the atmosphere to increase on the order of 0.1 bar (Figure 1). This will be accomplished by degassing of $\mathrm{CO}_{2}$ via volcanism to accumulate in the atmosphere. Timescale for this process is estimated to be about 2-3 millions years under the condition of the present degassing rate. If the volcanic activity remains to be very low (that may have caused the global glaciation), this 
timescale would be prolonged to 10 millions years. However, when ice becomes dusty owing to volcanic eruption during this stage, the surface albedo would decrease, which reduces a required pressure of $\mathrm{CO}_{2}$ to escape from the globally ice-covered state. In this case, timescale for this stage would be much shorter than the timescale estimated above.

Deglaciation stage: It is difficult to estimate timescale for this stage. This is because seasonal change of the solar incident flux would play an important role in melting the ice, that is, excess melting during summer season will accelerate the net melting of the frozen ocean and the continental ice sheet.

Once the equatorial ocean melts, latitudinal heat transport will be increased, which accelerates melting of the ocean. Preliminary result of the timescale for melting the frozen ocean is estimated to be several thousands years or less. As will be shown in the next stage, when this timescale is short enough compared with a decrease in the atmospheric $\mathrm{CO}_{2}$ level, the atmosphere just after this stage would still have a large amount of $\mathrm{CO}_{2}$.

Recovery stage: In the case of rapid melting of ice and snow, the partial pressure of $\mathrm{CO}_{2}$ in the atmosphere remains to be about 0.1 bar. As a result, the globally-averaged surface temperature will be more than $320 \mathrm{~K}$. Such an extreme hot climate should enhance water cycle (evaporation and precipitation) and also the silicate weathering rate. Consequently, the partial pressure of $\mathrm{CO}_{2}$ will decrease from 0.1 bar to the "normal" level owing to intensive silicate weathering followed by carbonate precipitation in the ocean. Timescale for this stage is estimated to be on the order of 100 thousands years.

The seawater is undersaturated with respect to carbonate owing to the high $p \mathrm{CO}_{2}$ level for the first 10 thousands years of this stage. As cations such as calcium ion are carried and accumulated into the ocean owing to intensive weathering, alkalinity of the seawater should increase. As a result, the $\mathrm{CO}_{2}$ in the atmosphere would be absorbed by the seawater. It takes 10 thousands years for the seawater to become saturated with carbonate. Then, a large amount of carbonate will precipitate at $20-30$ times the present precipitation rate. This may correspond to the "cap carbonate rocks" observed just above the glacial deposits in the Late Proterozoic [2].

It should be noted that carbonates within the top layer of deep-sea sediments at this time should dissolve into the seawater because the seawater is undersaturated with respect to carbonates. Therefore, it is important to find such evidence because it might imply for very high $p \mathrm{CO}_{2}$ level expected just after the globally ice-covered event.
References: [1] Kirschvink J. L. (1992) In The Proterozoic Biosphere (Schopf J. W. and Klein C., Eds.), Cambridge Univ. Press, New York, 51-52. [2] Hoffman P. F. et al. (1998) Science, 281, 1342-1346. [3] Budyko M. I. (1969) Tellus, 21, 611-619. [4] Sellers W. D. (1969) J. Appl. Meteor., 8, 392-400. [5] Caldeira K. and Kasting J. F. (1992) Nature, 359, 226-228. [6] Ikeda T. and Tajika E. (1999) GRL, 26, 349-352. [7] Tajika E. (1999) Chikyukagaku (Geochemistry), 33, 255-263. [8] Berner R. A. (1994) Am. J. Sci., 294, 56-91. [9] Tajika E. (1998) EPSL, 160, 695-707. [10] Walker J. C. G. et al. (1981) JGR, 86, 9776-9782.

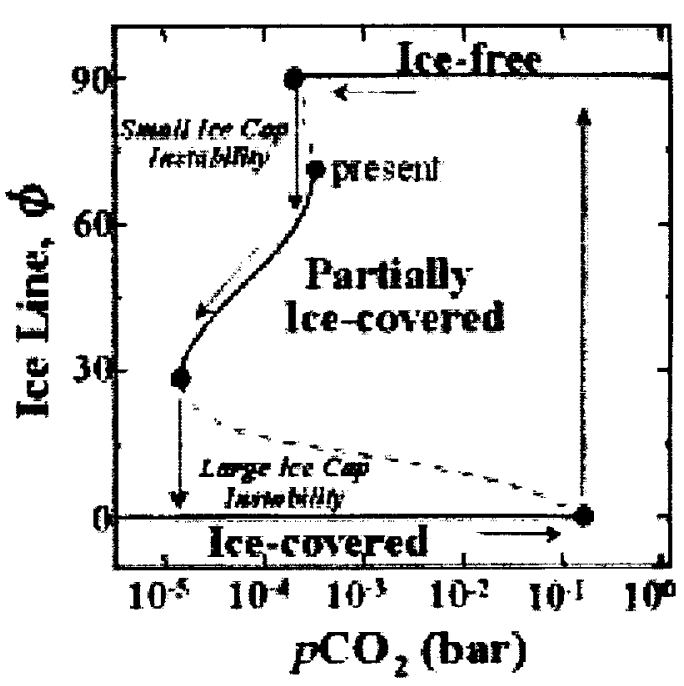

Figure 1. Steady state ice edge latitude against partial pressure of the atmospheric $\mathrm{CO}_{2}$ under the condition of the present solar constant. 
NUMERICAL SIMULATIONS OF CHICXULUB IMPACT CRATERING. T. Takata, Miyagi University of Education(Aoba, Sendai, 980-0845 JAPAN, toshiko@ipc.miyakyo-u.ac.jp).

Introduction: Chicxulub impact cratering on Yucatan peninsula is the most plausible scenario to cause the global environmental change and the consequent catastrophic extinction at the K/T boundary [1]. The size of Chicxulub crater is estimated as $180 \mathrm{~km}$ [1], or 260 $340 \mathrm{~km}[2]$, in diameter, however, in any cases, the impact could result in enormous consequences on the environments. Recent geological investigations delineate the lithologic environment in this area at $\mathrm{K} / \mathrm{T}$ time (65Myr). The impact site was shallow sea platform containing $2-4 \mathrm{~km}$ thick carbonate and evaporite rocks (mainly limestone, dolomite, and gypsum) overlying the basement rock of andesite [3].

The possible detailed scenarios for the impact cratering to trigger the global climate change are following:

1. Release of water vapor into the atmosphere resulted in the global warming $[4,5]$

2. Release of carbon dioxide into the atmosphere resulted in the global warming [4,5].

3. Enormous amount of fine dust ejected from the crater floated in the stratosphere for a long duration and screened the surface from the solar radiation, and resulted in the global cooling [6].

4. The production of NO due to impact heating and the global distribution of $\mathrm{NO}_{2}$ could bring on the nitric acid rain, and resulted in some influences on the biosphere [7].

5. Or else; e.g., the production of $\mathrm{SO}_{2}$ aerosols [8], or the destruction of the ozone layer.

6. The combination of above mechanisms.

The key scenario to threaten various Cretaceous species with extinction has been discussed for a long time, but not clearly elucidated. Here, to clarify the possibility of above scenarios, effects of Chicxulub impact cratering on the climate change are simulated using numerical techniques.

Methods: Numerical simulations using Smoothed Particle Hydrodynamics (SPH) technique [9] are conducted to realize the impact of a meteoroid on the Chicxulub crater lithology. A target consists of basement rock, overlaid by $3 \mathrm{~km}$ thick - carbonate rock layer. All the target materials are initially stabilized and in hydrostatic equilibrium. Because of the ambiguity of the crater size, the impact velocities and the size of the impactor vary from $5-20 \mathrm{~km} / \mathrm{s}$, and $25-30 \mathrm{~km}$, respectively. This range of impact energies satisfies the minimum and maximum estimates of the size of the crater (figure 1).
Various numerical simulations of Chicxulub impact have been employed $[10,11,12,13,14,15]$. The uniqueness of SPH calculations is the trajectory of the ejecta can be easily followed.

\section{Results and Discussions:}

\section{Water vapor:}

The ocean water within the radius of $60 \mathrm{~km}$ from the impact site is vaporized, in maximum. If the depth of the sea floor is $500 \mathrm{~m}, 5000 \mathrm{G}$ ton of water vapor is ejected into the atmosphere. This amount is almost equal to $<10 \%$ of the present vapor pressure, if it is distributed all over the world.

\section{2. $\mathrm{CO}_{2}$}

Laboratory shock experiments of $50 \%$ porous chalk occurs result in the decarbonation of $90 \%$ of the available $\mathrm{CO}_{2}$ at $10 \mathrm{GPa}$ [16]. Assuming that the carbonate pressurized up to $10 \mathrm{GPa}$ decarbonates, the mass of the carbonate pressurized to more than $10 \mathrm{GPa}$ indicates that the production of $\mathrm{CO}_{2}$ is $2 \times 10^{16} \mathrm{~kg}$, in maximum. This mass of $\mathrm{CO}_{2}$ is several times the $\mathrm{CO}_{2}$ inventory in the present atmosphere, however, due to the warm climate of Cretaceous and higher inventory of $\mathrm{CO}_{2}$ in the atmosphere [17], the ejected $\mathrm{CO}_{2}$ mass is only less than 2 times the $\mathrm{CO}_{2}$ inventory in the Cretaceous atmosphere. This results in the increase of the global atmospheric temperature of $<5 \mathrm{~K}$.

\section{Dust:}

Assuming that $0.1 \%$ of the materials ejected up to the stratosphere are fine dust, which stay in the atmosphere for a long time, the total mass of the fine dust floating in the stratosphere is $10^{14}-10^{15} \mathrm{~kg}$. If they are distributed globally, the average thickness of the dust layer becomes $0.1-1 \mathrm{~mm}$. This amount is more than $10^{3}$ times the eruptions from the biggest volcanic eruption on the earth [18]. Thus, Long term floating of the dust-aerosols could block the solar radiation.

4. $\mathrm{NO}_{2}$ :

The productions of NO more than $10^{40}$ molecules, or $10^{38}$ molecules, affect on the survival of organisms, globally or locally, respectively [7]. If the atmosphere is highly shocked, the shocked gas is blown off from the terrestrial gravitational field. The efficiency of direct heating of the atmosphere by impact cratering is less than $0.01 \%$ of the impact energy. Assuming that the NO production in the ejecta plume is $10^{16}$ molecules /J [7], the NO production becomes $<10^{37}$ molecules. Therefore, the effect of NO production is smaller than the critical amount for nitric acid rain to have a global impact. 
In our simulations, the production of the enormous amount of dust of terrestrial and extraterrestrial origin is confirmed. The climate system should have been affected globally by the impact-dust and cooling of the atmosphere due to blocking solar radiation by dust floating in the atmosphere is expected for a long time. Induced $\mathrm{H}_{2} \mathrm{O}$ and $\mathrm{CO}_{2}$ could locally affect on the warming, although the cloud formation could increase the surface albedo, and result in cooling and restoring inventories of water and $\mathrm{CO}_{2}$ in the atmosphere. The possibility of the nitric acid rain is small, because of the escape of the highly shocked gas to the space.

References: [1] Hildebrand A. R. et al. (1991) Geology, 19, 867-872. [2] Sharpton V. L. et al. (1993) Science, 261, 1564-1567. [3] Swisher C. C. III et al. (1992) Science, 257, 954-958. [4] Emiliani C. et al. (1981) Earth. Planet. Sci. Lett., 55, 317-334. [5] O'Keefe J. D. and T. J. Ahrens (1989) Nature, 228, 247-249. [6] Alvarez L. W. et al. (1980) Science, 208, 1095-1108. [7] Prinn R. G. and B. Fegley (1987) Earth. Planet. Sci. Lett., 83, 1-15. [8] Pope K. O. et al. (1997) JGR, 102, 21645-21664. [9] Gingold R. A. and J. J. Monaghan (1977) Month. Not. Astr. Soc., 181, 375. [10] O'Keefe J. D. and T. J. Ahrens (1982) GSA Special paper, 190,103-120. [11] Roddy D. J. et al. (1987) 1. J. Impact. Eng., 5, 525-541. [12] Takata T. and T. J. Ahrens (1994) LPl publ. 825, 125-136. [13] Ivanov B. A. et al. (1996) GSA special paper, 307, 125-139. [14] Pierazzo E. et al. (1998) JGR, 103, 28607-28625. [15] O'Keefe J. D. and T. J. Ahrens (1999) JGR, 104, 27091-27104. [16] Tyburczy J. A. and T. J. Ahrens (1986) JGR, 91, 4730-4744. [17] Kasting J. F. and O. B. Toon (1989) in Origin and evolution of planetary and satellite atmospheres, eds. Atreya S. K. et al., 423-449. [18] Tanaka M. (1995) Dictionary of Volcanoes, 259-269 (Japanese).

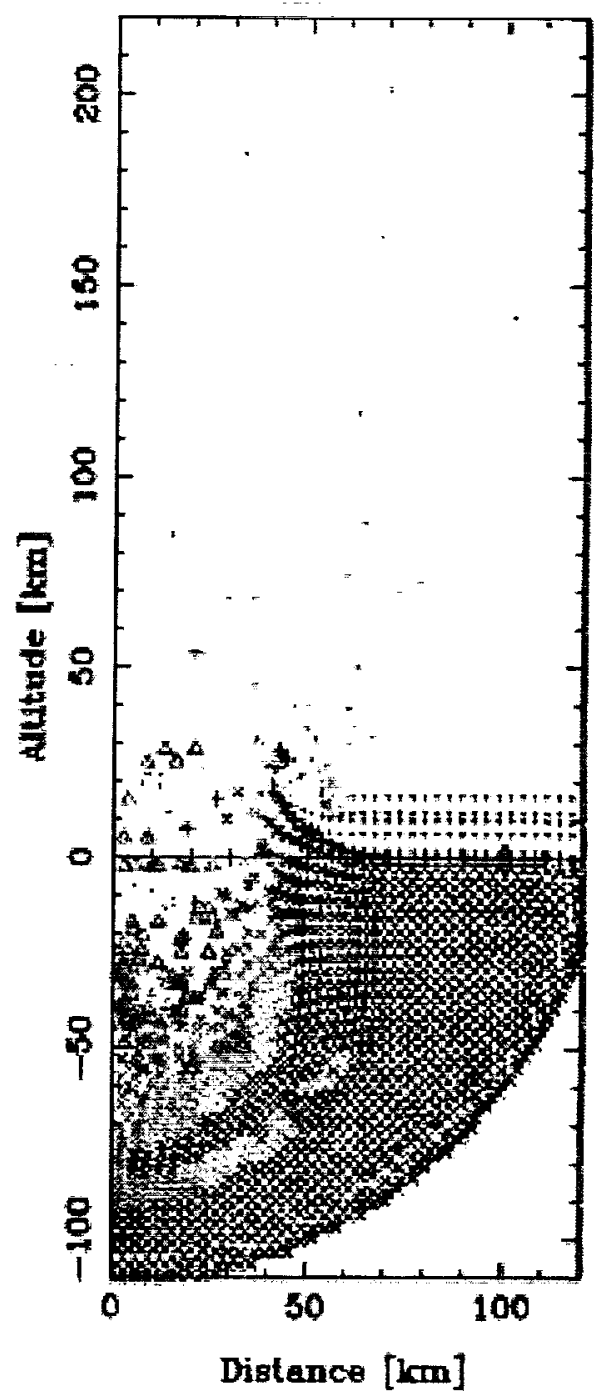

Figure 1: SPH simulation of the impact of a meteoroid of the diameter of $25 \mathrm{~km}$ on the Chicxulub target. Color represents the temperature of materials. Symbols of triangles, crosses, and dots represent the meteoroid, target materials, and the atmosphere, respectively. 
GLOBAL ATMOSPHERIC PERTURBATIONS CAUSED BY NATURAL HAZARDS. A. V. Teterev and L. V. Rudak, Faculty of Applied Mathematics and Computer Science, Belarus State University, 4, F. Skorina avenue, Minsk, 220050, Belarus (teterev@fpm.bsu.unibel.by).

Introduction: Natural catastrophes which can cause extinction of living organisms should be accompanied by consequences [1] that essentially influence conditions of their habitation. The most significant factor is changes in temperature, i.e. in global climate. This factor affects all kinds of habitats and therefore influences living condition of all organisms. Moreover, in contrast to any other factors, the range of temperatures, at which organic life is still possible, is extremely limited. The global change of the climate is connected to changes in balance between energy flows that are coming to and going away from the Earth. Violation of the energy balance can occur due to changes in atmospheric properties because such changes are most probable. For performing modeling for long-term climate prediction it is necessary to specify as exactly as possible perturbations caused by global natural catastrophes. This research is devoted to numerical simulation of large-scale perturbations caused by various catastrophic events. Results on numerical simulation of catastrophes with consequences which could affect the local or global climate on the Earth are presented. At modeling a goal was pursued to study evolution of catastrophes at the whole range of times at which compressibility of medium cannot be neglected.

Collision with Dust: A special group of catastrophes consists of phenomena which decrease the solar energy flow outside the Earth's atmosphere. One of these is passing of the Solar System through areas with increased concentration of cosmic dust or surrounding of the Earth by a dust medium arisen as a result of ejection at an impact of a large asteroid at the surface of other planet or due to collision of such asteroids in the immediate neighborhood of the Earth. Since the nearest to the Earth large cosmic body is the Moon, it is a matter of special interest to consider consequences of asteroid impacts at its surface [2]. Giant craters on the Moon clearly demonstrate reality of such events. Due to small gravitational force and absence of atmosphere the main part of ejected substance can leave the area of Moon's attraction. Impacts at which mass of substance ejected beyond the area of attraction will be sufficient to essentially decrease a solar energy flow and to change the Earth's climate are highly improbable. However, ejected masses attracted to the terrestrial atmosphere by the Earth's gravitational field can significantly affect atmospheric parameters. All such phenomena lead to a problem of interaction between highvelocity superrarefied formations and the Earth's atmosphere. Depending on nature of origin of such objects their velocity relative to the Earth varies from $10 \mathrm{~km} / \mathrm{s}$ to $70 \mathrm{~km} / \mathrm{s}$ and even greater. Their sizes and density of their substances can vary even more essentially. In numerical modeling of consequences of such collisions both relatively small in a planetary scale $(-10 \mathrm{~km})$ and large formations $(-1000 \mathrm{~km})$ have been considered.

Impacts of Asteroids and Comets: Simulations of impacts of cosmic objects of different size and composition at a solid surface and into water basins were carried out. Results of these simulations are interesting because they can provide explanations for some questions of solar system evolution [3] and allow one to predict possible consequences of asteroid and comet impacts at planetary surfaces [4]. Impacts into water basins can cause extinction of living organisms due to several reasons. First of all, it is a direct destruction of organisms by a shock wave, high-velocity flows and by heating of water. However, these effects are local even at large catastrophes. More serious consequences can be caused due to ejection of huge salty water masses to the high altitudes because it can result in violation of integrity of the ozone shield of the atmosphere.

Catastrophic Eruptions: Ashes ejected at eruption of Krakatau had rounded the Earth several times before completely fell out on the surface [5]. Apparently, this emption had some local influence on weather conditions. Therefore it is interesting to simulate similar eruption of a larger scale. One of the considered cases is when a wide channel directed to a magma chamber is formed due to explosion of chilled magma. It was supposed that magma temperature at the chamber is $\sim 1300 \mathrm{C}$, mass content of water reached $2-4 \%$. The pressure of magma at the bottom of the chamber was given equal to pressure of granite at the same depth. Consequently, magma pressure at the upper level of the chamber was $\sim 300 \mathrm{~atm}$. greater than the pressure in granite at the same level. The moment of violation of integrity of chilled magma was considered as a starting moment of eruption.

Eruptions due to Impacts: Often some catastrophes can be sources for the others with even more destructive consequences. For example, earthquakes come along with large-scale volcanic eruptions and tsunamis. Krakatau eruption itself did not bring any victims, but tsunami formed after volcano collapse killed more than 35 thousands people [5]. Consider a characteristic case of interconnection of natural catastrophes, when an asteroid impact causes a volcanic eruption. A numerical simulation of an impact of $2 \mathrm{~km}$ diameter asteroid into the area of a magma chamber has been performed. The ceiling of the chamber was on the depth of $10 \mathrm{~km}$ relative to the Earth's surface and its bottom - on the depth of $20 \mathrm{~km}$. At $25 \mathrm{~s}$ the bottom of the crater came close to the chamber and breakout of magma into the crater occurred. Due to rapid magma decompression eruption was started. Thus a large impact catastrophe was aggravated by a powerful volcanic eruption.

References: [1] Toon O. B. and Zahnle K. et al. (1994) Hazards due to comets and asteroids, 791-826. [2] O'Keefe J. D. and Ahrens Th. J. (1975) LPS VI, 2831-2844. [3] Lissauer J. J. (1993) Annu. Rev. Astron. Astrophys., 31, 129-174. [4] Melosh H. J. (1989) Impact Cratering: A Geologic process. [5] Ritmann A. (1960) Vulkane und Ihre Tatigkeit. 
IMPACT HEATING DURING FORMATION OF THE VREDEFORT STRUCTURE. E. P. Turtle' and E. Pierazzo', 'Lunar and Planetary Lab., University of Arizona, Tucson, AZ 85721-0092; turtle@lpl.arizona.edu

Introduction: Large meteorite impacts such as the one that created the Vredefort structure in South Africa about two billion years ago result in significant heating of the target. The temperatures that are achieved in these events are significant for post-impact metamorphism as well as the development of hydrothermal systems. We developed a series of numerical models to investigate the formation of shock features around the Vredefort structure [1]. From these simulations we have also been able to determine the temperature distribution in the target during and after the formation of the impact crater. Here we present the thermal results from our simulations of an impact by a projectile 10 $\mathrm{km}$ in diameter. This would create a $\sim 80 \mathrm{~km}$ diameter transient crater and result in a $-120-160 \mathrm{~km}$ diameter final crater. This is within the size range predicted by our earlier simulations of the formation of shock features at Vredefort [1], although it is low compared to other estimates [2]

Numerical Modeling: We used the 2-D hydrocode CSQ [3] coupled with the semianalytical equation of state, ANEOS [4], to model the contact and compression and excavation stages of the impact (see detailed description in [1]). One hundred massless, Lagrangian tracer particles were distributed throughout the target to record the conditions of the material. From these we calculated the change in temperature due to the impactgenerated shock wave. Figure I shows the maximum increases in temperature achieved in the target during the passage of the shock wave. Figure 2 shows how the temperatures have changed from their original values after the shock wave has passed $(t \approx 14.6 \mathrm{~s})$.

We then simulated excavation and collapse of the transient crater using the finite-element code Tekton ([5], details of modeling procedure are described in [1]). We applied the resulting displacements to the locations of the tracer particles at the end of the hydrocode simulation to determine the temperature distribution after formation of the final crater. Figure 3 shows the changes from original temperatures immediately after the transient crater has collapsed to the final crater.

These simulations show that, at least initially, there is little heating outside the final crater itself. We plan to expand our modeling to investigate the thermal evolution of the impact structure and its implications. In addition to these temperature distributions we will also present our results for larger projectiles.

References: [1] Turtle E.P. and Pierazzo E. (1998) Meteoritics and Flanet. Soi., 33, 483-490. [2] Grieve R.A.F. and Therriault A. (2000) Ann. Rev. Earth Flanet. Sci., 28, in press. [3] Thompson S.L. (1979) CSQ Users manual, Sandia Natl. Labs. [3] Thompson S.L. and Lauson H.S. (1972 Tech. Rept. \#S-RK-61 0714, Sandia Natl. Labs. [5] Melosh H.J. and Raefsky A. (1980) Geophys. J. R. Astr. Sas., 60, 333-354.

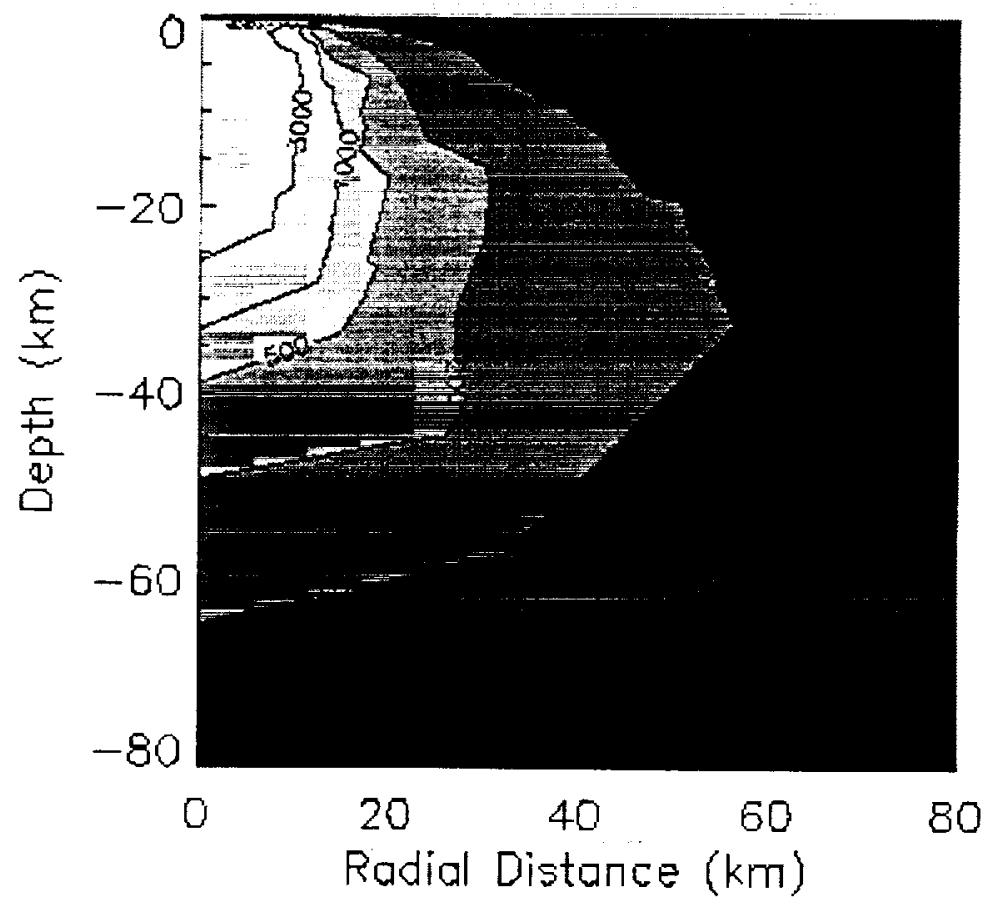

Fig. I: Contours $(50,200,500,1000$ and $3000 \mathrm{~K}$ ) of peak temperature increases during passage of the shock wave (small jags in contour lines are artifacts of interpolation from the unevenly distributed tracer particle locations to a regular grid). 


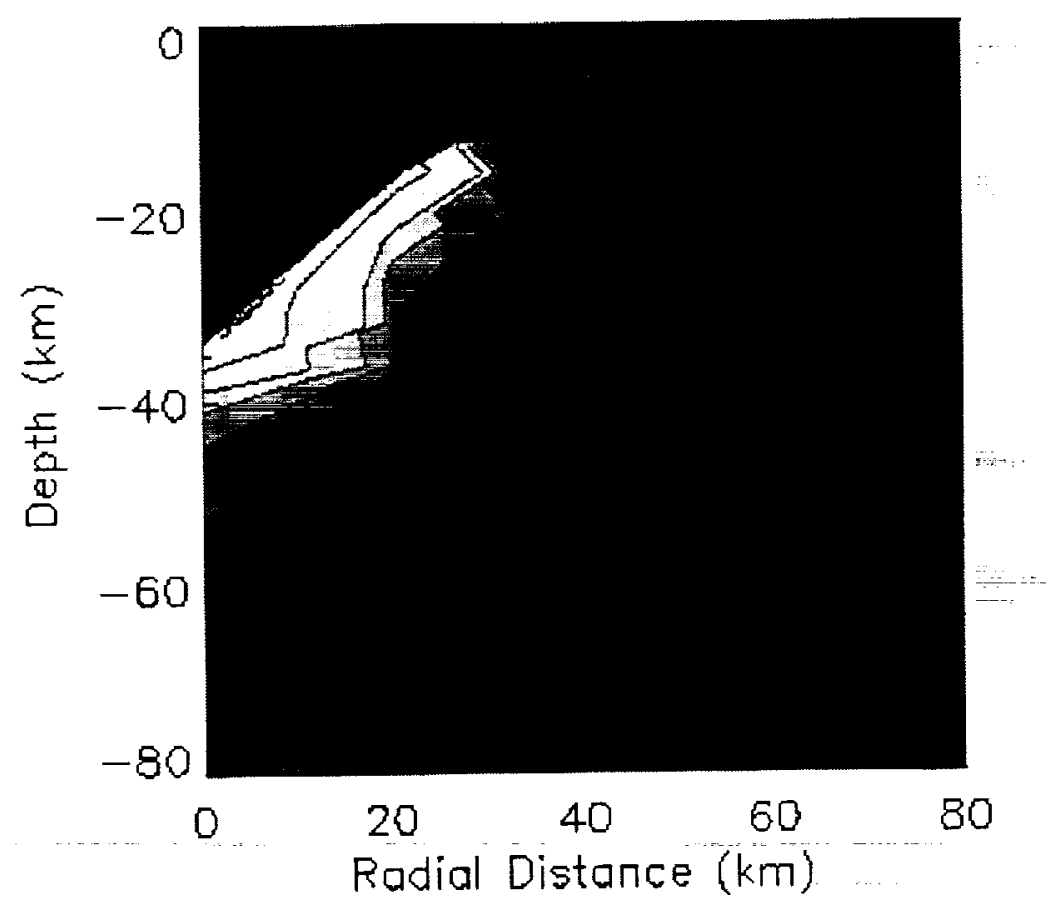

Fig. 2: Contours $(50,200,500,1000$ and $300 \mathrm{~K})$ of change from initial temperature after passage of the shock wave and crater excavation (small jags in contour lines are artifacts of interpolation from the unevenly distributed tracer particle locations to a regular grid).

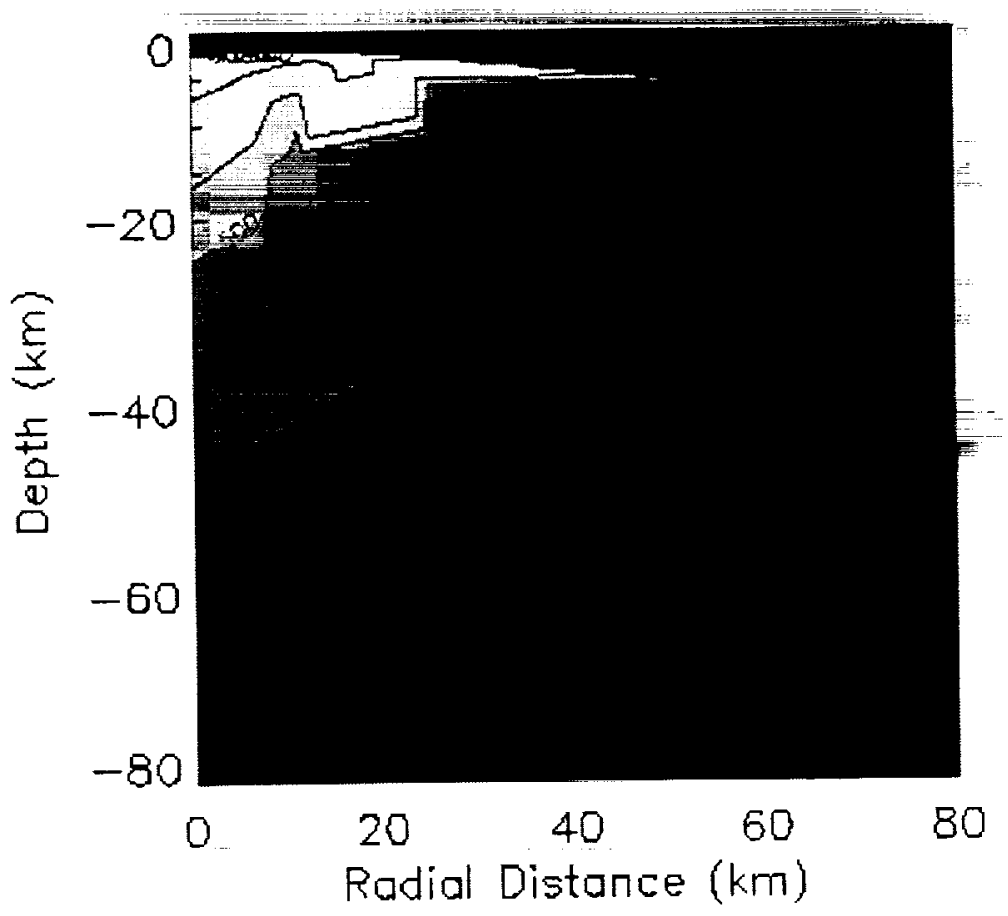

Fig. 3: Contours $(50,200,500,1000$ and $300 \mathrm{~K})$ of change from initial temperature immediately after crater collapse (small jags in contour lines are artifacts of interpolation from the unevenly distributed tracer particle locations to a regular grid). 
THE P/T BOUNDARY ON LAND: A SUMMARY. Peter D. Ward, University of Washington, Seattle WA 98195, USA.

New results by both paleobotanists and vertebrate paleontologists have shown that the $\mathrm{P} / \mathrm{T}$ extinction on land was highly catastrophic. Less well know is the timespan of the extinction. In this presentation I will document the results of new collections of mammal-like reptiles form the Karoo basin of South Africa and attempt to synthesize what we know, what we do not know, and implications of this research. 
CHANGING FLUVIAL ENVIRONMENTS IN THE KAROO BASIN, SOUTH AFRICA, AS A RESULT OF THE PERMIAN-TRIASSIC MASS EXTINCTION

Peter Ward ${ }^{1}$, David R. Montgomery ${ }^{1}$, and Roger Smith ${ }^{2}$

1. Dept. of Geological Sciences, Univ. Washington, Seattle, WA 98195

2. South African Museum, Cape Town, South Africa

The Permo-Triassic transition in the Karoo Basin of South Africa was characterized by a rapid and apparently basin-wide change from meandering to braided river systems as evidenced by preserved sedimentary facies. This changeover has been hypothesized as a cause of the catastrophic extinction of Permian vertebrate taxa. Here we propose that rather than causing the extinction, the changeover in fluvial systems in the ancient Karoo Basin was a consequence of a major die off of plant life in the basin. Evidence from other basins containing fluvial P/T boundary sections suggests that a catastrophic terrestrial die off of vegetation produced a dramatic increase in sediment yield, recorded in the change in fluvial stratigraphy, as well as in the global - ${ }^{13} \mathrm{C}$ excursion across the P/T boundary.

The Permian-Triassic extinction killed more than $90 \%$ of marine species and about $70 \%$ of terrestrial vertebrate families (Erwin, 1994). Numerous global causal mechanisms for the P/T mass extinction have been proposed, including asteroid/comet impact (Rampino and Haggerty, 1996; Bowring et al., 1998; Retallack, 1998), environmental shifts (Thackery et al., 1990; Stanley and Wang, 1994; Smith, 1995; Retallack, 1999), oceanic anoxia (Wignall and Twitchett, 1996; Isozaki, 1997) or overturn (Knoll et al., 1996), volcanism (Campbell et al., 1992; Renne et al., 1995) and synergistic combinations among the above (Erwin, 1993, 1994; Bowring et al., 1998; Morante, 1996; Retallack, 1999). Unraveling the ultimate cause of the chain of environmental change and stress preserved in the geologic record rests on the difficult and often underconstrained interpretation of causality from the sedimentary record.

To date most research into the cause of this mass extinction has taken place in marine facies. Far less is known about the pattern of extinction in non-marine facies, and especially among terrestrial vertebrate taxa. Perhaps the best studied record of vertebrate taxa across the Permo/Triassic boundary is found in the Karoo Basin of South Africa, which records an apparently complete stratigraphic record of the Permian through the Triassic in the interior of southern Pangea (King, 1991; Rubidge, 1995; Smith, 1995), and contains numerous, well-exposed P/T boundary sections with relatively abundant vertebrate fossils. The extinction among the Karoo vertebrate fauna was severe: Rubidge (1995) reported that only 6 of the 44 reptilian genera recovered to date from the highest Permian biostratigraphic zone (Dicynodon Assemblage Zone) are found in the succeeding lowest Triassic zone (Lystrosaurus Assemblage Zone). The plant fossil record is poorly known for the Karoo Basin because of diagenesis, but correlative strata elsewhere in Gondwanaland record a major floral extinction pulse at the boundary (Anderson et al, 1999).

There have been relatively few specific hypotheses attempting to explain the extinction of the Dicynodon Zone taxa in the Karoo Basin. King (1990) suggested that the extinction was protracted, and due to climatic cooling in the region. Smith (1995), on the other hand, made the seminal observation that a change in sedimentary facies that he observed across the P/T boundary in one region of the Karoo Basin is consistent with a changeover from a basin dominated by meandering rivers to one dominated by braided river systems. He suggested that this change in facies patterns was brought about by a pulse of tectonism along the southern margin of the basin, 
which increased the slope of rivers flowing northward into the foreland, and concluded that this radical change in fluvial style in the Karoo Basin over an approximately 50,000 year interval during the Permian-Triassic transition was the ultimate cause of the extinction in the basin. According to this hypothesis, the actual killing mechanism would have been the changing floodplain environment.

Subsequent to Smith's 1995 work, MacLeod et al. (1998; in press) correlated the paleontologically defined boundary at Smith's study site with marine P/T boundary sections in China and Europe by demonstrating the presence in the Bethulie section of a pronounced isotopic excursion, and also demonstrating synchroneity between the marine and non-marine extinctions at this time. This subsequent work also indirectly dates the P/T boundary in the Karoo as being approximately 250 million years in age (Renne, 1995; Bowring et al, 1999). Here we extend the observation of Smith (1995) by showing that a facies transition across the P/T boundary from meandering to braided river systems is nearly basin wide (and perhaps even a global phenomenon). We also show that such a large-scale facies change could have been brought about by elimination of deeply rooted plants in the basin. Because of the timing of this transition, we conclude that this environmental change was a consequence, rather than a cause of the P/T event in the Karoo Basin. The increased sediment yield that would have resulted from a basin wide change in vegetation sufficient to trigger such widespread and sustained fluvial response would have drastically increased terrestrial exports of organic and inorganic sediment (and therefore ${ }^{13} \mathrm{C}$ ) to the oceans and contributed to the dramatic loss of shallow water marine taxa across $\mathrm{P} / \mathrm{T}$ boundary sections. 
PRIMARY EJECTA, TSUNAMI REWORKING, TECTONIC DISMEMBERMENT: RECONSTRUCTING THE LATE DEVONIAN ALAMO BRECCIA AND CRATER, NEVADA. J. E. Warme ${ }^{1}$ and A. K. Chamberlain', 'Department of Geology and Geological, Engineering, Colorado School of Mines, Golden, CO 80401, jwarme@mines.edu, ${ }^{2}$ Cedarstrat, P. O. Box 36, Hiko, NV 89017.

The Alamo Breccia is the formal middle Member of the Upper Devonian (Frasnian) Guilmette Formation in southern Nevada. The Breccia crops out in 15 or more mountain ranges over an area of $10,000+$ square kilometers, distributed in a eastward-extending semicircle centered approximately $150 \mathrm{~km}$ north of Las Vegas. Its thickness ranges from about $130 \mathrm{~m}$ in the center to a feather edge of less than $1 \mathrm{~m}$, averaging about $50 \mathrm{~m}$. Its volume probably exceeds 500 cubic kilometers.

The Guilmette Formation represents a shallow-water carbonate platform, exhibiting approximately 150 typical shallowing-upward cycles. The Alamo Breccia was first recognized as a stratigraphic anomaly within the Guilmette. The Breccia commonly forms a massive cliff containing countless whole and fragmented stromatoporoids that were previously interpreted as reef and reef debris. The presence of a spectrum of lithoclasts ranging from gravel-sized to slabs hundreds of meters long, and the absence of obvious reef mounds, warranted investigation of the origin of the Breccia. The anomalous occurrence, apparent catastrophic nature, and discovery of a mild iridium anomaly, disseminated shocked quartz, and spectacular beds of carbonate impact spherules, that superficially resemble volcanic lapilli, all confirmed the impact genesis of the Breccia.

The Alamo Breccia has been divided into three lateral zones. The central Zone 1 occurs only in one range and contains the thickest $(130 \mathrm{~m})$ but relatively finest-grained deposit. The largest clasts at the base are about $20 \mathrm{~m}$ in maximum dimension, and the main body of the breccia is a thick cobble- to mud-sized graded unit. In the intermediate Zone 2 the Breccia averages about $60 \mathrm{~m}$ in thickness and contains the largest clasts. Some are as much as $500 \mathrm{~m}$ in length; one documented example is 100 thick, occupying $95 \%$ of the height of the Breccia. In many localities the large clasts, which are the shattered remains of the in situ carbonate platform, are discontinuous, and the entire thickness of the Breccia is comprised of smaller clasts and matrix. In the peripheral Zone 3 the Breccia thins from approximately $6 \mathrm{~m}$ to a feather edge, and is an overall graded bed.

Recent analysis of the Breccia texture showed that internally it is composed of a chaotic lower segment and an overlying series of graded beds that become thinner and finer-grained upward. The thicker lower segment contains a spectrum of clast sizes in a matrix that is commonly muddy and highly variable in texture and fabric. Many of the clasts were preserved in the process of disintegration whereby their margins have dilated and transformed into matrix. Some clasts are internally fractured, dilated and deformed. This unit is interpreted as primary ejecta. Overlying it are as many as $\mathbf{4}$ graded units, especially well developed over much of Zone 2 . Each unit has a sharp base that is commonly deformed by loading from the overlying unit and injected by the underlying one, ascribed to penecontemporaneous dewatering processes. These units are well sorted, graded and clast-imbricated. They are interpreted as sequential tsunami deposits of diminishing force.

Interpretation of the Alamo Breccia, and the location of the crater, has been hindered by the puzzling semicircular distribution of the deposit. The character of the facies of the encompassing Guilmette Formation, and unraveling of the complicated regional structure provides a solution. Zone 2 contains two dominant facies overlying the Breccia. In some Zone 2 localities the Guilmette contains abundant sandstone beds interbedded with the carbonates but no stromatoporoid reefs. In others it contains reefs and little or no sandstone. A balanced cross-section that restores the stacked thrust faults in the region to their original position places the sandstones west of Zone 1 and leaves the reef facies to the east. Zone one, which is highly altered under the fresh-appearing Breccia, is interpreted as a thrust slice containing a portion of the crater. The provenance of the sandstones is interpreted to be a subdued highland fringing the west margin of the platform, perhaps as an early stage of the Antler Orogeny that began in the Late Devonian. The reefs are interpreted to occupy the deeper parts of the platform, which contained one or more depressions.

Upon restoration, the distribution of the Alamo Breccia approaches circular. In this analysis, the regional Alamo Breccia Member is used to constrain tectonic solutions for this complicated region, and the surviving tectonic test explains the current lopsided distribution of the Breccia. 


\section{LARGE AERIAL BURSTS; AN IMPORTANT CLASS OF TERRESTRIAL ACCRETION- ARY EVENTS. John T. Wasson, University of California, Los Angeles, CA 90095-1567, and Mark B. E. Boslough, Sandia Laboratories, Albuquerque, NM 87185-0820.}

The remarkable Tunguska event occurred on the morning of 30 Jun 1908 . A large meteoroid was totally disrupted at an altitude of ca. 8 $\mathrm{km}$, the resulting explosion (here designated an aerial burst) having an energy of the order of 15 MT (TNT equivalent) [Vasilyev, 1998]. The blast wave leveled trees over an area of about $2000 \mathrm{~km}^{2}$. The first field investigation two decades later showed extensive evidence of charring of the forest debris; the maximum thermal pulse at ground zero is estimated to be $238 \mathrm{~J} \mathrm{~cm}^{-2}$ [Korobeinikov et al., 1983], sufficient to heat $0.16 \mathrm{~g}$ of dry continental crust to $1500 \mathrm{~K}$ and melt it.

Although Tunguska is the largest aerial burst recorded in human history, there are good reasons to believe that it is one of a continuum of such accretionary events that extends from events $<10^{3}$ times smaller to events $>10^{6}$ times larger. The smallest documented members of the set are the type-III fireballs recorded by the cameras of fireball networks [Ceplecha et al., 1998]. A number of events of intermediate size are recorded by military satellites [Tagliaferri et al., 1995].

It would appear that a combination of two circumstances are required to generate aerial bursts appreciably larger in magnitude than Tunguska: (1) the meteoroid must be weak enough to disrupt during atmospheric passage, and (2) the atmospheric entry angle must be relatively oblique. If we assume a density of 2 $\mathrm{g} \mathrm{cm}^{-3}$, the radius of the Tunguska meteoroid is estimated to be about $40 \mathrm{~m}$. Its entry angle seems to have been in the range $20-45^{\circ}$ relative to the horizontal [Bronshten, 1999]. Modeling by Hills and Goda [1999] indicates that a friable meteorite (strength of $1 \bullet 10^{8}$ dynes $\mathrm{cm}^{-2}$ ) must have a radium $100 \mathrm{~m}$ to deposit half its energy at the Earth's solid surface at an entry angle of $90^{\circ}$ and a geocentric velocity of $18 \mathrm{~km}$ $\mathrm{s}^{-1}$. These authors estimate that a $500 \mathrm{~m}$ projectile will lose half its energy at $10 \mathrm{~km}$ if its entry angle is $20^{\circ}$.

For Tunguska-size object the blast effects are more dramatic than the thermal effects, but thermal effects dominate as the size of the event increases. The reason for this is that, as the size of the event increases, the central region finds itself surrounded by atmosphere that is also hot, and loses its ability to cool itself by radiation in directions other than vertical. Because there is so little mass above the hot gas, expansion results in negligible cooling.

Below this central region of the burst we can expect vegetation to be fully incinerated. In moist, vegetated areas or regions covered by water, much of the heat energy is expended on the latent heat of vaporization of $\mathrm{H}_{2} \mathrm{O}$ and carbonaceous compounds, and the temperatures of unvaporized solid (or liquid) materials remain relatively low. In contrast, if the surface below the burst is desert-like, the radiation is capable of melting a several $\mathrm{mm}$ of the sand or rock.

When large craters such as Chicxulub form, the ejecta is thrown above the atmosphere and scattered around all regions of the globe. The entry of this ejecta into the atmosphere causes large amounts of heating, creating conditions much like those resulting from an aerial burst. Thus, the incineration of vegetation is common to these two phenomena. The chief environmental difference is one of scale, the Chicxulub event being global, the mega-Tunguska events regional.

Materials which we interpret to be the products of giant aerial bursts are the layered (or 
Muong-Nong-type) tektites found over a region having an area of $\approx 8 \bullet 10^{5} \mathrm{~km}^{2}$ in Southeast Asia and the Libyan Desert Glass (LDG) found over a region having an area of $\approx 7 \bullet 10^{3}$ $\mathrm{km}^{2}$ in Western Egypt. These are glassy materials which were formed by the melting of surficial materials on the local continental crust. Compositions of layered tektites are about the same as the local continental crust; a small enrichment in $\mathrm{SiO}_{2}$ may be a selection effect resulting from an increased resistance to devitrification or weathering. The LDG is $\approx 98 \% \mathrm{SiO}_{2}$, similar in composition to the adjacent Great Sand Sea. The layering common to both these materials is inferred to have resulted from down-slope flow of a melt sheet. This flow implies that temperatures remained high $(>2400 \mathrm{~K})$ for several minutes.

The most common origin ascribed to these materials in the past is ejection from craters. However, there is no evidence that large amounts of fully molten materials are ever ejected from terrestrial craters, and any such ejecta would be expected to quench when it returns to the surface. Cratering events do not offer a mechanism to keep thin layers of melt hot enough to flow tens of $\mathrm{cm}$. In addition, melt production is most efficient a the bottoms of craters, whereas all layered tektites have high $10 \mathrm{Be}$ contents requiring that much or most of the target have been a surficial soil.

The very low density $\left(1.3 \mathrm{~g} \mathrm{~cm}^{-3}\right)$ of the asteroid Mathilde [Veverka et al., 1999] suggests that it is a flying rubble pile. It is plausible that a sizable fraction of asteroids and comets are primordial materials that were never compacted, and have essentially no strength. If this is correct, then many of the asteroids striking the Earth may be these strengthless objects. Another fact in support of this hypothesis is the high fraction of low-strength fireballs observed by the photographic networks; weak meteoroids are recognized because they break up higher in the atmosphere. According to the summary of Ceplecha et al. [1998], only $32 \%$ of photographed meteoroids have the strength of irons or anhydrous chondrites. Another $33 \%$ are friable, having strengths similar to $\mathrm{CM}$ chondrites, and the remaining $35 \%$ are designated "cometary" because they break up very high at extremely low dynamic pressures.

Given the strength of the interplanetary source it is plausible that aerial bursts should comprise an important fraction of the accretionary events occurring on the Earth. A goal of our future research is to better calibrate the relationship between entry angle and the fraction of the kinetic energy deposited in the atmosphere, and thus to estimate the magnitude-frequency of such events. Our preliminary modeling indicates that highly oblique impacts of relatively strong meteoroids can deposit most of their kinetic energy in the atmosphere even though much of the projectile penetrates to the surface.

\section{References:}

Bronshten V. A. (1999) Meteorit. Planet. Sci. 34, 723-728.

Ceplecha Z. et al. (1998) Space Sci. Rev.84, 327.

Hills J. G. and Goda M. P. (1998) Planet. Space Sci. 46, 219-229.

Korobeinikov V. P. et al. (1983) In Meteoric Studies, Nauka, 5-24 (in Russian).

Tagliaferri E..et al. (1995. In Hazards Due to Comets and Asteroids (T. Gehrels, Ed.) 199-200, Univ. Arizona.

Veverka J. et al. (1999) Icarus 140, 3-16.

Vasilyev N. V. (1998) Planet. Space. Sci. 46, 129. 
EXTENT AND DURATION OF THE PERMO-TRIASSIC SUPERANOXIC EVENT. P. B. Wignall', 'Department of Earth Sciences, University of Leeds, Leeds LS2 9JT, UK (wignall@earth.leeds.ac.uk).

Introduction: The end-Permian mass extinction is intimately associated with the development of oxygenpoor bottom waters in many Permo-Triassic boundary sections. In both eastern and western Tethyan locations the demise of Permian marine fauna coincides closely with the development of dysaerobic facies in the late latidentatus/changxingensis conodont zone [1]. Organic enrichment is rarely developed, perhaps because of low productivity conditions but the development of dysoxia/anoxia is recognised from a combination of geochemical indices (DOP, authigenic U enrichment, S/C plots), sedimentary petrography (small size and abundance of pyrite framboids, fine lamination) and palaeoecological data (e.g. low oxygen tolerant "paper pecten" bivalves, absence of benthic conodonts).

Lethal Anoxia: Discrete anoxic events occur at many levels in the geological record and most are not associated with mass extinctions. The lethal consequences of Late Permian anoxia/dysoxia stems from its development in extraordinarily shallow waters. In sections from Spitsbergen cross-bedded sandstones of pyrite are developed in the lower shoreface [2], whilst pyrite-rich facies occur in innermost ramp settings of the Dolomites, and in southern Sichuan dysaerobic facies occur in shallow platform settings immediately above reefs [1]. The origins of this shallow-water anoxia are unclear, but may be bound up with the rapid global warming and ocean stagnation that characterises this interval [3].

Extent and Duration. The onset and cessation of the Permo-Triassic anoxic event records intriguing regional and bathymetric variation. Oxygen-poor bottom waters initially formed in the deep-water (abyssal?) around the beginning of the Late Permian as seen in the accreted terrances of Japan [4]. However, dysoxic bottom waters did not appear in shallower water settings, such as the carbonate ramps of northern Italy, until near the close of the Permian. Throughout equatorial Tethys this event appears near synchronous and unrelated to environmental location. Thus, in South China, dysaerobic facies develop in deep basinal (Shangsi), base of slope (Meishan) and inner platform (Laolongdong) sections at the same time. Thus, extrinsic factors, such as climate and oceanography, rather than intrinsic factors, such as water depth and basin location, are probably responsible for the event. Recent work in Boreal latitudes (Spitsbergen, E. Greenland) indicates that the onset of anoxia occurred at precisely the same time and in a similarly diverse range of marine settings (basin centre within a syn-rift basin, inner shelf of a passive margin).
Interestingly, in high southern palaeolatitudes, (e.g. Madagascar, the Salt Range (Pakistan), southern Tibet) the anoxic event appears to have occurred later (within the basal Triassic Griesbachian Stage) and to have been not nearly so intense. For example, in the highlycondensed Selong section of Tibet the anoxic event is recorded as a single layers of pyrite crystals in bioturbated, pelagic carbonates.

Like the onset of the anoxic/dysoxic event, its termination appears to have been widely synchronous (at least in equatorial Tethyan and Boreal palaeolatitudes) and to have been unrelated to local facies changes pointing once again to an extrinsic cause. In most regions this event occurs within the late Griesbachian and is marked by the abrupt appearance of pervasive bioturbation. Anoxia persisted in the deep oceans until the end of the Scythian [4], and also locally in the deepwater centres of some epicontinental basins [5].

Discussion: The anoxic event that straddles the Permian-Triassic boundary is the most severe event of its kind know from the Phanerozoic record. Only the topmost $10-20 \mathrm{~m}$ of water may have remained oxygenated at this time. The lesser intensity and much shorter duration of this event on the Perigondwanan margin implies that this area may have been a refuge to some extent from this crisis. However, the first evidence of recovery of benthic marine communities in the aftermath of the anoxia is seen from high Boreal palaeolatitudes [2]. Tethyan benthic recovery only initiated after the Scythian suggesting that environmental stresses (not necessarily oxygen-restriction) may have persisted in this region throughout this interval.

\section{-References:}

[1] Wignall P.B. and Hallam A. (1996) Palaeogeog. Palaeoclim. Palaeoecol. Palaios 11, 587-596.

[2] Wignali P.B. et al. [1998] Geol. Mag. 135, 47 62.

[3] Wignall P.B. and Twitchett R.J. [1996] Science $272,1155-1158$.

[4] Isozaki Y. [1997] Science 276, 235-238.

[5] Woods A.D. et al. (1999) Geology, 27, 645648. 
PALAEOECOLOGY OF A POST-EXTINCTION REEF: FAMENNIAN (LATE DEVONIAN) OF THE CANNING BASIN, WESTERN AUSTRALIA. Rachel Wood, Department of Earth Sciences, University of Cambridge, Downing Street, Cambridge CB2 3EQ, UK (rw43@esc.cam.ac.uk).

Many of the potential problems associated with understanding the ecological effects of mass extinction events can be overcome by analysis of in situ communities. Study of continuous carbonate sequences can also introduce taphonomic controls, as well as eliminating the risk of biases introduced by facies changes or exceptionally preserved biotas.

Reefs are widely supposed to be decimated after mass extinctions, yet the palaeoecology of postextinction reef communities has received little detailed attention. Windjana Gorge, in the Canning Basin, Western Australia, offers an unique succession of continuous reef-building from the late Frasnian to early Famennian (late Devonian), so enabling a comparison of changing palaeoecologies across the Frasnian/Famennian extinction boundary.

Like the Frasnian reef communities of Windjana Gorge, Famennian reef ecologies were dominated by microbial communities, with the calcimicrobes Shuguria, Rothpletzella, and Girvanella remaining important holdover taxa. Famennian representatives, however, grew in novel and previously undocumented morphological forms. Calcimicrobes grew as complex intergrowths of encrusters and cryptic forms which, together with lithistid sponges, formed spectacular laminar-sheet complexes up to over 2.5 $\mathrm{m}$ in diameter and $0.30 \mathrm{~m}$ thick. The abundance and diversity of lithistid sponges within shallow water margin and back-reef ecologies also contrasts markedly with that of Frasnian reefs. Fifteen species are now identified from the Windjana Limestone, where only two were previously documented. These communities grew in a shallow, high-energy environment where sediments were dominated by coated grains, and where rapid, early lithification was prevalent.

These observations demonstrate that a quite novel reef ecology, rather than a remnant of the preextinction community, was established in the immediate aftermath of the Frasnian/Famennian mass extinction event. The morphological habit of the Famennian calcimicrobe-sponge complexes is noteworthy for mimicking the elevated stromatoporoid sponge growth forms that were eliminated by the extinction event, suggesting that vacated ecospace was utilised in a similar way. As such, there was no change in either tiering or a substantial reduction in biodiversity of the reef community. There is little evidence to support idea of either resurgence or invasion of taxa from deeper waters. These observations suggest that where stable carbonate platforms persisted, reef-building could continue. They also overturn received opinion that all reef biotas are more susceptible to collapse - and slower to recover - than any other communities. Such studies also highlight the need to document ecosystem recovery after mass extinction events using detailed field analyses rather than simple compilations of global diversity changes. 